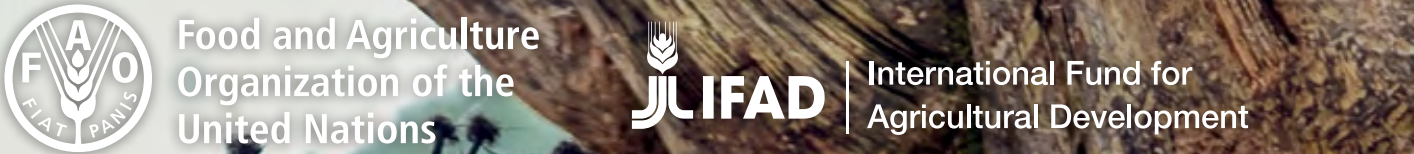

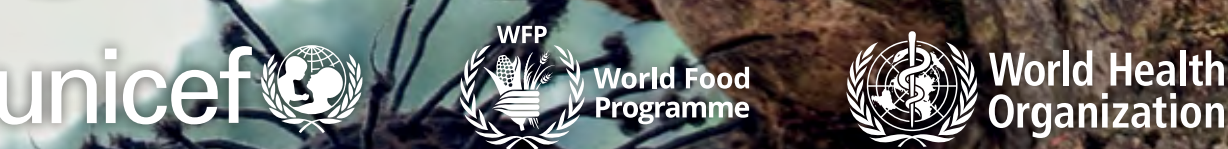

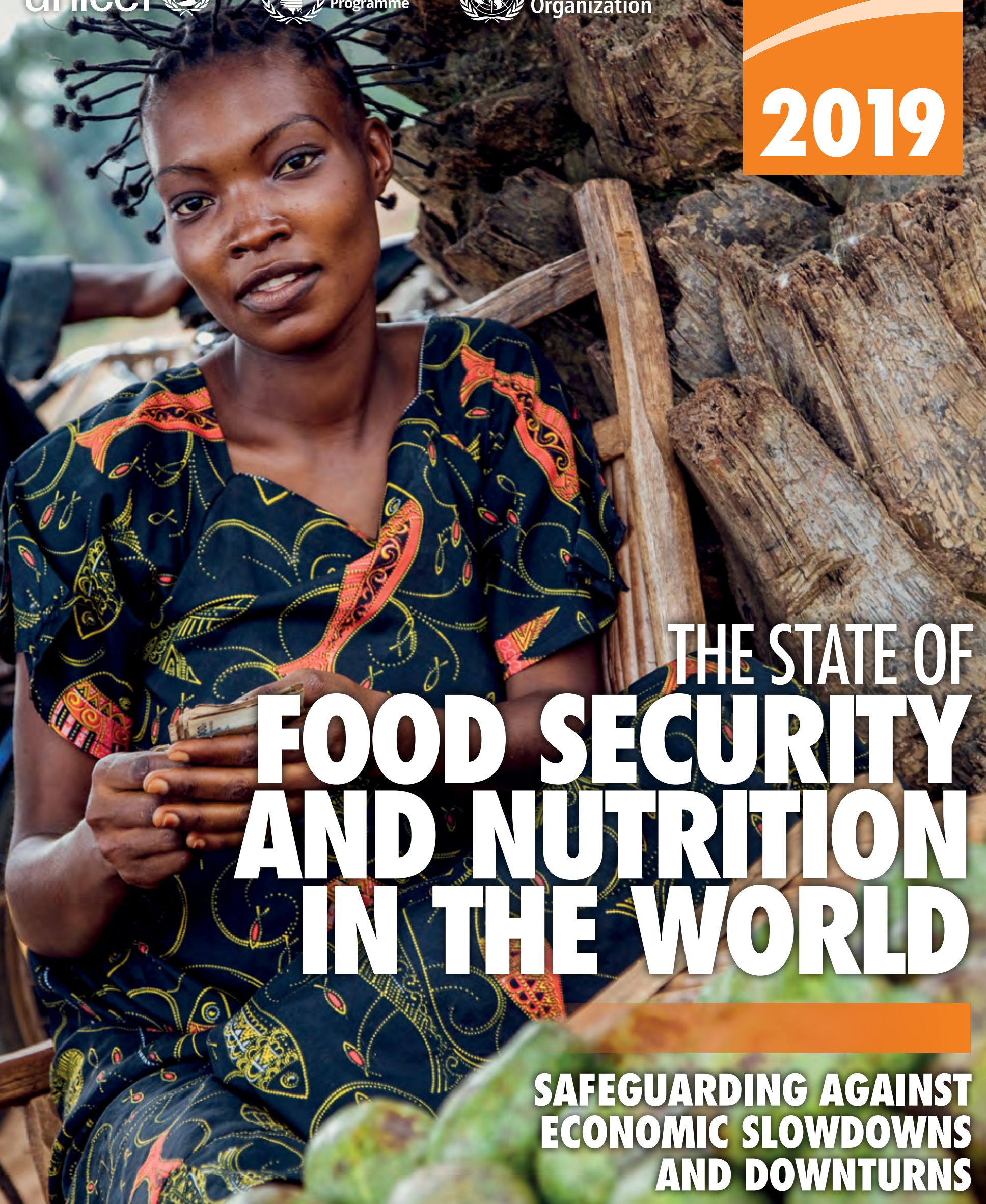


This flagship publication is part of THE STATE OF THE WORLD series of the Food and Agriculture Organization of the United Nations.

Required citation:

FAO, IFAD, UNICEF, WFP and WHO. 2019. The State of Food Security and Nutrition in the World 2019

Safeguarding against economic slowdowns and downturns. Rome, FAO.

Licence: CC BY-NC-SA 3.0 IGO.

The designations employed and the presentation of material in this information product do not imply the expression of any opinion whatsoever on the part of the Food and Agriculture Organization of the United Nations (FAO), the International Fund for Agricultural Development (IFAD), the United Nations Children's Fund (UNICEF), the World Food Programme (WFP) or the World Health Organization (WHO) concerning the legal or development status of any country, territory, city or area or of its authorities, or concerning the delimitation of its frontiers or boundaries. The mention of specific companies or products of manufacturers, whether or not these have been patented, does not imply that these have been endorsed or recommended by FAO, IFAD, UNICEF, WFP or WHO in preference to others of a similar nature that are not mentioned.

The designations employed and the presentation of material in the maps do not imply the expression of any opinion whatsoever on the part of FAO, IFAD, UNICEF, WFP or WHO concerning the legal or constitutional status of any country, territory or sea area, or concerning the delimitation of frontiers.

All reasonable precautions have been taken by FAO, IFAD, UNICEF, WFP and WHO to verify the information contained in this publication. However, the published material is being distributed without warranty of any kind, either expressed or implied. The responsibility for the interpretation and use of the material lies with the reader. In no event shall FAO, IFAD, UNICEF, WFP and WHO be liable for damages arising from its use.

\section{ISBN 978-92-5-131570-5}

C) FAO 2019

(c) (i) $\$$

Some rights reserved. This work is made available under the Creative Commons Attribution-NonCommercial-ShareAlike 3.0 IGO licence (CC BY-NC-SA 3.0 IGO; https://creativecommons.org/licenses/by-nc-sa/3.0/igo).

Under the terms of this licence, this work may be copied, redistributed and adapted for non-commercial purposes, provided that the work is appropriately cited. In any use of this work, there should be no suggestion that FAO endorses any specific organization, products or services. The use of the FAO logo is not permitted. If the work is adapted, then it must be licensed under the same or equivalent Creative Commons licence. If a translation of this work is created, it must include the following disclaimer along with the required citation: "This translation was not created by the Food and Agriculture Organization of the United Nations (FAO). FAO is not responsible for the content or accuracy of this translation. The original English edition shall be the authoritative edition."

Any mediation relating to disputes arising under the licence shall be conducted in accordance with the Arbitration Rules of the United Nations Commission on International Trade Law (UNCITRAL) as at present in force.

Third-party materials. Users wishing to reuse material from this work that is attributed to a third party, such as tables, figures or images, are responsible for determining whether permission is needed for that reuse and for obtaining permission from the copyright holder. The risk of claims resulting from infringement of any third-party-owned component in the work rests solely with the user

Sales, rights and licensing. FAO information products are available on the $F A O$ website (www.fao.org/publications) and can be purchased through publications-sales@fao.org. Requests for commercial use should be submitted via: www.fao.org/contact-us/licence-request. Queries regarding rights and licensing should be submitted to: copyright@fao.org. 


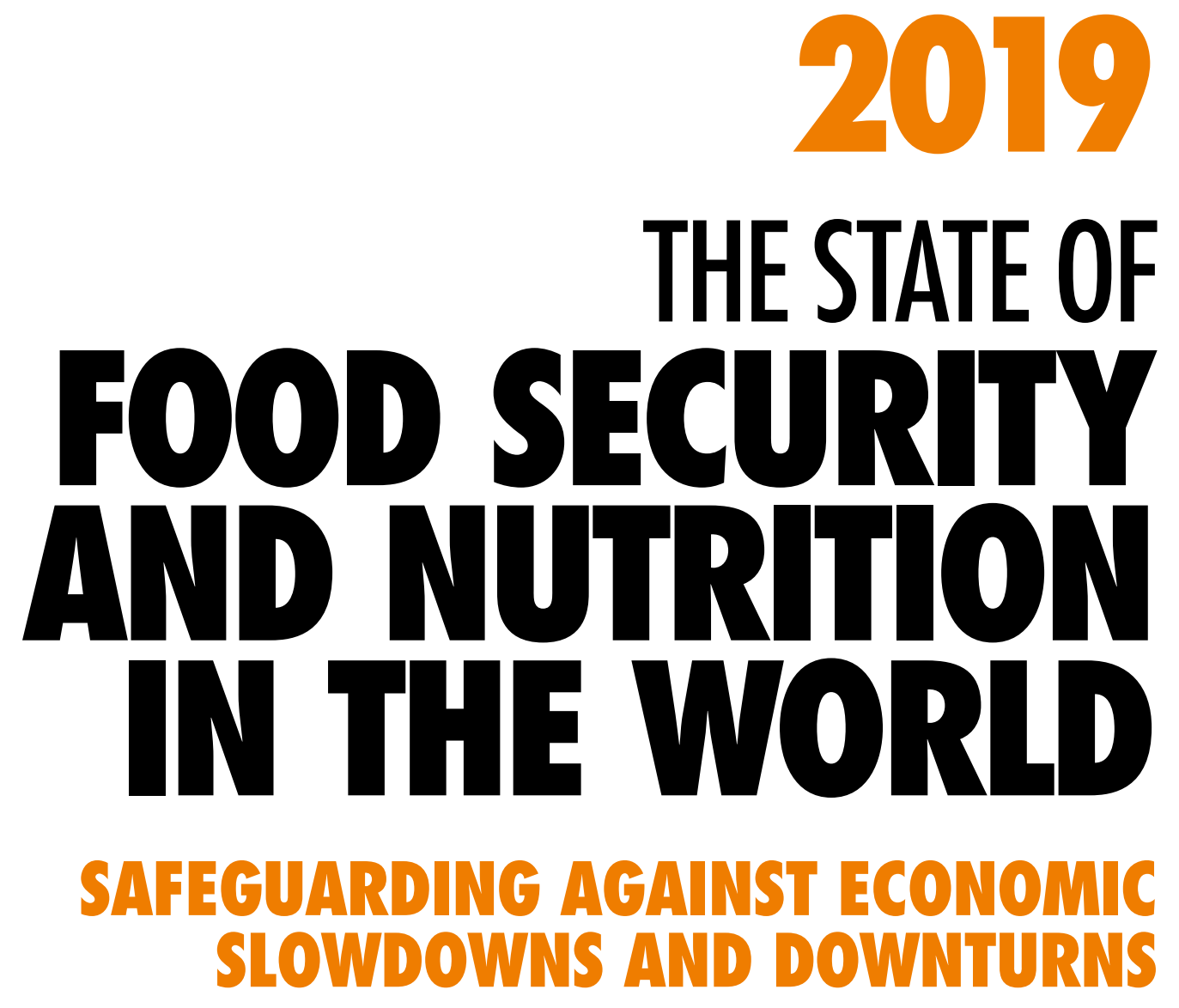

Food and Agriculture Organization of the United Nations Rome, 2019 
FOREWORD

METHODOLOGY

ACKNOWLEDGEMENTS

ACRONYMS AND ABBREVIATIONS

KEY MESSAGES

EXECUTIVE SUMMARY

\section{PART 1}

\section{FOOD SECURITY AND NUTRITION} AROUND THE WORLD IN 2019

1.1 Recent trends in hunger and food insecurity

1.2 Progress towards global nutrition targets

1.3 Towards an integrated understanding of food security and nutrition for health and well-being

\subsection{Conclusions}

\section{PART 2}

\section{SUSTAINED ESCAPES FROM FOOD INSECURITY} AND MALNUTRITION IN THE FACE OF ECONOMIC SLOWDOWNS AND DOWNTURNS

2.1 Economic slowdowns and downturns and their impact on food security and nutrition

2.2 Commodity dependence and its relevance for food security and nutrition

2.3 Nexus between economic growth, poverty, and food security and nutrition: the role of inequality

2.4 Policies for achieving sustainable escapes from food insecurity and malnutrition in the context of economic slowdowns and downturns 2.5 Conclusions

\section{ANNEX 7}

Glossary

NOTES

\section{ANNEX 3}

\section{ANNEX 4}

\section{ANNEX 5}

\section{ANNEX 6}

121

122

PoU change point definitions, methodology and country lists

Economic growth and change in $\mathrm{PoU}$ between 2011 and 2017

The main drivers of crisis-level acute food insecurity in 2018

Commodity dependence definitions and country lists 


\section{TABLES}

1 Prevalence of undernourishment (PoU) in the world, 2005-2018

2 Number of undernourished people in the world, 2005-2018

3 Prevalence of moderate or severe food insecurity, and severe food insecurity only, measured with the Food Insecurity Experience Scale, 2014-2018

4 Number of people experiencing moderate or severe food insecurity, and severe food insecurity only, measured with the Food Insecurity Experience Scale, 2014-2018

5 Association between food insecurity and various forms of malnutrition: cross-country analysis based on national data

6 Association between food insecurity and overweight or obesity in different age groups: micro-level data analysis from selected countries

7 Association between household food insecurity, child stunting and wasting, and anaemia in women of reproductive age: micro-level data analysis from selected countries

8 Economic shocks were significant secondary and tertiary drivers of food crises in 2018

9 High levels of commodity-export and -import dependence negatively affect food security

10 Government spending on social and health sectors and UHC coverage in high commodity-dependent countries

8
11 Coping strategies, their availability in times of economic slowdowns and downturns and possible negative effects

12 Multisectoral policies for reducing poverty, and the constraints that must be overcome to improve food security and nutrition

116

A1.1 Progress towards the Sustainable Development Goals (SDGs): Prevalence

of undernourishment, moderate or severe food insecurity, selected forms of malnutrition, exclusive breastfeeding and low birthweight

A1.2 Progress towards the Sustainable Development Goals (SDGs): Number of people who are affected by undernourishment, moderate or severe food insecurity and selected forms of malnutrition; number of infants exclusively breastfed and number of babies born with low birthweight

A2.1 Definition of variables and sources

A2.2 Definition of variables and sources

\section{A2.3 Results}

162

A2.4 Malnutrition indicators

by age/sex class

(dependent variables)

163

A2.5 Independent variables

164

A3.1 Countries with an increase in PoU change point corresponding to economic slowdowns or downturns, years 2011-2017

A4.1 Descriptive statistics of PoU and economic growth between 2011 and 2017
A4.2 Regression of the change in PoU and economic growth between 2011 and 2017

A4.3 Regression of the change in PoU between 2011 and 2017 and the three drivers of $\mathrm{PoU}$ increase

A4.4a Estimated coefficients of the regressions between the change in PoU (between 2011 and 2017) and the three drivers of PoU - drivers regressed separately for each income group

175

A4.4b Estimated coefficients of

the regressions between the change in PoU (between 2011 and 2017) and the three drivers of PoU - drivers regressed together for each income group

175

A5.1 Countries and territories with food crises in correspondence with economic shocks, 2018

A6.1 Definition of country

commodity-export and commodity-import dependence

A6.2 Countries and territories by typology of primary commodity dependence (1995-2017)

A6.3 Countries with economic slowdowns or downturns in correspondence to an increase in PoU change point and/or affected by food crises

\section{FICURES}

1 The number of undernourished people in the world has been on the rise since 2015, and is back to levels seen in 2010-2011

2 Undernourishment is rising 
3 Undernourishment increases sharply in countries affected by conflict in sub-Saharan Africa

4 Droughts are one of the factors behind the recent increase in undernourishment in sub-Saharan Africa

5 Western Asia is the only subregion in Asia where undernourishment is on the rise

12

6 Undernourishment is on the rise in Western Asian countries affected by popular uprisings in the recent past

7 Increasing undernourishment in South American countries is putting upward pressure on the Latin America and the Caribbean regional average

8 The Bolivarian Republic of Venezuela shows a significant increase in the prevalence of undernourishment in recent years

13

9 Even though Asia still predominates, more than thirty percent of the undernourished in the world live in Africa

14

10 Over the past five years (2014-2018), total levels of food insecurity have been on the rise at the global level, mainly due to increases in Africa and Latin America

19

11 The concentration and distribution of food insecurity by severity differs greatly across the regions of the world

20

12 As the country level of income falls, the prevalence of food insecurity increases and so does the proportion of severe food insecurity over the total

11
13 The numbers of undernourished and of food insecure have been on

10 the rise in recent years, after a decade-long decline in extreme poverty and undernourishment

14 In every continent, the prevalence of food insecurity is slightly higher for women than for men, with the largest differences found in Latin America (2016-2018 three-year averages)

15 Progress on malnutrition is too slow to achieve the 2025 and 2030 global nutrition targets

16 Stunting, wasting and overweight still impact the lives of far too many children under 5 years

30

17 Overweight prevalence increases over the life course and is highest in adulthood

33

18 Across all regions, the prevalence of overweight is increasing in all age groups, with particularly steep trends among adults and school-age children, including adolescents

19 The increase in prevalence of obesity between 2000 and 2016 has been even larger than that of overweight

20 The gap between urban and rural areas in mean body mass index is closing

21 Examples of policies and programmes aimed at preventing or reducing overweight and obesity

22 Real GDP per capita growth has been uneven since the 2008-2009 sharp global downturn

23 Consecutive years of economic slowdowns and downturns since 2011 in many subregions

$24 \mathrm{PoU}$ increasing change points associated with the occurrence of economic slowdowns and downturns

25 Low-income countries face higher increases in hunger as a result of decreases in economic growth (between 2011 and 2017)

26 Commodity prices (though high) fell year on year from 2011 to $2016 \mathbf{6 3}$

27 Many low- and middle-income countries are high commodity-dependent countries

65

28 Between 2003 and 2017, high commodity-dependent countries faced steeper declines in economic growth compared to low commodity-dependent countries - for those with rising hunger the situation was even worse

66

29 Potential negative impacts of international commodity price reductions on food security and nutrition in commodity-dependent economies: transmission channels

69

39

53

35

36

31 Prevalence of undernourishment (PoU) and child stunting rates are correlated with extreme poverty at the country level

32 High levels of child stunting are not only found in the poorest households 
33 Most of the world's extreme poor now live in Africa, but the majority of the world's hungry and children affected by stunting live in Asia

34 High and persistent levels of income inequality in low- and middle-income countries

92

35 Income inequality is rising in nearly half the countries of the world including in several low-income countries and some middle-income countries

36 Some countries have reduced income inequality, while for others it has worsened

37 Inequality in the distribution of agricultural land is high in many countries in sub-Saharan Africa

\section{BOXES}

1 Two indicators for SDG Target 2.1 to monitor progress on ending hunger and ensuring access to food for all

2 Revised series of estimates of the prevalence of undernourishment and projections for 2018

98
3 Computing FIES-based estimates so that they are globally comparable

4 How do estimates of food insecurity compare to other important indicators of human development?

25

5 Different food security assessments for different objectives

6 Overweight and obesity and the effect of malnutrition throughout the life cycle

7 Risk factors for overweight and obesity in school-age children

8 Double-duty actions to address all forms of malnutrition in the context of humanitarian assistance

9 What are economic slowdowns and downturns?

10 Why did world hunger not rise during the global food and financial crises?

56

11 What is commodity dependence and how is it measured?

12 Economic slowdown and the cost of basic food in Colombia
13 Explaining poverty and food security and nutrition trends in China and India: the pattern of growth and initial inequalities

14. Addressing inequality in the context of economic growth in Brazil - a way out of hunger and malnutrition

15 Increasing opportunities for indigenous populations is key to nurturing their dietary diversity

100

16 Gender dimensions of inequality in agriculture and rural areas

101

17 Social protection is critical for food security and nutrition, especially during economic slowdowns and downturns

105

18 Homegrown school feeding as a way to prevent undesirable coping strategies

106

19 Boosting small-scale farming for diversification and market integration in Sao Tome and

Principe, and Senegal

20 Trade policy, food systems, and food security and nutrition 


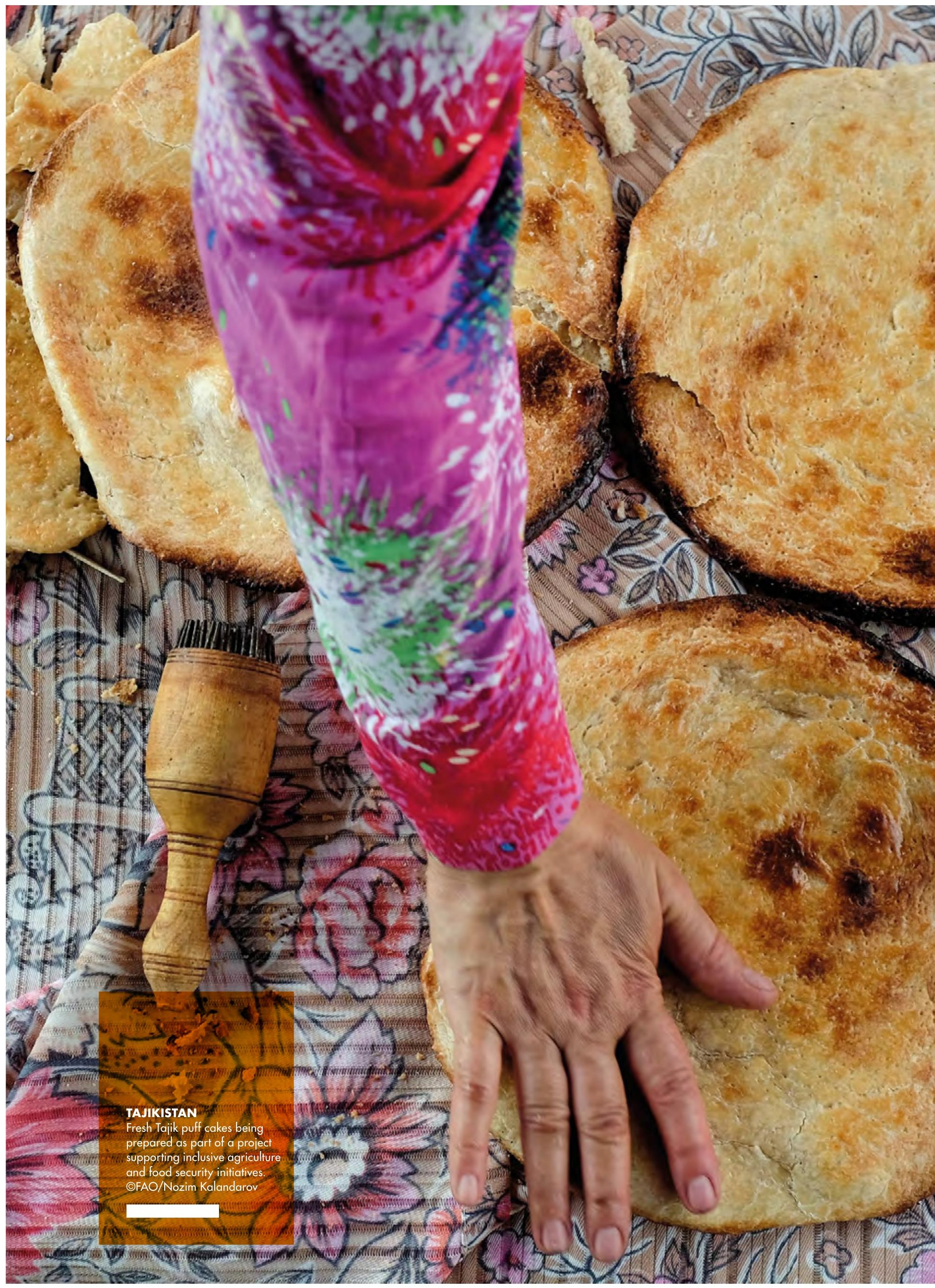




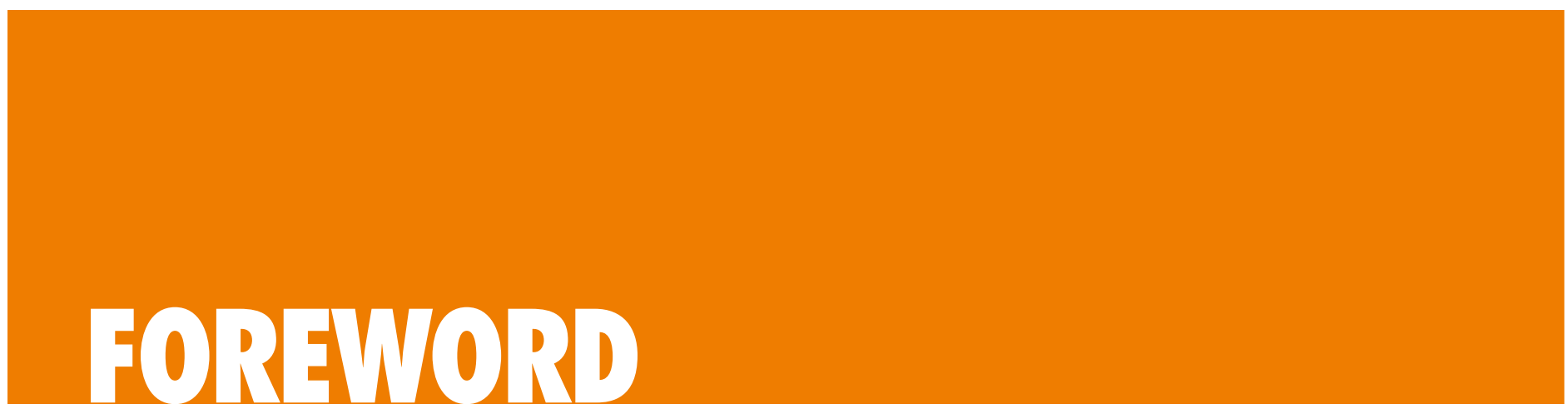

The 2030 Agenda for Sustainable Development puts forward a transformational vision recognizing that our world is changing, bringing with it new challenges that must be overcome if we are to live in a world without hunger, food insecurity and malnutrition in any of its forms.

The world population has grown steadily, with most people now living in urban areas. Technology has evolved at a dizzying pace, while the economy has become increasingly interconnected and globalized. Many countries, however, have not witnessed sustained growth as part of this new economy. The world economy as a whole is not growing as much as expected. Conflict and instability have increased and become more intractable, spurring greater population displacement. Climate change and increasing climate variability and extremes are affecting agricultural productivity, food production and natural resources, with impacts on food systems and rural livelihoods, including a decline in the number of farmers. All of this has led to major shifts in the way in which food is produced, distributed and consumed worldwide - and to new food security, nutrition and health challenges.

This is the third year that we have jointly produced The State of Food Security and Nutrition in the World. It reaffirms our commitment to working together to overcome these emerging challenges and free the world from hunger, food insecurity and malnutrition.
Recent editions of the report showed that the decline in hunger the world had enjoyed for over a decade was at an end, and that hunger was again on the rise. This year, the report shows that the global level of the prevalence of undernourishment has stabilized; however, the absolute number of undernourished people continues to increase, albeit slowly.

More than 820 million people in the world are still hungry today, underscoring the immense challenge of achieving the Zero Hunger target by 2030. Hunger is rising in almost all subregions of Africa and, to a lesser extent, in Latin America and Western Asia. We welcome the great progress seen in Southern Asia in the last five years, but the prevalence of undernourishment in this subregion is still the highest in Asia.

Another disturbing fact is that about 2 billion people in the world experience moderate or severe food insecurity. The lack of regular access to nutritious and sufficient food that these people experience puts them at greater risk of malnutrition and poor health. Although primarily concentrated in low- and middle-income countries, moderate or severe food insecurity also affects 8 percent of the population in Northern America and Europe. In every continent, the prevalence rate is slightly higher among women than men.

With regard to nutrition indicators, we are faring no better. If current trends continue, 
we will meet neither the 2030 SDG Target to halve the number of stunted children nor the 2025 World Health Assembly target to reduce the prevalence of low birthweight by 30 percent. This year's report warns that one in seven live births (20.5 million babies born globally) was characterized by low birthweight in 2015 - many of these low birthweight babies were born to adolescent mothers. The trends of overweight and obesity give us additional reason for concern, as they continue to rise in all regions, particularly among school-age children and adults. The most recent data show that obesity is contributing to 4 million deaths globally and is increasing the risk of morbidity for people in all age groups.

Our actions to tackle these troubling trends will have to be bolder, not only in scale but also in terms of multisectoral collaboration, involving the agriculture, food, health, water and sanitation, education, and other relevant sectors; and in different policy domains, including social protection, development planning and economic policy.

As we seek solutions, we must keep in mind the fragile state of the world economy. Since the sharp 2008-2009 global economic downturn, there has been an uneven pace of recovery in many countries, and the global economic outlook is darkening again.
This year, importantly, the report notes that hunger has been increasing in many countries where economic growth is lagging. Strikingly, the majority of these countries are not low-income countries, but middle-income countries and countries that rely heavily on international trade of primary commodities. Economic shocks are also prolonging and worsening the severity of acute food insecurity in food crisis contexts. Left unattended, these trends may have very unwelcome implications for malnutrition in all its forms. Moreover, we see that economic slowdowns and downturns disproportionally challenge food security and nutrition where inequalities in the distribution of income and other resources are profound.

We must recognize the importance of safeguarding food security and nutrition in times of economic difficulty. We must invest wisely during periods of economic booms to reduce economic vulnerability and build capacity to withstand and quickly recover when economic turmoil erupts. We must foster pro-poor and inclusive structural transformation focusing on people and placing communities at the centre to reduce economic vulnerabilities and set ourselves on track to ending hunger, food insecurity and all forms of malnutrition while "leaving no one behind". 
To make our transformational vision pro-poor and inclusive, we must integrate food security and nutrition concerns into poverty reduction efforts to make the most of the synergies between eradicating poverty, hunger, food insecurity and malnutrition. We must also ensure that reducing gender inequalities and social exclusion of population groups is either the means to, or the outcome of, improved food security and nutrition.
This will require accelerated and aligned actions from all stakeholders and countries, including tireless and more integrated support from the United Nations and the international community to countries in support of their development priorities, through multilateral agreements and means of implementation, so that countries can embark on a pro-poor and inclusive path to transformation in a people-centred way to free the world from poverty, inequalities, hunger, food insecurity and malnutrition in all its forms.

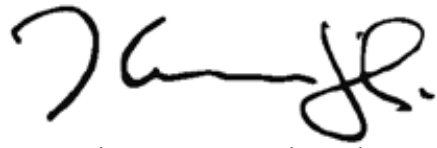

José Graziano da Silva FAO Director-General

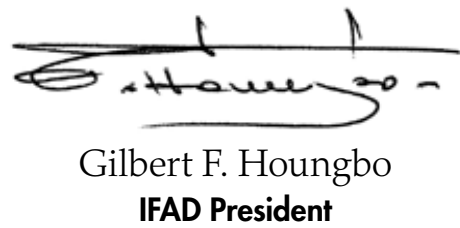

IFAD President

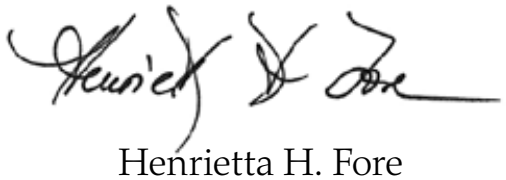

UNICEF Executive Director

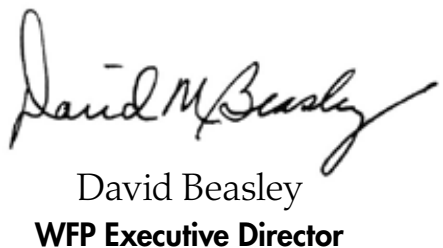

WFP Executive Director

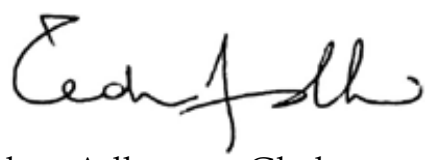

Tedros Adhanom Ghebreyesus

WHO Director-General 
The State of Food Security and Nutrition in the World 2019 has been prepared by the FAO Agricultural Development Economics Division in collaboration with the Statistics Division of the Economic and Social Development Department and a team of technical experts from FAO, IFAD, UNICEF, WFP and WHO.

A senior advisory team consisting of designated senior managers of the five UN publishing partners guided the production of the report. Led by FAO, this team decided on the outline of the report and defined its thematic focus. It further gave oversight to the technical writing team composed of experts from each of the five co-publishing agencies. Background technical papers were prepared to support the research and data analysis undertaken by the members of the writing team.

The writing team produced a number of interim outputs, including an annotated outline, first draft and final draft of the report. These were reviewed, validated and cleared by the senior advisory team at each stage in the preparation process. The final report underwent a rigorous technical review by senior management and technical experts from different divisions and departments within each of the five UN agencies, both at headquarters and decentralized offices. Finally, the report underwent executive review and clearance by the heads of agency of the five co-publishing partners. 


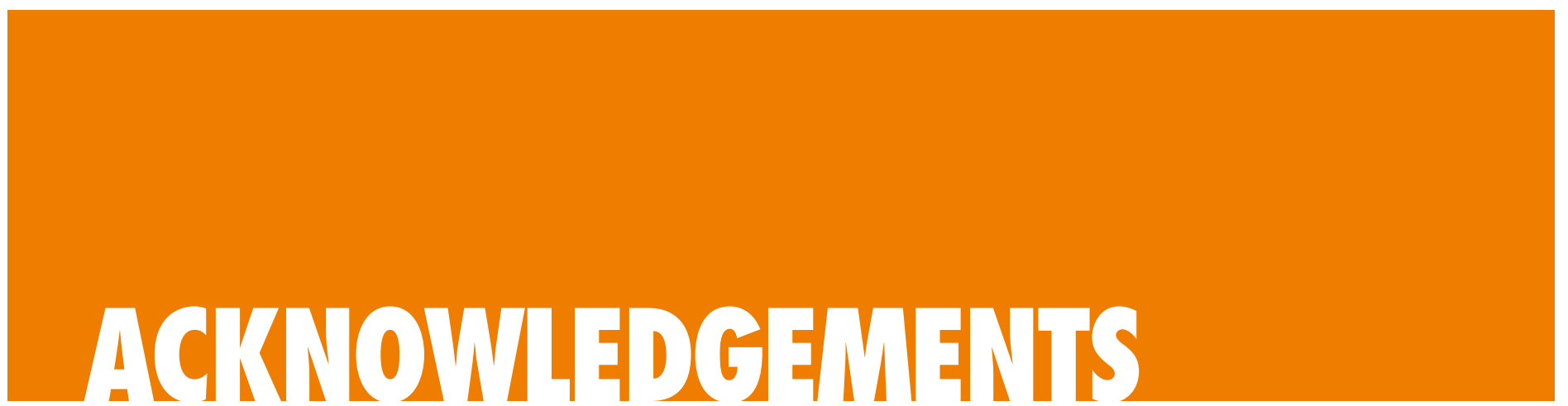

The State of Food Security and Nutrition in the World 2019 was jointly prepared by the Food and Agriculture Organization of the United Nations (FAO), the International Fund for Agricultural Development (IFAD), the United Nations Children's Fund (UNICEF), the World Food Programme (WFP) and the World Health Organization (WHO).

Under the overall guidance of Maximo Torero Cullen, the direction of the publication was carried out by Marco V. Sánchez Cantillo and José Rosero Moncayo, with the overall coordination of Cindy Holleman, the Editor of the publication, all of whom are from the FAO Economic and Social Development Department (ES). The development of the report was guided by a Steering Committee consisting of agency representatives from the five co-publishing partners: Marco V. Sánchez Cantillo (Chair), Sara Savastano (IFAD), Victor Aguayo (UNICEF), Arif Husain (WFP) and Francesco Branca (WHO). Rui Benfica, Alessandra Garbero and Tisorn Songsermsawas (IFAD), Roland Kupka (UNICEF), Yvonne Forsén (WFP), and Marzella Wüstefeld (WHO) contributed to the coordination and provided technical editorial support. Valuable comments and final approval of the report were provided by the executive heads and senior staff of the five co-authoring agencies.

Part 1 of the report was coordinated by Anne Kepple (FAO). Section 1.1 was prepared by Carlo Cafiero with Juan Feng, Mauro Del Grossi, Anne Kepple and Sara Viviani with input from Piero Conforti and Meghan Miller (FAO). Section 1.2 was prepared by Chika Hayashi and Vrinda Mehra (UNICEF) and Laurence Grummer-Strawn (WHO), with input from Anna Lartey, Dalia Mattioni and Trudy Wijnhoven (FAO); Julia Krasevec, Richard Kumapley and Roland Kupka (UNICEF); Mica Jenkins and Jennifer Rosenzweig (WFP); and Melanie Cowan, Katrin Engelhardt, Kaia Engesveen, Karen McColl, Kuntal Saha and Marzella Wüstefeld (WHO), with design support from Nona Reuter (UNICEF). Section 1.3 was prepared by Carlo Cafiero with Abdul Sattar, Cristina Alvarez, Juan Feng, Mauro Del Grossi, Adeeba Ishaq, Anne Kepple and Firas Yassin (FAO); with input from Laurence Grummer-Strawn (WHO). José Rosero Moncayo provided editorial support and input to Part 1.

Part 2 of the report was coordinated by Cindy Holleman (FAO). Sections 2.1, 2.2 and 2.3 were prepared by Cindy Holleman with input from Giovanni Carrasco Azzini, Valentina Conti, Kostas Stamoulis, Margaret Wagah and Trudy Wijnhoven (FAO); Aslihan Arslan, Rui Benfica, Antonella Cordone, Mattia Prayer Galletti, Steven Jonckheere and Tisorn Songsermsawas (IFAD); Oscar Caccavale, Friederike Greb and Lena Hohfeld (WFP); and Karen McColl, Nicole Valentine and Marzella Wüstefeld (WHO). Section 2.4 was prepared by Ana Paula de la O Campos, with input from Kostas Stamoulis and Leopoldo Tornarolli (FAO); Anja Lund Lesa (IFAD); Enrique Delamónica and Roland Kupka (UNICEF); Carmen Burbano and David Ryckembusch (WFP) and Lina Mahy, Karen McColl, Helen Walls and Marzella Wüstefeld (WHO). Marco V. Sánchez Cantillo provided editorial support and input to Part 2.

Numerous colleagues from different technical units and departments across the five co-publishing agencies provided valuable technical comments and input to the report. An agency-wide technical clearance process facilitated a comprehensive technical review by many technical experts. 
Filippo Gheri was responsible for preparing the undernourishment estimates and projections under the supervision of Carlo Cafiero (FAO). Chiamaka Nwosu was responsible for preparing the aggregates for the FIES-based estimates, based on input files prepared by Marinella Cirillo under the supervision of Carlo Cafiero and Sara Viviani (FAO). Supporting data were provided by Salar Tayyib and the Food Balance Sheets team of the FAO Statistics Division and by Boubaker Ben Belhassen, Josef Schmidhuber and the Commodity Balance Sheet team of the FAO Trade and Markets Division. Richard Kumapley (UNICEF) was responsible for consolidating the nutrition data, with input from Chika Hayashi, Julia Krasevec and Vrinda Mehra (UNICEF); and Elaine Borghi and Lisa Rogers (WHO). Valentina Conti (FAO) was responsible for preparing the data and econometric analysis for Part 2 and Annexes 3-6 under the supervision of Cindy Holleman, with data analysis support from Stefania Di Giuseppe and conflict and food crises data input from Aurelien Mellin (FAO).

Support for report production came from Giovanni Carrasco Azzini, Andrew Park and Daniela Verona in the FAO Economic and Social Development Department.

The FAO Meeting Programming and Documentation Service provided printing services and carried out the translations, in addition to the contributors mentioned above.

The FAO Library and Publications Group (OCCP), part of the Office for Corporate Communication, provided editorial support, design and layout, as well as production coordination, for editions in all six official languages. The FAO Internet and Internal Communications Group (OCCI) provided additional design support for Part 1. 


\section{Acroyms

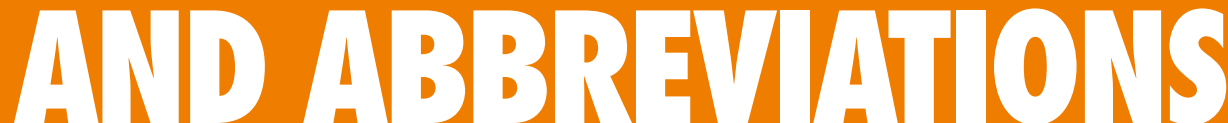

\begin{tabular}{|c|c|c|c|}
\hline BMI & Body mass index & LAC & Latin America and the Caribbean \\
\hline CGP & Child Grant Programme & LICs & Low-income countries \\
\hline \multirow[t]{2}{*}{ CH } & \multirow{2}{*}{$\begin{array}{l}\text { Cadre Harmonisé (harmonized } \\
\text { framework) }\end{array}$} & MDER & Minimum dietary energy requirement \\
\hline & & MENA & Middle East and North Africa \\
\hline CV & Coefficient of variation & \multirow[t]{2}{*}{ MGNREGS } & Mahatma Gandhi National Rural \\
\hline DEC & Dietary energy consumption & & Employment Guarantee Scheme \\
\hline DES & Dietary energy supply & MICs & Middle-income countries \\
\hline FAO & $\begin{array}{l}\text { Food and Agriculture Organization } \\
\text { of the United Nations }\end{array}$ & NCD & Non-communicable disease \\
\hline FDI & Foreign direct investment & PAFA & Agricultural Value Chains Support Project \\
\hline FIES & Food Insecurity Experience Scale & PAL & Physical activity level \\
\hline \multirow[t]{2}{*}{$\mathbf{F I}_{\text {mod+sev }}$} & \multirow{2}{*}{$\begin{array}{l}\text { Prevalence of moderate or severe } \\
\text { food insecurity }\end{array}$} & PoU & Prevalence of undernourishment \\
\hline & & PPP & Purchasing power parity \\
\hline $\mathbf{F l}_{\text {sev }}$ & Prevalence of severe food insecurity & PSNP & Productive Safety Net Programme \\
\hline FSIN & Food Security Information Network & RFM & Risk Financing Mechanism \\
\hline GAM & Global acute malnutrition & SDGs & Sustainable Development Goals \\
\hline GDP & Gross domestic product & SIDS & Small Island Developing States \\
\hline GIEWS & $\begin{array}{l}\text { Global Information and Early Warning } \\
\text { System on Food and Agriculture }\end{array}$ & ToT & Terms of trade \\
\hline GIS & Geographic information system & UHC & Universal health coverage \\
\hline GRFC & Global Report on Food Crises & UNDP & United Nations Development Programme \\
\hline HLPE & $\begin{array}{l}\text { High Level Panel of Experts on Food } \\
\text { Security and Nutrition }\end{array}$ & UNESCO & $\begin{array}{l}\text { United Nations Educational, Scientific } \\
\text { and Cultural Organization }\end{array}$ \\
\hline HSNP & Hunger Safety Net Programme & UNICEF & United Nations Children's Fund \\
\hline \multirow[t]{2}{*}{ ICN2 } & Second International Conference on & USD & United States dollar \\
\hline & rition & WASH & Water, sanitation and hygiene \\
\hline IFAD & $\begin{array}{l}\text { International Fund for Agricultural } \\
\text { Development }\end{array}$ & WDI & World Development Indicators \\
\hline \multirow{3}{*}{$\begin{array}{l}\text { ILO } \\
\text { IPC }\end{array}$} & International Labour Organization & WFP & World Food Programme \\
\hline & Integrated Food Security Phase & WHA & World Health Assembly \\
\hline & Classification & WHO & World Health Organization \\
\hline
\end{tabular}


KAYM MEXY!CEFS

$\rightarrow$ After decades of steady decline, the trend in world hunger - as measured by the prevalence of undernourishment - reverted in 2015, remaining virtually unchanged in the past three years at a level slightly below 11 percent. Meanwhile, the number of people who suffer from hunger has slowly increased. As a result, more than 820 million people in the world were still hungry in 2018, underscoring the immense challenge of achieving the Zero Hunger target by 2030 .

$\rightarrow$ Hunger is on the rise in almost all African subregions, making Africa the region with the highest prevalence of undernourishment, at almost 20 percent. Hunger is also slowly rising in Latin America and the Caribbean, although its prevalence is still below 7 percent. In Asia, Western Asia shows a continuous increase since 2010, with more than 12 percent of its population undernourished today.

This year's report introduces a second indicator for monitoring SDG Target 2.1: the Prevalence of Moderate or Severe Food Insecurity based on the Food Insecurity Experience Scale (FIES). While severe food insecurity is associated with the concept of hunger, people experiencing moderate food insecurity face uncertainties about their ability to obtain food, and have been forced to compromise on the quality and/or quantity of the food they consume. $\rightarrow$ Considering all people in the world affected by moderate levels of food insecurity together with those who suffer from hunger, it is estimated that over 2 billion people do not have regular access to safe, nutritious and sufficient food, including 8 percent of the population in Northern America and Europe.

$\rightarrow$ One in seven newborns, or 20.5 million babies globally, suffered from low birthweight in 2015; no progress has been made in reducing low birthweight since 2012. The number of children under five years in the world affected by stunting, by contrast, has decreased by 10 percent in the past six years. However, with 149 million children still stunted, the pace of progress is too slow to meet the 2030 target of halving the number of stunted children.

$\rightarrow$ Overweight and obesity continue to increase in all regions, particularly among school-age children and adults. In 2018, an estimated 40 million children under five were overweight. In 2016, 131 million children 5-9 years old, 207 million adolescents and 2 billion adults were overweight. About a third of overweight adolescents and adults, and 44 percent of overweight children aged 5-9 were obese. The economic costs of malnutrition are staggering. 
$\rightarrow$ Analysis of household and individual level data from selected countries across all regions shows that food insecurity plays an important role as a determinant of many different forms of malnutrition. In upper-middleand high-income countries in particular, living in a food-insecure household is a predictor of obesity in school-age children, adolescents, and adults.

$\rightarrow$ Previous editions of this report show how conflict and climate variability and extremes are exacerbating the above trends. This year the report shows that the uneven pace of economic recovery and continuing poor economic performance in many countries after the 2008-2009 global economic downturn are also undermining efforts to end hunger and malnutrition. Episodes of financial stress, elevated trade tensions and tightening financial conditions are contributing to uncertain global economic prospects.

$\rightarrow$ Hunger has increased in many countries where the economy has slowed down or contracted, mostly in middle-income countries. Furthermore, economic shocks are contributing to prolonging and worsening the severity of food crises caused primarily by conflict and climate shocks.

$\rightarrow$ Out of 65 countries where recent adverse impacts of economic slowdowns and downturns on food security and nutrition have been strongest, 52 countries rely heavily on primary commodity exports and/or imports. $\rightarrow$ Economic slowdowns or downturns disproportionally undermine food security and nutrition where inequalities are greater. Income inequality increases the likelihood of severe food insecurity, and this effect is 20 percent higher for low-income countries compared with middleincome countries. Income and wealth inequalities are also closely associated with undernutrition, while more complex inequality patterns are associated with obesity.

$\rightarrow$ To safeguard food security and nutrition, it is critical to already have in place economic and social policies to counteract the effects of adverse economic cycles when they arrive, while avoiding cuts in essential services, such as health care and education, at all costs. In the longer term, however, this will only be possible through fostering pro-poor and inclusive structural transformation, particularly in countries that rely heavily on trade in primary commodities.

$\rightarrow$ To ensure that structural transformation is pro-poor and inclusive requires integrating food security and nutrition concerns into poverty reduction efforts, while ensuring that reducing gender inequalities and social exclusion of population groups is either the means to, or outcome of, improved food security and nutrition. 


\section{FX:CDJIIY SIMMMARY}

\section{ADVANCING THE MONITORING OF FOOD SECURITY AND NUTRITION IN THE ERA OF THE 2030 AGENDA FOR SUSTAINABLE DEVELOPMENT}

Two years ago, this annual report was transformed to meet the needs of a new era in monitoring the progress made towards achieving a world without hunger and malnutrition in all its forms, within the framework of the Sustainable Development Goals (SDGs). Specifically, the report began in 2017 to monitor progress towards both the targets of ending hunger and ensuring access to food by all (SDG Target 2.1) and of eliminating all forms of malnutrition (SDG Target 2.2). Given the broadened scope to include a focus on nutrition, the report was renamed The State of Food Security and Nutrition in the World, and UNICEF and the World Health Organization (WHO) joined the traditional partnership of FAO, IFAD and WFP in preparing it. To provide better guidance on how to meet the challenges of the changing world, the report was also expanded to include an in-depth thematic analysis on the underlying factors and drivers behind the observed food security and nutrition trends, and to link progress towards improved food security and nutrition with other SDGs.

This report has traditionally tracked world hunger using the prevalence of undernourishment (PoU), one of the indicators used to monitor global progress towards SDG Target 2.1. This year the report takes another step forward by reporting, for the first time, another indicator of the global SDG monitoring framework: the prevalence of moderate or severe food insecurity based on the Food Insecurity Experience Scale (FIES). The 2030 Agenda, by including this indicator, recognizes that food insecurity is more than hunger. The Zero Hunger goal aims not simply to "eradicate hunger", but also to "ensure access by all people [...] to safe, nutritious and sufficient food all year round" (SDG Target 2.1) and to "eradicate all forms of malnutrition" (SDG Target 2.2). Fortunately, data-gathering and measurement tools are rapidly evolving to meet the monitoring challenges presented by the new agenda and this report now includes this new indicator of food insecurity. The report thus reflects a more comprehensive approach to monitoring progress towards eliminating hunger, food insecurity and malnutrition and to understanding the interrelationships between them.

\section{AFTER A DECADE OF STEADY DECLINE, THE NUMBER OF PEOPLE SUFFERING FROM HUNGER IN THE WORLD HAS SLOWLY INCREASED FOR SEVERAL YEARS IN A ROW, UNDERSCORING THE IMMENSE CHALLENGE OF ENDING HUNGER BY 2030}

The two most recent editions of this report already offered evidence that the decline seen in the prevalence of undernourishment in the world over a decade had ended, and that hunger was slowly on the rise. Evidence available this year confirms that the global level of the prevalence of undernourishment has remained virtually unchanged in the last three years, at a level slightly below 11 percent. The absolute number of people suffering from hunger, however, continues to increase, albeit slowly. More than 820 million people in the world are hungry today, underscoring the immense challenge of achieving the Zero Hunger target by 2030 .

Hunger is on the rise in almost all subregions of Africa, where the prevalence of undernourishment has reached levels of 22.8 percent in sub-Saharan Africa, and to 
a lesser extent in Latin America. In Asia, despite great progress in the last five years, Southern Asia is still the subregion where the prevalence of undernourishment is highest, at almost 15 percent, followed by Western Asia, at over 12 percent, where the situation is worsening. Looking across regions, the undernourished population is distributed unevenly, with the majority living in Asia (more than 500 million). The number has been increasing steadily in Africa where it reached almost 260 million people in 2018, with more than 90 percent living in sub-Saharan Africa.

A broader look at the extent of food insecurity, beyond hunger, shows that 17.2 percent of the world population, or 1.3 billion people, have experienced food insecurity at moderate levels. This means that they do not have regular access to nutritious and sufficient food - even if they are not necessarily suffering from hunger, they are at greater risk of various forms of malnutrition and poor health. The combination of moderate and severe levels of food insecurity brings the estimate to 26.4 percent of the world population, amounting to a total of about 2 billion people.

In high-income countries, too, sizeable portions of the population lack regular access to nutritious and sufficient food. Eight percent of the population in Northern America and Europe is estimated to be food insecure, mainly at moderate levels of severity.

A closer examination of the estimates of food insecurity (moderate and severe) points also to a gender gap. In every continent, the prevalence of food insecurity is slightly higher among women than men, with the largest differences found in Latin America.

\section{CHILDHOOD STUNTING IS DECREASING TOO SLOWLY AND ANAEMIA IN WOMEN PERSISTS; BUT OVERWEIGHT AND OBESITY ARE ACTUALIY RISING IN MOST COUNTRIES, CALLING ATTENTION TO THE NEED FOR GREATER EFFORTS TO HALT AND REVERSE THIS GROWING EPIDEMIC}

This year the report takes a closer look at data on overweight and obesity, a serious public health challenge affecting people of all ages. Obesity is on the rise in almost all countries, contributing to 4 million deaths globally. The increase in prevalence of obesity between 2000 and 2016 has been even faster than that of overweight. No region is exempt from the epidemic of overweight and obesity. The prevalence of overweight is increasing in all age groups, with particularly steep increases among school-age children and adults. Throughout the world, most school-age children do not eat enough fruit or vegetables, regularly consume fast food and carbonated soft drinks, and are not physically active on a daily basis. Multifaceted, multisectoral approaches are needed to halt and reverse the obesity epidemic. Policies to protect, promote and support breastfeeding and to increase the availability and affordability of nutritious foods that constitute a healthy diet are required, along with measures to create healthier food environments and limit consumption of harmful fats, salt and sugars.

It is encouraging to note that the number of stunted children has declined by 10 percent over the past six years, but this rate of reduction is too slow to achieve the 2030 target of a 50 percent reduction in the number of stunted children. While the prevalence of stunting is decreasing in almost every region, the extent of progress varies considerably. 
Africa has made the least progress in reducing stunting prevalence since 2012. In 2018, Africa and Asia accounted for more than nine out of ten of all stunted children globally, representing 39.5 percent and 54.9 percent of the global total, respectively.

In the next ten years, urgent action is needed to achieve other global nutrition targets as well. Only 40 percent of infants under six months are exclusively breastfed, which is far from the 2030 target of 70 percent. In 2018, 7.3 percent of children were wasted, and this must be reduced by more than half to reach the target of less than 3 percent by 2030 . Anaemia currently affects 33 percent of women of reproductive age - more than double the 2030 target of 15 percent.

Low birthweight estimates are included for the first time in this year's edition of the report, following the release of new global estimates. They indicate that one in seven live births, or 20.5 million babies globally, suffered from low birthweight in 2015. New evidence this year also shows that no progress has been made in reducing the prevalence of low birthweight since 2012. This lack of progress signals that it will be difficult to achieve the World Health Assembly global goal of a 30 percent reduction in the prevalence of low birthweight infants by 2030. This is concerning, as low birthweight newborns have a higher risk of dying in the first month of life, and those who survive are more likely to suffer from stunted growth and face increased risk of adult-onset chronic conditions including obesity and diabetes.

Beyond the immense human costs of malnutrition, the economic costs are staggering. It is projected that undernutrition will reduce Gross Domestic Product (GDP) by up to 11 percent in Africa and Asia, while obesity costs USD 2 trillion annually, largely driven by the value placed on lost economic productivity, plus direct healthcare costs worldwide. The various forms of malnutrition are intertwined throughout the life cycle and between generations, with undernutrition in foetal and early life contributing to stunted physical growth and higher risk of overweight and chronic diseases like diabetes later in life. The UN Decade of Action on Nutrition, based on the ICN2 Framework for Action, emphasizes that tackling malnutrition in all its forms is not the domain of any one sector alone. The health, education, agriculture, social protection, planning and economic policy sectors all have a role to play, as well as legislators and other political leaders.

Moderate levels of food insecurity - defined as uncertain access to food of sufficient quality and/or quantity, but not so extreme that it causes insufficient dietary energy intake (undernourishment) - can increase the risk of seemingly divergent forms of malnutrition, including overweight and obesity. Analysis of household and individual level data from selected countries across all regions reveals that food insecurity plays an important role as a determinant of different forms of malnutrition in all countries studied. In upper-middle- and high-income countries, living in a food-insecure household is a predictor of obesity in school-age children, adolescents and adults. Factors that help to explain the link between food insecurity and overweight and obesity include the higher cost of nutritious foods (and their substitution with cheaper foods that are high in fats and sugar), the stress of living with uncertain access to food, and physiological adaptations to food restrictions. 


\section{ECONOMIC SLOWDOWNS AND DOWNTURNS POSE CHALENGES FOR FOOD SECURITY AND NUTRITION; CREATING SUSTAINED ESCAPES REQUIRES SAFEGUARDING AGAINST THESE AND TACKLING INCREASING INEQUALITIES}

Previous editions of this report identified that conflict, climate variability and extremes, and economic slowdowns were behind the recent rise in hunger. The previous two editions respectively provided an in-depth analysis on the first two drivers. This year the report looks closely at the third key driver, economic slowdowns, broadening the focus to also include economic downturns.

The risk that the unwelcome trends in hunger, food insecurity and malnutrition described above will continue is particularly high today, considering the fragile state and worrisome outlook of the world economy. The latest global economic prospects warn of slowing and stalled economic growth in many countries, including emerging and developing economies. Most regions rebounded after the sharp 2008-2009 global economic downturn, but the recovery has been uneven and short lived, as many countries have experienced generally declining trends in economic growth since 2011. Episodes of financial stress, elevated trade tensions and tightening financial conditions are clouding global economic prospects.

New evidence confirms hunger has been on the rise for many of the countries where the economy slowed down or contracted. Most countries (65 out of 77) that experienced a rise in undernourishment between 2011 and 2017 simultaneously suffered an economic slowdown or downturn. Strikingly, the majority of these cases involved not low-income countries, but middle-income countries. Economic shocks have also prolonged and worsened the impact of conflict and climate events on acute food insecurity requiring urgent humanitarian assistance in food crisis countries. In more than half of the countries affected by food crises in 2018, the compounding impact of multiple economic shocks worsened the severity of acute food insecurity, affecting 96 million people.

Marked declines in primary commodity prices have contributed to economic slowdowns and downturns during the 2011-2017 period, mainly affecting countries highly dependent on primary commodity exports and/or imports. Most countries (52 out of 65) that saw undernourishment rise during recent economic slowdowns and downturns are countries whose economies are highly dependent on primary commodities for export and/or imports. In 2018, most of the countries (81 percent) where economic shocks worsened the severity of the food crises were high primary commodity-dependent countries.

Economic events generally affect food security and nutrition, depending on the extreme poverty level, but also on the existence of inequalities in income distribution as well as in access to basic services and assets, many of which result from social exclusion and the marginalization of groups. Where inequality is greater, economic slowdowns and downturns have a disproportionate effect on food security and nutrition for lower-income populations. Inequality increases the likelihood of severe food insecurity and this effect is 20 percent higher for low-income countries compared with middle-income countries. Income and wealth inequalities are also closely associated with undernutrition, while more complex inequality patterns are associated with obesity. 
This report calls for action on two fronts: the first, safeguarding food security and nutrition through economic and social policies that help counteract the effects of economic slowdowns or downturns, including guaranteeing funding of social safety nets and ensuring universal access to health and education; and, the second, tackling existing inequalities at all levels through multisectoral policies that make it possible to more sustainably escape from food insecurity and malnutrition. Acting on these two fronts requires short- and long-term policy responses that will depend on institutional capacity and availability of contingency mechanisms and funds to support them. The latter, in turn, requires strengthening the savings capacity of the economy when it is growing, so as to make countercyclical policies feasible when the need arises.

In the short term, countries need to protect incomes and purchasing power, particularly for the most affected households, through social protection programmes, including cash transfers and school feeding; public works programmes that help reduce unemployment; health sector policies that protect the poor against catastrophic out-of-pocket healthcare costs; and, if needed, policies aimed at reducing excessive volatility of food prices. In the longer term, countries need to invest wisely during periods of economic booms to reduce economic vulnerabilities and inequalities; build capacity to withstand shocks; maintain health and other social expenditures; use policy tools to create healthier food environments; and quickly recover when economic turmoil erupts. This requires balancing a set of policies and investments to achieve a structural transformation that also fosters poverty reduction and more egalitarian societies. It is imperative, in particular, that countries with economies that are highly dependent on primary commodities foster such inclusive structural transformation to reduce their economic vulnerability.

This structural transformation, involving agriculture and food systems, must help ensure that food security and nutrition objectives are met. This will depend on the type of commodities and the quality of food that is generated under this process, and will require fostering better access to more nutritious foods that constitute a healthy diet to all. Policymakers must also ensure that policies that facilitate trade also help achieve nutrition objectives. Integrating food security and nutrition concerns into poverty reduction efforts, while increasing synergies between poverty reduction, hunger and malnutrition eradication must also be part of the transformation. Furthermore, reducing gender inequalities and those inequalities arising from social discrimination and exclusion of population groups needs to be either the means to improving food security and nutrition, or the outcome of doing so.

The trends, findings and policy recommendations briefly presented in this executive summary are discussed in much greater detail in the two parts of this report.

Part 1 presents the most recent trends in hunger, food insecurity and malnutrition in all its forms with a focus on monitoring progress on SDG Targets 2.1 and 2.2. It introduces for the first time one of the indicators of the SDG monitoring framework for SDG Target 2.1: the prevalence of moderate or severe food insecurity based on the Food Insecurity Experience Scale (FIES). This year's report also presents for the first time low birthweight estimates. The last section of Part 1 presents new evidence on the links between moderate or severe food insecurity and the various forms of malnutrition. 
Part 2 looks closely at the role that economic slowdowns and downturns have played in recent food security and nutrition trends. The analysis ultimately points to guidance on what short- and long-term policies are necessary to safeguard food security and nutrition, either during episodes of economic turmoil or in preparation for them. This is particularly relevant today given the alarming signs in the world economy, so that policy considerations are relevant to achieving the goals of ending hunger and all forms of malnutrition by 2030 (SDG Targets 2.1 and 2.2) as well as other related SDGs, especially - though not exclusively - eradicating extreme poverty (SDG 1), ensuring decent work and inclusive economic growth (SDG 8), and reducing inequalities (SDG 10). 


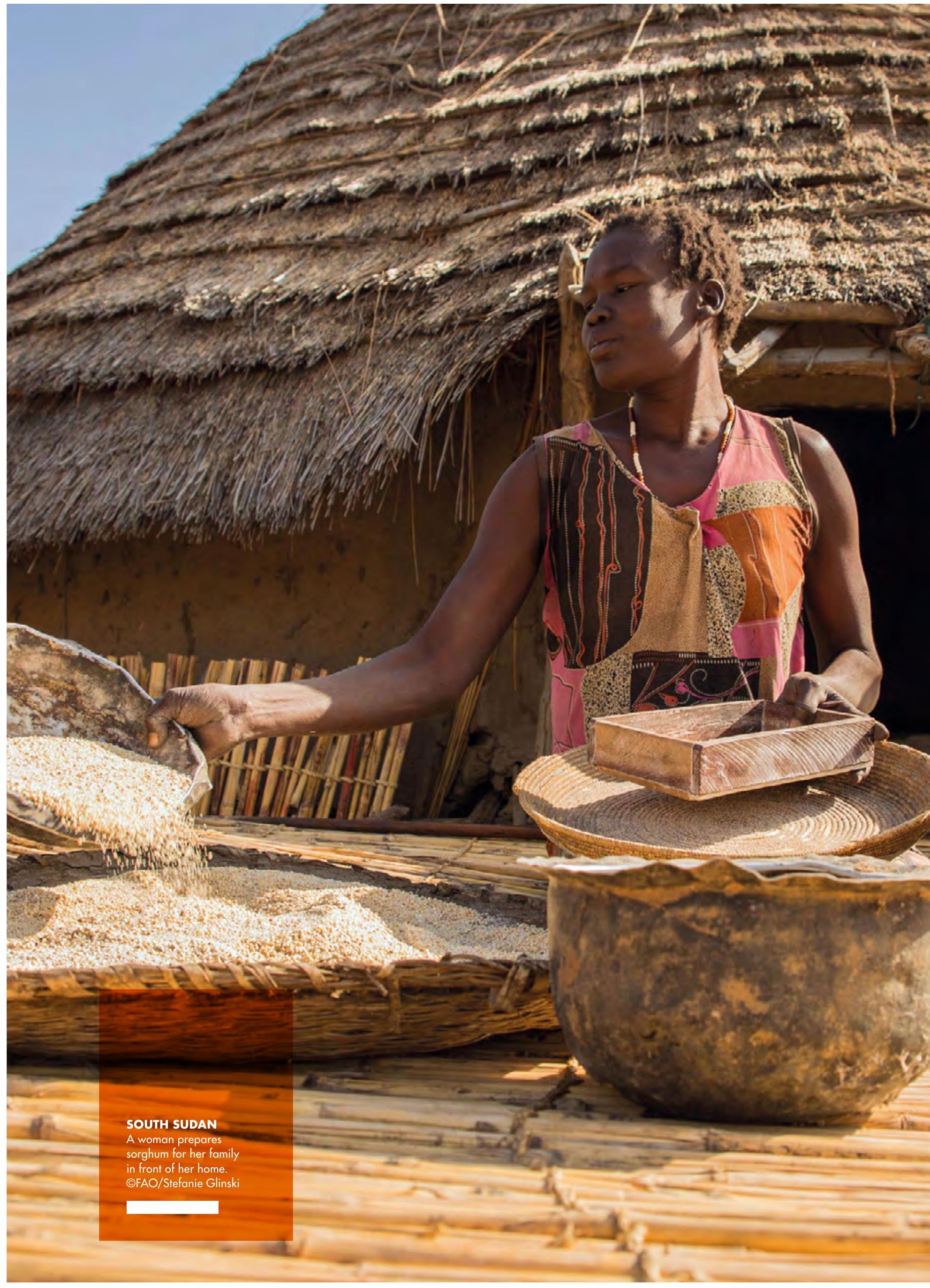




\section{FOOD SECURITY AWD NiRilor AROUD THE WOR T T 2019}

Much has changed since 1974, when FAO first began reporting on the extent of hunger in the world. The world population has grown steadily, with most people now living in urban areas. Technology has evolved at a dizzying pace, while the economy has become increasingly interconnected and globalized. All of this has led to major shifts in the way in which food is produced, distributed and consumed worldwide. But these transformations have also brought about worrying developments in malnutrition. Although the prevalence of child stunting has decreased significantly over the past 20 years, overweight and obesity, and diet-related non-communicable diseases, are rapidly on the rise.

This vastly different world calls for new ways of thinking about hunger and food insecurity and their consequences for nutrition. The imperative is to make sure no one suffers from hunger.

But we must also recognize that there are many people who, while not "hungry" in the sense that they suffer physical discomfort caused by severe lack of dietary energy, may still be food insecure. They have access to food to meet their energy requirements, yet are uncertain that it will last, and may be forced to reduce the quality and/or quantity of the food they eat in order to get by. This moderate level of severity of food insecurity can contribute to various forms of malnutrition and has serious consequences for health and well-being.

The UN member countries recognized the importance of going beyond hunger when they set universal and ambitious targets for the 2030 Agenda for Sustainable Development. The "Zero Hunger" goal aims not simply to "eradicate hunger", but also to "ensure access by all people [...] to safe, nutritious and sufficient food all year round" (SDG Target 2.1) and to "eradicate all forms of malnutrition" (SDG Target 2.2). For this reason, this report was renamed The State of Food Security and Nutrition in the World in 2017. Since then it has reported on nutrition indicators, in addition to food security indicators.

Part 1 of this year's report aims to bring new ways of thinking to bear on the latest trends in hunger, food insecurity, and various forms of malnutrition. Section 1.1 presents global, regional and subregional figures of hunger and introduces a new indicator of food insecurity that goes beyond hunger to include moderate levels of food insecurity. Section 1.2 presents the latest figures for seven nutrition indicators, including three SDG 2 indicators of child malnutrition (stunting, wasting and overweight), with a spotlight on the rapid rise in overweight and obesity. The links between food insecurity and nutritional outcomes - particularly overweight and obesity - are explored in Section 1.3. 


\section{W. RECENT TRENDS IN HUNGER AND FOOD INSECURITY}

\section{KEY MESSAGES}

$\rightarrow$ After decades of steady decline, the trend in world hunger - as measured by the prevalence of undernourishment - reverted in 2015, remaining virtually unchanged in the past three years at a level slightly below 11 percent. Meanwhile, the number of people who suffer from hunger has slowly increased. As a result, more than 820 million people in the world are still hungry today, underscoring the immense challenge of achieving the Zero Hunger target by 2030 .

$\rightarrow$ This recent trend is confirmed by estimates of severe food insecurity in the world based on the Food Insecurity Experience Scale (FIES), which is another way to monitor hunger.

$\rightarrow$ Hunger is on the rise in almost all subregions of Africa, the region with the highest prevalence of undernourishment, at almost 20 percent. It is also rising slowly in Latin America and the Caribbean, although the prevalence there is still below 7 percent. In Asia, where undernourishment affects 11 percent of the population, Southern Asia saw great progress in the last five years but is still the subregion with the highest prevalence of undernourishment, at almost 15 percent, followed by Western Asia at over 12 percent, where the situation is worsening.

$\rightarrow$ Estimates of SDG Indicator 2.1.2, which monitors progress towards the target of ensuring access to food for all, reveal that a total of about 2 billion people in the world experience some level of food insecurity, including moderate. People who are moderately food insecure may not necessarily suffer from hunger, but they lack regular access to nutritious and sufficient food, putting them at greater risk of various forms of malnutrition and poor health.

$\rightarrow$ This new indicator also reveals that even in high-income countries, sizeable portions of the population lack regular access to nutritious and sufficient food; 8 percent of the population in Northern America and Europe is estimated to be food insecure, mainly at moderate levels.

\section{$\rightarrow$ In every continent, the prevalence of food} insecurity is slightly higher among women than men, with the largest differences found in Latin America.

\section{Food insecurity is more than just hunger}

The main indicator for monitoring progress on the eradication of hunger in the world reported in this report is the prevalence of undernourishment, or PoU (SDG Indicator 2.1.1). Beginning in 2017, the prevalence of severe food insecurity based on the Food Insecurity Experience Scale (FIES) was also included in the report as another, complementary indicator of hunger using a different approach.

This year's report now takes a step forward by also reporting, for the first time, estimates of the prevalence of moderate or severe food insecurity based on the FIES (SDG Indicator 2.1.2).

This indicator provides a perspective on global food insecurity relevant for all countries of the world: one that looks beyond hunger towards the goal of ensuring access to nutritious and sufficient food for all (Box 1). As estimates of SDG Indicator 2.1.2 refer to the total number of people suffering from food insecurity, including at moderate levels, it should come as no surprise that they correspond to a much higher number of people than those who suffer from hunger. 

AND ENSURING ACCESS TO FOOD FOR ALL

The SDG framework endorsed by member countries of the UN Statistical Commission in March 2017 and adopted by the UN General Assembly on 6 July $2017^{1}$ includes two indicators for monitoring SDG Target 2.1: the prevalence of undernourishment PoU (SDG Indicator 2.1.1) and prevalence of moderate or severe food insecurity based on the Food Insecurity Experience Scale - FIES (SDG Indicator 2.1.2).

SDG Indicator 2.1.1, the prevalence of undernourishment (PoU), is FAO's traditional indicator used to monitor hunger at the global and regional levels. It is computed from aggregated country-level data on food available for human consumption (compiled annually for most countries in the world in FAO's Food Balance Sheets) and on less frequently obtained data on food consumption from surveys, available for a growing (but still partial) number of countries. For each country, the distribution of average, daily dietary energy consumption in the population is compared with the distribution of dietary energy needs (derived from the composition of the population by age, gender and physical activity levels) to produce an estimate of the proportion of the population that lacks enough dietary energy for a healthy, active life.

SDG Indicator 2.1.2, the prevalence of moderate or severe food insecurity in the population $\left(\mathrm{FI}_{\text {mod+sev }}\right)$ based on the Food Insecurity Experience Scale (FIES), was developed by FAO to complement the information provided by the PoU and to provide a broader perspective on the food access dimension of food security. ${ }^{2}$ The approach relies on data obtained by directly asking people through surveys about the occurrence of conditions and behaviours that are known to reflect constrained access to food. Based on their responses to the FIES Survey Module items, the individuals surveyed are assigned a probability of being in one of three classes, as defined by two globally set thresholds: food secure or marginally insecure; moderately food insecure; and severely food insecure. The $\mathrm{FI}_{\text {mod+sev }}$ is the cumulative probability of being in the two classes of moderate and severe food insecurity. A separate indicator $\left(\mathrm{FI}_{\text {sev }}\right)$ is computed by considering only the severe food insecurity class.

\section{TWO INDICATORS FOR SDG TARGET 2.1 TO MONITOR PROGRESS ON ENDING HUNGER AND ENSURING ACCESS TO FOOD FOR ALL}

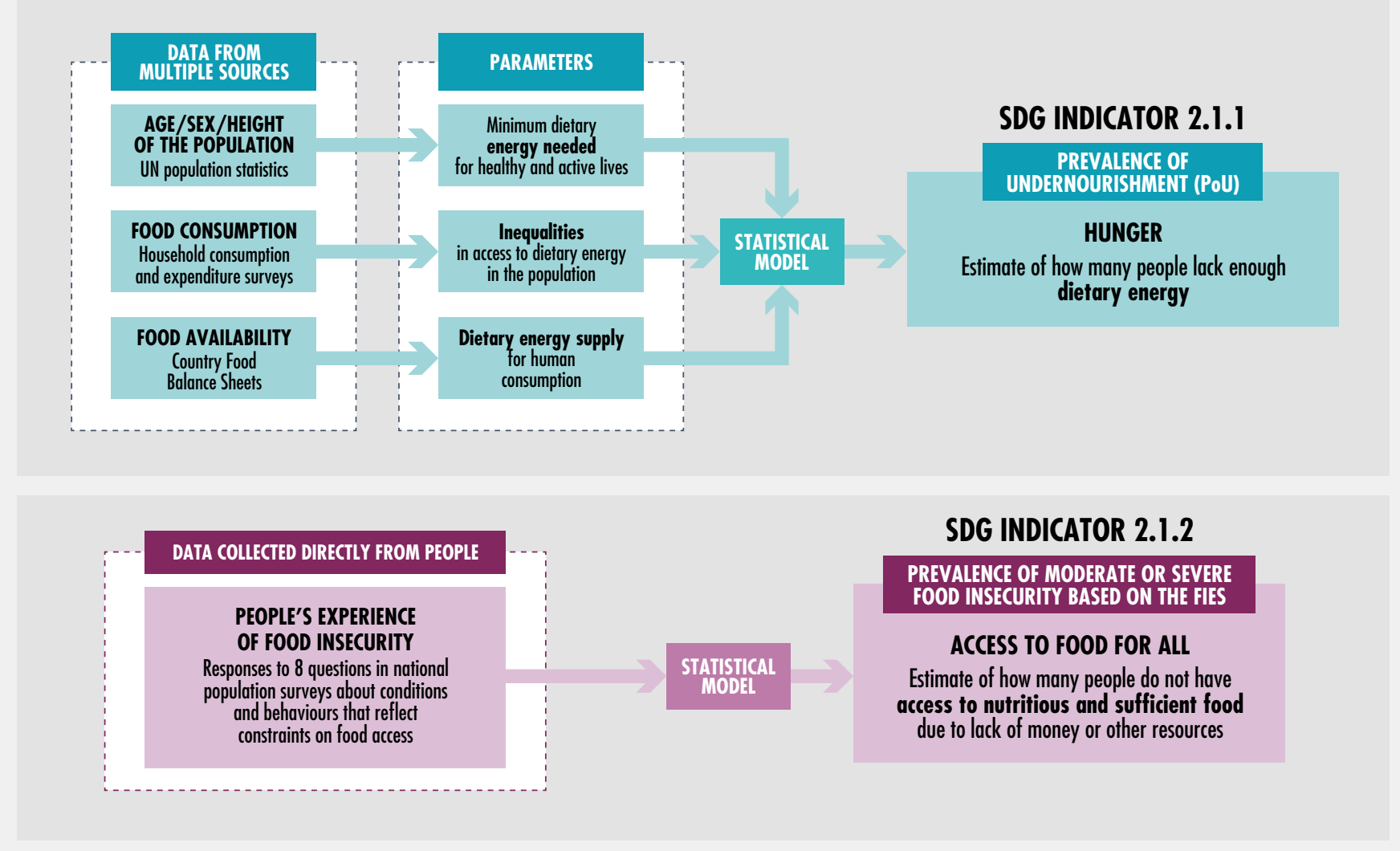


People experiencing moderate food insecurity face uncertainties about their ability to obtain food and have been forced to reduce, at times during the year, the quality and/or quantity of food they consume due to lack of money or other resources. It thus refers to a lack of consistent access to food, which diminishes dietary quality, disrupts normal eating patterns, and can have negative consequences for nutrition, health and well-being. People facing severe food insecurity, on the other hand, have likely run out of food, experienced hunger and, at the most extreme, gone for days without eating, putting their health and well-being at grave risk.

The figure below illustrates the meaning of food security, moderate food insecurity and severe food insecurity, with each category shown as a proportion of the total population. $\mathrm{Fl}_{\mathrm{sev}}$ can be considered a complementary indicator to the $\mathrm{PoU}$ in measuring the extent of hunger. SDG Indicator 2.1.2 $\left(\mathrm{FI}_{\text {modtsev }}\right)$ is the proportion of the total population represented by those who experience food insecurity at moderate or severe levels combined. This indicator is particularly relevant for countries where severe food deprivation may no longer be of concern, but where sizeable pockets of food insecurity still remain. In this sense, it is an indicator that is fully aligned with the universality principles of the 2030 Agenda.

As a measure of access to adequate food, Indicator 2.1.2 brings the perspective of the Right to Food to the SDG monitoring framework. Countries can use the FIES to obtain data-based evidence about the distribution and severity of food insecurity to build political will and implement policies to effectively realize the human right to adequate food, leaving no one behind.

The full potential of the FIES to generate statistics that inform policy is realized when the tool is applied in large national population surveys that allow for detailed analyses of the food-insecurity situation by income, gender, age, race, ethnicity, migratory status, disability, geographic location, or other policy-relevant characteristics. This is already the case for a growing number of countries.

\section{EXPLANATION OF FOOD-INSECURITY SEVERITY LEVELS MEASURED BY THE FIES IN SDG INDICATOR 2.1.2}

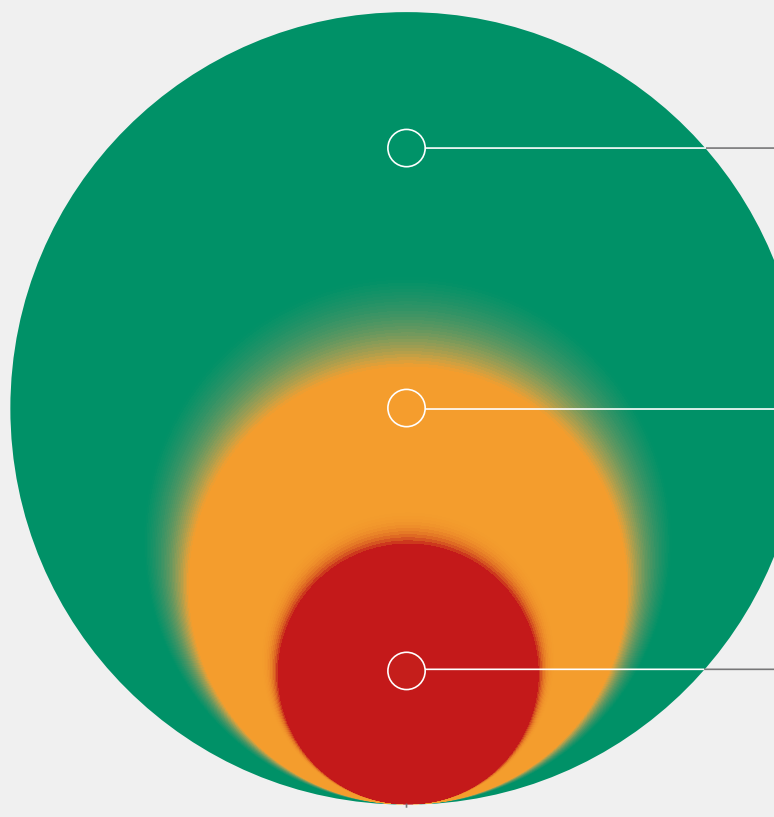

SOURCE: FAO
FOOD SECURITY

Adequate access to food in both quality and quantity

' UN. 2017. United Nations Statistical Commission - 48th Session (2017). In: UNSD - United Nations Statistical Commission [online]. New York, USA. [Cited 4 April 2019]. https://unstats.un.org/unsd/statcom/48th-session; and UN. 2017. Indicator 2.1.2: Prevalence of moderate or severe food insecurity in the population, based on the Food Insecurity Experience Scale (FIES). [Cited 4 April 2019]. https://unstats.un.org/sdgs/metadata/files/Metadata-02-01-02.pdf

${ }^{2}$ The other three dimensions of food security are food availability, utilization and stability. 
FIGURE 1

THE NUMBER OF UNDERNOURISHED PEOPLE IN THE WORLD HAS BEEN ON THE RISE SINCE 2015, AND IS BACK TO LEVELS SEEN IN 2010-2011

17 1107
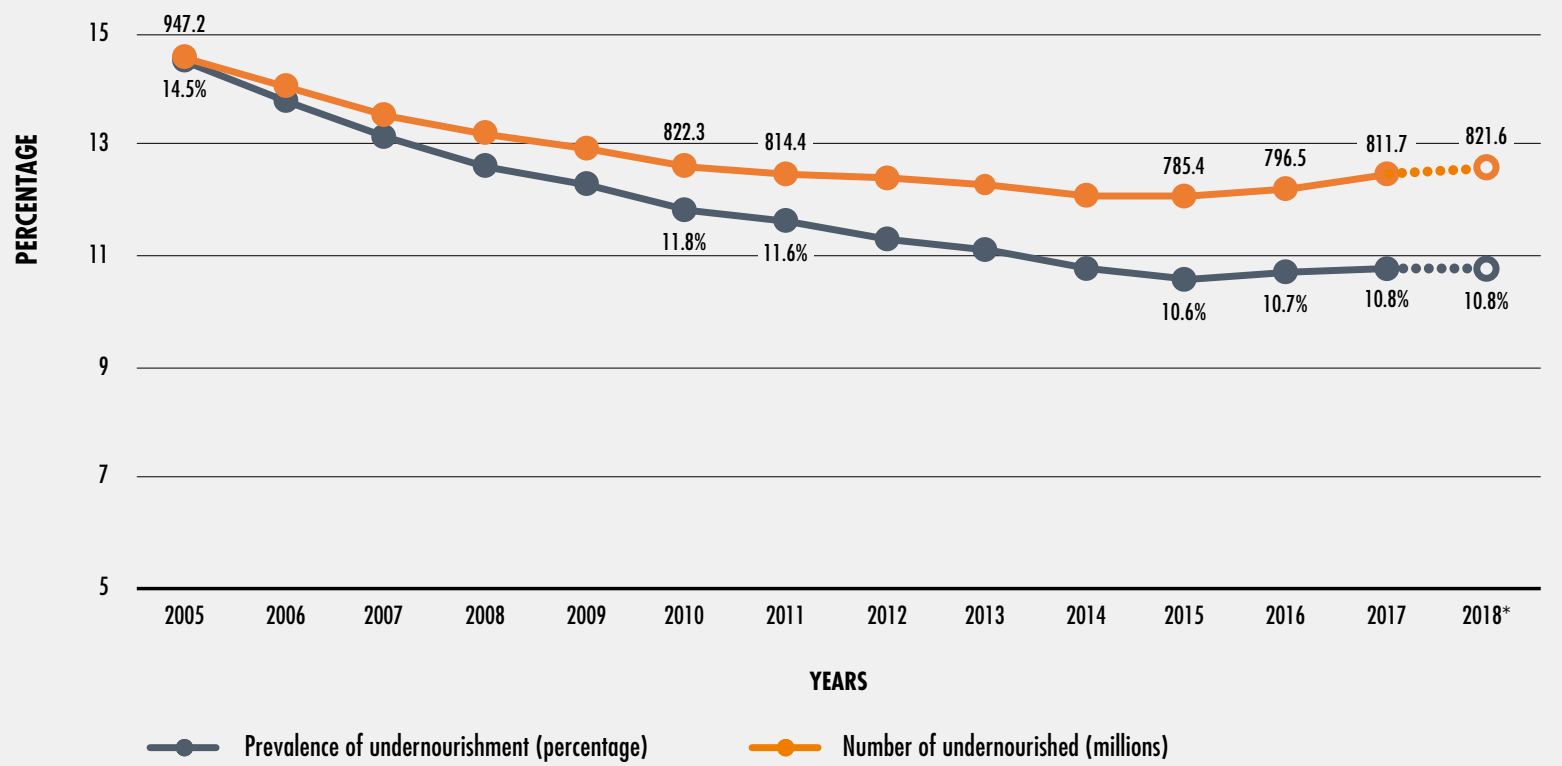

327

NOTES: * Values for 2018 are projections as illustrated by dotted lines and empty circles. The entire series was carefully revised to reflect new information made available since the publication of the last edition of the report; it replaces all series published previously. See Box 2. SOURCE: FAO.

\section{SDG Indicator 2.1.1 \\ Prevalence of undernourishment (PoU)}

The two most recent editions of The State of Food Security and Nutrition in the World already offered evidence that the decades-long decline in the prevalence of undernourishment in the world had ended and that hunger was slowly on the rise. Additional evidence available this year confirms that the global level of the PoU has remained virtually unchanged at a level slightly below 11 percent, while the total number of undernourished (NoU) has been slowly increasing for several years in a row. ${ }^{1}$ This means that today, a little over 820 million people suffer from hunger, corresponding to about one in every nine people in the world (Figure 1, Tables 1 and 2). This underscores the immense challenge posed by achieving the Zero Hunger target by 2030 .

The situation is most alarming in Africa, where since 2015 the PoU shows slight but steady increases in almost all subregions. It has reached levels of 26.5 percent and 30.8 percent in Middle and Eastern Africa, respectively, with rapid 
BOX 2

REVISED SERIES OF ESTIMATES OF THE PREVALENCE OF UNDERNOURISHMENT AND PROJECTIONS FOR 2018

The PoU series is always revised prior to publication of each new edition of The State of Food Security and Nutrition in the World. This is done in order to take into account any new information that FAO has received since the release of the previous edition. As this process usually implies possible backward revisions of the entire series, readers should avoid comparing the PoU values across different editions of this report and always refer to the most current report, including the time series covering past years.

This year's main revision involved an update of the Food Balance Sheet series used to estimate the average Dietary Energy Supply (DES) for the 53 countries with the largest number of undernourished people, bringing them up to date through 2017. When needed to produce PoU estimates for the most recent periods, the DES was projected based on rates of growth in the total availability of dietary energy from cereals and meats. These rates were deduced from the series of commodity balances prepared by FAO's Trade and Markets Division. ${ }^{1}$

An estimate of the coefficient of variation (CV) of per capita levels of habitual, daily energy consumption in the population was obtained from suitable national household surveys and carried forward from the last available year. For countries for which there was no food consumption survey covering the period 2014-2018, the CV was projected based on indirect evidence, including observed changes in the reported prevalence of severe food insecurity estimated using the FIES. This was done in order to capture possible recent changes in the inequality on access to food, which would be reflected in $\mathrm{Fl}_{\text {sev }}$.

Minimum dietary energy requirements (MDER) for 2018 were computed based on the 2018 projected population structure from The World Population Prospects, 2017 Revision. $^{2}$

I FAO Trade and Markets Division has developed and maintained a Commodity Balance Sheet database (XCBS) that provides up-to-date and elementary information for analysis of the state of agricultural commodity markets at global and regional levels, as well as the food situation of all countries in the world. The XCBS contains balance sheet-structured data for the major commodities in the following groups: cereals, dairy, meat, oil-bearing crops, sugar, tropical beverages, bananas and citrus since the 1980s. Data from the XCBS are used in a number of systems and publications, such as FAO Global Information and Early Warning System, Agricultural Market Information System, Food Outlook and Crop Prospects and Food Situation. ${ }^{2}$ For further details, see the methodological note in Annex IB.

growth in recent years, especially in Western Africa (Figure 2).

As highlighted in past editions of this report, these trends are mostly driven by a combination of factors, including conflicts and extreme weather events, currently affecting a number of countries in Africa. In conflict-affected countries in sub-Saharan Africa ${ }^{2}$ for instance, the number of undernourished people increased by 23.4 million between 2015 and 2018 - a significantly sharper increase compared with countries not exposed to conflicts (Figure 3).
An even more dramatic, longer-term impact on food security seems to be associated with exposure to drought. Countries classified as drought-sensitive ${ }^{3}$ in sub-Saharan Africa have seen the prevalence of undernourishment increase from 17.4 to 21.8 percent over the last six years, while in the same period the PoU actually dropped (from an average of 24.6 to 23.8 percent) in the other countries of the region. The number of undernourished people in drought-sensitive countries has increased by 45.6 percent since 2012 (Figure 4). 
TABLE 1

PREVALENCE OF UNDERNOURISHMENT (PoU) IN THE WORLD, 2005-2018

\begin{tabular}{|c|c|c|c|c|c|c|}
\hline & \multicolumn{6}{|c|}{ Prevalence of undernourishment (\%) } \\
\hline & 2005 & 2010 & 2015 & 2016 & 2017 & $2018^{*}$ \\
\hline WORLD & 14.5 & 11.8 & 10.6 & 10.7 & 10.8 & 10.8 \\
\hline AFRICA & 21.2 & 19.1 & 18.3 & 19.2 & 19.8 & 19.9 \\
\hline Northern Africa & 6.2 & 5.0 & 6.9 & 7.0 & 7.0 & 7.1 \\
\hline Sub-Saharan Africa & 24.3 & 21.7 & 20.9 & 22.0 & 22.7 & 22.8 \\
\hline Eastern Africa & 34.3 & 31.2 & 29.9 & 31.0 & 30.8 & 30.8 \\
\hline Middle Africa & 32.4 & 27.8 & 24.7 & 25.9 & 26.4 & 26.5 \\
\hline Southern Africa & 6.5 & 7.1 & 7.8 & 8.5 & 8.3 & 8.0 \\
\hline Western Africa & 12.3 & 10.4 & 11.4 & 12.4 & 14.4 & 14.7 \\
\hline ASIA & 17.4 & 13.6 & 11.7 & 11.5 & 11.4 & 11.3 \\
\hline Central Asia & 11.1 & 7.3 & 5.5 & 5.5 & 5.7 & 5.7 \\
\hline Eastern Asia & 14.1 & 11.2 & 8.4 & 8.4 & 8.4 & 8.3 \\
\hline South-eastern Asia & 18.5 & 12.7 & 9.8 & 9.6 & 9.4 & 9.2 \\
\hline Southern Asia & 21.5 & 17.2 & 15.7 & 15.1 & 14.8 & 14.7 \\
\hline Western Asia & 9.4 & 8.6 & 11.2 & 11.6 & 12.2 & 12.4 \\
\hline Western Asia and Northern Africa & 8.0 & 7.1 & 9.2 & 9.5 & 9.8 & 9.9 \\
\hline LATIN AMERICA AND THE CARIBBEAN & 9.1 & 6.8 & 6.2 & 6.3 & 6.5 & 6.5 \\
\hline Caribbean & 23.3 & 19.8 & 18.3 & 18.0 & 18.0 & 18.4 \\
\hline Latin America & 8.1 & 5.9 & 5.3 & 5.5 & 5.7 & 5.7 \\
\hline Central America & 8.4 & 7.2 & 6.3 & 6.1 & 6.1 & 6.1 \\
\hline South America & 7.9 & 5.3 & 4.9 & 5.3 & 5.5 & 5.5 \\
\hline OCEANIA & 5.5 & 5.2 & 5.9 & 6.0 & 6.1 & 6.2 \\
\hline NORTHERN AMERICA AND EUROPE & $<2.5$ & $<2.5$ & $<2.5$ & $<2.5$ & $<2.5$ & $<2.5$ \\
\hline
\end{tabular}

NOTES: * Projected values. See Box 2 and Annex IB for a description of how the projections are made. For country compositions of each regional/subregional aggregate, see Notes on geographic regions in statistical tables inside the back cover. SOURCE: FAO.

This overall dire picture of undernourishment in Africa is consistent with the extent of poverty in the region. With a headcount ratio of 41 percent, sub-Saharan Africa accounted for 56 percent of the world's extreme poor in 2015, according to the World Bank Group. ${ }^{4}$ However, this is not just a problem of extreme poverty. Even resource-rich countries in these regions still have high rates of undernourishment (Tables Al.1 and Al.2 in Annex 1A), suggesting that something more crucial is at play in terms of the structure of their food systems, and that still much more should be done to improve distribution and consumption of food. Some of the fundamental determinants of undernourishment related to underlying economic structures and inequalities are discussed in Part 2 of this report.

In Asia, the PoU has been steadily decreasing in most regions, reaching 11.4 percent in 2017. The exception is Western Asia, where the PoU has increased since 2010 to reach more than 12 percent of the population (Figure 5). This level in the region is second only to Southern Asia, which, despite great progress in the last five years, is still the subregion where undernourishment is highest, at almost 15 percent. 
TABLE 2

NUMBER OF UNDERNOURISHED PEOPLE IN THE WORLD, 2005-2018

\begin{tabular}{|c|c|c|c|c|c|c|}
\hline & \multicolumn{6}{|c|}{ Number of undernourished (millions) } \\
\hline & 2005 & 2010 & 2015 & 2016 & 2017 & $2018^{*}$ \\
\hline WORLD & 947.2 & 822.3 & 785.4 & 796.5 & 811.7 & 821.6 \\
\hline AFRICA & 196.0 & 199.8 & 217.9 & 234.6 & 248.6 & 256.1 \\
\hline Northern Africa & 9.7 & 8.5 & 15.5 & 16.1 & 16.5 & 17.0 \\
\hline Sub-Saharan Africa & 176.7 & 180.6 & 202.4 & 218.5 & 232.1 & 239.1 \\
\hline Eastern Africa & 113.5 & 118.6 & 119.3 & 126.9 & 129.8 & 133.1 \\
\hline Middle Africa & 36.2 & 36.5 & 37.9 & 41.1 & 43.2 & 44.6 \\
\hline Southern Africa & 3.6 & 4.2 & 5.0 & 5.5 & 5.4 & 5.3 \\
\hline Western Africa & 33.0 & 31.9 & 40.3 & 45.0 & 53.7 & 56.1 \\
\hline ASIA & 688.6 & 572.1 & 518.7 & 512.3 & 512.4 & 513.9 \\
\hline Central Asia & 6.5 & 4.6 & 3.8 & 3.8 & 4.0 & 4.1 \\
\hline Eastern Asia & 219.1 & 178.4 & 138.1 & 137.8 & 138.1 & 137.0 \\
\hline South-eastern Asia & 103.8 & 75.9 & 61.9 & 61.9 & 61.1 & 60.6 \\
\hline Southern Asia & 339.8 & 293.1 & 286.1 & 278.3 & 276.4 & 278.5 \\
\hline Western Asia & 19.4 & 20.1 & 28.8 & 30.5 & 32.7 & 33.7 \\
\hline Western Asia and Northern Africa & 29.1 & 28.6 & 44.3 & 46.6 & 49.2 & 50.6 \\
\hline LATIN AMERICA AND THE CARIBBEAN & 51.1 & 40.7 & 39.1 & 40.4 & 41.7 & 42.5 \\
\hline Caribbean & 9.1 & 8.0 & 7.7 & 7.6 & 7.7 & 7.8 \\
\hline Latin America & 42.1 & 32.6 & 31.5 & 32.9 & 34.0 & 34.7 \\
\hline Central America & 12.4 & 11.6 & 10.9 & 10.6 & 10.7 & 11.0 \\
\hline South America & 29.6 & 21.1 & 20.6 & 22.2 & 23.2 & 23.7 \\
\hline OCEANIA & 1.8 & 1.9 & 2.3 & 2.4 & 2.5 & 2.6 \\
\hline NORTHERN AMERICA AND EUROPE & n.r. & n.r. & n.r. & n.r. & n.r. & n.r. \\
\hline
\end{tabular}

NOTES: * Projected values. See Box 2 and Annex IB for a description of how the projections are made.

n.r. = not reported, as the prevalence is less than 2.5 percent. Regional totals may differ from the sum of subregions, due to rounding. For country compositions of each regional/subregional aggregate, see Notes on geographic regions in statistical tables inside the back cover. SOURCE: FAO.

Within the Western Asian subregion, the difference is striking between countries that have been affected by popular uprisings in Arab states and other conflicts, ${ }^{5}$ and those that have not been affected. For those affected countries, Figure 6 shows an increase in the PoU from the already higher value of 17.8 percent, to 27.0 percent, almost doubling the number of undernourished between 2010 and 2018. The PoU did not change during the same period in the other countries in the region.

In Latin America and the Caribbean (LAC), rates of undernourishment have increased in recent years, largely as a consequence of the situation in South America, where the PoU increased from 4.6 percent in 2013 to 5.5 percent in 2017 (Figure 7). In fact, South America hosts the majority (68 percent) of the undernourished in Latin America.

The increase observed in recent years is due to the economic slowdown in several countries, particularly the Bolivarian Republic of Venezuela, where the PoU increased almost fourfold, from 6.4 percent in 2012-2014 to 21.2 percent in 2016-2018 (Figure 8). During the same recession period, inflation in the country was reported to have reached circa 10 million percent and growth in the real GDP worsened, going from negative 
FIGURE 2

\section{UNDERNOURISHMENT IS RISING RAPIDLY IN WESTERN AFRICA}

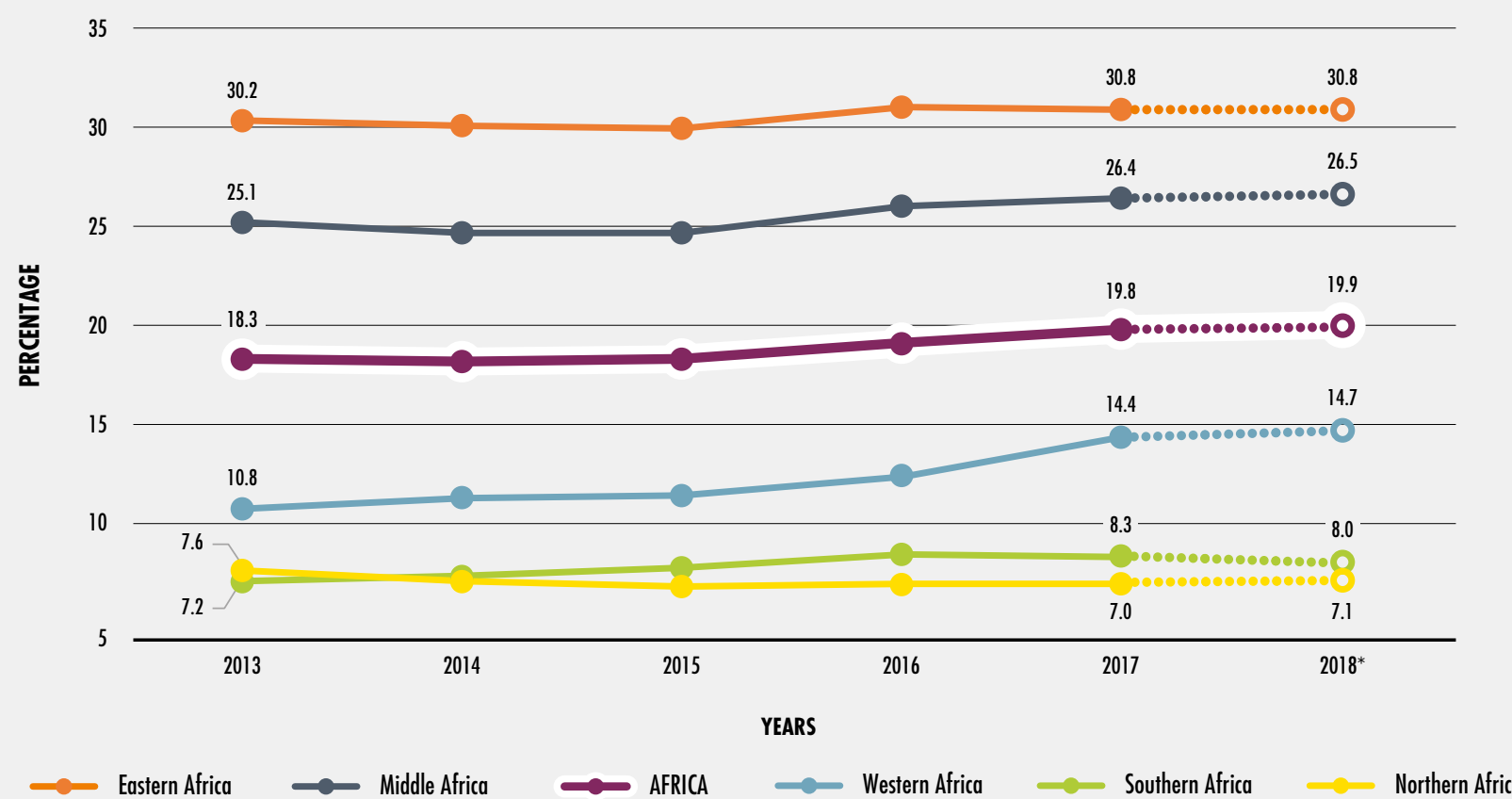

NOTES: * Projected values, illustrated by dotted lines and empty circles.

SOURCE: FAO.

\section{FIGURE 3}

UNDERNOURISHMENT INCREASES SHARPLY IN COUNTRIES AFFECTED BY CONFLICT IN SUB-SAHARAN AFRICA

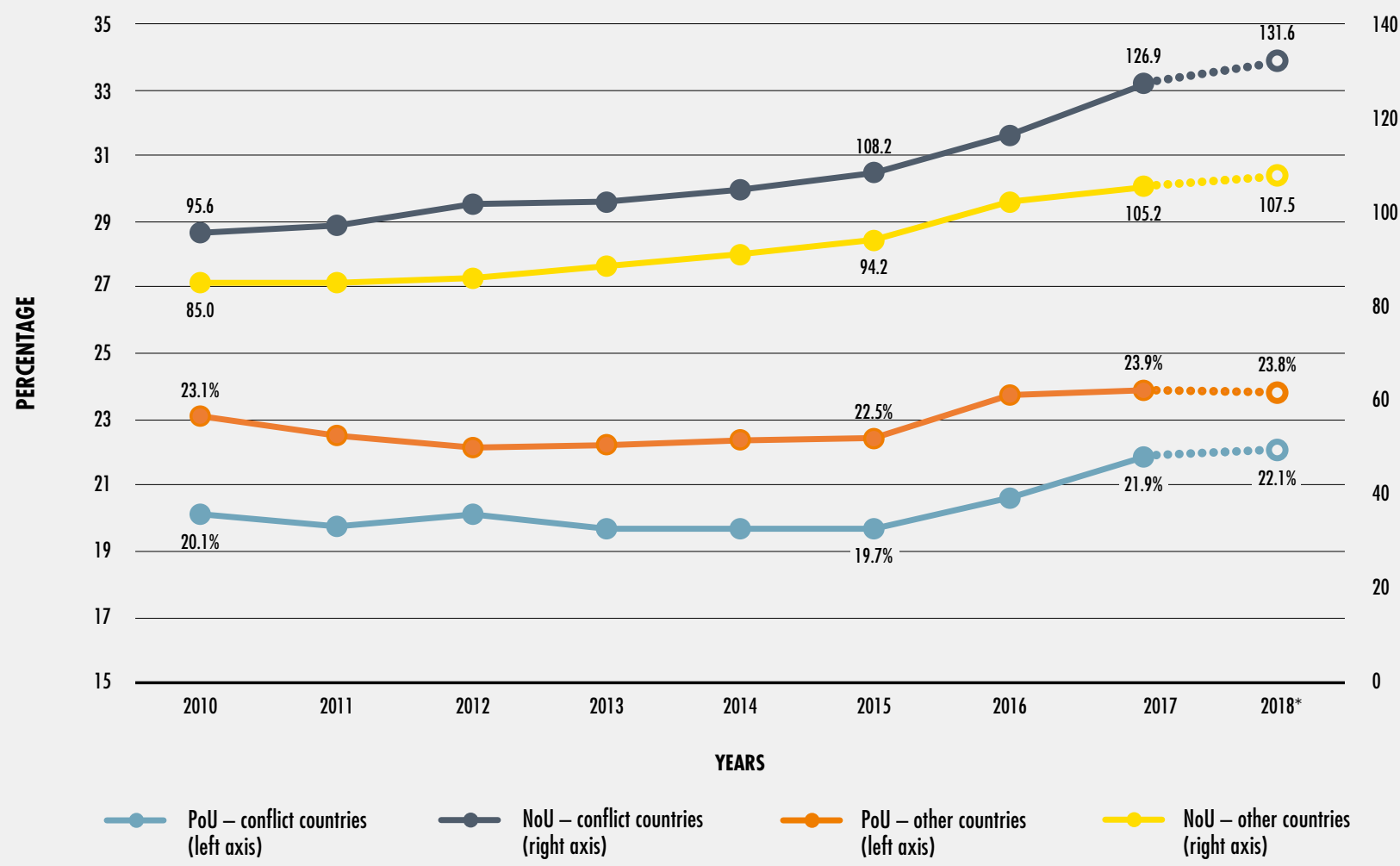

NOTES: * Projected values, illustrated by dotted lines and empty circles. 
FIGURE 4

DROUGHTS ARE ONE OF THE FACTORS BEHIND THE RECENT INCREASE IN UNDERNOURISHMENT IN SUB-SAHARAN AFRICA

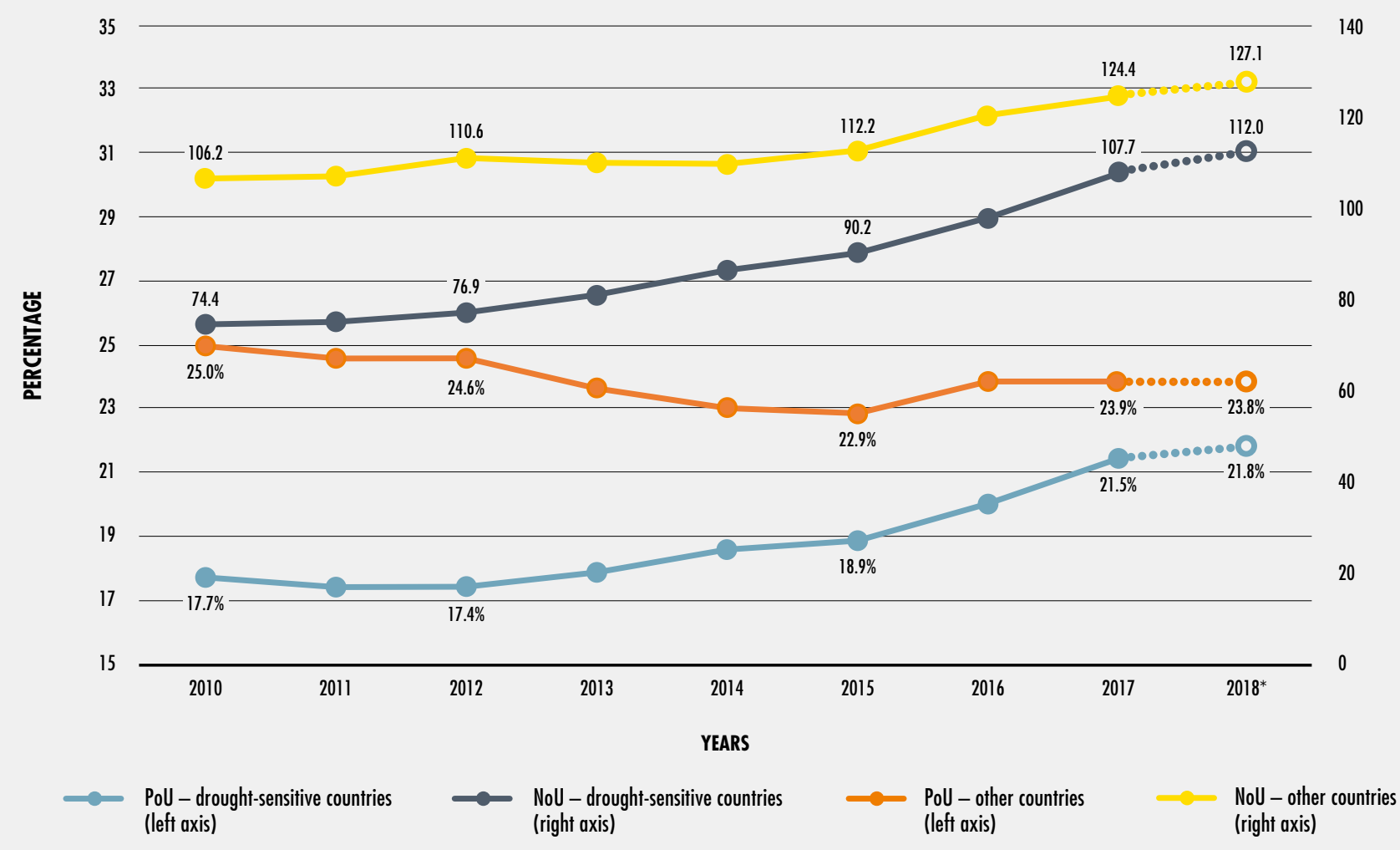

NOTES: * Projected values, illustrated by dotted lines and empty circles. SOURCE: FAO.

3.9 percent in 2014 to an estimated negative 25 percent in $2018 .^{6}$

By contrast, prevalence rates of undernourishment in Central America and the Caribbean, despite being higher than those in South America, have been decreasing in recent years. This is consistent with the economic growth pattern observed in these subregions, where real GDP grew at a rate of about 4 percent between 2014 and 2018, with moderate rates of inflation consistently below 3 percent in the same period. ${ }^{7}$
Analysis of the distribution of the undernourished population across regions in the world shows that the majority (more than 500 million) live in Asia (Figure 9). The number has been increasing steadily in Africa, where it reached almost 260 million people in 2018, with more than 90 percent living in sub-Saharan Africa.

Given these figures and the trends observed over the last decade, achieving Zero Hunger by 2030 appears to be an increasingly daunting challenge. 
FIGURE 5

WESTERN ASIA IS THE ONLY SUBREGION IN ASIA WHERE UNDERNOURISHMENT IS ON THE RISE

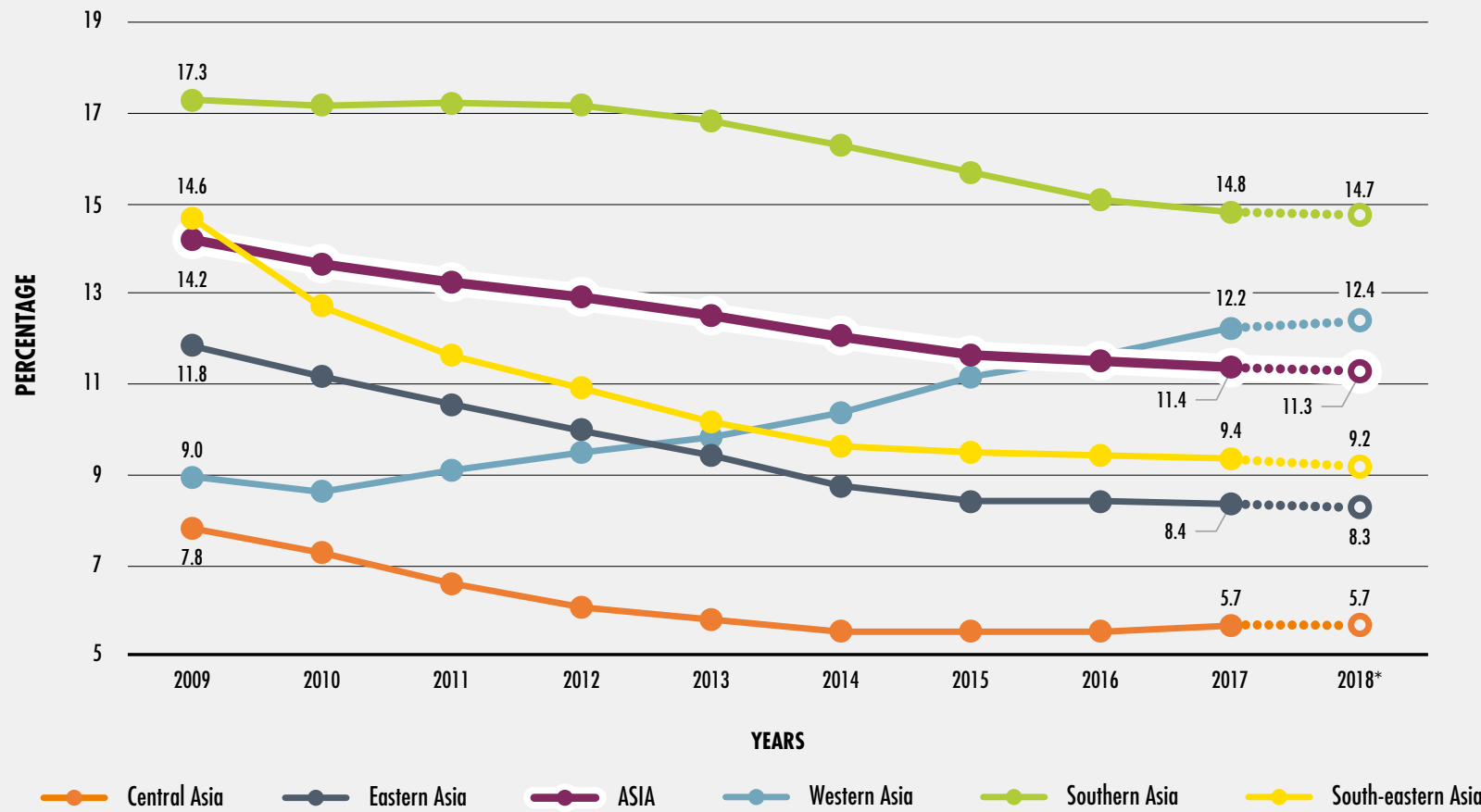

NOTES: * Projected values, illustrated by dotted lines and empty circles.

SOURCE: FAO.

FIGURE 6

UNDERNOURISHMENT IS ON THE RISE IN WESTERN ASIAN COUNTRIES AFFECTED BY POPULAR UPRISINGS IN THE RECENT PAST

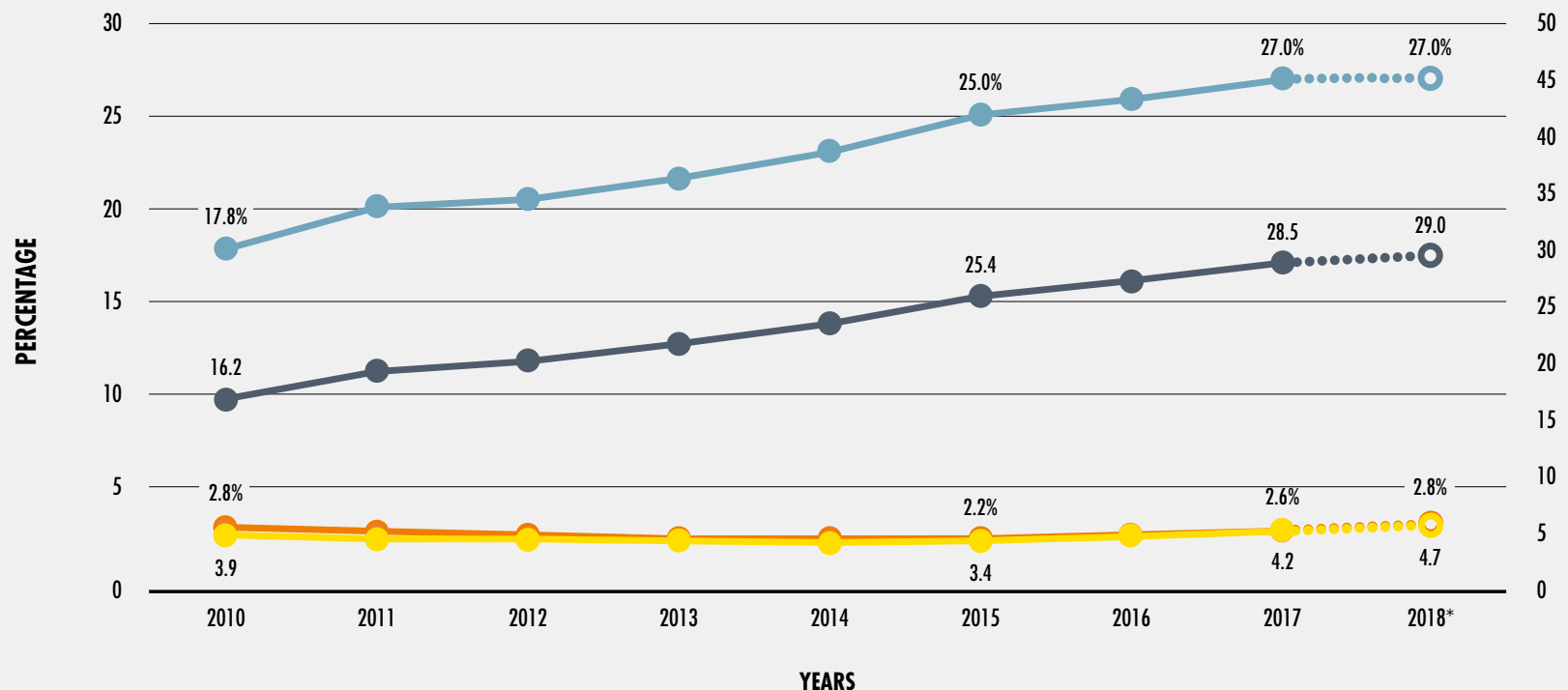

- PoU - Arab countries affected by popular uprisings (left axis) $\quad-$ PoU - other countries in Western Asia (left axis)
$\rightarrow$ NoU - Arab countries affected by popular uprisings (right axis) $\quad$ NoU - other countries in Western Asia (right axis)

NOTES: * Projected values, illustrated by dotted lines and empty circles.

SOURCE: FAO. 
FIGURE 7

INCREASING UNDERNOURISHMENT IN SOUTH AMERICAN COUNTRIES IS PUTIING UPWARD PRESSURE ON THE LATIN AMERICA AND THE CARIBBEAN REGIONAL AVERAGE

20

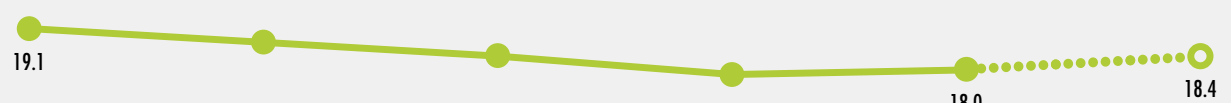

15

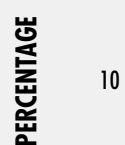

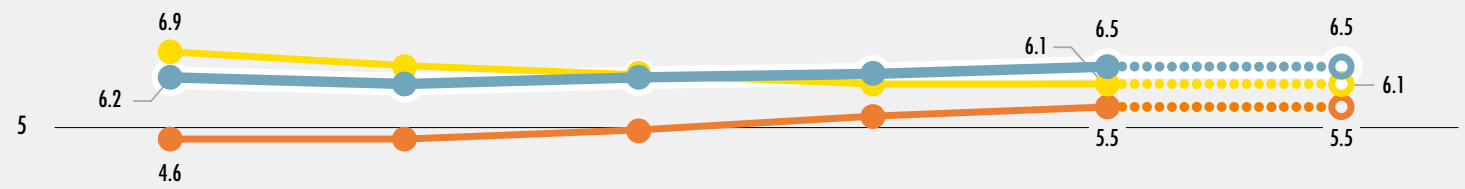

0

2013

2014

2015

2016

2017

$2018^{*}$

YEARS

Caribbean

Central America

- LATIN AMERICA AND THE CARIBBEAN

$\longrightarrow$ South America

NOTES: * Projected values, illustrated by dotted lines and empty circles.

SOURCE: FAO.

\section{FIGURE 8}

THE BOLIVARIAN REPUBLIC OF VENEZUELA SHOWS A SIGNIFICANT INCREASE

IN THE PREVALENCE OF UNDERNOURISHMENT IN RECENT YEARS

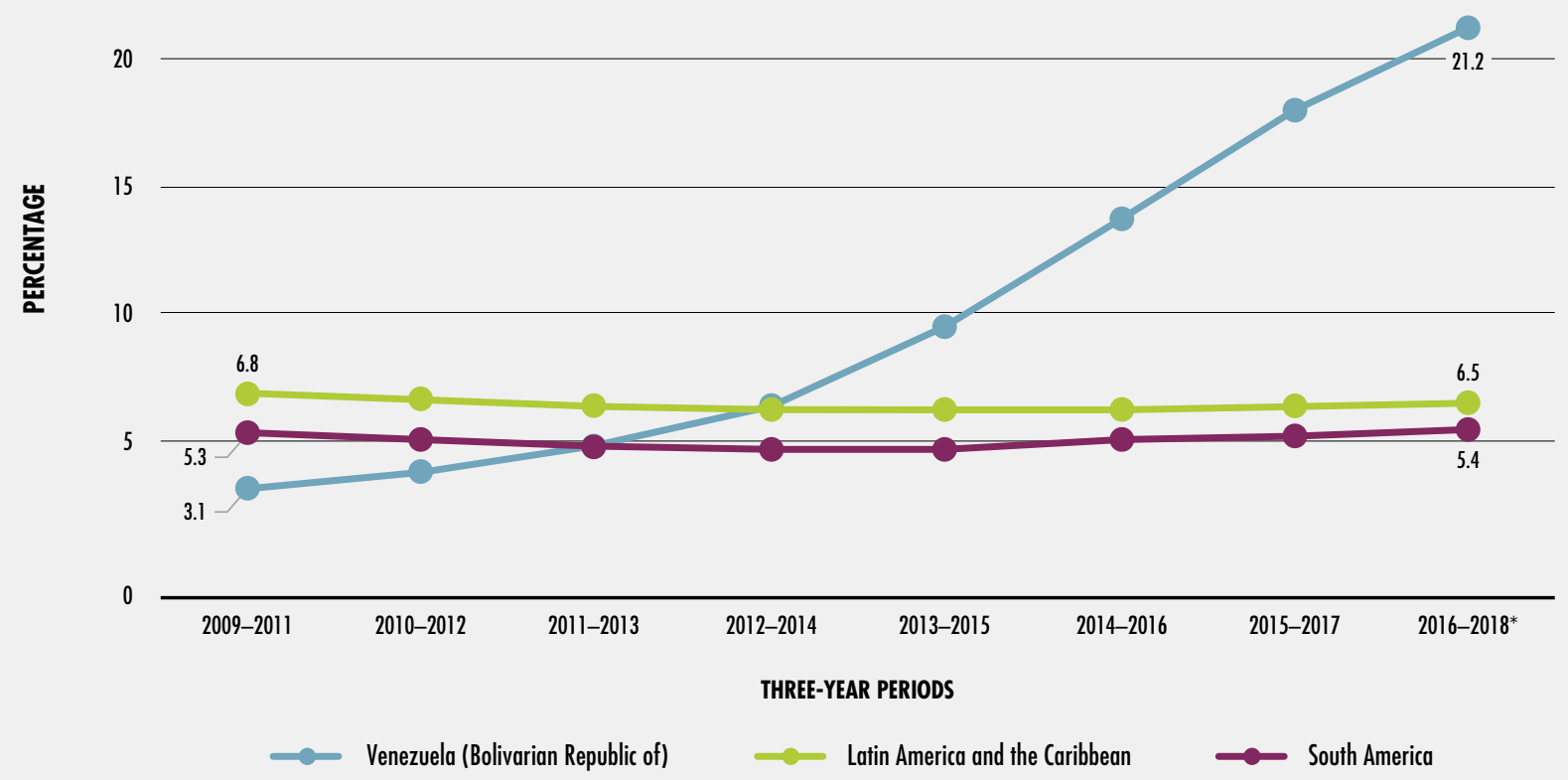

NOTES: * 2018 estimates in the 2016-2018 three-year averages are projected values. 


\section{DISTRIBUTION OF UNDERNOURISHMENT IN THE WORLD (IN MILLIONS) IN 2018*}
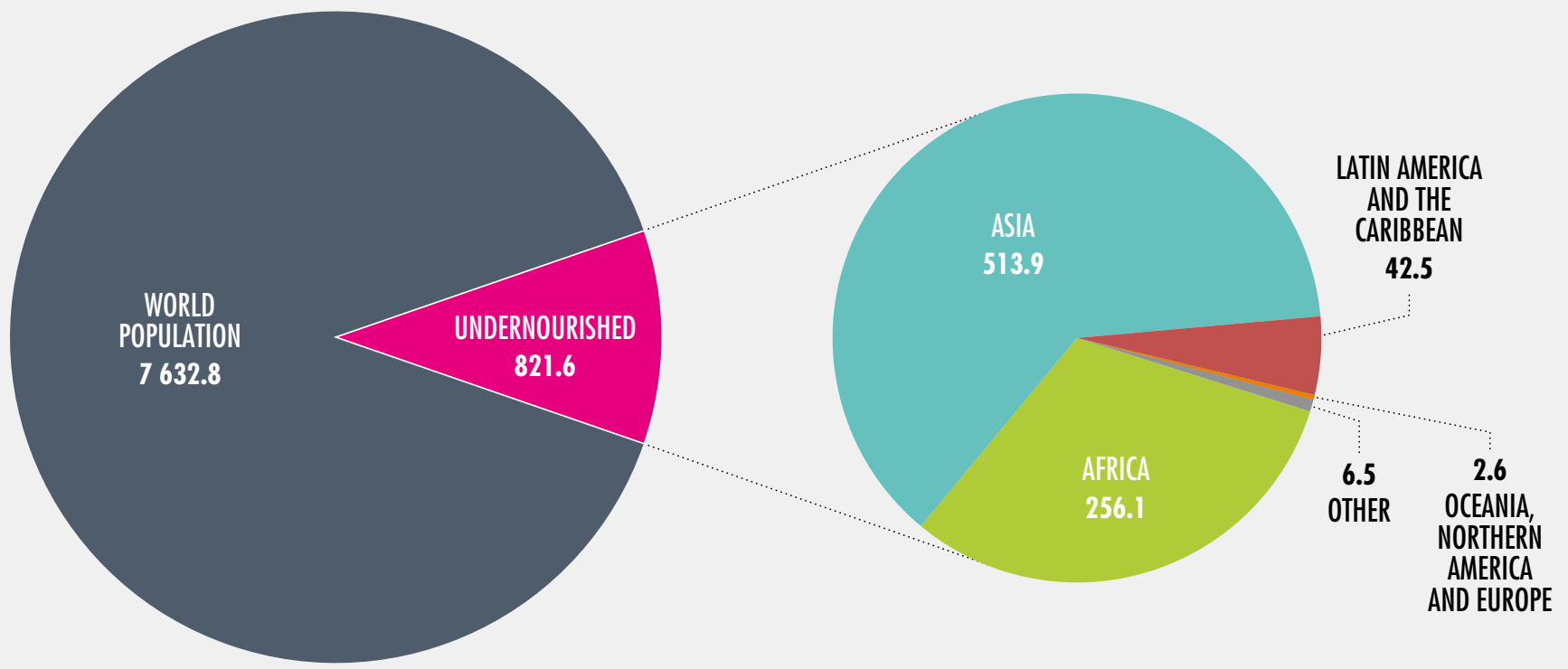

NOTES: * Projected values.

SOURCE: FAO.

\section{SDG Indicator 2.1.2}

\section{Prevalence of moderate or severe food} insecurity in the population, based on the FIES

The 2017 and 2018 editions of The State of Food Security and Nutrition in the World already presented estimates of the prevalence of severe food insecurity. As explained in those editions, the prevalence of severe food insecurity is expected to approximate the PoU, as both indicators reflect the extent of severe food deprivation. However, differences may exist because these indicators are based on different sources of data and methodologies (Box 1).
The 2019 edition introduces estimates of the prevalence of food insecurity combining moderate and severe levels to report on SDG Indicator 2.1.2 (Box 1). This second indicator thus refers to an expanded range of food-insecurity severity that encompasses moderate levels. This was in response to the need, in the context of the universal 2030 Agenda, for indicators that are relevant for all countries in the world - "developed" as well as "developing" countries - to monitor progress towards the very ambitious target of ensuring access to safe, nutritious and sufficient food by all people (SDG Target 2.1). 
TABLE 3

PREVALENCE OF MODERATE OR SEVERE FOOD INSECURITY, AND SEVERE FOOD INSECURITY ONLY, MEASURED WITH THE FOOD INSECURITY EXPERIENCE SCALE, 2014-2018

\begin{tabular}{|c|c|c|c|c|c|c|c|c|c|c|}
\hline & \multicolumn{5}{|c|}{$\begin{array}{l}\text { Prevalence of severe food insecurity } \\
\text { in the total population (\%) }\end{array}$} & \multicolumn{5}{|c|}{$\begin{array}{l}\text { Prevalence of moderate or severe food } \\
\text { insecurity in the total population (\%) }\end{array}$} \\
\hline & 2014 & 2015 & 2016 & 2017 & 2018 & 2014 & 2015 & 2016 & 2017 & 2018 \\
\hline WORLD & 8.0 & 7.7 & 8.0 & 8.7 & 9.2 & 23.2 & 23.2 & 24.1 & 25.6 & 26.4 \\
\hline AFRICA & 18.1 & 19.0 & 21.9 & 22.9 & 21.5 & 47.6 & 48.3 & 52.6 & 54.3 & 52.5 \\
\hline Northern Africa & 8.6 & 7.2 & 9.3 & 10.1 & 8.0 & 27.1 & 22.9 & 27.8 & 35.2 & 29.5 \\
\hline Sub-Saharan Africa & 20.3 & 21.7 & 24.8 & 25.8 & 24.6 & 52.4 & 54.2 & 58.3 & 58.7 & 57.7 \\
\hline Eastern Africa & 23.9 & 25.1 & 27.8 & 28.7 & 25.9 & 58.2 & 59.7 & 64.8 & 65.5 & 62.7 \\
\hline Middle Africa & n.a. & n.a. & n.a. & n.a. & n.a. & n.a. & n.a. & n.a. & n.a. & n.a. \\
\hline Southern Africa & 21.4 & 20.6 & 30.7 & 30.8 & 30.6 & 45.3 & 45.9 & 53.5 & 53.6 & 53.6 \\
\hline Western Africa & 12.9 & 14.4 & 16.5 & 17.7 & 17.6 & 43.7 & 45.3 & 47.3 & 47.7 & 47.9 \\
\hline ASIA & 7.0 & 6.3 & 5.9 & 6.4 & 7.8 & 20.0 & 19.4 & 19.5 & 20.6 & 22.8 \\
\hline Central Asia & 2.0 & 1.8 & 2.8 & 3.6 & 3.2 & 11.2 & 11.1 & 12.6 & 17.3 & 17.3 \\
\hline Eastern Asia & 0.5 & $<0.5$ & 0.9 & 1.0 & 1.1 & 6.5 & 6.4 & 6.5 & 10.3 & 9.8 \\
\hline South-eastern Asia & 4.5 & 3.7 & 4.2 & 5.8 & 5.2 & 19.6 & 17.3 & 19.0 & 21.5 & 20.4 \\
\hline Southern Asia & 13.7 & 12.4 & 10.6 & 10.9 & 14.4 & 31.4 & 30.8 & 30.3 & 28.1 & 34.3 \\
\hline Western Asia & 8.7 & 8.9 & 9.3 & 10.3 & 9.9 & 29.1 & 29.1 & 28.3 & 30.1 & 29.5 \\
\hline Western Asia and Northern Africa & 8.6 & 8.1 & 9.3 & 10.2 & 9.0 & 28.1 & 26.2 & 28.1 & 32.5 & 29.5 \\
\hline LATIN AMERICA AND THE CARIBBEAN & n.a. & n.a. & n.a. & n.a. & n.a. & n.a. & n.a. & n.a. & n.a. & n.a. \\
\hline Caribbean & n.a. & n.a. & n.a. & n.a. & n.a. & n.a. & n.a. & n.a. & n.a. & n.a. \\
\hline Latin America & 7.7 & 6.5 & 7.8 & 9.9 & 9.0 & 24.2 & 25.9 & 28.5 & 33.8 & 30.9 \\
\hline Central America & 12.9 & 10.3 & 8.5 & 12.7 & 10.6 & 36.7 & 33.7 & 26.2 & 37.3 & 31.5 \\
\hline South America & 5.6 & 4.8 & 7.5 & 8.8 & 8.3 & 19.1 & 22.7 & 29.5 & 32.3 & 30.6 \\
\hline OCEANIA & n.a. & n.a. & n.a. & n.a. & n.a. & n.a. & n.a. & n.a. & n.a. & n.a. \\
\hline NORTHERN AMERICA AND EUROPE & 1.5 & 1.5 & 1.2 & 1.2 & 1.0 & 9.6 & 9.6 & 8.7 & 8.5 & 8.0 \\
\hline
\end{tabular}

NOTES: n.a. = not available, as data are available only for a limited number of countries, representing less than 50 percent of the population in the region. For country compositions of each regional/subregional aggregate, see Notes on geographic regions in statistical tables inside the back cover. SOURCE: FAO.

The FIES-based food-insecurity estimates presented in this edition are based on a combination of data: those collected by FAO using the FIES survey module in more than 140 countries, and those collected by national institutions in a number of countries in the Americas, Africa and Asia using the FIES or other similar experience-based food-security questionnaires. Results are made comparable for all countries by calibrating them against the FIES global reference scale (Box 3$).^{8}$

\section{Severe food insecurity}

According to the latest estimates, 9.2 percent of the world population (or slightly more than 700 million people) were exposed to severe levels of food insecurity in 2018, implying reductions in the quantity of food consumed to the extent that they have possibly experienced hunger (Tables 3 and 4). Not surprisingly, the figure for 2018 and the levels over the period between 2014 and 2018, are broadly consistent with those of the prevalence of undernourishment, confirming the complementarity between the two indicators in monitoring the extent of severe food deprivation, or "hunger".

However, there is a slight difference in trends over the five-year period, with $\mathrm{FI}_{\text {sev }}$ increasing slowly and the PoU remaining unchanged. This can be explained by the fact that while the PoU estimates " 
Experience-based food security measurement scales have been in use for many years in a number of countries, mainly in the Americas. To create categories for different levels of food insecurity, each country has chosen its own national thresholds, as well as its own naming systems. For example, in the United States of America households are classified as having "high", "marginal", "low" or "very low food security"; while in Brazil or in Mexico they use the terms "mild", "moderate" or "severe" food insecurity. However, although the labels used are similar, the resulting classes are not directly comparable across different countries.

With the objective of ensuring truly comparable classifications, FAO launched the Voices of the Hungry Project in 2012. As described below, it was necessary to establish a global reference scale on which the thresholds for classification into severe and moderate food insecurity could be set, and to develop procedures to calibrate scores obtained in different countries against this global standard.'

The eight items (questions) that compose the FIES survey module are chosen to represent a range of experiences, common to many cultures, that cover a broad range of severity on the underlying scale of food insecurity, from mild to severe. However, the position of each item on this scale of severity is not imposed a priori, and may vary across countries. The statistical measurement model used to analyse the data (Rasch model) ${ }^{2}$ allows for the identification of the relative position of the various items along a severity scale, based on patterns of responses to the eight items, with the basic idea being that the more severe an experience is, the less likely respondents are to report it. Each country thus obtains its own scale but they are not directly comparable across countries.

To establish the global FIES reference scale, FAO followed a process that is similar to what has been common in many other applications of measurement principles, for example, the establishment of the Coordinated Universal Time, which is used to regulate clocks and time globally. In that case, the average of the time kept by over 400 highly precise atomic clocks in over 50 laboratories worldwide is used to ensure one common standard reference time. To establish the FIES reference scale, FAO used data collected in more than 140 countries worldwide, from 2014 through 2016 and followed process (consisting mainly of two steps) that led to assigning each FIES item a position on what became the standard severity scale.
FIES measures obtained in different countries need to be equated before comparing them, to make sure they are expressed on the same reference scale, and common thresholds are used.

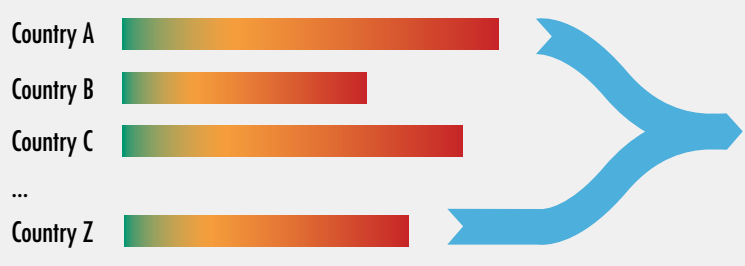

Global FIES reference scale

\begin{tabular}{l|l|l} 
& & \\
Food secure & Moderately & Severely \\
or mildly & food insecure & food insecure \\
food insecure & &
\end{tabular}

\section{The FIES Survey Module}

During the last 12 months, was there a time when, because of lack of money or other resources:

1 You were worried you would not have enough food to eat?

2 You were unable to eat healthy and nutritious food?

3 You ate only a few kinds of foods?

4 You had to skip a meal?

5 You ate less than you thought you should?

6 Your household ran out of food?

7 You were hungry but did not eat?

8 You went without eating for a whole day?

\section{Step 1. Assigning a severity level to each item}

\section{The FIES survey module has been applied in more than 140 countries worldwide.}

This has generated a distribution of severity levels for each of eight the items (questions) that compose the FIES survey module.

The median value is chosen as the severity level associated to the item on the global FIES scale.

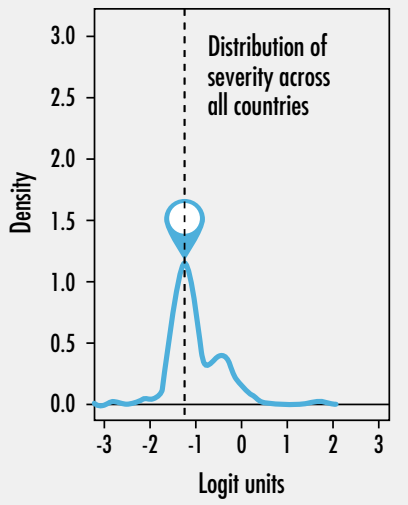




\section{Step 2. Mapping the severity levels on the FIES global reference scale}
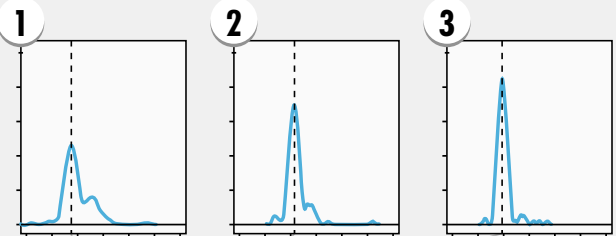

4
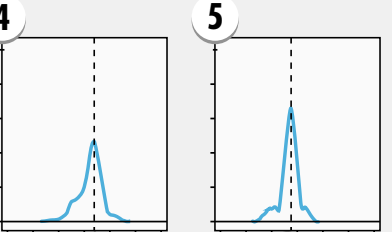

(4)

6

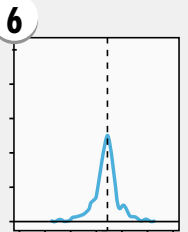

7

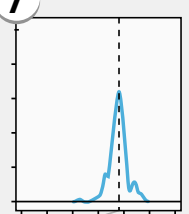

8

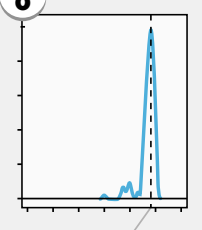

8

(7)

(1) 2

(5)

FIES GLOBAL SCALE

Once the global reference scale has been established, the process of calibrating each country's FIES measures against the FIES global standard is a relatively simple one and can be referred to as an "equating" procedure. Conceptually, converting FIES-based measures obtained in a given country at a given moment, into measures expressed on the global reference scale is like converting temperature readings from Fahrenheit to Celsius, or measures of length from the Imperial to the metric system. It simply requires the identification of "anchor" points for which measures in the two scales are known. In the FIES methodology, such anchor points are given by the subset of items that can be considered common to the national and the global scale, once the national scale has been appropriately rescaled.

It is important to mention that, though unlikely, differences in interpretation based on language or cultural context could potentially limit the ability to accurately produce estimates using the FIES global reference scale. Research is ongoing to further refine the current methodology and to limit the potential risk of inducing a bias when adjusting country results to the global reference scale.

\section{Calibrating the national scale against the FIES global reference scale}

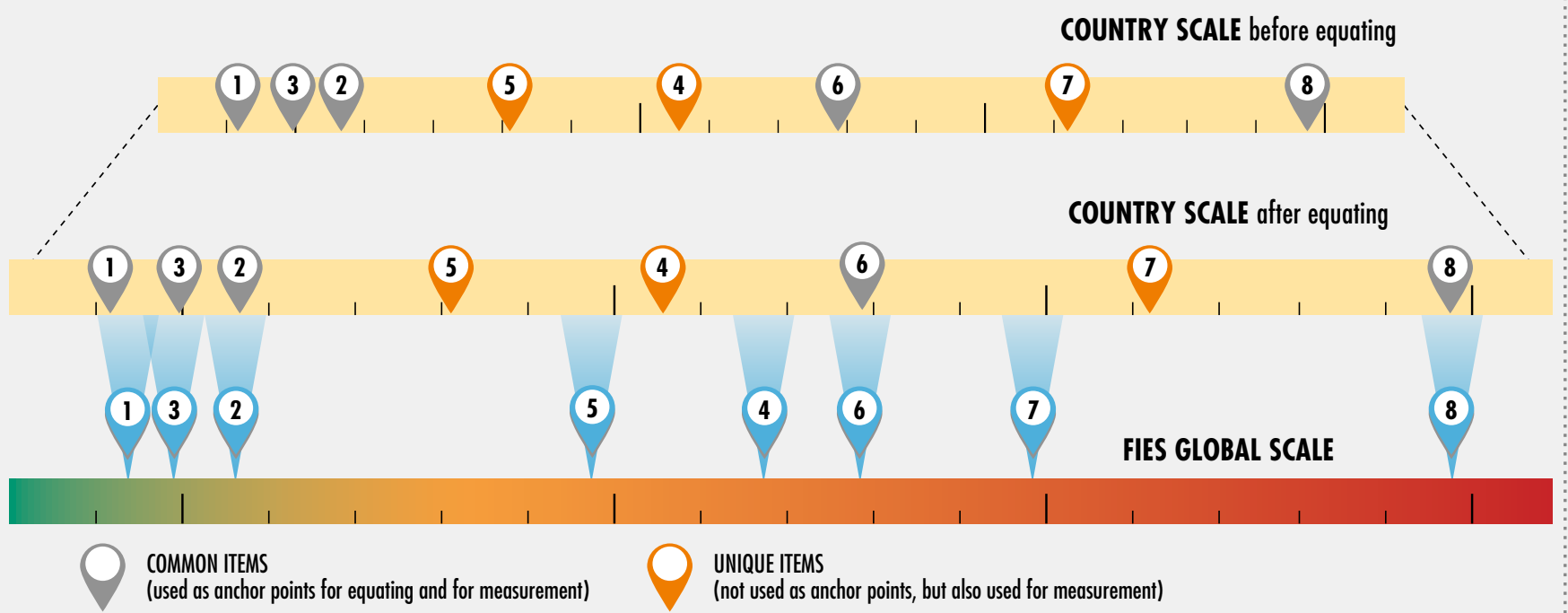

1 See C. Cafiero, S. Viviani and M. Nord. 2017. Food security measurement in a global context: the Food Insecurity Experience Scale. Measurement, 116 (February 2018 ): $146-152$.

${ }^{2}$ The Rasch model is a statistical model used in various fields of human and social sciences, to obtain estimates of the magnitude of unobservable, measurable traits (i.e. "latent" traits) from discrete data that represent the responses given to a set of appropriately chosen items. For a thorough introduction to the Rasch model, see T.G. Bond and C.M. Fox. 2015. Applying the Rasch model: fundamental measurement in the human sciences. London, Routledge; and M. Nord. 2014. Introduction to item response theory applied to food security measurement: basic concepts, parameters, and statistics [online]. Rome, FA0. [Cited 24 April 2019]. http://www.fao.org/3/a-i3946e.pdf 
TABLE 4

NUMBER OF PEOPLE EXPERIENCING MODERATE OR SEVERE FOOD INSECURITY, AND SEVERE FOOD INSECURITY ONLY, MEASURED WITH THE FOOD INSECURITY EXPERIENCE SCALE, 2014-2018

\begin{tabular}{|c|c|c|c|c|c|c|c|c|c|c|}
\hline & \multicolumn{5}{|c|}{$\begin{array}{l}\text { Number of severely } \\
\text { food-insecure people (millions) }\end{array}$} & \multicolumn{5}{|c|}{$\begin{array}{l}\text { Number of moderately or severely } \\
\text { food-insecure people (millions) }\end{array}$} \\
\hline & 2014 & 2015 & 2016 & 2017 & 2018 & 2014 & 2015 & 2016 & 2017 & 2018 \\
\hline WORLD & 585.0 & 568.2 & 600.4 & 657.6 & 704.3 & 1696.3 & 1712.3 & 1801.9 & 1929.6 & 2013.8 \\
\hline AFRICA & 210.7 & 226.7 & 268.2 & 287.5 & 277.0 & 554.1 & 577.1 & 644.1 & 682.0 & 676.1 \\
\hline Northern Africa & 19.1 & 16.3 & 21.2 & 23.6 & 19.0 & 59.8 & 51.6 & 63.8 & 82.1 & 70.2 \\
\hline Sub-Saharan Africa & 191.6 & 210.4 & 246.9 & 263.9 & 258.0 & 494.3 & 525.5 & 580.3 & 599.9 & 605.8 \\
\hline Eastern Africa & 93.0 & 100.2 & 114.3 & 121.3 & 112.5 & 226.1 & 238.4 & 266.0 & 276.3 & 271.7 \\
\hline Middle Africa & n.a. & n.a. & n.a. & n.a. & n.a. & n.a. & n.a. & n.a. & n.a. & n.a. \\
\hline Southern Africa & 13.4 & 13.1 & 19.8 & 20.1 & 20.2 & 28.3 & 29.1 & 34.4 & 34.9 & 35.3 \\
\hline Western Africa & 44.4 & 50.9 & 59.6 & 66.0 & 67.2 & 149.9 & 159.7 & 171.1 & 177.6 & 182.8 \\
\hline ASIA & 305.9 & 280.0 & 264.8 & 288.5 & 353.6 & 875.6 & 858.2 & 871.1 & 928.0 & 1038.5 \\
\hline Central Asia & 1.3 & 1.2 & 1.9 & 2.5 & 2.3 & 7.6 & 7.6 & 8.8 & 12.2 & 12.4 \\
\hline Eastern Asia & 7.5 & 6.8 & 15.4 & 16.6 & 18.4 & 105.4 & 104.4 & 106.3 & 169.9 & 162.7 \\
\hline South-eastern Asia & 27.9 & 23.7 & 27.3 & 37.5 & 34.3 & 123.2 & 109.9 & 122.1 & 139.6 & 134.0 \\
\hline Southern Asia & 247.1 & 225.4 & 195.8 & 204.2 & 271.7 & 565.7 & 561.3 & 559.6 & 525.8 & 649.1 \\
\hline Western Asia & 21.9 & 22.9 & 24.5 & 27.6 & 27.0 & 73.7 & 75.0 & 74.3 & 80.6 & 80.2 \\
\hline Western Asia and Northern Africa & 41.0 & 39.2 & 45.7 & 51.2 & 46.0 & 133.4 & 126.6 & 138.1 & 162.7 & 150.5 \\
\hline LATIN AMERICA AND THE CARIBBEAN & n.a. & n.a. & n.a. & n.a. & n.a. & n.a. & n.a. & n.a. & n.a. & n.a. \\
\hline Caribbean & n.a. & n.a. & n.a. & n.a. & n.a. & n.a. & n.a. & n.a. & n.a. & n.a. \\
\hline Latin America & 45.1 & 38.0 & 46.5 & 59.8 & 54.7 & 141.2 & 152.6 & 170.0 & 203.2 & 187.8 \\
\hline Central America & 21.9 & 17.8 & 14.8 & 22.5 & 19.0 & 62.5 & 58.2 & 45.9 & 66.1 & 56.7 \\
\hline South America & 23.1 & 20.2 & 31.7 & 37.3 & 35.7 & 78.7 & 94.4 & 124.1 & 137.1 & 131.2 \\
\hline OCEANIA & n.a. & n.a. & n.a. & n.a. & n.a. & n.a. & n.a. & n.a. & n.a. & n.a. \\
\hline NORTHERN AMERICA AND EUROPE & 16.1 & 16.3 & 13.4 & 13.6 & 10.6 & 105.2 & 104.7 & 95.8 & 93.7 & 88.7 \\
\hline
\end{tabular}

NOTES: n.a. = not available, as data are available only for a limited number of countries, representing less than 50 percent of the population in the region.

For country compositions of each regional/subregional aggregate, see Notes on geographic regions in statistical tables inside the back cover.

SOURCE: FAO.

"reflect structural factors that influence the availability of and the inequality in access to food, $\mathrm{FI}_{\text {sev }}$ estimates are more sensitive to short-term factors affecting people's direct experiences in accessing food, as reported in surveys. In addition, the PoU for recent years is computed based on inevitably less timely data, particularly those from household surveys. Therefore the PoU may fail to capture the impact of very recent phenomena that might have affected the extent of inequality in food consumption. Estimates of $\mathrm{FI}_{\mathrm{sev}}$ instead, fully reflect these phenomena. It is expected that the two series will tend to converge more closely over time. ${ }^{9}$
Consistent with the findings for the PoU, Africa is the region with the highest prevalence of severe food insecurity, reaching 21.5 percent in 2018, up from 18.1 percent in 2014.

Severe food insecurity is also increasing in Latin America, driven by South America where $\mathrm{FI}_{\text {sev }}$ reached 8.3 percent in 2018.

Finally, Asia shows a mixed picture. While the percentage of people exposed to severe food insecurity decreased from 2014 to 2017 a trend that is consistent with the PoU results - $\mathrm{FI}_{\mathrm{sev}}$ shows a marked increase in 2018 that 


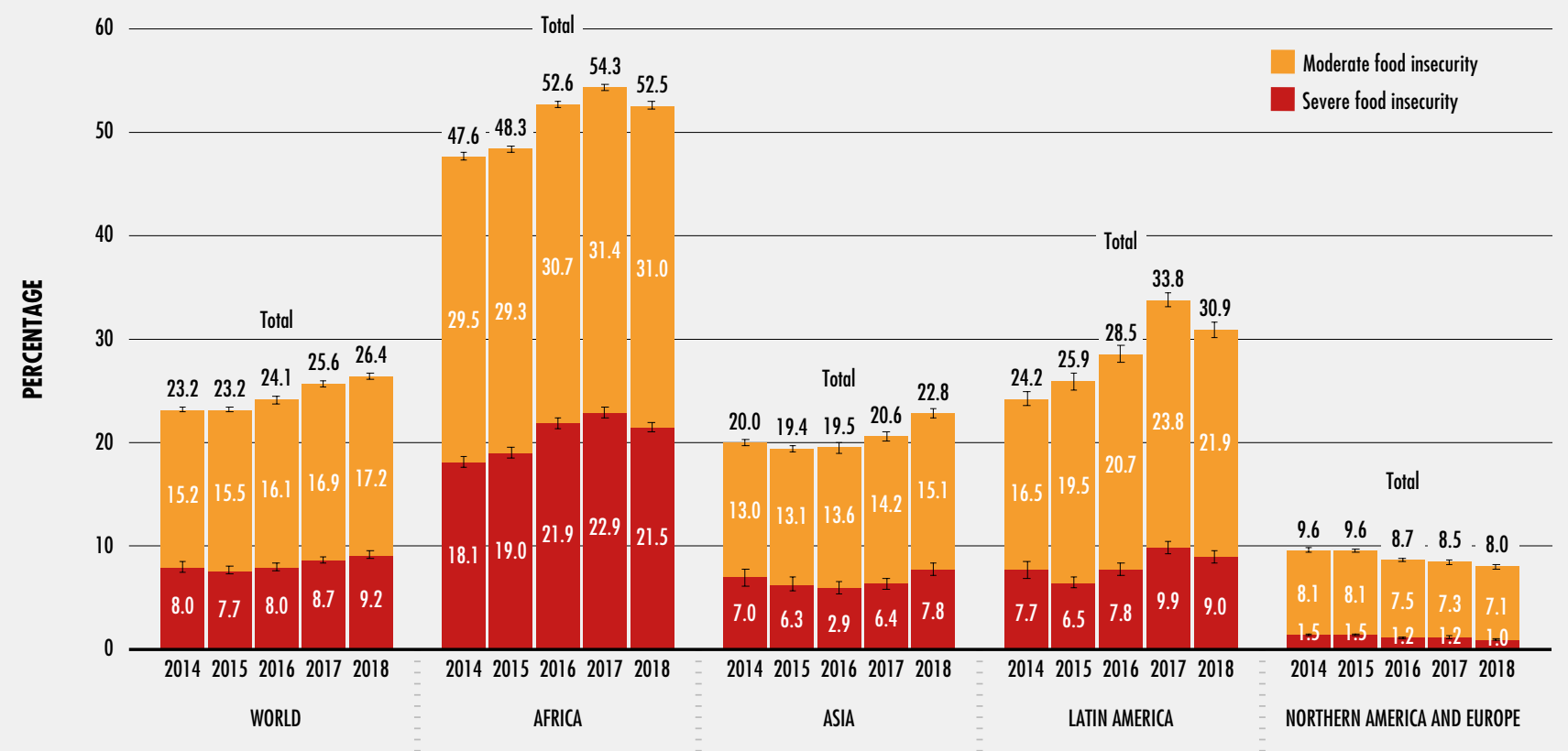

NOTES: Differences in total are due to rounding of figures to the nearest decimal point. SOURCE: FAO.

is not mirrored by the projected PoU values.

The increase is concentrated in Southern Asia, where $\mathrm{FI}_{\text {sev }}$ increased from less than 11 percent in 2017 to more than 14 percent in 2018. This possibly reflects an increase in the unemployment rate in India between 2017 and $2018,^{10}$ and especially in Pakistan, where growth is expected to slow down significantly. ${ }^{11}$

\section{Moderate or severe food insecurity}

A broader look at the extent of food insecurity beyond severe levels and hunger reveals that an additional 17.2 percent of the world population, or 1.3 billion people, have experienced food insecurity at moderate levels.
This implies that these additional 1.3 billion people did not have regular access to nutritious and sufficient food, even if they were not necessarily suffering from hunger, thus putting them at greater risk of various forms of malnutrition and poor health than the food secure population.

The combination of moderate and severe levels of food insecurity brings the estimated $\mathrm{FI}_{\text {mod+sev }}$ (SDG Indicator 2.1.2) to 26.4 percent of the world population, amounting to a total of about 2 billion people (Table 3 and 4). Figure 10 shows that, since 2014 when FAO first started collecting FIES data, levels of food insecurity 


\section{FIGURE 11}

\section{THE CONCENTRATION AND DISTRIBUTION OF FOOD INSECURITY BY SEVERITY} DIFFERS GREATLY ACROSS THE REGIONS OF THE WORLD

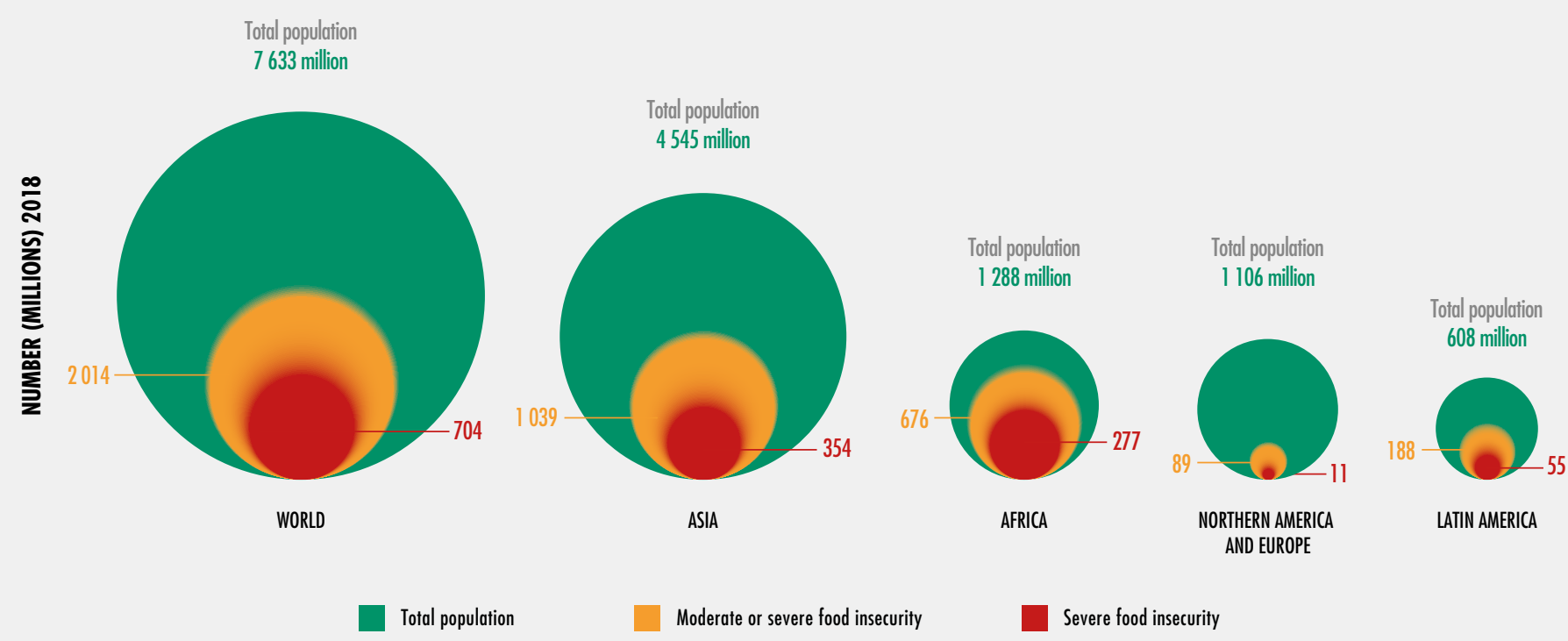

SOURCE: FAO.

have been on the rise at the global level as well as in most regions of the world.

Total food insecurity (moderate or severe) is much higher in Africa than in any other part of the world. Here $\mathrm{FI}_{\text {mod+sev }}$ affects more than half of the population. Latin America is next, with a prevalence of food insecurity of more than 30 percent, followed by Asia at 23 percent and Northern America and Europe at 8 percent.

Also revealing are the differences observed within regions (Table 3). In Asia, total food insecurity is much higher for Southern Asia (34.3 percent in 2018) than for Eastern Asia (less than 10 percent). In Africa, total food insecurity is also higher for the Southern region (53.6 percent in 2018) and the Eastern region (62.7 percent) compared with Western Africa (47.9 percent). It is at its lowest in Northern Africa (29.5 percent), where the food-insecurity profile is much more similar to that of the Western Asia region than that of the other regions in Africa.

The distribution of food-insecure people in the world presented in Figure 11 shows that, from a total of 2 billion suffering from food insecurity, 1.04 billion (52 percent) are in Asia; 676 million (34 percent) are in Africa; and 188 million (9 percent) are in Latin America. The figure also illustrates the difference across regions in the distribution of the population by food-insecurity severity level. For example, in addition to being the region with the highest overall prevalence of food insecurity (Table 3), Africa is also the region where severe levels represent the largest share of the total. In Latin America, and even more in Northern America and Europe, the proportion 


\section{FIGURE 12}

\section{AS THE COUNTRY LEVEL OF INCOME FALLS, THE PREVALENCE OF FOOD INSECURITY INCREASES AND SO DOES THE PROPORTION OF SEVERE FOOD INSECURITY OVER THE TOTAL}

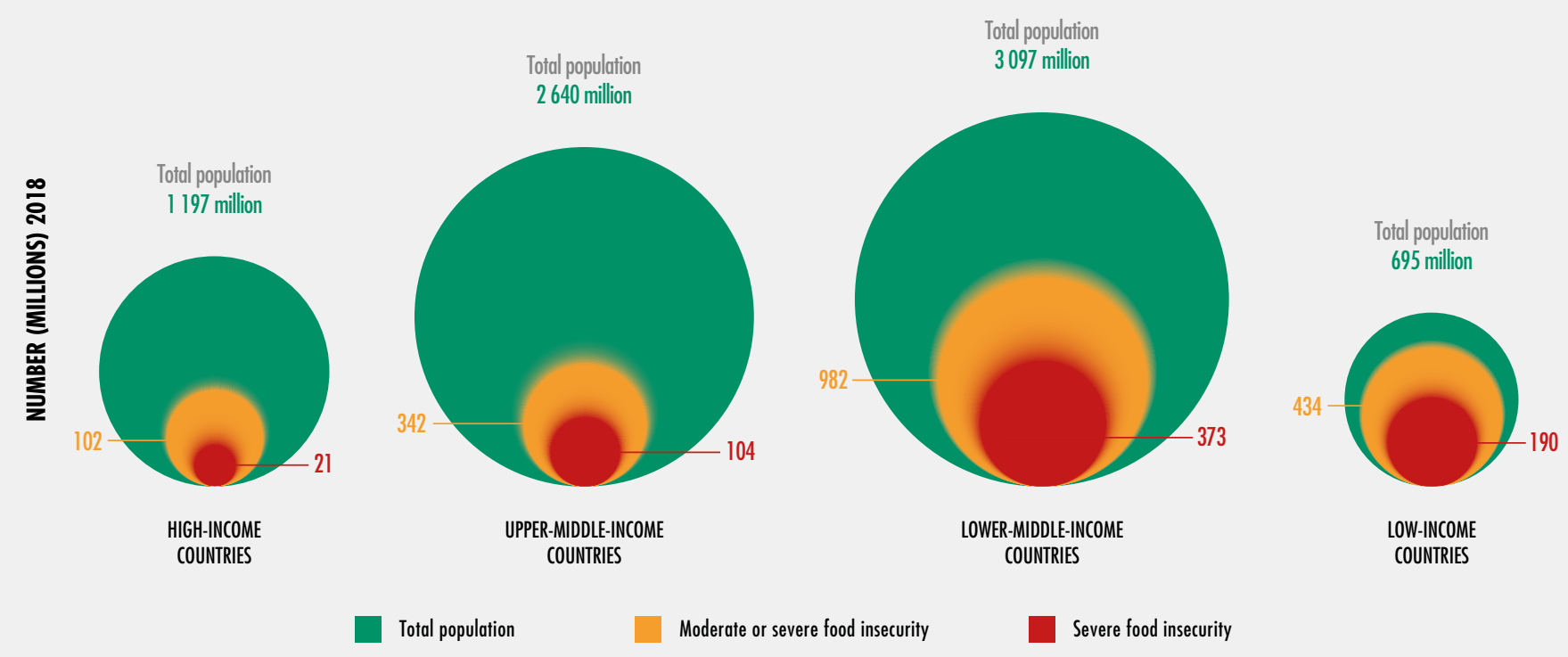

SOURCE: FAO

of food insecurity experienced at severe levels is much smaller.

Different patterns in food-insecurity severity emerge also when countries are grouped by income level. Figure 12 shows that, as the level of income falls, not only does the prevalence of food insecurity increase, but so does the proportion of severe food insecurity over the total. In 2018, low-income countries, with a total population of only 695 million, were home to 434 million food-insecure individuals (62 percent of the total), 190 million of whom (equivalent to 27 percent of the total population) were severely food insecure. In contrast, high-income countries were home to 102 million food-insecure individuals ( 9 percent of the total), of whom 21 million (barely 2 percent of the total) were considered to be severely food insecure.
A combined look at past and recent trends in hunger, food insecurity and poverty

The introduction of a new indicator to measure food insecurity allows for a more nuanced view of the state of food insecurity in the world and of recent trends.

Figure 13 shows trends in the number of undernourished, food-insecure and extreme poor ${ }^{12}$ people in the world from 2005 to 2018, contrasting them against the growth in the world's population over the same period.

These indicators provide a consistent picture. Both extreme poverty and undernourishment have been declining from 2005 to 2015, though at different rates. The number of undernourished and the number of extreme poor were very close as of 2015, with both 
FIGURE 13

THE NUMBERS OF UNDERNOURISHED AND OF FOOD INSECURE HAVE BEEN ON THE RISE IN RECENT YEARS, AFTER A DECADE-LONG DECLINE IN EXTREME POVERTY AND UNDERNOURISHMENT

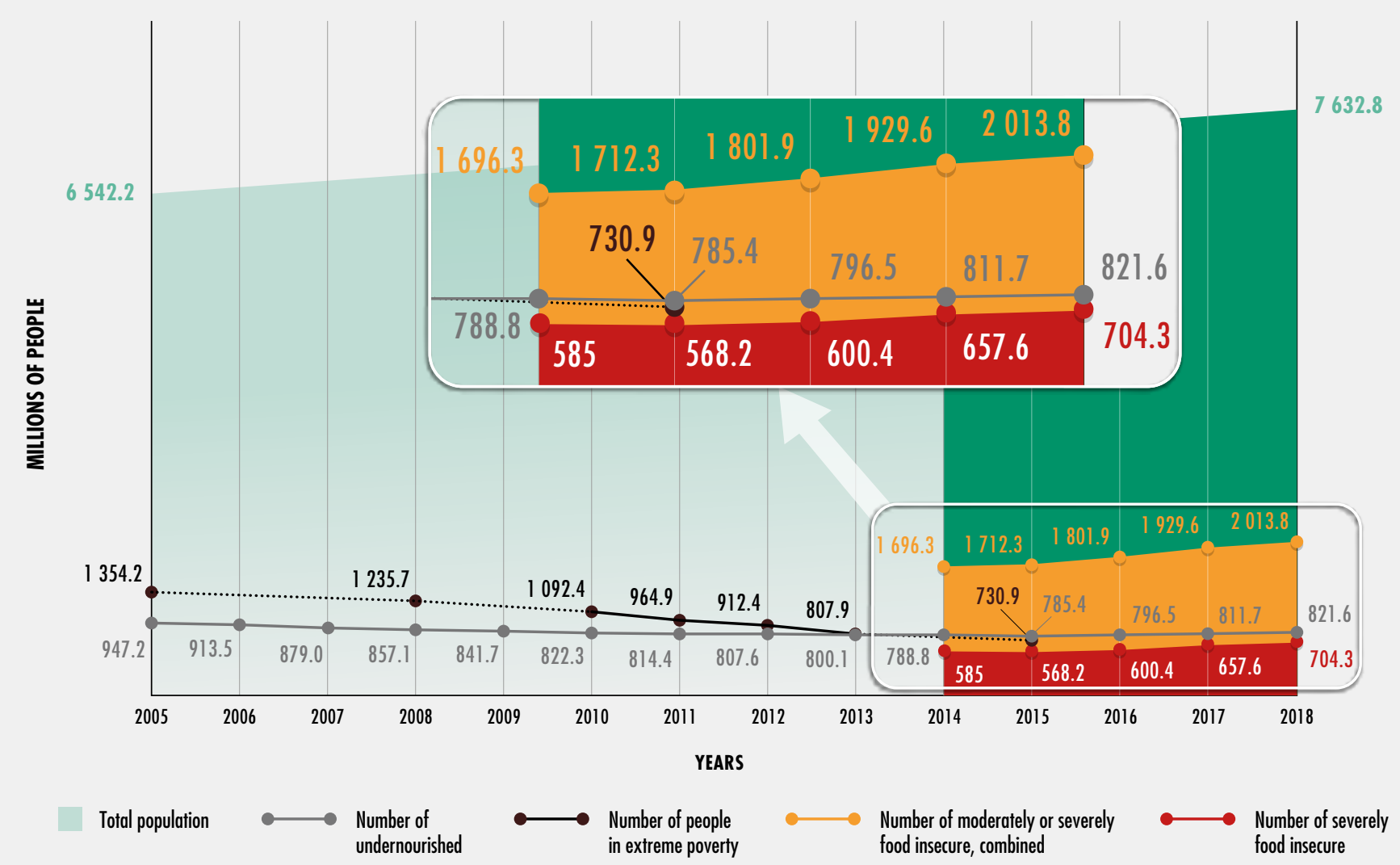

SOURCE: FAO for number of undernourished, number of moderately or severely food insecure and number of severely food insecure; PovcalNet: an online analysis tool for global poverty monitoring. In: The World Bank [online]. Washington, DC. [Cited 9 May 2019]. http://iresearch.worldbank.org/PovcalNet/home.aspx for number of people in extreme poverty.

slightly higher than the number of severely food insecure.

To put this in context, one can observe in Figure 13 that even with an increase in world population from 6.5 to 7.6 billion during 2005-2018, the number of undernourished has fallen from almost 950 million people to about 820 million. This is reflected in a reduction of the PoU from 14.5 percent in 2005 to 10.8 percent in 2018 .
The figure also reveals the benefits of using FIES data to obtain a more detailed assessment of the most recent years. By zooming in on the period between 2014 and 2015, one notes the close correspondence between the number of severely food insecure, extreme poor and undernourished, and also the comparable increasing trends between the number of undernourished and the number of people affected by severe food insecurity. 
FIGURE 14

IN EVERY CONTINENT, THE PREVALENCE OF FOOD INSECURITY IS SLIGHTLY HIGHER FOR WOMEN THAN FOR MEN, WITH THE LARGEST DIFFERENCES FOUND IN LATIN AMERICA (2016-2018 THREE-YEÁR AVERAGES)

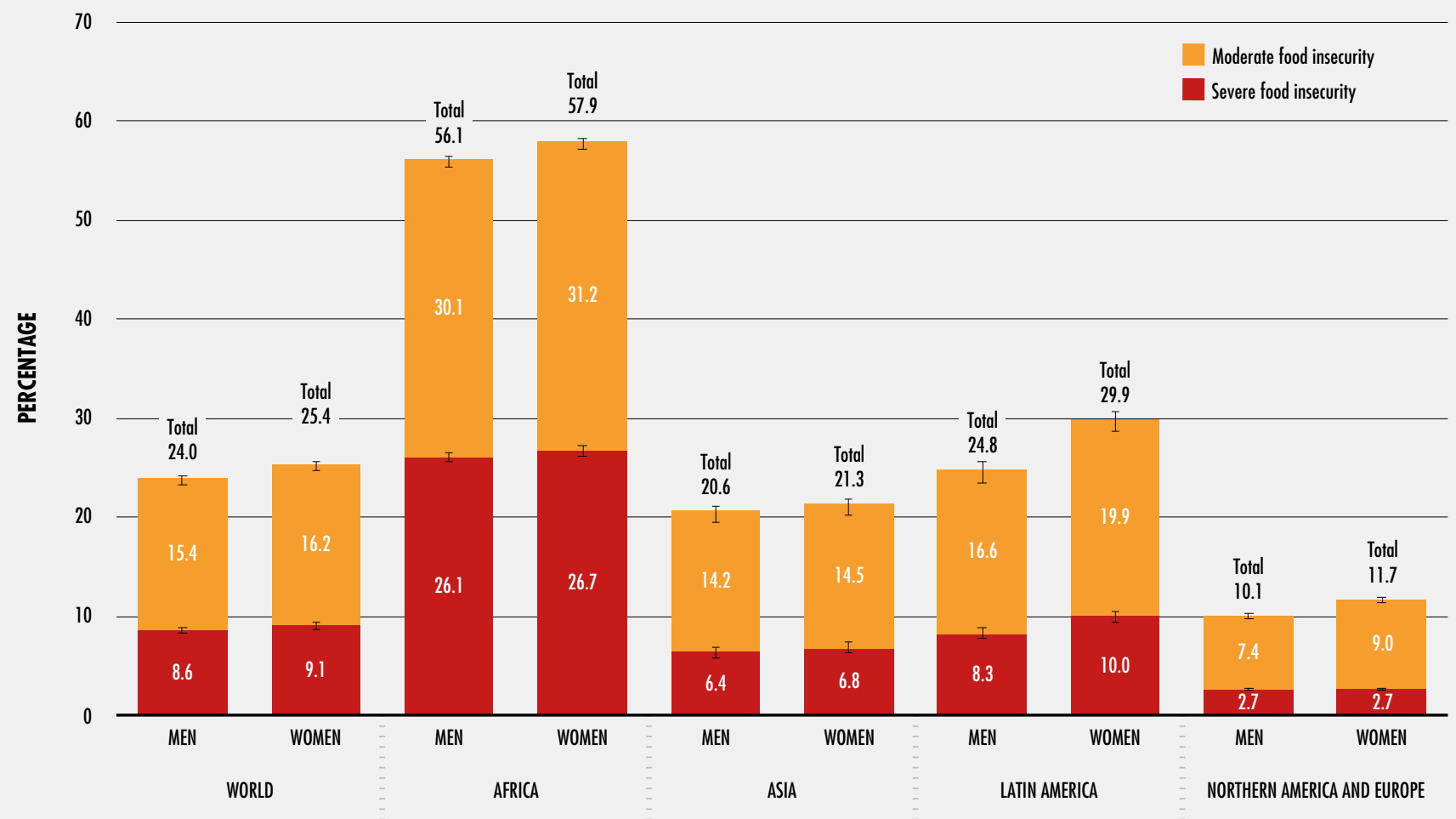

NOTES: Differences in total are due to rounding of figures to the nearest decimal point. SOURCE: FAO.

The picture also highlights that most of the increase in food insecurity since 2014, from 1.7 billion to 2.0 billion, has occurred at moderate levels (as seen in the sharper increase for total food insecurity compared with that of severe food insecurity). This increase parallels the troubling increase in overweight and obesity covered in Section 1.3, which will explore in detail the links between food insecurity at moderate or severe levels and various forms of malnutrition, with a focus on overweight and obesity.

\section{Gender differences in food insecurity}

The FIES data collected by FAO in more than 140 countries over five years at the individual (rather than household) level provide a unique opportunity to conduct a differential analysis of the incidence of food insecurity by gender.

Figure 14 presents the prevalence of food insecurity estimated separately for men and women worldwide and in all continents (except Oceania). It reveals that in every continent, 
the prevalence of food insecurity is slightly higher in women than in men, with the largest differences found in Latin America. Differences are statistically significant, as they extend beyond the margins of error represented with small vertical bars in the figure.

A more extensive analysis conducted by pooling all data collected by FAO in 145 countries in 2014, 2015, 2016 and 2017, shows that area of residence, poverty status and education level are significant determinants of the difference in food insecurity levels between men and women (see Annex 2 for the methodology). Globally, the gender gap in food insecurity appears to be larger among the less-educated, poorer strata of the population, and in urban (large city and suburbs) settings. After controlling for area of residence (rural or small town versus large city or suburbs), poverty status and education level of the respondents, the chances of being food insecure are still approximately 10 percent higher for women than for men. This finding reveals that other - possibly subtler - forms of discrimination make access to food more difficult for women, even when they have the same income and education levels as men and live in similar areas.

Another study using global FIES data found that gender differences in household income, educational attainment and social networks explain most of the gender gap in food insecurity. ${ }^{13}$ This suggests that policies that address gender inequality in employment opportunities and educational attainment may also have an impact on food insecurity. Part 2 of this report looks more closely at the different gender dimensions of inequality that affect food security and nutrition, both within communities and within households, and outlines the policies and approaches needed to address these.

\section{Global FIES data provide evidence of both causes} and consequences of food insecurity at the household and individual levels

Studies using the FIES or comparable experience-based food-insecurity measures comprise a growing body of evidence on causes and consequences of food insecurity at the household and individual levels. Three studies in particular - one using FIES data collected by FAO through the Gallup ${ }^{\circledR}$ World Poll in the global sample of nearly 140 countries, ${ }^{14}$ and two others focusing specifically on sub-Saharan Africa ${ }^{15}$ and Arab countries ${ }^{16}$ - concluded that the likelihood of being food insecure was higher for people who were unemployed and had low levels of education and household income, corroborating the results of the analysis of country-level indicators presented in Box 4. In the first study, it was also found that people with low social capital and weak social networks were more likely to be food insecure. Elsewhere, yet another study using the global FIES data found that food insecurity was strongly and negatively associated with subjective well-being, regardless of household income level or social support. This was found to be true in countries of all income classes, but more so in high-income countries. In fact, food insecurity explained poor physical health and lower subjective well-being more than other indicators of living conditions such as household income, shelter and housing, and employment. ${ }^{17}$

Food insecurity can affect health and well-being in many ways, with potentially negative consequences for mental, social and physical well-being. Many studies using experience-based food-insecurity scales have documented negative psychosocial effects of food insecurity in women and children. ${ }^{18}$ Furthermore, one particular study using the global FIES data found that food insecurity is associated with poorer mental health and specific psychosocial stressors across global regions independent of socio-economic status. ${ }^{19}$

There is also a large body of evidence on the links between food insecurity and nutritional outcomes (as described in the 2018 report). Together with the evidence cited above, this growing body of research highlights the value of experience-based measures of food insecurity like the FIES. It is worth emphasizing, as well, that the FIES-based indicators and the PoU are not to be confused with indicators used in food crisis situations (Box 5).

The next section presents the latest figures on progress towards ending all forms of malnutrition, with a special focus on overweight and obesity. The final section of Part 1 discusses new evidence on the relationship between food insecurity and various forms of malnutrition. 
National prevalence estimates of moderate or severe food insecurity $\left(\mathrm{FI}_{\text {mod+sev }}\right)$ based on the FIES rank countries in ways that are strongly correlated with the rankings produced by other key indicators of human development (see table below). As one would expect, countries with a lower prevalence of food insecurity also tend to have lower levels of poverty and income inequality and higher labour force participation rates, GDP per capita, literacy rates and gender equity.

Additionally, countries with a lower prevalence of food insecurity tend to have higher Human Capital Indices, pointing to a strong link between food security and the well-being and development of nations.

The table also shows that the prevalence of food insecurity is higher in countries with higher ratios of dependents (people younger than 15 and older than $64)$ to the working-age population (age dependency ratio) and a larger percentage of the population living in rural areas. Prevalence of food insecurity is also lower in countries with greater political stability and less violence, a theme addressed in depth in the 2017 edition of this report.

Countries where health expenditure per capita is lower, and where a larger proportion of the population lacks access to safely managed water and sanitation, also tend to be countries with a higher prevalence of food insecurity. Access to these health-related public services also has a strong effect on two key indicators of the state of a nation's health - child mortality and life expectancy - with which national prevalence of food insecurity are highly correlated. Child mortality tends to be higher and life expectancy lower in countries with higher rates of food insecurity.

\section{CORRELATION BETWEEN COUNTRY ESTIMATES OF FOOD INSECURITY AND OTHER COUNTRY-LEVEL INDICATORS OF HUMAN DEVELOPMENT AND WELL-BEING}

\begin{tabular}{|c|c|c|c|}
\hline \multirow{2}{*}{ Indicator } & \multirow{2}{*}{ Period } & \multicolumn{2}{|c|}{$\mathbf{F I}_{\text {modtsev }}$} \\
\hline & & $\mathbf{N}$ & 2016-2018 \\
\hline \multicolumn{4}{|l|}{ Poverty, inequality and economic growth } \\
\hline GDP per capita & 2017 & 138 & -0.829 \\
\hline Poverty headcount & $2013-2017^{*}$ & 88 & 0.752 \\
\hline GINI index income inequality & $2013-2017^{*}$ & 104 & 0.622 \\
\hline Labour force participation rate & 2017 & 137 & -0.229 \\
\hline \multicolumn{4}{|l|}{ Human capital and gender } \\
\hline Human Capital Index & 2017 & 132 & -0.895 \\
\hline Literacy rate & $2013-2017^{*}$ & 61 & -0.675 \\
\hline Gender Development Index & 2017 & 137 & -0.426 \\
\hline \multicolumn{4}{|l|}{ Demographics } \\
\hline Age dependency ratio & 2015 & 138 & 0.612 \\
\hline Rural population & 2015 & 135 & 0.517 \\
\hline Political stability and absence of violence & 2017 & 140 & -0.589 \\
\hline \multicolumn{4}{|l|}{ Health-related public services } \\
\hline Health expenditure per capita & 2015 & 135 & -0.829 \\
\hline Basic drinking water services & 2015 & 137 & -0.806 \\
\hline Basic sanitation services & 2015 & 138 & -0.792 \\
\hline \multicolumn{4}{|l|}{ Health and well-being } \\
\hline Child mortality rate, under 5 years & 2017 & 137 & 0.874 \\
\hline Life expectancy at birth & 2016 & 139 & -0.815 \\
\hline Prevalence of undernourishment (PoU) & $2016-2018$ & 133 & 0.842 \\
\hline
\end{tabular}

NOTES: The table presents coefficients of Spearman rank correlations, all significant at the $p=0.01$ level. The Spearman rank correlation between two variables is the linear correlation between the ranked values of those two variables - i.e. in the above analysis, the correlation between country rankings based on the two variables. * Used value for the most recent year available during this period. $\mathrm{N}=$ number of countries with valid values. For a description of the variables and details of the analysis, see Annex 2 . SOURCE: FAO. 
The State of Food Security and Nutrition in the World and the Global Report on Food Crises (GRFC)' ${ }^{1}$ are both multi-partnership efforts that provide assessments of food security around the world which complement each other. However, they have distinct objectives and rely on different data and methodologies, so it is important to clarify the difference between the numbers that these two reports provide.

While the GRFC has a narrow focus on acute food insecurity for countries experiencing food crises, the scope of this report is much broader: its objective is to monitor food insecurity in the entire world, on a regular basis. It is obvious, then, that the two reports must be informed by different types of data and analytic methods.

All the indicators used for SDG monitoring and reported here are arguably ill suited to reflect the most current conditions during emergencies, a reason why current data for some of the countries that are experiencing conflicts are not reported in this report. However, that is not the purpose of the report. The two indicators used here to measure hunger ( $\mathrm{PoU}$ and $\mathrm{FI}_{\text {sev }}$ ), for example, are meant to reliably capture long-term trends at global and regional levels, while providing the best possible assessment of the most recent structural situation at country level. For this reason, they should not be too conditioned by possibly temporary, short-term fluctuations, typical of acute crises, which are the main focus of the indicators presented in the GRFC.

PoU and $\mathrm{Fl}_{\text {sev }}$ estimate the extent of severe food deprivation in a population, seen as a chronic condition, and are based on validated, official data which are available with some delay due to various rounds of cleaning and vetting.

The GRFC, on the other hand, focuses on acute food insecurity and is mainly based on analytic approaches such as the Integrated Food
Security Phase Classification/Cadre Harmonisé (IPC/CH). Since timeliness is of the essence in crisis situations, rapid estimates are needed of how many people are facing crisis conditions or worse (IPC/CH Phase 3 or above), at the worst (peak) moment in the year, based on all available evidence, including non-official sources.

In other words, while chronic food insecurity as captured by $\mathrm{PoU}$ or $\mathrm{FI}_{\text {sev }}$ is a long-term or persistent inability to meet food consumption requirements, acute or transitory food insecurity as captured in GRFC numbers is a short-term, possibly temporary, inability to meet food consumption requirements related to sporadic crises, conditions that can be highly susceptible to change and can manifest in a population within a short time frame, as a result of sudden changes or shocks.

This is why this report's estimates of the number of undernourished people in the world at 821.6 million in 2018 must not be directly compared with the figure of around 113 million people in 53 countries facing crisis conditions or worse in 2018, as reported in the 2019 GRFC.

Having clarified that, however, it is worth stressing again how the two reports are highly complementary. Acute and chronic food insecurity are not mutually exclusive phenomena. Indeed, repeated shocks and persistent crises can provoke upticks in severe food insecurity, eventually forcing households into destitution and chronic poverty, and potentially leading to starvation. While acute food insecurity may require shorter-term interventions that address immediate causes, interventions tackling root causes may also be important to prevent repeated transitory acute food insecurity, which may lead to chronic food insecurity. Decision makers worldwide can largely benefit from the findings of the two reports. 


\subsection{PROGRESS TOWARDS GLOBAL NUTRITION TARGETS}

\section{KEY MESSAGES}

$\rightarrow$ Low birthweight estimates, included for the first time in this year's edition of the report following the release of new global estimates, indicate that one in seven live births -20.5 million babies globally - suffered from low birthweight in 2015. If current trends continue, the 2025 World Health Assembly target of a 30 percent reduction in the prevalence of low birthweight will not be met.

$\rightarrow$ Globally, the prevalence of stunting among children under five years is decreasing. The number of stunted children has also declined by 10 percent over the past six years, but with 149 million children still stunted, progress needs to be accelerated to achieve the 2030 target of halving the number of stunted children.

$\rightarrow$ A closer look at the SDG indicators of wasting, stunting, and childhood overweight reveal striking regional differences. In 2018, Africa and Asia bear the greatest share of all forms of malnutrition, accounting for more than nine out of ten of all stunted children, over nine out of ten of all wasted children, and nearly three-quarters of all overweight children worldwide.

$\rightarrow$ Malnutrition is linked across the life cycle, with undernutrition in foetal and early life contributing to both immediate and long-term health problems such as stunted physical growth, coronary heart disease, stroke, diabetes, and abdominal obesity, as well as economic costs due to loss of human capital.

$\rightarrow$ Globally, the prevalence of overweight is increasing in all age groups, with particularly steep increases among school-age children and adults. The increase in prevalence of obesity between 2000 and 2016 has been even faster than that of overweight. $\rightarrow$ Both overweight and obesity are significant health problems, but obesity in particular is linked to higher mortality and morbidity risks.

$\rightarrow$ Throughout the world, most school-age children do not eat enough fruit or vegetables, regularly consume fast food and carbonated soft drinks, and are not physically active on a daily basis.

$\rightarrow$ Tackling all forms of malnutrition will require bold multisectoral action, involving the health, food, education, social protection, planning and economic policy sectors. Food environments must be transformed to make nutritious foods more available and affordable. Relevant actions that countries can implement as outlined in the ICN2 Framework for Action are encouraged under the UN Decade of Action on Nutrition.

This section assesses global and regional trends and patterns to track progress towards seven nutrition indicators used to monitor global World Health Assembly targets for nutrition. This year the report takes a closer look at data on overweight and obesity, a serious public health challenge affecting people of all ages. For the first time, data on overweight and obesity among school-age children and adolescents are included and the section highlights some of the dietary and physical activity behaviours that contribute to overweight and obesity in this age group. The trends described emphasize the urgent need for actions aimed at improving access to nutritious and sufficient food for all.

Malnutrition exists in multiple forms.

Maternal and child undernutrition contributes to 45 percent of deaths in children under five. ${ }^{20}$ Overweight and obesity are on the rise in almost all countries, contributing to 4 million deaths globally. ${ }^{21}$ The economic costs of malnutrition are staggering - obesity is projected to cost USD 2 trillion annually, largely driven by the value placed on lost economic productivity plus direct health care costs worldwide, ${ }^{\mathbf{2 2}}$ while it is projected that undernutrition will reduce GDP by up to 11 percent in Africa and Asia. ${ }^{23}$ The various forms of malnutrition are intertwined throughout the life cycle, with maternal undernutrition, low birthweight and child stunting giving rise to increased risk of overweight later in life. 


\section{Global trends}

This year, also for the first time, low birthweight estimates are included in the report. These indicate that one in seven live births, or 20.5 million babies globally, suffered from low birthweight in $2015 .{ }^{24}$ Low birthweight newborns have a higher risk of dying in the first 28 days of life; those who survive are more likely to suffer from stunted growth and lower intelligence quotient IQ, and face increased risk of adult-onset chronic conditions including obesity and diabetes. ${ }^{25}$ Data show that little progress has been made since 2012, with an estimated 14.6 percent of all babies worldwide born with low birthweight in 2015 (Figure 15). If current trends continue, the goal to achieve a 30 percent reduction in the prevalence of low birthweight infants by 2025 will not be met.

Estimates of exclusive breastfeeding reveal some progress at the global level, with 41.6 percent of infants under six months being exclusively breastfed in 2018 (based on the most recent data for each country between 2013 and 2018) compared with 37 percent of infants in 2012 (based on the most recent data for countries between 2005 and 2012).

Globally, the prevalence of stunting among children under five years is decreasing, with 21.9 percent affected in 2018. The number of stunted children has also decreased from 165.8 million in 2012 to 148.9 million in 2018 . Although this represents a 10.1 percent decline over this six-year period, it falls short of the 20 percent decline required over the same period to be on track for the 2030 target of reducing the number of children by one-half with reference to the 2012 baseline.

Globally, 7.3 percent (49.5 million) children under five years of age are wasted, which falls short of the target of reducing and maintaining childhood wasting to less than 5 percent for 2025 and 3 percent for 2030. In 2018, childhood overweight affected 40.1 million children under five worldwide. The global prevalence of overweight among children under five has not improved, increasing from 5.5 percent in 2012 (the baseline year of the WHA targets) to 5.9 percent in 2018.
As of 2016, one in three (32.8 percent) women of reproductive age ( $15-49$ years) across the globe was still affected by anaemia. Since 2012, the global prevalence of anaemia has remained unchanged, making it extremely challenging to achieve the 2025 target of a 50 percent reduction. At the same time, adult obesity continues to rise, from 11.7 percent in 2012 to 13.2 percent in 2016 . As a result, we are not on track to meet the global target to halt the rise in adult obesity.

\section{Regional patterns}

Global estimates of various nutrition indicators do not reveal the wide variations that exist between regions. For instance, in 2015, an estimated 14.6 percent of babies born globally were low birthweight, with wide variations across regions - from 7.0 percent in Northern America and Europe to 17.3 percent in Asia. ${ }^{26}$

A closer look at the SDG indicators of wasting, stunting, and childhood overweight reveals striking regional differences as well (Figure 16). While the prevalence of stunting is decreasing in almost every region, the extent of progress varies considerably, with Africa seeing the least progress in reducing stunting prevalence since 2012. In 2018, Africa and Asia accounted for more than nine out of ten of all stunted children globally, representing 39.5 percent and 54.9 percent respectively (bottom of Figure 16). No clear conclusions can be made for Oceania, as the confidence limits around the estimates are very wide for this region.

In 2018, 49.5 million children under five were affected by acute malnutrition or wasting. All regions had prevalence levels considered "medium" (between 5 and 9 percent) for childhood wasting except Latin America and the Caribbean, which had a very low prevalence (1.3 percent). In Asia and Oceania, nearly one in ten (9.4 percent) children were wasted. Overall in 2018, more than two-thirds of all wasted children under five lived in Asia.

Globally, overweight affected 40.1 million children under five years of age in 2018. While Asia and Africa had the lowest overweight prevalence (5.2 percent and 4.9 percent respectively), together they accounted for " 


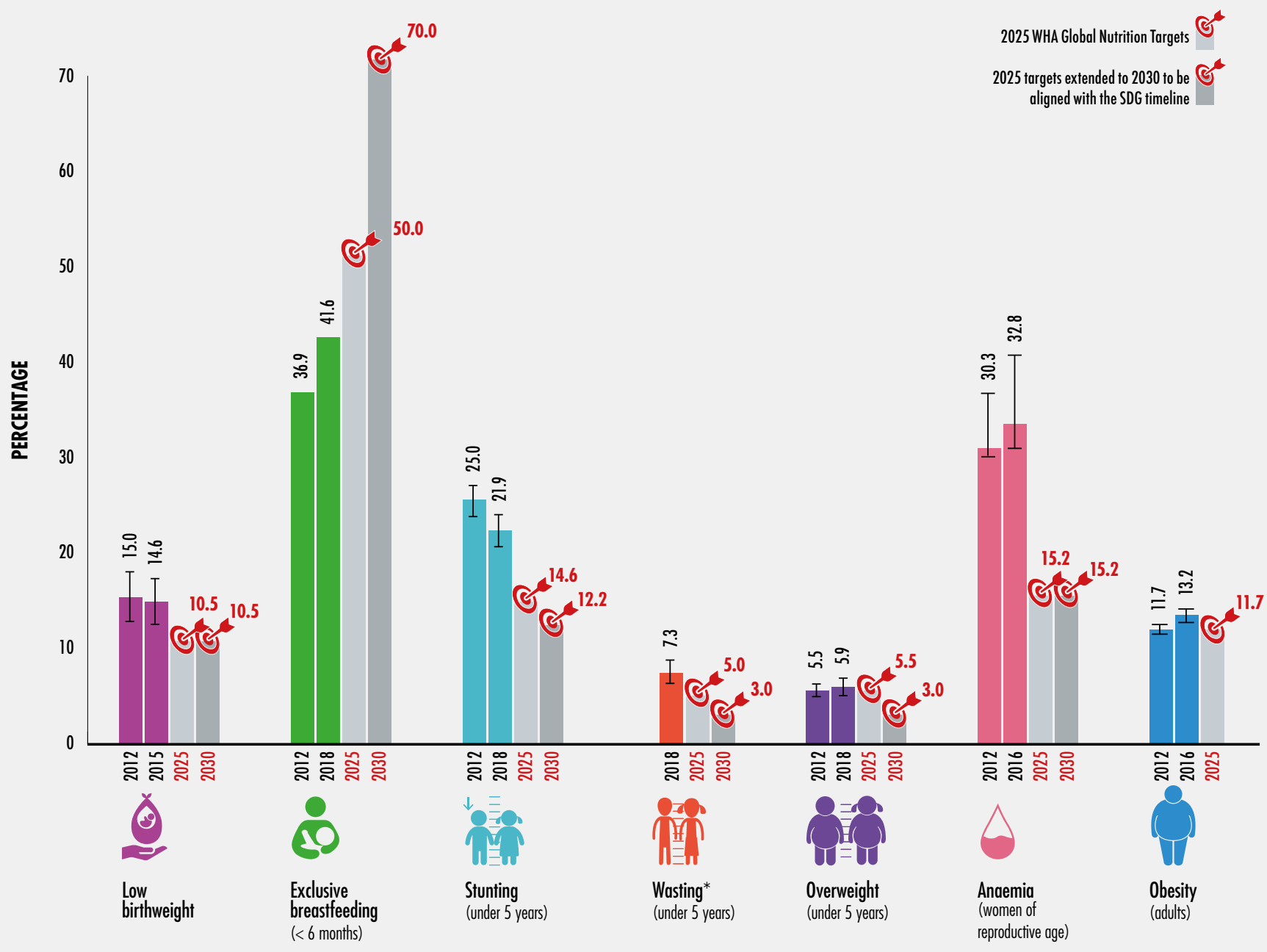

NOTES: * Wasting is an acute condition that can change frequently and rapidly over the course of a calendar year. This makes it difficult to generate reliable trends over time with the input data available and, as such, this report provides only the most recent global and regional estimates.

SOURCES: Data for stunting, wasting and overweight are based on UNICEF, WHO and International Bank for Reconstruction and Development/World Bank. 2019. UNICEF-WHO-The World Bank: Joint child malnutrition estimates - Levels and trends (March 2019 edition) [online]. https://data.unicef.org/topic/nutrition, www.who.int/nutgrowthdb/estimates, https://data. worldbank.org; data for exclusive breastfeeding are based on UNICEF. 2019. Infant and Young Child Feeding: Exclusive breastfeeding, Predominant breastfeeding. In: UNICEF Data: Monitoring the Situation of Children and Women [online]. https://data.unicef.org/topic/nutrition/infant-and-young-child-feeding; data for anaemia are based on WH0. 2017. Global Health Observatory (GHO). In: World Health Organization [online]. Geneva, Switzerland. [Cited 2 May 2019] http://apps.who.int/gho/data/node.imr.PREVANEMIA?lang=en; data for adult obesity are based on WHO. 2017. Global Health Observatory (GHO). In: World Health Organization [online]. Geneva, Switzerland. [Cited 2 May 2019]. http://apps.who.int/gho/ data/node.main.A900A?lang=en; and data for low birthweight are based on UNICEF and WHO. 2019. UNICEF-WHO Low Birthweight Estimates: levels and trends 2000-2015, May 2019. In: UNICEF data [online]. New York, USA, UNICEF [Cited 16 May 2019]. https://data.unicef.org/resources/unicef-who-low-birthweight-estimates-levels-and-trends-2000-2015 


\section{FIGURE 16}

\section{STUNTING, WASTING**** AND OVERWEIGHT STILL IMPACT THE LIVES OF FAR TOO MANY}

CHILDREN UNDER 5 YEARS

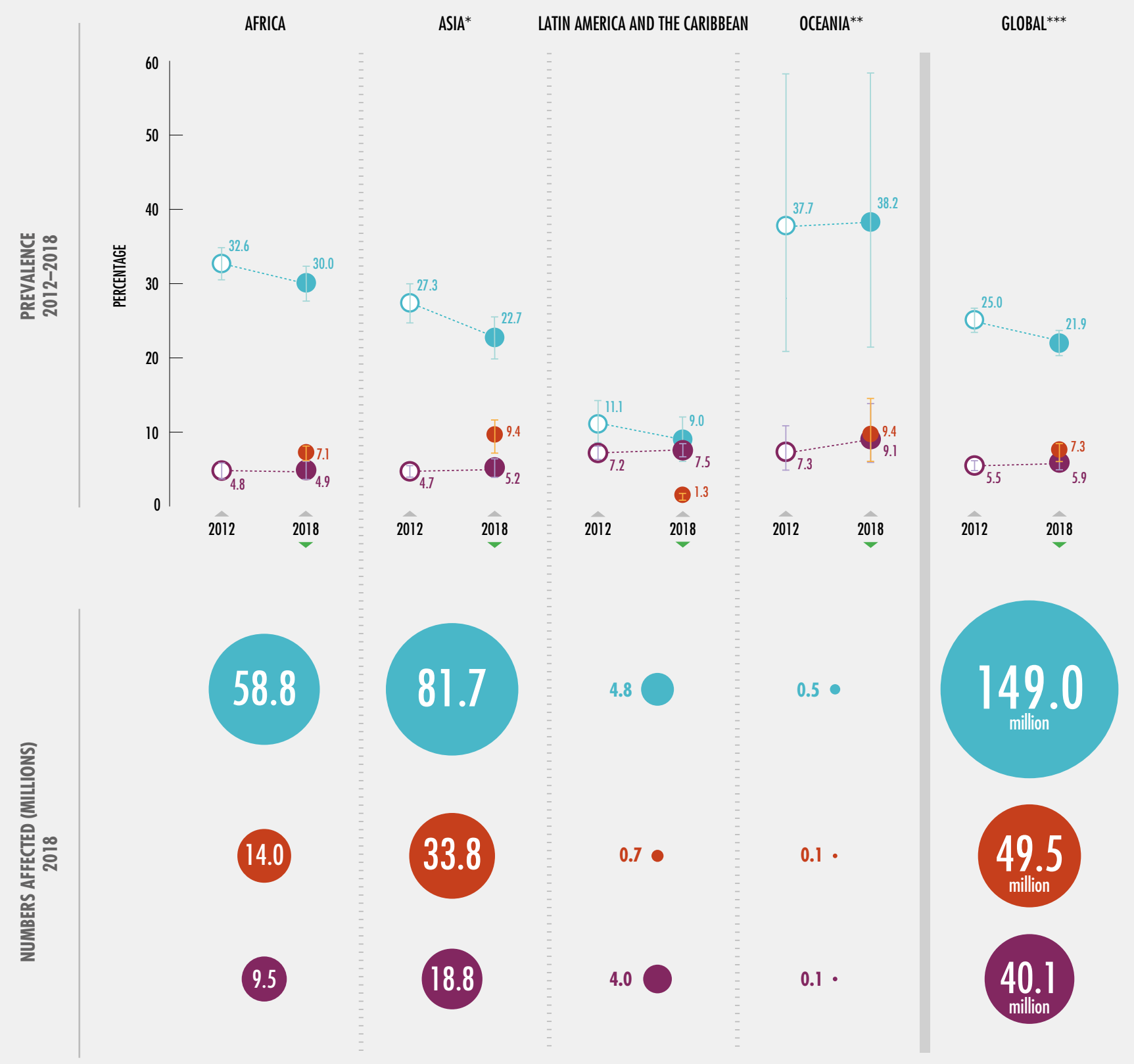

NOTES: * Asia excluding Japan; ** Oceania excluding Australia and New Zealand; *** the Global total factors in estimates for "more developed regions" (includes Australia, New Zealand, Northern America and Europe) but estimates for these regions are not displayed due to low population coverage.

**** Wasting is an acute condition that can change frequently and rapidly over the course of a calendar year. This makes it difficult to generate reliable trends over time with the input data available - as such, this report provides only the most recent global and regional estimates.

SOURCES: UNICEF, WHO and International Bank for Reconstruction and Development/World Bank. 2019. UNICEF-WHO-The World Bank: Joint child malnutrition estimates - Levels and trends (March 2019 edition) [online]. https://data.unicef.org/topic/nutrition; www.who.int/nutgrowthdb/estimates; https://data.worldbank.org 
nearly three-quarters of all overweight under-fives in the world (46.9 percent in Asia and 23.8 percent in Africa). Oceania has the highest prevalence of overweight, with almost one in ten (9.1 percent) affected. This region is an example of a population affected by the multiple burden of malnutrition, with prevalence of both acute malnutrition (wasting) and overweight approaching the 10 percent cut-off for being classified at "high" levels in 2018. There has not been a significant change in prevalence or numbers of children under five affected by overweight for any region between 2012 and 2018.

In 2018, Africa and Asia had the highest prevalence of exclusive breastfeeding with more than two in five infants under six months benefiting from this life-saving practice. Conversely, however, these two regions have the highest prevalence of anaemia among women of reproductive age. In 2016, the prevalence of anaemia among women of reproductive age in Africa and Asia was more than double the rate in Northern America and Europe, with no region showing a decline in anaemia among women of reproductive age since 2012 (Regional patterns for adult overweight are discussed in the next section).

\section{Spotlight on overweight and obesity}

Overweight and obesity pose health problems throughout the life cycle. Among adults, obese people have higher rates of mortality due to an increased risk of cardiovascular disease, cancer and diabetes. Children who are overweight are at a higher risk of type 2 diabetes, high blood pressure, asthma and other respiratory problems, sleep disorders, and liver disease. ${ }^{\mathbf{2 7}}$ They may also suffer from the psychological effects of low self-esteem, depression, and social isolation. ${ }^{\mathbf{2 8}}$ Overweight and obesity during childhood often persist into adulthood, leading to lifelong health problems. The national economic costs, resulting from increased healthcare costs and lost economic productivity, are tremendous. ${ }^{29}$

The definitions of overweight and obesity are somewhat different depending on the age group, making comparisons between them difficult. For children under five, overweight is defined as weight-for-height greater than 2 standard deviations above the WHO growth reference standard median. The term "obesity" is generally not used for children under five. For school-age children and adolescents (aged 5-19 years), being overweight indicates having a body mass index (BMI)-for-age greater than 1 standard deviation above the WHO growth reference standard median, whereas obesity is defined as having a BMI-for-age of more than 2 standard deviations above the median. In the case of adults, overweight is defined as having a BMI greater than or equal to 25; likewise, obesity is defined as a BMI greater than or equal to 30 . For this report, the term overweight is used to be inclusive of obesity among school-age children, adolescents and adults unless otherwise noted.

At its most basic level, overweight results from a persistent condition of dietary energy consumption exceeding energy expenditure. While genetics can increase an individual's susceptibility to overweight, it cannot explain population-level increases over time. Intrauterine growth, infant feeding, and eating habits during preschool are significant determinants of overweight and obesity during adulthood. There is increasing evidence indicating the importance of good nutrition and physical activity in early life as a determinant of long-term energy balance. Unfortunately, modernization and economic development have led to an increased availability of energy-dense foods and to poor dietary practices, while at the same time reducing levels of physical activity, a major determinant of energy expenditure. Food security, i.e. access to nutritious and sufficient food, is also known to be a key factor. Box 6 provides a more in-depth description of the links between maternal nutrition, malnutrition in early life and overweight later in life, illustrating life-cycle and intergenerational effects.

In 2018, an estimated 5.9 percent (40 million) children under five were affected by overweight. Globally in 2016, one in five school-age children (20.6 percent) and adolescents (17.3 percent) were overweight, or 131 million children aged 5-9 years and 207 million adolescents. In the same year, nearly two in five adults (38.9 percent) were overweight, representing 2 billion adults worldwide (Figure 17). 
An increased risk for overweight and obesity can be imprinted early in life through intergenerational and early life influences; such influences have contributed to a growing crisis in overweight since 2000, as shown in Figure 18. During foetal and early life, undernutrition, potentially due to food insecurity, leads to changes in physiology and metabolism that not only stunt physical growth and negatively impact human capital, but also increase the risk of non-communicable diseases (NCDs) later in life. ${ }^{1}$ To illustrate, there is ample evidence linking low birthweight to increased risks of coronary heart disease, stroke, diabetes, and abdominal obesity. ${ }^{2}$ The adverse effect of poor foetal growth on NCD risk can be amplified by growth failure in the first years after birth and rapid weight gain later in life. ' Girls who experienced poor foetal growth, especially when coupled with poor catch-up growth during infancy, are more likely to become stunted as adults and consequently more likely to give birth to low-birthweight babies, thus projecting poor nutrition alongside increased NCD risk to the next generation. ${ }^{3}$

In addition to the link between early undernutrition and subsequent risk of NCDs, another mechanism that increases NCD and obesity risk along the life cycle is that overweight or excess weight gain during pregnancy increases the risk of gestational diabetes and large size at birth, which in turn is linked to increased risk of overweight and obesity later in life. ${ }^{4}$ Irrespective of birthweight, excessive weight gain in early childhood is predictive of overweight and obesity in adolescence 5 and adulthood. ${ }^{6}$ To effectively address the growing problem of overweight and obesity and to prevent its perpetuation across generations, it is clear that a life-cycle approach is required that promotes access to nutritious foods, optimal infant feeding and nutrition as well as healthy growth along the entire life course, from foetal life to adulthood.

\section{AN INCREASED RISK OF OVERWEIGHT AND OBESITY CAN BE IMPRINTED EARLY IN LIFE THROUGH INTERGENERATIONAL AND EARLY LIFE INFLUENCES}

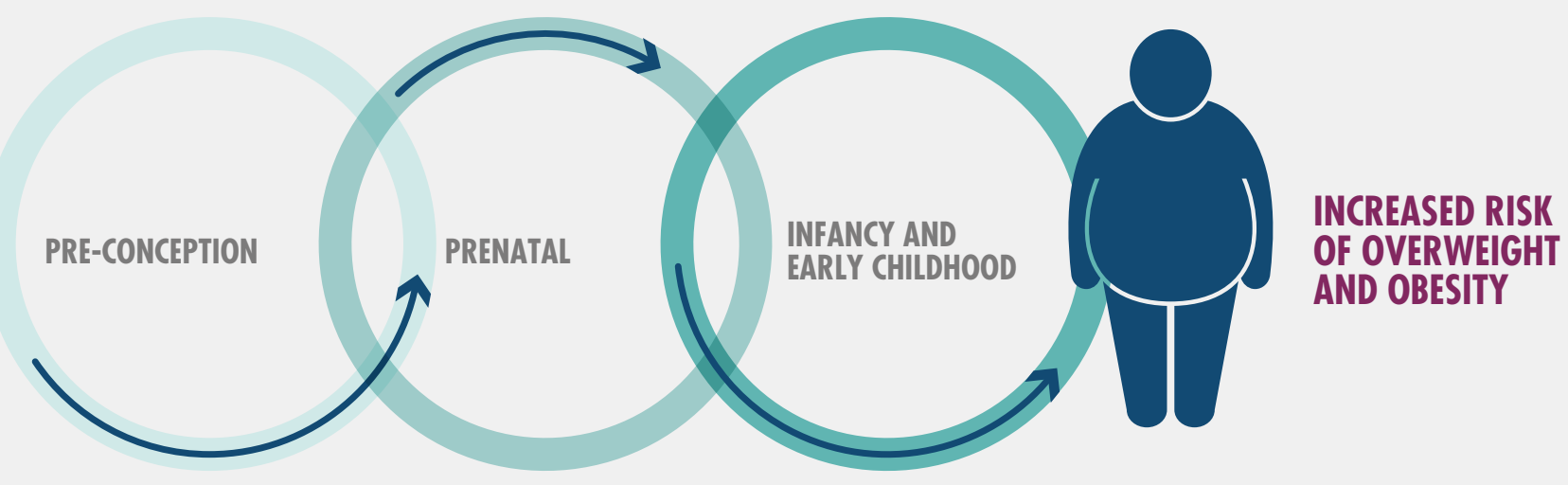

SOURCE: UNICEF

' C.G. Victora, L. Adair, C. Fall, P.C. Hallal, R. Martorell, L. Richter and H.S. Sachdev. 2008. Maternal and child undernutrition: consequences for adult health and human capital. The Lancet, 371(9609): 340-357.

${ }^{2}$ D. Barker and C. Osmond. 1986. Infant mortality, childhood nutrition, and ischaemic heart disease in England and Wales. The Lancet, 327(8489): 1077-1081; C. Osmond, D.J. Barker, P.D. Winter, C.H. Fall and S.J. Simmonds. 1993. Early growth and death from cardiovascular disease in women. BMJ (Clinical research ed.), 307(6918): 1519-1524; I. Darnton-Hill, C. Nishida and W. James. 2004. A life course approach to diet, nutrition and the prevention of chronic diseases. Public Health Nutrition, 7(1a): 101-121; A.C. Ravelli, J.H. van der Meulen, C. Osmond, D.J. Barker and 0.P. Bleker. 1999. Obesity at the age of $50 \mathrm{y}$ in men and women exposed to famine prenatally. The American Journal of Clinical Nutrition, 70(5): 811-816.

${ }^{3}$ I. Darnton-Hill, C. Nishida and W. James. 2004. A life course approach to diet, nutrition and the prevention of chronic diseases. Public Health Nutrition, 7(la): 101-121.

${ }^{4}$ R.C.W. Ma and B.M. Popkin. 2017. Intergenerational diabetes and obesity - A cycle to break? PLOS Medicine, 14(10): e1002415.

${ }^{5}$ M. Geserick, M. Vogel, R. Gausche, T. Lipek, U. Spielau, E. Keller, R. Pfäffle, W. Kiess and A. Körner. 2018. Acceleration of BMI in early childhood and risk of sustained obesity. New England Journal of Medicine, 379(14): 1303-1312.

${ }^{6}$ Z.J. Ward, M.W. Long, S.C. Resch, C.M. Giles, A.L. Cradock and S.L. Gortmaker. 2017. Simulation of growth trajectories of childhood obesity into adulthood. New England Journal of Medicine, 377(22): 2145-2153. 


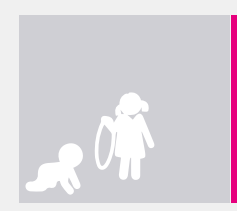

Preschool children $(<5$ years)

Total population $=678$ million, of whom

40 million

(or 5.9\%) are overweight

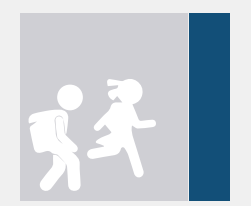

School-age children (5-9 years)

Total population $=638$ million, of whom

131 million

(or $20.6 \%$ ) are overweight

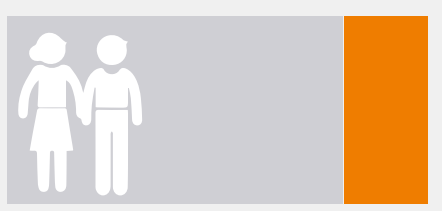

Adolescents (10-19 years)

Total population $=1.2$ billion, of whom

207 million (or $17.3 \%$ ) are overweight

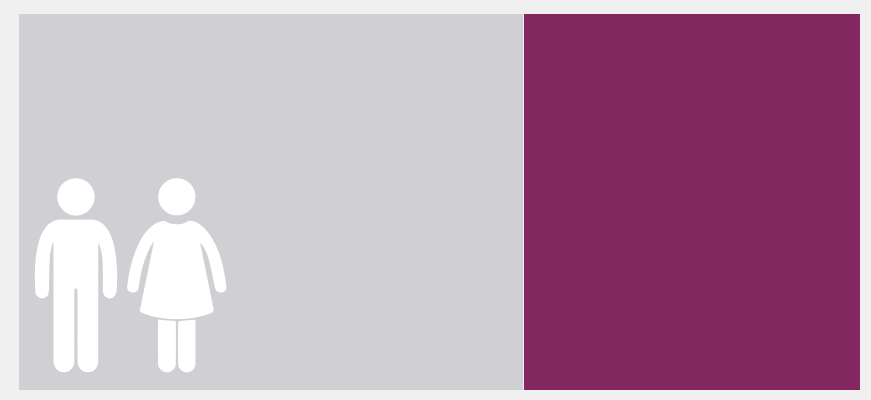

Adults (18+ years)

Total population $=5.1$ billion, of whom

2 billion

(or $38.9 \%$ ) are overweight

SOURCES: Data for overweight in preschool children are based on UNICEF, WHO and International Bank for Reconstruction and Development/World Bank. 2019. UNICEF-WHO-The World Bank: Joint child malnutrition estimates - Levels and trends (March 2019 edition) [online]. https://data.unicef.org/topic/nutrition, www.who.int/nutgrowthdb/estimates, https://data. worldbank.org; data for overweight in school-age children, adolescents and adults are based on NCD Risk Factor Collaboration (NCD-RisC). 2017. Worldwide trends in body-mass index, underweight, overweight, and obesity from 1975 to 2016: a pooled analysis of 2416 population-based measurement studies in 128.9 million children, adolescents, and adults. The Lancet, 390(10113): 2627-2642.

The prevalence of overweight is increasing in all age groups, with particularly steep trends among school-age children and adults (Figure 18). Among school-age children, the prevalence has nearly doubled since 2000. Over half of adults and over a quarter of school-age children in Northern America, Oceania, Latin America and the Caribbean, and Europe were overweight in 2016.

No region is exempt from this overweight crisis. All have experienced an increase of roughly ten percentage points in the prevalence of overweight among adults since 2000. Among school-age children, the upward trend is particularly steep in Asia and appears to be accelerating. In Northern America, on the other hand, while the prevalence of overweight is higher than in any other region, the trend shows some sign of levelling off in recent years. Among preschool children (under five years old), however, the prevalence of overweight is much lower and trends are less dramatic - only in Northern America and Oceania has overweight increased in this age group by more than a percentage point since 2000 .

While the rise in the prevalence of overweight in children and adults is alarming, of even greater concern is the high proportion of 


\section{FIGURE 18}

ACROSS ALL REGIONS, THE PREVALENCE OF OVERWEIGHT IS INCREASING IN ALL AGE GROUPS, WITH PARTICULARLY STEEP TRENDS AMONG ADULIS AND SCHOOL-AGE CHILDREN, INCLUDING ADOLESCENTS

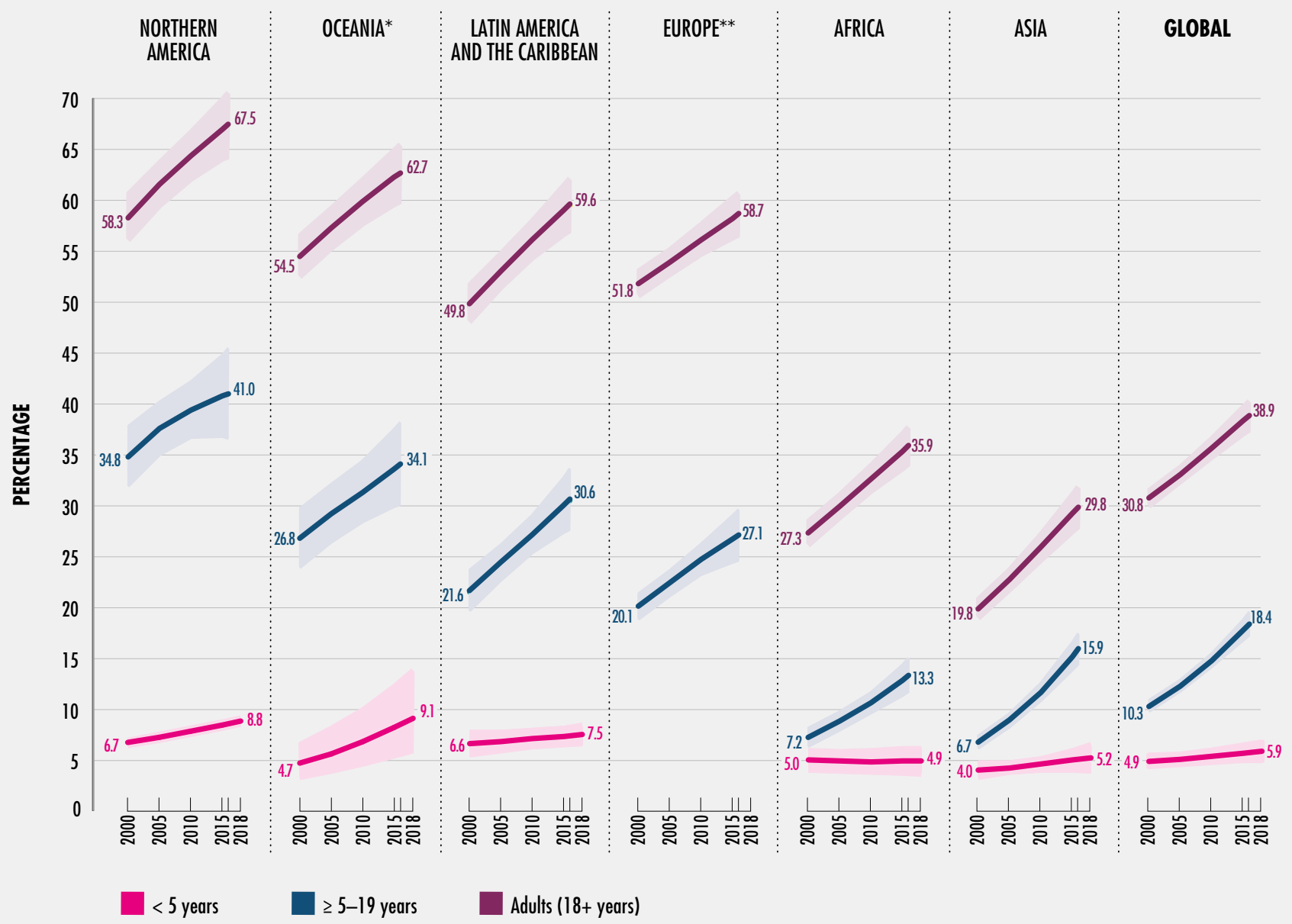

NOTES: * Estimates for children under five for Oceania exclude Australia and New Zealand. ${ }^{* *}$ Estimates for children under five for Europe are not displayed due to insufficient population coverage. Trends in prevalence of overweight for children under five are based on data between 2000 and 2018. Trends for school-age children and adolescents (5-19 years) and adults are based on data between 2000 and 2016.

SOURCES: Data for overweight in preschool children are based on UNICEF, WHO and International Bank for Reconstruction and Development/World Bank. 2019. UNICEF-WHO-The World Bank: Joint child malnutrition estimates - Levels and trends (March 2019 edition) [online]. https://data.unicef.org/topic/nutrition, www.who.int/nutgrowthdb/estimates, https://data. worldbank.org; data for overweight in school-age children, adolescents and adults are based on NCD Risk Factor Collaboration (NCD-RisC). 2017. Worldwide trends in body-mass index, underweight, overweight, and obesity from 1975 to 2016 : a pooled analysis of 2416 population-based measurement studies in 128.9 million children, adolescents, and adults. The Lancet, 390(10113): 2627-2642. 


\section{FIGURE 19}

\section{THE INCREASE IN PREVALENCE OF OBESITY BETWEEN 2000 AND 2016 HAS BEEN EVEN LARGER} THAN THAT OF OVERWEIGHT
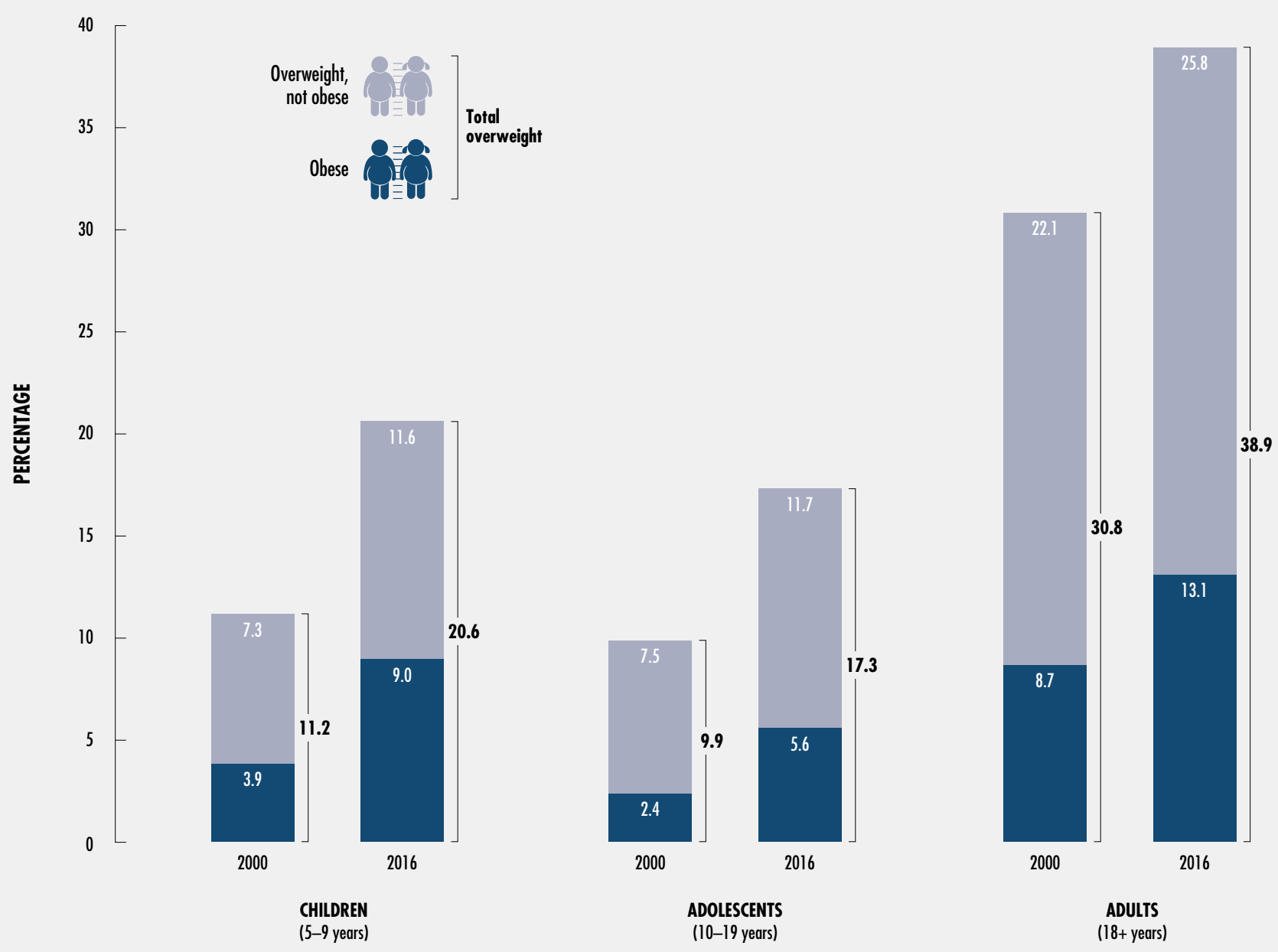

SOURCE: NCD Risk Factor Collaboration (NCD-RisC). 2017. Worldwide trends in body-mass index, underweight, overweight, and obesity from 1975 to 2016: a pooled analysis of 2416 population-based measurement studies in 128.9 million children, adolescents, and adults. The Lancet, 390(10113): 2627-2642.

prevalence represented by obesity, as obese people face far more severe health consequences and higher mortality risks compared with non-obese people. As of 2016, about a third of overweight adolescents and adults, and 44 percent of overweight children aged 5-9, were obese (Figure 19). In addition, the relative rate of increase in the prevalence of obesity between 2000 and 2016 has been even faster than that of overweight: the prevalence of obesity more than doubled among children and adolescents over this time period. 


\section{FIGURE 20}

\section{THE GAP BETWEEN URBAN AND RURAL AREAS IN MEAN BODY MASS INDEX IS CLOSING}

30

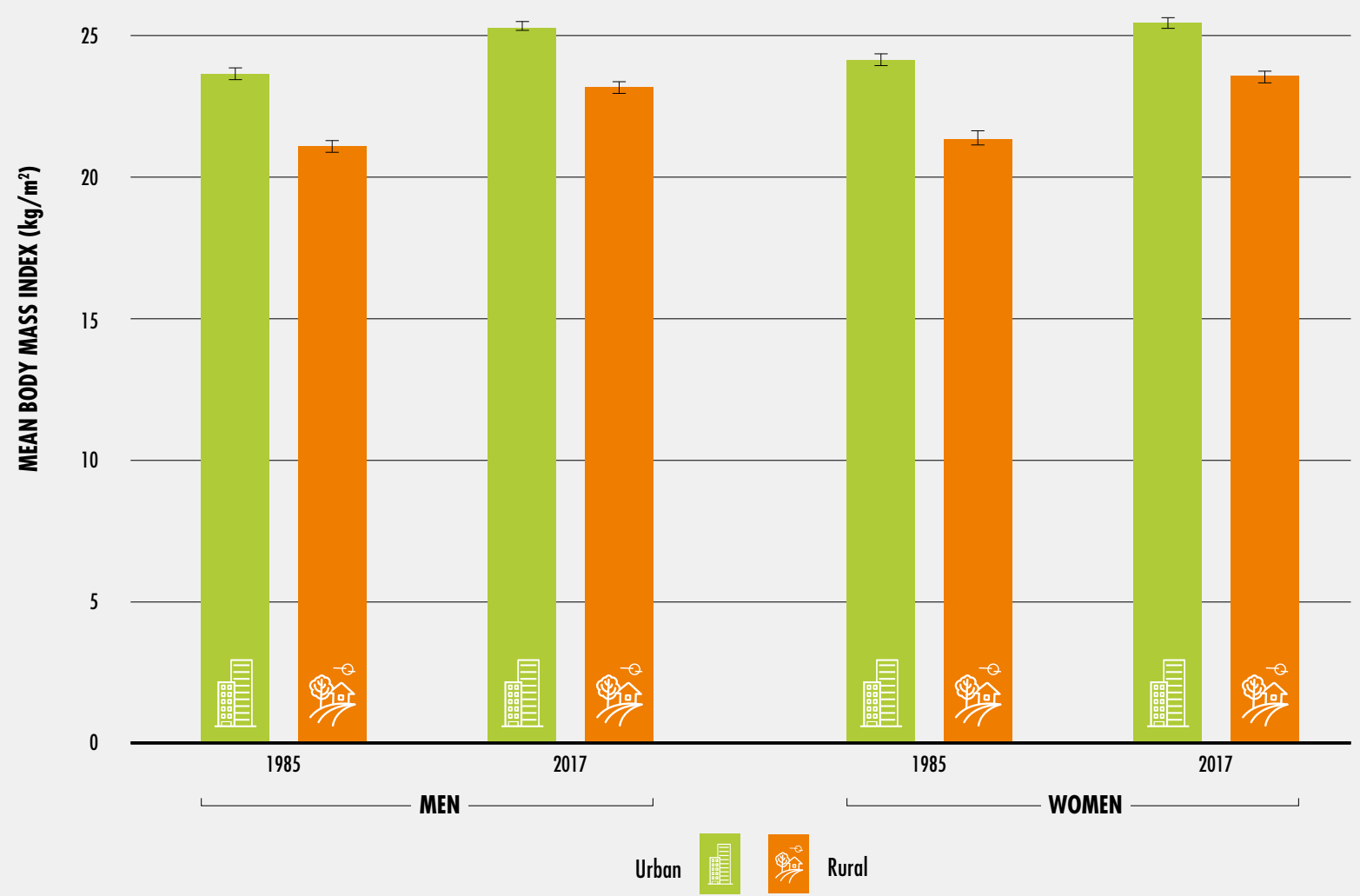

SOURCE: NCD Risk Factor Collaboration (NCD-RisC). 2019. Rising rural body-mass index is the main driver of the global obesity epidemic in adults. Nature, 569: 260-264.

Globally, mean BMI among adults is

higher in urban areas than in rural areas.

However, this gap has been closing as BMI has

been increasing more rapidly in rural areas

than in urban areas (Figure 20). This pattern is seen worldwide, but particularly in low- and middle-income countries. ${ }^{30}$ The problem of malnutrition in rural areas is clearly shifting from one dominated by undernutrition to a significant problem of the multiple burden of malnutrition. Among children under five, differences in the prevalence of overweight by areas of urban or rural residence are quite small. Additionally, there is no notable difference in the prevalence of overweight by sex for any age group. 


\section{Taking action to promote better nutrition and reverse obesity trends}

Several global initiatives provide roadmaps to halt and reverse the obesity epidemic. The creation of an environment that enables and promotes healthy diets is central to all of these, referring to a balanced, diverse and appropriate selection of foods eaten over time to ensure that the needs for essential nutrients are met, and that consumption of harmful fats, salt and sugars is limited. ${ }^{31}$ Unhealthy diet is now the leading risk factor for deaths worldwide. To counter this, the Global Action Plan for the Prevention and Control of Noncommunicable Diseases 2013-2020 outlines policy options for promoting physical activity and healthy diets. ${ }^{32}$ Another initiative, the WHO Commission on Ending Childhood Obesity proposes strategies to end childhood obesity that focus on healthy diets, physical activity, preconceptional and prenatal care, school health, and weight management. ${ }^{33}$ It includes actions that are urgently needed to address the problems of unhealthy diets and inadequate physical activity found to be prevalent among school-age children around the world (Box 7). Finally, the Comprehensive Implementation Plan for Maternal, Infant and Young Child Nutrition, endorsed by the World Health Assembly in 2012, has challenged the world to prevent any increase in preschool overweight over the next decade. ${ }^{34}$

These initiatives highlight the need for a multifaceted, multisectoral approach to address the burden of overweight and obesity globally. In light of this, in 2016, the United Nations endorsed the ICN2 Framework for Action ${ }^{35}$ and declared a Decade of Action on Nutrition. ${ }^{36}$ Tackling all forms of malnutrition is not the domain of any one sector alone: the health, education, agriculture, social protection, planning and economic policy sectors all have a role to play, as well as legislators and other political leaders. A range of actions is needed, aimed at the individual, household, community, national and even global levels.

Healthcare systems must provide appropriate support, education and counselling for individuals and families to promote breastfeeding (starting with supportive policies in hospital) and prevent and treat overweight and obesity. Schools can play an influential role by providing environments that shape and enable healthier food choices through exposure to nutritious foods, combined with nutrition education and limiting exposure to foods or beverages high in fats, sugars or salt and to marketing communication for such foods in or around schools. More broadly, transformation of food systems is essential in delivering safe, affordable and sustainable diets. Social protection programmes can also support access to nutritious food especially for disadvantaged populations.

Poorer communities often face physical and economic barriers to obtaining nutritious foods, putting them at higher risk of food insecurity and malnutrition. There is growing recognition of the need for actions that address factors at the community and national levels. ${ }^{37}$ Governments have a range of policy options to choose from to improve access to affordable healthy diets. These range from "hard" policies such as standards and regulations to "soft" policies such as the provision of information and education. Figure 21 presents examples of policies and programmes being implemented by countries and cities with the aim of preventing or reducing overweight and obesity. Some of these actions are described below.

Nutritious foods that contribute to a healthy diet must be readily available and affordable. In order to foster greater physical access to nutritious foods, local governments can take several measures, such as providing fiscal or non-fiscal incentives to increase the number of food outlets that offer fresh and nutritious food in neighbourhoods and communities ${ }^{\mathbf{3 8}}$ (including open-air markets), discouraging the sale of fast food near schools through zoning, ${ }^{39}$ and improving the availability of nutritious foods in restaurants through the use of non-fiscal incentives such as voluntary certification schemes. ${ }^{40}$

Nutritious foods have become relatively more expensive than foods high in fat, sugar and/ or salt, in high-income countries as well as emerging economies such as Brazil, China, Mexico and South Africa. ${ }^{41}$ The affordability of highly processed, energy-dense foods (as well as spatial-temporal access to nutritious food) " 
The Global School-Based Student Health Survey (GSHS) provides a standard methodology to enable countries to collect comparable information on health status, risk behaviours and protective factors related to the leading causes of morbidity and mortality among 13-15 year old students. ${ }^{1}$ The survey includes information on a number of risk factors for overweight and obesity in school-age children, including low intake of fruits and vegetables, eating at fast food restaurants, consumption of soft drinks, low physical activity, and sedentary behaviour. ${ }^{2}$ The data provide insights on prevalence and behavioural trends and can be used for advocacy, programme planning, targeting and evaluation. The data presented here include results from 73 countries that have carried out surveys in the past ten years.

The GSHS asks students to report on their fruit and vegetable consumption in the past 30 days.
Roughly half of the countries reported that between 10 and 30 percent of students do not eat any fruit at all, and a quarter reported that between 10 and 30 percent of their students do not eat any vegetables at all. All but one of the countries found that the majority of their students ate less than five or more servings of fruit or vegetables per day, and in all but 15 of these countries over two-thirds of students did not eat this recommended amount (see figure below). Fruit and vegetable consumption is highest among the countries of Oceania.

Nearly 70 percent of countries reported that at least half of their students eat fast food on a weekly basis. Furthermore, 27 countries reported that at least two in every ten students eat fast food at least three times per week.

All countries found that one out of five students consumed carbonated soft drinks at least once a

\section{THROUGHOUT THE WORLD, BEHAVIOURS OF SCHOOL-AGE CHILDREN INCREASE THEIR RISK OF BECOMING OVERWEIGHT OR OBESE}

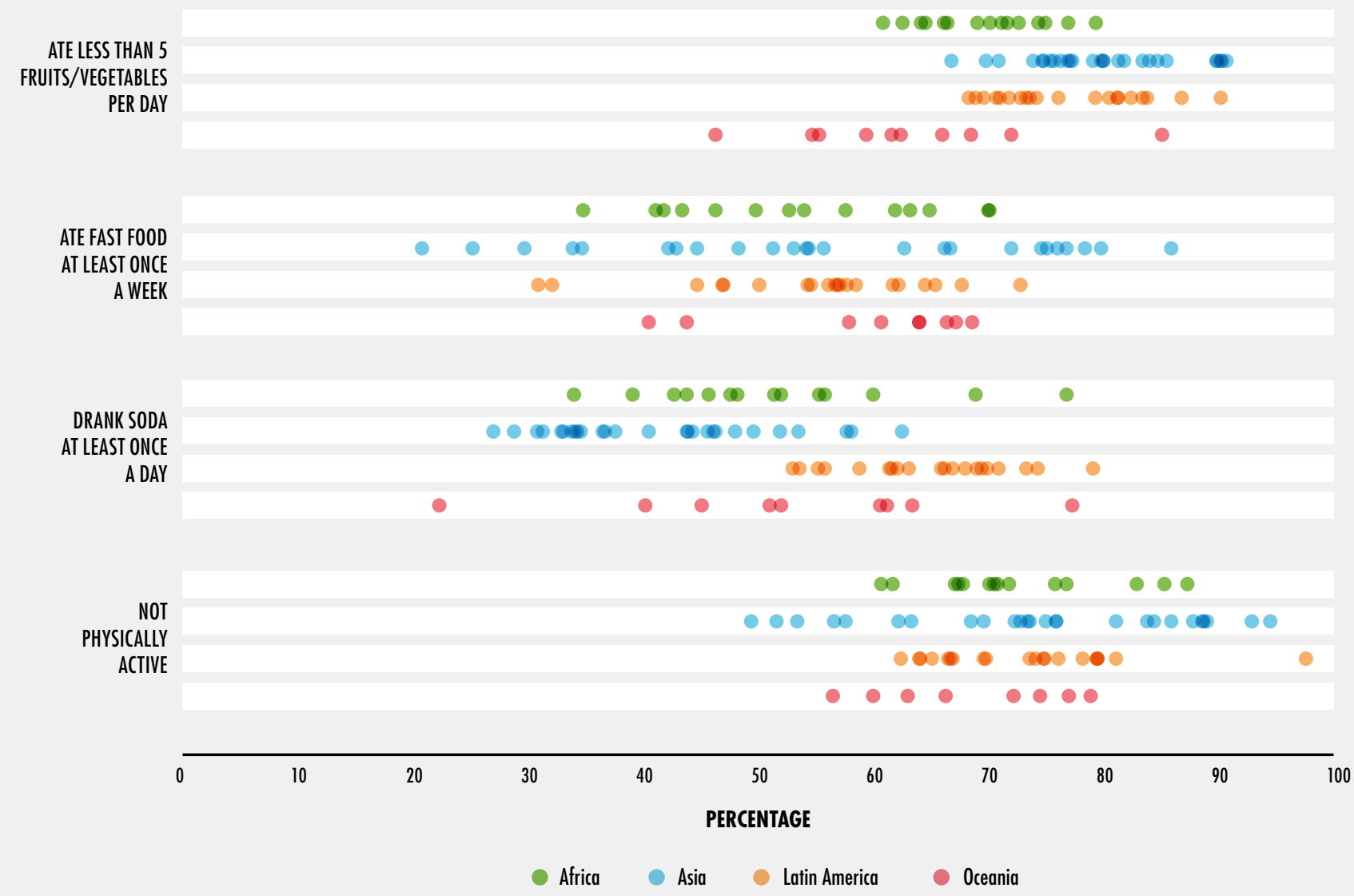

NOTES: Each point represents data from each country in the region.

SOURCE: WH0. 2019. NCDs | Global school-based student health survey (GSHS). In: World Health Organization [online] Geneva, Switzerland. [Cited 25 April 2019].

https://www.who.int/ncds/surveillance/gshs/en 
day, with more than half reporting that at least one out of every two students consumed soft drinks daily. Soda consumption was found to be highest in Latin America.

Regarding physical activity and sedentary behaviour, students were asked how many days in the past seven days they had been physically active for at least 60 minutes per day - the recommended level of activity for this age group as well as how much time per day they had spent in sedentary activities. None of the countries reported that a majority of their students had attained the recommended level of physical activity, and all but one reported having fewer than one in three students who had attained the recommended level. More than half of the countries reported that at least one in three students were spending three or more hours in sedentary activities every day.

' WHO. 2019. NCDs | Global school-based student health survey (GSHS). In: World Health Organization [online]. Geneva, Switzerland. [Cited 25 April 2019]. https://www.who.int/ncds/surveillance/gshs/en

${ }^{2}$ WHO. 2013. Global School-Based Student Health Survey (GSHS) 2013 Core Questionnaire Modules [online]. Geneva, Switzerland. https://www.who.int/ncds/surveillance/gshs/GSHS_Core_Modules_2013_English.pdf

\section{FIGURE 21}

\section{EXAMPLES OF POLICIES AND PROGRAMMES AIMED AT PREVENTING OR REDUCING OVERWEIGHT AND OBESITY}

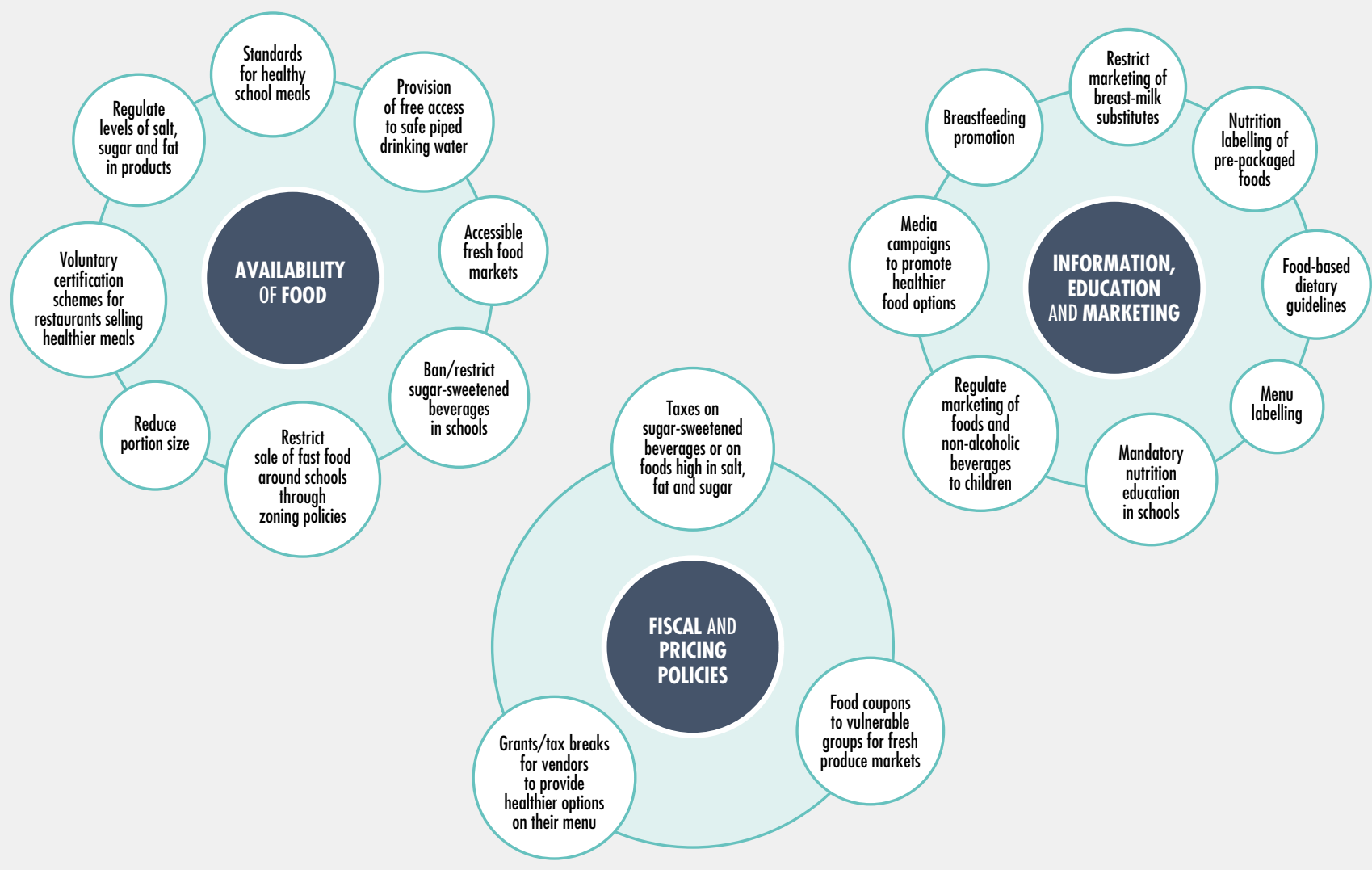

SOURCE: Developed by WHO and FAO for this publication based on: World Cancer Research Fund International. 2019. NOURISHING database. In: World Cancer Research Fund International database [online]. London. [Cited 25 April 2019]. https://www.wcrf.org/int/policy/nourishing-database; WHO. 2019. Global database on the Implementation of Nutrition Action (GINA). https://www.who.int/nutrition/gina/en 
" has been identified as a main determinant of whether food insecurity is associated with obesity in low- and middle-income countries; such foods tend to be widely available in upper-middle- and high-income countries, and are often cheaper than fresh and nutritious foods. ${ }^{42}$ To increase economic access to healthy diets, effective options are available to local and national governments, such as food assistance programmes that provide low-income families and individuals with supplemental funds to purchase fruit and vegetables or promotion of healthy food retail development through fiscal incentives. Some studies have shown that consumption of subsidized fruits and vegetables can be increased in the range of 10 to 30 percent. ${ }^{43}$ Policymakers can also use economic incentives such as taxes aimed at decreasing the demand for foods high in fat, sugar and/ or salt and subsidies to make nutritious foods more affordable. ${ }^{44}$ Taxes on sugar-sweetened beverages in particular have been found to reduce purchases and/or consumption of these products, not only due to the price increase, but also by raising awareness about the resulting health benefits. ${ }^{45}$ There is some evidence that the effects of food taxes are stronger on low-income groups because they are more price-responsive, and may therefore gain the most health benefits - especially if taxes are complemented with targeted subsidies for more nutritious foods. ${ }^{46}$ Furthermore, such taxes can also prompt manufacturers to reformulate their products (e.g. by reducing sugar content). ${ }^{\mathbf{4 7}}$

There are a number of other policy tools available to national governments to promote healthy eating and prevent overweight and obesity. These include incentives to encourage fruit and vegetable production, regulatory instruments that shape nutrition labelling, ${ }^{\mathbf{4 8}}$ food standards and appropriate procurement rules for schools and other public institutions, and national food-based dietary guidelines. Provision of free access to safe and affordable piped drinking water is crucial to promoting health everywhere; easy accessibility to safe piped drinking water in schools provides a healthy alternative to the consumption of sugar-sweetened beverages. Other important policy measures include restrictions on marketing of breast-milk substitutes, regulation of the marketing of foods and non-alcoholic beverages to children, and regulatory standards for maximum levels of salt, sugar and fat in specific products. Government-led reformulation programmes can lead to reductions in the levels of salt, sugar and fat across the spectrum of processed food and drink products, including the elimination of industrially produced trans fats. ${ }^{49}$

Importantly, no single measure alone can reverse the overweight and obesity trends; rather, there must be a multifaceted approach that combines different types of policies and interventions.

This section of the report has documented the persistent challenge of undernutrition coupled with rising overweight and obesity, known as the "multiple burden of malnutrition". Recognizing that both the drivers and solutions to the multiple facets of this burden are intricately linked, "double-duty actions" have been identified that can address the problems of undernutrition and obesity simultaneously. ${ }^{50}$ The potential impact for double-duty actions emerges from addressing the shared drivers underlying different forms of malnutrition, and from shared platforms that can be used to address them. Many of the policies outlined above are examples of such actions. For example, initiatives to promote and protect breastfeeding can protect against stunting and wasting in childhood, reduce the risk of overweight and obesity later in life, and regulate maternal weight in the postpartum period. School food and nutrition programmes can include the provision of meals to children who are food insecure while also ensuring that they are exposed to nutritious foods. Social protection programmes aimed at ensuring food security for vulnerable populations can be designed in a manner which supports healthy eating habits and promotes dietary diversity.

Double-duty actions thus offer integrated solutions that address the shared drivers of different forms of malnutrition in many different contexts, including the context of humanitarian emergencies and protracted crises, where physical access to and affordability of nutritious foods is often severely compromised. Even in such contexts, where the priority is often to treat and prevent undernutrition, these actions are needed to combat the multiple burden of malnutrition by promoting healthy diets (Box 8). " 
BOX 8

DOUBLE-DUTY ACTIONS TO ADDRESS ALL FORMS OF MALNUTRITION IN THE CONTEXT OF HUMANITARIAN ASSISTANCE

Approximately two billion people live in countries affected by fragility, conflict and violence. ' Although humanitarian programmes must focus on saving lives and providing food in sufficient quantities to protect and promote food security, there is increasing recognition of the existence of multiple forms of malnutrition in crisis situations that must also be addressed. ${ }^{2}$

The reality of the global distribution of different types of malnutrition is complex. ${ }^{2}$ Wasting and stunting occur in both crisis and stable contexts, and there is significant overlap in the risk factors for and consequences of these forms of malnutrition. ${ }^{3}$ Simultaneously, there is growing awareness of the shared drivers of obesity and undernutrition, ${ }^{4}$ and the existence of diet-related non-communicable diseases in humanitarian contexts. ${ }^{5}$

This complexity demands an increase in focus on all forms of malnutrition in both humanitarian and development contexts. Double-duty actions are needed, with a dual focus on meeting immediate needs and reducing future risk and vulnerability. In order to design context-specific programmes able to respond to the multiple burden of malnutrition, programme designers and policymakers also need to make better use of data, with a focus on certain key questions: Is there an enabling environment for good nutrition in a given context? Is nutritious food available? Can people afford it? Do they choose it?

Humanitarian actors currently use a variety of approaches to protect food security, promote good nutrition and ultimately save lives.

Conditional cash-based assistance, for example, can improve access to and affordability of nutritious foods, thus enabling vulnerable people, including those affected by crises, to improve their diets by purchasing food through retail outlets. Both the amount of cash relative to people's needs, and people's choices on how to use it, affect the potential impact that this cash can have on nutrition. In many contexts, a strong strategy for social and behavioural change communication may be required to ensure that cash is used to purchase nutritious food and does not contribute to an increased risk of overweight and obesity.

In Bangladesh for instance, e-vouchers distributed to refugees for use in designated food outlets in camps allow individuals to improve their diets through the purchase of nutritious, fresh foods. E-vouchers provide access to 20 different food items, 12 of which are mandatory (i.e. e-voucher recipients are required to purchase these specific items) while the remaining 8 can be chosen from other food items that are available in the store. This approach helps to ensure the quality of the foods purchased while still respecting individual choices. Guidelines set for retailers aim at selling at least three items of fresh food including fruits and vegetables. The financial support provided through e-vouchers combined with nutrition education and awareness-raising (e.g. on healthy diets and cooking methods) is a strong example of a package of double-duty interventions that can simultaneously address multiple forms of malnutrition.

Although progress has been made in improving the affordability and accessibility of high-quality, nutritious foods for vulnerable people, challenges persist related to supply and demand. Ongoing work to strengthen local markets, improve efficiencies in the retail sector, reduce the price of food while maintaining or increasing profitability, and utilize point-of-sale data to understand purchasing patterns, are all double-duty actions than can help address the growing problem of the multiple burden of malnutrition in humanitarian contexts.

\footnotetext{
${ }^{1}$ International Development Association (IDA). 2019. Conflict and Fragility. In: IDA - World Bank Group [online]. Washington, DC. [Cited 25 April 2019$]$. http://ida.worldbank.org/theme/conflict-and-fragility

${ }^{2}$ Development Initiatives. 2018. Global Nutrition Report 2018. Shining a light to spur action on nutrition. Bristol, UK.

${ }^{3}$ Emergency Nutrition Network (ENN). 2018. Child wasting and stunting: Time to overcome the separation. A Briefing Note for policy makers and programme implementers [online]. [Cited 25 April 2019]. https://www.ennonline.net/attachments/2912/WaSt-policy-brief.pdf

${ }^{4}$ WHO. 2017. Double-duty actions for nutrition. Policy Brief [online]. Geneva, Switzerland. [Cited 24 April 2019]. https://apps.who.int/iris/bitstream/handle/10665/255414/WHO-NMH-NHD-17.2-eng.pdf?ua=1

${ }^{5}$ S. Aebischer Perone, E. Martinez, S. du Mortier, R. Rossi, M. Pahud, V. Urbaniak, F. Chappuis, 0. Hagon, F. Jacquérioz Bausch and D. Beran. 2017. Non-communicable diseases in humanitarian settings: ten essential questions. Conflict and Health, 11(17).
} 
In summary, many of the policies discussed here aim to increase access to nutritious and sufficient food - an objective embedded in SDG Target 2.1 to "end hunger and ensure access by all people, in particular the poor and people in vulnerable situations, including infants, to safe, nutritious and sufficient food all year round". In the section that follows, the focus will be on how restricted access to food, i.e. food insecurity as measured by the FIES, is linked to different forms of malnutrition.

\subsection{TOWARDS}

\section{AN INTEGRATED} UNDERSTANDING OF FOOD SECURITY AND NUTRITION FOR HEALTH AND WELL-BEING

\section{KEY MESSAGES}

$\rightarrow$ Countries with higher prevalence of moderate or severe food insecurity based on the FIES tend to have higher rates of adult obesity, when controlling for national rates of undernourishment and poverty.

$\rightarrow$ A closer look at household and individual level data from selected countries across all regions, reveals that food insecurity plays an important role as a determinant of different forms of malnutrition.

$\rightarrow$ In upper-middle- and high-income countries, living in a food-insecure household is a predictor of obesity in school-age children, adolescents and adults.

$\rightarrow$ In low- and lower-middle-income countries, household food insecurity tends to be negatively associated with overweight and obesity, or is not associated at all.

$\rightarrow$ Children living in households classified as moderately or severely food insecure in a number of countries in Latin America and Africa are more likely to be stunted compared with those living in food-secure households.
To accelerate progress towards ending hunger and achieving food security and improved nutrition, as required by SDG 2, it is important to fully grasp the connections between food insecurity and malnutrition, and the drivers underlying both. A better understanding of these links can lead to more effective policies aimed at addressing the specific challenges faced by countries and the international community. As discussed in the preceding section, forms of undernutrition such as child stunting and anaemia in women are persistent problems in many countries, and countries of all income levels are seeing a rise in overweight and obesity. The total number of obese people in the world (roughly 822 million, including overweight children under five, for whom obesity data are not available) surpassed the total number of undernourished people (796.5 million, derived from the PoU) in 2016. ${ }^{51}$

Moderate levels of food insecurity - defined as uncertain access to food of sufficient quality and/or quantity, but not so extreme that it causes insufficient dietary energy consumption (undernourishment) - can increase the risk of seemingly divergent forms of malnutrition. The 2018 edition of the report $^{52}$ described multiple pathways whereby food insecurity may contribute to different forms of malnutrition, including overweight and obesity. Household food insecurity can affect the quantity and quality of dietary intake, hence impacting on maternal nutrition, child growth and development and potentially increasing vulnerability to infectious diseases, as well as the risk of anaemia in women. Mothers who are food insecure are also more stressed and likely to be depressed, which can negatively affect breastfeeding and care practices. Other factors that help to explain the link between food insecurity and overweight and obesity include the higher cost of nutritious foods (and their substitution with cheaper foods that are high in fats and sugar), the stress of living with uncertain access to food, and physiological adaptations to periodic food restrictions.

This section presents new evidence on the links between moderate or severe food 
insecurity and various forms of malnutrition. The analytic approach is two-pronged, but conditioned by data availability. First, as measures of the prevalence of food insecurity and of the various forms of malnutrition in the national population exist for many countries, the analysis looks at whether the prevalence of moderate food insecurity helps to explain differences between countries in the prevalence of adult obesity, overweight among school-age children and adolescents, child stunting and wasting, and anaemia in women. Next, there is a more in-depth study of the role of household food insecurity in predicting malnutrition outcomes in individuals using data at the micro level from a limited number of countries in Africa, Asia and the Americas.

\section{Links between food insecurity and various forms of malnutrition at the country level}

The top panel of Table 5 reports the results of the Spearman rank correlation coefficient between the prevalence of moderate or severe food insecurity and that of each of the five forms of malnutrition, across all countries for which both indicators are available at the national level. ${ }^{\mathbf{5 3}}$

The correlations between the prevalence of moderate or severe food insecurity and all nutrition outcomes are statistically significant $(p$-values $<0.01)$. The exception is child wasting, where significance is only marginally below the 10 percent $\mathrm{p}$-value. The correlation is negative for adult obesity, overweight among both children and adolescents, and positive for child stunting and anaemia in women of reproductive age (Table 5, top panel).

In other words, it appears that countries with a higher prevalence of moderate or severe food insecurity (combined) tend to have a lower prevalence of child and adolescent overweight and adult obesity and a higher prevalence of anaemia and child stunting. Such correlations, however, could be spurious - for example, they could be due to a correlation that exists, across countries, between the prevalence of moderate or severe food insecurity and other aspects, such as the incidence of poverty. To explore whether the detected link exists because moderate or severe food insecurity is relevant per se, and not simply a reflection of other structural indicators, a cross-country regression analysis was conducted for each of the nutrition outcome indicators, against the prevalence of moderate or severe food insecurity, introducing national measures of undernourishment (as a proxy for severe food insecurity) and extreme poverty as controls. ${ }^{54}$

The results (Table 5, bottom panel) show that when controls are included, the correlation with moderate or severe food insecurity remains significant only for adult obesity but in reverse direction - and for anaemia in women.

The reversal of the sign of the association between moderate or severe food insecurity and adult obesity, which becomes positive, means that moderate food insecurity can indeed contribute to obesity, in certain conditions. If one focuses attention on countries of similar levels of undernourishment and poverty, obesity rates are higher in those where moderate food insecurity is also higher. This result is in line with the preliminary findings described in the 2017 report which showed how national rates of food insecurity were positively associated with adult obesity in high- and upper-middle-income countries. ${ }^{55}$ Combined with the negative correlation that is found for extreme poverty, this provides additional evidence of the fact that, as national economies grow, people facing difficulties in accessing food, as captured by an experience-based indicator of food insecurity, have a higher risk of obesity. ${ }^{56}$

This analysis presents a number of limitations due to the nature of the data used, i.e. global data at the macro level. It is clearly insufficient to fully account for the reasons for the differential impact of food insecurity on adult obesity and other forms of malnutrition in different conditions. More insights can be gained from analysis of data at the household and individual levels that combine measures of food insecurity and of nutritional outcome, as explored in the next section. 
TABLE 5

ASSOCIATION BETWEEN FOOD INSECURITY AND VARIOUS FORMS OF MALNUTRITION: CROSS-COUNTRY ANALYSIS BASED ON NATIONAL DATA

\begin{tabular}{|c|c|c|c|c|c|c|}
\hline & Obesity & Overv & & Stunting & Wasting & Anaemia \\
\hline & Adults & $\begin{array}{l}\text { School-age } \\
\text { children and } \\
\text { adolescents }\end{array}$ & $\begin{array}{l}\text { Children } \\
<5 \text { years }\end{array}$ & $\begin{array}{l}\text { Children } \\
<5 \text { years }\end{array}$ & $\begin{array}{l}\text { Children } \\
<5 \text { years }\end{array}$ & $\begin{array}{l}\text { Women } \\
15-49 \text { years }\end{array}$ \\
\hline Spearman rank correlations & \multicolumn{6}{|c|}{ Correlation coefficients ( $p$-values) } \\
\hline $\begin{array}{l}\text { Prevalence of moderate } \\
\text { or severe food insecurity }\end{array}$ & $\begin{array}{c}-0.442^{* * *} \\
(0.000)\end{array}$ & $\begin{array}{l}-0.525^{* * *} \\
(0.000)\end{array}$ & $\begin{array}{c}-0.543^{* * *} \\
(0.000)\end{array}$ & $\begin{array}{l}0.632^{* * *} \\
(0.000)\end{array}$ & $\begin{array}{l}0.292^{*} \\
(0.057)\end{array}$ & $\begin{array}{l}0.577^{* * *} \\
(0.000)\end{array}$ \\
\hline Regression analyses & \multicolumn{6}{|c|}{ Coefficients ( $p$-values) } \\
\hline $\begin{array}{l}\text { Prevalence of moderate } \\
\text { or severe food insecurity }\end{array}$ & $\begin{array}{l}0.308^{* *} \\
(0.031) \\
\end{array}$ & $\begin{array}{l}-0.033 \\
(0.813) \\
\end{array}$ & $\begin{array}{l}-0.132 \\
(0.503) \\
\end{array}$ & $\begin{array}{c}0.001 \\
(0.995) \\
\end{array}$ & $\begin{array}{l}-0.035 \\
(0.885) \\
\end{array}$ & $\begin{array}{l}0.404^{* *} \\
(0.011) \\
\end{array}$ \\
\hline Prevalence of undernourishment & $\begin{array}{c}-0.379^{* * *} \\
(0.002) \\
\end{array}$ & $\begin{array}{l}-0.279 * * \\
(0.016) \\
\end{array}$ & $\begin{array}{l}-0.064 \\
(0.675) \\
\end{array}$ & $\begin{array}{l}0.222^{*} \\
(0.077) \\
\end{array}$ & $\begin{array}{l}0.305^{*} \\
(0.096) \\
\end{array}$ & $\begin{array}{c}0.161 \\
(0.214) \\
\end{array}$ \\
\hline Prevalence of extreme poverty & $\begin{array}{c}-0.635^{* * *} \\
(0.000) \\
\end{array}$ & $\begin{array}{c}-0.470^{* * *} \\
(0.000)\end{array}$ & $\begin{array}{c}-0.438^{* *} \\
(0.041) \\
\end{array}$ & $\begin{array}{l}0.638^{* * *} \\
(0.001)\end{array}$ & $\begin{array}{c}0.211 \\
(0.404) \\
\end{array}$ & $\begin{array}{c}0.090 \\
(0.542) \\
\end{array}$ \\
\hline Number of countries & 86 & 86 & 47 & 43 & 43 & 87 \\
\hline
\end{tabular}

NOTES: The Spearman rank correlation between two variables is the linear correlation between the ranked values of those two variables - i.e. in the analysis presented in the first row above, the correlation between country rankings based on the two variables. $p$-values in parathenses. ${ }^{*} p<0.1 ;{ }^{* *} p<0.05 ;{ }^{* * *} p<0.01$. Adults are $\geq 18$ years old; school-age children and adolescents are 5-19 years old. For a description of the variables and details of the regression model, see the technical note in Annex 2.

SOURCE: M. Del Grossi, A. Sattar, C. Alvarez-Sanchez, A. Ishaq, S. Viviani, J. Feng, F. Yassin and C. Cafiero. forthcoming. The relevance of food security for nutrition: an empirical analysis at country level. Technical Paper. Rome, FAO.

\section{Links between food insecurity and various forms of malnutrition at the household and individual levels}

This section presents the results of a statistical analysis of micro-level data obtained from nationally representative surveys that included measures of household food insecurity and also of nutritional outcomes of their members. The ultimate objective of the analysis was to determine if living in a food-insecure household increases the probability of being affected by one of the various forms of malnutrition.

To ensure consistent measurement of food insecurity, one of the criteria used to select the surveys was that they should include either the FIES or a similar experience-based tool to measure household food insecurity, along with the nutritional outcome measures of individuals in the household. Although the number of such surveys covering both food security at the household level and nutrition at the individual level has increased, there are still too few to be able to provide a global assessment. Nevertheless, the study provides useful evidence from eight countries of diverse income levels from three main regions of the world.

As a preliminary step, the food-insecurity measure in each survey was calibrated to the global reference scale following the FIES methodology. This resulted in a measure that permitted classification of each household as being food secure or food insecure in a consistent way across the countries covered (Box 3). Then, logistic regressions of the nutrition outcome condition were run at the individual level for each of the relevant population groups, as a function of the household food-insecurity status, controlling for age, sex, socio-economic status, household size/dependency ratio, and urban/rural residence. For child malnutrition outcomes, the analyses also controlled for maternal education and for access to clean drinking water and basic sanitation facilities (see Annex 2 and Ishaq et al. ${ }^{57}$ for a full description of the methodology and results). 


\section{ASSOCIATION BETWEEN FOOD INSECURITY AND OVERWEIGHT OR OBESITY IN DIFFERENT AGE GROUPS:} MICRO-LEVEL DATA ANALYSIS FROM SELECTED COUNTRIES

\begin{tabular}{|c|c|c|c|c|c|c|c|c|c|}
\hline \multirow[b]{2}{*}{ Population group } & \multirow[b]{2}{*}{$\begin{array}{l}\text { Malnutrition } \\
\text { outcome }\end{array}$} & \multicolumn{8}{|c|}{ Country } \\
\hline & & $\begin{array}{l}\text { United } \\
\text { States of } \\
\text { America }\end{array}$ & Mexico & Brazil & Pakistan & Nepal & Kenya & Nigeria & Malawi \\
\hline \multirow[b]{2}{*}{ Children $<5$ years } & \multirow[b]{2}{*}{ Overweight } & \multicolumn{8}{|c|}{ Odd-ratios ( $p$-values) } \\
\hline & & $\begin{array}{c}0.893 \\
(0.731) \\
\end{array}$ & $\begin{array}{c}0.927 \\
(0.522) \\
\end{array}$ & $\begin{array}{c}1.422^{*} \\
(0.061) \\
\end{array}$ & n.a. & n.a. & $\begin{array}{c}0.848 \\
(0.152) \\
\end{array}$ & $\begin{array}{c}0.818 \\
(0.279) \\
\end{array}$ & $\begin{array}{l}0.735^{*} \\
(0.099) \\
\end{array}$ \\
\hline \multirow{2}{*}{$\begin{array}{l}\text { School-age } \\
\text { children and } \\
\text { adolescents }\end{array}$} & Overweight & $\begin{array}{c}0.905 \\
(0.407) \\
\end{array}$ & $\begin{array}{c}0.933 \\
(0.260) \\
\end{array}$ & $\begin{array}{l}1.698^{* *} \\
(0.042) \\
\end{array}$ & $\begin{array}{c}0.684^{* * *} \\
(0.009)\end{array}$ & $\begin{array}{c}0.951 \\
(0.924) \\
\end{array}$ & $\begin{array}{c}0.774^{* * *} \\
(0.000)\end{array}$ & n.a. & n.a. \\
\hline & Obesity & $\begin{array}{l}1.487^{*} \\
(0.055) \\
\end{array}$ & $\begin{array}{c}1.098 \\
(0.117) \\
\end{array}$ & $\begin{array}{l}2.866^{* *} \\
(0.015) \\
\end{array}$ & $\begin{array}{l}0.573^{* *} \\
(0.027)\end{array}$ & n.a. & n.a. & n.a. & n.a. \\
\hline Adults & Obesity & $\begin{array}{c}1.499^{* * *} \\
(0.001)\end{array}$ & $\begin{array}{c}1.170^{* * *} \\
(0.006)\end{array}$ & $\begin{array}{l}1.223^{* *} \\
(0.018)\end{array}$ & $\begin{array}{l}0.564^{* *} \\
(0.031)\end{array}$ & $\begin{array}{c}0.999 \\
(0.995)\end{array}$ & $\begin{array}{c}0.708^{* * *} \\
(0.000)\end{array}$ & n.a. & n.a. \\
\hline
\end{tabular}

NOTES: Coefficient estimates are standardized and transformed to represent odd-ratios. Values less than one indicate negative associations. $p$-values in parathenses. ${ }^{*} p<0.1$; ${ }^{* *} p<0.05{ }^{* * *} p<0.01$. All $p$-values are based on robust standard errors taking into account clustering of individuals by household. "n.a." data not available or insufficient number of observations to run the regression. Adults are $\geq 18$ years old: school-age children and adolescents are 5-19 years old. Control variables differ by country, depending on each outcome. See the technical note in Annex 2 for details and Ishaq et al. for more detailed results.

SOURCE: A. Ishaq, C. Alvarez-Sanchez, M. Del Grossi, S. Viviani, J. Feng, F. Yassin, A. Kepple, A. Sattar and C. Cafiero. forthcoming. The relevance of household food security for nutrition: an empirical analysis based on survey data. Technical Paper. Rome, FAO.

The analysis (full results not shown here) reveals that living in a household classified as food insecure contributes to explain the status of being affected by one or another form of malnutrition in different population groups, in seven of the eight countries studied. Indeed, in five of them, household food insecurity is found to be associated with more than one form of malnutrition.

Table 6 summarizes the results of regressions of overweight and obesity on household food insecurity only, not showing the coefficient estimates of other covariates. ${ }^{58}$

The table shows how the association of food insecurity with overweight and obesity (across different age groups) varies depending on the income level of the country. In the low- and lower-middle-income countries considered, living in a food-insecure household either decreases the likelihood of being overweight or obese (Kenya and Pakistan) or has a very weak (Malawi) or no association (Nepal and Nigeria). In upper-middle- and high-income countries (Brazil, Mexico and the United States of America), food insecurity increases the likelihood of being overweight or obese, at least in some age groups. In Brazil, food insecurity is statistically correlated with obesity in the two age groups considered ( $p$-value $<0.05)$, while in the United States of America and Mexico the statistical significance of the association is strong ( $p$-value $<0.01)$ for adults. The association for obesity in school-age children and adolescents is less strong for the United States and not statistically significant at the conventional significance levels for Mexico $(\mathrm{p}$-value $=0.117)$. Although this analysis was not designed to prove the hypothesis, the different direction of the association of food insecurity with adult obesity depending on the income level of the country is consistent with other evidence that a positive relationship is more likely in settings where highly processed, energy-dense foods are low-cost. ${ }^{59}$ As mentioned in Section 1.2, in upper-middleand high-income countries, such foods are ubiquitously available and cheap, while fresh, nutritious foods are often out of reach for those living on lower incomes. But in many low- and lower-middle-income countries, highly-processed, energy-dense foods are not readily available or affordable. 
TABLE 7

ASSOCIATION BETWEEN HOUSEHOLD FOOD INSECURITY, CHILD STUNTING AND WASTING, AND ANAEMIA IN WOMEN OF REPRODUCTIVE AGE: MICRO-LEVEL DATA ANALYSIS FROM SELECTED COUNTRIES

\begin{tabular}{|c|c|c|c|c|c|c|c|c|}
\hline \multirow[b]{2}{*}{ Population group } & \multirow[b]{2}{*}{$\begin{array}{l}\text { Malnutrition } \\
\text { outcome }\end{array}$} & \multicolumn{7}{|c|}{ Country } \\
\hline & & $\begin{array}{l}\text { United } \\
\text { States of } \\
\text { America }\end{array}$ & Mexico & Brazil & Nepal & Kenya & Nigeria & Malawi \\
\hline & & \multicolumn{7}{|c|}{ Odd-ratios ( $p$-values) } \\
\hline \multirow{2}{*}{ Children } & Stunting & n.a. & $\begin{array}{l}1.215^{* *} \\
(0.045)\end{array}$ & $\begin{array}{l}1.665^{*} \\
(0.097)\end{array}$ & $\begin{array}{c}1.029 \\
(0.814)\end{array}$ & $\begin{array}{l}1.224^{*} \\
(0.099)\end{array}$ & $\begin{array}{c}0.906 \\
(0.705)\end{array}$ & $\begin{array}{l}1.373^{* *} \\
(0.022)\end{array}$ \\
\hline & Wasting & n.a. & n.a. & n.a. & $\begin{array}{c}1.291 \\
(0.127)\end{array}$ & $\begin{array}{c}0.727 \\
(0.125)\end{array}$ & $\begin{array}{l}2.791^{* *} \\
(0.010)\end{array}$ & $\begin{array}{c}1.019 \\
(0.947)\end{array}$ \\
\hline $\begin{array}{l}\text { Women, } \\
15-49 \text { years }\end{array}$ & Anaemia & $\begin{array}{c}0.709 \\
(0.207)\end{array}$ & $\begin{array}{l}1.132^{* *} \\
(0.035)\end{array}$ & $\begin{array}{l}1.410^{* *} \\
(0.035)\end{array}$ & $\begin{array}{c}1.069 \\
(0.597)\end{array}$ & n.a. & n.a. & n.a. \\
\hline
\end{tabular}

NOTES: Coefficient estimates are standardized and transformed to represent odd-ratios. Values less than one indicate negative associations. $p$-values in parathenses. ${ }^{*} p<0.1$; ${ }^{* *} \mathrm{p}<0.05 ;{ }^{* * *} \mathrm{p}<0.01$. All $\mathrm{p}$-values are based on robust standard errors, taking into account clustering of individuals by household. "n.a." data not available or insufficient number of observations to run the regression. Adults are $\geq 18$ years old: school-age children and adolescents are 5-19 years old. Control variables differ by country, depending on each outcome. See the technical note in Annex 2 for details and Ishaq et al. for more detailed results.

SOURCE: A. Ishaq, C. Alvarez-Sanchez, M. Del Grossi, S. Viviani, J. Feng, F. Yassin, A. Kepple, A. Sattar and C. Cafiero. forthcoming. The relevance of household food security for nutrition: an empirical analysis based on survey data. Technical Paper. Rome, FAO.

Table 7 summarizes the results of the analysis of association between household food insecurity and child undernutrition and anaemia in women of reproductive age, when controlling for other factors (see Annex 2 for details). Household food insecurity is associated with indicators of child undernutrition in most of the countries studied. Children living in food-insecure households in Brazil, Kenya, Malawi and Mexico are more likely to be stunted compared with those living in food-secure households. In Nigeria they are more likely to be wasted. No association is found in Nepal.

The association between food insecurity and anaemia in women of reproductive age could only be analysed in four of the eight countries due to data availability. In Brazil and Mexico, living in a food-insecure household was found to increase the likelihood of women being anaemic. In Nepal the prevalence of anaemia is similar among food-secure and food-insecure women. No association between food insecurity and anaemia is found in the United States of America.
As the analysis was conducted by controlling for income levels, ${ }^{60}$ it shows that, in general, the experience of food insecurity has implications for malnutrition regardless of the socio-economic status of the household. This points to the need for policies to go beyond merely addressing poverty and specifically improve access to food.

\subsection{CONCLUSIONS}

The trends in food insecurity and malnutrition in all its forms described in Part 1 pose a significant challenge to achieving SDG 2. The numbers of people suffering from hunger and food insecurity are no longer declining on the contrary, they have been slowly on the rise in the last few years. While progress in bringing down the prevalence of stunting in children and increasing the rate of exclusive breastfeeding is to be commended, the rapid increase in obesity is alarming, and no region or income group is exempt from this problem. The global number of obese people surpassed the number of undernourished people already in 2016. Children facing hunger 
and food insecurity may have a higher risk of overweight, obesity and NCDs later in life, and unhealthy diets are now the leading risk factor for deaths worldwide. Therefore, it is imperative to continue addressing the urgent needs of those who are hungry, while at the same time going beyond hunger and ensuring access not only to sufficient food, but also to nutritious foods that constitute a healthy diet. In the search for a better understanding of how to achieve this, the new FIES-based indicator of moderate or severe food insecurity represents a valuable tool.
Trends of the past several decades, as well as persistent socio-economic and geographic inequalities in food insecurity and malnutrition, highlight the need to address factors operating at the community, national and international levels that contribute to such inequalities. The second part of this report delves deeper into some of the fundamental determinants of food insecurity and malnutrition related to underlying economic structures and inequalities. 


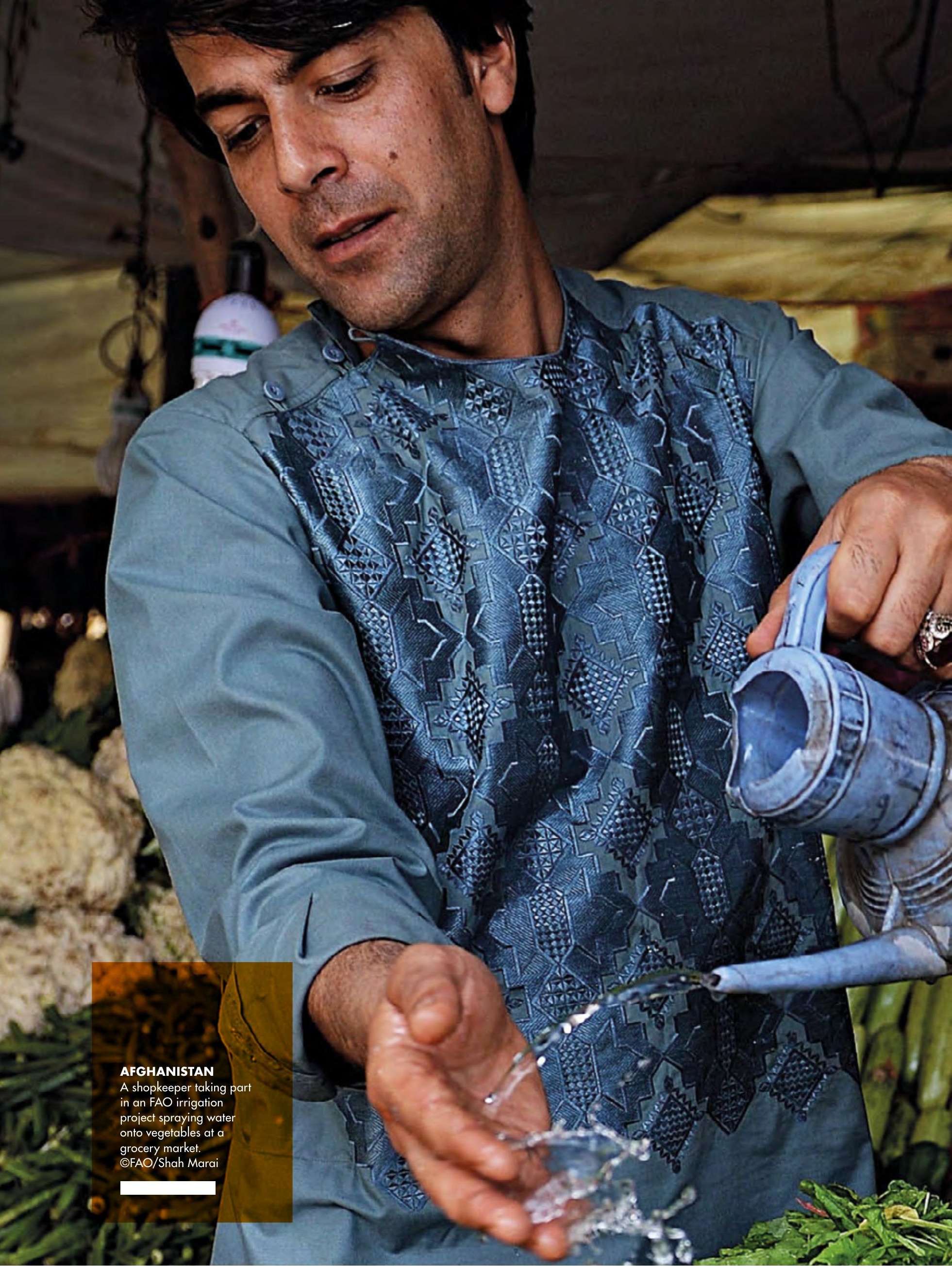




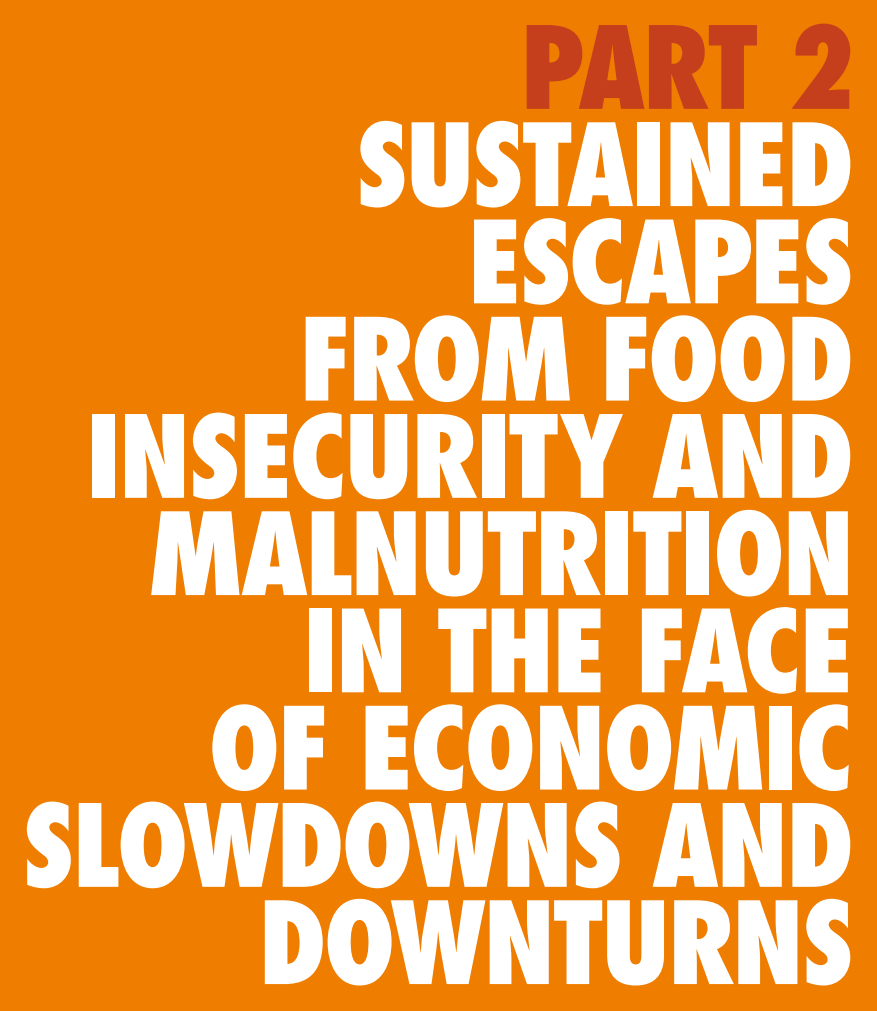


As shown in Part 1 of this report, almost one out of every nine people in the world suffers from hunger, and the number of hungry people is growing, albeit slowly. At the same time, reductions in child stunting are insufficient to meet global goals, and obesity and overweight are on the rise.

Previous editions of this report have identified three drivers behind these problematic trends: conflict, climate and economic slowdowns. These drivers are complex and often interact with compounding effects that challenge food security and nutrition in multiple ways. Unless greater and more targeted efforts are made to address these drivers and the underlying causes of hunger and malnutrition, it is increasingly clear that the goal of ending hunger and all forms of malnutrition by 2030 will not be achieved.

In 2017, this report made it clear that efforts to fight hunger and malnutrition in conflict-affected situations must go hand in hand with actions for immediate humanitarian assistance and long-term development that builds resilience and helps sustain peace. In 2018, the report called for urgent action to scale up and accelerate policies and programmes to build climate resilience.

This year, this second part of the report looks more closely at how the third key driver, economic slowdowns - and, more specifically, also economic downturns - has contributed to the recent rise in hunger with possible implications for nutrition. This is critical to understanding future trends in hunger and malnutrition, especially given the dark predictions of the latest global economic prospects, with slowing and stalled economic growth in many countries, including emerging and developing economies.
Indeed, episodes of financial stress, elevated trade tensions and tightening financial conditions are all contributing to bleaker global economic prospects. $^{1}$

Importantly, the impact of economic slowdowns and downturns on food security and nutrition cannot be separated from the root causes of hunger and malnutrition: poverty, inequality and marginalization. Part 2 therefore looks closely at the relationship between poverty and food security and nutrition, and how they interact with inequality and marginalization to threaten food security and nutrition.

The purpose of the analysis is to provide guidance on how these challenges can be overcome to end hunger and malnutrition in all its forms. The last section thus presents policies and programmes that can protect the most vulnerable from the impact of economic slowdowns and downturns, while fostering food security and nutrition from a perspective of more inclusive economic growth. Ending hunger and malnutrition by 2030 (SDG Targets 2.1 and 2.2) will require greater efforts and integrated approaches to eradicate extreme poverty (SDG 1), ensure decent work and inclusive economic growth (SDG 8), and reduce inequalities (SDG 10). 


\subsection{ECONOMIC SLOWDOWNS AND DOWNTURNS AND THEIR IMPACT ON FOOD SECURITY AND NUTRITION}

\section{KEY MESSAGES}

$\rightarrow$ The outlook for the global economy has darkened, reflecting risks of increasing trade tensions and rising global borrowing costs.

$\rightarrow$ Hunger has been on the rise in countries where the economy has slowed down or contracted. The uneven pace of global economic recovery raises concerns regarding prospects for ending hunger and malnutrition in all its forms.

$\rightarrow$ Most countries (84 percent) that experienced a rise in undernourishment between 2011 and 2017 simultaneously suffered an economic slowdown or downturn - and the majority of these are middle-income countries.

$\rightarrow$ While conflict and climate shocks were the key drivers of food crises in 2018, economic shocks were significant secondary and tertiary drivers in more than half of the countries affected by food crises and worsened the severity of these food crises for 96 million people. $\rightarrow$ Rises in the prevalence of undernourishment in countries that faced economic downturns tend to be higher (5.1 percentage points) than countries vulnerable to climate extremes (2.3 percentage points higher) and countries that experienced conflict (2.2 percentage points higher).

\section{How are economic slowdowns and downturns relevant to the quest to eradicate hunger and malnutrition?}

Hunger has been on the rise in many countries where the economy has slowed down or contracted. Between 2011 and 2017, this increase coincided with an economic slowdown or downturn in 65 out of 77 countries.

Economic shocks that typically result in economic slowdowns or downturns tend to be significant secondary and tertiary drivers that prolong and worsen the severity of food crises, especially in countries experiencing acute food insecurity requiring urgent humanitarian assistance. ${ }^{2}$ In 2018, economic shocks featured prominently in 33 out of the 53 countries that suffered from food crises, affecting more than 96 million people (Table 8).

An economic slowdown generally means economic activity is sluggish, although it continues to grow. When there is no growth, the economy has reached a downturn (Box 9). These economic phenomena often lead to a rise in unemployment and decline in wages and incomes, challenging access to food and essential social services for the poor. People's access to high-quality, nutritious food, which tends to be less affordable - especially for poor people who spend a large portion of their income on food can be affected, as can access to basic services such as health care. 
One of the primary measures used to gauge the health of a country's economy is gross domestic product (GDP). Often referred to as the size of the economy, it is the total value of economic activity within a country measured as the total value of goods and services produced during a given period of time. The economic growth rate is the percentage increase or decrease of GDP from one period to another.

An economic slowdown is when economic activity is growing at a slower pace. In other words, there still is growth in economic activity, but at a slower rate than before. An economic slowdown occurs when real GDP growth declines from one period of time to another but is still positive, usually measured in quarters of a year.

An economic downturn is when there is no growth, but rather a period of decline in economic activity. It refers to a period of economic contraction or negative economic growth as measured by the growth rate in real GDP. An economic recession, ${ }^{1}$ often used synonymously with economic downturn, is a temporary or short-term downturn in economic growth, usually occurring over at least two consecutive quarters of decline. Stagnation is period where an economy grows at an extremely low rate without actually entering a recession.

An economic shock is an unexpected or unpredictable event that is external to the specific economy and can either harm or boost it. A global financial crisis causing bank lending or credit to fall, or an economic downturn in a major trading partner of a country, reflect demand-side shocks that can have multiple effects on spending and investment. A steep rise in oil and gas prices, natural disasters that result in sharp falls in production, or conflict that disrupts trade and production, are examples of supply-side shocks.

See Annex 3 for the full definitions used in the analysis of this report, as well as the methodology applied in the measuring of economic slowdowns and downturns.

1S. Claessens and M. Ayhan Kose. 2009. What is a recession? Finance \& Development, March 2009, 46(1). (also available at https://www.imf.org/external/pubs/ft/ fandd/2009/03/basics.htm).

The uneven pace of global economic recovery from slowdowns further raises concerns regarding prospects for ending hunger and malnutrition in all its forms. Recent world economic reports highlight that slowdowns, stagnation and outright recessions are evident in several economies and already leading to increased unemployment and declines in income. ${ }^{3}$ There may soon be yet another global economic downturn. Early this year, the IMF revised its forecast for global growth to the lowest level since the global financial crisis a decade ago, as the outlook dimmed in most major economies. ${ }^{4}$

This dark outlook reflects increasing risks related to rising trade tensions, weakening investments, increasing government and corporate debt, and rising borrowing costs. According to the World Bank, further escalation of trade tensions and the associated uncertainty could weaken growth even further. ${ }^{5}$ Moreover, the outlook for commodity prices, especially oil, is vulnerable to policy-related risks and the collective intervention of many countries particular through trade policies - may amplify international price movements, and may not be effective in protecting the most vulnerable populations groups. ${ }^{6}$

Trade tensions, which are increasingly taking a toll on business confidence, are a particular concern. After strong growth in 2017 and 2018, the global economy's slowdown reflects a confluence of factors, including US-China trade tensions. Global trade has also slowed considerably. Moreover, escalation and tariff hikes between the two largest economies of the world could further weaken growth and put pressure on the price of commodities. This is because higher tariffs will increase the price of imported goods, disrupt global value chains, 


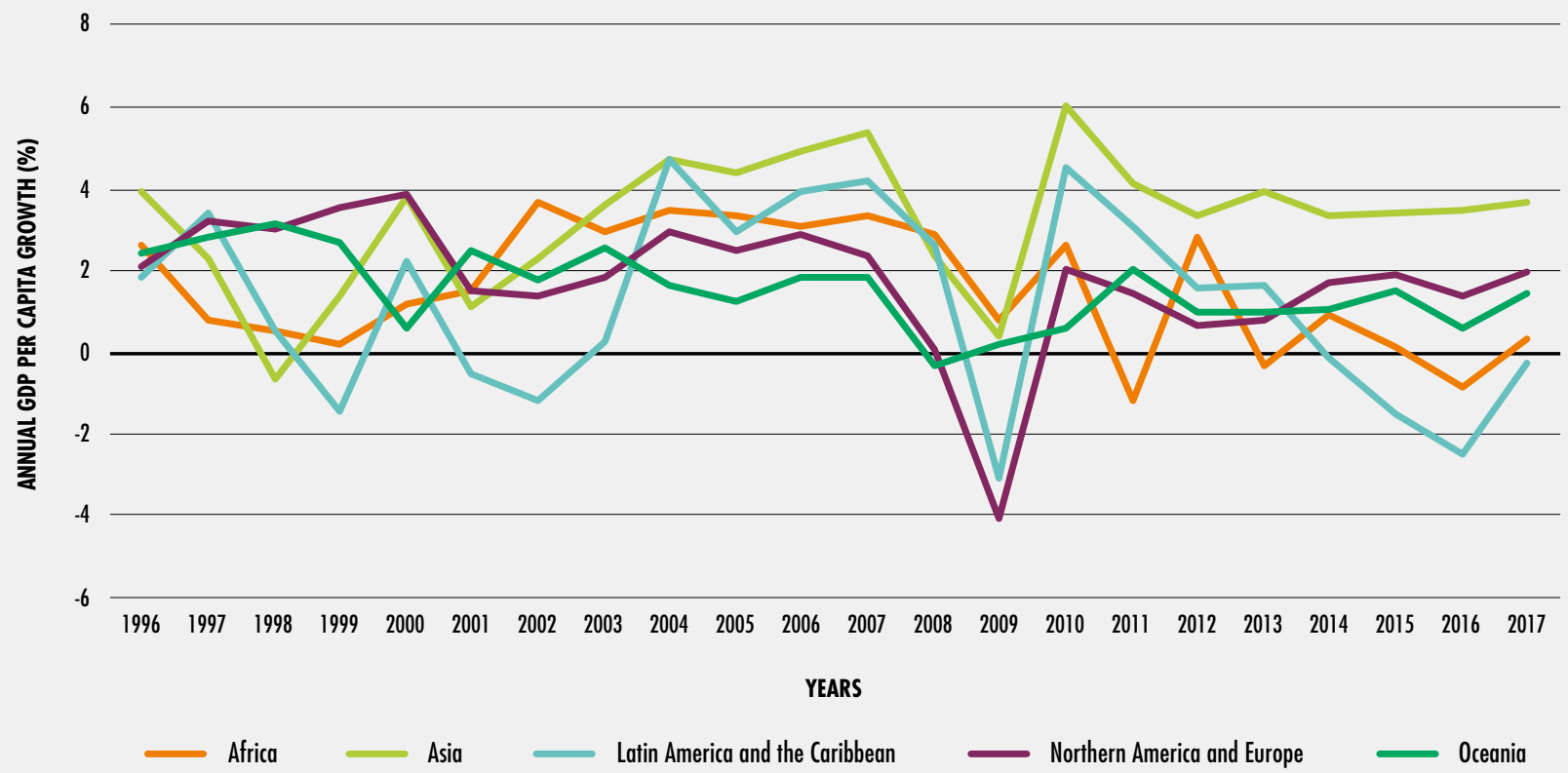

NOTES: Annual rate of per capita GDP growth at constant 2010 prices that occurred in the five regions during the period 1996-2017.

SOURCES: UN. 2019. National Accounts - Analysis of Main Aggregates. In: UNSTATS [online]. New York, USA. [Cited 6 May 2019] https://unstats.un.org/unsd/snaama; and for North America and Europe UNCTAD. 2019. Gross domestic product: Total and per capita, growth rates, annual. In: UNCTADSTAT [online]. New York, USA. [Cited 14 May 2019]. https://unctadstat.unctad.org/wds/TableViewer/tableView.aspx?Reportld=109

reduce productivity, increase uncertainty and weaken investment. ${ }^{7}$

Global demand for commodities could slow down by one-third over the next decade, ${ }^{8}$ especially for agriculture and metals, and countries dependent on commodity exports may struggle to adjust. Rising risks combined with high vulnerabilities will challenge emerging and developing economies' ability to manage economic shocks.

A bleak economic outlook may translate into more poverty and inequality, hindering efforts to eradicate hunger and malnutrition in all its forms. While extreme poverty rates have declined from 54 percent in 1990 to 41 percent in 2015 in sub-Saharan Africa, the number of extreme poor increased by 136 million people during this period, i.e. from 277 to 413 million. Even more worrying, inequality is rising in nearly half of the countries around the world, including in several low- and middle-income countries. ${ }^{9}$

\section{Trends in economic slowdowns and downturns}

The percentage variation of real GDP per capita growth from one period to another, or economic growth rate, is typically used to gauge whether an economy is slowing down or contracting. In most regions, this rate rebounded after the sharp 2008-2009 global economic downturn. But the recovery was uneven and short lived, as many countries experienced generally declining trends in growth since 2011 (Figure 22). Real GDP per capita growth is also being challenged particularly in countries with rapidly growing populations, like those in Africa and South Asia, regions with some of the highest levels of food insecurity and malnutrition in the world (Table 1). 


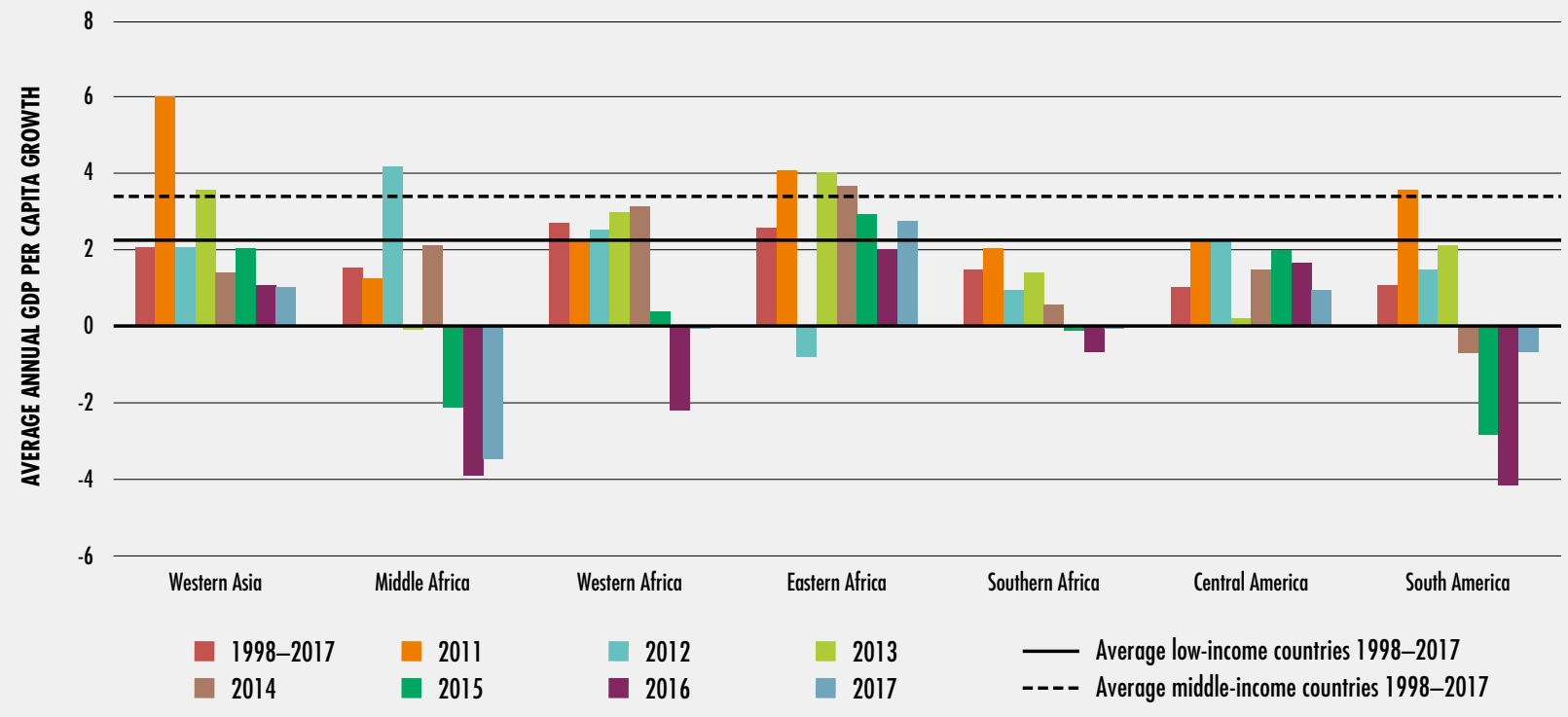

NOTES: Annual rate of per capita GDP growth at constant 2010 prices for seven subregions during the period 1998-2017.

SOURCE: UN. 2019. National Accounts - Analysis of Main Aggregates. In: UNSTATS [online]. New York, USA. [Cited 6 May 2019] https://unstats.un.org/unsd/snaama

Within subregions, the situation is worse. In the last few years, real GDP per capita growth on average declined in seven subregions, five of which experienced negative growth in different years (Figure 23). In 2018, these five subregions combined were home to almost 263 million undernourished people and more than 56 million stunted children under the age of five. Further setbacks are expected to continue in many of these regions, including in Middle, Southern and West Africa; Western Asia; and Latin America and the Caribbean. ${ }^{10}$

Economic slowdowns and downturns can be triggered by myriad factors. International factors can negatively affect economic growth for specific countries through trade flows, world prices, foreign direct investment (FDI) and other foreign exchange flows (remittances, foreign borrowing, aid and so forth). National factors, notably monetary, fiscal and trade policies, as well as investment and sectoral policies can also drive economic slowdowns and downturns. But there may also be non-economic factors driving economic deceleration, including political factors, conflict and climate shocks. Some of these factors can be felt across borders. For example, widespread civil insecurity can disrupt production and trade flows and lead to migration.

\section{Rises in undernourishment in places where the economy slowed down or contracted}

As seen from Part 1, both the prevalence of undernourishment and the number of undernourished people in the world began to increase in 2016. For many countries, especially low- and lower-middle-income countries, as well as countries affected by conflict and adverse climate events, undernourishment was on the rise as early as 2011. It was only in 2016 that the number of countries with rising undernourishment became sufficient for the increase to be reflected in the global aggregate of world hunger."

Establishing a direct causal relationship between economic growth and undernourishment is complicated, given how the PoU is computed and smoothed over time. ${ }^{12}$ On the other hand, examining whether increasing change points in the prevalence of undernourishment is inversely associated with the real GDP per capita growth rate is straightforward. ${ }^{13}$ An increasing change 


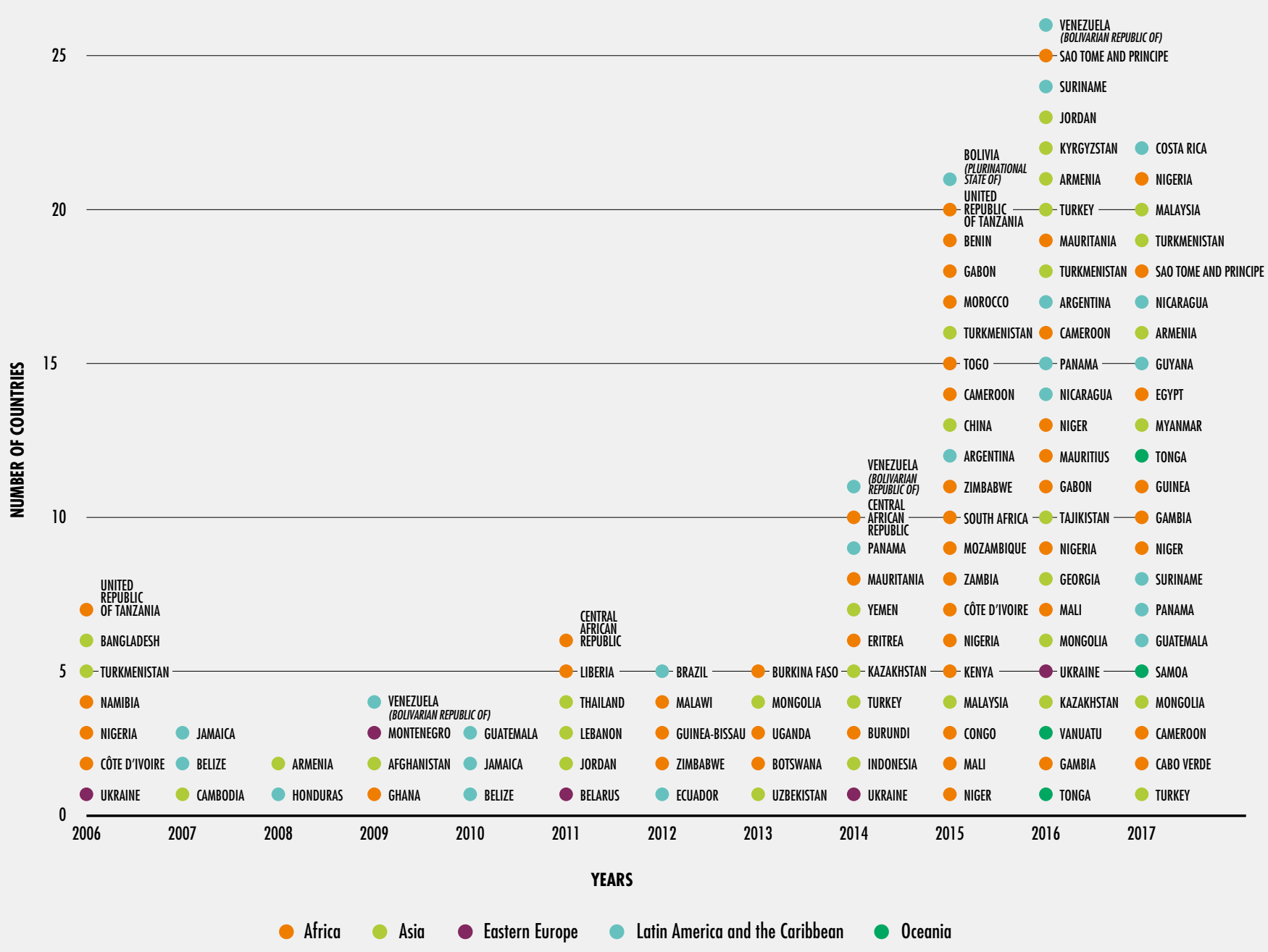

NOTES: The number of countries with an increasing change point in the prevalence of undernourishment (PoU) which occurs in correspondence with an economic slowdown or downturn by year, between 2006 and 2017, where each year is the middle year for the PoU three-year average; that is, for example, 2017 for 2016-2018. See Annex 3 for the methodology and list of countries with PoU increasing change points related to economic slowdowns or downturns. The analysis includes some countries with imputed PoU, see Annex 3 for methodology and list of countries.

SOURCES: FAO for PoU; for economic slowdowns and downturns, UN. 2019. National Accounts - Analysis of Main Aggregates. In: UNSTATS [online]. New York, USA. [Cited 6 May 2019]. https://unstats.un.org/unsd/snaama

point refers to the statistically significant increase in the prevalence of undernourishment for two consecutive years (see Annex 3 for the methodology).

During the period 2011-2017, out of the 120 increasing change points in the PoU of 77 countries (out of a sample of 134 low- and middle-income countries), 96 increasing change points in 65 countries corresponded with the occurrence of an economic slowdown or downturn (Figure 24, see Annex 3 for the list of countries). This means that for 84 percent of the countries, the rise in undernourishment since 2011 coincided with the occurrence of economic slowdowns or downturns. Moreover, many of these countries saw increasing change points in PoU coinciding with an economic slowdown or downturn in more than one year: 17 countries saw them in two years, and seven countries saw them in three out of the seven years. The period 2014-2015 is particularly striking as it corresponds to the years in which many regions and countries had experienced three or more years of economic slowdown, often culminating in economic downturn. Interestingly, the PoU 
As seen from Part 1 of this report, the number of people undernourished in the world as a whole declined steadily from 2005 to 2015 (Figure 1). The global food crisis of 2007-2008 and the global financial crisis of 2008-2009 occurred in between. So how was this possible?

These crises were preceded by a period of sustained economic growth in the world (Figure 22), including in different developing regions, which are home to millions of undernourished people and people affected by malnutrition. Subsequently, the global economic downturn in Latin America and the Caribbean, North America and Europe, and slowdown in other regions during 2008-2009 was short lived and the world economy started to grow again in 2010 . While this refers to aggregate trends for the world and across regions, it is still interesting to see that only nine countries witnessed the simultaneous occurrence of an economic slowdown or downturn and an increase in the PoU during these crises (Figure 24).

In addition to growth, other factors came into play to prevent an increase in the number of undernourished people during these crises. During the global food crisis, for example, international food prices increased sharply between 2007 and early 2008, reaching their highest level in the summer of 2008.' Many countries responded to the food price surge with policies softening the pass-through of international prices on markets and households ${ }^{2}-a$ transmission mechanism explained later in this report. There is evidence that the increase in domestic prices was significantly lower and that domestic prices were also less volatile than world prices. ${ }^{3}$ Furthermore, FAOSTAT data show that the production of cereals increased in low- and middle-income countries during the global food crisis. This may also have been an important factor mediating the increase in domestic prices and contributing to employment creation and improvements in food security.

An additional explanation would be the coping mechanisms of net food-consuming households. A cross-country analysis of how families coped with the high food price crisis shows relatively large increases in dietary energy consumption among the highest income quintiles in urban areas in Guatemala, Honduras and Nicaragua. This indicates that households were consuming more energy-dense foods such as street foods or fast foods instead of more nutritious, diversified but costly diets. While these coping mechanisms of households help maintain overall dietary energy reduction, they may affect nutrition with long-term and potentially intergenerational negative effects on health and productivity. ${ }^{4}$

The global financial crisis, on the other hand, originated as a result of a financial "meltdown" in developed countries with serious implications for the real economy, affecting several parts of the world. However, with the exception of transition countries in Central and Eastern Europe, financial institutions in developing countries were not affected by "financial contagion". Developing countries' banks did not hold "contaminated" assets (i.e. those including sub-prime mortgages). Therefore, the major channels of transmission were through trade and financial flows between developed and developing countries. The effects were short lived considering the resumption of economic growth in 2010 (Figure 22).

Many developing countries took advantage of the period of sustained economic growth preceding the crisis to implement fiscal and economic reforms. Following the Latin American and Asian crises of the 1990s, several countries had carried out macroeconomic reforms to make their economies more resilient to shocks, including closer bank supervision and reserve accumulation. Many countries were also able to implement policies aimed at reducing or neutralizing antisocial effects of economic cycles, such as policies encouraging spending during downturns - also known as countercyclical policies. Using a sample of 33 lowand middle-income countries, a study shows that the majority of these (20 countries) increased public social expenditure relative to total public expenditure during the global financial crisis. ${ }^{5}$

Although hunger declined steadily during both the global food crisis and financial crisis, not only for the world but also across developing regions (see Table 1 in Part 1 for changes in the PoU between 2005 and 2010), it is likely that the state of food security and nutrition did change in some countries ${ }^{6}$ and some population groups may have experienced increased hunger or malnutrition. The variation may not have been reflected in the numbers at the national level, however, as probably only the 
most vulnerable households before the two crises, experienced food insecurity during these crises, as studies for some countries show. ${ }^{6}$ Some national reports also point to increased prevalence of different forms of malnutrition in certain population groups: in China, for example, the prevalence of stunting among infants ${ }^{7}$ in poorer rural areas increased between 2008 and $2010 .^{8}$

\footnotetext{
${ }^{1}$ For more details on the factors behind rising food prices during this period, see: C.L. Gilbert. 2010. How to understand high food prices. Journal of Agricultural Economics, 61(2): $398-425$.

${ }^{2}$ M. Demeke, G. Pangrazio and M. Maetz. 2011. Country responses to turmoil in global food markets. In A. Prakash, ed. 2011. Safeguarding food security in volatile global markets, pp. 183-209. Rome, FAO.

${ }^{3}$ D. Dawe, C. Morales-Opazo, J. Balié and G. Pierre. 2015. How much have domestic food prices increased in the new era of higher food prices? Global Food Security, 5: 1-10.

${ }^{4} \mathrm{M}$. Robles and M. Torero. 2009. Understanding the impact of high food prices in Latin America. Economía, 10(2): 117-164.

${ }^{5}$ UN. 2016. World Economic and Social Survey 2014/15. Learning from national policies supporting MDG implementation. New York, USA.

${ }^{6} \mathrm{M}$. Vilar-Compte, S. Sandoval-0lascoaga, A. Bernal-Stuart, S. Shimoga and A. Vargas-Bustamante. 2015. The impact of the 2008 financial crisis on food security and food expenditures in Mexico: a disproportionate effect on the vulnerable. Public Health Nutrition, 18(16): 2934-2942.

7 Children under 2 years of age.

${ }^{8} \mathrm{C}$. Chen, W. He, Y. Wang, L. Deng and F. Jia. 2011. Nutritional status of children during and post-global economic crisis in China. Biomedical and Environmental Sciences, $24(4): 321-328$.
}

only increased in a handful of countries during two consecutive crises: the global food crisis and the global financial crisis (for explanations of this, see Box 10).

The greatest number of countries where rising undernourishment occurred while the economy slowed down or stagnated are in Africa (32). Several are in Asia (17), followed by Latin America and the Caribbean (11), Oceania (3) and Eastern Europe (2). The majority of them (44 out of 65 ) are middle-income countries; 19 (out of 65) are low-income countries, of which 17 are located in Africa with the exception of Tajikistan and Yemen.

Notably, 80 percent of the countries (52 out of 65) that experienced an increase in undernourishment while their economy slowed down or contracted depend highly on food and fuel commodity imports and/or oil and other primary commodity exports for foreign exchange and tax revenue generation (see Annex 6 for list of countries by commodity dependence). ${ }^{14}$ As noted above, world prices are one of the international factors that can contribute to the deterioration of a country's economic state.
A sharp and persistent reduction of commodity prices affects commodity-dependent countries, triggering a number of economy-wide effects, including reductions in foreign exchange and tax revenue, with potentially adverse impacts on food security and nutrition.

To provide statistical evidence that the relationship between changes in undernourishment and economic slowdowns and downturns is more than a simple corresponding occurrence, a regression analysis comparing the difference in the PoU and the real GDP per capita growth between 2011 and $2017^{15}$ was carried out. It points to a statistically significant correlation between the two (see Annex 4 for model and results). On average, a ten percent decrease in economic growth between 2011 and 2017 corresponds to a 1.5 percentage point increase in the PoU between 2011 and 2017. Furthermore, countries that have experienced economic downturns show significant increases in the PoU between 2011 and 2017, equal to 5.1 percentage points higher than countries with economies that have not contracted.

The correlation, as expected, varies from country to country. On average, low-income countries 
FIGURE 25

LOW-INCOME COUNTRIES FACE HIGHER INCREASES IN HUNGER AS A RESULT OF DECREASES IN ECONOMIC GROWTH (BETWEEN 2011 AND 2017)

30

20

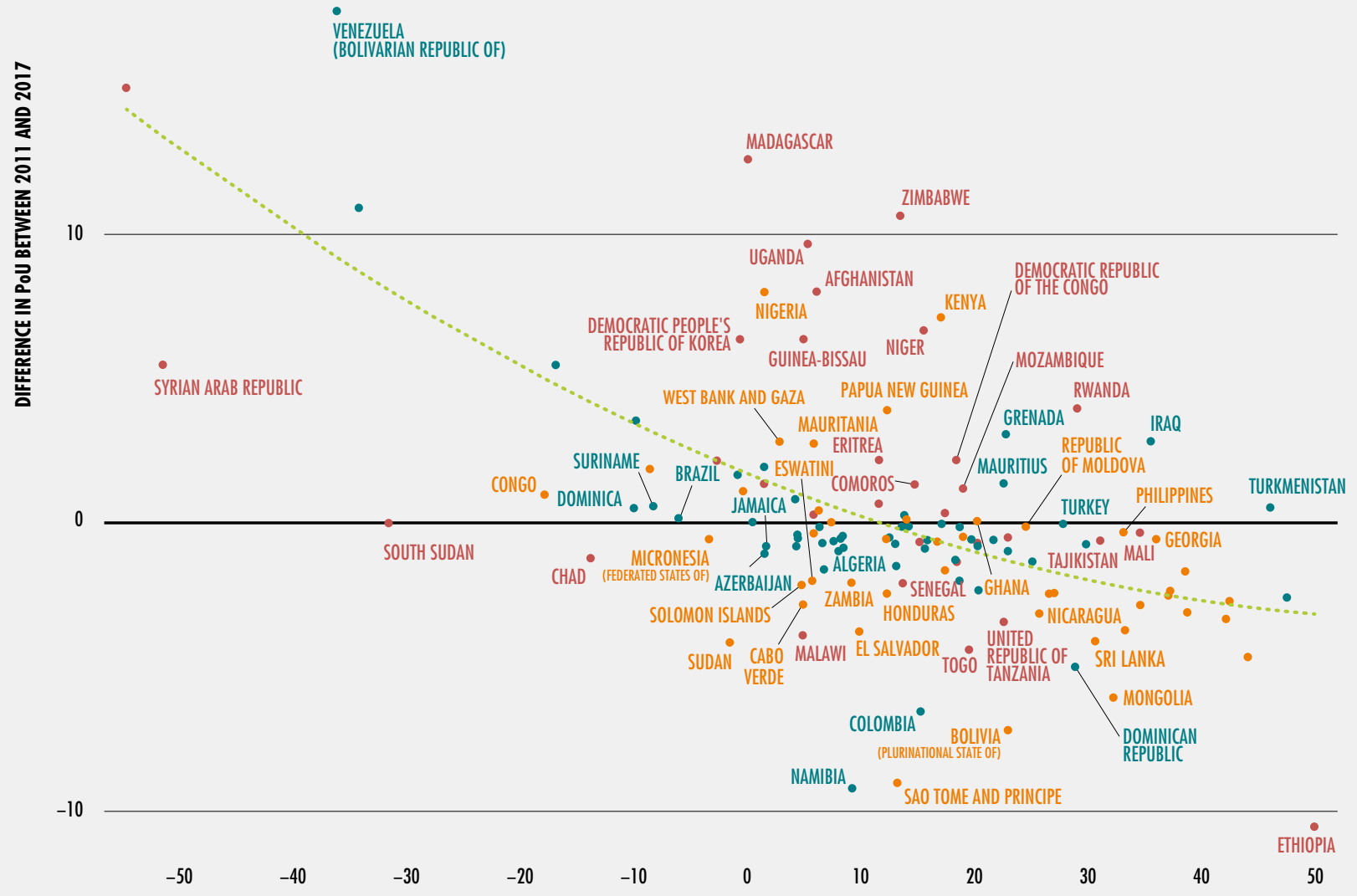

ECONOMIC GROWTH BETWEEN 2011 AND 2017

NOTES: Difference in the level of the PoU between the years 2011 and 2017 (y-axis) is plotted against the economic growth (expressed in percentage) between the years 2011 and 2017 ( $x$-axis). Economic growth is computed using GDP per capita at constant 2010 prices, comparing the level of GDP per capita in 2011 and 2017. The three categories of countries are defined based on the level of country income that follows the World Bank classification in 2017. Country names are not reported for countries falling inside the 95 percent confidence interval (close to the fitted line), but a list of these countries is provided in Annex 3 . West Bank and Gaza is a territory and follows the World Bank classification. The analysis includes some countries with imputed PoU, see Annex 3 for methodology and list of countries.

SOURCES: FAO for PoU; UN. 2019. National Accounts - Analysis of Main Aggregates. In: UNSTATS [online]. New York, USA. [Cited 6 May 2019] https://unstats.un.org/unsd/snaama for GDP per capita growth at constant 2010 prices used to compute economic growth. 
had higher increases in the PoU between 2011 and 2017 when compared with middle-income countries (Figure 25 and Table A4.2 in Annex 4).

It is also important to explore the interaction between economic downturns with the two other drivers of the rising trend in hunger: conflict and climate. Economic downturns show the highest correlation with increases in PoU in terms of magnitude of the estimated coefficient, almost double that of vulnerability to climate and conflict. In fact, countries with economic downturns have a 5.1 percentage point higher PoU than countries without, whereas countries with vulnerability to climate and conflict have a 2.3 and 2.2 percentage point higher PoU, respectively (see Table A4.3 in Annex 4).

When PoU increases are estimated within income groups, upper-middle-income countries with economic downturns show the highest PoU increase, i.e. a 6.3 percentage point higher PoU increase between 2011 and 2017 than upper-middle-income countries without economic downturns. On the contrary, low-income countries are those with the highest PoU increase associated with climate vulnerability and conflict. These countries experience a 4.8 percentage point higher PoU increase in the presence of climate vulnerability compared to low-income countries without and, when affected by conflict, they report a 5.5 percentage point higher $\mathrm{PoU}$ (see Tables A4.4a and b in Annex 4). First, this is in line with studies suggesting that conflicts are more likely to erupt in low-income economies, leading to the most dangerous increases in hunger. ${ }^{16}$ Second, low-income countries are the only countries that experience a significant PoU increase associated with vulnerability to climate (see Tables A4.4a and b in Annex 4). Quite importantly, this result deriving from a macro-level analysis, confirms extensive findings from the microeconomic literature that climate extremes have a disproportionately negative effect on the poorest populations living in remote areas in terms of consumption and food security. ${ }^{17}$ Although a correlation analysis describes the association between the three drivers and the change in PoU, it is difficult to disentangle the contribution of each of the three drivers, given that conflict and climate shocks can also affect economic growth, and therefore indirectly affect undernourishment.

\section{Economic slowdowns and downturns worsen global food crises}

Countries experiencing crisis levels of acute food insecurity also typically experience economic disarray. In the last three years (2016-2018), more than 100 million people every year have faced periods of acute food insecurity. ${ }^{18}$ In 2018, 113 million people across 53 countries and territories faced crisis levels of acute food insecurity or worse (IPC Phase 3 and above or equivalent) ${ }^{19}$ where urgent humanitarian actions were needed to save lives and livelihoods, as well as to address high or above-average acute malnutrition.

Analysis of acute food insecurity, including the drivers behind the food crisis, carried out at the country level, sheds light on how economic slowdowns and downturns worsen food crises. ${ }^{20}$ It shows that, in 2018, conflict remained the key driver of food crises, affecting around 74 million people, two-thirds of whom faced acute food insecurity. Climate and natural disasters were the primary driver of acute food insecurity for another 29 million people. Economic shocks were the primary driver of acute food insecurity for 10.2 million people.

While economic shocks are rarely the primary drivers of food crises, they are significant secondary or tertiary drivers of them. In many instances, significant economic shocks - or even not-so-significant shocks that occur in fragile economies - can undermine economic activity, worsen the severity of acute food insecurity, and prolong the duration of the crisis. In fact, more than 96 million people in 33 countries who suffered from acute food insecurity in 2018 lived in places where the economy was undergoing economic shocks of rising unemployment, lack of regular work, currency depreciation and high food prices (Table 8 and Annex 5 for the list of countries by economic shock). ${ }^{21}$ The economy of most of these countries (27 out of 33) was contracting, according to their real GDP per capita growth for 2015-2017.

In food crisis contexts, the interaction between conflict and economic slowdowns and downturns is particularly important. Not only is conflict the main driver behind food crises, 
ECONOMIC SHOCKS WERE SIGNIFICANT SECONDARY AND TERTIARY DRIVERS OF FOOD CRISES IN 2018

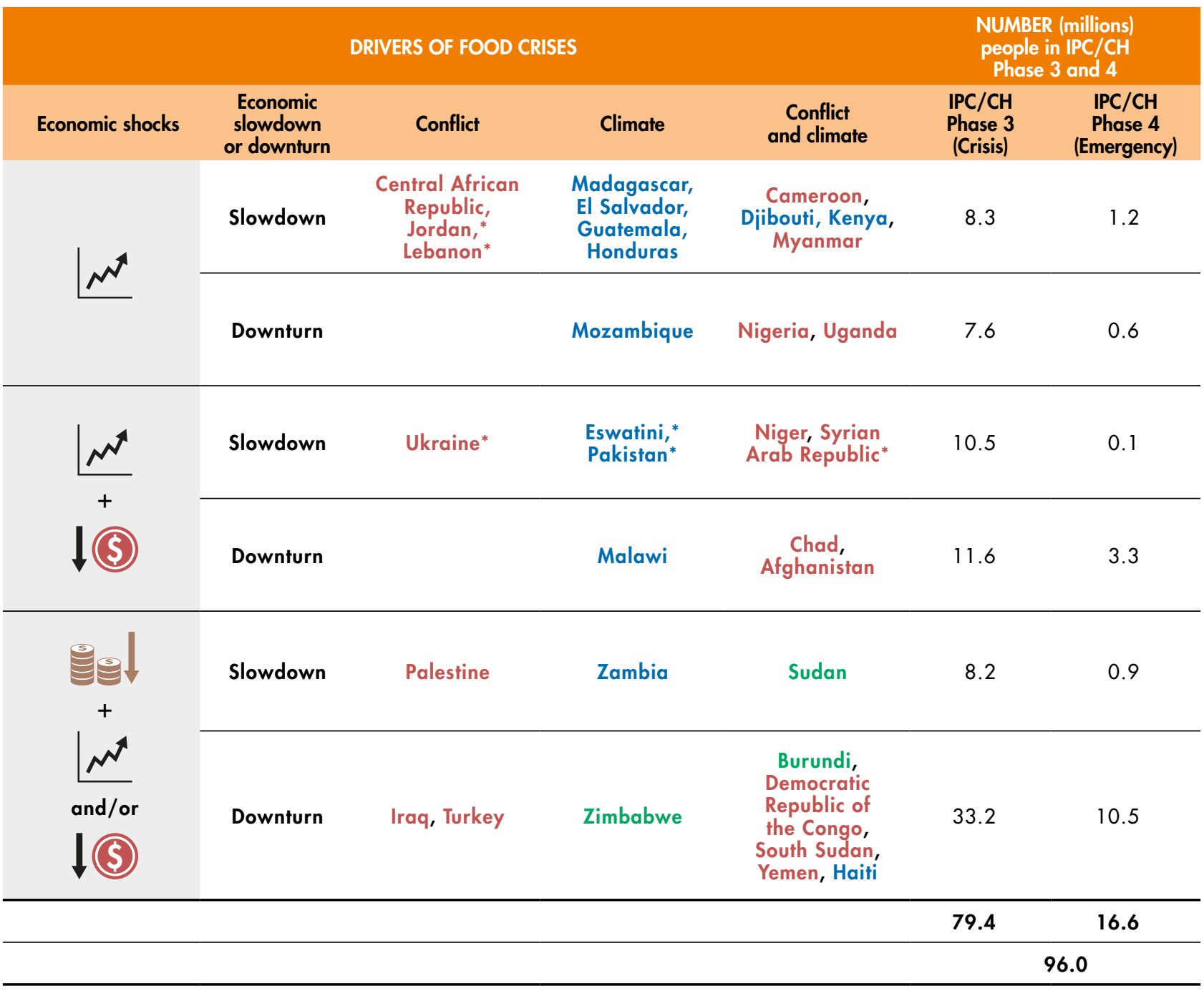

$\Lambda$ High food price

NOTES: Countries affected by food crises in 2018 where economic shocks are a driver of acute food insecurity as identified by the Global Report on Food (rises 2019 (GRFC). Information on economic shocks as drivers of food crises was not available in the GRFC 2019 for Jordan, Lebanon, Myanmar and Turkey. For these countries the information is obtained from the FAO Global Information and Early Warning System (GIEWS) Country briefs referring to the year 2018. When the main driver of a food crisis is conflict, countries are highlighted in red; when the main driver is climate shocks, countries are highlighted in blue; when the main driver is economic shocks, countries are highlighted in green. Countries denoted by the asterisk $\left({ }^{*}\right)$ do not experience economic slowdowns or downturns. Economic slowdowns and downturns are identified when they either occur in years 2015-2016 or 2016-2017 and are computed using the annual rate of per capita growth at constant prices. See Annex 5 for the list of food crisis countries with a full description of economic shocks.

SOURCES: FAO elaboration based on FSIN. 2019. Global Report on Food Crises 2019 [online]. [Cited 24 April 2019]. http://www.fsinplatform.org/sites/default/files/resources/files/ GRFC_2019-Full_Report.pdf and for economic slowdowns and downturns, UN. 2019. National Accounts - Analysis of Main Aggregates. In: UNSTATS [online]. New York, USA. [Cited 6 May 2019]. https://unstats.un.org/unsd/snaama and for additional information on economic shocks, FA0. 2019. GIEWS - Global Information and Early Warning System. In: FAO [online]. Rome. [Cited 19 June 2019]. http://www.fao.org/giews/en/

but it also often triggers economic slowdowns, downturns and deep economic recessions that compound the severity and duration of the food crisis. ${ }^{22}$ In 2018, conflict and civil insecurity were the major driver of food crises in 21 countries - 14 of them experienced deep economic recessions with an average negative difference of 2.4 percentage points in economic growth between years 2014 and 2017. ${ }^{23}$

Economic slowdowns and downturns often lead to increased levels of unemployment and limited income opportunities, which erode household purchasing power, exacerbating food insecurity 
and malnutrition. ${ }^{24}$ The loss of income and unemployment in turn feature as key contributing factors in several of the food crises, especially in countries facing economic downturns (Table 8).

As the next section shows, persistent slowdowns and sharp downturns in the economy can drain foreign currency reserves, potentially triggering national currency depreciations with a number of knock-on effects detrimental to food security and nutrition, including food price inflation. This is especially the case for countries dependent on food imports. Seventy-five percent of the countries with food crises that also suffered from economic shocks are net food importers (25 out of 33) with the value of food imports outweighing the country's value of food exports.

Economic slowdowns and downturns can constrain national financial capacities to provide essential services, protect the poor and respond effectively to crises. Furthermore, political instability limits the capacity of governments to support their populations during food crises, and therefore economic downturns, especially if they are severe, can further compound the impacts of this instability on food crises.

Economic slowdowns and downturns can also lower the resilience capacity of households to respond to other shocks - including climate shocks. For example, the climatic impact of El Niño in Southern Africa in 2016 led to more than 12 million food-insecure people in need of urgent humanitarian action in six countries. The impact of this phenomenon was intensified by already ongoing economic slowdowns and downturns in several countries, which weakened households' capacity to respond effectively to the climate shock and contributed to lowering the resilience of households already debilitated by a poor agricultural season in 2015. This was the case for Eswatini (formerly Swaziland), Mozambique and Zimbabwe. While households may be able to cope with and recover from transitory shocks, multiple and recurring shocks are increasingly the norm, adding to the vulnerability of the poor. Aggregate and recurring shocks tend to result in poverty traps or slips back into poverty, generating harmful effects on present food security and nutrition, and on future generations. ${ }^{25}$

\subsection{COMMODITY DEPENDENCE AND ITS RELEVANCE FOR FOOD SECURITY AND NUTRITION}

\section{KEY MESSAGES}

$\rightarrow$ Eighty percent of the countries (52 out of 65) with a rise in hunger during recent economic slowdowns and downturns are countries whose economies are highly dependent on primary commodities for export and/or import.

$\rightarrow$ In 2018, 807 million undernourished people and 154 million stunted children under the age of five lived in low- and middle-income countries: of these, respectively, around 381 million and 73 million lived in high commodity-dependent countries. The latter also were home to almost 109 million out of the 113 million people facing crisis levels of acute food insecurity requiring urgent humanitarian actions.

$\rightarrow$ Changes in commodity prices affect the relative value of exports and imports in these countries. Foreign exchange drains, depreciation and devaluation of currencies may pass through the economic system, resulting in rising domestic prices, unemployment, loss of wages, and consequently loss of incomes.

$\rightarrow$ These events pose macroeconomic aggregate shocks affecting multiple households, rather than idiosyncratic shocks that only affect a single household. Many vulnerable households see their purchasing power reduced, while coping strategies they use during idiosyncratic once-off shocks are not effective.

$\rightarrow$ The need to change consumption patterns can lead vulnerable households to cut spending on a range of basic services for health and disease prevention or shift away from nutrient-rich foods towards more energy-dense but nutrient-poor foods. Households may also see the supply of basic services compromised if the fiscal space to provide essential social public expenditure becomes more limited. 


\section{Commodity price trends and booms}

International, regional and national factors can harm economic activity in ways that challenge food security and nutrition. Understanding the mechanisms through which economic slowdowns and downturns contribute to the recent, unwelcoming trends in food security and nutrition can be approached from different angles as it is ultimately country-specific. However, there is a steady trend affecting many of the countries where hunger is lately on the rise.

Low- and middle-income countries are, by and large, well integrated with the world economy, though to different degrees and in different ways. They trade goods and services with other countries, invest in them or receive investors from them, and exchange different types of flows, including financial capital, foreign aid, foreign borrowing, remittances and others. This integration, of course, exposes them to external vulnerabilities depending on the structural features of their economies.

In this regard, a key vulnerability arises relating to what these countries produce and what they trade with the rest of the world: essentially, primary commodities. The trend in rising commodity prices that started in 2003 and the period of extreme price volatility in 2008 have been followed by largely declining global commodity prices for five consecutive years from 2011 to 2016 (Figure 26). As a result, commodity prices fell by more than nine percent in this period. As indicated earlier, global commodity demand is also in decline and the outlook is that its growth could slow over the next decade, especially for agriculture and metals.

Although global commodity price levels are still higher than during the pre-commodity price boom in 2007-2008, most countries that are highly dependent on exporting commodities to generate revenues have not been able to use their commodity windfalls during commodity price booms to diversify their economies and reduce their vulnerability to price shocks. Today many are as commodity dependent as before, if not more so, with few exceptions such as Argentina, China and Mexico. ${ }^{26}$ There are many reasons for this. Diversification and upgrading of the productive structures and capabilities from which wealth is created and distributed are not easy tasks and take years to achieve. ${ }^{27}$ Effective policies, effective collaboration between public and private sectors, and high levels of investment are also needed.

Furthermore, benefits during boom periods are by far outweighed by the negative impacts caused by price volatility and low-price periods, which tend to be longer than boom periods. ${ }^{28}$ Moreover, the negative impacts on net food importers during periods of high food prices can be extremely severe, as witnessed during the food price crises of 2007-2008 and 2010-2012.

\section{Why does commodity dependence matter?}

Commodity dependence matters because it increases the vulnerability of countries to world price swings. The vulnerability to changing commodity prices arises as countries produce and trade commodities and, in most cases, low- and middle-income countries are world price-takers that cannot affect them. They may not be in a position to influence these prices alone. They may also not be in a position to undergo the structural transformation to move them away from commodity dependence.

The association between economic performance and commodity prices in commodity-dependent countries is strong and therefore makes them especially vulnerable to the volatility of global commodity prices. ${ }^{29}$ Recent slowdowns and downturns in economic growth in many regions are largely explained by marked declines in commodity prices. This is mainly affecting countries dependent on primary commodity exports, particularly in South America, but also other regions including Asia and some countries in Africa. ${ }^{30}$

Countries from these regions are commodityexport-dependent as they derive the bulk of their export earnings from primary commodities. This report not only focuses on this type of countries, but also on countries showing commodity-import dependence and net food-import dependence (see Box 11 for 


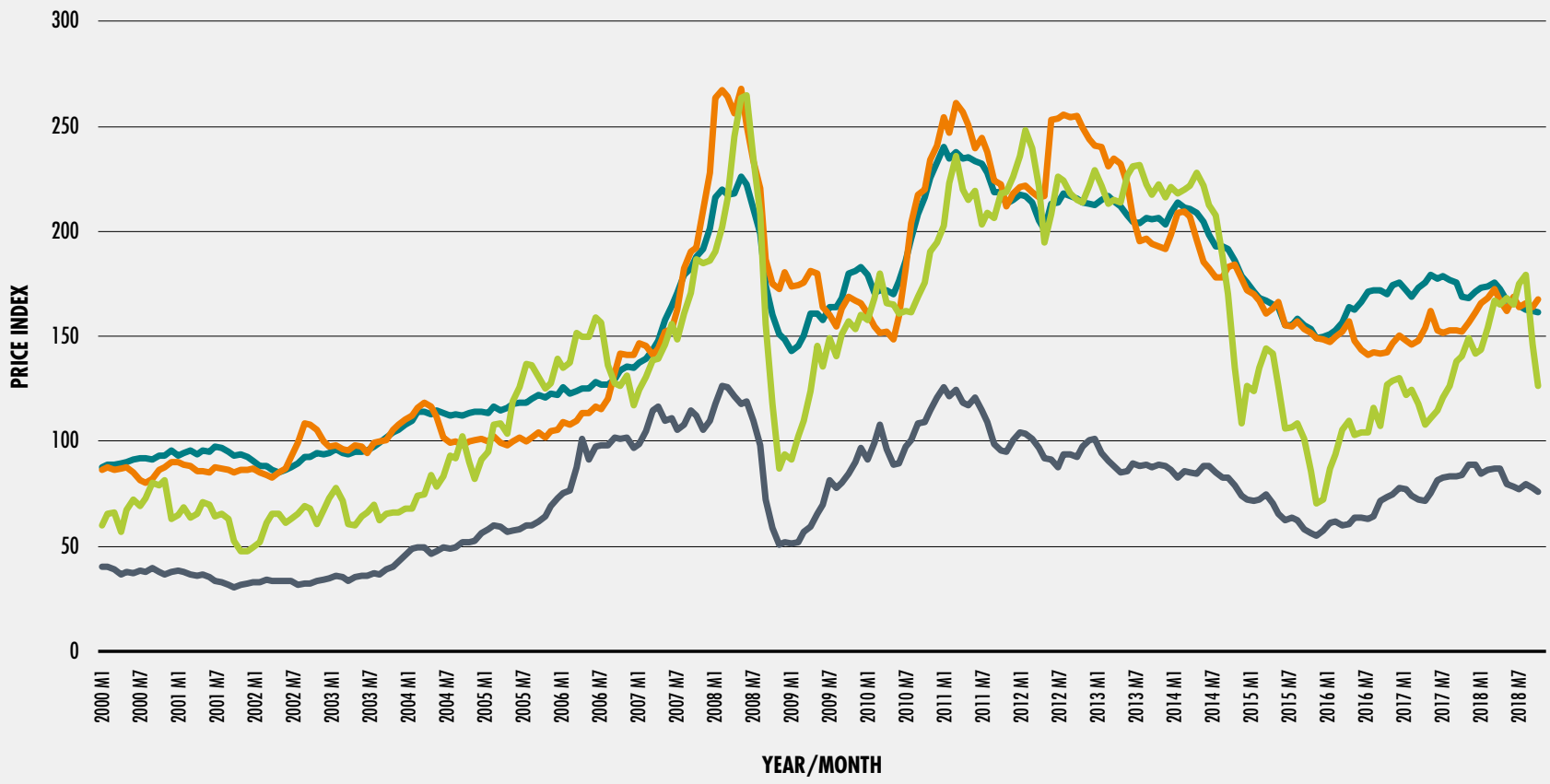

- FAO food price index $\longrightarrow$ FAO cereal price index $\longrightarrow$ Metals and minerals price index Crude oil price index

NOTES: The plot shows the trend of FAO monthly food and cereal price indices (composite measures of food prices) expressed as a percentage of 2002-2004 averages, the crude oil price index expressed as a percentage of 2016 (the average of three spot prices: Dated Brent, West Texas Intermediate, and the Dubai Fateh), and the metals and minerals price index expressed as a percentage of 2010. Monthly food prices are plotted for years 2000-2018.

SOURCES: FA0. 2019. FA0 Food Price Index. In: FA0 - World Food Situation [online]. Rome. [Cited 5 May 2019]. http://www.fao.org/worldfoodsituation/foodpricesindex for food and cereal food price indices; IMF. 2019. IMF Primary Commodity Prices. In: IMF [online]. Washington, DC. [Cited 6 May 2019]. https://www.imf.org/en/Research/commodity-prices for the crude oil index; World Bank. 2019. Commodity Markets. In: World Bank [online]. Washington, DC. [Cited 6 May 2019] http://www.worldbank.org/en/research/commodity-markets for metals and minerals index

definitions). Commodity-import-dependent countries have a high ratio of food and fuel imports to total merchandise trade, while commodity-export-dependent countries derive the bulk of their export earnings from primary commodities. Net food importers are countries where the value of imports of basic foodstuffs outweighs the value of food exports. Out of a total of 134 low- and middle-income countries studied for the period 1995-2017, 102 countries are classified according to the three types of high commodity dependence, whereas the remaining 32 are low commodity dependent.

High commodity-dependent countries exhibit combinations of commodity-import and -export dependence, which entail different vulnerabilities to commodity prices and links with food security and nutrition. For example, out of 134 low- and middle-income countries in the period 1995-2017, 34 are high commodity-export-dependent but low commodity-import-dependent, 25 are 
Commodity-export-dependent countries or territories derive the bulk of their export earnings from primary commodities, such as minerals, ores, metals, fuels, agriculture raw materials and food. This report defines high commodity-export-dependent countries as those who generate more than 60 percent of their merchandise export revenues from food, agriculture and raw materials; minerals, ores, and metals; and/or energy commodities. Following UNCTAD and FAO, this threshold corresponds to the minimum threshold denoting the most negative association between commodity-export dependence and human development.

Commodity-import-dependent countries or territories have a high ratio of commodity imports to total import merchandise traded. This includes essential goods, such as food items and fuel. The report defines high commodity-import-dependent countries as those where the share of the value of food and fuel imports is more than 30 percent of the total merchandise. This threshold is the average for developing countries in 1995-2014 and the one applied in the UNCTAD and $\mathrm{FAO}^{\prime}$ analysis.

Net food importers are countries or territories where the value of imports of basic foodstuffs outweighs the value of exports of basic foodstuffs. This report defines high net food importers as those countries having a negative average food trade balance in the years from 2013 to 2015 , following the UNCTAD and FAO definition. ${ }^{2}$

' UNCTAD and FA0. 2017. Commodities and Development Report 2017. Commodity markets, economic growth and development. New York, USA, UNCTAD. ${ }^{2}$ See Annex 6 for the methodology and list of countries by different categories.

high commodity-import-dependent but low commodity-export-dependent, and 43 are both high commodity-export- and commodity-importdependent (Figure 27).

Out of the 134 low- and middle-income countries, 97 are net food importers. Of these, 80 also show some degree of commodity dependence: 23 high commodity-export dependence, 20 high commodity-import dependence, and 37 have both types of dependence (Figure 27, see Annex 6 for the list of countries by type of commodity dependency and income level).

International commodity price shocks and volatility can potentially create harmful impacts for food security and nutrition in all combinations of high commodity dependence. For example, as highlighted above, most of the countries (52 out of 65) that experienced rising undernourishment in correspondence with economic deceleration during 2011-2017 are highly dependent on primary commodity exports and/or imports, of which many (42 out of 65) rely heavily on oil and other primary commodity export revenues. For several of the countries affected by food crises considered above, most of which are net food-import dependent (25 out of 33), inflationary pressure stemming from the depreciation of national currencies against the US dollar was a key factor that contributed to an escalation in food prices. In 2018 most (27 out of 33 or 81 percent) of the food crisis countries where economic shocks worsened the severity of acute food insecurity were high primary commodity-dependent countries.

In 2018, 807 million undernourished people and 154 million stunted children under the age of five lived in low- and middle-income countries: of these, respectively, around 381 million and 73 million lived in high commodity-dependent countries. For countries facing food crises, the 2018 situation was even worse: almost 109 million out of the 113 million people facing crisis levels of acute food insecurity requiring urgent humanitarian actions $^{31}$ also lived in low- and middle-income, high commodity-dependent countries.

A close examination of real GDP per capita growth in low- and middle-income countries during the recent period of commodity price declines between 2011 and 2017 exposes a staggering difference in economic growth 


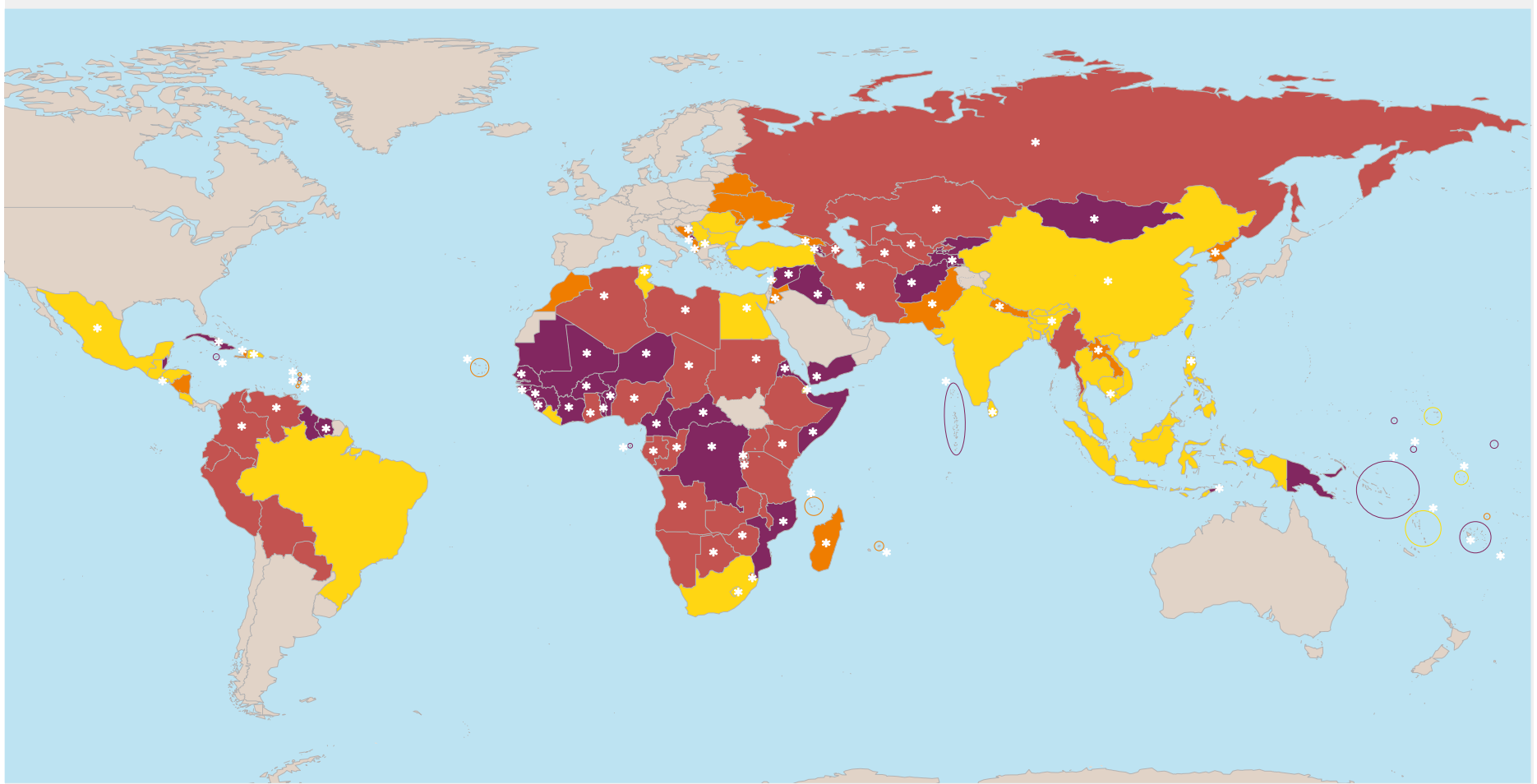

Low commodity-dependent (low import and low export) countries

High commodity-export- and low commodity-import-dependent countries
- High commodity-import- and low commodity-export-dependent countries $\varepsilon_{3}$ Net food importers

High commodity-dependent (high import and high export) countries

NOTES: The map shows low- and middle-income countries by the four categories of export (CXD) and import (CMD) commodity dependence: i) low commodity-import- and low commodityexport-dependent; ii) low commodity-export- and high commodity-import-dependent; iii) high commodity-export- and low commodity-import-dependent; iv) high commodity-export- and high commodity-import-dependent. High commodity-export (-import) dependence is identified when $X X D>0.6$ (CMD $>0.3$ ). Net food importers are those countries with a negative average food trade balance during the years 2013-2015. For further information see Annex 6. Areas with insufficient data coverage are denoted in grey.

The final boundary between the Republic of the Sudan and the Republic of South Sudan has not yet been determined. Final status of the Abyei area has not yet been determined. SOURCES: Typology of commodity dependence is an FAO elaboration based on UNCTAD. 2019. UNCTADStat. In: UNCTAD [online]. New York, USA. [Cited 13 May 2019] https://unctadstat.unctad.org/wds/ReportFolders/reportFolders.aspx; UNCTAD. 2019. Economic groups and composition [online]. New York, USA. [Cited 29 May 2019]. https://unctadstat.unctad.org/EN/Classifications/DimCountries_EconomicsGroupings_Hierarchy.pdf

between countries with high commodity dependence and those without this characteristic during this period. Average real GDP per capita growth for high commodity-dependent countries declined sharply and steadily between 2012 and 2015, followed by some improvement in economic growth but still significantly lower than that of low commodity-dependent countries (Figure 28). Moreover, many of the high commodity-dependent countries (67 out of 102) also witnessed a rise in hunger or a worsening food crisis situation during the same period. For these countries, economic slowdowns were sharper and economic downturns were deeper and longer lasting.

Many of the high commodity-dependent countries experienced deep economic recessions with negative economic growth (downturns) occurring over several consecutive years between 2011 and 2017. Twenty-three high commodity-dependent countries underwent 


\section{FIGURE 28}

BETWEEN 2003 AND 2017, HIGH COMMODITY-DEPENDENT COUNTRIES FACED STEEPER

DECLINES IN ECONOMIC GROWTH COMPARED TO LOW COMMODITY-DEPENDENT COUNTRIES FOR THOSE WITH RISING HUNGER THE SITUATION WAS EVEN WORSE

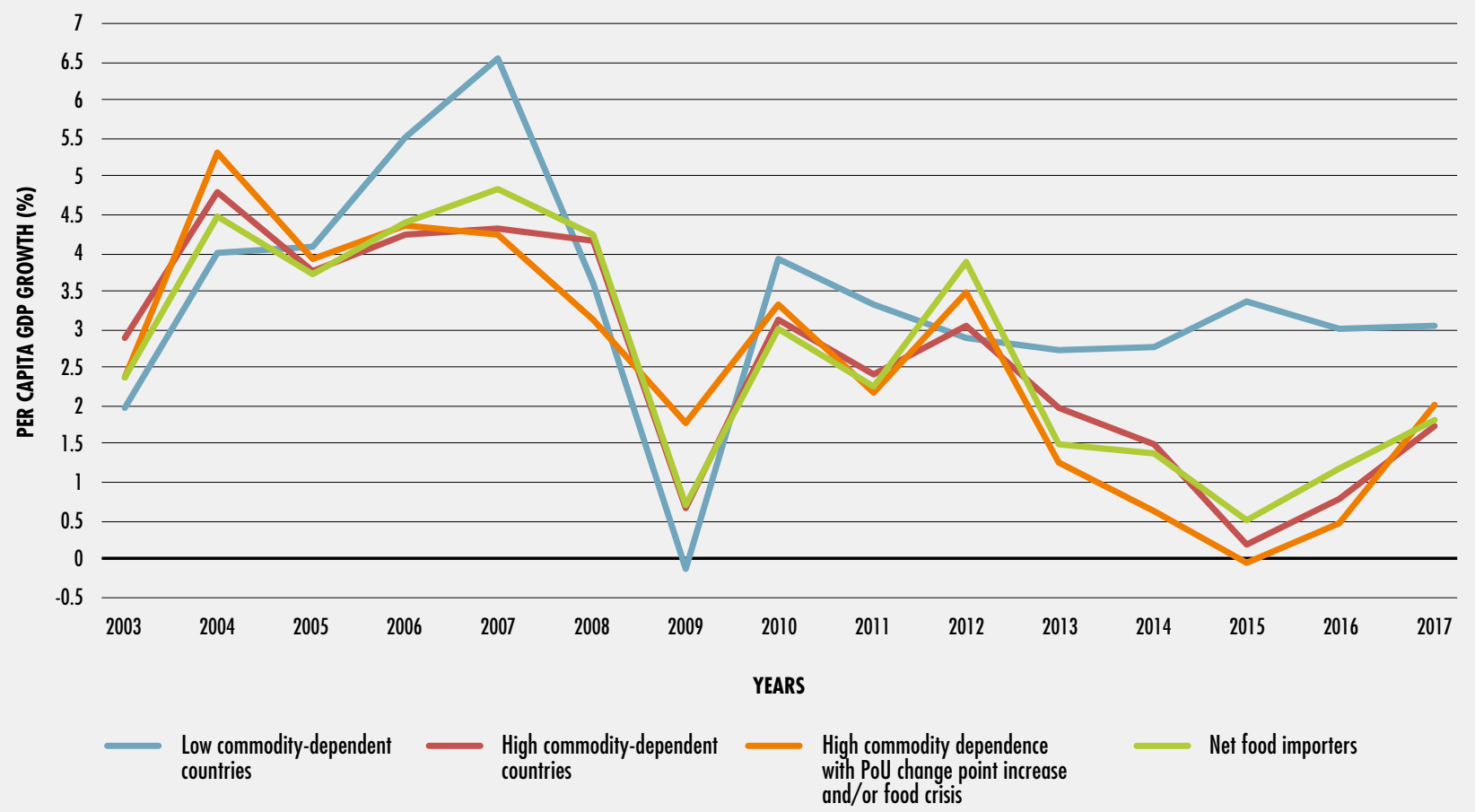

NOTES: Trends in real GDP per capita (2003-2017) plotted for high commodity-dependent countries denoted by the red line (either high commodity-export dependence, high commodity-import dependence, or both high commodity-export/commodity-import dependence); high commodity-dependent countries that also experience PoU change point increase and/or food crisis (orange line); net food importers (green line); low commodity-dependent countries (blue line). The trend of per capita GDP growth is shown for the four categories as an unweighted average.

SOURCES: FAO for PoU; FSIN. 2019. Global Report on Food Crises 2019 [online]. [Cited 24 April 2019]. http://www.fsinplatform.org/sites/default/files/resources/files/GRFC_2019-Full_ Report.pdf for countries affected by food crises; and UN. 2019. National Accounts - Analysis of Main Aggregates. In: UNSTATS [online]. New York, USA. [Cited 6 May 2019] https://unstats. un.org/unsd/snaama for real GDP per capita growth.

two or more consecutive years of negative growth and most of these (15 countries) also saw rises in undernourishment in this period or a worsening food crisis situation in 2018 (see Table A6.3 in Annex 6 for the list of countries and the number of consecutive years of downturns).

Among high commodity-dependent countries, especially high commodity-export-dependent countries, increases in undernourishment associated with economic slowdowns or downturns depend on the main sector of country exports. Countries dependent on exports of fuel, minerals and metals have been the most exposed to downturns - even if these commodities come from very different sectors. Specifically,
35 percent (14 out of 40 ) of the countries with downturns in 2016-2017 were dependent on said exports.

A recent FAO study sampling 129 low- and middle-income countries during 1995-2017 finds that high levels of export and import dependence on primary commodities have a statistically significant and negative effect on food security (Table 9). ${ }^{32}$ In the period considered, an average increase of primary commodity-export dependence by 1 percent leads to a 2.2 percent increase in the PoU per year on average. For commodity-import dependence, the correlation is stronger, as it causes an average increase in undernourishment of 3.8 percent per year. This average effect is 


\section{HIGH LEVELS OF COMMODITY-EXPORT AND -IMPORT DEPENDENCE NEGATIVELY AFFECT FOOD SECURITY}

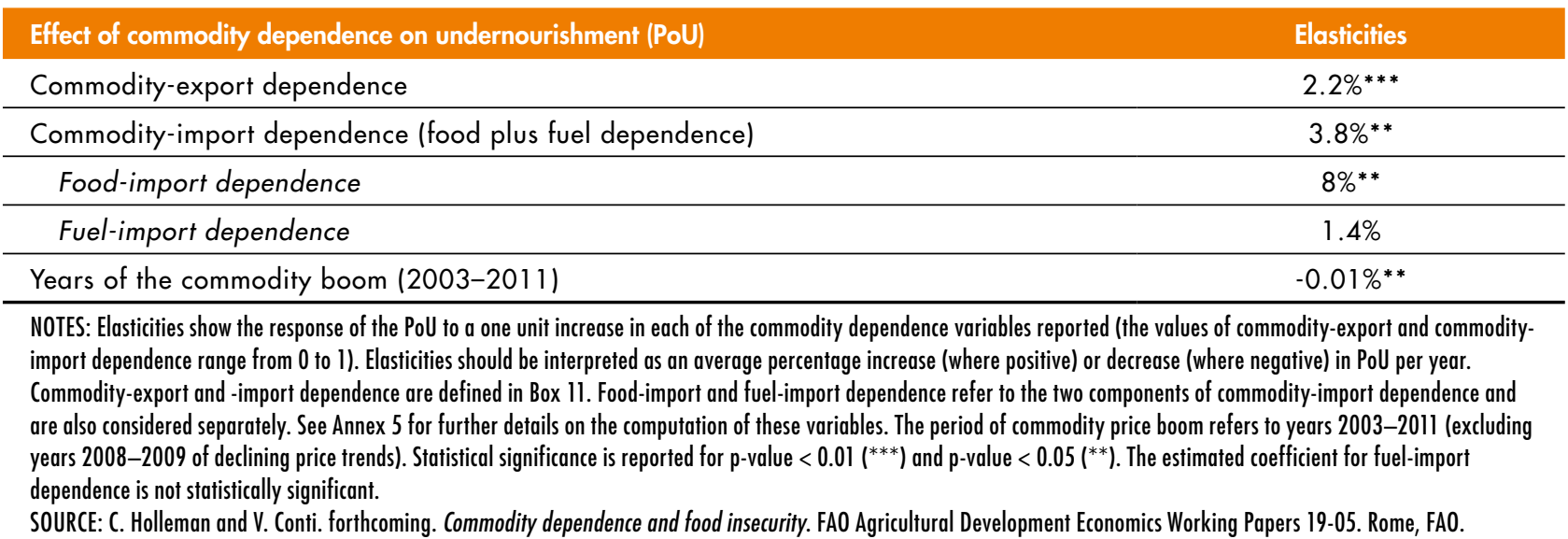

shown to be even stronger for low-income countries, compared with middle-income countries, since they experience a higher level of the PoU in the presence of commodity dependence.

The same FAO study also finds that, when commodity-import dependence is unpacked, food-import dependence has a bigger and stronger effect on the PoU than fuel-import dependence. Food-import dependence is associated with an 8 percent increase in PoU per year on average, whereas fuel-import dependence does not report a statistically significant coefficient.

The two successive and sharp commodity price booms in 2007-2008 and 2010-2011 offered an economic bonanza to most commodity-exportdependent countries (Figure 26 and 28). Many registered a large increase in export revenues and generally saw increased economic growth. For net food importers and high commodityimport-dependent countries, however, such price booms can create additional challenges for food security and nutrition. This can particularly be the case for net buyers of food through imported food price inflation. On the other hand, high food prices, especially cereal prices, can be a strong incentive for increased agricultural production, whereby the positive effects of this outweigh the negative effects of high food prices (e.g. for net buyers of food) with overall positive net effects on food security and nutrition. This was the case in many countries during the 2007-2008 global food crisis (Box 10).

New FAO evidence suggests that economic growth, even if strong during price booms for high commodity-export-dependent countries, does not necessarily translate into improved food security and nutrition. ${ }^{33}$ This study finds that, during the period 1995-2017, both food-import dependence and export dependence on primary commodities have a negative effect on PoU, even when controlling for the price booms between 2003 and 2011 (excluding the sharp commodity price drop in 2008-2009, see Figure 26). The years of the commodity price booms seem to have a positive effect on hunger, although the effect is very small (Table 9). Economic growth in many of these cases is not fairly distributed and does not trickle down sufficiently, and in some cases not at all to the poorest and most food-insecure and malnourished populations - as further explained next in the report.

This is consistent with a recent comprehensive study of 202 countries over the period between 1995 and 2014, which finds that high levels of commodity dependence are statistically significant and negatively affect social (education and health) and human development in general and results are statistically significant. This effect was found to pass through several channels, including the negative secular terms of trade affecting commodity-dependent 
developing countries, slow economic growth, high macroeconomic instability and political instability. ${ }^{34}$ This finding is further supported by another study that finds "non-monetary" indicators of development (e.g. health and education) are negatively correlated with commodity dependence through macroeconomic volatility and distributional inequalities. ${ }^{35}$

\section{Commodity dependence and food security and nutrition: transmission channels}

\section{Designing policies to help offset the} vulnerability that arises with high commodity dependence requires a thorough understanding of the potential effects. These effects are mediated through a number of direct and indirect channels that link global commodity markets with domestic economic, social and human development outcomes, including food security and nutrition. The transmission channels in such contexts are complex, and a given commodity price change does not affect all commodity-dependent countries in a uniform manner. Figure 29 presents a simplified overview of these transmission channels.

The transmission channels can be grouped into four broad areas, which are the main subject of analysis in this section. They are:

\footnotetext{
- Direct impacts emanating as the change in commodity prices affects terms of trade, exchange rate adjustments and the balance of payments.

\section{- Secondary indirect effects of these macroeconomic impacts on: \\ $\checkmark$ domestic prices, including food; \\ - unemployment, declining wages and loss of income; and \\ - health and social services.}

Ultimately, an important critical factor that determines whether the direct and indirect impacts affect food security and nutrition is the ability of individuals and households to cope with these economic-related shocks. The last part of this section takes a closer look at how people cope and when their coping capacities fail.

\section{Terms of trade, exchange rate and balance} of payments

Macroeconomic performance in commodity-dependent countries tends to move with commodity price cycles. Economic activity and growth and external and fiscal balances deteriorate/improve during commodity price downswings/upswings, whether the latter entail long periods of falling/rising commodity prices or shorter commodity price swings that last only few years. ${ }^{36}$

From the perspective of low-income countries, especially those where the principal means of foreign exchange earnings come from the exports of primary commodities, unstable commodity prices create macroeconomic instabilities and complicate macroeconomic management (Figure 29).

\section{Terms of trade shocks and volatility}

Sharp declines or increases in international primary commodity prices can lead to changes in the terms of trade (ToT) for commodity-dependent countries. That is to say, the ratio between the prices at which a country sells its exports and the prices it pays for its imports is affected. A reduction in this ratio reflects a deterioration in the ToT which can have implications on economic growth, with further economy-wide implications as both supply and demand factors respond to the shock.

In fact, ToT shocks have been shown to carry the highest economic output costs among a range of external shocks for a large number of developing countries. ${ }^{37}$ Low-income countries are especially vulnerable. The IMF has found that low-income countries are almost six times more often affected by severe ToT fluctuations and changes than developed countries. ${ }^{38}$

World economic reports confirm that sharp and continuous declines in international commodity prices from 2011 to 2016 led to substantial shifts in the ToT and a sharp deterioration of GDP growth in commodity-dependent countries. ${ }^{39}$ Of course, the extent to which a variation in the export or import price of a commodity affects the ToT will depend on the relative share of the commodity in the country's total exports and imports, as well as on the magnitude of the price shock. Similar variations in export and import prices may also offset one another. 


\section{FIGURE 29}

\section{POTENTIAL NEGATIVE IMPACTS OF INTERNATIONAL COMMODITY PRICE REDUCTIONS ON FOOD SECURITY AND NUTRITION IN COMMODITY-DEPENDENT ECONOMIES: TRANSMISSION CHANNELS}

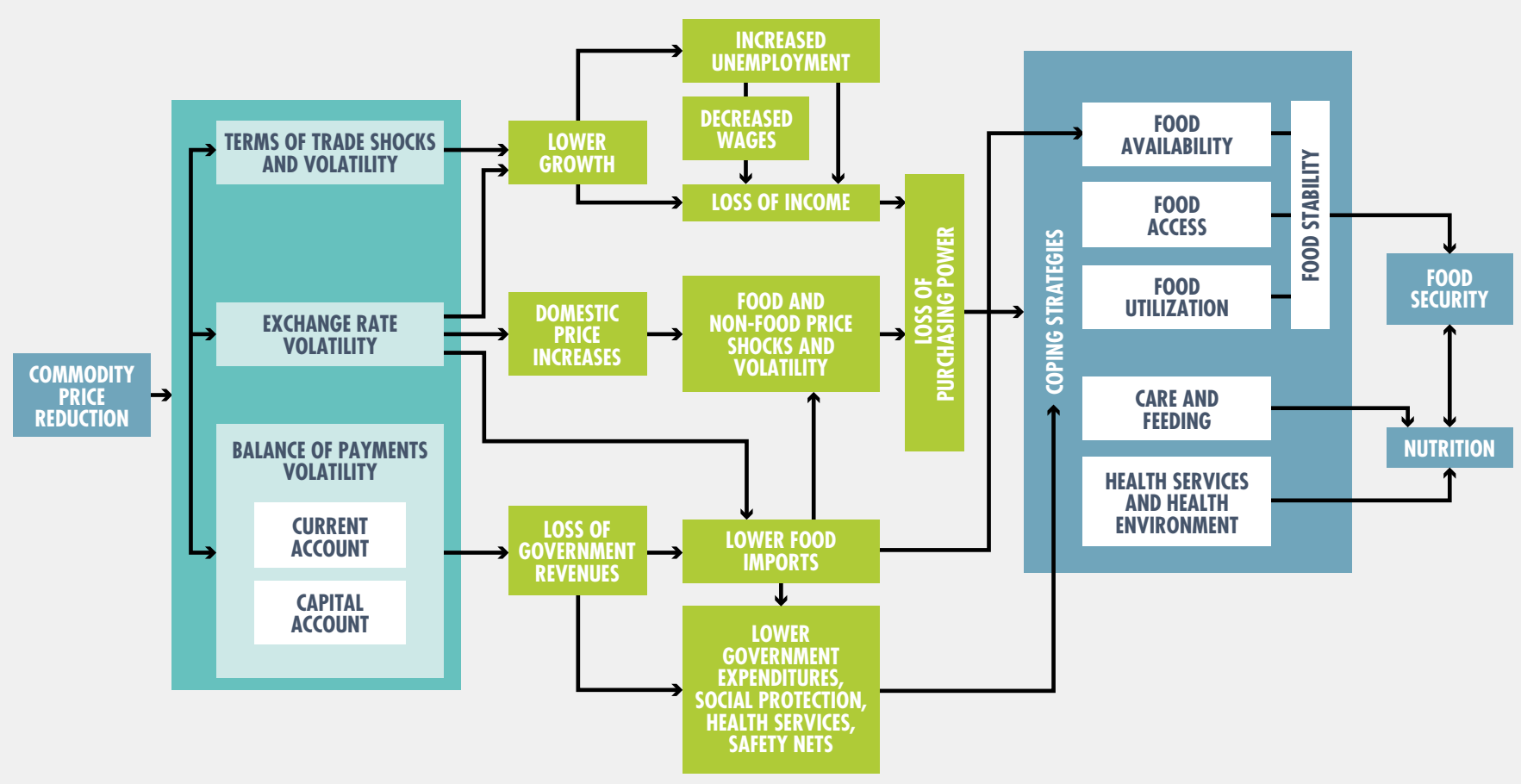

SOURCE: Based on diagram from UNCTAD and FA0. 2017. Commodities and Development Report 2017. Commodity markets, economic growth and development. New York, USA, UNCTAD, but modified for this report to focus on the specific transmission channels that affect food security and nutrition.

Most fuel and mineral exporters (e.g. Congo, Gabon, Nigeria, Zambia) witnessed a deterioration of their ToT as a result of the price declines between April 2011 and August 2015. ${ }^{40}$ This, combined with the depreciation in their exchange rates and a loss of commodity revenue, led to deteriorations in the fiscal stance and stung GDP growth.

Studies also show that commodity price volatility can result in less economic growth, even over longer periods of time, especially in resource-rich, commodity-export-dependent countries. ${ }^{41}$ This is because the ToT of economies dependent on primary commodities tend to deteriorate in the long run due to secular decline in primary commodities relative to prices of manufactured goods. Therefore, reliance on commodity exports that lose value over time is not such a viable strategy for boosting economic growth ${ }^{42}$ - let alone for eliminating external vulnerability through diversification.

Shocks transmitted from ToT through the economy are also challenging to government budgets. In many low-income commodity-dependent countries, especially commodity-export-dependent countries, sharp declines and persisting low prices in the main export commodities can drain not only export revenues but also fiscal revenues. 
Recent declines in commodity prices since 2011 led to a deterioration in public finances for many commodity-export-dependent countries (oil and non-oil exporters) in Asia, Africa, North Africa and the Middle East, and in Latin America and the Caribbean. For example, public revenues of African commodity-dependent countries shrank from an average of 26 percent of GDP during 2004-2007 to 21 percent of GDP in 2011-2014. This partially explains why these countries' average primary budget balances went from a surplus of 3.6 percent of GDP to a deficit of 1.8 percent of GDP between the two periods. In response, many commodity-dependent countries increased their borrowing in order to shore up their finances. ${ }^{43}$

Such deteriorations in the fiscal stance may threaten the continuity of social programmes, safety nets, and other components of economic and social development plans. Food access can be negatively affected owing to governments' more limited fiscal space to protect poor households against rising domestic prices. Generally, lower foreign exchange could also affect food availability through reduced food-import capacity. Contingency mechanisms and funds are critical to prevent these vulnerabilities from potentially harming food security, as further explained in Section 2.4.

Commodity-dependent countries that face such reductions in fiscal revenues in the wake of low or declining commodity prices may need to increase borrowing to cover shortfalls, thus leading to increasing public debt, which in turn can further compromise long-term growth and development, and lead to higher debt-repayment schedules. For instance, many South American commodity exporters have seen sharp increases in fiscal deficits that resulted in higher public debt-to-GDP ratios. ${ }^{44}$

\section{Exchange rate adjustment and balance of payments}

Commodity prices affect the amount of foreign exchange in commodity-dependent countries, as they alter the value of exports and imports in foreign currency. The balance of payments records these economic transactions.
A change in the foreign exchange available to an economy will be reflected in the price of foreign goods relative to the price of domestic goods, or real exchange rate. A net inflow/net outflow of foreign exchange will thus result in an appreciation/depreciation of the real exchange rate - other things being equal. By this definition, both the ToT and the real exchange rate may be affected simultaneously.

When countries' reserves of foreign exchange are insufficient to prevent unfavourable exchange rate adjustments, they may adjust the number of units of their currency that are needed to purchase a unit of a given foreign currency or nominal exchange rate, so as to restore the balance of payments. Lower commodity prices, for example, may lead to a decrease of foreign exchange in the markets of the commodity-exporting countries as their export revenues fall, thus causing a real exchange rate depreciation. Countries that possess a domestic currency may devalue it to restore the income of their exporters in local currency. Depreciation and devaluation of currencies may pass through the system resulting in domestic price increases.

In Colombia and Chile, for example, falling international prices for the countries' export commodities - respectively crude oil and copper - led to reduced export earnings and declining reserves in United States dollars (USD), triggering a devaluation of the local currency against USD (Figure 30). Conditional on international price developments for agricultural commodities, this can imply more expensive food imports, reduced domestic food availability, and rising food prices.

For many commodity-dependent countries that experienced an increase in undernourishment or worsening food crises, the decline in commodity prices from 2011 to 2016 is associated with significant depreciations. This was especially the case for many commodity-dependent countries in Africa. For example, in 2015 many currencies including the Zambian kwacha, the Angolan kwanza and the Nigerian naira, recorded some of their strongest depreciations against USD in several years. ${ }^{45}$ This pushed up the prices of non-commodity imports, further amplifying the sharp deterioration in their terms of trade. 

CHILEAN CURRENCIES

\section{A) COLOMBIAN PESO AND CRUDE OIL PRICE}

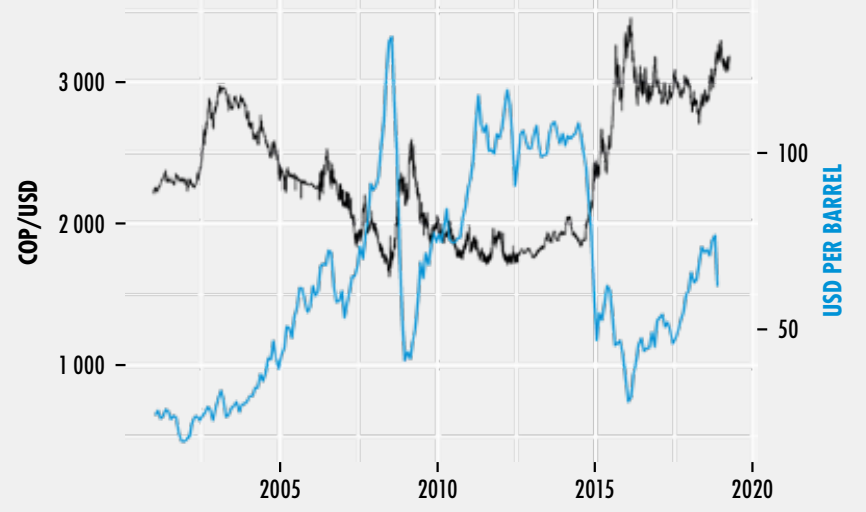

B) CHILEAN PESO AND COPPER PRICE

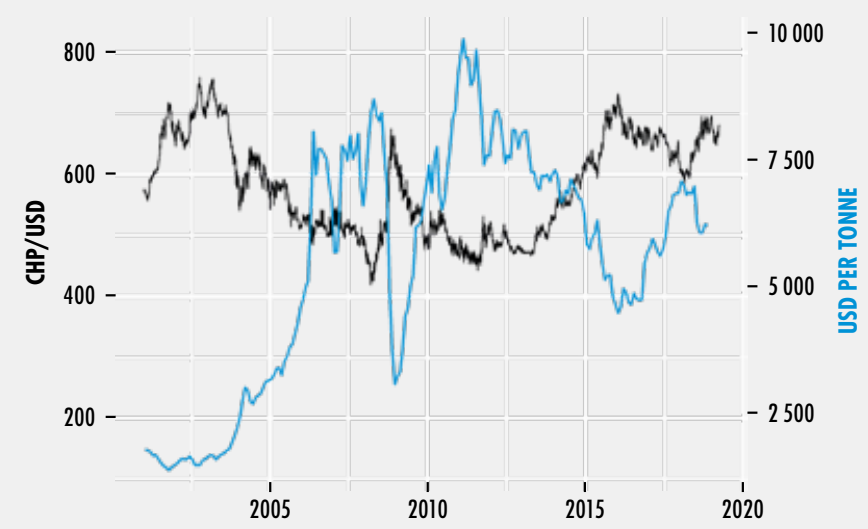

NOTES: The figure shows the relationship between Colombian exchange rates and crude oil price (graph A) and Chilean exchange rates and copper price (graph B) for years 2001-2018. Daily data are used to plot exchange rates and monthly data for commodity prices. COP (CHP) is Colombian peso (Chilean peso) and COP/USD (CHP/USD) refers to the amount of Colombian peso (Chilean peso) for 1 USD.

SOURCES: WFP elaboration based on Trading Economics. 2019. Trading Economics [online]. [Cited 25 April 2019]. https://tradingeconomics.com for exchange rate data; World Bank. 2019. Commodity Markets. In: World Bank [online]. Washington, DC. [Cited 6 May 2019]. http://www.worldbank.org/en/research/commodity-markets for commodity prices

\section{Rising domestic prices, including food}

International commodity price fluctuations can also transmit effects into the economy through exchange rate adjustments (Figure 29). Large depreciations are associated with domestic price increases and large devaluations tend to be associated with large declines in output, consumption and imports. ${ }^{46}$ The pass-through of international commodity price developments to local domestic prices varies by commodity, country and over time. ${ }^{47}$ Nonetheless, it can be particularly challenging for food security and nutrition, as it can affect people's access to food, care and feeding, as well as access to health services - unless exceptional conditions prevail to offset these effects, as seems to have been the case during the global food and financial crises (Box 10).

As highlighted above, declining commodity prices may result in depreciation and devaluation of currencies that may pass through the system resulting in domestic price increases, including food prices. An alternative situation may be that food imports become more expensive owing to rising international commodity prices, with domestic food prices following suit. Both situations can be particularly challenging to net food importers. While the degree and speed of pass-through depends on the country in either of these two situations, the effect of higher food prices will flow through the food value chain from wholesale to retail prices. This poses a challenge to food security and nutrition if the country has limited capacity to substitute food imports with domestically produced food, and it is not obvious that all domestic food producers will benefit from higher food prices.

South Sudan's currency devaluations in 2015, for example, immediately triggered significant food price inflation and eroded purchasing power of a majority of the country's poor and vulnerable. In cases like this, devaluation usually raises imported food prices and shifts 
the food parity price (the rural-urban terms of trade) in favour of agriculture/local produce. However, insignificant tradeable surplus by most farmers (due to low agricultural productivity), coupled with low levels of market integration and linkages, may exclude a number of farming populations from benefiting from rising prices of locally produced commodities. This was the chain of events in South Sudan, which led to increased levels of acute food insecurity and malnutrition levels, as populations struggled to access food - particularly troubling, given that 43 percent of the population of South Sudan are market dependent for their food needs. ${ }^{\mathbf{4 8}}$

In these situations, households that need to buy food are immediately affected by higher domestic retail prices as the cost of food relative to their incomes increases (Box 12). While this is clearly the case in urban areas, it holds in rural settings as well. Even farmers, labourers or rural landowners, who are involved in agricultural activities, can be net food buyers and negatively affected by higher prices. Moreover, when rural incomes are strongly interlinked through multiplier effects, ${ }^{49}$ food price drawbacks might spill over to net food sellers and leave even them worse off. ${ }^{50}$ However, once transmitted to producers, higher food prices also stimulate agricultural production. In the medium term, they can thus work to the benefit of the rural community by increasing agricultural employment and generating opportunities to earn an income up the value chain. However, the example of South Sudan shows that when agricultural productivity and market integration are low, a number of farming populations may not benefit from rising prices of locally produced food.

Food prices play a key role also for dietary diversity. Even for smallholder farmers who cover most of their dietary energy from subsistence production, purchased foods can critically contribute to the variety and quality of their diets. ${ }^{51}$ Costs tend to rise with dietary quality, ${ }^{\mathbf{5 2}}$ and a common strategy for coping with reduced purchasing power is to shift dietary patterns towards cheaper food. As a result, nutrient intake is compromised in the wake of surging prices. This coping strategy seems to have been used during the global food crisis (Box 10).
A complex interplay between the nature and magnitude of food price changes, food availability, and the nutrient content of substitutes will determine the impact of rising prices on nutrition. The effect does not, however, take place uniformly. Households in low-income countries are prone to being disproportionately affected ${ }^{53}$ as are urban households ${ }^{54}$ and women and children. ${ }^{55}$ Whereas the influence of food price increases on nutrition through quality substitution is immediate, less direct channels are seen in the long term. For example, limiting health expenditure to save money for food can lead to more frequent, prolonged or more severe illness. This has negative implications for the body's uptake of essential nutrients. ${ }^{56}$

\section{Unemployment and loss of income and wages} World and domestic price adjustments, such as those described so far, bring about complex responses in the real economy. These responses from the supply and aggregate-demand sides will generate a number of "quantity" adjustments, including in employment and other areas, that can in turn trigger additional economy-wide effects, including in domestic prices and income.

For commodity-dependent countries, sluggish economic activity as a result of falling commodity prices can lead to unemployment, loss of wages and, consequently, loss of incomes (Figure 29). ${ }^{57}$ And unemployment and loss of income are significantly related to food insecurity for the general population. ${ }^{\mathbf{5 8}}$

For example, the declining economic and negative growth observed in Latin America and the Caribbean during 2012-2016 was largely associated with marked declines in commodity prices, mainly affecting South America. ${ }^{59}$ The urban unemployment rate reached 8.9 percent in 2016, representing an increase of 1.6 percentage points from 2015 . The declining GDP and the rise in unemployment resulted in lower wages or other forms of household incomes. After several years of marked reductions in poverty, the number of poor people rose from 166 million to 175 million between 2013 and 2015, increasing from 28.1 percent to 29.2 percent of the population. 
The case of Colombia illustrates the effects of an economic slowdown on the affordability of food via the described transmission channels.

Falling international prices for Colombia's export commodities, particularly crude oil, led to reduced export earnings and declining reserves in United States dollars, triggering a devaluation of the Colombian peso (COP) against the United States dollar (USD) - see Figure 30 .

Between 2012 and 2017, GDP per capita growth plummeted, along with significant current account imbalances and local currency depreciation. At the same time, household income stayed put when expressed in real terms, while inflation rose steadily up to 2016 (see table below).
To make the impact of this economic slowdown on the affordability of food more tangible, it is helpful to look at the cost of a basic plate of food; for example, through the "Counting the beans" index developed by WFP, which provides a cross-country comparison of a stew made of beans or other pulses, paired with a carbohydrate staple that matches local preferences.' The building block of the index is the meal-to-income ratio, which is the cost of a stew of beans as a share of daily earnings. The effect of the economic slowdown on the affordability of food is obvious in the Colombian case: in 2016, every Colombian had to allocate on average three percent of their daily income to afford such a basic plate of food, which is more than the yearly allocation in the 2012-2015 period.

\section{MEAL-TO-INCOME IN COLOMBIA DURING AN ECONOMIC SLOWDOWN}

\begin{tabular}{|c|c|c|c|c|c|c|c|c|c|}
\hline Colombia & & & & 2012 & 2013 & 2014 & 2015 & 2016 & 2017 \\
\hline Slowdown & $\begin{array}{l}\text { GDP per } \\
\text { capita } \\
\text { growth }\end{array}$ & (a) & (annual \%) & 2.99 & 3.85 & 3.41 & 2.12 & 1.15 & 0.91 \\
\hline \multirow{6}{*}{$\begin{array}{l}\text { Transmission } \\
\text { channels }\end{array}$} & $\begin{array}{l}\text { Current } \\
\text { account } \\
\text { balance }\end{array}$ & (a) & (million, in USD) & -11.366 & -12.504 & -19.768 & -18.586 & -12.129 & -10.359 \\
\hline & \multirow{2}{*}{$\begin{array}{l}\text { Exchange } \\
\text { rate } \\
\text { COP/USD* }\end{array}$} & (a) & Nominal & 1.797 & 1.869 & 2.002 & 2.742 & 3.054 & 2.951 \\
\hline & & & Real & 2.65 & 3.29 & 3.48 & 3.77 & 4.24 & 5.21 \\
\hline & \multirow{2}{*}{$\begin{array}{l}\text { Income } \\
\text { (in COP*) }\end{array}$} & (b) & Nominal & 30.596 & 32.683 & 34.675 & 34.837 & 37.078 & 39.229 \\
\hline & & & Real & 28.677 & 30.027 & 30.960 & 29.626 & 29.328 & 29.746 \\
\hline & Prices & & Inflation (annual \%) & 3.17 & 2.02 & 2.9 & 4.99 & 7.51 & 4.31 \\
\hline \multirow{3}{*}{$\begin{array}{l}\text { Cost of } \\
\text { basic food }\end{array}$} & \multirow{3}{*}{$\begin{array}{l}\text { Stew of } \\
\text { beans } \\
\text { (in COP) }\end{array}$} & (c) & Nominal & 892 & 756 & 792 & 1.009 & 1.117 & 965 \\
\hline & & & Real & 836 & 694 & 707 & 858 & 883 & 731 \\
\hline & & & Meal-to-income (\%) & 2.91 & 2.31 & 2.28 & 2.9 & 3.01 & 2.46 \\
\hline
\end{tabular}

NOTES: *COP is Colombian peso and COP/USD refers the amount of Colombian peso for 1 USD.

SOURCES: (a) World Bank. 2019. World Development Indicators. In World Bank DataBank [online]. Washington, DC [Cited 10 February 2019]. https://databank.worldbank.org; (b) IL0. 2019. Data collection on wages and income. In: International Labour Organization [online]. Geneva, Switzerland. [Cited 6 May 2019] https://www.ilo.org/travail/ areasofwork/wages-and-income/WCMS_142568/lang-en/index.htm; and (c) WFP calculations based on WFP. 2019. Economic Analysis. In: VAM - Food security analysis [online]. Rome. [Cited 13 May 2019]. http://dataviz.vam.wfp.org/economic_explorer/prices and FAO. 2019. GIEWS FPMA Tool - monitoring and analysis of food prices. In: FAO [online]. Rome. [Cited 13 May 2019]. http://www.fao.org/giews/food-prices/tool/public/\#/home and NUMBE0. 2019. Prices by country. In: NUMBEO [online]. [Cited 13 May 2019]. https://www.numbeo.com/cost-of-living/prices_by_country.jsp 

The pass-through effects on unemployment and income will vary from country to country depending on what sectors are producing the primary commodities upon which the country is dependent. For example, the oil and diamonds sectors typically create little employment and are weakly linked with the rest of the economy. On the other hand, in agriculture, particularly where export crops are grown by smallholder producers, the impacts can be more widely spread.

Sharp and declining commodity prices may, through reduced incomes, force households to adopt coping strategies that do not necessarily improve food security and nutrition.

\section{Agricultural employment and smallholder food producers}

The impacts of economic slowdowns and downturns can be felt particularly hard in agriculture, both because of what happens within the sector and because of urban-rural linkages. These impacts can be especially harmful to countries lagging behind in terms of economic development and transformation.

The levels of structural and rural transformation of the economies (i.e. the relative levels of dependence on agriculture, degree of agricultural and non-farm diversification, commercialization and productivity), will determine the extent to which economies are capable of coping with the challenges. The extent to which rural-urban linkages weaken as the economy deteriorates will determine the impacts on agricultural and rural off-farm employment and the welfare of smallholder food producers.

The impacts on agriculture can be particularly significant in low-income countries.

The agricultural sector accounts for substantial shares of employment and output in these countries. In 2017, agricultural employment accounted for 68 percent of total employment, and agricultural output accounted for about 26 percent of GDP in low-income countries. ${ }^{60}$

More generally, as employment, wages and household income fall, particularly in urban areas, there will likely be less demand for agricultural production from rural areas. ${ }^{61}$ Shrinking employment opportunities, including those for rural migrants, result in lower remittances from urban areas and more limited farm investments in rural space.

Among the four dimensions of food security - availability, access, utilization and stability access is the principal channel between economic shocks and food security and nutrition, mainly through two pillars of availability (supply through the market or home-production) and affordability (household income from farm and non-farm activities), both of which are directly related to agricultural income and non-farm employment. ${ }^{62}$

Downturns and price volatility can significantly undermine the livelihoods and income of small-scale food producers, agricultural labourers and the rural poor, in particular those who are net food buyers, forcing them to reduce their consumption in quantity and quality. ${ }^{63}$ Conversely, in some circumstances price spikes might be beneficial for farmers, as, due to increased prices, they have a higher incentive to produce crops. Often, food producers cope with the impacts of economic shocks by focusing their production and consumption of food on staple crops. While doing so allows them to sustain dietary energy intake, it might lead to a deterioration, in dietary diversity. In other words, improving their productivity and the availability of cash income along with nutrition-sensitive behavioural change are critical for them to access higher quality and more diversified diets. Broad-based income growth, grounded on a diversified set of economic activities, including off-farm activities, can bring shifts in nutrition towards balanced dietary patterns.

The impacts of economic slowdowns on food security and nutrition are demonstrated in Haiti, Nepal and the Niger. Amid a global financial crisis coupled with high food prices, households' food security, as measured by dietary diversity, reduced by 5 percent in Nepal, 8 percent in the Niger, and 23 percent in Haiti due to increased food prices. ${ }^{64}$ In the Indian Himalayas, economic slowdown coupled with natural resource depletion and climate change 
negatively impacted on food production and employment opportunities. This resulted in increased threats to food security due to lower purchasing power. ${ }^{65}$

Recent research on the effects of export-led agricultural growth on agricultural labour shows that high-value export sectors create formal employment opportunities in rural areas and can transform the low-productivity smallholder based labour market into a high-productivity modern agro-industrial sector, thereby fostering rural transformation. ${ }^{66}$ When the agro-industry and the smallholder sector are spatially close to each other, direct investment and consumption linkages can lead to increased incomes and non-farm employment, ${ }^{67}$ which improve household capacity to deal with risks including those caused by economic slowdowns and downturns. The ultimate effects of slowdowns and downturns on households depend on whether they are global, regional or national. Whereas a global downturn may stall the overall rural transformation process by setting back the direct and spillover effects of export sectors on labour markets (and hence livelihoods), a regional or national economic slowdown or downturn could potentially be weathered if countries are sufficiently open to international trade. ${ }^{68}$

\section{Health and social intersectoral effects}

Cuts to health and social sector spending precipitated by economic slowdowns or downturns can have negative impacts on food security and nutrition, particularly in high commodity-dependent countries with potentially lifelong and intergenerational implications for health and development (Figure 29).

Social sector expenditure - comprising health, education and welfare/social protection spending - are core pillars for promoting health, well-being and health equity in current and future generations. ${ }^{69}$ Within the health sector, the universal health coverage (UHC) approach has demonstrated positive impacts on population health and health equity. ${ }^{70}$ Similarly, education and social welfare policies have demonstrable impacts on health and well-being through nutrition pathways such as improved feeding practices. ${ }^{71}$

By ensuring universal health coverage and providing social safety nets, government spending on these essential services contribute to poverty reduction and improving population health, which in turn reinforce food security and nutrition. ${ }^{72}$ However, economic slowdowns and downturns caused by unfavourable commodity price shocks can drain fiscal revenues and have implications for public budgets in commodity-dependent countries, which are not all in a position to counteract these changes.

Cuts in health spending could affect nutrition through reduced provision of, or access to, quality essential services for infant, young child and maternal nutrition mainly delivered through the health system. Reductions in other areas of social spending could impact directly or indirectly on nutrition due to a deteriorating health environment, increasing the risk of infectious diseases that can exacerbate malnutrition, or due to reduced provisions for social protection such as school feeding, cash or food vouchers.

Despite the global recession and slow economic growth experienced over the past decade, it has been observed that government fiscal capacity, as measured by the share of overall government spending in GDP, had grown across all groups of countries. ${ }^{73}$ However, allocations from fiscal space to essential social expenditure overall have been under pressure since 2010, after an initial period of expansion following the economic crisis of $2008-2009 .{ }^{74}$

Public health expenditure as a percentage of total government expenditure, while increasing in some country groupings, has decreased in low-income countries overall from 7.9 percent in 2000 to 6.8 percent in 2016. In high commodity-dependent countries, the decrease has been even greater. ${ }^{75}$ Health expenditure as a percentage of total government expenditure in high commodity-dependent countries during the 2008-2015 period contracted by 1.3 percent for low-income countries (compared with an increase for this specific period in other low-income countries), by 0.6 percentage 


\begin{tabular}{|c|c|c|c|c|c|c|c|c|c|c|c|c|c|c|c|c|c|c|}
\hline \multirow[b]{3}{*}{$\begin{array}{l}\text { Country } \\
\text { income } \\
\text { group }\end{array}$} & \multicolumn{8}{|c|}{$\begin{array}{l}\text { Public spending on health as a percent } \\
\text { of general government spending }(\%)^{* *}\end{array}$} & \multicolumn{8}{|c|}{$\begin{array}{l}\text { Proportion of total government spending } \\
\text { on essential services (education) } \\
\qquad(\%)^{* * *}\end{array}$} & \multirow{2}{*}{\multicolumn{2}{|c|}{$\begin{array}{c}\text { UHC essential } \\
\text { service coverage } \\
(\%)^{* * * *} \\
\text { High } \\
\text { commodity-dependen } \\
\text { countries }\end{array}$}} \\
\hline & \multicolumn{4}{|c|}{$\begin{array}{c}\text { High } \\
\text { commodity-dependent countries }\end{array}$} & \multicolumn{4}{|c|}{ All other countries } & \multicolumn{4}{|c|}{$\begin{array}{c}\text { High } \\
\text { commodity-dependent countries }\end{array}$} & \multicolumn{4}{|c|}{ All other countries } & & \\
\hline & $n$ & 2008 & 2015 & $\begin{array}{c}\text { Change } \\
(\%)\end{array}$ & $\mathbf{n}$ & 2008 & 2015 & $\underset{(\%)}{\text { Change }}$ & $\mathbf{n}$ & $\begin{array}{c}2008 \\
(2007-10)\end{array}$ & 2015 & $\underset{(\%)}{\text { Change }}$ & n & $\begin{array}{c}2008 \\
(2007-10)\end{array}$ & $\begin{array}{c}2015 \\
(2011-15)\end{array}$ & $\begin{array}{c}\text { Change } \\
(\%)\end{array}$ & n & 2015 \\
\hline Low & 18 & 10.1 & 8.8 & -1.3 & 16 & 15.9 & 17.1 & 1.2 & 14 & 16.0 & 15.7 & -0.3 & 16 & 15.9 & 17.1 & 1.2 & 19 & 40 \\
\hline $\begin{array}{l}\text { Lower- } \\
\text { middle }\end{array}$ & 11 & 9.7 & 9.1 & -0.6 & 23 & 17.3 & 17.5 & 0.2 & 6 & 14.9 & 12.6 & -2.3 & 22 & 17.3 & 17.5 & 0.2 & 10 & 49 \\
\hline $\begin{array}{l}\text { Upper- } \\
\text { middle }\end{array}$ & 13 & 11.9 & 11.6 & -0.3 & 32 & 15.3 & 15.4 & 0.1 & 7 & 16.3 & 15.0 & -1.3 & 31 & 15.3 & 15.4 & 0.1 & 12 & 65 \\
\hline High* & 2 & 10.9 & 13.9 & 3.0 & 45 & 12.9 & 13.0 & 0.1 & 1 & 11.0 & 10.4 & -0.6 & 48 & 12.9 & 13.0 & 0.1 & 1 & 68 \\
\hline Total & 44 & & & & 116 & & & & 28 & & & & 117 & & & & 42 & \\
\hline
\end{tabular}

NOTES: * For the high-income country group, among high commodity-import- and commodity-export-dependent countries, two countries counted in food and fuel group (Seychelles and Palau) and one country counted in food group (Palau). UHC refers to universal health coverage.

SOURCES: ** WHO. 2017. Global Health Observatory (GHO). In: World Health Organization [online]. Geneva, Switzerland. [Cited 2 May 2019]. http://apps.who.int/gho/data/node.imr.PREVANEMIA?lang=en); *** UN. 2019. SDG Indicators. In: United Nations - Sustainable Development Goals [online]. New York, USA. [Cited 6 May 2019] https://unstats.un.org/sdgs/indicators/database; ${ }^{* * * *}$ WHO. 2018. World health statistics 2018: monitoring health for the SDGs. Geneva, Switzerland. 
points for lower-middle-income countries, and by 0.3 percent percentage points for upper-middle-income countries (Table 10). Decreased public health expenditure coupled with low rates of expenditure and reductions in other essential social expenditure have health repercussions through impaired food security and nutrition and other impact pathways, in particular for poorer populations.

Reduced health spending affects the quality and effectiveness of health services, for example through less frequent service provision, shortages of medication and equipment or supplies, and reduced staff numbers and lower staff morale. This can impact nutrition directly through reduced micronutrient supplementation, breastfeeding support and other essential nutrition actions for mothers, infants and young children; and indirectly through reduced services affecting family planning, antenatal care and interventions to prevent or control infectious diseases or diet-related non-communicable diseases. ${ }^{76}$ During economic crises, populations tend to switch from private to public services, when funding and services are already under pressure. ${ }^{77}$ Moreover, user fees are often introduced or increased, which can lead to delays in seeking health care and ultimately to poorer health outcomes. ${ }^{78}$ These user fees can also drive people into poverty, ${ }^{79}$ limiting household budgets for needed food.

Similarly, reduced government budgets can affect other important social expenditures, including for education (Table 10). Education expenditures for high commodity-dependent countries decreased as a percentage of total government expenditure between 2008 and 2015 - by 0.3 percentage points and 2.0 percentage points in low-income and lower-middle-income countries, respectively. Reduced education expenditures is a problem in its own right, but it also means less investment in school infrastructure relevant to health, such as for safe water and sanitation, which affects the risk of infectious disease, ${ }^{\mathbf{8 0}}$ such as diarrhoea, and can exacerbate or be exacerbated by undernutrition. ${ }^{81}$ Governments also struggle to maintain social protection measures during economic slowdowns and downturns, including cash and food transfers, food vouchers and school meals, which are particularly important for food security and nutrition. ${ }^{\mathbf{8 2}}$

In addition, the ways in which families have to cope with economic crises can impact infant and young childcare, including breastfeeding practices. Economic pressures on mothers to work soon after childbirth can reduce their ability to exclusively breastfeed for six months, while pressures on government budgets and private sector employers may undermine maternity provision. Resource constraints can also compromise caregivers' ability to provide optimal care to infants and young children due to increased workload, time pressures or poor health. ${ }^{83}$

\section{How households cope and when they fail}

Households facing a reduction in purchasing power as a result of economic events have to look for ways to cope with these shocks to maintain food security and consumption to the extent possible (Figure 29).

Due to their economy-wide nature, economic slowdowns and downturns pose macroeconomic aggregate shocks affecting multiple households, which are different from idiosyncratic shocks that affect only a single household, such as the illness of a household member. This means that many coping strategies that are used during idiosyncratic shocks are ineffective in the face of such aggregate shocks. ${ }^{84}$

During economic slowdowns and downturns, wages can decline and jobs might be more difficult to find, and consequently households losing their employment might have to take up lower paying jobs, often in the informal sector. In such circumstances, household members normally not involved in salaried activities for example, women and younger members still in school - might need to look for employment. Households may also try to make use of any savings or insurance mechanism at their disposal (Table 11).

However, with increased prices, savings will buy less food than before. Households might find it more difficult to borrow from family members or access informal insurance groups such as village funds, if many households are facing economic 


\section{TABLE 11 \\ COPING STRATEGIES, THEIR AVAILABILITY IN TIMES OF ECONOMIC SLOWDOWNS AND DOWNTURNS AND POSSIBLE NEGÁTIVE EFFECTS}

\begin{tabular}{ll}
\hline Coping strategy & $\begin{array}{l}\text { Availobility in times of economic } \\
\text { slowdowns and downturns }\end{array}$ \\
\hline $\begin{array}{l}\text { Adjusting labour supply } \\
\text { Changing employment }\end{array}$ & $\begin{array}{l}\text { Lower availability and lower wages than } \\
\text { in economically strong situations. } \\
\text { Possibility of increased underemploymen } \\
\text { levels. }\end{array}$ \\
\hline $\begin{array}{l}\text { Taking up of additional } \\
\text { employment (also former } \\
\text { non-employed household } \\
\text { members such as children } \\
\text { and women), outmigration }\end{array}$ & $\begin{array}{l}\text { Lower availability and lower wages than } \\
\text { in economically strong situations. }\end{array}$ \\
$\begin{array}{l}\text { Internal and international migration to } \\
\text { unaffected areas/countries might be an } \\
\text { option, if household can afford it. }\end{array}$
\end{tabular}

Return migration to the village, employment in agriculture
Effective only if labour productivity is high enough and there is significant labour demand.

Increased food prices are an advantage if household can increase agricultural production.
Possible negative effects of applying the coping strategy

Lower wages leading to lower income and potential participation in the informal sector.

Reduction of other activities such as breastfeeding and care work, taking children out of school, with possible negative effects on human capital formation and the intergenerational cycle of malnutrition. Increased work burdens for family members left behind when other family members migrate out.

Loss of labour if there is outmigration.

Reduction of remittances and, potentially, unemployment when labour demand shrinks.

\section{Adjusting disposable income}

Using savings
Less effective when purchasing power weakens.
Depletion of resources (which are the basis of livelihoods) and, as a result, weakened resilience against future shocks.

Depletion of resources, reduction of future earnings potential.

Risk of indebtedness. people sell their assets.

\author{
including land \\ Formal or informal \\ borrowing
}

Selling (productive) assets,
Informal networks might be weakened through aggregate shocks; interest rates might be high for vulnerable households.

Public spending on formal safety nets might be reduced.
Formal public safety nets

Quality of safety net programmes could be affected. Increased food insecurity and malnutrition for the most vulnerable groups if food or cash transfers are reduced.

\begin{tabular}{lll}
\hline $\begin{array}{l}\text { Formal private insurance } \\
\text { schemes }\end{array}$ & $\begin{array}{l}\text { Often no access for most vulnerable } \\
\text { households. }\end{array}$ & None. \\
\hline $\begin{array}{l}\text { Involvement in criminal or } \\
\text { socially unacceptable }\end{array}$ & $\begin{array}{l}\text { Less effective if applied by many } \\
\text { members of the community. }\end{array}$ & $\begin{array}{l}\text { Loss of human dignity and social status in } \\
\text { the community, may face legal prosecution. }\end{array}$
\end{tabular}

prostitution

\section{Adjusting consumption}

Reducing spending on other goods in order to maintain food consumption

Availability not affected. Costs of publicsector health services may increase if budgetary constraints lead to an increase in user fees.

Shifting dietary patterns Availability not affected. towards cheaper foods
Possible reduction of health and education expenditures might have negative long-term effects on health and human capital.

Increased consumption of street foods and shifting towards more starchy foods and away from micronutrient rich vegetables, fruits, meat and dairy products can lead to various forms of malnutrition with negative long-term effects.

Will lead to malnutrition with negative short and long-term effects.

Splits up families.
Reducing number of

household members, by sending away children, for example
Availability not affected.

Difficult, if most households of the social network are affected. 
difficulties at the same time. Also, public spending on safety nets might decrease during economic slowdowns, thereby leaving behind many households in need. ${ }^{85}$

One coping strategy which has been shown in some countries to work well in times of economic slowdowns and downturns is return migration to the village of origin. As food prices rise, farmers benefit from the labour supply of returned migrants and from increased agricultural production, enabling them to better cope with job losses and reduced remittances of affected migrants. ${ }^{86}$ Alternatively, workers might seek job opportunities in other countries, thus increasing the inflow of remittances.

While the availability of coping strategies is restricted for households in general, coping is particularly challenging for vulnerable households, as they are endowed with fewer assets to deplete and often have weaker social networks for support. They are more often forced to take up coping strategies that help in the short term while jeopardizing future earning possibilities and the human capital of the household, such as taking children out of school, possibly leading them into an intergenerational poverty trap. ${ }^{87}$

For example, they may have to sell assets that are essential for their livelihood, such as the last female animals in their livestock, productive tools or seeds, or they may be forced to incur too much debt. The need to change consumption patterns can lead to reduced spending on education and health, or shifts in nutrition away from nutrient-rich foods, such as vegetables or meat, towards more starchy foods. While securing access to sufficient dietary energy in the short term, this behaviour will have negative long-term effects on people's nutrition and health and human capital ${ }^{\mathbf{8 8}}$ as seen during the global food crisis (Box 10).

\subsection{NEXUS BETWEEN ECONOMIC GROWTH, POVERTY, AND FOOD SECURITY AND NUTRITION: THE ROLE OF INEQUALITY}

\section{KEY MESSAGES}

$\Rightarrow$ Economic events will ultimately affect food security and nutrition, depending on extreme poverty levels and the extent to which the poor face exclusion due to different inequalities. However, outcomes may vary from country to country.

$\rightarrow$ While extreme poverty is one of the underlying causes of food insecurity and malnutrition, food-insecure and malnourished people are not always members of the poorest households. Most of the hungry and undernourished populations today live in middle-income countries.

$\rightarrow$ Inequalities are one of the myriad reasons why extreme poverty reduction does not necessarily translate into improved food security and nutrition. Socially excluded and marginalized groups are at increased risk of food insecurity, unhealthy diets, malnutrition in all its forms and poor health outcomes.

$\Rightarrow$ Income inequality is rising in several low- and middle-income countries. Inequalities are also seen in accessing basic services and assets, between and within households. All of this is making it more difficult for poor and marginalized groups to benefit from economic growth.

$\rightarrow$ Inequalities not only prevent the most food-insecure and malnourished people from being helped by economic growth; they also make these people more vulnerable in the face of economic slowdowns and downturns. 


\section{Poverty and socio-economic inequalities also matter}

Economic slowdowns and downturns generate a number of direct and indirect impacts that flow through different transmission channels and challenge food security and nutrition. Many of these impacts can be generalized. They are transmitted through prices and economy-wide responses that would behave in a similar manner in most low- and middle-income countries. Declining commodity prices trigger unambiguous economic effects in high commodity-dependent countries with implications for food security and nutrition.

The final impact on food security and nutrition, however, depends on how many poor people live in the country and the extent to which they face exclusion due to inequalities. On the one hand, economic slowdowns and downturns tend to be correlated with increases in poverty and inequality. On the other hand, poverty, inequalities and marginalization are some of the underlying causes of hunger and malnutrition in all its forms. But the relationships between these factors are not so simple, for a number of reasons.

First, it is not always true that robust economic growth helps to reduce poverty and improve food security and nutrition. ${ }^{89}$ Economic growth, although necessary, may not be sufficient to ensure poverty reduction, food security and nutrition. Many countries have achieved economic growth, but show poor records in terms of poverty alleviation 90 and improvements in food security and nutrition.

Second, poverty, food security and nutrition do not always move in unison. Countries can achieve robust economic growth and poverty reduction, but this does not always translate into improved food security and nutrition. The disconnect has become even more apparent recently, as many countries have made significant progress in reducing poverty but not in improving food security and nutrition indicators. ${ }^{91}$

Third, when poverty reduction does result in increased food security, this does not necessarily mean nutritional status will be improved as well. Poverty and food insecurity is only weakly linked with malnutrition, and there may be other factors at play. For example, stunting in children is not only related to the quality of diet, but also to hygiene, health care and maternal nutrition during pregnancy, among others. High-quality foods might not be evenly distributed among household members or households may not have access to adequate sanitation, safe drinking water and health care.

The next section explores the nexus between economic growth, poverty, ${ }^{92}$ and food security and nutrition. In doing so, it looks at the central role of inequality in shaping the outcomes of food security and nutrition in this nexus. Understanding the relationships is critical if countries are to design targeted policies and programmes to address food insecurity and malnutrition.

A key feature of the 2030 Agenda for Sustainable Development is the recognition of the interconnectedness between the SDGs. Ignoring the nexus between economic growth, poverty, food security and nutrition, and the role inequalities play within this nexus, could push policies and programmes designed to end hunger and malnutrition to miss their mark and fail. Rooting out hunger and malnutrition in all its forms will require an integrated understanding to inform solutions that are not exclusively relevant for SDG 2 (ending hunger and malnutrition in all its forms) but also other SDGs, particularly - albeit not exclusively - SDG 1 (ending poverty in all of its manifestations), ${ }^{93}$ SDG 8 (promoting inclusive and sustainable economic growth), and SDG 10 (reducing inequalities).

\section{Disentangling the nexus}

To better understand the nexus between economic growth, poverty, and food security and nutrition, it is important to recognize that these are multidimensional concepts that are multidirectional in their relationship to one another (e.g. hunger is a result of poverty, but hunger itself is a cause of poverty). Evidence also indicates that stunting contributes to intergenerational transmission of poverty and deprivation, which often explains intergenerational effects on linear growth of children. ${ }^{94}$ 
Poverty, food security and nutrition are interrelated, but they are also distinct from one another. ${ }^{95}$ They often move together, but they are also different and have unique determinants, so they are not always correlated. For example, poverty can be on the decline, while progress in reducing food insecurity and malnutrition stagnates or even reverses course.

Unpacking the nexus between economic growth, poverty, food security and nutrition is complex. Therefore, this section will look at three separate linkages and relationships. First, evidence on the links between economic growth and poverty reduction will be reviewed, followed by the links between economic growth and food security and nutrition, and then the links between poverty and food security and nutrition.

\section{Economic growth and poverty reduction}

Sustained economic growth is one of the most critical factors in alleviating poverty. Numerous cross-country studies and statistical evidence confirm that the main determinant of poverty reduction is the pace of economic growth. ${ }^{96}$ There is clear evidence for the positive association, but the magnitude or strength of the effect varies across countries.

For example, one study found that growth in average incomes as measured by GDP per capita explained approximately half of the variations in short-run changes of poverty level. ${ }^{97}$ Another study on 14 countries between 1990 and 2003 found that a one percent increase in GDP per capita reduced poverty by 1.7 percent. ${ }^{98}$ For some countries such as Viet Nam, the reduction was spectacular - a halving of the poverty rate from 58 percent to 29 percent, or almost 8 percent a year. Poverty rates have declined between 3 percent and 6 percent per year in El Salvador, Ghana, India, Tunisia and Uganda.

World price shocks and macroeconomic adjustments affecting economic growth directly, such as those described in Section 2.2, can potentially affect poverty. For countries with high primary commodity dependence, the degree of macroeconomic stability, in particular avoiding inflationary shocks, is a critical factor. The sectoral composition of economic growth can also explain in some cases why given rates of economic growth can lead to different rates of poverty reduction.

The rate at which poverty shrinks as growth accelerates differs from country to country, given the initial level of income inequality in the country and changes in income inequality over time. ${ }^{99}$ For example, Senegal and Burkina Faso had similar levels of economic growth 2.2 percent per capita per year - over a similar timeframe. ${ }^{100}$ But poverty declined by 2.5 percent annually in Senegal and by just 1.8 percent in Burkina Faso. Senegal made more progress because it had less inequality as a result of pro-poor growth policies introduced in the 1990s. Another study found that for countries where income inequality was very high, a 1 percent increase in average household income levels had a much lower impact on poverty (0.6 percent reduction) than it did in countries where inequality was low (4.3 percent). ${ }^{101}$

By comparison, between 2001 and 2017, Mali experienced limited economic growth with an average GDP per capita growth of 1.9 percent. ${ }^{102}$ However, the country still made significant strides in reducing poverty and improving social indicators. An important part of Mali's success in poverty reduction can be attributed to its remarkable performance in reducing inequality. The country's Gini coefficient has fallen from 39.9 in 2001 to 33 in 2011, making Mali's growth performance an inclusive one. More importantly, calculations by the World Bank ${ }^{103}$ show that 82 percent of the poverty reduction performance of the country between 2001 and 2010 can be attributed to better distribution of consumption among households - the remaining 18 percent seems to be mostly explained by the average increase in consumption. Of course, these gains have been threatened by the conflict in the country that erupted in 2012.

In addition to the initial level of income inequality, the pattern of economic growth and different initial conditions in human development reflecting a number of other inequalities beyond income also factor in to determine whether economic growth translates into poverty reduction (Box 13).

Income inequality can also reduce the impact of future economic growth on poverty reduction. ${ }^{104}$ " 
BOX 13

EXPLAINING POVERTY AND FOOD SECURITY AND NUTRITION TRENDS IN CHINA AND INDIA: THE PATIERN OF GROWTH AND INITIAL INEQUALITIES

China and India have enjoyed significant economic growth in recent years. Between 1990 and 2017, the two countries had an average GDP per capita growth rate of 8.6 percent and 4.5 percent, respectively. ${ }^{1}$ However, the effects of growth within each country have been different.

The figure below shows that in both countries the increase in GDP per capita has been accompanied by poverty reduction. China's poverty rate declined from 88 percent in 1981 to 0.7 percent in 2015 . In comparison, India's poverty reduction seems relatively more modest ${ }^{1}$ - moving from 48.9 percent in 1987 to 21.2 percent in 2011 , or to 13.4 percent in 2015 if another World Bank source is used. ${ }^{2}$ For the period 1999-2005, the income elasticity of poverty in China was estimated at 1.51. This means that a 1 percent increase in GDP per capita was associated with poverty reduction rates of 1.51 percent. During the same period, India had an income elasticity of poverty of only 0.4 .

Regarding hunger and malnutrition, the $\mathrm{PoU}$ decreased from 15.9 percent in 2002-2004 to 8.8 percent in 2015-2017 in China, compared with a decrease from 22.2 percent in 2002-2004 to 14.8 percent in 2015-2017 in India. Stunting in children under five years of age fell from 17.8 percent in 2000 to 8.1 percent in 2013 in China. In India, it fell from 54.2 percent to 38.4 percent between 2000 and 2015 , which is still a high prevalence, compared with a global average of 23.2 percent in 2015 . $^{1,3}$

The unique growth patterns and inequality levels in each country may help explain the differences observed in the countries in terms of poverty and food security and nutrition trends:

\section{DECREASING POVERTY HEADCOUNT RATIO AND RAISING GDP PER CAPITA IN CHINA AND INDIA (1981-2015)}

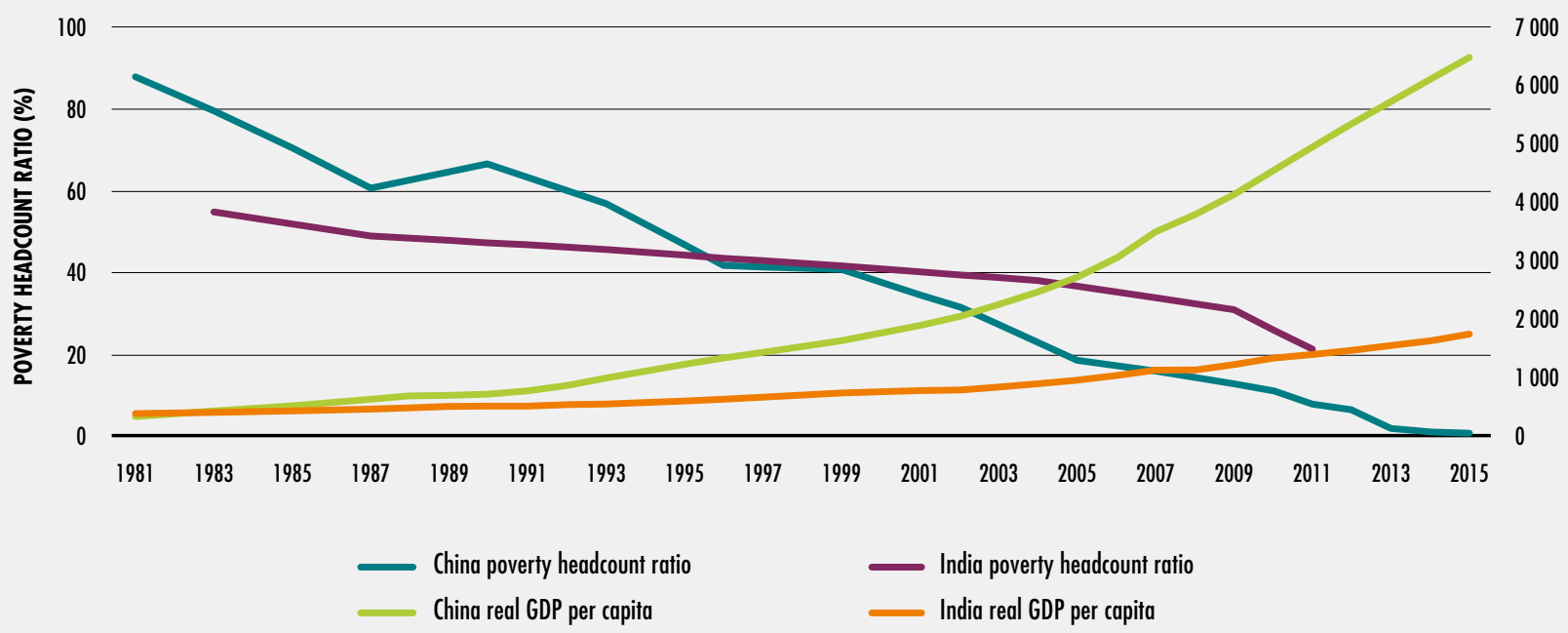

NOTES: Poverty headcount ratio in China and India (left axis) refers to USD 1.90 a day (2011 PPP); GDP per capita (right axis) is expressed in constant USD 2010. SOURCE: FAO elaboration based on World Bank. 2019. PovcalNet: an online analysis fool for global poverty monitoring. In: World Bank [online]. Washington, DC. [Cited 9 February 2019]. http://iresearch.worldbank.org/PovcalNet/home.aspx. 
a. The pattern of economic growth in China, especially in the 1980s, shows that the primary sector, where most of the poor derive their livelihoods, was one of the most dynamic sectors behind GDP growth. On the other hand, in India the rate of growth has been higher in the industrial and services sectors than in agriculture. ${ }^{4}$

b. The responsiveness of poverty reduction to growth is generally higher when initial inequality is lower. This seems to have been the case for income inequality in China, where in 1983 the Gini coefficient was 28.3. In India, the Gini coefficient that year was $31.5 .^{5}$ At the same time, land was much more equally allocated in China than in India during the 1980s. ${ }^{6}$ Furthermore, the Gini coefficient for urban and rural areas in 1983-84 was 24.7 and 18.5, respectively, in China, compared with 30.0 in urban areas and 33.3 in rural areas in India. ${ }^{7}$

c. Finally, different initial conditions in human development also played an important role. Health and education standards were much better in China in the 1980s than they were in India. ${ }^{8}$ In 1980, China had 2.2 hospital beds per 1000 people compared with 0.8 in India. This number increased to 3.8 in 2011, while it decreased to 0.7 in India. Differences in literacy rates were also important. Only in 2011 India was able to reach the levels of literacy that China had in 1982, amounting to more than 65 percent. $^{9}$

' World Bank. 2019. World Development Indicators. In: World Bank DataBank [online]. Washington, DC. [Cited 10 February 2019]. https://databank.worldbank.org

${ }^{2}$ World Bank. 2019. Poverty \& Equity Brief - India. April 2019 [online]. Washington, DC. [Cited 16 May 2019]. https://databank.worldbank.org/data/download/poverty/33EF03BB9722-4AE2-ABC7-AA2972D68AFE/Global_POVEQ_IND.pdf

${ }^{3}$ FA0. 2019. FAOSTAT. In: FAO [online]. Rome. [Cited 8 February 2019]. www.fao.org/faostat/en/\#home; FAO, IFAD, UNICEF, WFP and WHO. 2018. The State of Food Security and Nutrition in the World 2018. Building climate resilience for food security and nutrition. Rome, FAO.

${ }^{4}$ Agricultural growth is three times as effective in reducing extreme poverty as growth in other sectors. L. Christiaensen, L. Demery and J. Kuhl. 2011. The (evolving) role of agriculture in poverty reduction - an empirical perspective. Journal of Development Economics, 96 (2): 239-254; M. Ravallion. 2009. A comparative perspective on poverty reduction in Brazil, China and India. Policy Research Working Paper 5080 [online]. Washington, DC, World Bank. [Cited 29 April 2019]. http://documents.worldbank.org/curated/ en/952341468218101551/pdf/WPS5080.pdf; I.S. Gill, A. Revenga and C. Zeballos. 2016. Grow, invest, insure: a game plan to end extreme poverty by 2030. Policy Research Working Paper 7892 [online]. Washington, DC, World Bank. [Cited 29 April 2019]. http://documents.worldbank.org/curated/en/924111479240600559/pdf/WPS7892.pdf

${ }^{5}$ United Nations University-World Institute for Development (UNU-WIDER). 2019. UNU-WIDER, World Income Inequality Database (WIID4). In: UNU-WIDER [online]. Helsinki [Cited 20 March 2019]. https://www.wider.unu.edu/database/world-income-inequality-database-wiid4

${ }^{6} \mathrm{M}$. Ravallion. 2009. A comparative perspective on poverty reduction in Brazil, China and India. Policy Research Working Paper 5080 [online]. Washington, DC, World Bank. [Cited 29 April 2019]. http://documents.worldbank.org/curated/en/952341468218101551/pdf/WPS5080.pdf

${ }^{7}$ World Bank. 2019. PovcalNet: an online analysis tool for global poverty monitoring. In: The World Bank [online]. Washington, DC. [Cited 9 February 2019]. http://iresearch.worldbank.org/PovcalNet/home.aspx

${ }^{8}$ I.S. Gill, A. Revenga and C. Zeballos. 2016. Grow, invest, insure: a game plan to end extreme poverty by 2030. Policy Research Working Paper 7892 [online]. Washington, DC, World Bank. [Cited 29 April 2019]. http://documents.worldbank.org/curated/en/924111479240600559/pdf/WPS7892.pdf

${ }^{9}$ World Bank. 2019. PovcalNet: an online analysis tool for global poverty monitoring. In The World Bank [online]. Washington, DC [Cited 9 February 2019]. http://iresearch.worldbank.org/PovcalNet/home.aspx 

as measured by the Gini coefficient from 0.55 to 0.45 , would cause poverty to drop by more than 15 percentage points in ten years. However, it would take 30 years to achieve the same reduction in poverty if inequality remained unchanged. ${ }^{105}$

\section{Economic growth, food security and nutrition} The relationship between economic growth and food security and nutrition has important policy implications. These involve pro-poor growth strategies to reduce hunger and child malnutrition, as well as the need for direct food security and nutritional investments. By extension, the implications also affect how limited financial resources are competitively allocated between different types of investments.

\section{How does economic growth contribute to nutrition?}

The relationship between increased national income (GDP per capita) and nutrition works through two complementary channels. When economic growth stimulates average incomes, populations may spend a larger part of their incomes on healthy, nutrition-relevant goods and services. Increased GDP may also boost state provision of nutrition-relevant services as well as social and health infrastructure - if governments use newly generated tax revenues to invest in them.

The role of economic growth in reducing child undernutrition remains a highly debated issue. For example, there is extensive empirical evidence that economic growth and child stunting are negatively correlated (i.e. the higher the economic growth, the lower the child stunting). However, evidence on the magnitude of this relationship varies across studies. ${ }^{106}$ One study finds a prominent role for economic growth, in which a 10 percent increase in GDP per capita would lead to a 6 percent reduction in child stunting prevalence. ${ }^{107}$ While this is in line with the findings of several studies, ${ }^{108}$ others find that child stunting would be decreased even more, for example by 7.3 percent. ${ }^{109}$ In contrast, still others find the relationship to be much weaker or even nonexistent. ${ }^{110}$
The relationships between economic growth and child stunting can also differ by region. For example, cross-country time series data suggest that the relationship is weaker in sub-Saharan Africa than in other regions."'1 For Africa as a whole, other variables such as maternal education, socio-economic status and poor maternal nutrition are more important in explaining the slow progress in reducing child undernutrition. ${ }^{112}$

Not only can economic growth affect child stunting, but the reverse may occur. ${ }^{113}$ A new study finds that a 10 percent increase in GDP per capita would reduce stunting prevalence by 2.7 percent. However, the reverse causality impacts of stunting on current growth estimate that a one percentage point increase in stunting prevalence would result in a 0.4 percent decrease in current GDP per capita. The study's back-of-the-envelope calculation suggests that stunting costs on average about 13.5 percent of GDP per capita in developing countries. ${ }^{114}$ If these recent findings on the negative reverse causality are correct, it implies that the results of earlier studies could be biased downwards and overstate the actual impact of economic growth towards child stunting reductions.

Despite the debate on the magnitude of effects, it is clear that while economic growth contributes to improvements in child nutrition, it does so only modestly and is not sufficient in many settings to accelerate reductions in child undernutrition. What matters most is addressing other causes of undernutrition, including access to nutritious foods for a healthy diet, improvement in women's status and education, feeding and care practices and quality health services. This requires implementation of nutrition-specific policies and interventions with a focus on vulnerable populations, regardless of whether there is economic growth. ${ }^{115}$

As for obesity and overweight, their relationship with economic growth is less clear-cut due to the paucity of research. However, evidence does suggest that the relationship varies depending on the income setting of the country. For example, a study using data from 175 countries found a positive relationship between body weight and GDP per capita growth. Seventy-two countries 
where GDP was below USD 3000 showed a significantly positive linear relationship between the body mass index (BMI) and GDP, whereas 102 countries where GDP was above USD 3000 showed no significant relationship between the two. ${ }^{116}$ Clearly, income growth alone does not necessarily guarantee healthier diets and improved nutritional status; other policies, for example those that create healthy food environments and facilitate and promote physically active lives, among others, are also needed.

\section{How does economic growth contribute to food security?}

There is even less empirical evidence on the links between economic growth and food security, partially due to the lack of common food-insecurity measures and data. Empirical analysis is increasingly common, however, given the development of the Food Insecurity Experience Scale (FIES) by FAO and with the newly available FIES panel data (for more details about FIES see Part 1). Recent studies provide consistent results and an important first indication of the relationship, although evidence is not conclusive and more research is required.

The results generally confirm that with increases in economic growth, there are concurrent declines in severe food insecurity. However, similar to child stunting, the magnitude of this relationship varies across countries. In this case, it varies by income level and the degree of income inequality of the country. ${ }^{117}$

One recent study for Latin America and the Caribbean finds that a 10 percent increase in a country's GDP per capita lowered the likelihood of moderate and severe food insecurity by 11.5 percentage points and severe food insecurity by 9.7 percentage points. ${ }^{118}$ Another study of 134 countries also finds the same negative relationship, but with much smaller effects and with statistically significant results only for low- and high-income countries. ${ }^{119}$

To complement these two studies, a new FAO analysis was conducted for this report, using newly available cross-country FIES panel data for 75 low- and middle-income countries. The results reconfirmed a negative relationship between GDP per capita and severe food insecurity. ${ }^{120}$

An FAO analysis found that the relationship between GDP per capita and undernourishment (as measured by the prevalence) was also negative. However, it was highly nonlinear, meaning that the relationship became progressively weaker at higher levels of development. The most recent data show that the strength of the relationship decreases sharply up to USD 2000 per capita in constant prices, which is within the lower-middle-income category (countries with income of USD 996-3 895 per capita). In other words, economic growth is more effective in reducing the PoU in low-income countries; as the level of a country's GDP per capita rises, the effect weakens. Most of the world's hungry, however, live in middle-income countries (see next section). So the potential contributions of economic growth to ending hunger are weaker than expected.

\section{Poverty reduction and food security and nutrition} It is commonly understood that poverty goes hand in hand with hunger and malnutrition. Poverty is indeed one of the underlying causes of food insecurity and malnutrition. However, they do not always move in unison, and in some cases they diverge from what is expected. Investigating why this is the case is critical for eradicating food insecurity and malnutrition.

The relationship between poverty, food security and nutrition is also bidirectional, meaning that food security and nutrition are both determinants and dimensions of poverty. Food insecurity, poor health and malnutrition are often reasons why households end up in poverty or sink further into it, if they are already poor. ${ }^{121}$

One reason is that poverty, food insecurity and malnutrition are distinct and multifaceted phenomena. ${ }^{122}$ Not all people who are food insecure and malnourished necessarily live in the poorest households. This is especially so when the problems of food insecurity and malnutrition are greater. Additionally, poverty reduction may not necessarily translate into better food security and nutrition due to existing inequalities. 
By definition, extreme poverty is the lack of sufficient income to meet basic dietary needs. It affects the ability of individuals and households to access healthy, nutritious foods that constitute a healthy diet through purchase or production, and is linked to minimal or inadequate access to essential health services.

The World Bank defines extreme poverty as living on less than USD 1.90 per day, which generally reflects the cost of enough dietary energy and other essentials to meet basic needs. This is a very low poverty threshold, as it is estimated based on the average of the national poverty lines of 15 very poor countries, adjusted for inflation using 2011 prices and taking into account differences in prices across countries (i.e. purchasing power parity - PPP). The main purpose is to help obtain a measure of extreme poverty comparable across countries.

Higher levels of extreme poverty as defined by the World Bank are correlated with higher rates of undernourishment as measured by the PoU, and higher rates of child stunting at the country level, with the latter relationship being nonlinear (Figure 31). The correlation coefficient between extreme poverty and undernourishment is 0.68 , and it is 0.62 between extreme poverty and child stunting. This indicates a moderate-to-strong correlation between poverty and these two measures of food security and nutrition.

Poverty explains around half of the observed variation in undernourishment and child stunting (i.e. R-squared of 0.50 and 0.57 for PoU and child stunting, respectively). However, there are also a number of countries where undernourishment and child stunting are higher than predicted by extreme poverty (countries above the line in Figure 31) and countries that have lower levels than predicted by extreme poverty (countries below the line in Figure 31).

Beyond the absolute levels of income or poverty, variability of income is critical and is often one of the main causes of food insecurity. ${ }^{\mathbf{1 2 3}}$ Income variability, even within the same year, can have a significant impact on food access. It is caused by a convergence of factors, such as weather-related shocks, that limit households' ability to smooth consumption over time, rendering access to food, health and nutrition vulnerable to economic shocks.

In addition to income variability, access to food is also conditioned by people's awareness and knowledge of food quality, as well as other factors that can cause significant differences when it comes to malnutrition among members of households at similar levels of poverty. Other factors include diverse consumption and intra-household distribution patterns, dietary habits, climate conditions and cultural factors. ${ }^{\mathbf{2 4}}$ There is also an array of public policies that can significantly affect non-income-based access to food and utilization of food, and access to basic health and social services critical to nutrition, as outlined in the ICN2 Framework for Action. ${ }^{125}$

At the household level, there is clear evidence that low levels of household income and household wealth are associated with different forms of malnutrition. For example, the poorest children are 2.26 times more likely to be stunted than the richest children. However, the extent of the income inequality in stunting varies considerably. For example, there is an elevenfold difference between the richest and the poorest children in Peru, and more than fivefold differences in Bolivia (Plurinational State of), Gabon, Honduras and Jordan. ${ }^{126}$ Other multi-country studies confirm that stunting prevalence is higher in households with lower wealth and income. ${ }^{127}$ Country data from Cambodia, ${ }^{128}$ Colombia, ${ }^{129}$ India, ${ }^{130}$ and Pakistan ${ }^{131}$ find a similar pattern.

While the analysis of selected country microdata also confirms that higher levels of child stunting are found in the poorest households, it also shows that not all stunted children live in the poorest households. In some countries this number can be quite large (Figure 32). For example, a recent study of 30 countries in sub-Saharan Africa found that around 75 percent of underweight women and children were not in the poorest 20 percent of households, and around half were not in the poorest 40 percent of households. ${ }^{132}$ The study also found that a larger share of undernourished people are members of non-poor families in countries with a higher overall incidence of undernutrition. " 


\section{A) RATIO BETWEEN EXTREME POVERTY AND POU}

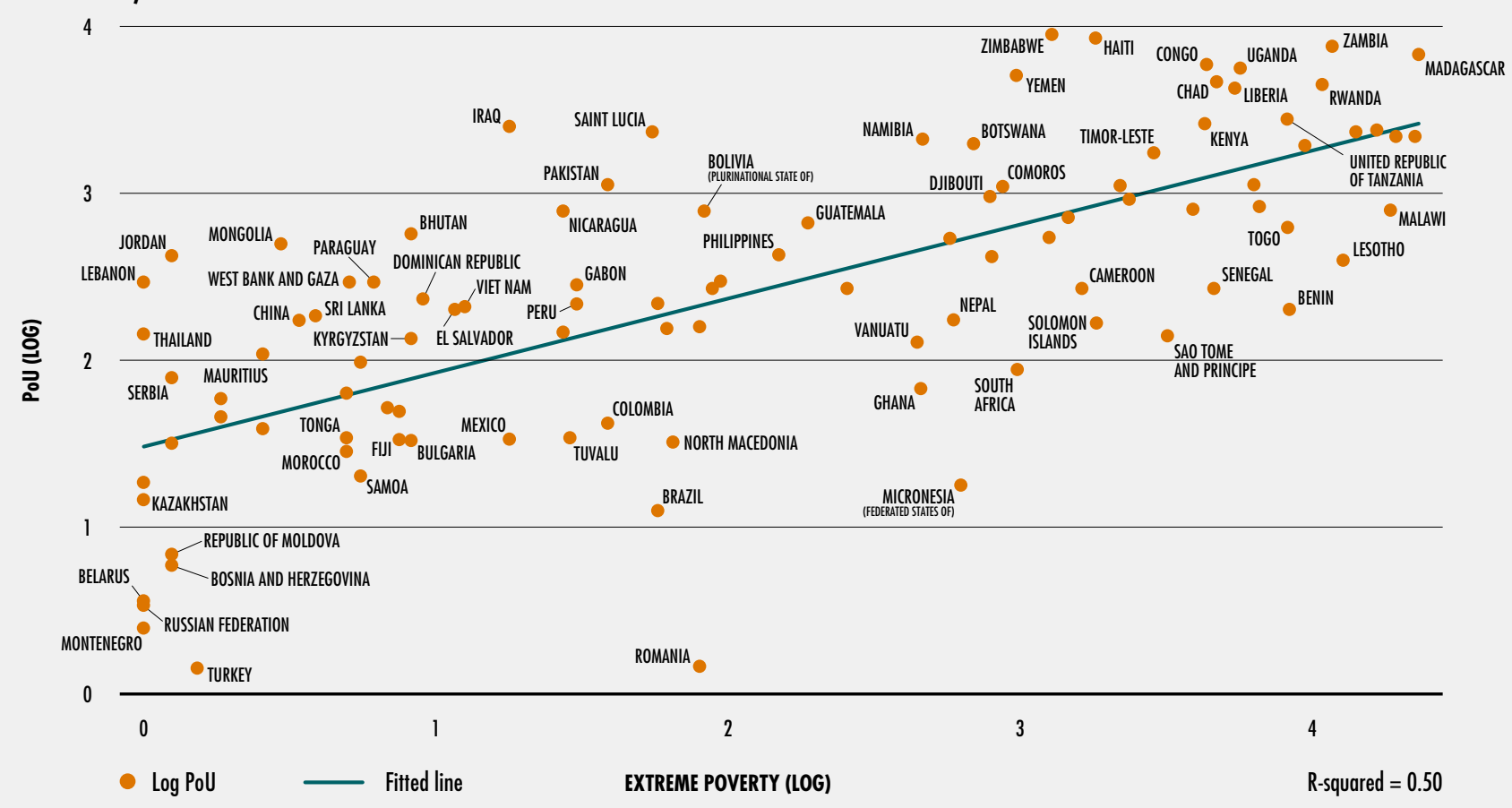

\section{B) RATIO BETWEEN EXTREME POVERTY AND STUNTING PREVALENCE}

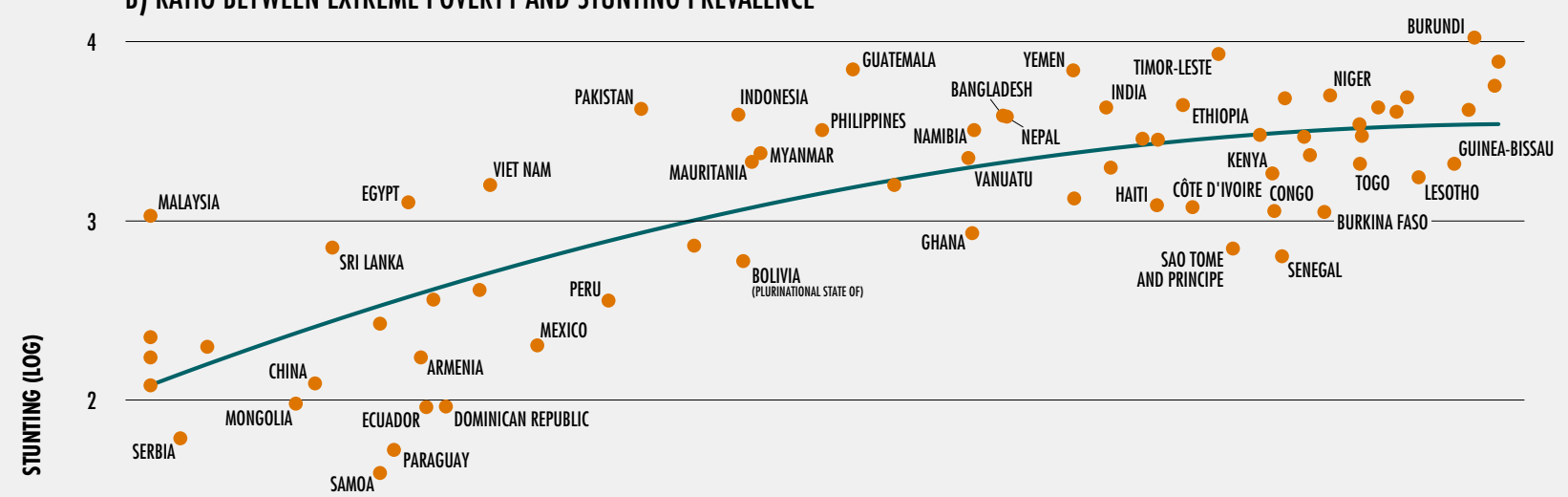

1

\begin{tabular}{lcccc}
\hline 0 & 1 & 2 & 3 & \\
\hline & Log stunting 2018 & Fitted line & EXTREME POVERTY (LOG) & R-squared = 0.57
\end{tabular}

NOTES: Correlation analysis between prevalence of undernourishment and extreme poverty (graph A) and child stunting and extreme poverty (graph B). Extreme poverty is measured by the Poverty Headcount Ratio at USD 1.90 per day; child stunting for children under 5 years of age and prevalence of undernourishment (PoU) are measured in year 2018. Extreme poverty is measured in the latest year available at country level between years 2010-2017. R-squared is 0.50 for the association between extreme poverty and the PoU, and 0.57 for the association between extreme poverty and child stunting. Country names are not reported in the graph for countries that fall inside the 95 percent confidence interval (close to the fitted line), but a list of these countries is provided in Annex 3 . The Former Yugoslav Republic of Macedonia is now officially called North Macedonia. West Bank and Gaza is a territory and follows the World Bank classification. The analysis includes some countries with imputed PoU, see Annex 3 for methodology and list of countries.

SOURCES: For poverty data, World Bank. 2019. World Development Indicators. In: World Bank DataBank [online]. Washington, DC. [Cited 9 May 2019]. https://databank.worldbank.org. For child stunting and PoU, see Annex IA. 


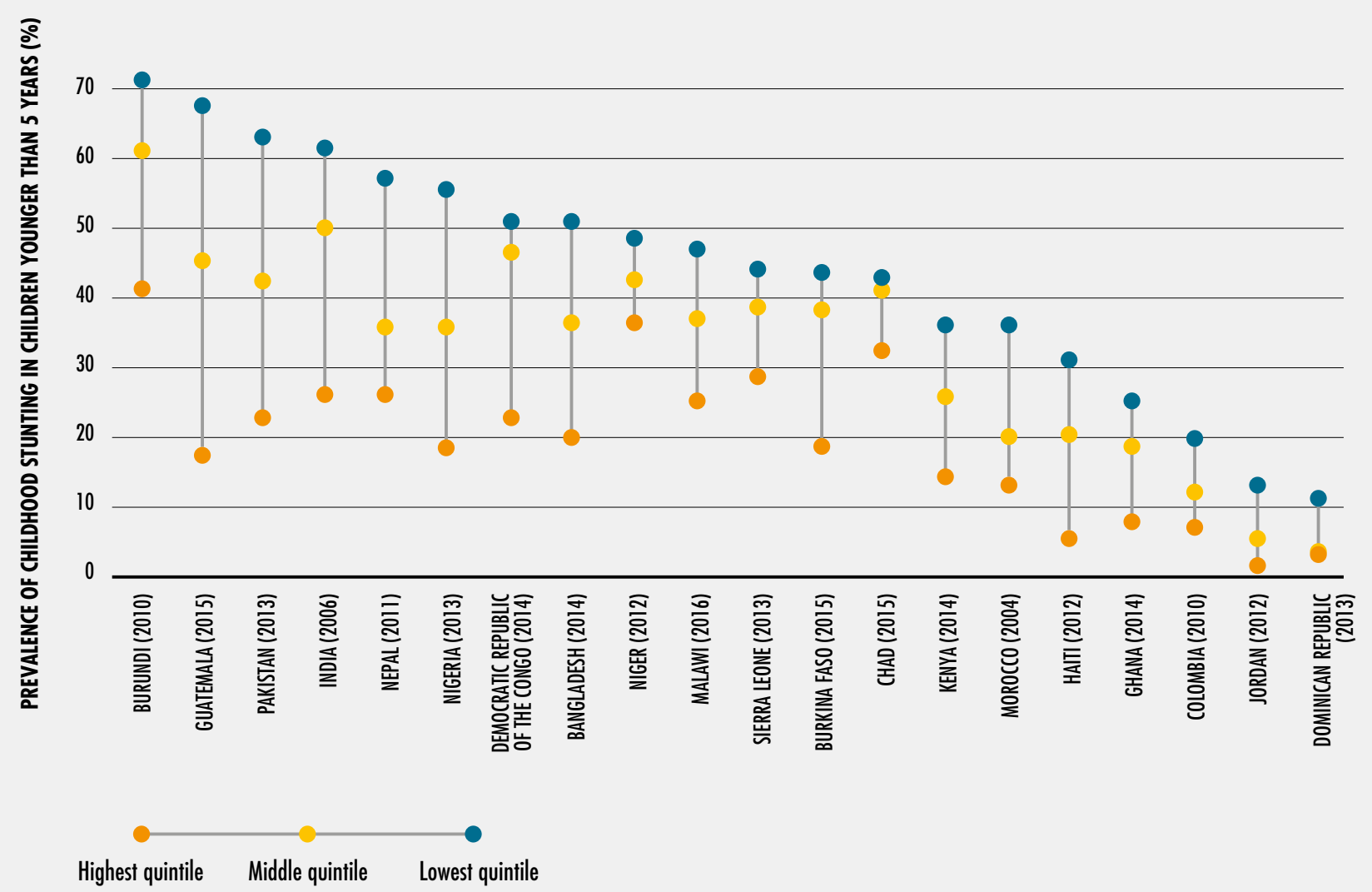

NOTES: Prevalence of stunting in children under five, by household income, plotted with range of income quintile from highest to lowest. The year when stunting is available is indicated in parentheses. Data are from the Demographics and Health Surveys (DHS) Program.

SOURCE: A. De la 0 Campos, C. Villani, B. Davis and M. Takagi. 2018. Ending extreme poverty in rural areas: sustaining livelihoods to leave no one behind. Rome, FAO.

"An important explanation of this finding is the existence of intra-household inequality, which is in line with evidence from a number of studies that find vulnerable individuals do not necessarily live in households that would normally be considered poor. As such, they are hidden from view in standard data sources on poverty. ${ }^{133}$

There are numerous studies that find that low socio-economic status is negatively associated with other nutrition-related indicators beyond child stunting, including child wasting, ${ }^{134}$ low birthweight, ${ }^{135}$ anaemia in women, ${ }^{136}$ and diet-related non-communicable diseases (NCDs). ${ }^{137}$

Lastly, in unpacking the linkages between poverty and food insecurity and malnutrition, it is important to keep in mind that poverty reduction does not ensure increased food security, and even when it does happen, increased food security does not necessarily 
imply improved nutritional status. Poverty or food insecurity and malnutrition are linked, but food security is only one underlying cause of nutrition besides adequate care for children and women, and sufficient health services and a healthy environment. Therefore, the linkages between food insecurity and malnutrition may be weak.

For example, high-quality foods might not be evenly distributed among household members, reflecting intra-household inequality. Households may not have access to basic services, such as adequate sanitation, safe drinking water and health care, which are critical underlying determinants of food security and nutrition. Adequate access to food and basic services often play a more important role in fighting hunger and delayed child growth and other forms of malnutrition, despite economic growth and income. ${ }^{138}$

Evidence for the possible disconnect between poverty reduction and eradication of food insecurity and malnutrition has important policy implications, given that anti-poverty policies in developing countries often assume that targeting poor households will be reasonably effective in reaching those who are malnourished. From a policy perspective, the evidence suggests that targeting relatively poor households will tend to work less well than reaching vulnerable women and children in countries where the overall problem of malnutrition is greater.

Furthermore, most of the hungry and undernourished people today do not live in the world's poorest countries. In 2017, more than 75 percent of the world's hungry, 78 percent of the stunted children and 64 percent of the extreme poor lived in middle-income countries - and only in a handful of these countries. ${ }^{139}$ Although the highest rates of poverty, hunger and child stunting are typically found in low-income countries, they do not make a substantive contribution to the total number of extreme poor nor the hungry in the world.

The geographical distribution of the number of extreme poor, undernourished and stunted children also show a different pattern (Figure 33). The distribution of global extreme poverty has
FIGURE 33

MOST OF THE WORLD'S EXTREME POOR NOW

LIVE IN AFRICA, BUT THE MAJORITY OF THE WORLD'S HUNGRY AND CHILDREN AFFECTED BY STUNTING LIVE IN ASIA
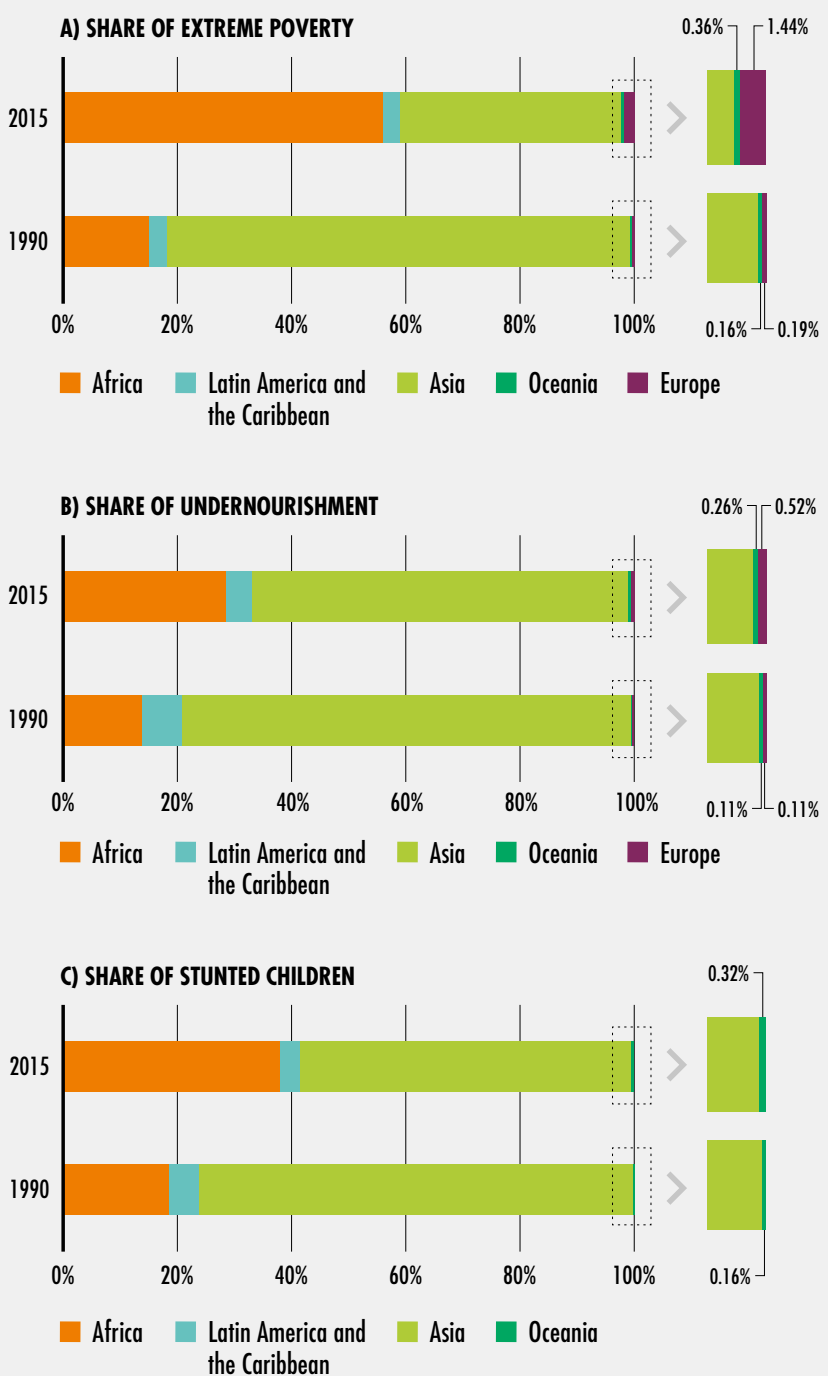

NOTES: Since the latest available data for extreme poverty are for 2015 , for comparability, the share of undernourished and stunted children are also taken from year 2015. The number of stunted children is not available for Europe. SOURCES: World Bank. 2019. PovcalNet: an online analysis tool for global poverty monitoring. In: The World Bank [online]. Washington, DC [Cited 9 May 2019]. http://iresearch.worldbank.org/PovcalNet/home.aspx for extreme poverty; FAO for PoU; UNICEF, WHO and World Bank. 2019. UNICEF-WHO-The World Bank: Joint child malnutrition estimates - Levels and trends (March 2019 edition) [online]. https://data.unicef.org/topic/nutrition; www.who.int/nutgrowthdb/estimates; https://data.worldbank.org for stunting. 
shifted dramatically from Asia to sub-Saharan Africa between 1990 and 2015. Most of the world's hungry and children affected by stunting still live in Asia.

\section{Relationship between poverty, overweight and obesity}

Like other indicators, in the case of overweight and obesity, the relationship with poverty is not so clear and generally tends to vary depending on the general income level of the country.

A systematic review of obesity shows that the association between socio-economic status and obesity appears to be positive for both men and women in low-income countries. Those who are more affluent or with higher educational attainment tend to be more likely to be obese. ${ }^{140} \mathrm{On}$ the other hand, more extensive evidence shows that in middle- and high-income countries, overweight and obesity are linked to lower socio-economic settings among women, with no association observed among men. ${ }^{141}$ In middle-income countries, the association becomes largely mixed for men and mainly negative for women. Obesity in children appears to be predominantly a problem of the rich in lowand middle-income countries. ${ }^{\mathbf{1 4 2}}$

The burden of obesity tends to shift towards poorer populations as countries move through the nutrition transition. ${ }^{143}$ This shift towards overweight and obesity in people with lower socio-economic status seems to be happening faster in low-income countries than it did in high-income countries. ${ }^{144}$

However, there are still inconsistencies in the data on this issue. A meta-analysis of the data from 62 scientific papers published between 1990 and 2015 concludes that the studies that investigated the association between socio-economic status and obesity in children point to ambiguous results. ${ }^{145}$ This meta-analysis finds that children with lower socio-economic status had higher risks of overweight and obesity, but the risks did not seem to increase with the income level of countries. Moreover, the inverse relationship - a higher risk of overweight and obesity associated with higher socio-economic status - was found in high-income countries and in more economically developed areas.
Overweight and obesity increase the risk of non-communicable diseases, which, in turn, can be linked to loss of income or earning potential due to illness as well as increased healthcare costs.

\section{The role of inequalities and marginalization in shaping food-security and nutrition outcomes}

It is clear from the evidence presented up until now that economic growth alone is not sufficient to reduce extreme poverty or improve food security and nutrition. In most cases, the rate at which extreme poverty shrinks as growth accelerates differs from country to country, given the initial level of income inequality in the country and changes in income inequality over time.

Inequality, not only in the distribution of income, but also in access to nutrition-relevant services and social and health infrastructure is critical in understanding why economic growth alone will not significantly reduce extreme poverty or food insecurity and malnutrition. Income inequality itself can result not only in undernutrition, but also overweight and obesity, as the higher costs of nutritious foods induces the poor to resort to cheap, energy-dense and nutrient-poor foods.

Furthermore, inequalities within households help explain why even when economic growth translates into extreme poverty reduction, it may not necessarily reduce food insecurity and malnutrition. Thus, reducing inequality plays an important role in reducing both undernourishment and malnutrition.

This is true at all times, not only for periods of economic boom. Inequalities are structural characteristics of countries that prevent the most food-insecure and malnourished people from being helped by economic growth, but they also expose and make them more vulnerable during periods of economic turmoil. In fact, evidence indicates that in countries that have greater levels of inequality, economic slowdowns and downturns have a disproportionately negative effect on food and nutrition security. ${ }^{146}$ 
This section looks more closely at the different forms of inequality and the evidence on how these inequalities work to shape outcomes of food security and nutrition. Five forms of inequality are explored: income inequality, inequalities between rural and urban populations, inequalities in asset distribution, marginalization and social exclusion, and intra-household inequality.

It is important to acknowledge that any analysis on inequality is challenging, as there is a lack of data disaggregated by wealth quintile, gender, age, geography and disability, which poses a significant barrier to addressing inequality and tackling undernourishment and malnutrition in marginalized groups. ${ }^{147}$ Data on prevalence and national averages of undernourishment and malnutrition are not sufficient to fully understand and address these issues.

\section{Inequality in income distribution}

Income inequality is a defining issue of our time. It is also a cause of entrenched uncertainty and vulnerability. ${ }^{\mathbf{1 4 8}}$ A country experiences income inequality when not every member of its population gets exactly the same share of the income the economy is generating. Although the world has made remarkable progress in reducing extreme poverty, income inequality remains high. This means that most of the reduction in poverty has been achieved through increased economic growth, not through reductions in income inequality. ${ }^{149}$

Income inequality has remained constant and high over the last 15 years (Figure 34 ). ${ }^{150}$ As a region, Latin America and the Caribbean shows the most progress in reducing income inequality, but still has the highest levels of inequality globally (Figure 34). Nonetheless, this overall progress in income distribution does not seem to be shown in the distribution of workers' remuneration. ${ }^{151}$

Measured by the shared prosperity premium ${ }^{152}$ - the difference between the annual income or consumption growth rate of the bottom 40 percent and the annual growth rate of the mean in the economy - inequality is rising in nearly half of the countries in the world, including many low- and middle-income countries (Figure 35).
However, when focusing only on low- and middle-income countries, the income distribution trend is mixed. In Figure 36, countries above the line have seen an increase in income inequality from 2000 to 2015, whereas those below the line have seen a reduction. Notably, several countries in Africa and Asia have seen large increases in income inequality over the last 15 years. Of the 78 countries shown in the figure, 58 are high commodity-dependent countries. In 12 of these countries, income inequality remained unchanged, while for 26 of these, inequality increased.

More importantly, 20 out of these 26 are high commodity-dependent countries.

Income inequality is shaped by the type of economic growth and the distribution of earnings from factor markets, particularly those of labour and capital. Countries in Latin America, where inequality remains high, implemented many reforms beginning in the 1990 s to open up their economies and promote export-led growth. Costa Rica is an example in the region of a country where the export sector was diversified. Interestingly, income inequality rose in Costa Rica as a result of the skill intensity of the new export sectors, which contributed to widening wage gaps. ${ }^{153}$

Income inequality also shapes the impact of economic growth. For instance, if economic growth is associated with rising income inequality (Kuznets curve), ${ }^{154}$ the poorest may not benefit from increased national income. ${ }^{155}$ The links between economic growth with increased average incomes and increased food and nutrition security can be weaker than expected, especially if there are high levels of income inequality. In the context of economic growth with high inequality, inequalities must be addressed to ensure a way out of hunger and malnutrition (Box 14).

Income inequality shapes the impact of economic deceleration or contraction on food security and nutrition. In countries where inequality is greater, economic slowdowns and downturns have a disproportionate effect on low-income populations in terms of food and nutrition security, since they use large portions of their income to buy food. 
FIGURE 34

\section{HIGH AND PERSISTENT LEVELS OF INCOME INEQUALITY IN LOW- AND MIDDLE-INCOME COUNTRIES}

\section{A) GINI INDEX INCOME INEQUALITY - BY REGION}

0.6

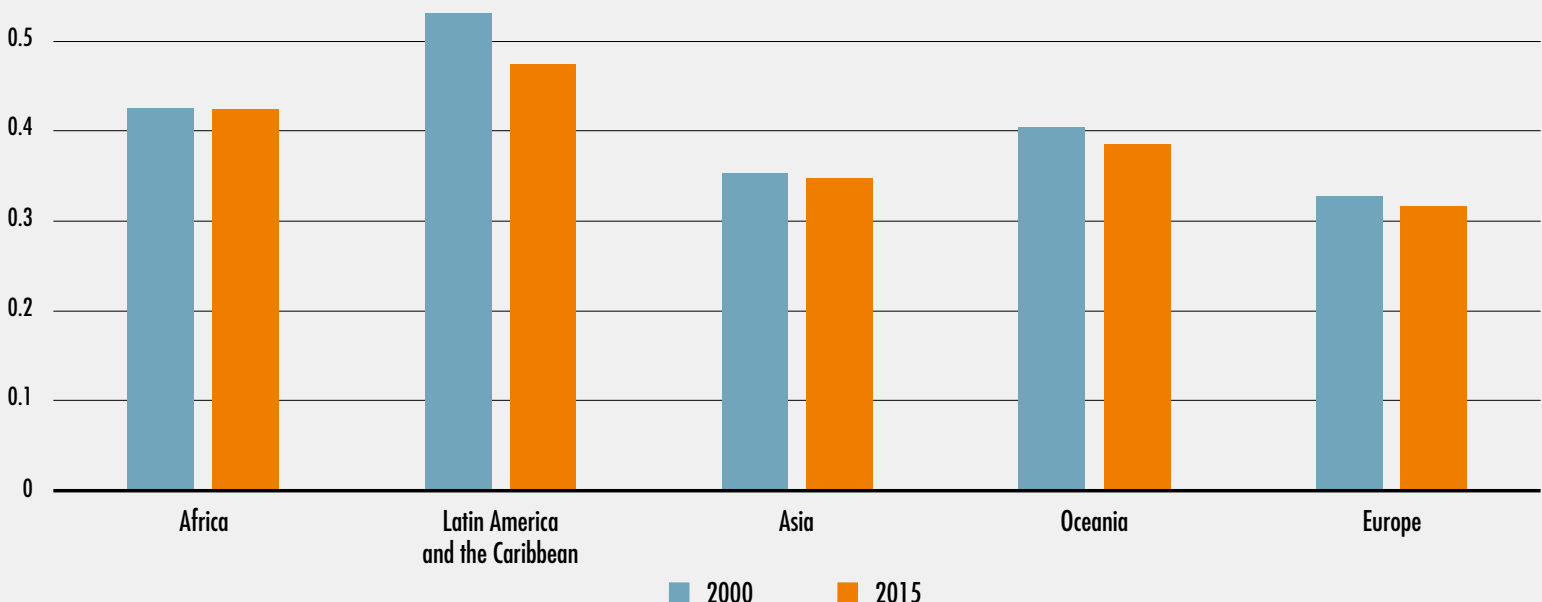

\section{B) RATIO BETWEEN THE INCOME SHARE OF THE RICHEST AND THE POOREST 20\% OF THE POPULATION - BY REGION}

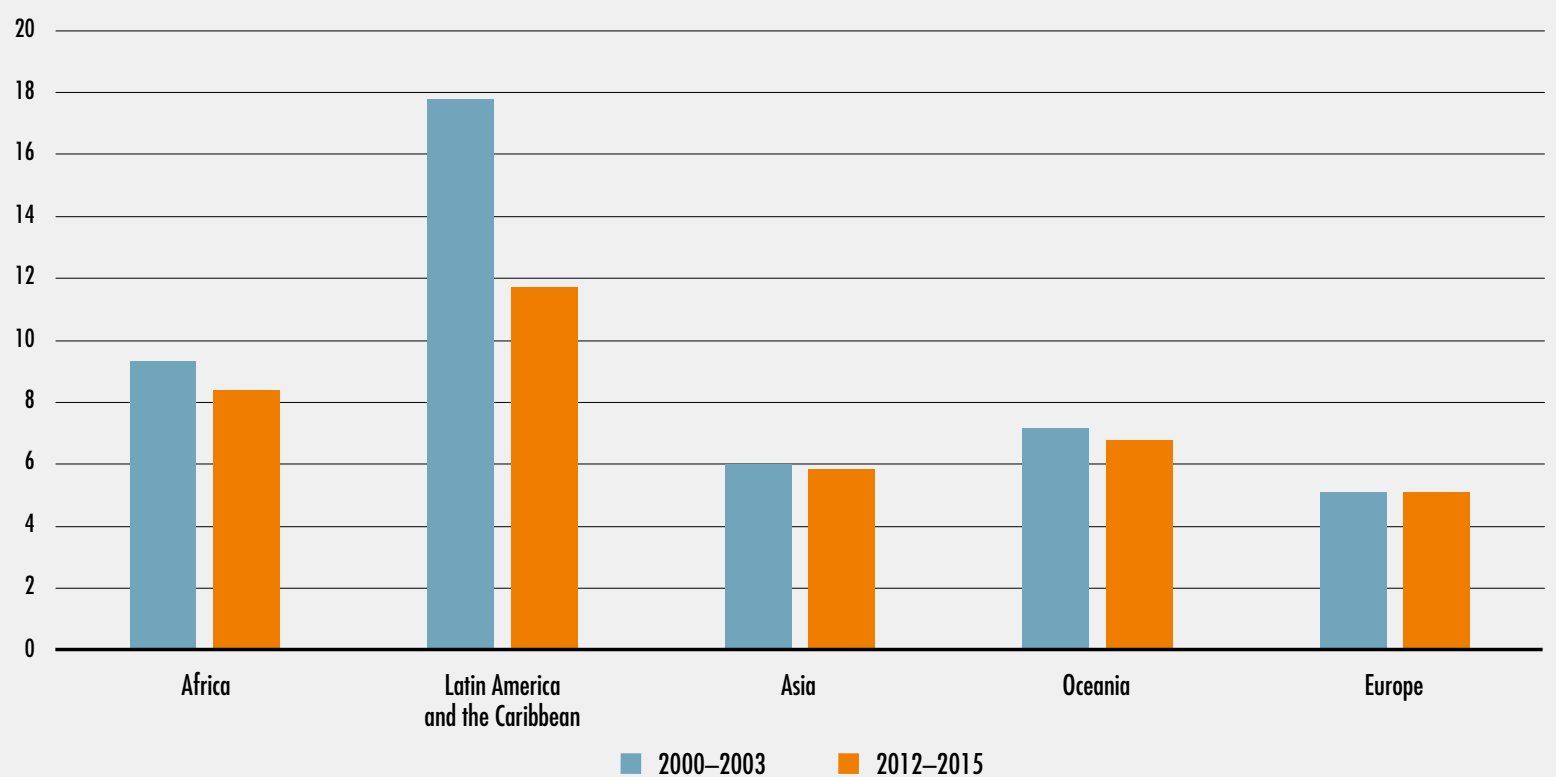

NOTES: Europe refers to low-income and middle-income countries in Eastern Europe. In particular, European countries include Albania, Belarus, Bosnia and Herzegovina, Bulgaria, Montenegro, North Macedonia, Republic of Moldova, Romania, Russian Federation, Serbia and Ukraine.

SOURCES: World Bank. 2019. PovcalNet: an online analysis tool for global poverty monitoring. In: The World Bank [online]. Washington, DC. [Cited 9 May 2019].

http://iresearch.worldbank.org/PovcalNet/home.aspx for the Gini index, World Bank. 2019. World Development Indicators. In: World Bank DataBank [online]. Washington, DC. [Cited 9 May 2019]. https://databank.worldbank.org for the income shares used to compute the ratios. 
FIGURE 35

INCOME INEQUALITY IS RISING IN NEARLY HALF THE COUNTRIES OF THE WORLD, INCLUDING IN SEVERAL LOW-INCOME COUNTRIES AND SOME MIDDLE-INCOME COUNTRIES

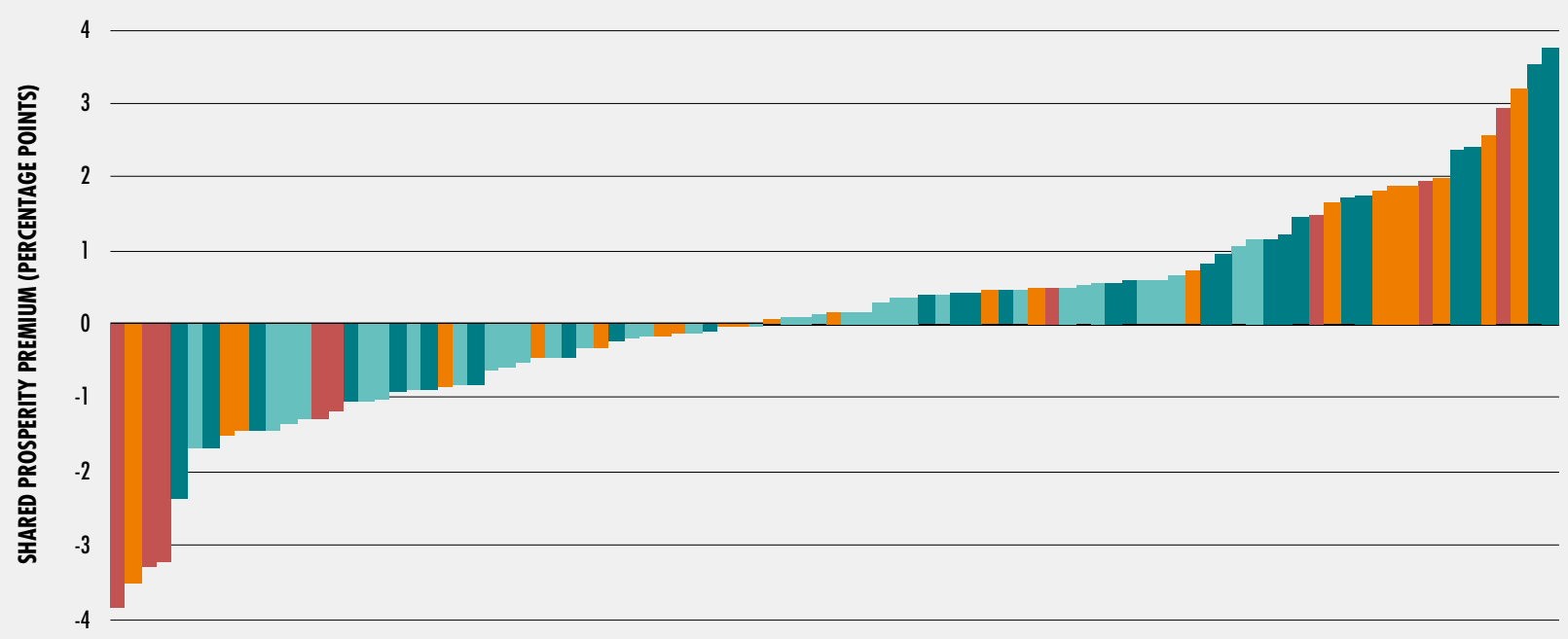

COUNTRIES ORDERED FROM LOWEST TO HIGHEST SHARED PROSPERITY PREMIUM

Low-income countries

Lower-middle-income countries

Upper-middle-income countries

High-income countries

NOTES: Shared prosperity premium is defined as the difference in growth between the average consumption or income per capita (2011 PPP USD per day) of the bottom 40 percent of the population, and the growth in income or consumption per capita of the mean population in a country. Since it is a difference between two growth rates, the shared prosperity premium is expressed in percentage points. Data on shared prosperity premium are available for 93 countries in the period 2011-2016. A positive (negative) shared prosperity premium means that the poorest 40 percent in a country are getting a larger (lower) share of the overall income.

SOURCE: World Bank. 2019. Global Database of Shared Prosperity. In: World Bank [online]. Washington, DC. [Cited 19 March 2019].

http://www.worldbank.org/en/topic/poverty/brief/global-database-of-shared-prosperity

Inequality increases the likelihood of severe food insecurity, and this effect is 20 percent higher for low-income countries compared with middle-income countries. An FAO study for 75 low- and middle-income countries finds that on average countries with a high Gini coefficient (higher than 0.35) have a 33 percentage point higher probability of experiencing severe food insecurity. ${ }^{156}$ Indeed, the prevalence of severe food insecurity is almost three times higher in countries with high income inequality (21 percent) compared with countries with low income inequality (7 percent).

Moreover, the same FAO study finds that in countries with high levels of inequality, increases in household income are highly correlated with a reduction in severe food insecurity. Where there is high inequality, this effect is almost three times more that of lower levels of inequality. A 10 percent increase in household income is associated with a 0.8 or 0.3 percentage point lower likelihood of severe food insecurity in countries with, respectively, high or lower inequality.

Income and wealth inequalities are also closely associated with undernutrition, while more complex inequality patterns are associated with obesity. Such inequality patterns associated with health conditions are seen in low- and middle-income countries. Economic inequalities 


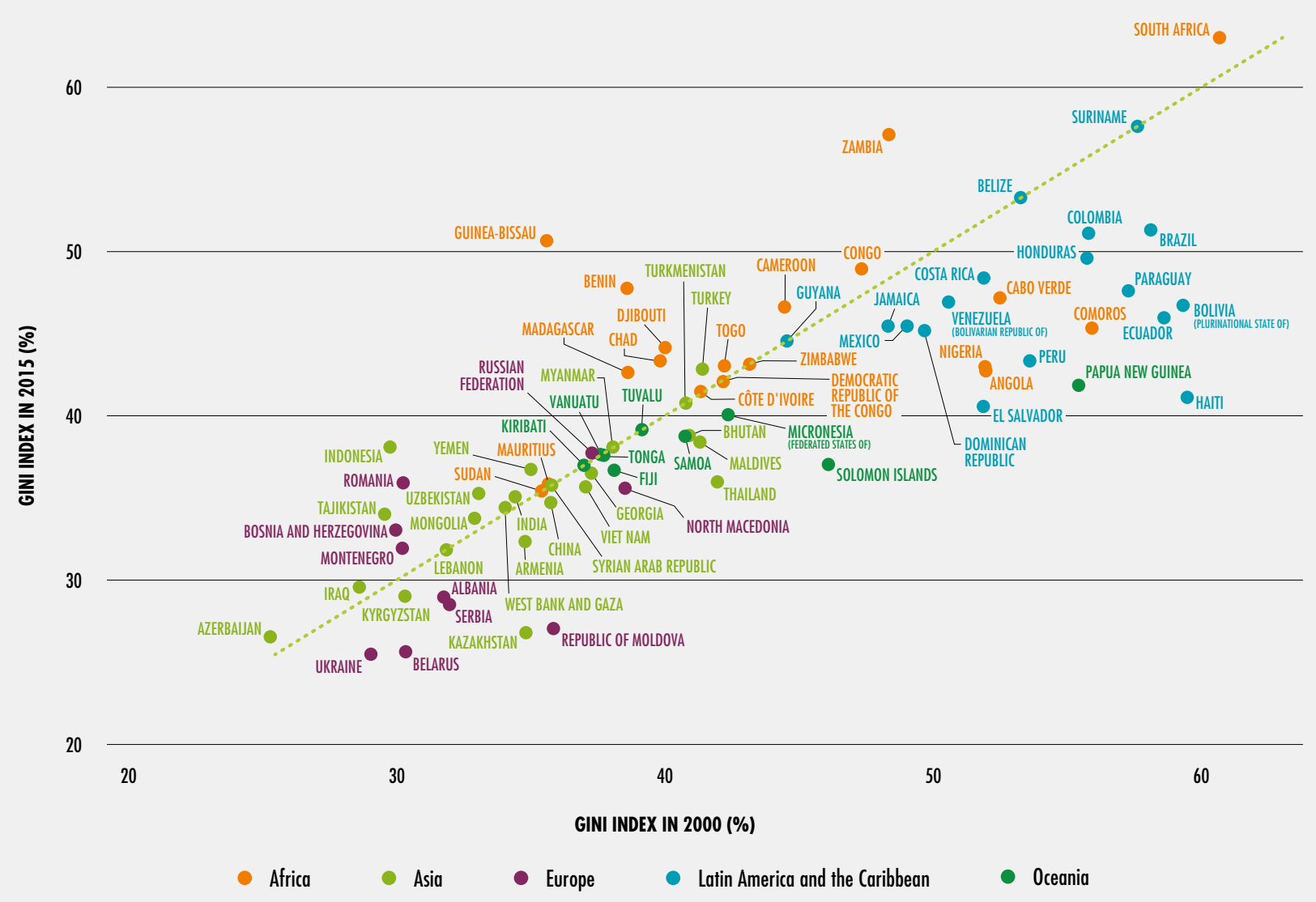

NOTES: As the Gini index is not available for all countries for all years, data available for 1996-2002, and for 2011-2015 are used to inform on Gini index in the past (2000) and on Gini index in recent years (2015), respectively. Only countries for which the Gini index is available in both the periods are used (total of 78 low- and middle-income countries, according to the World Bank classification of country income in 2017). Europe refers to the following low- and middle-income countries: Albania, Belarus, Bosnia and Herzegovina, Montenegro, North Macedonia, Republic of Moldova, Romania, Russian Federation, Serbia and Ukraine. West Bank and Gaza is a territory that follows the World Bank classification.

SOURCE: C. Holleman and V. Conti. (forthcoming). Role of income inequality in shaping outcomes on food insecurity. FAO Agricultural Development Economics Working Papers 19-06. FAO. Rome.

play a significant role as lower levels of income compromise access to health, nutrition and care. For example, in most countries, stunting prevalence among children younger than five years of age is about 2.5 times higher in the lowest wealth quintile compared with the highest wealth quintile. ${ }^{157}$ Moreover, within countries, there are also substantial inequalities between regions and population subgroups.
Inequality in access to basic services - within and between rural and urban areas

Around 40 percent of the inequality in low- and lower-middle-income countries is due to the gap in living standards between rural and urban populations, ${ }^{158}$ with the standards being lower for people living in rural areas. Around two-thirds of the world's poor live in rural areas with an even higher share in low-income countries. ${ }^{159}$ " 
Brazil's high and persistent inequalities in income and in access to basic services such as education and health care are well known. However, in the 2000s inequality declined substantially, while the economy grew at an annual rate of 3.2 percent between 1999 and 2014. ${ }^{1}$ The Gini coefficient dropped from 59 in 1999 to 51 in 2014, and income grew substantially among the poorest. As a result, the reductions in poverty and inequality followed a similarly impressively downward pattern during the 2000s (figure below): 26.5 million Brazilians exited poverty between 2004 and 2014.

The prevalence of undernourishment ( $\mathrm{PoU})$ was reduced from 11.9 percent in 1999-2001 to less than 2.5 percent in 2008-2010. ${ }^{2}$ At the same time, the rate of stunting for children under five years of age was reduced by 6 percent per year between 1996 and 2007, reaching 7.1 percent. ${ }^{3}$ While Brazil made considerable progress in reducing stunting, obesity rates remained high and continue to climb.

The increase in household income combined with strong and coordinated social, education, health policies as well as policies favourable to the productive sectors have been key for poverty and inequality reduction during 2002-2014. Nearly two-thirds of the annual poverty reduction rate in the country could be explained by the effects of median-income growth, especially up until 2008. ${ }^{4}$ The effect of coordinated policies was also important, especially when the growth effect diminished.

Among these policies, Fome Zero represented a key initiative of the new Brazilian Government in 2003. It transformed food security and nutrition into a crucial issue in the social and economic policy strategy, and also mainstreamed hunger eradication into the political agenda. ${ }^{5}$

\section{DECREASING POVERTY HEADCOUNT RATIO AND GINI INDEX IN BRAZIL (YEARS 1999-2015)}

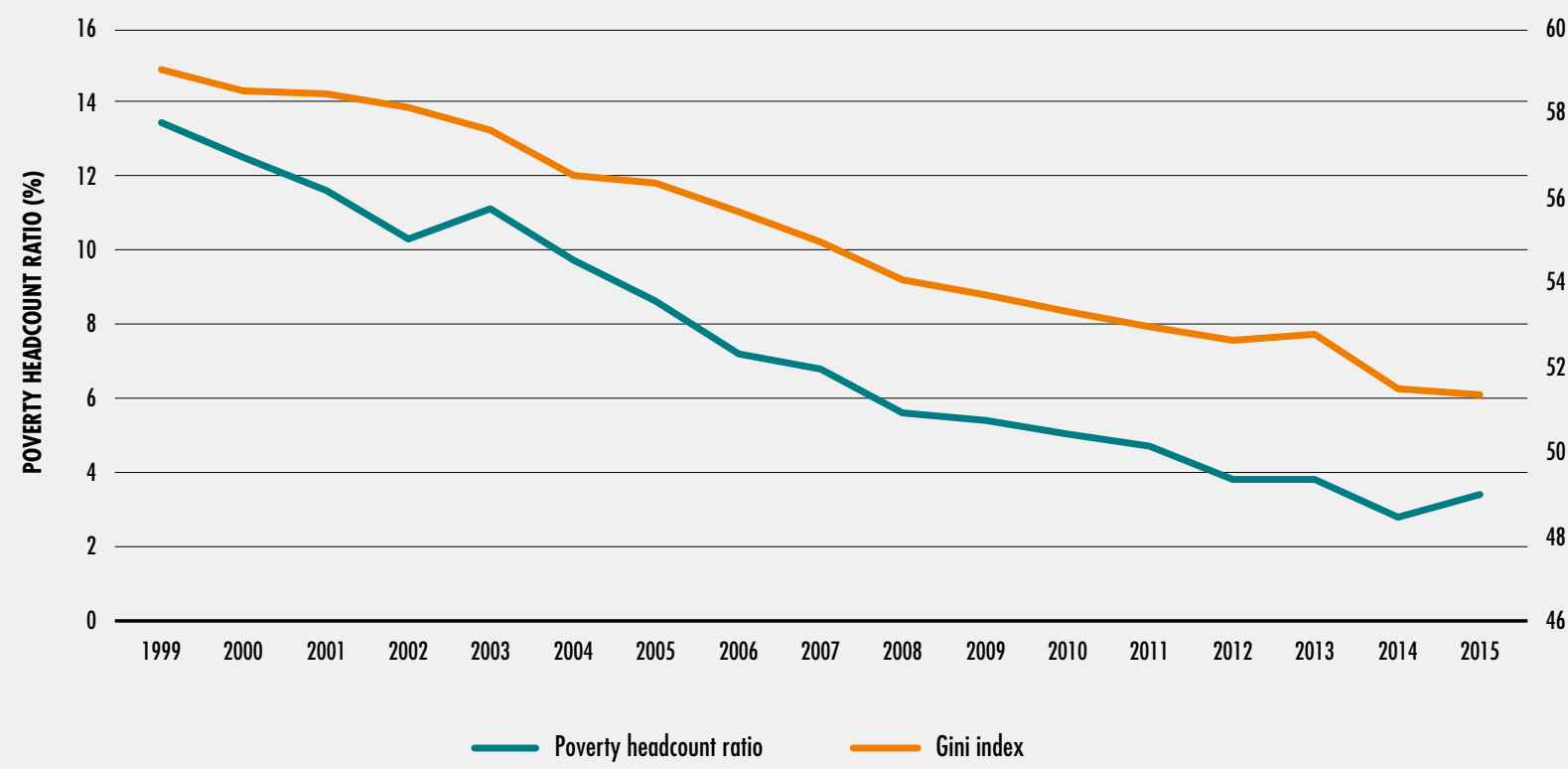

NOTES: Poverty headcount ratio in Brazil (left axis) refers to USD 1.90 a day (2011 PPP). Since data on the Gini index and extreme poverty are not available for 2000 and 2010, mean imputation is applied for these years using information on the year before and after. For instance, the Gini index in 2000 is the average of the Gini index in 1999 and 2001

SOURCE: FAO elaboration based on data from World Bank. 2019. PovcalNet: an online analysis tool for global poverty monitoring. In: The World Bank [online]. Washington, DC. [Cited 9 May 2019]. http://iresearch.worldbank.org/PovcalNet/home.aspx 
Fome Zero and its successor, Brasil sem Miseria, coordinated several programmes in diverse sectors: cash transfers, school feeding, access to health, family farming, productive inclusion and access to water, housing and sanitation facilities, among others. ${ }^{6}$ One of these is Bolsa Familia, Brazil's flagship conditional cash transfer (CCT) programme. Between 2004 and 2014, Bolsa Familia increased its expenditure from 0.29 percent to 0.46 percent of annual GDP, and household coverage from 6.6 million to 14 million households. ${ }^{7}$

It is estimated that the cash transfer component of Bolsa Familia has been responsible for 25 percent of extreme poverty reduction and near 15 percent of poverty reduction since $2004 .^{8}$ Its distribution effect could explain between 1 percent and 1.5 percent of the annual Gini coefficient reduction in the country. ${ }^{9}$ Other policies directed specifically to rural populations have been important for the observed poverty and inequality reduction process. For example, Brazil is one of the few countries of the LAC region that has a non-contributive pension mechanism especially designed towards rural populations - Previdência Rural. Several studies have shown the importance of the programme for the income of vulnerable rural populations. ${ }^{10}$

\section{' World Bank. 2019. World Development Indicators. In: World Bank DataBank [online]. Washington, DC. [Cited 9 May 2019]. https://databank.worldbank.org ${ }^{2}$ FAO. 2019. FAOSTAT. In: FAO [online]. Rome. [Cited 6 May 2019]. http://www.fao.org/faostat/en/\#home}

${ }^{3}$ M. Keefe. 2016. Nutrition and equality: Brazil's success in reducing stunting among the poorest. In IFPRI. 2016. Nourishing millions: Stories of change in nutrition, pp. 99-105. Washington, $\mathrm{DC}$.

${ }^{4}$ Economic Commission for Latin America and the Caribbean (ECLAC). 2018. Panorama Social de América Latina 2017. Santiago de Chile.

${ }^{5}$ C. Guerra Tomazini and C. Kerches da Silva Leite. 2016. Programa Fome Zero e o paradigma da segurança alimentar: ascensão e queda de uma coalizão? Revista de Sociologia e Politica, 24(58): 13-30.

${ }^{6}$ T. Campello, T. Falcão and P. Vieira da Costa. 2015. Brasil sin Miseria. Brasilia, Ministerio de Desarrollo Social y Combate al Hambre.

${ }^{7}$ S. Cecchini and B. Atuesta. 2017. Programas de transferencias condicionadas en América Latina y el Caribe: Tendencias de cobertura e inversión. Santiago de Chile, ECLAC. ${ }^{8}$ National poverty lines of RS 89 and RS 178 (2018), respectively.

9 P.H.G. Ferreira de Souza, R.G. Osorio, L.H. Paiva and S. Soares. 2018. Os efeitos do Programa Bolsa Família sobre a pobreza e a desigualdade: um balanço dos primeiros 15 anos. In Silva, Falcão Tiago. 2018. Bolsa Família 15 anos (2003 - 2018), pp. 155-191. Brasilia, ENAP.

${ }^{10}$ R.P. De Oliveira and J.R. De Aquino. 2017. A previdência rural e sua importância para as famílias pobres no nordeste: resultados de um estudo de caso no Rio Grande do Norte. Revista Economica do Nordeste, 48(1): 115-130; G.D. Nunes Souto, C. Becker and A. Troian. 2018. Effects of rural social security in a settlement of agrarian reform: case study in Santana do Livramento/RS. Brazilian Journal of Development, 4(6): 2876-2897.

Despite recent progress, rural areas may not always fully benefit from advances in national economic development and may experience lower levels of public investment in infrastructure and poorer access to essential services, including quality health care, education, water and sanitation, ${ }^{160}$ which negatively impacts people's livelihoods, food security and nutrition.

Country-level data show that in many low- and middle-income countries, the prevalence of stunting among children is higher in rural as compared to urban areas, according to joint WHO, UNICEF and World Bank global data on malnutrition. ${ }^{161}$ Furthermore, according to a pooled data analysis from multiple countries, women in rural areas have an increased risk of anaemia compared with those living in urban areas, especially among women with lower socio-economic status. ${ }^{162}$ However, the differences in prevalence of overweight among young children between urban and rural areas are quite small, and the gap in adult obesity rates between urban and rural areas is narrowing (see Part 1 of this report). 
Regarding feeding practices, research findings indicate that infants in rural areas have higher levels of exclusive breastfeeding and continued breastfeeding for the first and second year than their urban peers. However, the complementary feeding practices are of poorer quality compared with those of urban areas. In urban areas, infants and young children are more likely to be fed with more diverse and frequent meals. ${ }^{163}$ Alarmingly, only one out of every six children aged 6-23 months in low- and middle-income rural and urban settings receives a minimum acceptable diet - i.e. one that meets both the minimum number of meals and minimum diet diversity. ${ }^{164}$

Inequalities in accessing basic services that are critical to eradicating hunger and malnutrition are also seen within urban areas. Massive rural-to-urban migration ${ }^{165}$ is creating "hidden cities" of extreme poor urban populations, including over 800 million people living in slum conditions who are often not accounted for in official statistics. ${ }^{166}$ These urban poor are particularly vulnerable to financial crises or food price hikes. ${ }^{167}$ While urban populations enjoy better health on average, moving to or living in an urban area does not necessarily guarantee this health for everyone, and inequalities within urban populations are growing. For example, rates of stunting among the poorest urban populations can be as high or even higher than rates among poor rural children. ${ }^{168}$ One-third of the world's stunted children now live in urban areas. ${ }^{169}$

For poor urban households, food security and nutrition are more dependent on families having cash to buy food and meet other needs than in poor rural households. This means that households rely on labour markets to provide jobs for family members with women often dependent on employment in the informal sector. Parents and other caregivers have to spend more time outside home with potential consequences for childcare and feeding. ${ }^{170}$ Furthermore, access to services such as health care, safe water and sanitation is unequal. ${ }^{171}$ Alarmingly, the nutrition transition, which has seen shifts in consumption patterns from traditional foods that are often more healthy to highly processed foods often high in dietary energy, saturated fat, sugars and salt, is happening fastest in the urban areas of low- and middle-income countries, bringing with it increased risk of overweight, obesity and diet-related diseases. ${ }^{172}$

The poorest of the poor are, therefore, most vulnerable to economic slowdowns and downturns whether they live in rural or urban areas. ${ }^{173}$ Inclusive development policies aligned across sectors, which address the vulnerability of the rural poor and protect and increase the resilience of the poorest urban populations, are needed. These are particularly important in the face of economic slowdowns or downturns. They can protect the poor when public and private expenditures in basic services are cut due to lack of fiscal space. And they can protect the poor from undesirable coping strategies with negative impacts on food security and nutrition, as described in Section 2.2.

As has already been shown, during economic crises, access to health care often deteriorates, particularly for poorer population groups. ${ }^{174}$ Government spending on publicly funded health services is often reduced in real terms, while healthcare demand tends to shift from private to public services because of the lower cost. ${ }^{175}$ Resource constraints during economic slowdowns and downturns may result in restricted access to health care, availability, cost and deterioration in the quality of services provided, especially among the poor and marginalized groups. ${ }^{176}$ These conditions are likely to disrupt treatment and subsequently worsen disease outcomes. ${ }^{177}$

Economic downturns and slowdowns also affect access to education. During times of economic crisis, governments' capacity to fund education is often reduced, and families may be less able to invest in education. At the same time, resource constraints may negatively impact the quality of education. ${ }^{178}$ Again, these constraints disproportionately affect poor and marginalized groups. Unless there are contingency mechanisms and funds in place to reverse such effects on education, there may be long-term effects on human capital and a higher risk that children are taken out of school so that they can contribute to a household's income, with consequences for their nutrition, as further explained below. ${ }^{179}$ 


\section{FIGURE 37 \\ INEQUALITY IN THE DISTRIBUTION OF \\ AGRICULTURAL LAND IS HIGH IN MANY COUNTRIES IN SUB-SAHARAN AFRICA}

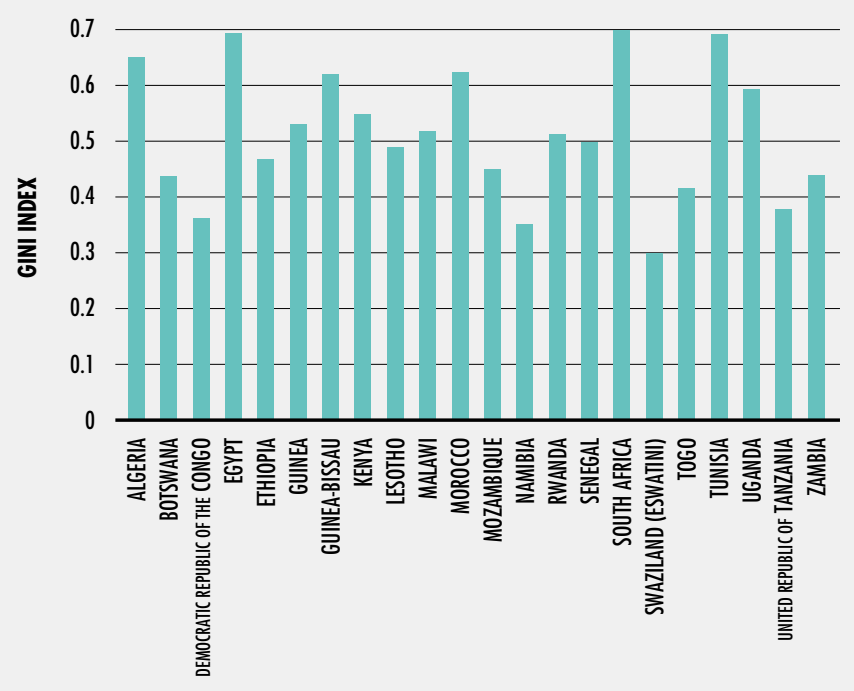

NOTES: The figure reports the Gini index for land distribution, mostly referring to year 2000 or around.

SOURCE: N. Cuffaro and G. D'Agostino. 2017. Land inequality and growth: meta-analysis and relevance for contemporary development in Africa. Working Paper $\mathrm{n}^{\circ} 222$ [online]. Rome, Università di Roma Tre. [Cited 5 May 2019]. http://dipeco.uniroma3.it/db/docs/WP\%20222.pdf

Inequality in the distribution of productive assets Evidence shows that equitable access to assets is a way through which economic progress for everyone can be enhanced. ${ }^{180}$ The greater the inequality in asset distribution such as land, water, capital, finance, education and health, the more difficult it is for the poor to participate in economic growth processes. This then slows the progress in reducing food insecurity and malnutrition. For example, poor people often have little education, which prevents them from participating in labour markets that offer higher wages. This in turn reduces the rate of overall economic growth, further harming the poor and challenging their food security and nutrition.
Land-resource scarcity and inequities are growing, with poor and marginalized population groups worldwide often having the least access to land. They are confined to "poverty traps" of marginal and degraded lands of poor quality soils, where they are vulnerable to climate variability and have no secure tenure. ${ }^{181}$ Women, for instance, make essential contributions to agriculture in low-income countries; yet, they have less access to productive resources and opportunities than men. ${ }^{182}$

Even in the context of sub-Saharan Africa, where arable land is relatively abundant as a whole compared with other regions, data at the country level reveal that the amount of suitable land per rural inhabitant varies considerably, and that about one-third of the countries have less than one hectare of land suitable for agriculture. Furthermore, recent data on inequality of land distribution shows that surplus land in the region is not only concentrated within relatively few countries, but that unequal distribution of land is very high in many countries (Figure 37). ${ }^{183}$

Inequality in land ownership not only challenges livelihoods, but also undermines the productive capacity of the population. One study found that less inequality in land ownership across agricultural populations, as opposed to inequality within the landholding class, has been associated with greater public provision of education. ${ }^{184}$

Women often have no security of tenure or access to financial credit. ${ }^{185}$ They are disproportionately represented among landless populations that face food insecurity and are unable to meet basic needs. This often pushes them into wage farm labour and endangers their livelihoods (Box 16). ${ }^{186}$

Like land access, water availability affects the livelihoods of billions globally and contributes to food security, nutrition and environmental health. ${ }^{187}$ Inequalities in water access in terms of availability, access, safety and sustainability are defined across geographical regions on the basis of gender, economic, political and power relations, and thus work prominently to the disadvantage of women, smallholder farmers, indigenous communities and pastoralists. ${ }^{188}$ Unfortunately, the multiple linkages between water, land, soils, food and 
inequalities are rarely addressed in policies and programmes for inclusive economic growth and sustainable development.

\section{Marginalization and social exclusion}

Social exclusion is a dynamic process embedded in unequal power relationships that operate across economic, political, social and cultural dimensions. The economic dimension is defined by access to and distribution of material resources necessary to sustain life. The political dimension relates to power dynamics and unequal patterns of both formal rights and the conditions in which rights are exercised, including access to services. ${ }^{189}$ These dimensions also affect food security and nutrition.

Given this context, socially excluded and marginalized groups - such as ethnic and religious minorities, indigenous populations and people with disabilities - are likely to be hit particularly hard by economic downturns. These groups already have poorer access to resources and essential services, and these inequalities are likely to increase during economic crises. ${ }^{190}$

Indigenous populations around the world, for example, are often affected by poor food security and nutrition. They frequently live in extreme poverty and in environments that have been damaged; or they have lost their land and no longer have access to traditional food sources. As a result, they are particularly exposed to different types of shocks, including climate and economic shocks (Box 15).

Minority ethnic groups are often at higher risk of different forms of malnutrition. Children in most disadvantaged ethnic groups in low- and lower-middle-income countries have on average 2.8 times the rate of stunting and six times the rate of wasting compared with their more advantaged peers, although the disparities are much higher in some countries. Additionally, ethnic disparities appear to be increasing in many countries. ${ }^{191}$ People living with a disability are also often more vulnerable to food insecurity and malnutrition, and this relationship is bidirectional through poor living conditions and lack of access to health services. ${ }^{192}$
Although analyses are limited, data from more developed economies show that socially disadvantaged groups are often at increased risk of malnutrition. Evidence from several middle- and high-income countries suggests that mothers from socially disadvantaged groups, including ethnic minorities and indigenous populations, have a higher risk of giving birth to babies of low birthweight ${ }^{193}$ and of being affected by anaemia. ${ }^{194}$ Furthermore, in lowand lower-middle-income countries differences in rates of childhood overweight between ethnic groups have been observed. ${ }^{195}$ In some high-income countries, rates of overweight and obesity among children and adolescents have been rising faster in minority ethnic populations living in low-income communities. ${ }^{196}$

\section{Inequality within households}

Inequalities of social, political and economic power are not only seen within societies as a whole, but also within households. They can make economic events particularly beneficial for some, but not for all members of the household.

At the household level, differential inequalities are determined by who has the power in deciding, for example, what is consumed. ${ }^{197}$ "Bargaining-power" models within households suggest that incomes are rarely pooled together. ${ }^{198}$ Consequently, gender inequalities and power struggles tend to exacerbate poverty and deprivation of food and nutritional security during periods of economic slowdown or downturn. Such intra-household inequalities often affect children negatively, depending on factors like gender, age, birth order, and mother's socio-economic status. ${ }^{199}$

The allocation of food can be severely constrained during economic slowdowns and downturns and this can be particularly challenging for some members of the household. More generally, while no systematic bias at the global level has been observed towards one specific age or sex group within a household concerning intra-household food distribution, ${ }^{200}$ wide consensus posits that women are disadvantaged in the allocation of food (Box 16). Also, pregnant women tend to receive relatively lower allocations, with likelihood of serious consequences for their own and their child's nutritional status. ${ }^{201}$ Moreover, " 
Indigenous peoples are disproportionately represented among food-insecure and hungry populations. ' For instance, Native Americans in the United States of America are at least twice as likely to be food insecure as non-Native Americans. ${ }^{2}$ In Guatemala, indigenous children aged below five are twice as likely to be stunted compared to non-indigenous children. ${ }^{3}$ Similarly, indigenous peoples are disproportionately affected by the prevalence of poverty. Despite their contributions to economic empowerment and social development, indigenous women often face marginalization and discrimination even within their own communities. ${ }^{4}$ While indigenous peoples represent 5 percent of the world's population, they represent 15 percent of the world's poor. ${ }^{5}$ In Ecuador, while the national poverty rate was 30 percent in 2012 , it was at 60 percent for the indigenous peoples. ${ }^{6}$

The prevalent loss of control over their territories and resources have left indigenous peoples impoverished in many countries. Resource-extracting development models pose threats to their lands, ${ }^{7}$ especially in the absence of documented land rights and tenure security. Recent changes in economic conditions, climate and access to natural resources have adversely affected their livelihood strategies, which further exacerbates the prevalence of poverty, food insecurity and hunger among these groups.

Indigenous peoples' territories cover about 22 percent of the global surface and contain 80 percent of the world's biodiversity. ${ }^{8}$ Because their lands and territories have not been subject to intensive development, they have been able to maintain biodiversity on these lands over millennia, which is central to their livelihoods and natural resource management strategies. ${ }^{9}$

Indigenous peoples' traditional food systems involve the production of diverse foods with minimal negative impact to the environment. These systems are anchored in sustainable livelihood practices, adapted to ecosystems of their territories, and are rooted in biodiversity conservation which ensures adequate dietary diversity. ${ }^{10}$ Many neglected and underutilized species that they cultivate are nutrient dense, functional foods, rich source of micronutrients, and have an untapped livelihood and nutritional potential. For instance, Marula, native in Southern and Eastern Africa, provides four times the content of vitamin $C$ contained in an orange. Marula has been promoted as a sustainable plant food for rural development. "Indigenous peoples' traditional farming practices including diversification of land use, crop rotations and crop diversification supports adaption to climate change. Their diets from foods harvested from forests to nutrient rich local fish, are diversified and suited to the local environments, and are a response to malnutrition.

Greater attention to address the inequalities that prevent harnessing the knowledge and nurturing indigenous peoples' traditional food systems, including through increased access through the natural resources they rely upon, will facilitate making their dietary diversity more sustainable in the face of economic and climate shocks.

'I. Anderson, B. Robson, M. Connolly, F. Al-Yaman, E. Bjertness, A. King, M. Tynan et.al. 2016. Indigenous and tribal peoples' health (The Lancet-Lowitja Institute Global Collaboration): a population study. The Lancet, 388(10040): 131-157; S. Lemke and T. Delormier. 2017. Indigenous peoples' food systems, nutrition, and gender: conceptual and methodological considerations. Maternal \& Child Nutrition, 13: el2499.

${ }^{2}$ C. Gundersen. 2007. Measuring the extent, depth, and severity of food insecurity: an application to American Indians in the USA. Journal of Population Economics, 21(1): 191-215.

${ }^{3}$ S. Fukuda-Parr. 2016. Re-framing food security as if gender equality and sustainability mattered. In M. Leach, ed. Gender equality and sustainable development, pp. 82-104. London, Routledge; New York, USA, Taylor \& Francis Group.

${ }^{4}$ UN. 2010. Gender and indigenous peoples [online]. New York, USA. [Cited 6 May 2019]. https://www.un.org/esa/socdev/unpfii/documents/Briefing\%20Notes\%20Gender\%20 and\%20Indigenous\%20Women.pdf

${ }^{5}$ H.V. Kuhnlein. 2017. Gender roles, food system biodiversity, and food security in indigenous peoples' communities. Maternal \& Child Nutrition, 13 : el2529.

${ }^{6} \mathrm{~L}$. Cord, M.E. Genoni and C. Rodríguez-Castelán, eds. 2015. Shared prosperity and poverty eradication in Latin America and the Caribbean. Washington, DC, World Bank.

${ }^{7}$ Economic Commission for Latin America and the Caribbean (ECLAC). 2014. Guaranteeing indigenous people's rights in Latin America: Progress in the past decade and remaining challenges. Summary. Santiago de Chile.

${ }^{8} \mathrm{C}$. Sobrevila. 2008. The role of indigenous peoples in biodiversity conservation: the natural but often forgotten partners. Washington, DC, World Bank.

${ }^{9}$ A. Kelles-Viitanen. 2008. Custodians of culture and biodiversity: Indigenous peoples take charge of their challenges and opportunities. Rome, IFAD.

${ }^{10}$ IFAD. 2015. Second global meeting of the Indigenous Peoples' Forum at IFAD. In: IFAD [online]. Rome. [Cited 24 April 2019]. https://www.ifad.org/en/web/latest/event/ asset $/ 39008834$

"R. Wynberg, J. Cribbins, R. Leakey, C. Lombard, M. Mander, S. Shackleton and C. Sullivan. 2002. Knowledge on Sclerocarya birrea subsp. caffra with emphasis on its importance as a non-timber forest product in South and southern Africa: a summary. Part 2: Commercial use, tenure and policy, domestication, intellectual property rights and benefit-sharin. The Southern African Forestry Journal, 196(1): 67-77. 
Women play an indispensable role in on-farm and off-farm activities, particularly in rural areas, which contribute to economic welfare and food security of their households. Approximately 43 percent of the global agricultural workforce is made up of women. ${ }^{1}$ The contribution of women to labour in African agriculture is regularly quoted in the range of 60-80 percent. Using individual, plot-level labour input data from nationally representative household surveys across six sub-Saharan African countries, recent evidence ${ }^{2}$ challenges the conventional wisdom by estimating the average female labour share in crop production at 40 percent. The evidence shows that this share was slightly above 50 percent in Malawi, Uganda and United Republic of Tanzania, and substantially lower in Nigeria (37 percent), Ethiopia (29 percent) and the Niger (24 percent).

The agricultural productivity of women has direct implications on income as well as on the food security of their households. Evidence suggests that increased income for women is associated with greater food consumption and improved nutritional status of household members. ${ }^{3}$

As economies grow and transform, new opportunities emerge for rural populations. Improved infrastructure and services, increased access to education, information, credit, technology, technical skills as well as improved access to agricultural value chains and markets open up new economic opportunities for both men and women. However, the extent to which women and men are able to benefit from these growing opportunities differs. ${ }^{4}$ Women often face greater challenges in accessing input factors (i.e. land, labour and financial services). For instance, less than 5 percent of women in North Africa and West Asia are agricultural landholders. In sub-Saharan Africa, the proportion of women holding agricultural land ranges widely from less than 5 percent in Mali up to 30 percent in Botswana and Malawi. ' Further, many women face greater difficulty than men accessing agricultural labour and formal financial services. ${ }^{2}$

Agricultural production outcomes also differ greatly between men and women. There is evidence that the gaps in agricultural productivity between women and men with similar-sized plots in a similar context range from 23 percent in United Republic of Tanzania, 24 percent in Ethiopia, 25 percent in Malawi, 33 percent in Uganda, and to 66 percent in the Niger. ${ }^{5}$ Traditional roles also require women to spend significant amounts of time on household chores and in caring for infants and young children, which limits their participation in income-generating opportunities that arise when economies grow. ${ }^{6}$ In developing countries, estimates indicate that women spend three hours more per day on unpaid work than men. ${ }^{2}$ Finally, when rural women migrate in search of greater employment opportunities, they often face barriers seeking decent work, training opportunities, assets and personal safety. ${ }^{7}$

However, narrowing the gender dimensions of inequality goes beyond strengthening women's economic opportunities and decision-making capacities in groups and organizations. It also requires an in-depth understanding of intra-household dynamics where, in some parts of the world, men and women within the same household pursue separate livelihood strategies. While women are typically disadvantaged in terms of access to resources, services and markets, and burdened by more onerous daily tasks, they also lack a voice in determining household priorities, spending patterns and distribution of benefits. This includes gender inequalities in intra-household food allocation, which can result in a gender gap in food and nutrition security. ${ }^{8}$ Consequently, what happens inside the family has substantial implications not only for individual motivation and well-being, but also for productivity and investments in agriculture and rural development, and more importantly for food and nutrition security within the household.

${ }^{1}$ FA0. 2011. The State of Food and Agriculture 2010-11. Women in agriculture, closing the gender gap for development. Rome.

${ }^{2}$ A. Palacios-Lopez, L. Christiaensen and T. Kilic. 2017. How much of the labor in African agriculture is provided by women? Food Policy, 67: 52-63.

${ }^{3}$ D. Thomas. 1990. Intra-household resource allocation: an inferential approach. The Journal of Human Resources, 25(4): 635-664; G.J. Bobonis. 2009. Is the Allocation of Resources within the Household Efficient? New Evidence from a Randomized Experiment. Journal of Political Economy, 117(3): 453-503.

${ }^{4}$ IFAD. 2016. Rural Development Report 2016. Fostering inclusive rural transformation. Rome.

${ }^{5}$ World Bank and ONE Campaign. 2014. Levelling the field: improving opportunities for women farmers in Africa [online]. Washington, DC, World Bank [Cited 6 May 2019]. http://documents.worldbank.org/curated/en/579161468007198488/pdf/860390WPOWBO0NOosure0date0March0180.pdf

${ }^{6}$ C.M. Blackden and Q. Wodon, eds. 2006. Gender, time use, and poverty in sub-Saharan Africa. World Bank Working Papers No. 73. Washington, DC, World Bank.

${ }^{7}$ International Organization for Migration (IOM). 2012. Rural women and migration [online]. Geneva, Switzerland. [Cited 6 May 2019]. https://www.iom.int/jahia/webdav/shared/ shared/mainsite/published_docs/brochures_and_info_sheets/Rural-Women-and-Migration-Fact-Sheet-2012.pdf

${ }^{8} \mathrm{~A}$. Chinyophiro. 2017. Gender in food and nutrition security: towards attaining the right to food [online]. UN Women, IFAD, FA0, WFP Expert Group Meeting - 'Challenges and opportunities in achieving gender equality and the empowerment of rural women and girls'. Rome, 20-22 September 2017. EGM/RWG/EP.4. [Cited 7 May 2019]. http://www.unwomen.org/-/media/headquarters/attachments/sections/csw/62/egm/ep4\%20\%20amon\%20chinyophiro.pdf?la=en\&vs=2826 

found that in periods of critical food shortages, the highest inequity within households tends to occur in households experiencing severe or unexpected food insecurity. ${ }^{\mathbf{2 0 2}}$

Increasingly, evidence on associations between intra-household inequalities and malnutrition indicates that females score worse on nutritional indicators compared with males. In Bangladesh, for instance, household survey data reveal that men tend to have much smaller dietary energy shortfalls compared with women. ${ }^{203}$ Of growing concern is the coexistence of underweight or stunted children with overweight mothers in the same households in various low- and middle-income countries, such as Bangladesh, Ghana, India, Kenya and Peru. ${ }^{204}$ This suggests increasing inequalities in economic and social access to resources. The combination of different inequalities contributing to stunting and overweight phenomena have been linked to maternal age at first birth, maternal short stature, family size and socio-economic status. ${ }^{205}$

\subsection{POLICIES FOR ACHIEVING SUSTAINABLE ESCAPES FROM FOOD INSECURITY AND MALNUTRITION IN THE CONTEXT OF ECONOMIC SLOWDOWNS AND DOWNTURNS}

\section{KEY MESSAGES}

$\rightarrow$ Responding to economic events that constrain households' purchasing power requires short- and long-term policy responses to safeguard food security and nutrition. Actions will depend on institutional capacity and availability of contingency mechanisms and funds to respond.

$\Rightarrow$ Countries need to protect incomes in the short term, particularly for the most affected households, through social protection programmes, public works programmes, or policies aimed at stabilizing food prices. At the same time, they need to avoid cuts in essential social services.

$\rightarrow$ Countries need to invest wisely during periods of economic boom to reduce economic vulnerabilities and build capacity to quickly recover when economic turmoil erupts. This requires balancing a set of policies for an inclusive transformation that is characterized by economic diversification, human capital accumulation and universal access to health care and other social services.

$\Rightarrow$ Given the rising importance of global trade in food and agricultural commodities, trade policy also needs to feature prominently in the minds of policymakers when promoting economic transformation that helps achieve food security and nutrition objectives.

$\rightarrow$ Integrating food security and nutrition concerns into poverty reduction efforts, while increasing synergies between poverty reduction and hunger eradication, helps accelerate both goals.

$\rightarrow$ When implementing these policies, reducing gender inequalities and social exclusion of population groups needs to be either the means to, or outcome of, improved food security and nutrition. 


\section{The imperative of safeguarding food security and nutrition}

In the absence of policies and resilience capacity to face economic slowdowns and downturns when they occur, households will suffer a decline in their purchasing power, either through income loss, higher domestic prices, or both. In attempting to meet their food needs with reduced budgets, while perhaps also facing higher food prices, households may resort to coping strategies that can further weaken their food security and nutritional status.

While adverse economic conditions affect food security and nutrition in all countries through the channels analysed in Section 2.2, their impact was stronger in countries depending heavily on commodity imports and exports in the most recent 2011-2017 period. Moreover, as was also discussed previously, economic slowdowns and downturns have different impacts on different population groups, and their effects on food security and nutrition cannot be separated from the underlying factors of poverty and inequality.

This final section spells out potential policy responses to safeguard food security and nutrition in the face of economic slowdowns and downturns. It considers short-term policies that can directly and immediately tackle the main transmission channels from which the impacts of economic slowdowns and downturns flow. In the longer term, the responses will need to be guided by a vision of development that fosters pro-poor and inclusive structural transformation, allowing countries to diversify their economies and reduce their commodity dependence, and ultimately lower their economic vulnerability. Moreover, this section makes the case for the need to enhance the synergies among different policies towards reducing poverty, inequalities, food insecurity and malnutrition, as these phenomena are not easily dissociated.

\section{Policies to respond to the key transmission channels of economic slowdowns and downturns}

The main transmission channels linking the effects of economic slowdowns and downturns to food security and nutrition (Figure 29) feature prominently in the earlier analysis of this second part of the report for a very good reason: their understanding is critical for policymakers to decide what to do when these economic events begin to appear. External events, including commodity price fluctuations, can have direct impacts through terms of trade, exchange rate and balance of payments. Secondary indirect effects may arise through inflation and food prices; unemployment, wages and income; and health expenditures. Food security and nutrition will be affected depending on the ability of individuals and households - strengthened by appropriate policies - to cope with these economic events.

As shall be seen below, food security and nutrition will ultimately be affected depending on the policy responses put in place to either bring about economic adjustment (e.g. through fiscal and trade policies), or to help strengthen the resilience of households to economic shocks, and thus prevent undesirable coping strategies (e.g. through social protection or social sectoral policies), or both. Indeed, there needs to be a unique set of policies to address the myriad of potential transmission channels that economic slowdowns and downturns present for food security and nutrition. Known as countercyclical policies, these should aim at smoothing out the cycles by targeting both the demand side and the supply side of the economy. Some of these policy responses are discussed here, in relation to the key transmission channels.

At the same time, the following discussion also shows that, in addition to responding to the transmission channels, policymakers must continue with some key existing policies for nutrition and health, including maintaining the delivery and the quality of relevant care and health services and ensuring universal access to those services as well as adequate access to water and sanitation. These basic policies tend to be highly affected by cuts in social spending during 
economic slowdowns and downturns if there is no contingency to prevent them.

\section{Curbing rising food prices or offsetting their effects}

International commodity price shocks and volatility transmit effects into the economy through exchange rate adjustments, as highlighted before. Declining commodity prices have resulted in currency depreciations and devaluations leading to domestic price increases. Policy responses in the face of this trend are both short and long term in nature. In the short term, there may be actions to offset the effect on domestic price increases, particularly food prices. In a different scenario, international food prices may rise, even if other commodity prices decline. In the long term, policies will target the supply side of the economy (to boost economic activity and diversification) so as to face down the secular downward trend of commodity prices, as further explained below.

Countries that depend on food imports are particularly vulnerable to commodity price fluctuations leading to an increase in food prices. When these prices rise significantly, poor households and those that are net food buyers can be highly affected. In most cases, the group of net food buyers includes poor farmers, who may not be able to take advantage of the rise in food prices by increasing their production (and earnings) and accessing markets.

To mitigate the negative impact of rising food prices on food security and nutrition, policymakers should consider different factors: the specific food items affected by the rising prices; the distribution of households between net food buyers and sellers; the possibility of substitution among different food items, without negatively affecting the quality of diets; and the potential negative effects of the policy response itself.

The most common policies that countries implement to promote food security and nutrition in the context of rising food prices can be classified into three groups. ${ }^{206}$ The first group includes universal policies aimed at reducing excessive volatility of food prices in the short term, such as restrictions on exports of staple food items, use of food stocks to boost the food supply, consumption subsidies for certain essential food items, and import tariff and consumption/sales tax cuts, among others. While implementing some of these policies can be necessary for political reasons, ${ }^{207}$ it should be stressed that they may not necessarily be first-best policies. Some of these measures can be rather costly if they provide a price subsidy not only to poor and vulnerable households, but to the general population. They can also create pervasive market distortions and, in a trade context, can create negative externalities for other countries.

Social protection measures and other policies aimed at protecting purchasing power and access to social services constitute the second group. Social protection programmes play a critical role in both helping households avoid negative coping mechanisms and in accelerating recovery after adverse economic episodes, through the creation of new economic opportunities and the fostering of human capital in the long run (Box 17). For example, homegrown school feeding is a social protection strategy with proven effects in preventing undesirable coping strategies (Box 18). These measures aimed at producing positive results in the short and long term may be preferable to policies aimed at reducing excessive volatility of food prices. In many cases these measures are targeted to those that most need them. But it is also important to ensure universal coverage to social services and social protection as this protects families in times of economic crisis from having to decide whether to spend money on food or health.

The third group comprises medium- and long-term policies to boost domestic production of food, such as free or subsidized input distribution, import-tariff or value-added tax cuts on fertilizers and technology for agricultural production, government-funded agricultural research and extension activities, and subsidies for the adoption of new technologies and irrigation.

These policies need to be carefully designed and implemented to avoid unintended consequences. For example, consumer subsidies for staple food (cereals, oil, sugar) in many countries of the Near East and North Africa region seem to be " 
Low-income countries are increasingly expanding their social protection systems, particularly social assistance, which may include social transfers and other programmes that ensure access to social services, social support and care services, in addition to legislation and policy reforms that ensure equity and non-discrimination. Social protection plays a critical role in improving poor households' access to food and health care, which are essential for adequate nutrition, particularly for women and children. ${ }^{1}$

Cash transfer programmes are social assistance programmes that are usually targeted at poor and vulnerable groups. ${ }^{2}$ Available evidence shows that these programmes improve household dietary diversity, increase food consumption ${ }^{3}$ and enhance productive capacity, with positive effects on the availability of more and higher quality food. ${ }^{4}$ However, their impact on diet diversity among young children is still inconclusive, ${ }^{5}$ and likewise the evidence in child nutritional status. ${ }^{6}$ Potential explanations include the multidimensional nature of the determinants of malnutrition, which require multisectoral approaches to see long-term changes; limited attention to explicit nutrition goals and actions; and poor service quality, which may explain the lack of overall nutrition benefits. ${ }^{7}$ Studies suggest that programmes with larger impacts are those that have a larger transfer size and are of long duration, are targeted at young children in low-income households, and include complementary nutritional features. ${ }^{8}$

In the humanitarian context, cash transfer programmes are also being increasingly used. An analysis of these programmes in over 62 countries 9 finds that they can support access to food and livelihoods, and prevent deteriorations in child nutrition. ${ }^{10}$

Launched in 2005, Ethiopia's Productive Safety Net Programme (PSNP) is one of the most important and largest social safety net programmes in Africa." It contributes to both reducing poverty and strengthening the resilience of vulnerable households in the face of recurrent climate hazards and other shocks. The PSNP is the only social protection programme which has considered food security and nutrition as well as Disaster Risk Reduction in its design since its inception. It is therefore a reference for other African countries on shock-responsive social protection. It currently covers 8 million beneficiaries nationwide. Most notably, the PNSP included a contingency budget equivalent to 20 percent of the base programme cost and a risk financing facility designed to respond to transitory needs of the chronically food insecure. When such contingency was exhausted, a Risk Financing Mechanism (RFM) was developed. The financial facility and the RFM were crucial to the impact and effectiveness of the PNSP in response to the 2011 Horn of Africa crises. ${ }^{12}$

${ }^{1}$ R. de Groot, T. Palermo, S. Handa, L.P. Ragno and A. Peterman. 2015. Cash transfers and child nutrition: what we know and what we need to know. Office of Research Working Paper No. 2015-07 [online]. Florence, Italy, UNICEF. [Cited 7 May 2019]. https://www.unicef-irc.org/publications/pdf/Social\%20protection\%20and\%20nutrition_layout.pdf; M.T. Ruel and H. Alderman. 2013. Nutrition-sensitive interventions and programmes: how can they help to accelerate progress in improving maternal and child nutrition? The Lancet, 382(9891): 536-551.

2 UNICEF. 2012. Integrated social protection systems: enhancing equity for children. UNICEF Social Protection Strategic Framework. New York, USA.

${ }^{3}$ M. Adato and L. Bassett. 2009. Social protection to support vulnerable children and families: the potential of cash transfers to protect education, health and nutrition. AIDS Care, 21(Suppl. 1): 60-75.

${ }^{4}$ B. Davis, S. Handa, N. Hypher, N. Winder Rossi, P. Winters and J. Yablonski, eds. 2016. From evidence to action: the story of cash transfers and impact evaluation in sub-Saharan Africa. New York, USA, UNICEF, Rome, FAO and Oxford, UK, Oxford University Press.

${ }^{5}$ R. de Groot, T. Palermo, S. Handa, L.P. Ragno and A. Peterman. 2017. Cash transfers and child nutrition: pathways and impacts. Development Policy Review, 35(5): 621-643.

${ }^{6} \mathrm{~F}$. Bastagli, J. Hagen-Zanker, L. Harman, V. Barca, G. Sturge, T. Schmidt and L. Pellerano. 2016. Cash transfers: what does the evidence say? A rigorous review of programme impact and of the role of design and implementation features. London, Overseas Development Institute (ODI); J. Manley, S. Gitter and V. Slavchevska. 2013. How effective are cash transfers at improving nutritional status? World Development, 48: 133-155.

${ }^{7}$ M.T. Ruel and H. Alderman. 2013. Nutrition-sensitive interventions and programmes: how can they help to accelerate progress in improving maternal and child nutrition? The Lancet, 382(9891): 536-551.

${ }^{8}$ R. de Groot, T. Palermo, S. Handa, L.P. Ragno and A. Peterman. 2015. Cash transfers and child nutrition: what we know and what we need to know. Office of Research Working Paper No. 2015-07 [online]. Florence, Italy, UNICEF. [Cited 7 May 2019]. https://www.unicef-irc.org/publications/pdf/Social\%20protection\%20and\%20nutrition_layout.pdf; M.T. Ruel and H. Alderman. 2013. Nutrition-sensitive interventions and programmes: how can they help to accelerate progress in improving maternal and child nutrition? The Lancet, 382(9891): 536-551; F. Bastagli, J. Hagen-Zanker, L. Harman, V. Barca, G. Sturge, T. Schmidt and L. Pellerano. 2016. Cash transfers: what does the evidence say? A rigorous review of programme impact and of the role of design and implementation features. London, $0 \mathrm{DI}$.

${ }^{9}$ WFP. 2019. Cash transfers. In: World Food Programme [online]. Rome. [Cited 5 May 2019]. https://wwwl.wfp.org/cash-transfers

10 P. Harvey and S. Bailey. 2011. Cash transfer programming in emergencies. Good Practice Review 11, June 2011. London, Humanitarian Practice Network, ODI.

11S. Coll-Black and J. Van Domelen. 2012. Designing and implementing a rural safety net in a low income setting: lessons learned from Ethiopia's Productive Safety Net Program 20052009. Washington, DC, World Bank.

${ }^{12}$ M. Hobson and L. Campbell. 2012. How Ethiopia's Productive Safety Net Programme (PSNP) is responding to the current humanitarian crisis in the Horn. Humanitarian Exchange, Number 53, February 2012. (also available at https://odihpn.org/wp-content/uploads/2012/03/humanitarianexchange053.pdf). 
BOX 18

HOMEGROWN SCHOOL FEEDING AS A WAY TO PREVENT UNDESIRABLE COPING STRATEGIES

During periods of economic difficulty, children face the risk of being taken out of school to contribute to the household income as well as of having less access to nutritious and balanced meals. Homegrown school feeding, which features among a number of possible social protection programmes, may help policymakers to reduce this risk. This innovative approach links school feeding programmes with local smallholder farmers to provide millions of school children with food that is safe, diverse, nutritious and above all local. Nearly half the world's school children, some 310 million, in low- and middle-income countries eat a daily meal at school, making this the most widespread safety net. Moreover, homegrown school feeding can not only tackle food insecurity for school-age children, but can also provide income benefits to communities at large.

The last ten years have seen a growing global consensus that school feeding programmes generate positive impacts, with the available evidence pointing to multiple benefits.' School feeding generates high returns in four critical areas that translate into human capital growth and sustainable development: increasing access to education, especially for girls; improving nutrition and health which, in turn, benefits cognition and learning, especially for the most vulnerable children; providing essential safety nets for poor children and their families; and stimulating local economies, especially in the agricultural sector.

The value of meals in school is equivalent to about 10 percent of families' income. For families with several children, that can mean substantial savings. At the same time, this may also generate new economic activity.

Linking local consumption to local production helps create a stable and predictable market for local farmers, especially smallholders, including many women and mothers. In Brazil, for example, 30 percent of all purchases for school feeding come from smallholder agriculture. Another example of a large-scale homegrown programme is in Nigeria, where 6 million locally sourced eggs and 80 tonnes of fish are consumed by 9.2 million schoolchildren across the nation every week.

With the schools as reliable markets, farmers earn more income, which they spend in other parts of the economy. As the process continues, school feeding programmes create local income multipliers and spillovers by linking the school feeding programmes to caterers, traders, households, businesses and other activities in the local economy. ${ }^{2}$ The Homegrown School Feeding Programme in rural Kenya, for instance, has a large income multiplier: each United States dollar (USD) transferred to a school for food purchases creates an additional USD 2.74 of total household nominal (cash) income in rural areas.

In recognition of the importance of school feeding programmes, many countries are including these initiatives in their strategies for achieving food security and implementing the 2030 Sustainable Development Agenda. Many governments are increasingly sourcing food for school feeding locally from smallholder farmers in a bid to boost local agriculture, strengthen local food systems and move people out of poverty.

1 D.A.P. Bundy, N. de Silva, S. Horton, D.T. Jamison and G.C. Patton, eds. 2018. Re-imagining school feeding: a high-return investment in human capital and local economies. Child and Adolescent Health and Development, Volume 8. Washington, DC, World Bank.

2 J.E. Taylor and M.J. Filipski. 2014. Beyond experiments in development economics: local economy-wide impact evaluation. Oxford, UK, Oxford University Press.

" promoting unbalanced diets, increasing the risk of malnutrition and health among the population. Poor diets distorted by subsidies can contribute to greater disease burden, lead to excess health expenditures of households and have economic impact on countries in terms of lost productivity and foregone economic growth associated with stunting and obesity. 


\section{Boosting job creation and incomes}

The real economy responds to world and domestic price adjustments in various ways, as noted already. When sluggish economic activity is the result, this will lead to unemployment, loss of wages and, consequently, loss of income. Before policies can be put in place to achieve the structural transformations that can shield the economy against these external shocks, policymakers may need to resort to other types of short-term responses to minimize or, even better, fully offset the impacts on food security and nutrition.

Social protection programmes can enable countries to protect the poor and vulnerable in the event of an economic slowdown or downturn, safeguarding their food security and nutrition, while also triggering other economic benefits. The example of school feeding illustrates the dual functionality of social protection in terms of improving food security and nutrition while promoting local economic activity (Box 18). But social protection can also foster human capital in the long run, including through the impacts on food security and nutrition, while enhancing the productive capacity of beneficiary households (Box 17). And because social protection is usually targeted towards poor and vulnerable groups, mainly through social assistance, it is a policy strategy than can tackle the inequalities that prevent many people from improving their food security and nutrition during economic booms - as has been the case for some low- and middle-income countries. ${ }^{208}$

To enhance their impact and role, countries are starting to develop risk-informed and shock-responsive systems during times of stability, strengthening certain mechanisms in order to identify not only the poorest households, but also those which could be most affected and in need of assistance when a shock occurs. ${ }^{209}$ Key features of these programmes include comprehensive social registries with information on poor and vulnerable households; and early-warning information systems to alert when, and in what manner, a programme response is required. To be effective, these programmes should be able not only to maintain the support provided at times of stability, but also to scale up at times of economic slumps. However, this can be particularly challenging during an economic slowdown or downturn if this leads to cuts in public social protection spending due to reduced government revenue. It requires both the existence of contingency mechanisms and funds - generated during periods of economic growth - and adequate institutional capacity. The successful scaling up of the system contributes to protect poor and vulnerable households, minimizing the likelihood that they use negative copying strategies with long-term consequences.

Kenya's Hunger Safety Net Programme (HSNP) is an example of a flexible and scalable social protection programme that provides a rapid response at times when the income of households is affected. ${ }^{210}$ During more stable times, it functions like a standard social assistance programme, delivering cash transfers to poor households in northern counties of Kenya. However, the HSNP is also prepared to quickly scale up its coverage to other vulnerable households during climate shocks, like droughts. ${ }^{211}$ For that purpose, the programme has registered all households living in high-risk locations and has opened a bank account for each of them. Using satellite data, an early warning system indicates when an area is affected by a severe weather event, allowing the programme to respond by delivering additional cash transfers to all the households in the affected areas.

Another important set of social assistance programmes are Public Works Programmes. These can be used as a short-term safety net to protect the purchasing power of poor and vulnerable households at times of economic slowdowns or downturns. ${ }^{212}$ Unlike cash transfers (Box 17), public works programmes do not require detailed information to identify their intended beneficiaries. They offer low-skill, low-paying temporary jobs, usually attracting those workers that are not able to find a job in the labour market. Through the generation of public jobs in the construction and rehabilitation of local infrastructure, this kind of programme provides poor households with a stable source of income during critical times and improves their access to basic services in the longer term. There are many costs and implications in terms of design and implementation, however, which should 
be taken into account when deciding on this type of intervention vis-à-vis unconditional cash transfers, particularly in fragile and crisis contexts. ${ }^{213}$

In some countries, for example the Republic of Korea after the crisis in 1997, public works programmes were implemented with the main objective of providing temporary jobs to unemployed workers. In others, such as Sri Lanka after the 2004 tsunami, programmes pursued a double objective: providing affected households with a reliable source of income and, at the same time, rebuilding community and basic infrastructure to speed up the recovery. Then there is the Mahatma Gandhi National Rural Employment Guarantee Scheme (MGNREGS), introduced by India in 2005, which is the largest public works programme in the world. Unlike the previous cases, the MGNREGS was not designed to address employment problems arising from an economic downturn or to rebuild infrastructure damaged by a natural disaster. Building on the experience of the state of Maharashtra, the MGNREGS instead guarantees up to 100 days of unskilled manual work on public projects during the lean seasons, at the statutory minimum wage, to all rural households. In this way, the programme helps rural households to stabilize their earnings and to smooth their consumption all along the year.

\section{Initial feasibility and subsequent sustainability of countercyclical policies}

One of the most important challenges faced by policymakers at the time of economic slowdowns or downturns is the limited amount of government resources to fund the implementation of public policies. Insufficient funding, or other political priorities, can hinder the possibility of maintaining and scaling up the support provided by the public sector to poor and vulnerable households. Establishing countercyclical financial mechanisms to safeguard regular, risk-informed and shock-responsive policies is fundamental to increasing resilience of households during critical times. Of course, this requires adequate institutional capacity to capitalize on episodes of economic boom in order to have the finances on hand when the situation becomes critical.
First and foremost, it is critical to strengthen the savings capacity of the economy before an economy slows down or contracts, so as to make countercyclical policies feasible in the first place. Commodity-dependent countries, in particular, would need to save more during periods of high commodity prices, and rely more on a set of existent tools such as, inter alia, automatic fiscal stabilizers, stabilization funds, sovereign wealth funds, macro-prudential norms, and the like. However, more broadly, there should also be actions to raise average saving rates in order to more durably insulate the stability of aggregate demand and avoid episodes of large (though temporary) real exchange rate appreciations. By limiting the size of macroeconomic disequilibria and providing more breathing room, higher saving rates should help reduce the risks of falling into restrictive policies, as has been the case in some countries. ${ }^{214}$ This can be critical to avoid reductions in public expenditure in priority sectors for food security and nutrition.

Fiscal policy also provides other instruments for generating funding, provided implementing reforms is fiscally and politically feasible. The available evidence ${ }^{215}$ indicates that most developing countries should enact reforms that simultaneously enhance the redistributive impact and improve the efficiency of fiscal policies. This would help generate additional fiscal space to safeguard policies aimed at protecting food security and nutrition at the time of slowdowns and downturns. On the tax side, developing countries may have room to increase the magnitude of tax revenues, and at the same time improve their composition (e.g. moving from indirect consumption taxes to direct income taxes). On the spending side, fiscal space could be generated by avoiding the fragmentation or inefficiency of social assistance programmes. The targeting of the different programmes could be improved as well, but this would entail additional costs and requirements that might make it unfeasible if economic conditions were unfavourable.

When contingency funds are available, programmes can be scaled up by, for example, providing extra support to current beneficiaries and/or by including new households among the beneficiaries. Two developing countries 
that were able to accomplish this in the past are Chile and Colombia. In these cases, countercyclical spending was financed by lowering overall spending in good times and increasing spending and/or borrowing in times of economic downturns. ${ }^{216}$ In the case of the state of Maharashtra in India, on the other hand, the rural Employment Guarantee Scheme is financed with taxes collected from the relatively richer urban households.

In the absence of contingency funds, countries can prioritize social spending during economic crises to increase their redistributive impact and protect food security and nutrition. A suitable alternative is refocusing policy responses towards those households most affected by the downturn and, in this way, increasing the positive effect of policies on food security and nutrition of the households most in need. Another alternative is relying on contributions of partners and donors. This is the case of the HSNP in Kenya, although the agency in charge (the National Drought Management Authority) is also working to increase the contribution of different levels of government.

\section{Fostering inclusive structural transformation to reduce economic vulnerability}

Section 2.2 of this report shows that the group of countries at higher risk of compromised food security and nutrition from economic slowdowns and downturns is mostly comprised of low- and lower-middle-income countries with high commodity dependence. Nevertheless, commodity dependence may be often unavoidable, particularly for countries in the first stages of development and structural transformation.

These countries should use the periods of commodity booms to invest wisely in order to develop other sectors of the economy and foster human capital accumulation to reduce inequalities and increase economic resilience. During these periods, these countries should not only ensure the adequate countercyclical mechanisms discussed previously but also implement long-term development actions with a structural development pathway in mind. ${ }^{217}$
This includes safeguarding and increasing expenditures on essential social services that will increase the resilience of households, and decrease population vulnerability to food insecurity and malnutrition, as prioritized in the Sustainable Development Goals. ${ }^{218}$

\section{Balancing policies and investments for inclusive transformation}

In pursuing a longer-term development strategy, countries will need to balance a set of policies and investments to achieve a structural transformation that also fosters poverty reduction and more egalitarian societies: i.e. pro-poor and inclusive transformation. During the early stages of transformation, countries need to seek broad-based growth that is labour intensive (especially for low-skilled labour), while investing heavily in the generation of human capital to enable the development of highly productive sectors and the diversification of their economies.

It is also important to understand labour markets and balance the right policies to meet labour demand and supply. As noted earlier, export-led growth strategies in Latin America led to a more unequal income distribution, precisely because of insufficient employment growth in modern sectors. There is evidence that investing in human capital without sufficient creation of skilled jobs results in high rates of unemployment (particularly for youth) and skill mismatches in the labour market, resulting in negative repercussions in terms of rising inequality of income and opportunities, and less poverty reduction. ${ }^{219}$ On the other hand, as economies continue to grow, countries (like many in Asia) are confronted by the need to upgrade the skills of their labour force to catch up with the labour demand of newly growing industries. ${ }^{220}$ It is important to overcome sectoral and spatial mismatches in the labour market looking at all employment possibilities (for example, through green jobs, entrepreneurship, skill training, diversification of on-farm/off-farm activities, and so forth) as well as incentives for sectoral mobility and migration (including seasonal/ circular migration).

Low- and lower-middle-income countries need to develop and expand their social protection 
systems while they wait the required time to see transformation in their economies and reap the rewards of investing in human capital. This may start from social assistance programmes that not only guarantee food security and a minimum income, but also support the poorest through both human capital accumulation and economic participation in society. ${ }^{\mathbf{2 2 1}}$ As countries move to more advanced stages of transformation, different types of social protection are needed to permanently support people's capacity to manage risk across the life cycle, moving from social insurance towards contributory social security. ${ }^{222}$ In this context, setting up measures to insure against setbacks to families, nations and regions, due to disabilities, recessions, disasters and disease, is another fundamental investment for safeguarding the progress made. ${ }^{\mathbf{2 2 3}}$ Investing in universal health coverage and primary health care is another important safeguard against such setbacks, and protects families from damaging out-of-pocket healthcare costs that can push families into poverty.

For transformation to be pro-poor and inclusive, in addition to investments, key reforms are often needed to enable more equal distribution of resources and access to social services. Examples of past reforms of this kind, and their positive impacts, have been seen in several countries, ${ }^{224}$ including the land reforms that transferred more land to poor farmers in the Republic of Korea and Taiwan Province of China (1940s to 1960s), and in Viet Nam (in the late 1980s and 1990s). China's establishment of the household responsibility system (1979) that held farmers responsible for the losses and profits of their agricultural activity boosted production and also massively reduced poverty in that country. The expansion of universal health insurance in Thailand (2000s) helped increase human capital, thus facilitating the participation of the poor in the economy.

The example of Costa Rica shows that moving away from commodity dependency is indeed possible. As noted earlier, this country has diversified its exports through trade reforms and an export-led growth strategy. Starting in the 1980s, it set up a number of initiatives to stimulate the diversification of the economy, including financial incentives (tax exemptions, subsidies, etc.) leading to the development of so-called "non-traditional exports" (i.e. pineapples, cut flowers, shrimps and textiles), which already in the 1990s had outpaced traditional exports (notably coffee and bananas). At the same time, food-related manufacturing developed and export-processing zones helped attract foreign direct investment inflows in the manufacturing and high-tech sectors. Growth in the services sector also contributed to the establishment of the strong tourism industry that exists today. ${ }^{\mathbf{2 2 5}}$ These transformations bore fruit to a large extent also because large investments had been made in human development. Costa Rica's education system has been a pioneer among Latin American countries, and has played an important role in the country's economic performance and in maintaining its democratic stability. ${ }^{\mathbf{2 2 6}}$

The role of agricultural development is also key for reducing food-import dependence and for achieving structural transformation in both low- and middle-income countries. ${ }^{\mathbf{2 2 7}}$ Countries with more suitable agricultural potential could invest to acquire a certain level of national staple production in order to lower food-import dependency. ${ }^{\mathbf{2 2 8}}$ At the same time, however, these countries should also seek to develop other sectors, capitalizing on initial investments in agriculture and its related industries. For "late transforming" low-income countries, where industrialization is lagging, agro-industrial development and strengthened rural-urban linkages have large potential for improving livelihoods and contributing to the eradication of poverty. ${ }^{229}$ Investing to diversify and better integrate small-scale agriculture into markets in low-income countries can lead to positive outcomes in terms of income generation (Box 19), which can potentially reduce poverty, food insecurity and malnutrition. Encouraging more diverse diets and enabling the accessibility of more diverse foods can help lower demand for food staples, ${ }^{\mathbf{2 3 0}}$ while stimulating the diversification of agricultural products, including that of local foods. ${ }^{\mathbf{2 3 1}}$ Finally, designing policies and interventions with a territorial perspective, recognizing the linkages of rural/agricultural areas with small cities/towns and larger cities, can lead to more dynamic growth of economic opportunities, including beyond agriculture. ${ }^{\mathbf{2 3 2}}$ 
Developing agro-industrial value chains opens up market opportunities for small-scale farmers, ${ }^{1}$ particularly in commodity-dependent countries such as Sao Tome and Principe, and Senegal. Sao Tome and Principe exports cocoa, and Senegal oil fuel, fishery products and gold; both are highly dependent on food imports. ${ }^{2}$ Commodity dependence makes them more vulnerable to commodity price shocks. Efforts by these countries to develop a sustainable and diversified agricultural sector in recent years have included policies and programmes to increase access to markets for small-scale producers (who make up the majority of these countries' workforces) while improving the quality of agricultural production. ${ }^{3}$

Senegal's agricultural sector accounts for 17.5 percent of its GDP. ${ }^{4}$ The country has experienced an economic slowdown since 2006, with its agricultural sector facing several shocks that have weakened its full potential. To address this challenge, the Government stepped up investment in agriculture to more than 10 percent of GDP annually beginning in 2009, and committed to transforming the agricultural sector. ${ }^{5}$ The Agricultural Value Chains Support Project (PAFA), for example, was implemented in the Groundnut Basin, a region that has suffered from high levels of poverty and food insecurity following a decline in global groundnut prices. The project aimed to improve the rural livelihoods and incomes of 16035 households by integrating small-scale producers into profitable and diversified value chains, and also to improve access to markets by establishing commercialization contracts with market operators.
The project was successful in increasing production commercialization of crops that had mainly been grown for domestic consumption. It also helped farmers to transition away from groundnut production, by investing in poultry rearing and vegetable growing. ${ }^{6}$ Evidence from an impact assessment of the project found that as a result of PAFA, crop income increased by 48 percent, and total income increased by 11.3 percent, within those households participating in the project. $^{7}$

The experience of Sao Tome and Principe shows that inclusive rural transformation can also be achieved through strengthening linkages between farms and markets, while also achieving positive outcomes in food security and nutrition. The Government launched the Participatory Smallholder Agriculture and Artisanal Fisheries Development Programme (PAPAFPA) in 2003, followed by the Smallholder Commercial Agriculture Project (PAPAC) in 2015. This helped promote the commercialization of organic, high quality cocoa, coffee and pepper by creating farmer cooperatives and establishing family plantations to increase sales to domestic and export markets. Results from the impact assessment of these programmes demonstrated positive and significant impacts on agricultural incomes (an increase of 46 percent, 77 percent of which was derived from cocoa, coffee and pepper); and on dietary diversity (an increase of 5 percent). Another result of the project was an increase in take-up of organic certification among the

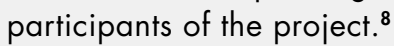

\footnotetext{
${ }^{1}$ T. Reardon, C.B. Barrett, J.A. Berdegué and J.F. Swinnen. 2009. Agrifood industry transformation and small farmers in developing countries. World Development, 37(11): $1717-1727$. 2 UNCTAD. 2017. The State of Commodity Dependence 2016. Geneva, Switzerland, and New York, USA.

${ }^{3}$ IFAD. 2016. Rural Development Report 2016. Fostering inclusive rural transformation. Rome.

${ }^{4} \mathrm{FAO}$. 2015. Senegal: country fact sheet on food and agriculture policy trends [online]. Rome. [Cited 7 May 2019]. http://www.fao.org/3/a-i484le.pdf

5 USAID. 2019. Increasing inclusive economic growth in Senegal. In: USAID [online]. Updated 9 April 2019. Washington, DC. [Cited 7 May 2019]. https://www.usaid.gov/senegal/factsheets/increasing-inclusive-economic-growth-senegal

${ }^{6}$ IFAD. 2018. Results from the field. IFAD Results Series Issue 3. Rome.

${ }^{7}$ A. Garbero, D. Diatta and M. Olapade. forthcoming. Impact assessment report: Agricultural Value Chains Support Project, Senegal.

${ }^{8}$ A. Garbero, M. Improta and S. Gonçalves. forthcoming. Impact assessment report: Smallholder Commercial Agriculture Project and Participatory Smallholder Agriculture and Artisanal Fisheries Development Programme, Sao Tome and Principe.
} 
n) could, at the same time, lower the negative impacts of economic slowdowns and downturns on food security and nutrition; however, agricultural transformation does not always necessarily meet food-security and nutrition objectives. Besides the pro-poor nature of transformation, the positive effects of agricultural transformation on food security and nutrition will depend on the type of commodities and the quality of food that is generated under this process, and on fostering better access for everyone to more nutritious foods. ${ }^{\mathbf{2 3} 3}$ The overlap of policies for food security and nutrition with others seeking to foster economic development, particularly those with a focus on poverty reduction, is further discussed in the last section.

Finally, an important point is that mobilizing investments for achieving economic diversification requires effective political leadership to address the related issues of governance and the political economy of economic and social transformation. For example, investment in human development in commodity-dependent countries, which are often low-income countries, tends to be low. ${ }^{\mathbf{2 3 4}}$ This is explained not only by lack of resources, but also by the level of democratization of governments and capacity of government institutions. When democratization and institutional capacity are lacking, it may result in some forms of rent-seeking that impede economic growth (or prevent countries from fully taking advantage of commodity price booms) and create further social inequalities.

\section{Making the most of trade for food security and nutrition}

While economic and export diversification and domestic market development are necessary to reduce the external vulnerability that challenges food security and nutrition, import diversification is also needed as part of a larger transformation, including in food systems, towards healthier diets. Therefore, international trade as a whole, and the global, regional and unilateral policies that shape it, also need to feature prominently in the minds of policymakers when promoting this transformation.
Global, regional and unilateral trade policies are more important than ever. It was highlighted earlier that a number of universal policies can help stabilize food prices, including restrictions on exports of staple food items, or import-tariff cuts. The latter can also boost domestic production of food in the medium and long term. However, the importance of trade policies extends beyond their role in stabilizing food prices and boosting food production. These policies need to be carefully crafted to be among the triggers of a sustainable transformation.

World agricultural and food markets are increasingly integrated. This is largely driven by trade and investment policy, which influences food systems at global, regional and national levels, shaping aspects of food environments such as food availability, prices, quality, and food-security and nutrition outcomes. ${ }^{\mathbf{2 3 5}}$

Broadly speaking, trade is good for food security. By moving food from surplus to deficit countries, trade can ensure the availability and variety of food, and promote access and stable prices. Trade can also promote dietary diversity, which is recognized as essential for adequate nutrient intake and human health. For some countries, especially low-income ones, diets reflect the diversity of foods produced, such as in Nepal. ${ }^{\mathbf{2 3 6}}$ At the same time, trade is associated with the "nutrition transition" where diets become richer in animal sourced foods, and highly-processed foods often high in fat, sugar and salt are more widely available as average income increases. For example, Mexico's exposure to food imports from the United States of America explains four percent of the rise in obesity prevalence among Mexican women between 1988 and 2012. ${ }^{\mathbf{2 3 7}}$

In spite of the benefits, policymakers still need to be careful that trade policies and agreements are not detrimental to nutrition objectives especially given that these policies rarely, if ever, consider healthy diets as their underlying rationale. ${ }^{238}$ This is quite important, considering that global trade in food and agricultural commodities has increased significantly, so there is potential for it to contribute to nutrition objectives, as noted above. This will not only require considering the impacts of trade policy on nutrition, but also enhanced coherence " 
International trade has the potential to make healthy foods available to populations and foster demand for healthier food commodities. Nonetheless, trade policy rarely, if ever, considers healthy diets as its underlying rationale. Thus, rather than driving healthy diets, trade is often associated with forms of malnutrition. ${ }^{1}$

As depicted in the figure below, trade of agricultural and food products is among the key factors mediating between trade policy and the food environment.

Other key factors include foreign direct investment and domestic policies addressing nutrition goals.

Global trade in food and agricultural commodities has increased significantly in the past half century, both in terms of the quantity and value of commodities traded. ${ }^{2}$ Also, foreign direct investment (FDI) has been on the rise, partly as a result of trade agreements. FDI in food and agriculture is a way of "domesticating" the food supply and deepening the capacity of the national food system, without increasing food imports. The health impacts of these changes are mixed and dependent on various factors, including whether the food products traded or the type of food-related FDI is healthy or unhealthy. FDI has been shown to be a key driver of growth in sugar-sweetened beverage (SSB) consumption. ${ }^{3}$
Increased trade in food and agricultural commodities has been accompanied by significant changes in the governance of trade. Increasingly, trade agreements are negotiated outside of the multilateral system of the World Trade Organization (WTO). The trade agreements negotiated both within the WTO system and outside of the WTO system are often characterized by power imbalances between participating countries and can be strongly influenced by the interests of multinational companies. Particularly problematic are regional and bilateral trade agreements that include unprecedented clauses, particularly strong investor protections with potentially deep impacts on domestic policy space. ${ }^{4}$

It is critical for country decision makers to consider the impacts of trade policy on nutrition, and to enhance coherence between trade policy and action on nutrition. However, achieving such policy coherence will require collaboration and coordination between two different stakeholder groups - from both the "trade" and "nutrition" communities - including agreement on policy objectives. This poses a significant challenge given the different worldviews, institutional

\section{CONCEPTUAL FRAMEWORK OF KEY RELATIONSHIPS BETWEEN TRADE POLICY, NUTRITION AND HEALTH OUTCOMES}

\section{TRADE POLICY}

\section{KEY AREAS OF MEDIATING IMPACT}

Trade in goods (imports/exports)

Foreign direct investment

Shaping policy and regulatory space for addressing nutrition goals

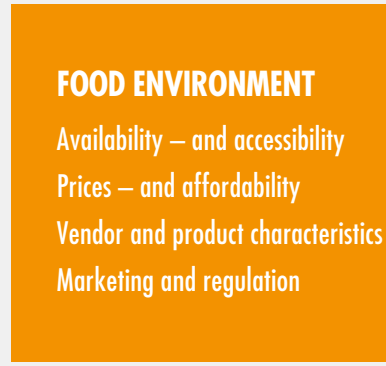

FOOD ACQUISITION AND CONSUMPTION
NUTRITION AND HEALTH OUTCOMES

SOURCES: Adapted from C. Turner, A. Aggawal, H. Walls, A. Herforth, A. Drewnowski, J. Coates, S. Kalamatianou and S. Kadiyala. 2018. Concepts and critical perspectives for food environment research: a global framework with implications for action in low- and middle-income countries. Global Food Security, 18: 93-101; S.G.D. Cuevas, L. Cornelsen, R. Smith and H. Walls. 2019. Economic globalization, nutrition and health: a review of quantitative evidence. Globalization and Health, 15: 15. 
norms, interests and power imbalances between the two communities. ${ }^{5}$

However, the positive news is that there have already been some agreements negotiated that point in the right direction. At the Second International Conference on Nutrition (ICN2), ${ }^{6} 164$ Members of FAO and WHO agreed upon and recognized the important impact of trade on nutrition, recommending two policy actions to improve availability and access of the food supply through trade, to ensure that trade agreements do not have a negative impact on the right to adequate food in other countries. Further, building on the ICN2 commitments, the UN Decade of Action on Nutrition ${ }^{7}$ identified six cross-cutting action areas, including: "trade and investment for improved nutrition", focusing on identification of opportunities to achieve global food security and nutrition targets through trade and investment policies; and the implementation of the Principles for Responsible Investments in Agriculture and Food Systems. ${ }^{8}$ Trade and investment are of critical importance in supporting healthier diets and contribute to the achievement of SDG 2 lending hunger and reducing malnutrition in all its forms by 2030).

\footnotetext{
${ }^{1}$ The food environment can be defined as "the interface that mediates people's food acquisition and consumption within the wider food system. It encompasses external dimensions such as the availability, prices, vendor and product properties and promotional information; and personal dimensions such as the accessibility, affordability, convenience and desirability of food sources and products" from C. Turner, A. Aggarwal, H. Walls, A. Herforth, A. Drewnowski, J. Coates, S. Kalamatianou and S. Kadiyala. 2018. Concepts and critical perspectives for food environment research: a global framework with implications for action in low- and middle-income countries. Global Food Security, 18: 93-101; H. Walls, R. Smith, S. Cuevas and J. Hanefeld. forthcoming. International trade and investment: still the foundation for addressing nutrition-related non-communicable diseases in the era of Trump? ${ }^{2}$ FA0. 2018. The State of Agricultural Commodity Markets 2018. Agricultural trade, climate change and food security. Rome.

3 P. Baker, S. Friel, A. Schram and R. Labonte. 2016. Trade and investment liberalization, food systems change and highly processed food consumption: a natural experiment contrasting the soft-drink markets of Peru and Bolivia. Globalization and Health, 12(1): 24; A. Schram, R. Labonte, P. Baker, S. Friel, A. Reeves and D. Stuckler. 2015. The role of trade and investment liberalization in the sugar-sweetened carbonated beverages market: a natural experiment contrasting Vietnam and the Philippines. Globalization and Health, $11(1): 41$. ${ }^{4}$ R. Baldwin. 2011. 21st Century Regionalism: Filling the gap between 21st century trade and 20th century trade rules. Staff Working Paper ERSD-2011-08 [online]. Geneva, Switzerland, World Trade Organization (WTO). [Cited 6 May 2019]. https://www.wto.org/english/res_e/reser_e/ersd201108_e.pdf; H.L. Walls, R.D. Smith and P. Drahos. 2015. Improving regulatory capacity to manage risks associated with trade agreements. Globalization and Health, 11: 14; D. Gleeson and S. Friel. 2013. Emerging threats to public health from regional trade agreements. The Lancet, 381(9876): 1507-1509.

${ }^{5}$ H. Walls, P. Baker and R. Smith. 2015. Commentary: Moving towards policy coherence in trade and health. Journal of Public Health Policy, 36(4): 491-501.

${ }^{6} \mathrm{FAO}$ and WH0. 2014. Conference Outcome Document: Framework for Action [online]. Second International Conference on Nutrition. Rome, 19-21 November 2014. ICN2 2014/3 Corr.l. [Cited 7 May 2019]. http://www.fao.org/3/a-mm215e.pdf

7 UN. 2019. Decade of Action on Nutrition (2016-2025). In: United Nations [online]. New York, USA. [Cited 7 May 2019]. www.un.org/nutrition

${ }^{8}$ Committee on World Food Security (CFS). 2014. Principles for responsible investment in agriculture and food systems - decision box [online]. Forty-first Session - "Making a Difference in Food Security and Nutrition". Rome, 13-18 0ctober 2014. CFS 2014/41/4 Add.1. [Cited 7 May 2019]. http://www.fao.org/3/a-ml620e.pdf
}

" between trade policy and action on nutrition. Achieving such policy coherence depends on strengthening cross-sectoral collaboration and coordination, and improving governance of policymaking processes at global, regional and country levels (Box 20).

\section{Multisectoral policies for sustaining escapes from food insecurity and malnutrition, with a focus on poverty and inequalities}

As seen earlier in the report, the impact of economic slowdowns and downturns on food security and nutrition cannot be separated from poverty and inequality issues. The interactions between poverty and hunger and malnutrition 
form a vicious trap, where poverty is a cause of hunger and where a lack of adequate and proper nutrition is itself an underlying cause of poverty. ${ }^{239}$ However, poverty reduction strategies and policies are not sufficient to reduce hunger and malnutrition, including in the context of economic slowdowns and downturns, particularly if important inequalities prevail. This last section looks at how multisectoral policies for food security and nutrition are linked to policies for the reduction of poverty and inequality. It points to the importance of reinforcing these with specific actions, focusing particularly on nutrition.

\section{How does poverty reduction play a role and what} policies can be strengthened?

The disconnect between poverty alleviation and improvements in food security and nutrition has recently become more apparent, as seen in Section 2.3. Several countries have made significant progress in reducing poverty; however, similar progress in food security and nutrition has not been realized.

Of course, the relationship between poverty and food security and nutrition is also complicated by the different ways in which these two phenomena are measured, and by the limited research that has addressed both in a comparative manner. Moreover, vulnerability to poverty and to food insecurity and malnutrition is also defined through different concepts; thus, in practice, it may be difficult to identify which phenomenon manifests first in a given situation in order to understand causal relationships. ${ }^{240}$ For example, poor households may go hungry after a period of utilizing and depleting their resource base, showing poverty and vulnerability to food insecurity, but not actual undernourishment. Similarly, food may suddenly become physically unavailable to a household due to a idiosyncratic shock, even for non-poor households with the resources to buy nutritious food. Higher incomes can also increase food consumption, but this does not guarantee positive outcomes in nutrition. ${ }^{241}$

From a policy perspective, these complexities have important implications. While similar policy instruments may apply in some cases for achieving both poverty reduction and food security, the specificities of food security and nutrition should be emphasized and addressed more comprehensively. ${ }^{\mathbf{2 4 2}}$ Table 12 helps explain the ways in which policies and actions for reducing poverty can follow a more coherent multisectoral approach to food security and nutrition, using the four pillars of food security. The table also highlights constraints that may prevent the poverty reduction policies from helping to improve food security and nutrition. Sociocultural factors may play an important role for the feasibility of all these multisectoral policies; however, they can be rather context specific. The table, nonetheless, identifies some of the cultural characteristics that generally act as constraints to achieving outcomes in food security and nutrition.

\section{Overcoming the constraints listed in Table 12} requires looking at coherent integrated policies for poverty reduction and eradication of food insecurity and malnutrition. However, because the relationship between these phenomena may be bidirectional, actions towards sustainable food security and nutrition should also consider a long-term view of poverty reduction and economic growth, as well as resilience through preparedness mechanisms and shock-responsive social protection.

A number of countries have been strengthening food security and nutrition outcomes in their poverty-reduction interventions.

Social protection (social assistance in particular) can help address some of the economic and social determinants of malnutrition, including when targeting all nutritionally vulnerable populations to food insecurity and malnutrition (including infants and young children, pregnant and lactating women, people living with HIV/AIDS, older people, and those who are sick) or when ensuring that appropriate linkages with health, education and agriculture are strategically made for food security and nutrition.

Nutrition-sensitive social protection (NSSP) can be made possible by fostering policy coherence across these sectors, and by facilitating programmes that integrate different components like social assistance (e.g. cash transfers), access to nutrition education, health services, and nutrition-sensitive agriculture. ${ }^{\mathbf{2 4 3}}$ For example, since 2013, Lesotho has been working to " 


\section{TABLE 12 \\ MULTISECTORAL POLICIES FOR REDUCING POVERTY, AND THE CONSTRAINTS THAT MUST BE OVERCOME TO IMPROVE FOOD SECURITY AND NUTRITION}

Poverty reduction policies addressing each food security pillar

\section{Physical availability of food*}

- Promoting poor farmers' productivity increases the production and the availability of food for the poor at the national level; however, this depends on the potential of the production frontier, type of crop and the market where agricultural production is sold.

- Facilitating trade of food products allows poor consumers to access food commodities at lower prices.
Constraints to achieving sustainable outcomes in food security and nutrition

\section{Economic and physical access to food**}

- Several poverty reduction policies aim to increase economic inclusion of the poor, which also expand their access to food and to productive resources (including land and water) and markets; and provide support to increase productivity and develop other incomegenerating opportunities.

- Ensuring a minimum income can be achieved through: social protection systems, work promotion programmes supporting agricultural production of poor farmers and their access to markets; and more broadly, rural development programmes, investment in employment generation, and developing entrepreneurship.

- Supporting long-term investments in children's education and school feeding, and ensuring their access to appropriate care and health services, also helps to expand their future economic prospects and reduce the intergenerational transmission of poverty.

- Basic infrastructure and roads, particularly in rural areas, and the development of markets in urban and peri-urban areas facilitates physical access to food.

\section{Food utilization***}

- Basic investments in the quality of diets; quality of health education; and water, sanitation and hygiene (WASH) can improve childcare and feeding practices, maternal nutrition, dietary choices of consumers and food preparation.

- Together with improvements in information on the quality of diets, these can help prevent diseases which can affect food utilization and exacerbate malnutrition.
- Cultural characteristics related to gender and social inequalities, as well as other behavioural aspects, could affect equal access to food by all members in the household. They could also affect the prioritization of food, particularly of quality food, over other expenditures. These factors affect both poor and non-poor households.

- Supporting women's economic empowerment, as part of poverty reduction efforts, may present trade-offs in terms of their time for breastfeeding, caring for infants and young children, and food preparation. Poverty-reduction programmes often fail to address these constraints and provide additional support, including working with the whole household to reconsider existing gender roles and share household responsibilities; this can compromise women's nutritional well-being as well as that of their families.

- Raising the profile of traditional foods and ensuring their affordability would also require that enhanced support is provided to poor farmers.

- In urban areas, fostering more enabling environments for healthy food choices can be supported by zoning policies and social support systems, including safe redistribution of unsold food for charities to improve access to healthy foods; promotion of urban agriculture; and shorter food supply chains that reconnect cities to their zones of influence.

- In the absence of universal health coverage, poor health and/or catastrophic out-of-pocket healthcare costs can undermine achievement or a minimum income or reduce expenditure available for food.

- More nutrition-specific interventions that address the immediate causes of malnutrition, and some of its underlying causes (e.g. lack of nutrition education) are often not seen as part of poverty reduction strategies. The food accessible to the poor, but also the non-poor, may be suboptimal for improved nutrition and health. Micronutrient deficiencies are often more prevalent among the poor.

- There are other issues related to the microbiome and its impact on food and agriculture, which simultaneously affect human nutrition.

- Women's lack of empowerment and intra-household gender relations, and women's lack of knowledge and understanding of nutritional issues jeopardize utilization. 
Poverty reduction policies addressing each food security pillar
Constraints to achieving sustainable outcomes in food security and nutrition

\section{Stability of the other three dimensions over time****}

- Actions to sustain economic growth and foster preparedness mechanisms can help improve resilience in the face of economic and climate-related shocks more broadly.

- Shock-responsive social protection systems can expand cash transfers (conditional or unconditional depending on the existing level of institutionality), cash for work or food for work programmes when covariate or intrinsic shocks occur.

- School feeding programmes and insurance mechanisms can enable the stability of food security over time.

NOTES: * Food availability addresses the "supply side" of food security and is determined by the level of food production, stock levels and net trade. ${ }^{* *}$ An adequate supply of food at the national or international level does not in itself guarantee household level food security. Concerns about insufficient food access have resulted in a greater policy focus on incomes, expenditure, markets and prices in achieving food security objectives. *** Utilization is commonly understood as the way the body makes the most of various nutrients in the food. Sufficient energy and nutrient intake by individuals are the result of good care and feeding practices, food preparation, diversity of the diet and intrahousehold distribution of food. Combined with good biological utilization of food consumed, this determines the nutritional status of individuals. ${ }^{* * * *}$ Even if your food intake is adequate today, you are still considered to be food insecure if you have inadequate access to food on a periodic basis, risking a deterioration of your nutritional status. Adverse weather conditions, political instability, or economic factors (unemployment, rising food prices) may have an impact on your food security status.

SOURCE: Social Protection Interagency Cooperation Board (SPIAC-B). forthcoming. Interagency social protection assessment tool on social protection programmes for food security and nutrition.

" improve the resilience and food and income security of the extreme poor by creating synergies between social protection and agriculture interventions. Lesotho's innovative approach complements the existing national cash transfer programme, the Child Grant Programme (CGP), with home gardening and nutrition kits and training, paying special attention to those households most affected by drought, which are not only poor but also vulnerable to food insecurity. Rigorous impact evaluations of the CGP and of additional interventions have provided strong evidence that, when all these elements are combined, a stronger impact in reducing poverty and nutrition is simultaneously achieved. ${ }^{\mathbf{2 4 4}}$

However, these efforts will not be enough to protect food security and nutrition, particularly during periods of economic slowdowns and downturns, if the multisectoral approach does not address determinants of nutrition such as food security, care, health, and water, sanitation and hygiene (WASH). The health system is the primary channel through which to address some of these determinants. ${ }^{245}$ In recent years, Ethiopia, Uganda and the United Republic of Tanzania have all been working to scale up their nutrition interventions in this regard. These three countries have focused on essential maternal, infant and young child nutrition during the first 1000 days. In Ethiopia, local evidence convinced policymakers of the need to address anaemia among adolescent girls. In Uganda, participatory district assessments brought stakeholders together around evidence-informed nutrition actions. And in the United Republic of Tanzania, district-level investments for nutrition increased when capacity was developed for planning and budgeting. ${ }^{246}$ Universal interventions for food security and nutrition like these are necessary in order to avoid leaving out not only the poor but also several other, non-poor populations who may be at risk of food insecurity.

\section{Economic and social inequalities impede progress in} food security and nutrition

Inequality can limit opportunities for households to escape poverty, food insecurity and malnutrition. Because of income inequality, the poor are not able to benefit from economic booms - as they disproportionally accrue less income compared to others - and nor do they have sufficient income streams to better cope during episodes of economic difficulty. But, as noted earlier, finding sustained escapes from food insecurity, malnutrition and poverty also depends on having adequate access to basic services, in particular: care, health and WASH. Unfortunately, there are still great inequalities 
within low- and middle-income countries in the access of these basic services. The reasons for the existing gaps need to be further analysed, including from a perspective of political economy and corruption prevention.

The stark inequalities that are observed between urban and rural areas in some developing countries demonstrate how processes of economic growth and transformation can be unequal. Poverty reduction and development efforts need to focus more on raising agricultural productivity and rural incomes, generating wider employment opportunities and integrating rural areas more effectively into mechanisms of national economic development. In doing so, it is important to conceive rural development as an endeavour that involves other actions beyond agriculture. In the twenty-first century, rurality cannot be seen to be synonymous with decline, as this view risks neglecting essential opportunities for economic growth and social development. The revalorization of rural spaces is needed, and with that, the adoption of rural policies that leverage regional assets rather than exclusively pursuing a compensatory approach. ${ }^{\mathbf{2 4 7}}$ At the same time, there is a need to increase the resilience and address the food security and nutrition needs of urban residents living in extreme poverty, including by creating healthier food environments and by ensuring that the urban poor are able to access WASH services from which, despite better urban provision, they are often excluded.

Often, inequality is nested within the household, with gender inequalities still persistent across all regions, and in both developed and developing countries. As seen in the previous sections and in Section 1.1 in Part 1, women are at higher risk of undernourishment than men, and women of reproductive age tend to be more vulnerable to food insecurity and malnutrition. In order to reduce gender inequalities, more dedicated and comprehensive policies and development approaches are required that specifically target women's economic empowerment and nutrition. Integrated approaches for women could include access to reproductive health services and nutrition services, care services, skills training and access to employment, maternity protection and social protection. In addition to assets and access to basic services, these approaches should directly address gender inequalities by focusing on the people involved: understanding who they want to be, what they want to do, and how they can achieve their goals using a joint vision and practical strategy. ${ }^{\mathbf{2 4 8}}$ At the same time, this requires understanding human behaviour, fostering community awareness, and identifying effective incentives for women to access services and support.

Beyond gender inequalities, other social inequalities derived from discrimination and exclusion of population groups based on ethnicity, caste or religion - also noted earlier - hamper any potential advancement in ensuring food security and good nutrition. Social discrimination and exclusion of these population groups can be reversed only through policies and social mobilization to address the multiple challenges they face. There are a number of possible actions to this end, including: legal, regulatory and policy frameworks to promote social inclusion; national public expenditure; improving access to and adequacy of public services (sometimes exclusively targeted to these population groups); empowering institutions, their organizational capacity and their participation in decision-making processes; increasing accountability to protect human rights; and working to gradually change discriminatory attitudes and behaviours. ${ }^{249}$

\subsection{CONCLUSIONS}

This year's report continues to signal the significant challenges that remain in the fight against hunger, food insecurity and malnutrition in all its forms. Part 2 calls for bolder actions to address these challenges in the face of economic slowdowns and downturns. The latest global economic prospects warn of slowing and stalled economic growth in many countries, including emerging and developing economies. Episodes of financial stress, elevated trade tensions, declining commodity prices, and tightening financial conditions are all contributing to these increasingly grim prospects. 
Part 2 has presented new evidence confirming that:

- hunger has been on the rise for many countries where the economy has slowed or contracted - strikingly, the majority of these are not low-income countries, but middle-income countries;

- economic shocks are prolonging and worsening the severity of acute food insecurity, in food crisis countries;

- economic slowdowns tend to be sharper and economic contractions deeper and longer lasting for commodity-dependent countries; and

> economic events generally have a harsher effect on food security and nutrition when extreme poverty and inequalities are greater.

Inequalities in income and in access to basic services and assets, as well as social exclusion and marginalization of groups, are preventing large numbers of people from reaping benefits during times of strong economic growth, or from coping adequately during periods of economic slowdowns or downturns. The new evidence in Part 2 points to the fact that these slowdowns and downturns disproportionally undermine food security and nutrition where inequalities are greater, particularly in middle-income countries. Income and wealth inequalities are also closely associated with undernutrition, while more complex inequality patterns are associated with obesity. Therefore, reducing these inequalities must be a primary goal, either as a means to improving food security and nutrition, or as an outcome of doing so.

The report calls for action on two fronts to safeguard food security and nutrition from economic slowdowns and downturns. In the short term, countries need to protect incomes so as to counteract economic adversity. To enhance the contingency mechanisms and financial capacity that policymakers need to respond, it is critical to strengthen savings capacity when the economy is growing, using available instruments (automatic fiscal stabilizers, stabilization funds, sovereign wealth funds, macro-prudential norms, and the like), so as to make countercyclical policies feasible. Policies may include targeted social protection programmes, including conditional or unconditional cash transfers and school feeding; public works programmes that help reduce unemployment; or policies aimed at stabilizing food prices, and protecting incomes from damaging out-of-pocket healthcare costs by ensuring full coverage of essential health services. The potential unintended consequences for nutrition must be carefully considered throughout, and cuts to essential social services, including health, must be avoided at all costs.

In the longer term, countries need to invest wisely during periods of economic booms to reduce economic vulnerabilities and build capacity to withstand and quickly recover when economic turmoil erupts. This requires balancing a set of policies and investments to achieve an inclusive structural transformation that diversifies the economy away from commodity dependence, while also fostering poverty reduction and more egalitarian societies.

This includes transforming agriculture and food systems such that the type of commodities and the quality of food that they produce contribute to improving access to more nutritious foods for all. Measures to increase dietary diversity and to create healthier food environments are required to prevent economic slowdowns or downturns from undermining the nutritional quality of diets. Policymakers must ensure that facilitating trade access does not have unintended negative consequences for food security and nutrition in sectors that would in principle be affected by the increase in trade access. Integrating food security and nutrition concerns into poverty reduction efforts, while increasing synergies between poverty reduction and hunger eradication, must also be part of the transformation.

Ensuring that this transformation is pro-poor and inclusive will not be possible by focusing on economic growth alone: it will require tackling existing inequalities at all levels, through multisectoral policies that keep these inequalities as the central focus. Ultimately, this kind of transformation will only materialize if policies effectively strengthen the economic resilience of countries to safeguard food security and nutrition at those times when the economy slows or contracts. 


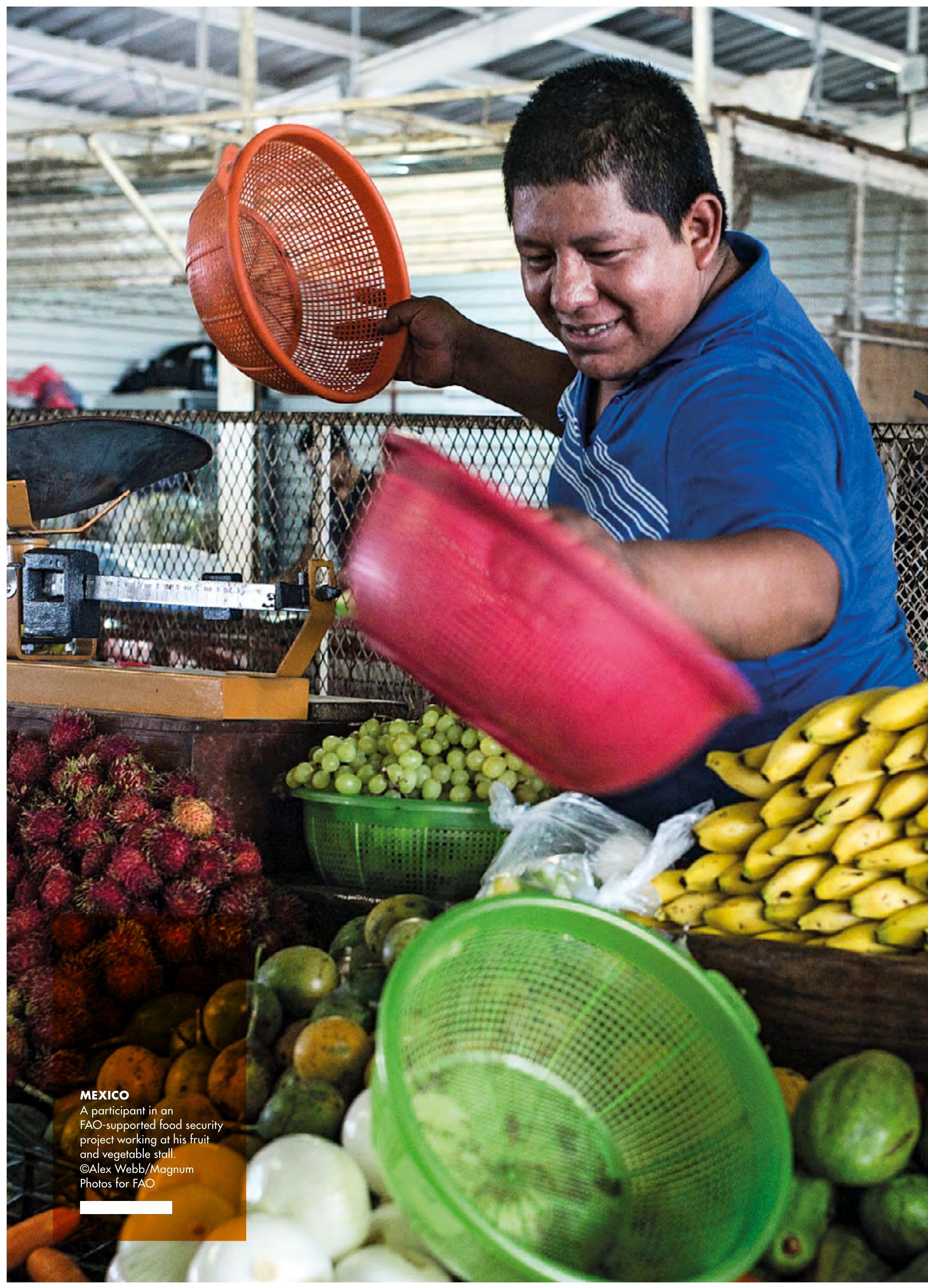




\section{ANNAX}

\section{ANNEX 1A. STATISTICAL TABLES TO PART 1}

TABLE AI.1

PROGRESS TOWARDS THE SUSTAINABLE DEVELOPMENT GOALS (SDGS): PREVALENCE OF UNDERNOURISHMENT, MODERATE OR SEVERE FOOD INSECURITY,

SELECTED FORMS OF MALNUTRITION, EXCLUSIVE BREASTFEEDING AND LOW BIRTHWEIGHT

\begin{tabular}{|c|c|c|c|c|c|c|c|c|c|c|c|c|c|c|c|c|c|c|c|}
\hline \multirow[t]{3}{*}{$\begin{array}{l}\text { REGIONS/ } \\
\text { SUBREGIONS/ } \\
\text { COUNTRIES }\end{array}$} & \multicolumn{2}{|c|}{ 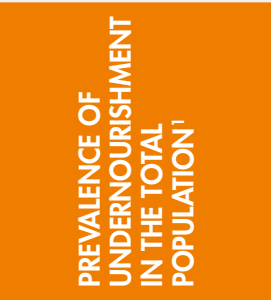 } & \multicolumn{2}{|c|}{ 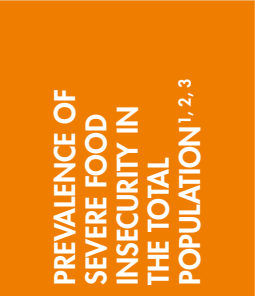 } & \multicolumn{2}{|c|}{ 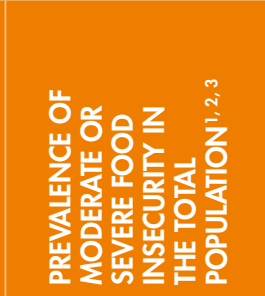 } & \multirow[t]{2}{*}{ 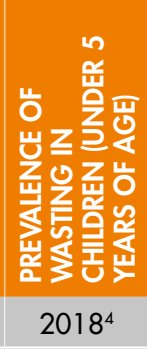 } & \multicolumn{2}{|c|}{ 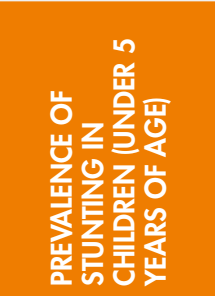 } & \multicolumn{2}{|c|}{ 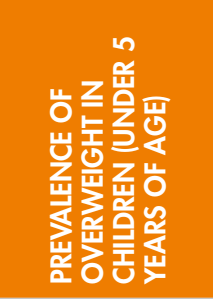 } & \multicolumn{2}{|c|}{ 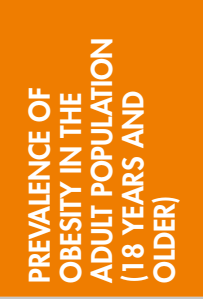 } & \multicolumn{2}{|c|}{ 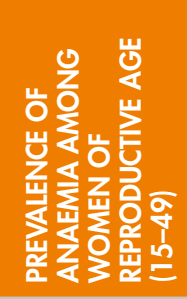 } & \multicolumn{2}{|c|}{ 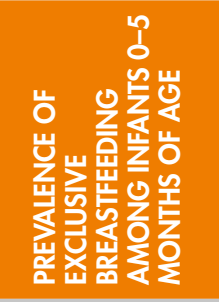 } & \multicolumn{2}{|c|}{ 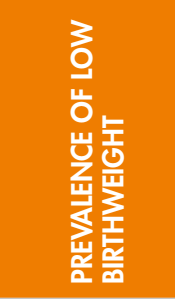 } \\
\hline & $2004-06$ & $2016-18$ & $2014-16$ & $2016-18$ & $2014-16$ & 2016-18 & & $2012^{5}$ & $2018^{4}$ & $2012^{5}$ & $2018^{4}$ & 2012 & 2016 & 2012 & 2016 & $2012^{6}$ & $2018^{7}$ & 2012 & 2015 \\
\hline & $\%$ & $\%$ & $\%$ & $\%$ & $\%$ & $\%$ & $\%$ & $\%$ & $\%$ & $\%$ & $\%$ & $\%$ & $\%$ & $\%$ & $\%$ & $\%$ & $\%$ & $\%$ & $\%$ \\
\hline WORLD & 14.4 & 10.7 & 7.9 & 8.7 & 23.5 & 25.4 & 7.3 & 25.0 & 21.9 & 5.5 & 5.9 & 11.7 & 13.2 & 30.3 & 32.8 & 36.9 & 41.6 & 15.0 & 14.6 \\
\hline $\begin{array}{l}\text { Least Developed } \\
\text { Countries }\end{array}$ & 28.6 & 23.6 & 20.3 & 22.4 & 49.4 & 52.5 & 8.5 & 37.7 & 32.1 & 3.2 & 3.9 & 4.4 & 5.4 & 39.3 & 39.6 & 44.9 & 50.8 & 16.2 & 15.6 \\
\hline $\begin{array}{l}\text { Land Locked } \\
\text { Developing Countries }\end{array}$ & 26.4 & 21.9 & 17.4 & 19.6 & 46.5 & 50.8 & 6.8 & 35.1 & 30.8 & 3.8 & 3.8 & 7.3 & 8.3 & 32.1 & 33.1 & 45.5 & 53.2 & 14.3 & 13.9 \\
\hline $\begin{array}{l}\text { Small Island } \\
\text { Developing States }\end{array}$ & 21.1 & 17.5 & n.a. & n.a. & n.a. & n.a. & n.a. & n.a. & n.a. & n.a. & n.a. & 18.6 & 20.9 & 30.0 & 31.5 & 36.6 & 31.6 & 11.2 & 11.1 \\
\hline $\begin{array}{l}\text { Low-income } \\
\text { countries }\end{array}$ & 30.3 & 27.7 & 23.0 & 25.8 & 54.0 & 58.3 & 7.4 & 38.1 & 34.2 & 3.3 & 3.1 & 5.7 & 6.8 & 38.2 & 38.4 & 43.5 & 49.9 & 14.8 & 14.3 \\
\hline $\begin{array}{l}\text { Lower-middle- } \\
\text { income countries }\end{array}$ & 19.6 & 13.8 & 10.7 & 10.9 & 29.6 & 30.6 & 11.6 & 35.7 & 31.1 & 3.7 & 3.9 & 6.5 & 7.6 & 42.2 & 43.0 & 39.4 & 47.6 & 20.6 & 19.9 \\
\hline $\begin{array}{l}\text { Upper-middle- } \\
\text { income countries }\end{array}$ & 11.6 & 7.1 & 7.5 & 8.7 & 26.0 & 28.6 & 1.8 & 9.2 & 6.3 & 7.2 & 7.4 & 12.2 & 13.8 & 22.3 & 26.1 & 28.7 & 23.9 & 7.4 & 7.3 \\
\hline $\begin{array}{l}\text { High-income } \\
\text { countries }\end{array}$ & $<2.5$ & $<2.5$ & 1.8 & 1.9 & 8.8 & 8.6 & $0.6^{\mathrm{a}}$ & 3.3 & $3.0^{\circ}$ & 6.7 & $7.2^{\mathrm{a}}$ & 22.6 & 24.6 & 15.4 & 18.0 & n.a. & n.a. & 7.6 & 7.6 \\
\hline $\begin{array}{l}\text { Low-income food- } \\
\text { deficit countries }\end{array}$ & 22.7 & 18.4 & n.a. & n.a. & n.a. & n.a. & 11.3 & 38.4 & 33.7 & 3.1 & 3.1 & 12.3 & 14.2 & 46.2 & 46.3 & 40.8 & 48.8 & 20.9 & 20.1 \\
\hline
\end{tabular}




\begin{tabular}{|c|c|c|c|c|c|c|c|c|c|c|c|c|c|c|c|c|c|c|c|}
\hline \multirow[t]{3}{*}{$\begin{array}{l}\text { REGIONS/ } \\
\text { SUBREGIONS/ } \\
\text { COUNTRIES }\end{array}$} & \multicolumn{2}{|c|}{ 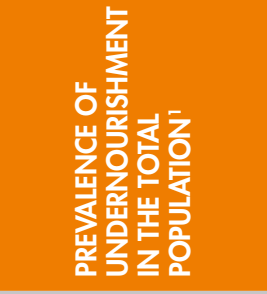 } & \multicolumn{2}{|c|}{ 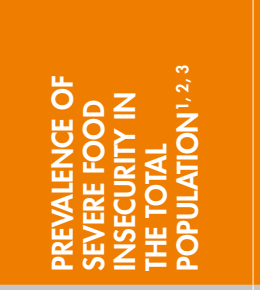 } & \multicolumn{2}{|c|}{ 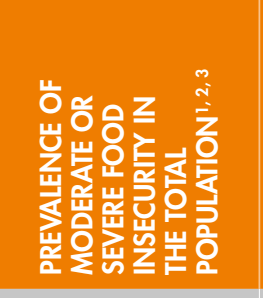 } & \multirow[t]{2}{*}{ 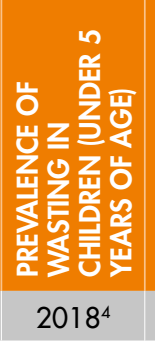 } & \multicolumn{2}{|c|}{ 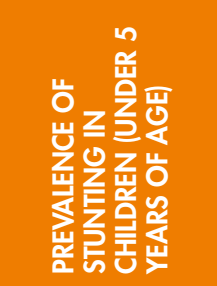 } & \multicolumn{2}{|c|}{ 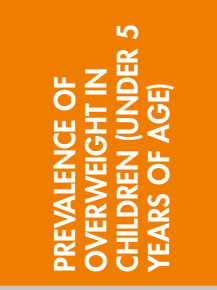 } & \multicolumn{2}{|c|}{ 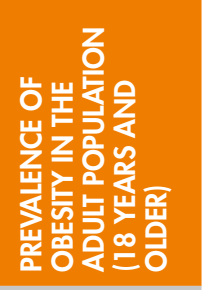 } & \multicolumn{2}{|c|}{ 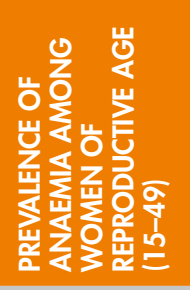 } & \multicolumn{2}{|c|}{ 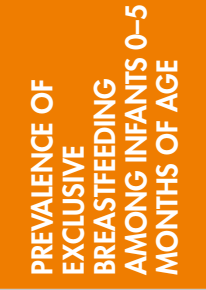 } & \multicolumn{2}{|c|}{ 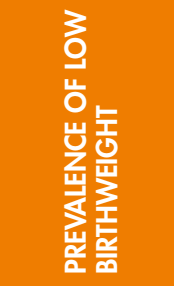 } \\
\hline & 2004-06 & 2016-18 & $2014-16$ & $2016-18$ & $2014-16$ & $2016-18$ & & $2012^{5}$ & $2018^{4}$ & $2012^{5}$ & $2018^{4}$ & 2012 & 2016 & 2012 & 2016 & $2012^{6}$ & $2018^{7}$ & 2012 & 2015 \\
\hline & $\%$ & $\%$ & $\%$ & $\%$ & $\%$ & $\%$ & $\%$ & $\%$ & $\%$ & $\%$ & $\%$ & $\%$ & $\%$ & $\%$ & $\%$ & $\%$ & $\%$ & $\%$ & $\%$ \\
\hline AFRICA & 21.3 & 19.6 & 19.7 & 22.1 & 49.5 & 53.1 & 7.1 & 32.6 & 30.0 & 4.8 & 4.9 & 10.4 & 11.8 & 37.7 & 37.7 & 35.6 & 43.7 & 14.1 & 13.7 \\
\hline Northern Africa & 6.1 & 7.1 & 8.4 & 9.1 & 25.9 & 30.8 & 8.5 & 19.2 & 17.2 & 9.7 & 10.6 & 22.5 & 25.4 & 30.9 & 31.8 & 40.5 & 44.7 & 12.4 & 12.2 \\
\hline Algeria & 8.8 & 3.9 & & & & & n.a. & 11.7 & n.a. & 12.4 & n.a. & 23.1 & 26.6 & 33.6 & 35.7 & 25.4 & n.a. & 7.3 & 7.3 \\
\hline Egypt & 5.4 & 4.5 & $9.4^{b}$ & 10.1 & $27.6^{6}$ & 36.0 & 9.5 & 30.7 & 22.3 & 20.4 & 15.7 & 27.9 & 31.1 & 29.3 & 28.5 & 52.8 & 39.5 & n.a. & n.a. \\
\hline Libya & n.a. & n.a. & & & & & n.a. & n.a. & n.a. & n.a. & n.a. & 28.3 & 31.8 & 30.5 & 32.5 & n.a. & n.a. & n.a. & n.a. \\
\hline Morocco & 5.7 & 3.4 & & & & & n.a. & 14.9 & n.a. & 10.8 & n.a. & 22.4 & 25.6 & 34.2 & 36.9 & 27.8 & n.a. & 17.5 & 17.3 \\
\hline Sudan & -- & 20.1 & n.a. & n.a. & n.a. & n.a. & 16.8 & 34.1 & 38.2 & 1.5 & 3.0 & 5.6 & 7.4 & 29.4 & 30.7 & 41.0 & 54.6 & n.a. & n.a. \\
\hline Tunisia & 5.6 & 4.3 & & & & & n.a. & 10.1 & n.a. & 14.2 & n.a. & 24.1 & 27.3 & 28.1 & 31.2 & 8.5 & n.a. & 7.5 & 7.5 \\
\hline $\begin{array}{l}\text { Northern Africa } \\
\text { (excluding Sudan) }\end{array}$ & 6.1 & 4.3 & 8.4 & 9.1 & 25.9 & 30.8 & n.a. & n.a. & n.a. & n.a. & n.a. & 25.4 & 28.7 & 31.2 & 32.1 & 40.4 & 39.5 & 11.5 & 11.4 \\
\hline Sub-Saharan Africa & 24.3 & 22.5 & 22.3 & 25.1 & 55.0 & 58.2 & 6.9 & 34.9 & 32.1 & 4.0 & 3.9 & 6.9 & 8.0 & 39.5 & 39.2 & 34.8 & 43.6 & 14.4 & 14.0 \\
\hline Eastern Africa & 34.4 & 30.9 & 25.7 & 27.5 & 60.9 & 64.3 & 6.0 & 38.6 & 35.2 & 4.4 & 4.3 & 4.3 & 5.2 & 30.6 & 31.2 & 48.7 & 59.8 & 13.8 & 13.4 \\
\hline Burundi & n.a. & n.a. & & & & & 5.1 & 57.6 & 55.9 & 2.9 & 1.4 & 3.5 & 4.4 & 25.6 & 26.7 & 69.3 & 82.3 & 15.5 & 15.1 \\
\hline Comoros & n.a. & n.a. & n.a. & n.a. & n.a. & n.a. & n.a. & 31.1 & n.a. & 10.6 & n.a. & 5.8 & 6.9 & 27.6 & 29.3 & 11.4 & n.a. & 24.2 & 23.7 \\
\hline Dijibouti & 32.2 & 18.9 & n.a. & n.a. & n.a. & n.a. & n.a. & 33.5 & n.a. & 8.1 & n.a. & 10.8 & 12.2 & 30.9 & 32.7 & 12.4 & n.a. & n.a. & n.a. \\
\hline Eritrea & n.a. & n.a. & n.a. & n.a. & n.a. & n.a. & n.a. & 52.0 & n.a. & 2.0 & n.a. & 3.2 & 4.1 & 36.9 & 38.1 & 68.7 & n.a. & n.a. & n.a. \\
\hline Ethiopia & 39.7 & 20.6 & & & & & 10.0 & 44.4 & 38.4 & 1.8 & 2.9 & 2.9 & 3.6 & 21.7 & 23.4 & 52.0 & 56.5 & n.a. & n.a. \\
\hline Kenya & 28.2 & 29.4 & $19.1^{\mathrm{c}}$ & $19.1^{c}$ & $56.5^{c}$ & $56.5^{c}$ & 4.2 & 35.5 & 26.2 & 5.0 & 4.1 & 4.8 & 6.0 & 27.5 & 27.2 & 31.9 & 61.4 & 11.7 & 11.5 \\
\hline Madagascar & 35.0 & 44.4 & n.a. & n.a. & n.a. & n.a. & 7.9 & 49.4 & 48.9 & n.a. & 1.1 & 3.6 & 4.5 & 36.6 & 36.8 & 41.9 & n.a. & 17.5 & 17.1 \\
\hline Malawi & 26.1 & 17.5 & $51.7^{c}$ & $51.7^{c}$ & $81.9 c$ & $81.9 c$ & 2.8 & 47.3 & 37.4 & 9.0 & 4.6 & 3.9 & 4.7 & 32.3 & 34.4 & 70.8 & 59.4 & 14.9 & 14.5 \\
\hline Mauritius & 5.2 & 6.5 & 5.2 & 6.2 & 13.0 & 18.5 & n.a. & n.a. & n.a. & n.a. & n.a. & 10.1 & 11.5 & 21.6 & 25.1 & n.a. & n.a. & 17.0 & 17.1 \\
\hline Mozambique & 37.0 & 27.9 & 39.5 & 42.5 & 63.7 & 68.6 & n.a. & 42.9 & n.a. & 7.8 & n.a. & 5.1 & 6.0 & 49.9 & 51.0 & 40.0 & 41.0 & 14.1 & 13.8 \\
\hline Rwanda & 44.5 & 36.8 & & & & & 2.0 & 44.3 & 36.9 & 6.9 & 5.6 & 3.8 & 4.8 & 19.4 & 22.3 & 83.8 & 86.9 & 8.2 & 7.9 \\
\hline Seychelles & n.a. & n.a. & $3.2^{c}$ & $3.2^{c}$ & $14.3^{c}$ & $14.3^{c}$ & n.a. & 7.9 & n.a. & 10.2 & n.a. & 12.5 & 14.6 & 20.3 & 22.3 & n.a. & n.a. & 11.0 & 11.7 \\
\hline
\end{tabular}




\begin{tabular}{|c|c|c|c|c|c|c|c|c|c|c|c|c|c|c|c|c|c|c|c|}
\hline \multirow[t]{3}{*}{$\begin{array}{l}\text { REGIONS/ } \\
\text { SUBREGIONS/ } \\
\text { COUNTRIES }\end{array}$} & \multicolumn{2}{|c|}{ 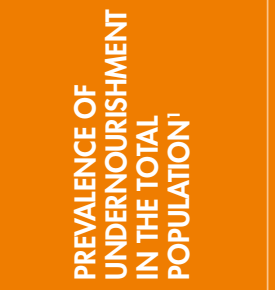 } & \multicolumn{2}{|c|}{ 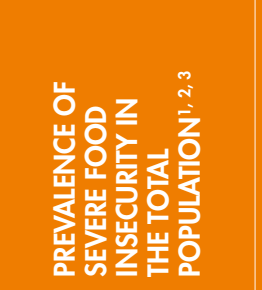 } & \multicolumn{2}{|c|}{ 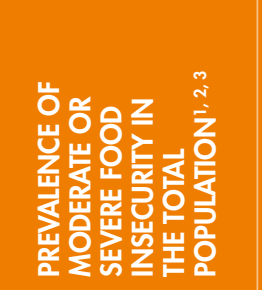 } & \multirow[t]{2}{*}{ 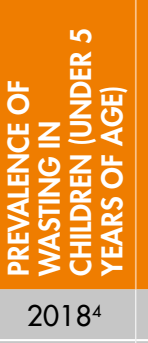 } & \multicolumn{2}{|c|}{ 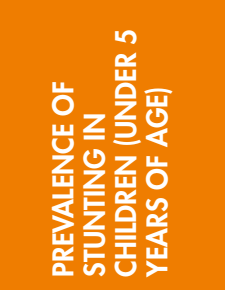 } & \multicolumn{2}{|c|}{ 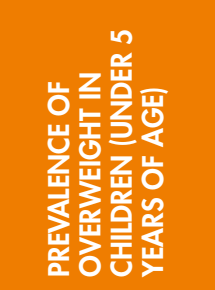 } & \multicolumn{2}{|c|}{ 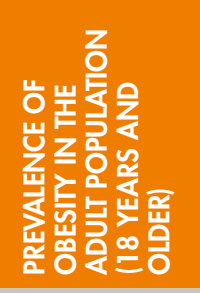 } & \multicolumn{2}{|c|}{ 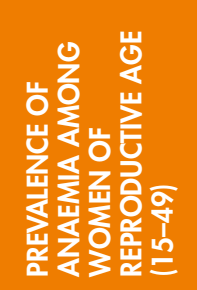 } & \multicolumn{2}{|c|}{ 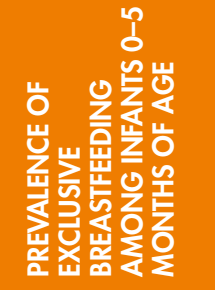 } & \multicolumn{2}{|c|}{ 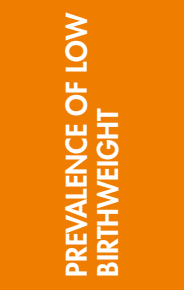 } \\
\hline & $2004-06$ & $2016-18$ & $2014-16$ & $2016-18$ & $2014-16$ & $2016-18$ & & $2012^{5}$ & $2018^{4}$ & $2012^{5}$ & $2018^{4}$ & 2012 & 2016 & 2012 & 2016 & $2012^{6}$ & $2018^{7}$ & 2012 & 2015 \\
\hline & $\%$ & $\%$ & $\%$ & $\%$ & $\%$ & $\%$ & $\%$ & $\%$ & $\%$ & $\%$ & $\%$ & $\%$ & $\%$ & $\%$ & $\%$ & $\%$ & $\%$ & $\%$ & $\%$ \\
\hline Somalia & n.a. & n.a. & n.a. & n.a. & n.a. & n.a. & n.a. & 25.3 & n.a. & 3.0 & n.a. & 5.9 & 6.9 & 43.5 & 44.4 & 5.3 & n.a. & n.a. & n.a. \\
\hline South Sudan & -- & n.a. & n.a. & n.a. & n.a. & n.a. & n.a. & 31.3 & n.a. & 5.8 & n.a. & n.a. & n.a. & 32.3 & 34.0 & 44.5 & n.a. & n.a. & n.a. \\
\hline Uganda & 24.1 & 41.0 & n.a. & n.a. & n.a. & n.a. & 3.5 & 33.7 & 28.9 & 5.8 & 3.7 & 3.4 & 4.1 & 38.6 & 37.2 & 62.3 & 65.5 & n.a. & n.a. \\
\hline $\begin{array}{l}\text { United Republic } \\
\text { of Tanzania }\end{array}$ & 34.4 & 30.7 & & & & & 4.5 & 34.9 & 34.5 & 5.2 & 3.7 & 5.8 & 7.1 & 29.6 & 28.5 & 48.7 & 59.0 & 10.7 & 10.5 \\
\hline Zambia & 51.1 & 46.7 & & & & & 6.2 & n.a. & 40.0 & n.a. & 6.2 & 5.4 & 6.5 & 31.2 & 33.7 & 59.9 & 72.0 & 11.9 & 11.6 \\
\hline Zimbabwe & 42.2 & 51.3 & & & & & 3.3 & 32.2 & 27.1 & 5.8 & 5.6 & 11.1 & 12.3 & 30.1 & 28.8 & 31.3 & 47.1 & 12.8 & 12.6 \\
\hline Middle Africa & 32.5 & 26.3 & n.a. & n.a. & n.a. & n.a. & 7.2 & 34.5 & 32.1 & 4.5 & 4.6 & 5.5 & 6.6 & 45.4 & 43.5 & 28.5 & 37.7 & 12.8 & 12.5 \\
\hline Angola & 54.8 & 25.0 & 22.2 & n.a. & 64.6 & n.a. & 4.9 & n.a. & 37.6 & n.a. & 3.4 & 5.6 & 6.8 & 47.3 & 47.7 & n.a. & 37.4 & 15.8 & 15.3 \\
\hline Cameroon & 20.3 & 9.9 & 35.6 & 44.2 & 62.2 & 71.2 & 5.2 & 32.6 & 31.7 & 6.4 & 6.7 & 8.1 & 9.5 & 41.7 & 41.4 & 19.9 & 28.0 & 12.1 & 12.0 \\
\hline $\begin{array}{l}\text { Central African } \\
\text { Republic }\end{array}$ & 39.5 & 59.6 & n.a. & n.a. & n.a. & n.a. & n.a. & 39.6 & n.a. & 1.9 & n.a. & 5.3 & 6.3 & 46.2 & 46.0 & 33.0 & n.a. & 14.8 & 14.5 \\
\hline Chad & 39.2 & 37.5 & n.a. & n.a. & n.a. & n.a. & 13.3 & 38.7 & 39.8 & 2.7 & 2.8 & 4.0 & 4.8 & 48.1 & 47.7 & 3.2 & 0.1 & n.a. & n.a. \\
\hline Congo & 40.2 & 40.3 & & & & & 8.2 & 24.4 & 21.2 & 3.5 & 5.9 & 7.1 & 8.4 & 53.8 & 51.9 & 20.2 & 32.9 & 11.8 & 11.6 \\
\hline $\begin{array}{l}\text { Democratic Republic } \\
\text { of the Congo }\end{array}$ & n.a. & n.a. & n.a. & n.a. & n.a. & n.a. & 8.1 & 43.4 & 42.7 & 4.7 & 4.4 & 4.6 & 5.6 & 44.7 & 41.0 & 36.4 & 47.3 & 11.1 & 10.8 \\
\hline Equatorial Guinea & n.a. & n.a. & n.a. & n.a. & n.a. & n.a. & n.a. & 26.2 & n.a. & 9.7 & n.a. & 6.2 & 7.4 & 44.1 & 43.7 & 7.4 & n.a. & n.a. & n.a. \\
\hline Gabon & 10.9 & 10.5 & & & & & n.a. & 17.0 & n.a. & 7.7 & n.a. & 12.0 & 13.4 & 58.3 & 59.1 & 5.1 & n.a. & 14.4 & 14.2 \\
\hline $\begin{array}{l}\text { Sao Tome and } \\
\text { Principe }\end{array}$ & 9.4 & 7.0 & n.a. & n.a. & n.a. & n.a. & 4.0 & 30.6 & 17.2 & 11.2 & 2.4 & 8.9 & 10.6 & 45.4 & 46.1 & 50.3 & 71.7 & 6.7 & 6.6 \\
\hline Southern Africa & 6.5 & 8.3 & 24.3 & 30.7 & 48.3 & 53.6 & 3.5 & 30.5 & 29.3 & 12.1 & 13.0 & 23.2 & 25.6 & 25.9 & 26.0 & n.a. & 35.0 & 14.3 & 14.2 \\
\hline Botswana & 31.9 & 26.4 & 35.0 & 41.3 & 62.3 & 70.0 & n.a. & n.a. & n.a. & n.a. & n.a. & 14.7 & 16.1 & 29.4 & 30.2 & 20.3 & n.a. & 15.9 & 15.6 \\
\hline Eswatini & 17.0 & 20.6 & n.a. & 29.5 & n.a. & 63.5 & 2.0 & 30.9 & 25.5 & 10.7 & 9.0 & 12.0 & 13.5 & 26.7 & 27.2 & 43.8 & 63.8 & 10.5 & 10.3 \\
\hline Lesotho & 11.7 & 13.1 & 50.1 & 50.0 & 78.6 & 77.8 & 2.8 & 39.3 & 33.4 & 7.3 & 7.5 & 12.0 & 13.5 & 27.2 & 27.4 & 52.9 & 66.9 & 14.8 & 14.6 \\
\hline Namibia & 25.1 & 27.3 & 41.4 & 39.0 & 66.0 & 67.9 & 7.1 & n.a. & 22.7 & n.a. & 4.0 & 12.9 & 15.0 & 24.7 & 23.2 & 22.1 & 48.3 & 15.7 & 15.5 \\
\hline South Africa & 4.4 & 6.2 & 22.0 & 29.2 & 45.4 & 51.1 & 2.5 & 27.2 & 27.4 & 17.2 & 13.3 & 24.5 & 27.0 & 25.7 & 25.8 & n.a. & 31.6 & 14.3 & 14.2 \\
\hline
\end{tabular}




\begin{tabular}{|c|c|c|c|c|c|c|c|c|c|c|c|c|c|c|c|c|c|c|c|}
\hline \multirow[t]{3}{*}{$\begin{array}{l}\text { REGIONS/ } \\
\text { SUBREGIONS/ } \\
\text { COUNTRIES }\end{array}$} & \multicolumn{2}{|c|}{ 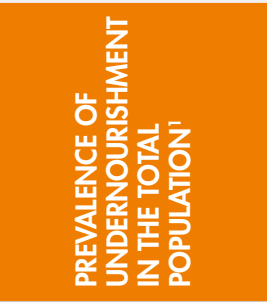 } & \multicolumn{2}{|c|}{ 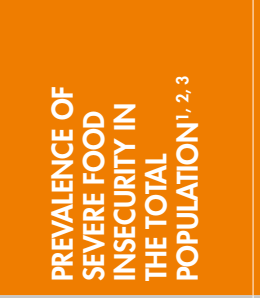 } & \multicolumn{2}{|c|}{ 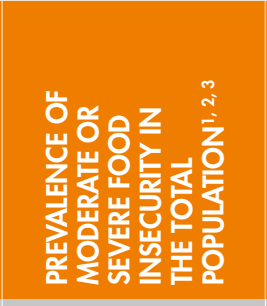 } & \multirow[t]{2}{*}{ 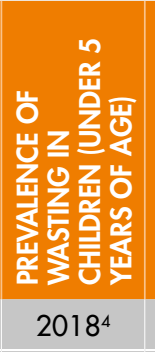 } & \multicolumn{2}{|c|}{ 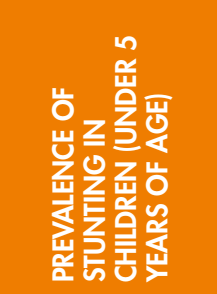 } & \multicolumn{2}{|c|}{ 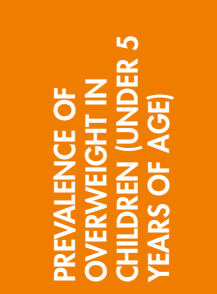 } & \multicolumn{2}{|c|}{ 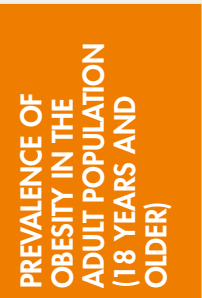 } & \multicolumn{2}{|c|}{ 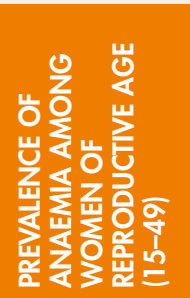 } & \multicolumn{2}{|c|}{ 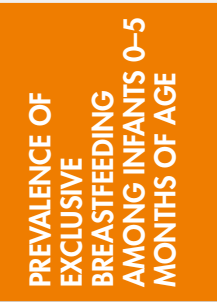 } & \multicolumn{2}{|c|}{ 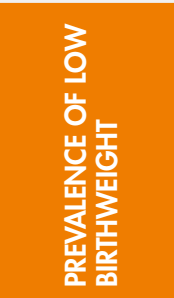 } \\
\hline & 2004-06 & 2016-18 & $2014-16$ & 2016-18 & $2014-16$ & 2016-18 & & $2012^{5}$ & $2018^{4}$ & $2012^{5}$ & $2018^{4}$ & 2012 & 2016 & 2012 & 2016 & $2012^{6}$ & $2018^{7}$ & 2012 & 2015 \\
\hline & $\%$ & $\%$ & $\%$ & $\%$ & $\%$ & $\%$ & $\%$ & $\%$ & $\%$ & $\%$ & $\%$ & $\%$ & $\%$ & $\%$ & $\%$ & $\%$ & $\%$ & $\%$ & $\%$ \\
\hline Western Africa & 12.3 & 13.9 & 14.6 & 17.3 & 45.4 & 47.6 & 8.1 & 31.5 & 29.2 & 2.4 & 2.1 & 6.4 & 7.7 & 50.0 & 49.3 & 22.1 & 31.4 & 15.6 & 15.2 \\
\hline Benin & 15.4 & 10.1 & & & & & 5.0 & n.a. & 32.2 & n.a. & 1.9 & 7.0 & 8.2 & 51.5 & 46.9 & 32.5 & 41.4 & 17.2 & 16.9 \\
\hline Burkina Faso & 24.9 & 20.0 & $9.1^{c}$ & n.a. & $40.7 \mathrm{c}$ & n.a. & 8.6 & 32.8 & 21.1 & 0.6 & 1.7 & 3.6 & 4.5 & 50.5 & 49.6 & 38.2 & 50.1 & 13.5 & 13.1 \\
\hline Cabo Verde & 14.0 & 12.6 & n.a. & $9.6^{c}$ & n.a. & $37.7^{\circ}$ & n.a. & n.a. & n.a. & n.a. & n.a. & 8.9 & 10.6 & 31.2 & 33.3 & 59.6 & n.a. & n.a. & n.a. \\
\hline Côte d'Ivoire & 20.0 & 19.0 & & & & & 6.1 & 29.9 & 21.6 & 3.2 & 1.5 & 7.6 & 9.0 & 51.8 & 52.9 & 11.8 & 23.1 & 15.8 & 15.5 \\
\hline Gambia & 15.1 & 10.2 & n.a. & 31.3 & n.a. & 54.1 & 11.0 & 21.2 & 24.6 & 1.1 & 3.2 & 7.3 & 8.7 & 57.2 & 57.5 & 33.5 & 46.8 & 17.2 & 16.8 \\
\hline Ghana & 9.3 & 5.5 & $7.9 \mathrm{c}$ & $7.9^{c}$ & $49.6^{c}$ & $49.6^{c}$ & 4.7 & 22.8 & 18.8 & 2.5 & 2.6 & 8.3 & 9.7 & 48.6 & 46.4 & 45.7 & 52.1 & 14.5 & 14.2 \\
\hline Guinea & 21.3 & 16.5 & 41.3 & 46.5 & 72.8 & 74.1 & 8.1 & 31.1 & 32.4 & 3.8 & 4.0 & 5.5 & 6.6 & 50.9 & 50.6 & 20.4 & 34.2 & n.a. & n.a. \\
\hline Guinea-Bissau & 24.4 & 28.0 & n.a. & n.a. & n.a. & n.a. & 6.0 & 32.2 & 27.6 & 3.2 & 2.3 & 6.8 & 8.2 & 44.0 & 43.8 & 38.3 & 52.5 & 21.8 & 21.1 \\
\hline Liberia & 39.4 & 37.2 & 62.4 & 62.2 & 85.0 & 86.2 & 5.6 & 41.8 & 32.1 & n.a. & 3.2 & 7.3 & 8.6 & 37.3 & 34.7 & 27.8 & 54.6 & n.a. & n.a. \\
\hline Mali & 11.1 & 6.3 & n.a. & n.a. & n.a. & n.a. & 13.5 & 27.8 & 30.4 & 1.0 & 1.9 & 5.9 & 7.1 & 54.8 & 51.3 & 20.2 & 37.3 & n.a. & n.a. \\
\hline Mauritania & 12.1 & 10.4 & & & & & 14.8 & 22.0 & 27.9 & 1.2 & 1.3 & 9.7 & 11.3 & 37.2 & 37.2 & 26.7 & 41.1 & n.a. & n.a. \\
\hline Niger & 15.1 & 16.5 & 31.0 & 51.7 & 66.4 & 83.0 & 10.1 & 43.5 & 40.6 & 3.1 & 1.1 & 3.9 & 4.7 & 49.2 & 49.5 & 23.3 & n.a. & n.a. & n.a. \\
\hline Nigeria & 6.5 & 13.4 & $6.5^{c}$ & n.a. & $36.4^{c}$ & n.a. & 10.8 & 35.8 & 43.6 & 2.9 & 1.5 & 6.4 & 7.8 & 49.9 & 49.8 & 14.7 & 23.3 & n.a. & n.a. \\
\hline Senegal & 21.6 & 11.3 & & & & & 9.0 & 15.5 & 16.5 & 0.7 & 0.9 & 6.2 & 7.4 & 53.5 & 49.9 & 37.5 & 42.1 & 18.9 & 18.5 \\
\hline Sierra Leone & 37.0 & 25.6 & 62.2 & 72.7 & 83.0 & 90.8 & 9.5 & 44.4 & 37.8 & 9.4 & 8.8 & 6.3 & 7.5 & 47.9 & 48.0 & 31.2 & 47.2 & 14.9 & 14.4 \\
\hline Togo & 26.0 & 16.1 & 34.3 & 32.2 & 66.9 & 68.1 & 6.6 & 29.7 & 27.6 & 1.6 & 2.0 & 5.9 & 7.1 & 50.0 & 48.9 & 62.1 & 57.2 & 16.3 & 16.1 \\
\hline $\begin{array}{l}\text { Sub-Saharan Africa } \\
\text { (including Sudan) }\end{array}$ & 24.4 & 22.4 & 21.8 & 24.4 & 53.9 & 57.2 & n.a. & n.a. & n.a. & n.a. & n.a. & 6.8 & 7.9 & 39.1 & 38.8 & 35.0 & 44.0 & 14.4 & 14.0 \\
\hline ASIA $^{*}$ & 17.2 & 11.4 & 6.4 & 6.7 & 19.6 & 21.0 & 9.4 & 27.3 & 22.7 & 4.7 & 5.2 & 6.0 & 7.3 & 33.5 & 36.6 & 38.8 & 41.2 & 17.8 & 17.3 \\
\hline Central Asia & 11.0 & 5.6 & 2.2 & 3.2 & 11.7 & 15.8 & 3.6 & 15.2 & 10.9 & 9.3 & 9.4 & 14.4 & 16.8 & 33.2 & 33.8 & 29.2 & 40.9 & 5.6 & 5.4 \\
\hline Kazakhstan & 5.9 & $<2.5$ & 0.9 & 1.9 & 7.0 & 9.3 & 3.1 & 13.1 & 8.0 & 13.3 & 9.3 & 18.7 & 21.3 & 29.4 & 30.7 & 31.8 & 37.8 & 6.1 & 5.4 \\
\hline Kyrgyzstan & 9.7 & 7.1 & 4.7 & 5.1 & 22.0 & 23.9 & 2.8 & 17.9 & 12.9 & 8.9 & 7.0 & 12.9 & 15.4 & 32.1 & 36.2 & 56.0 & 40.9 & 5.6 & 5.5 \\
\hline
\end{tabular}




\begin{tabular}{|c|c|c|c|c|c|c|c|c|c|c|c|c|c|c|c|c|c|c|c|}
\hline \multirow[t]{3}{*}{$\begin{array}{l}\text { REGIONS/ } \\
\text { SUBREGIONS/ } \\
\text { COUNTRIES }\end{array}$} & \multicolumn{2}{|c|}{ 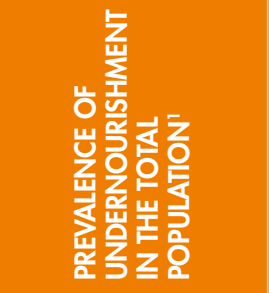 } & \multicolumn{2}{|c|}{ 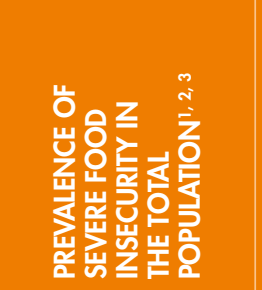 } & \multicolumn{2}{|c|}{ 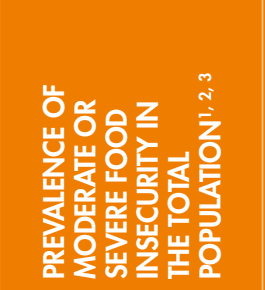 } & \multirow[t]{2}{*}{ 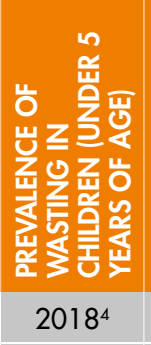 } & \multicolumn{2}{|c|}{ 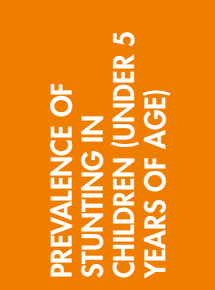 } & \multicolumn{2}{|c|}{ 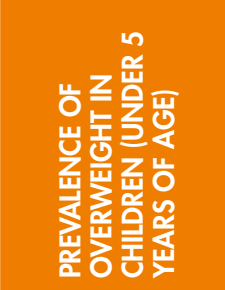 } & \multicolumn{2}{|c|}{ 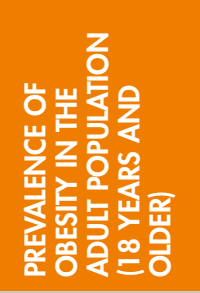 } & \multicolumn{2}{|c|}{ 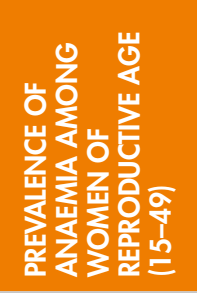 } & \multicolumn{2}{|c|}{ 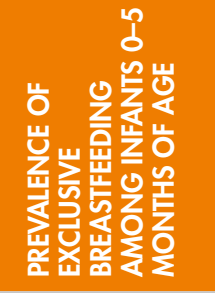 } & \multicolumn{2}{|c|}{ 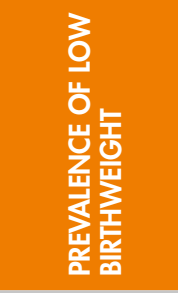 } \\
\hline & $2004-06$ & $2016-18$ & $2014-16$ & $2016-18$ & $2014-16$ & $2016-18$ & & $2012^{5}$ & $2018^{4}$ & $2012^{5}$ & $2018^{4}$ & 2012 & 2016 & 2012 & 2016 & $2012^{6}$ & $2018^{7}$ & 2012 & 2015 \\
\hline & $\%$ & $\%$ & $\%$ & $\%$ & $\%$ & $\%$ & $\%$ & $\%$ & $\%$ & $\%$ & $\%$ & $\%$ & $\%$ & $\%$ & $\%$ & $\%$ & $\%$ & $\%$ & $\%$ \\
\hline Tajikistan & n.a. & n.a. & 5.3 & 9.6 & 18.8 & 29.6 & 5.6 & 26.8 & 17.5 & 6.7 & 3.3 & 10.4 & 12.6 & 29.7 & 30.5 & 32.6 & 35.8 & 5.7 & 5.6 \\
\hline Turkmenistan & 4.8 & 5.4 & n.a. & n.a. & n.a. & n.a. & 4.2 & n.a. & 11.5 & n.a. & 5.9 & 14.9 & 17.5 & 31.1 & 32.6 & 10.9 & 58.3 & 5.0 & 4.9 \\
\hline Uzbekistan & 14.5 & 6.3 & & & & & n.a. & n.a. & n.a. & n.a. & n.a. & 12.9 & 15.3 & 36.8 & 36.2 & 23.8 & n.a. & 5.3 & 5.3 \\
\hline Eastern Asia* & 14.0 & 8.4 & 0.6 & 1.0 & 6.4 & 8.9 & 1.7 & 7.9 & 4.9 & 6.3 & 6.3 & 5.0 & 6.4 & 20.8 & 26.1 & 28.6 & 19.9 & 5.1 & 5.1 \\
\hline China & 15.2 & 8.5 & & & & & 1.9 & 9.4 & 8.1 & 6.6 & 9.1 & 5.1 & 6.6 & 20.7 & 26.4 & 27.6 & 18.6 & 5.0 & 5.0 \\
\hline China, mainland & 15.5 & 8.6 & & & & & n.a. & n.a. & n.a. & n.a. & n.a. & n.a. & n.a. & n.a. & n.a. & n.a. & n.a. & n.a. & n.a. \\
\hline $\begin{array}{l}\text { Taiwan Province of } \\
\text { China }\end{array}$ & 4.7 & 3.5 & & & & & n.a. & n.a. & n.a. & n.a. & n.a. & n.a. & n.a. & n.a. & n.a. & n.a. & n.a. & n.a. & n.a. \\
\hline $\begin{array}{l}\text { China, Hong Kong } \\
\text { SAR }\end{array}$ & $<2.5$ & $<2.5$ & & & & & n.a. & n.a. & n.a. & n.a. & n.a. & n.a. & n.a. & n.a. & n.a. & n.a. & n.a. & n.a. & n.a. \\
\hline China, Macao SAR & 14.6 & 11.2 & n.a. & n.a. & n.a. & n.a. & n.a. & n.a. & n.a. & n.a. & n.a. & n.a. & n.a. & n.a. & n.a. & n.a. & n.a. & n.a. & n.a. \\
\hline $\begin{array}{l}\text { Democratic People's } \\
\text { Republic of Korea }\end{array}$ & 35.4 & 47.8 & n.a. & n.a. & n.a. & n.a. & 2.5 & 27.9 & 19.1 & $<0.1$ & 2.3 & 6.1 & 7.1 & 30.0 & 32.5 & 68.9 & 71.4 & n.a. & n.a. \\
\hline Japan & $<2.5$ & $<2.5$ & $<0.5$ & 0.6 & 2.3 & 2.8 & n.a. & 7.1 & n.a. & 1.5 & n.a. & 3.8 & 4.4 & 19.4 & 21.5 & n.a. & n.a. & 9.6 & 9.5 \\
\hline Mongolia & 31.0 & 13.4 & 3.2 & 5.4 & 20.9 & 27.1 & 1.3 & 15.5 & 7.3 & 6.7 & 11.7 & 16.3 & 19.6 & 16.3 & 19.5 & 65.7 & 58.3 & 5.5 & 5.4 \\
\hline Republic of Korea & $<2.5$ & $<2.5$ & $<0.5^{c}$ & $<0.5$ & $4.8^{c}$ & 5.4 & n.a. & 2.5 & n.a. & 7.3 & n.a. & 4.4 & 4.9 & 18.4 & 22.7 & n.a. & n.a. & 5.4 & 5.8 \\
\hline $\begin{array}{l}\text { Eastern Asia } \\
\text { (excluding China, } \\
\text { mainland) }\end{array}$ & 5.8 & 7.2 & $<0.5$ & 0.6 & 3.8 & 4.5 & n.a. & n.a. & n.a. & n.a. & n.a. & n.a. & n.a. & n.a. & n.a. & n.a. & n.a. & 8.5 & 8.4 \\
\hline South-eastern Asia & 18.4 & 9.4 & 4.1 & 5.1 & 18.7 & 20.3 & 8.7 & 29.1 & 25.0 & 5.7 & 7.7 & 5.3 & 6.7 & 25.9 & 28.3 & 33.5 & n.a. & 12.4 & 12.3 \\
\hline Brunei Darussalam & $<2.5$ & 3.2 & n.a. & n.a. & n.a. & n.a. & n.a. & 19.7 & n.a. & 8.3 & n.a. & 12.3 & 14.7 & 13.9 & 16.9 & n.a. & n.a. & 12.1 & 10.8 \\
\hline Cambodia & 20.0 & 16.4 & 17.1 & 14.2 & 48.9 & 44.9 & 9.8 & 39.8 & 32.4 & 1.9 & 2.2 & 2.7 & 3.5 & 46.0 & 46.8 & 72.8 & 65.2 & 12.6 & 12.1 \\
\hline Indonesia & 19.4 & 8.3 & $1.1^{\mathrm{c}}$ & $1.0^{\circ}$ & $8.7^{c}$ & $8.1^{\mathrm{c}}$ & 13.5 & 39.2 & 36.4 & 12.3 & 11.5 & 5.4 & 6.9 & 26.2 & 28.8 & 40.9 & n.a. & 10.2 & 10.0 \\
\hline $\begin{array}{l}\text { Lao People's } \\
\text { Democratic Republic }\end{array}$ & 27.0 & 16.5 & n.a. & n.a. & n.a. & n.a. & n.a. & 44.2 & n.a. & 2.0 & n.a. & 3.4 & 4.5 & 36.5 & 39.7 & 39.7 & 44.4 & 17.7 & 17.3 \\
\hline Malaysia & 3.9 & 2.5 & & & & & 11.5 & n.a. & 20.7 & n.a. & 6.0 & 12.7 & 15.3 & 22.2 & 24.9 & n.a. & 40.3 & 11.3 & 11.3 \\
\hline Myanmar & 32.0 & 10.6 & n.a. & n.a. & n.a. & n.a. & 6.6 & 35.1 & 29.4 & 2.6 & 1.5 & 4.4 & 5.7 & 41.7 & 46.3 & 23.6 & 51.2 & 12.5 & 12.3 \\
\hline
\end{tabular}




\begin{tabular}{|c|c|c|c|c|c|c|c|c|c|c|c|c|c|c|c|c|c|c|c|}
\hline \multirow[t]{3}{*}{$\begin{array}{l}\text { REGIONS/ } \\
\text { SUBREGIONS/ } \\
\text { COUNTRIES }\end{array}$} & \multicolumn{2}{|c|}{ 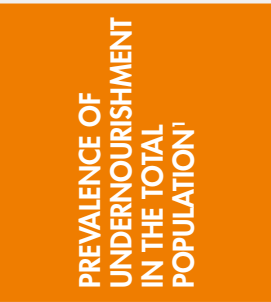 } & \multicolumn{2}{|c|}{ 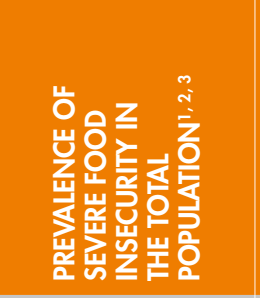 } & \multicolumn{2}{|c|}{ 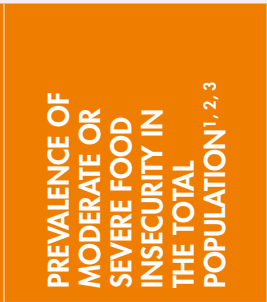 } & \multirow[t]{2}{*}{ 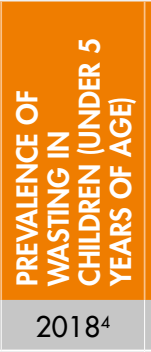 } & \multicolumn{2}{|c|}{ 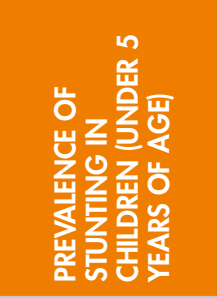 } & \multicolumn{2}{|c|}{ 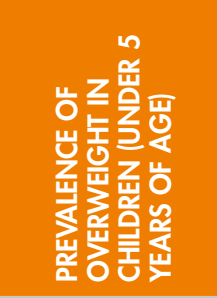 } & \multicolumn{2}{|c|}{ 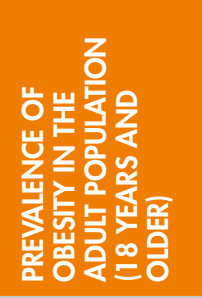 } & \multicolumn{2}{|c|}{ 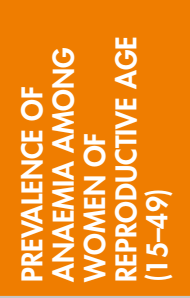 } & \multicolumn{2}{|c|}{ 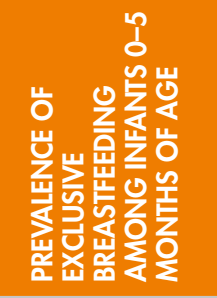 } & \multicolumn{2}{|c|}{ 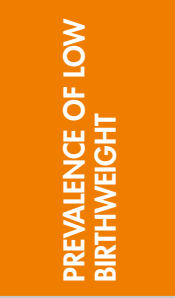 } \\
\hline & 2004-06 & 2016-18 & $2014-16$ & $2016-18$ & $2014-16$ & $2016-18$ & & $2012^{5}$ & $2018^{4}$ & $2012^{5}$ & $2018^{4}$ & 2012 & 2016 & 2012 & 2016 & $2012^{6}$ & $2018^{7}$ & 2012 & 2015 \\
\hline & $\%$ & $\%$ & $\%$ & $\%$ & $\%$ & $\%$ & $\%$ & $\%$ & $\%$ & $\%$ & $\%$ & $\%$ & $\%$ & $\%$ & $\%$ & $\%$ & $\%$ & $\%$ & $\%$ \\
\hline Philippines & 16.3 & 13.3 & 11.2 & 15.0 & 45.4 & 52.5 & 7.1 & 33.6 & 33.4 & 4.3 & 3.9 & 5.0 & 6.0 & 18.0 & 15.7 & 33.0 & n.a. & 20.4 & 20.1 \\
\hline Singapore & n.a. & n.a. & 0.7 & 1.0 & 2.8 & 4.1 & n.a. & n.a. & n.a. & n.a. & n.a. & 6.1 & 6.6 & 19.0 & 22.2 & n.a. & n.a. & 9.7 & 9.6 \\
\hline Thailand & 12.5 & 7.8 & & & & & 5.4 & 16.4 & 10.5 & 10.9 & 8.2 & 8.4 & 10.8 & 26.3 & 31.8 & 12.3 & 23.0 & 10.8 & 10.5 \\
\hline Timor-Leste & 31.3 & 24.9 & n.a. & n.a. & n.a. & n.a. & 10.5 & 57.5 & 50.9 & 5.8 & 1.4 & 2.4 & 2.9 & 33.1 & 41.3 & 50.8 & 50.2 & n.a. & n.a. \\
\hline Viet Nam & 18.2 & 9.3 & 1.8 & 2.3 & 16.4 & 14.5 & 6.4 & 22.7 & 24.6 & 4.4 & 5.3 & 1.5 & 2.1 & 21.0 & 24.2 & 17.0 & 24.0 & 8.4 & 8.2 \\
\hline Southern Asia & 21.1 & 14.9 & 12.2 & 12.0 & 30.8 & 30.9 & 14.6 & 38.1 & 32.7 & 2.9 & 3.1 & 4.2 & 5.2 & 48.2 & 48.7 & 46.8 & 53.9 & 27.2 & 26.4 \\
\hline Afghanistan & 33.2 & 29.8 & 15.4 & 18.3 & 45.2 & 54.3 & 9.5 & n.a. & 40.9 & n.a. & 5.4 & 3.7 & 4.5 & 37.4 & 42.0 & n.a. & 43.1 & n.a. & n.a. \\
\hline Bangladesh & 16.6 & 14.7 & 11.1 & 10.2 & 32.3 & 30.5 & 14.4 & 42.0 & 36.2 & 1.6 & 1.6 & 2.6 & 3.4 & 40.3 & 39.9 & 55.9 & 55.3 & 29.0 & 27.8 \\
\hline Bhutan & n.a. & n.a. & n.a. & n.a. & n.a. & n.a. & n.a. & 33.5 & n.a. & 7.6 & n.a. & 4.5 & 5.8 & 39.2 & 35.6 & 48.7 & 51.4 & 11.9 & 11.7 \\
\hline India & 22.2 & 14.5 & & & & & 20.8 & n.a. & 37.9 & n.a. & 2.4 & 3.0 & 3.8 & 51.3 & 51.4 & 46.4 & 54.9 & n.a. & n.a. \\
\hline $\begin{array}{l}\text { Iran } \\
\text { (Islamic Republic of) }\end{array}$ & 6.1 & 4.9 & & & & & n.a. & 6.8 & n.a. & n.a. & n.a. & 22.0 & 25.5 & 27.9 & 30.5 & 53.1 & n.a. & n.a. & n.a. \\
\hline Maldives & 18.2 & 10.3 & n.a. & n.a. & n.a. & n.a. & n.a. & 18.6 & n.a. & 6.1 & n.a. & 5.9 & 7.9 & 41.1 & 42.6 & 45.3 & n.a. & 12.0 & 11.7 \\
\hline Nepal & 16.0 & 8.7 & 8.8 & 7.8 & 29.4 & 31.6 & 9.6 & 40.5 & 36.0 & 1.5 & 1.2 & 3.0 & 3.8 & 35.4 & 35.1 & 69.6 & 65.2 & 22.6 & 21.8 \\
\hline Pakistan & 23.3 & 20.3 & & & & & 7.1 & 43.0 & 37.6 & 6.4 & 2.5 & 6.3 & 7.8 & 50.1 & 52.1 & 37.0 & 47.5 & n.a. & n.a. \\
\hline Sri Lanka & 18.2 & 9.0 & & & & & 15.1 & 14.7 & 17.3 & 0.6 & 2.0 & 4.3 & 5.4 & 30.3 & 32.6 & 75.8 & 82.0 & 16.6 & 15.9 \\
\hline $\begin{array}{l}\text { Southern Asia } \\
\text { (excluding India) }\end{array}$ & 18.3 & 15.7 & 9.9 & 9.2 & 38.6 & 35.6 & n.a. & n.a. & n.a. & n.a. & n.a. & n.a. & n.a. & n.a. & n.a. & 47.7 & 51.4 & n.a. & n.a. \\
\hline Western Asia & 9.5 & 12.1 & 8.9 & 9.8 & 28.8 & 29.3 & 4.0 & 17.5 & 15.1 & 8.2 & 9.0 & 25.7 & 28.6 & 33.9 & 36.1 & 31.9 & 24.0 & 10.0 & 9.9 \\
\hline Armenia & 7.8 & 4.3 & 3.2 & 4.0 & 28.8 & 34.3 & 4.5 & 20.9 & 9.4 & 16.5 & 13.7 & 18.5 & 20.9 & 24.7 & 29.4 & 34.1 & 44.5 & 8.0 & 9.0 \\
\hline Azerbaijan & 5.5 & $<2.5$ & & & & & 3.2 & 16.4 & 17.8 & 10.4 & 14.1 & 17.1 & 19.9 & 36.2 & 38.5 & 10.8 & 12.1 & 7.0 & 7.3 \\
\hline Bahrain & n.a. & n.a. & & & & & n.a. & n.a. & n.a. & n.a. & n.a. & 26.2 & 28.7 & 41.4 & 42.0 & n.a. & n.a. & 10.2 & 11.9 \\
\hline Cyprus & 5.7 & 5.6 & & & & & n.a. & n.a. & n.a. & n.a. & n.a. & 20.9 & 22.6 & 21.6 & 25.2 & n.a. & n.a. & n.a. & n.a. \\
\hline
\end{tabular}




\begin{tabular}{|c|c|c|c|c|c|c|c|c|c|c|c|c|c|c|c|c|c|c|c|}
\hline \multirow[t]{3}{*}{$\begin{array}{l}\text { REGIONS/ } \\
\text { SUBREGIONS/ } \\
\text { COUNTRIES }\end{array}$} & \multicolumn{2}{|c|}{ 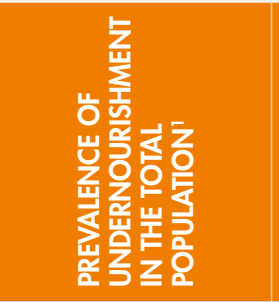 } & \multicolumn{2}{|c|}{ 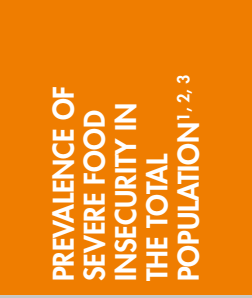 } & \multicolumn{2}{|c|}{ 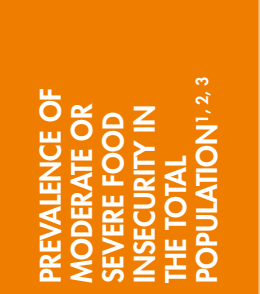 } & \multirow[t]{2}{*}{ 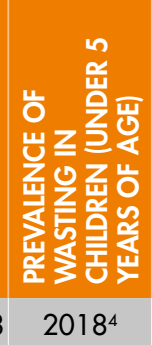 } & \multicolumn{2}{|c|}{ 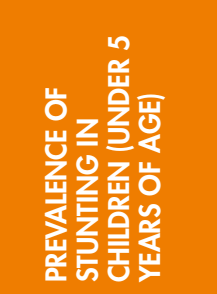 } & \multicolumn{2}{|c|}{ 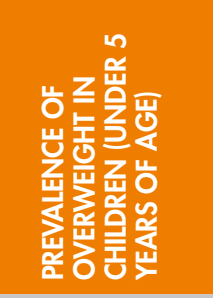 } & \multicolumn{2}{|c|}{ 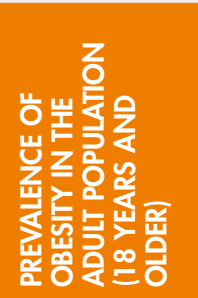 } & \multicolumn{2}{|c|}{ 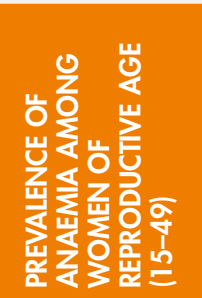 } & \multicolumn{2}{|c|}{ 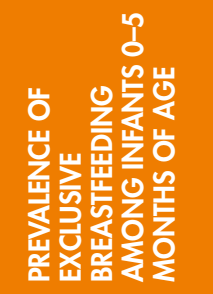 } & \multicolumn{2}{|c|}{ 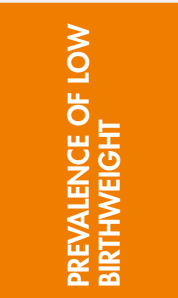 } \\
\hline & $2004-06$ & 2016-18 & $2014-16$ & $2016-18$ & $2014-16$ & 2016-18 & & $2012^{5}$ & $2018^{4}$ & $2012^{5}$ & $2018^{4}$ & 2012 & 2016 & 2012 & 2016 & $2012^{6}$ & $2018^{7}$ & 2012 & 2015 \\
\hline & $\%$ & $\%$ & $\%$ & $\%$ & $\%$ & $\%$ & $\%$ & $\%$ & $\%$ & $\%$ & $\%$ & $\%$ & $\%$ & $\%$ & $\%$ & $\%$ & $\%$ & $\%$ & $\%$ \\
\hline Georgia & 7.2 & 7.9 & 7.0 & 7.6 & 30.6 & 34.5 & n.a. & 11.3 & n.a. & 19.9 & n.a. & 20.3 & 23.3 & 25.8 & 27.5 & 54.8 & n.a. & 4.8 & 6.1 \\
\hline Iraq & 28.2 & 29.0 & & & & & n.a. & 22.1 & n.a. & 11.4 & n.a. & 25.0 & 27.4 & 29.0 & 29.1 & 19.4 & 25.8 & n.a. & n.a. \\
\hline Israel & $<2.5$ & $<2.5$ & $1.1^{\mathrm{c}}$ & $1.2^{c}$ & $8.3^{c}$ & $8.6^{c}$ & n.a. & n.a. & n.a. & n.a. & n.a. & 25.3 & 26.7 & 13.1 & 15.7 & n.a. & n.a. & 8.0 & 7.8 \\
\hline Jordan & 6.6 & 12.2 & & & & & n.a. & 7.8 & n.a. & 4.7 & n.a. & 30.3 & 33.4 & 30.8 & 34.7 & 22.7 & 25.5 & 13.9 & 13.8 \\
\hline Kuwait & $<2.5$ & 2.8 & & & & & 3.1 & 4.3 & 4.9 & 9.5 & 6.0 & 34.3 & 37.0 & 21.0 & 23.8 & n.a. & n.a. & 9.9 & 9.9 \\
\hline Lebanon & 3.4 & 11.0 & n.a. & n.a. & n.a. & n.a. & n.a. & n.a. & n.a. & n.a. & n.a. & 28.8 & 31.3 & 28.1 & 31.2 & n.a. & n.a. & 9.3 & 9.2 \\
\hline Oman & 10.5 & 6.8 & n.a. & n.a. & n.a. & n.a. & 7.5 & 9.8 & 14.1 & 1.7 & 4.4 & 20.2 & 22.9 & 36.3 & 38.2 & n.a. & 32.8 & 10.6 & 10.5 \\
\hline Palestine & n.a. & n.a. & n.a. & $4.4^{c}$ & n.a. & $26.3^{c}$ & n.a. & n.a. & n.a. & n.a. & n.a. & n.a. & n.a. & n.a. & n.a. & n.a. & n.a. & 8.5 & 8.4 \\
\hline Qatar & n.a. & n.a. & n.a. & n.a. & n.a. & n.a. & n.a. & n.a. & n.a. & n.a. & n.a. & 30.6 & 33.9 & 25.8 & 27.7 & 29.3 & n.a. & 7.5 & 7.3 \\
\hline Saudi Arabia & 7.9 & 7.1 & & & & & n.a. & n.a. & n.a. & n.a. & n.a. & 31.6 & 35.0 & 41.5 & 42.9 & n.a. & n.a. & n.a. & n.a. \\
\hline Syrian Arab Republic & n.a. & n.a. & n.a. & n.a. & n.a. & n.a. & n.a. & 27.6 & n.a. & 17.9 & n.a. & 22.7 & 25.8 & 31.7 & 33.6 & 42.6 & n.a. & n.a. & n.a. \\
\hline Turkey & $<2.5$ & $<2.5$ & & & & & 1.9 & 12.5 & 9.9 & 9.7 & 11.1 & 29.0 & 32.2 & 29.0 & 30.9 & 41.6 & 30.1 & 11.6 & 11.4 \\
\hline United Arab Emirates & 4.1 & 2.6 & & & & & n.a. & n.a. & n.a. & n.a. & n.a. & 24.5 & 29.9 & 25.7 & 27.8 & n.a. & n.a. & 12.7 & 12.7 \\
\hline Yemen & 30.1 & 38.9 & n.a. & n.a. & n.a. & n.a. & 16.4 & 46.6 & 46.4 & 1.5 & 2.5 & 11.8 & 14.1 & 65.5 & 69.6 & n.a. & 9.7 & n.a. & n.a. \\
\hline $\begin{array}{l}\text { Central Asia and } \\
\text { Southern Asia }\end{array}$ & 20.7 & 14.5 & 11.9 & 11.7 & 30.1 & 30.4 & 14.1 & 37.2 & 31.8 & 3.2 & 3.4 & 4.6 & 5.7 & 47.7 & 48.2 & 46.0 & 53.6 & 26.4 & 25.5 \\
\hline $\begin{array}{l}\text { Eastern Asia and } \\
\text { South-eastern Asia* }\end{array}$ & 15.2 & 8.7 & 1.6 & 2.2 & 9.9 & 12.1 & 4.5 & 16.1 & 12.8 & 6.1 & 6.9 & 5.1 & 6.5 & 22.2 & 26.7 & 30.5 & 23.2 & 8.1 & 8.0 \\
\hline $\begin{array}{l}\text { Western Asia and } \\
\text { Northern Africa }\end{array}$ & 8.0 & 9.7 & 8.7 & 9.5 & 27.5 & 30.0 & 6.2 & 18.3 & 16.1 & 8.9 & 9.8 & 24.2 & 27.2 & 32.5 & 34.1 & 37.1 & 33.9 & 11.2 & 11.1 \\
\hline $\begin{array}{l}\text { LATIN AMERICA } \\
\text { AND THE } \\
\text { CARIBBEAN }\end{array}$ & 9.1 & 6.5 & n.a. & n.a. & n.a. & n.a. & 1.3 & 11.1 & 9.0 & 7.2 & 7.5 & 21.7 & 24.1 & 21.2 & 22.0 & 30.7 & n.a. & 8.7 & 8.7 \\
\hline Caribbean & 23.4 & 18.1 & n.a. & n.a. & n.a. & n.a. & 3.0 & 10.2 & 8.3 & 6.3 & 7.0 & 21.9 & 24.8 & 30.4 & 31.3 & 29.3 & 25.7 & 10.1 & 9.9 \\
\hline $\begin{array}{l}\text { Antigua and } \\
\text { Barbuda }\end{array}$ & n.a. & n.a. & n.a. & n.a. & n.a. & n.a. & n.a. & n.a. & n.a. & n.a. & n.a. & 17.0 & 19.1 & 21.5 & 22.1 & n.a. & n.a. & 9.1 & 9.1 \\
\hline
\end{tabular}




\begin{tabular}{|c|c|c|c|c|c|c|c|c|c|c|c|c|c|c|c|c|c|c|c|}
\hline \multirow[t]{3}{*}{$\begin{array}{l}\text { REGIONS/ } \\
\text { SUBREGIONS/ } \\
\text { COUNTRIES }\end{array}$} & \multicolumn{2}{|c|}{ 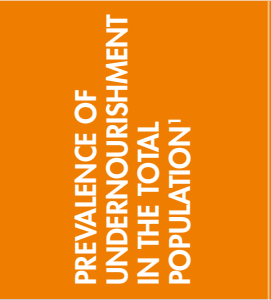 } & \multicolumn{2}{|c|}{ 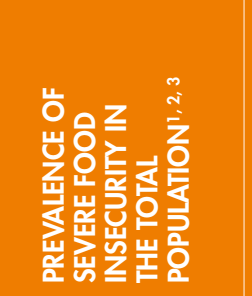 } & \multicolumn{2}{|c|}{ 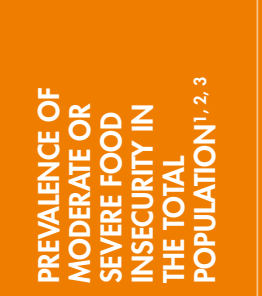 } & \multirow[t]{2}{*}{ 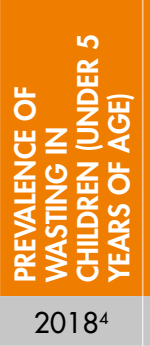 } & \multicolumn{2}{|c|}{ 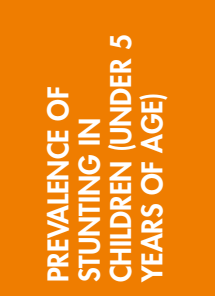 } & \multicolumn{2}{|c|}{ 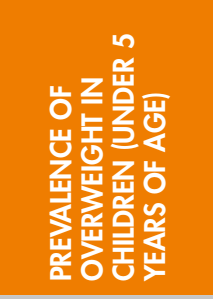 } & \multicolumn{2}{|c|}{ 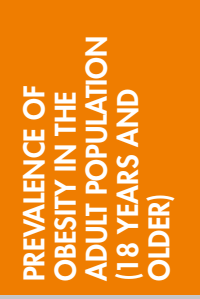 } & \multicolumn{2}{|c|}{ 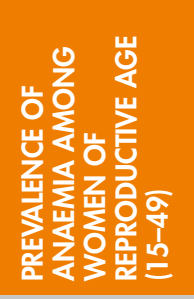 } & \multicolumn{2}{|c|}{ 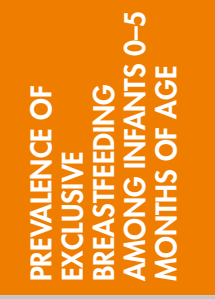 } & \multicolumn{2}{|c|}{ 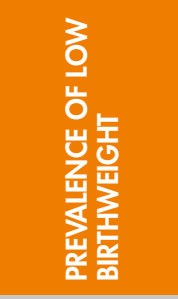 } \\
\hline & $2004-06$ & $2016-18$ & $2014-16$ & $2016-18$ & $2014-16$ & $2016-18$ & & $2012^{5}$ & $2018^{4}$ & $2012^{5}$ & $2018^{4}$ & 2012 & 2016 & 2012 & 2016 & $2012^{6}$ & $2018^{7}$ & 2012 & 2015 \\
\hline & $\%$ & $\%$ & $\%$ & $\%$ & $\%$ & $\%$ & $\%$ & $\%$ & $\%$ & $\%$ & $\%$ & $\%$ & $\%$ & $\%$ & $\%$ & $\%$ & $\%$ & $\%$ & $\%$ \\
\hline Bahamas & n.a. & n.a. & n.a. & n.a. & n.a. & n.a. & n.a. & n.a. & n.a. & n.a. & n.a. & 29.7 & 32.1 & 22.3 & 23.1 & n.a. & n.a. & 13.2 & 13.1 \\
\hline Barbados & 5.9 & 3.9 & n.a. & n.a. & n.a. & n.a. & n.a. & 7.7 & n.a. & 12.2 & n.a. & 22.2 & 24.8 & 20.7 & 21.6 & 19.7 & n.a. & n.a. & n.a. \\
\hline Cuba & $<2.5$ & $<2.5$ & n.a. & n.a. & n.a. & n.a. & n.a. & n.a. & n.a. & n.a. & n.a. & 24.3 & 26.7 & 24.3 & 25.1 & 48.6 & 32.8 & 5.2 & 5.3 \\
\hline Dominica & 5.7 & 6.2 & n.a. & n.a. & n.a. & n.a. & n.a. & n.a. & n.a. & n.a. & n.a. & 25.6 & 28.2 & 23.5 & 24.4 & n.a. & n.a. & n.a. & n.a. \\
\hline Dominican Republic & 24.4 & 9.5 & & & & & 2.4 & n.a. & 7.1 & n.a. & 7.6 & 23.5 & 26.9 & 29.5 & 29.7 & 8.0 & 4.6 & 11.4 & 11.3 \\
\hline Grenada & n.a. & n.a. & n.a. & n.a. & n.a. & n.a. & n.a. & n.a. & n.a. & n.a. & n.a. & 17.5 & 20.2 & 22.8 & 23.5 & n.a. & n.a. & n.a. & n.a. \\
\hline Haiti & 57.1 & 49.3 & n.a. & n.a. & n.a. & n.a. & 3.7 & 22.0 & 21.9 & 3.6 & 3.4 & 17.2 & 20.5 & 46.1 & 46.2 & 39.3 & 39.9 & n.a. & n.a. \\
\hline Jamaica & 7.0 & 8.0 & & & & & 3.6 & 6.8 & 6.0 & 7.8 & 8.3 & 21.9 & 24.4 & 21.8 & 22.5 & 23.8 & n.a. & 14.7 & 14.6 \\
\hline Puerto Rico & n.a. & n.a. & n.a. & n.a. & n.a. & n.a. & n.a. & n.a. & n.a. & n.a. & n.a. & n.a. & n.a. & n.a. & n.a. & n.a. & n.a. & n.a. & n.a. \\
\hline Saint Kitts and Nevis & n.a. & n.a. & n.a. & n.a. & n.a. & n.a. & n.a. & n.a. & n.a. & n.a. & n.a. & 20.4 & 23.1 & n.a. & n.a. & n.a. & n.a. & n.a. & n.a. \\
\hline Saint Lucia & n.a. & n.a. & $4.5^{c}$ & $4.5^{c}$ & $22.2^{c}$ & $22.2^{c}$ & n.a. & 2.5 & n.a. & 6.3 & n.a. & 17.4 & 19.8 & 21.4 & 21.9 & 3.5 & n.a. & n.a. & n.a. \\
\hline $\begin{array}{l}\text { Saint Vincent and the } \\
\text { Grenadines }\end{array}$ & 9.1 & 5.7 & n.a. & n.a. & n.a. & n.a. & n.a. & n.a. & n.a. & n.a. & n.a. & 20.8 & 23.8 & 23.9 & 24.8 & n.a. & n.a. & n.a. & n.a. \\
\hline Trinidad and Tobago & 11.8 & 5.5 & n.a. & n.a. & n.a. & n.a. & n.a. & 9.2 & n.a. & 11.4 & n.a. & 16.7 & 19.7 & 21.8 & 22.5 & 21.5 & n.a. & 12.5 & 12.4 \\
\hline Central America & 8.3 & 6.1 & 10.5 & 10.6 & 32.2 & 31.7 & 0.9 & 16.0 & 12.9 & 6.6 & 6.9 & 24.2 & 26.6 & 15.3 & 15.5 & 21.3 & 33.9 & 8.8 & 8.7 \\
\hline Belize & 4.6 & 7.5 & n.a. & n.a. & n.a. & n.a. & 1.8 & 19.3 & 15.0 & 7.9 & 7.3 & 19.9 & 22.4 & 21.0 & 21.7 & 14.7 & 33.2 & 8.7 & 8.6 \\
\hline Costa Rica & 5.4 & 4.8 & 4.8 & 5.2 & 21.4 & 23.2 & n.a. & 5.6 & n.a. & 8.1 & n.a. & 22.4 & 25.7 & 13.3 & 14.9 & 32.5 & n.a. & 7.3 & 7.5 \\
\hline El Salvador & 10.5 & 9.0 & 13.5 & 12.7 & 42.3 & 40.0 & 2.1 & 20.8 & 13.6 & 5.7 & 6.4 & 20.4 & 22.7 & 18.9 & 22.7 & 31.4 & 46.7 & 10.4 & 10.3 \\
\hline Guatemala & 15.8 & 15.2 & 15.6 & 16.4 & 43.1 & 43.6 & 0.8 & 48.0 & 46.7 & 4.9 & 4.9 & 16.6 & 18.8 & 17.5 & 16.4 & 49.6 & 53.2 & 11.2 & 11.0 \\
\hline Honduras & 17.0 & 12.9 & 18.5 & 17.7 & 52.4 & 49.3 & n.a. & 22.6 & n.a. & 5.2 & n.a. & 16.9 & 19.4 & 16.3 & 17.8 & 30.7 & n.a. & 11.0 & 10.9 \\
\hline Mexico & 5.5 & 3.6 & 9.0 & 8.9 & 28.5 & 28.0 & 2.0 & 13.6 & 10.0 & 9.0 & 5.3 & 26.0 & 28.4 & 14.7 & 14.6 & 14.4 & 30.1 & 8.0 & 7.9 \\
\hline Nicaragua & 24.4 & 17.0 & & & & & n.a. & 17.3 & n.a. & 8.3 & n.a. & 19.3 & 21.8 & 13.9 & 16.3 & 31.7 & n.a. & 10.8 & 10.7 \\
\hline Panama & 22.9 & 10.0 & & & & & n.a. & 19.0 & n.a. & 9.7 & n.a. & 20.2 & 22.5 & 24.0 & 23.4 & n.a. & 21.5 & 10.2 & 10.1 \\
\hline
\end{tabular}




\begin{tabular}{|c|c|c|c|c|c|c|c|c|c|c|c|c|c|c|c|c|c|c|c|}
\hline \multirow[t]{3}{*}{$\begin{array}{l}\text { REGIONS/ } \\
\text { SUBREGIONS/ } \\
\text { COUNTRIES }\end{array}$} & \multicolumn{2}{|c|}{ 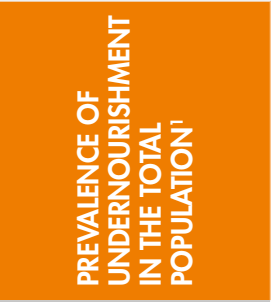 } & \multicolumn{2}{|c|}{ 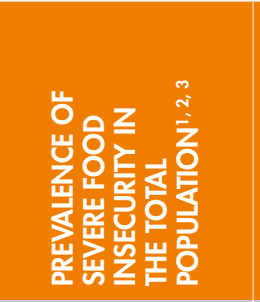 } & \multicolumn{2}{|c|}{ 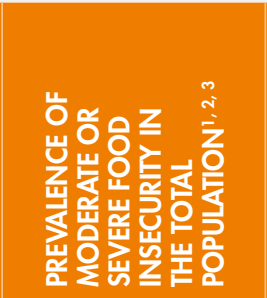 } & \multirow[t]{2}{*}{ 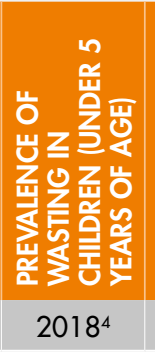 } & \multicolumn{2}{|c|}{ 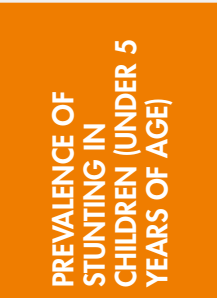 } & \multicolumn{2}{|c|}{ 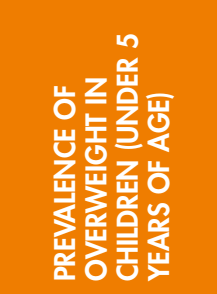 } & \multicolumn{2}{|c|}{ 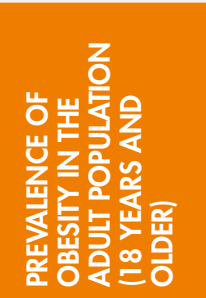 } & \multicolumn{2}{|c|}{ 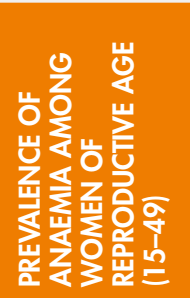 } & \multicolumn{2}{|c|}{ 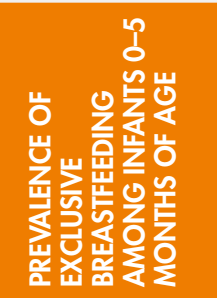 } & \multicolumn{2}{|c|}{ 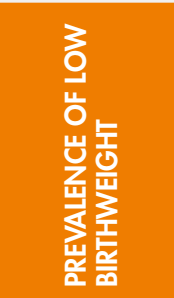 } \\
\hline & 2004-06 & 2016-18 & $2014-16$ & 2016-18 & $2014-16$ & 2016-18 & & $2012^{5}$ & $2018^{4}$ & $2012^{5}$ & $2018^{4}$ & 2012 & 2016 & 2012 & 2016 & $2012^{6}$ & $2018^{7}$ & 2012 & 2015 \\
\hline & $\%$ & $\%$ & $\%$ & $\%$ & $\%$ & $\%$ & $\%$ & $\%$ & $\%$ & $\%$ & $\%$ & $\%$ & $\%$ & $\%$ & $\%$ & $\%$ & $\%$ & $\%$ & $\%$ \\
\hline South America & 7.9 & 5.4 & 6.0 & 8.2 & 23.8 & 30.8 & $1.3^{\mathrm{a}}$ & 8.9 & $7.1^{\circ}$ & 7.6 & $7.8^{\circ}$ & 20.8 & 23.0 & 22.7 & 23.9 & 36.3 & n.a. & 8.6 & 8.6 \\
\hline Argentina & 4.7 & 4.6 & 5.8 & 11.3 & 19.1 & 32.1 & n.a. & n.a. & n.a. & n.a. & n.a. & 26.3 & 28.5 & 15.9 & 18.6 & 32.0 & n.a. & 7.1 & 7.3 \\
\hline $\begin{array}{l}\text { Bolivia } \\
\text { (Plurinational State of) }\end{array}$ & 30.3 & 17.1 & & & & & 2.0 & 18.1 & 16.1 & 8.7 & 10.1 & 16.8 & 18.7 & 30.1 & 30.2 & 64.3 & 58.3 & 7.3 & 7.2 \\
\hline Brazil & 4.6 & $<2.5$ & & & & & n.a. & n.a. & n.a. & n.a. & n.a. & 19.9 & 22.3 & 25.3 & 27.2 & 38.6 & n.a. & 8.4 & 8.4 \\
\hline Chile & 3.9 & 2.7 & n.a. & $3.4^{c}$ & n.a. & $13.6^{\circ}$ & 0.3 & 2.0 & 1.8 & 9.5 & 9.3 & 26.6 & 28.8 & 11.6 & 15.0 & n.a. & n.a. & 6.0 & 6.2 \\
\hline Colombia & 9.7 & 4.8 & & & & & n.a. & 12.6 & n.a. & 4.8 & n.a. & 19.9 & 22.1 & 22.3 & 21.1 & n.a. & n.a. & 10.0 & 10.0 \\
\hline Ecuador & 17.0 & 7.9 & $7.1^{\mathrm{c}}$ & $7.1^{c}$ & $23.3^{c}$ & $23.3^{c}$ & 1.6 & 25.4 & 23.9 & 7.5 & 8.0 & 17.3 & 19.3 & 18.4 & 18.8 & n.a. & n.a. & 11.3 & 11.2 \\
\hline Guyana & 9.4 & 8.1 & n.a. & n.a. & n.a. & n.a. & 6.4 & 19.3 & 11.3 & 6.7 & 5.3 & 16.6 & 19.2 & 33.4 & 32.3 & 31.3 & 21.1 & 15.8 & 15.6 \\
\hline Paraguay & 11.9 & 10.7 & & & & & 1.0 & 10.7 & 5.6 & 11.3 & 12.4 & 16.7 & 19.0 & 20.5 & 22.8 & 24.4 & 29.6 & 8.2 & 8.1 \\
\hline Peru & 19.6 & 9.7 & & & & & 0.5 & 18.4 & 12.9 & 7.2 & 8.0 & 17.2 & 19.1 & 20.0 & 18.5 & 67.4 & 64.2 & 9.5 & 9.4 \\
\hline Suriname & 10.9 & 8.5 & n.a. & n.a. & n.a. & n.a. & n.a. & 8.8 & n.a. & 4.0 & n.a. & 24.2 & 26.5 & 23.4 & 24.1 & 2.8 & n.a. & 14.9 & 14.7 \\
\hline Uruguay & 4.3 & $<2.5$ & 6.6 & 7.6 & 20.6 & 25.3 & n.a. & 10.7 & n.a. & 7.2 & n.a. & 26.8 & 28.9 & 18.3 & 20.8 & n.a. & n.a. & 7.9 & 7.6 \\
\hline $\begin{array}{l}\text { Venezuela } \\
\text { (Bolivarian Republic of) }\end{array}$ & 10.5 & 21.2 & & & & & n.a. & 13.4 & n.a. & 6.4 & n.a. & 23.3 & 25.2 & 22.9 & 23.9 & n.a. & n.a. & 8.6 & 9.1 \\
\hline OCEANIA & 5.5 & 6.1 & n.a. & n.a. & n.a. & n.a. & n.a. & n.a. & n.a. & n.a. & n.a. & 26.5 & 28.9 & 14.8 & 16.5 & n.a. & n.a. & 7.8 & 7.9 \\
\hline $\begin{array}{l}\text { Australia and New } \\
\text { Zealand }\end{array}$ & $<2.5$ & $<2.5$ & 2.7 & 3.6 & 11.2 & 13.5 & n.a. & n.a. & n.a. & n.a. & n.a. & 28.2 & 30.7 & 8.3 & 9.5 & n.a. & n.a. & 6.2 & 6.4 \\
\hline Australia & $<2.5$ & $<2.5$ & 2.7 & 3.5 & 11.3 & 13.4 & n.a. & n.a. & n.a. & n.a. & n.a. & 27.9 & 30.4 & 8.1 & 9.1 & n.a. & n.a. & 6.3 & 6.5 \\
\hline New Zealand & $<2.5$ & $<2.5$ & 2.7 & 4.1 & 10.6 & 14.0 & n.a. & n.a. & n.a. & n.a. & n.a. & 29.5 & 32.0 & 9.7 & 11.6 & n.a. & n.a. & 5.9 & 5.7 \\
\hline $\begin{array}{l}\text { Oceania excluding } \\
\text { Australia and New } \\
\text { Zealand }\end{array}$ & n.a. & n.a. & n.a. & n.a. & n.a. & n.a. & 9.4 & 37.7 & 38.2 & 7.3 & 9.1 & 20.1 & 22.4 & 33.2 & 35.4 & 56.8 & n.a. & 10.0 & 9.9 \\
\hline Melanesia & n.a. & n.a. & n.a. & n.a. & n.a. & n.a. & n.a. & n.a. & n.a. & n.a. & n.a. & 18.4 & 20.7 & 33.9 & 35.9 & 56.8 & n.a. & 10.1 & 9.9 \\
\hline Fiii & 4.3 & 3.7 & n.a. & n.a. & n.a. & n.a. & n.a. & n.a. & n.a. & n.a. & n.a. & 27.2 & 30.0 & 29.8 & 31.0 & n.a. & n.a. & n.a. & n.a. \\
\hline
\end{tabular}




\begin{tabular}{|c|c|c|c|c|c|c|c|c|c|c|c|c|c|c|c|c|c|c|c|}
\hline \multirow[t]{3}{*}{$\begin{array}{l}\text { REGIONS/ } \\
\text { SUBREGIONS/ } \\
\text { COUNTRIES }\end{array}$} & \multicolumn{2}{|c|}{ 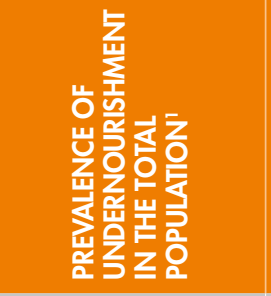 } & \multicolumn{2}{|c|}{ 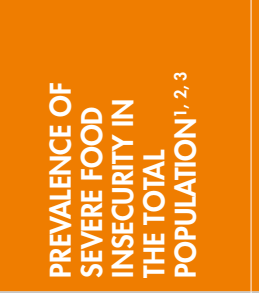 } & \multicolumn{2}{|c|}{ 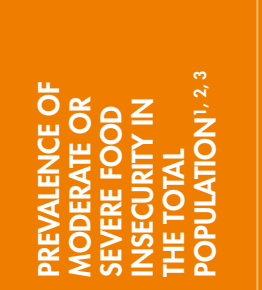 } & \multirow[t]{2}{*}{ 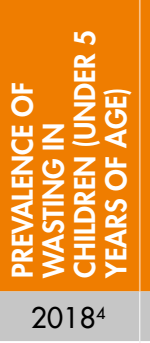 } & \multicolumn{2}{|c|}{ 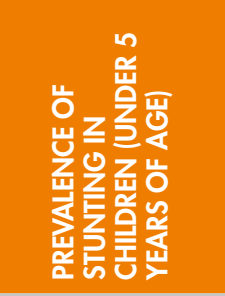 } & \multicolumn{2}{|c|}{ 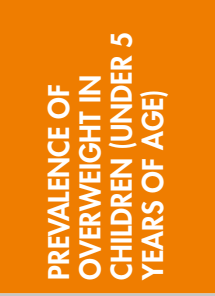 } & \multicolumn{2}{|c|}{ 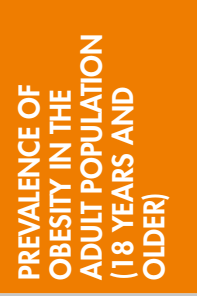 } & \multicolumn{2}{|c|}{ 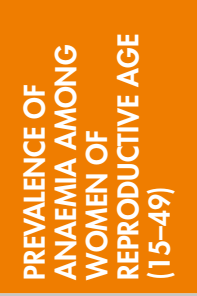 } & \multicolumn{2}{|c|}{ 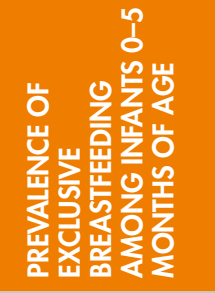 } & \multicolumn{2}{|c|}{ 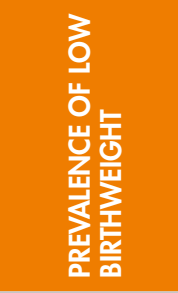 } \\
\hline & $2004-06$ & $2016-18$ & $2014-16$ & $2016-18$ & $2014-16$ & $2016-18$ & & $2012^{5}$ & $2018^{4}$ & $2012^{5}$ & $2018^{4}$ & 2012 & 2016 & 2012 & 2016 & $2012^{6}$ & $2018^{7}$ & 2012 & 2015 \\
\hline & $\%$ & $\%$ & $\%$ & $\%$ & $\%$ & $\%$ & $\%$ & $\%$ & $\%$ & $\%$ & $\%$ & $\%$ & $\%$ & $\%$ & $\%$ & $\%$ & $\%$ & $\%$ & $\%$ \\
\hline New Caledonia & 8.2 & 7.1 & n.a. & n.a. & n.a. & n.a. & n.a. & n.a. & n.a. & n.a. & n.a. & n.a. & n.a. & n.a. & n.a. & n.a. & n.a. & n.a. & n.a. \\
\hline Papua New Guinea & n.a. & n.a. & n.a. & n.a. & n.a. & n.a. & n.a. & 49.5 & n.a. & 13.7 & n.a. & 17.1 & 19.4 & 34.4 & 36.6 & 56.1 & n.a. & n.a. & n.a. \\
\hline Solomon Islands & 11.9 & 8.9 & n.a. & n.a. & n.a. & n.a. & 8.5 & n.a. & 31.6 & n.a. & 4.5 & 17.9 & 20.5 & 38.4 & 38.9 & 73.7 & 76.2 & n.a. & n.a. \\
\hline Vanuatu & 7.0 & 7.2 & n.a. & n.a. & n.a. & n.a. & 4.4 & n.a. & 28.5 & n.a. & 4.6 & 20.7 & 23.5 & 24.1 & 24.0 & 39.5 & 72.6 & 11.0 & 10.9 \\
\hline Micronesia & n.a. & n.a. & n.a. & n.a. & n.a. & n.a. & n.a. & n.a. & n.a. & n.a. & n.a. & 44.2 & 46.8 & 22.3 & 25.1 & 69.0 & n.a. & 9.4 & 9.3 \\
\hline Kiribati & 4.6 & 2.7 & n.a. & n.a. & n.a. & n.a. & n.a. & n.a. & n.a. & n.a. & n.a. & 43.0 & 45.6 & 23.8 & 26.1 & 69.0 & n.a. & n.a. & n.a. \\
\hline Marshall Islands & n.a. & n.a. & n.a. & n.a. & n.a. & n.a. & 3.5 & n.a. & 34.8 & n.a. & 4.1 & 50.1 & 52.4 & 24.1 & 26.6 & 27.3 & 42.3 & n.a. & n.a. \\
\hline $\begin{array}{l}\text { Micronesia } \\
\text { (Federated States of) }\end{array}$ & n.a. & n.a. & n.a. & n.a. & n.a. & n.a. & n.a. & n.a. & n.a. & n.a. & n.a. & 38.6 & 41.6 & 19.5 & 23.3 & n.a. & n.a. & n.a. & n.a. \\
\hline Nauru & n.a. & n.a. & n.a. & n.a. & n.a. & n.a. & n.a. & n.a. & n.a. & n.a. & n.a. & 59.3 & 60.7 & n.a. & n.a. & 67.2 & n.a. & n.a. & n.a. \\
\hline Palau & n.a. & n.a. & n.a. & n.a. & n.a. & n.a. & n.a. & n.a. & n.a. & n.a. & n.a. & 52.5 & 54.9 & n.a. & n.a. & n.a. & n.a. & n.a. & n.a. \\
\hline Polynesia & 3.7 & 3.6 & n.a. & n.a. & n.a. & n.a. & n.a. & n.a. & n.a. & n.a. & n.a. & 43.9 & 46.5 & 23.0 & 27.6 & 51.6 & 70.3 & 8.1 & 8.1 \\
\hline American Samoa & n.a. & n.a. & n.a. & n.a. & n.a. & n.a. & n.a. & n.a. & n.a. & n.a. & n.a. & n.a. & n.a. & n.a. & n.a. & n.a. & n.a. & n.a. & n.a. \\
\hline Cook Islands & n.a. & n.a. & n.a. & n.a. & n.a. & n.a. & n.a. & n.a. & n.a. & n.a. & n.a. & 53.0 & 55.3 & n.a. & n.a. & n.a. & n.a. & 3.5 & 3.5 \\
\hline French Polynesia & 3.9 & 4.2 & n.a. & n.a. & n.a. & n.a. & n.a. & n.a. & n.a. & n.a. & n.a. & n.a. & n.a. & n.a. & n.a. & n.a. & n.a. & n.a. & n.a. \\
\hline Nive & n.a. & n.a. & n.a. & n.a. & n.a. & n.a. & n.a. & n.a. & n.a. & n.a. & n.a. & 46.0 & 49.3 & n.a. & n.a. & n.a. & n.a. & n.a. & n.a. \\
\hline Samoa & 3.5 & 2.7 & n.a. & n.a. & n.a. & n.a. & 3.9 & n.a. & 4.9 & n.a. & 5.3 & 42.9 & 45.5 & 25.4 & 31.3 & 51.3 & 70.3 & n.a. & n.a. \\
\hline $\begin{array}{l}\text { Tokelau } \\
\text { (Associate Member) }\end{array}$ & n.a. & n.a. & n.a. & n.a. & n.a. & n.a. & n.a. & n.a. & n.a. & n.a. & n.a. & n.a. & n.a. & n.a. & n.a. & n.a. & n.a. & n.a. & n.a. \\
\hline Tonga & n.a. & n.a. & n.a. & n.a. & n.a. & n.a. & n.a. & 8.1 & n.a. & 17.3 & n.a. & 43.3 & 45.9 & 19.0 & 21.3 & 52.2 & n.a. & n.a. & n.a. \\
\hline Tuvalu & n.a. & n.a. & n.a. & n.a. & n.a. & n.a. & n.a. & n.a. & n.a. & n.a. & n.a. & 47.8 & 51.0 & n.a. & n.a. & 34.7 & n.a. & n.a. & n.a. \\
\hline $\begin{array}{l}\text { NORTHERN AMERICA } \\
\text { AND EUROPE }\end{array}$ & $<2.5$ & $<2.5$ & 1.4 & 1.1 & 9.3 & 8.4 & n.a. & n.a. & n.a. & n.a. & n.a. & 26.7 & 29.0 & 15.4 & 17.8 & n.a. & n.a. & 7.0 & 7.0 \\
\hline Northern America & $<2.5$ & $<2.5$ & 1.0 & 1.0 & 9.9 & 8.8 & 0.4 & 2.7 & 2.6 & 8.0 & 8.8 & 34.1 & 36.7 & 10.6 & 12.9 & 25.5 & 34.7 & 7.9 & 7.9 \\
\hline Bermuda & n.a. & n.a. & n.a. & n.a. & n.a. & n.a. & n.a. & n.a. & n.a. & n.a. & n.a. & n.a. & n.a. & n.a. & n.a. & n.a. & n.a. & n.a. & n.a. \\
\hline
\end{tabular}




\begin{tabular}{|c|c|c|c|c|c|c|c|c|c|c|c|c|c|c|c|c|c|c|c|}
\hline \multirow[t]{3}{*}{$\begin{array}{l}\text { REGIONS/ } \\
\text { SUBREGIONS/ } \\
\text { COUNTRIES }\end{array}$} & \multicolumn{2}{|c|}{ 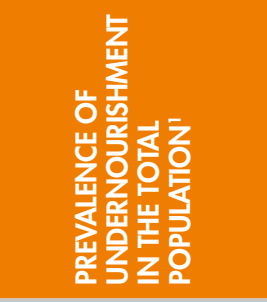 } & \multicolumn{2}{|c|}{ 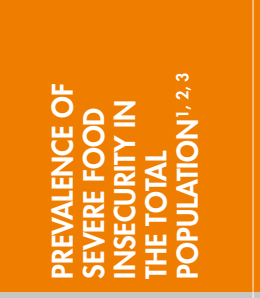 } & \multicolumn{2}{|c|}{ 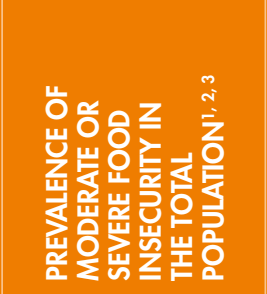 } & \multirow[t]{2}{*}{ 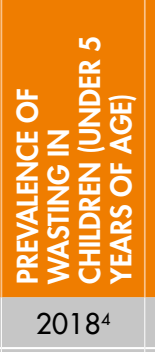 } & \multicolumn{2}{|c|}{ 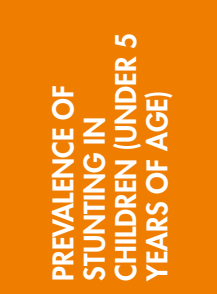 } & \multicolumn{2}{|c|}{ 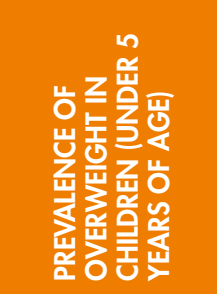 } & \multicolumn{2}{|c|}{ 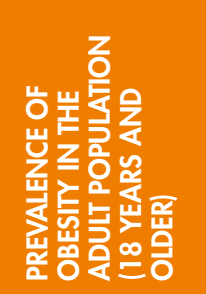 } & \multicolumn{2}{|c|}{ 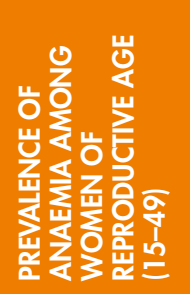 } & \multicolumn{2}{|c|}{ 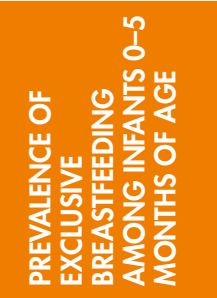 } & \multicolumn{2}{|c|}{ 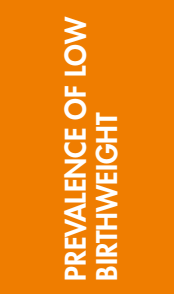 } \\
\hline & 2004-06 & 2016-18 & $2014-16$ & 2016-18 & $2014-16$ & 2016-18 & & $2012^{5}$ & $2018^{4}$ & $2012^{5}$ & $2018^{4}$ & 2012 & 2016 & 2012 & 2016 & $2012^{6}$ & $2018^{7}$ & 2012 & 2015 \\
\hline & $\%$ & $\%$ & $\%$ & $\%$ & $\%$ & $\%$ & $\%$ & $\%$ & $\%$ & $\%$ & $\%$ & $\%$ & $\%$ & $\%$ & $\%$ & $\%$ & $\%$ & $\%$ & $\%$ \\
\hline Canada & $<2.5$ & $<2.5$ & $0.6^{c}$ & n.a. & $5.0^{c}$ & n.a. & n.a. & n.a. & n.a. & n.a. & n.a. & 28.8 & 31.3 & 8.5 & 9.5 & n.a. & n.a. & 6.2 & 6.4 \\
\hline Greenland & n.a. & n.a. & n.a. & n.a. & n.a. & n.a. & n.a. & n.a. & n.a. & n.a. & n.a. & n.a. & n.a. & n.a. & n.a. & n.a. & n.a. & n.a. & n.a. \\
\hline $\begin{array}{l}\text { United States } \\
\text { of America }\end{array}$ & $<2.5$ & $<2.5$ & $1.1^{c}$ & $1.0^{c}$ & $10.5^{c}$ & $9.2^{c}$ & 0.4 & 2.1 & 3.5 & 6.0 & 9.4 & 34.7 & 37.3 & 10.9 & 13.3 & 25.5 & 34.7 & 8.1 & 8.0 \\
\hline Europe & $<2.5$ & $<2.5$ & 1.6 & 1.2 & 9.0 & 8.2 & n.a. & n.a. & n.a. & n.a. & n.a. & 23.4 & 25.4 & 17.6 & 20.2 & n.a. & n.a. & 6.6 & 6.5 \\
\hline Eastern Europe & $<2.5$ & $<2.5$ & 1.2 & 1.0 & 11.0 & 10.5 & n.a. & n.a. & n.a. & n.a. & n.a. & 23.9 & 25.8 & 22.1 & 24.2 & n.a. & n.a. & 6.2 & 6.1 \\
\hline Belarus & 3.0 & $<2.5$ & & & & & n.a. & n.a. & n.a. & n.a. & n.a. & 24.6 & 26.6 & 20.4 & 22.6 & 19.0 & n.a. & 4.9 & 5.1 \\
\hline Bulgaria & 6.5 & 3.6 & 1.7 & 2.1 & 14.1 & 11.8 & n.a. & n.a. & n.a. & n.a. & n.a. & 25.3 & 27.4 & 24.2 & 26.4 & n.a. & n.a. & 9.4 & 9.6 \\
\hline Czechia & $<2.5$ & $<2.5$ & 0.6 & $<0.5$ & 5.8 & 3.8 & n.a. & n.a. & n.a. & n.a. & n.a. & 26.6 & 28.5 & 23.3 & 25.7 & n.a. & n.a. & 7.9 & 7.8 \\
\hline Hungary & $<2.5$ & $<2.5$ & 1.2 & 0.8 & 10.6 & 8.3 & n.a. & n.a. & n.a. & n.a. & n.a. & 26.4 & 28.6 & 23.6 & 25.8 & n.a. & n.a. & 8.6 & 8.8 \\
\hline Poland & $<2.5$ & $<2.5$ & 1.7 & 0.7 & 8.7 & 5.3 & n.a. & 2.9 & 2.6 & n.a. & n.a. & 23.4 & 25.6 & 23.5 & 25.7 & n.a. & n.a. & 5.7 & 5.9 \\
\hline Republic of Moldova & n.a. & n.a. & 1.6 & 2.8 & 20.0 & 25.4 & n.a. & 6.4 & n.a. & 4.9 & n.a. & 18.3 & 20.1 & 25.6 & 26.8 & 36.4 & n.a. & 5.0 & 5.0 \\
\hline Romania & $<2.5$ & $<2.5$ & 5.5 & 4.0 & 19.2 & 14.7 & n.a. & n.a. & n.a. & n.a. & n.a. & 22.1 & 24.5 & 24.6 & 26.7 & n.a. & n.a. & 8.3 & 8.2 \\
\hline Russian Federation & $<2.5$ & $<2.5$ & $<0.5$ & $<0.5^{c}$ & 8.2 & $6.2^{c}$ & n.a. & n.a. & n.a. & n.a. & n.a. & 23.9 & 25.7 & 21.3 & 23.3 & n.a. & n.a. & 6.0 & 5.8 \\
\hline Slovakia & 6.2 & 3.4 & 0.5 & $<0.5$ & 5.7 & 4.7 & n.a. & n.a. & n.a. & n.a. & n.a. & 20.4 & 22.4 & 24.5 & 26.6 & n.a. & n.a. & 8.0 & 7.6 \\
\hline Ukraine & $<2.5$ & 3.5 & 1.8 & 1.8 & & & n.a. & n.a. & n.a. & n.a. & n.a. & 24.2 & 26.1 & 21.3 & 23.5 & 19.7 & n.a. & 5.4 & 5.6 \\
\hline Northern Europe & $<2.5$ & $<2.5$ & 3.1 & 1.7 & 8.6 & 6.0 & n.a. & n.a. & n.a. & n.a. & n.a. & 25.2 & 27.5 & 12.6 & 16.0 & n.a. & n.a. & 6.1 & 6.0 \\
\hline Denmark & $<2.5$ & $<2.5$ & 0.8 & 1.0 & 5.7 & 5.3 & n.a. & n.a. & n.a. & n.a. & n.a. & 19.8 & 21.3 & 13.4 & 16.3 & n.a. & n.a. & 5.3 & 5.3 \\
\hline Estonia & 4.2 & 2.9 & 1.1 & 1.3 & 9.7 & 8.6 & n.a. & n.a. & n.a. & n.a. & n.a. & 22.3 & 23.8 & 23.4 & 25.6 & n.a. & n.a. & 4.4 & 4.3 \\
\hline Finland & $<2.5$ & $<2.5$ & 2.3 & 2.0 & 9.3 & 8.3 & n.a. & n.a. & n.a. & n.a. & n.a. & 23.2 & 24.9 & 13.1 & 15.9 & n.a. & n.a. & 4.2 & 4.1 \\
\hline Iceland & $<2.5$ & $<2.5$ & 1.7 & 1.5 & 6.4 & 6.7 & n.a. & n.a. & n.a. & n.a. & n.a. & 21.3 & 23.1 & 13.2 & 16.1 & n.a. & n.a. & 3.9 & 4.2 \\
\hline Ireland & $<2.5$ & $<2.5$ & $3.6^{d}$ & 2.8 & $9.5^{d}$ & 6.6 & n.a. & n.a. & n.a. & n.a. & n.a. & 23.9 & 26.9 & 12.2 & 14.8 & n.a. & n.a. & 5.3 & 5.9 \\
\hline Latvia & $<2.5$ & $<2.5$ & 1.4 & 1.2 & 10.4 & 10.0 & n.a. & n.a. & n.a. & n.a. & n.a. & 24.2 & 25.7 & 22.9 & 25.1 & n.a. & n.a. & 4.5 & 4.5 \\
\hline Lithuania & $<2.5$ & $<2.5$ & 0.5 & $<0.5$ & 13.8 & 11.2 & n.a. & n.a. & n.a. & n.a. & n.a. & 26.7 & 28.4 & 23.2 & 25.5 & n.a. & n.a. & 4.5 & 4.5 \\
\hline
\end{tabular}




\begin{tabular}{|c|c|c|c|c|c|c|c|c|c|c|c|c|c|c|c|c|c|c|c|}
\hline \multirow[t]{3}{*}{$\begin{array}{l}\text { REGIONS/ } \\
\text { SUBREGIONS/ } \\
\text { COUNTRIES }\end{array}$} & \multicolumn{2}{|c|}{ 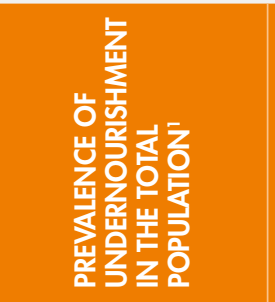 } & \multicolumn{2}{|c|}{ 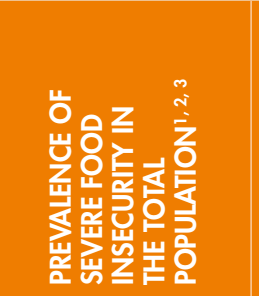 } & \multicolumn{2}{|c|}{ 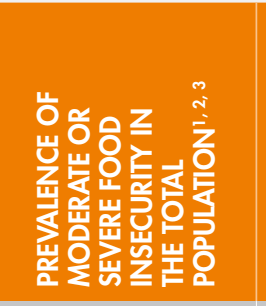 } & \multirow[t]{2}{*}{ 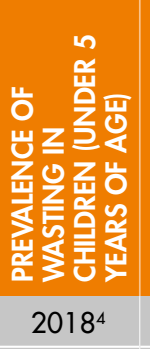 } & \multicolumn{2}{|c|}{ 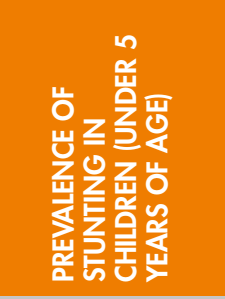 } & \multicolumn{2}{|c|}{ 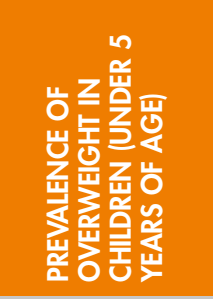 } & \multicolumn{2}{|c|}{ 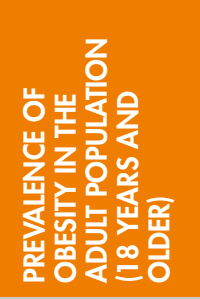 } & \multicolumn{2}{|c|}{ 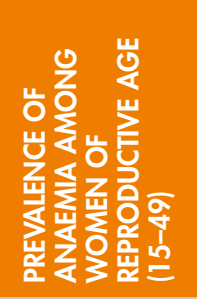 } & \multicolumn{2}{|c|}{ 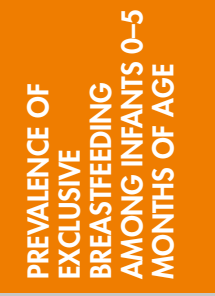 } & \multicolumn{2}{|c|}{ 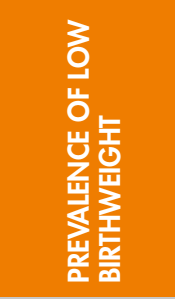 } \\
\hline & $2004-06$ & $2016-18$ & $2014-16$ & $2016-18$ & $2014-16$ & $2016-18$ & & $2012^{5}$ & $2018^{4}$ & $2012^{5}$ & $2018^{4}$ & 2012 & 2016 & 2012 & 2016 & $2012^{6}$ & $2018^{7}$ & 2012 & 2015 \\
\hline & $\%$ & $\%$ & $\%$ & $\%$ & $\%$ & $\%$ & $\%$ & $\%$ & $\%$ & $\%$ & $\%$ & $\%$ & $\%$ & $\%$ & $\%$ & $\%$ & $\%$ & $\%$ & $\%$ \\
\hline Norway & $<2.5$ & $<2.5$ & 1.1 & 1.1 & 5.0 & 5.1 & n.a. & n.a. & n.a. & n.a. & n.a. & 23.0 & 25.0 & 12.7 & 15.3 & n.a. & n.a. & 4.7 & 4.5 \\
\hline Sweden & $<2.5$ & $<2.5$ & 0.8 & 1.0 & 4.5 & 5.4 & n.a. & n.a. & n.a. & n.a. & n.a. & 20.4 & 22.1 & 12.8 & 15.4 & n.a. & n.a. & 3.8 & 2.4 \\
\hline $\begin{array}{l}\text { United Kingdom of } \\
\text { Great Britain and } \\
\text { Northern Ireland }\end{array}$ & $<2.5$ & $<2.5$ & 4.0 & 1.8 & 9.3 & 5.6 & n.a. & n.a. & n.a. & n.a. & n.a. & 26.9 & 29.5 & 11.5 & 15.3 & n.a. & n.a. & 6.9 & 7.0 \\
\hline Southern Europe & $<2.5$ & $<2.5$ & 1.6 & 1.7 & 9.8 & 9.4 & n.a. & n.a. & n.a. & n.a. & n.a. & 22.8 & 24.6 & 15.8 & 18.6 & n.a. & n.a. & 7.2 & 7.3 \\
\hline Albania & 10.9 & 6.2 & 10.1 & 11.1 & 38.7 & 38.6 & 1.6 & 23.2 & 11.3 & 23.2 & 16.4 & 19.9 & 22.3 & 22.7 & 25.3 & 37.1 & 36.5 & 4.6 & 4.6 \\
\hline Andorra & n.a. & n.a. & n.a. & n.a. & n.a. & n.a. & n.a. & n.a. & n.a. & n.a. & n.a. & 26.6 & 28.0 & 11.6 & 13.9 & n.a. & n.a. & 7.5 & 7.4 \\
\hline $\begin{array}{l}\text { Bosnia and } \\
\text { Herzegovina }\end{array}$ & 3.2 & $<2.5$ & 1.4 & 1.1 & 9.8 & 9.2 & n.a. & 8.9 & n.a. & 17.4 & n.a. & 17.7 & 19.4 & 27.1 & 29.4 & 18.2 & n.a. & 3.4 & 3.4 \\
\hline Croatia & 2.9 & $<2.5$ & 0.7 & 0.9 & 6.4 & 7.8 & n.a. & n.a. & n.a. & n.a. & n.a. & 24.9 & 27.1 & 25.2 & 27.3 & n.a. & n.a. & 4.8 & 5.1 \\
\hline Greece & $<2.5$ & $<2.5$ & 2.3 & 2.8 & 16.1 & 17.4 & n.a. & n.a. & n.a. & n.a. & n.a. & 25.4 & 27.4 & 13.1 & 15.9 & n.a. & n.a. & 8.7 & 8.7 \\
\hline Italy & $<2.5$ & $<2.5$ & 1.1 & 1.0 & 8.1 & 7.1 & n.a. & n.a. & n.a. & n.a. & n.a. & 21.4 & 22.9 & 14.4 & 17.3 & n.a. & n.a. & 7.0 & 7.0 \\
\hline Malta & $<2.5$ & $<2.5$ & & & & & n.a. & n.a. & n.a. & n.a. & n.a. & 29.5 & 31.0 & 13.7 & 16.4 & n.a. & n.a. & 7.0 & 6.3 \\
\hline Montenegro & -- & $<2.5$ & 2.2 & 2.1 & 13.0 & 12.0 & 2.8 & n.a. & 9.4 & n.a. & 22.3 & 23.1 & 24.9 & 22.8 & 25.2 & 19.3 & 16.8 & 5.2 & 5.5 \\
\hline North Macedonia & 6.1 & 3.2 & 3.7 & 3.2 & 14.3 & 13.2 & n.a. & 4.9 & n.a. & 12.4 & n.a. & 21.9 & 23.9 & 19.5 & 23.3 & 23.0 & n.a. & 8.8 & 9.1 \\
\hline Portugal & $<2.5$ & $<2.5$ & 4.2 & 3.2 & 15.7 & 11.5 & n.a. & n.a. & n.a. & n.a. & n.a. & 21.0 & 23.2 & 14.7 & 17.5 & n.a. & n.a. & 8.5 & 8.9 \\
\hline Serbia & -- & 5.7 & 1.3 & 1.6 & 10.6 & 11.7 & 3.9 & 6.6 & 6.0 & 15.6 & 13.9 & 21.6 & 23.5 & 24.9 & 27.2 & 13.4 & 12.8 & 4.6 & 4.5 \\
\hline Slovenia & $<2.5$ & $<2.5$ & & & & & n.a. & n.a. & n.a. & n.a. & n.a. & 20.6 & 22.5 & 21.9 & 24.4 & n.a. & n.a. & 6.2 & 6.1 \\
\hline Spain & $<2.5$ & $<2.5$ & 1.2 & 1.5 & 7.1 & 7.5 & n.a. & n.a. & n.a. & n.a. & n.a. & 25.0 & 27.1 & 13.8 & 16.6 & n.a. & n.a. & 8.2 & 8.3 \\
\hline Western Europe & $<2.5$ & $<2.5$ & 1.3 & 1.0 & 5.5 & 5.0 & n.a. & n.a. & n.a. & n.a. & n.a. & 22.4 & 24.2 & 14.0 & 17.0 & n.a. & n.a. & 7.0 & 6.9 \\
\hline Austria & $<2.5$ & $<2.5$ & 1.1 & 1.2 & 5.7 & 4.4 & n.a. & n.a. & n.a. & n.a. & n.a. & 20.1 & 21.9 & 14.4 & 17.3 & n.a. & n.a. & 6.9 & 6.5 \\
\hline Belgium & $<2.5$ & $<2.5$ & 3.1 & 3.6 & 9.2 & 10.3 & n.a. & n.a. & n.a. & n.a. & n.a. & 22.9 & 24.5 & 13.4 & 16.2 & n.a. & n.a. & 6.9 & 7.3 \\
\hline France & $<2.5$ & $<2.5$ & 1.5 & 0.8 & 6.8 & 6.4 & n.a. & n.a. & n.a. & n.a. & n.a. & 21.6 & 23.2 & 14.9 & 18.1 & n.a. & n.a. & 7.4 & 7.4 \\
\hline
\end{tabular}




\begin{tabular}{|c|c|c|c|c|c|c|c|c|c|c|c|c|c|c|c|c|c|c|c|}
\hline \multirow[t]{3}{*}{$\begin{array}{l}\text { REGIONS/ } \\
\text { SUBREGIONS/ } \\
\text { COUNTRIES }\end{array}$} & \multicolumn{2}{|c|}{ 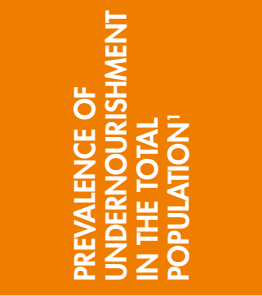 } & \multicolumn{2}{|c|}{ 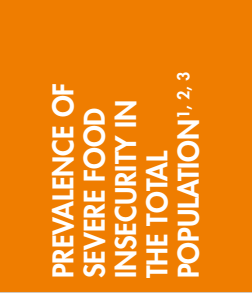 } & \multicolumn{2}{|c|}{ 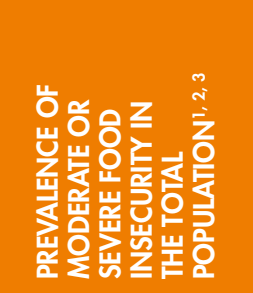 } & \multirow[t]{2}{*}{ 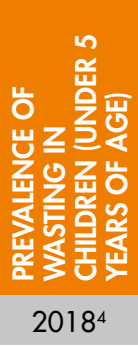 } & \multicolumn{2}{|c|}{ 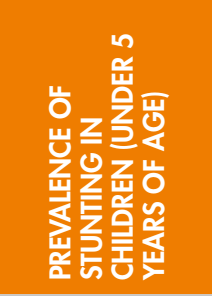 } & \multicolumn{2}{|c|}{ 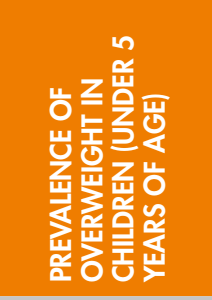 } & \multicolumn{2}{|c|}{ 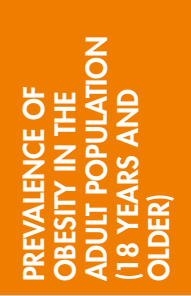 } & \multicolumn{2}{|c|}{ 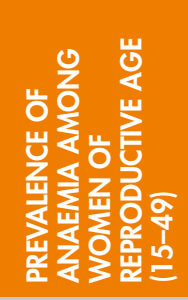 } & \multicolumn{2}{|c|}{ 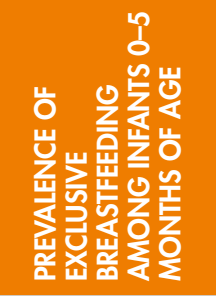 } & \multicolumn{2}{|c|}{ 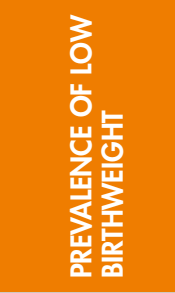 } \\
\hline & 2004-06 & 2016-18 & $2014-16$ & $2016-18$ & $2014-16$ & 2016-18 & & $2012^{5}$ & $2018^{4}$ & $2012^{5}$ & $2018^{4}$ & 2012 & 2016 & 2012 & 2016 & $2012^{6}$ & $2018^{7}$ & 2012 & 2015 \\
\hline & $\%$ & $\%$ & $\%$ & $\%$ & $\%$ & $\%$ & $\%$ & $\%$ & $\%$ & $\%$ & $\%$ & $\%$ & $\%$ & $\%$ & $\%$ & $\%$ & $\%$ & $\%$ & $\%$ \\
\hline Germany & $<2.5$ & $<2.5$ & 0.9 & 0.7 & 4.1 & 3.6 & n.a. & n.a. & n.a. & n.a. & n.a. & 23.7 & 25.7 & 13.4 & 16.3 & n.a. & n.a. & 6.8 & 6.6 \\
\hline Luxembourg & $<2.5$ & $<2.5$ & 1.2 & 0.8 & 4.7 & 3.3 & n.a. & n.a. & n.a. & n.a. & n.a. & 22.4 & 24.2 & 13.3 & 16.1 & n.a. & n.a. & 6.8 & 6.5 \\
\hline Netherlands & $<2.5$ & $<2.5$ & 1.5 & 1.3 & 5.5 & 4.3 & n.a. & n.a. & n.a. & n.a. & n.a. & 21.0 & 23.1 & 13.4 & 16.4 & n.a. & n.a. & 6.2 & 6.2 \\
\hline Switzerland & $<2.5$ & $<2.5$ & 1.1 & 0.8 & 4.0 & 3.1 & n.a. & n.a. & n.a. & n.a. & n.a. & 19.6 & 21.2 & 15.1 & 18.3 & n.a. & n.a. & 6.5 & 6.5 \\
\hline
\end{tabular}

1 Regional estimates are included when more than 50 percent of population is covered. To reduce the margin of error estimates are presented as three-year averages.

${ }^{2} \mathrm{FAO}$ estimate of the percentage of people in the total

population living in households where at least one adult has been found to be food insecure. To reduce the impact of year-to-year sampling variability, estimates are presented as three-year averages.

${ }^{3}$ Country-level results are presented only for those countries for which estimates are based on official national data (see note c) or as provisional estimates, based on FAO data collected through the Gallup World Poll, for countries whose national relevant authorities provided permission to publish them. Note that consent to publish does not necessarily imply validation of the estimate by the national authorities involved and that the estimate is subject to revision as soon as suitable data from official national sources are available. Global,

regional and subregional aggregates reflect data collected in approximately 150 countries.
${ }^{4}$ For regional estimates, values correspond to the model predicted estimate for the year 2018. For countries, the lates data available from 2013 to 2018 are used.

${ }^{5}$ For regional estimates, values correspond to the model

predicted estimate for the year 2012. For countries, the latest data available from 2005 to 2012 are used.

${ }^{6}$ Regional estimates are included when more than 50 percent of population is covered. For countries, the latest data available from 2005 to 2012 are used.

Regional estimates are included when more than 50 percent of population is covered. For countries, the latest data available from 2013 to 2018 are used.

* Wasting, stunting, and overweight under 5 years of age and low birthweight regional aggregates exclude Japan.
Consecutive low population coverage; interpret with caution b. The Central Agency for Public Mobilization \& Statistics (CAPMAS) reports an estimate of severe food insecurity of 1.3 percent for 2015, based on HIECS data, using the WFP consolidated approach for reporting indicators of food security. Note that the two estimates are not directly comparable due to different definitions of "severe food insecurity".

c. Based on official national data.

d. The Government of Ireland reports estimates of the

"Proportion of the population at risk of food poverty" produced by the Central Statistics Office (CSO) and Economic and Social Research Institute (ESRI) as part of the Survey on Income and Social Conditions (SILC) 2015, as a proxy for SDG indicator 2.1.2. See https://irelandsdg.geohive.ie/datasets/sdg-2-1-2 prevalence-of-moderate-or-severe-food-insecurity-in-thepopulation-based-on-the-food-insecurity-experience-scalenuts-3-2015-ireland-cso-0si
$<2.5=$ proportion of undernourishment less than 2.5 percent $<0.5=$ prevalence of severe food insecurity less than 0.5 percent.

n.a. $=$ data not available. 
TABLE A1.2

PROGRESS TOWARDS THE SUSTAINABLE DEVELOPMENT GOALS (SDGS): NUMBER OF PEOPLE WHO ARE AFFECTED BY UNDERNOURISHMENT, MODERATE OR SEVERE FOOD INSECURITY AND SELECTED FORMS OF MALNUTRITION; NUMBER OF INFANTS EXCLUSIVELY BREASTFED AND NUMBER OF BABIES BORN WITH LOW BIRTHWEIGHT

\begin{tabular}{|c|c|c|c|c|c|c|c|c|c|c|c|c|c|c|c|c|c|c|c|}
\hline \multirow[t]{3}{*}{$\begin{array}{l}\text { REGIONS/ } \\
\text { SUBREGIONS/ } \\
\text { COUNTRIES }\end{array}$} & \multicolumn{2}{|c|}{ 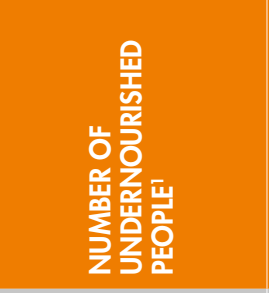 } & \multicolumn{2}{|c|}{ 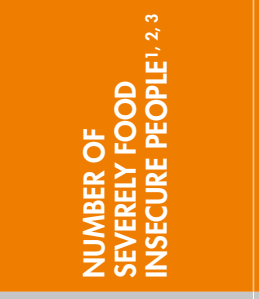 } & \multicolumn{2}{|c|}{ 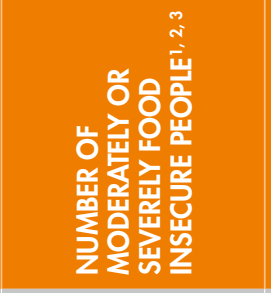 } & \multirow[t]{2}{*}{ 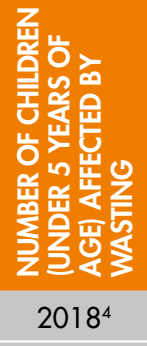 } & \multicolumn{2}{|c|}{ 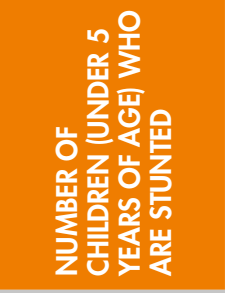 } & \multicolumn{2}{|c|}{ 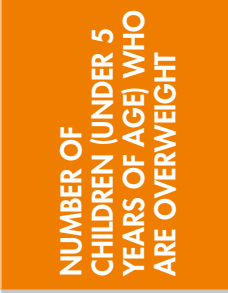 } & \multicolumn{2}{|c|}{ 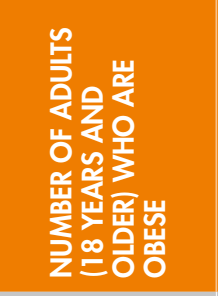 } & \multicolumn{2}{|c|}{ 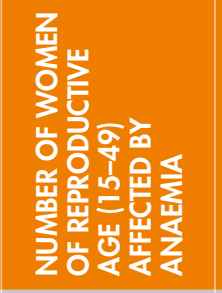 } & \multicolumn{2}{|c|}{ 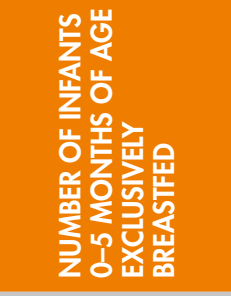 } & \multicolumn{2}{|c|}{ 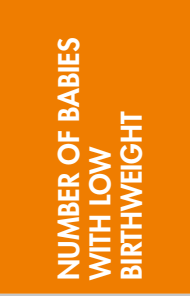 } \\
\hline & $2004-06$ & 2016-18 & $2014-16$ & $2016-18$ & 2014-16 & 2016-18 & & $2012^{5}$ & $2018^{4}$ & $2012^{5}$ & $2018^{4}$ & 2012 & 2016 & 2012 & 2016 & $2012^{6}$ & $2018^{7}$ & 2012 & 2015 \\
\hline & (millions) & (millions) & (millions) & (millions) & (millions) & (millions) & (millions) & (millions) & (millions) & (millions) & (millions) & (millions) & (millions) & (millions) & (millions) & (millions) & (millions) & (millions) & (millions) \\
\hline WORLD & 940.5 & 809.9 & 584.6 & 654.1 & 1736.8 & 1915.1 & 49.5 & 165.8 & 149.0 & 36.7 & 40.1 & 563.7 & 672.3 & 552.2 & 613.2 & 49.7 & 56.6 & 20.9 & 20.5 \\
\hline $\begin{array}{l}\text { Least Developed } \\
\text { Countries }\end{array}$ & 215.7 & 236.9 & 194.7 & 225.0 & 473.1 & 526.6 & 12.5 & 50.8 & 47.3 & 4.4 & 5.7 & 20.5 & 28.3 & 85.0 & 95.3 & 12.6 & 15.6 & 4.9 & 4.9 \\
\hline $\begin{array}{l}\text { Land Locked } \\
\text { Developing Countries }\end{array}$ & 97.5 & 110.1 & 83.7 & 98.7 & 223.6 & 255.7 & 5.0 & 23.8 & 22.7 & 2.6 & 2.8 & 17.0 & 21.9 & 34.6 & 39.7 & 6.5 & 8.1 & 2.2 & 2.2 \\
\hline $\begin{array}{l}\text { Small Island } \\
\text { Developing States }\end{array}$ & 12.5 & 11.8 & n.a. & n.a. & n.a. & n.a. & n.a. & n.a. & n.a. & n.a. & n.a. & 7.3 & 8.7 & 4.9 & 5.3 & 0.4 & 0.4 & 0.1 & 0.1 \\
\hline $\begin{array}{l}\text { Low-income } \\
\text { countries }\end{array}$ & 159.5 & 202.8 & 160.2 & 189.4 & 376.0 & 427.1 & 8.6 & 40.2 & 39.7 & 3.5 & 3.6 & 16.8 & 22.7 & 52.8 & 60.1 & 9.6 & 12.1 & 3.3 & 3.3 \\
\hline $\begin{array}{l}\text { Lower-middle- } \\
\text { income countries }\end{array}$ & 479.1 & 409.1 & 307.1 & 324.4 & 853.7 & 907.3 & 36.0 & 109.4 & 96.8 & 11.3 & 12.1 & 114.9 & 145.3 & 308.8 & 333.4 & 24.5 & 30.0 & 13.9 & 13.5 \\
\hline $\begin{array}{l}\text { Upper-middlle- } \\
\text { income countries }\end{array}$ & 276.4 & 183.4 & 87.3 & 103.2 & 304.1 & 340.2 & 3.3 & 16.4 & 11.3 & 12.8 & 13.2 & 231.3 & 271.6 & 153.1 & 176.5 & 10.5 & 8.4 & 2.8 & 2.7 \\
\hline $\begin{array}{l}\text { High-income } \\
\text { countries }\end{array}$ & n.r. & n.r. & 21.5 & 22.4 & 105.5 & 103.9 & $0.4^{a}$ & 2.3 & $2.1^{\mathrm{a}}$ & 4.8 & $5.0^{a}$ & 201.6 & 225.7 & 40.2 & 46.5 & n.a. & n.a. & 1.0 & 1.0 \\
\hline $\begin{array}{l}\text { Low-income food- } \\
\text { deficit countries }\end{array}$ & 518.9 & 524.9 & n.a. & n.a. & n.a. & n.a. & 38.7 & 126.7 & 115.3 & 10.3 & 10.7 & $<0.1$ & $<0.1$ & 300.1 & 325.3 & 27.5 & 34.3 & 14.9 & 14.5 \\
\hline AFRICA & 196.4 & 246.4 & 235.2 & 277.6 & 591.7 & 667.4 & 14.0 & 57.1 & 58.8 & 8.5 & 9.5 & 58.5 & 73.5 & 98.9 & 109.8 & 13.3 & 17.7 & 5.6 & 5.7 \\
\hline Northern Africa & 9.6 & 16.5 & 18.9 & 21.3 & 58.4 & 72.1 & 2.4 & 4.9 & 4.9 & 2.5 & 3.0 & 29.1 & 35.5 & 17.2 & 18.6 & 2.2 & 2.5 & 0.7 & 0.7 \\
\hline Algeria & 2.9 & 1.6 & & & & & n.a. & 0.5 & n.a. & 0.5 & n.a. & 6.0 & 7.4 & 3.5 & 3.8 & 0.2 & n.a. & $<0.1$ & $<0.1$ \\
\hline Egypt & 4.2 & 4.4 & $8.8^{b}$ & 9.8 & $25.9^{b}$ & 35.1 & 1.1 & 2.9 & 2.7 & 1.9 & 1.9 & 14.2 & 17.1 & 6.5 & 6.7 & 1.3 & 0.9 & n.a. & n.a. \\
\hline Libya & n.a. & n.a. & & & & & n.a. & n.a. & n.a. & n.a. & n.a. & 1.1 & 1.3 & 0.5 & 0.6 & n.a. & n.a. & n.a. & n.a. \\
\hline Morocco & 1.7 & 1.2 & & & & & n.a. & 0.5 & n.a. & 0.3 & n.a. & 4.8 & 5.9 & 3.1 & 3.5 & 0.2 & n.a. & 0.1 & 0.1 \\
\hline Sudan & -- & 8.2 & n.a. & n.a. & n.a. & n.a. & 1.0 & 1.9 & 2.2 & 0.1 & 0.2 & 1.1 & 1.6 & 2.7 & 3.1 & 0.5 & 0.7 & n.a. & n.a. \\
\hline Tunisia & 0.6 & 0.5 & & & & & n.a. & 0.1 & n.a. & 0.1 & n.a. & 1.9 & 2.3 & 0.9 & 1.0 & $<0.1$ & n.a. & $<0.1$ & $<0.1$ \\
\hline
\end{tabular}




\begin{tabular}{|c|c|c|c|c|c|c|c|c|c|c|c|c|c|c|c|c|c|c|c|}
\hline \multirow[t]{3}{*}{$\begin{array}{l}\text { REGIONS/ } \\
\text { SUBREGIONS/ } \\
\text { COUNTRIES }\end{array}$} & \multicolumn{2}{|c|}{ 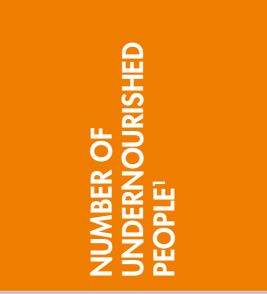 } & \multicolumn{2}{|c|}{ 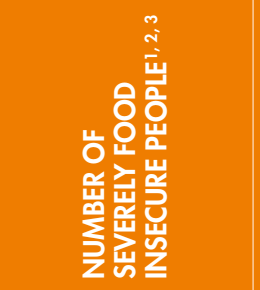 } & \multicolumn{2}{|c|}{ 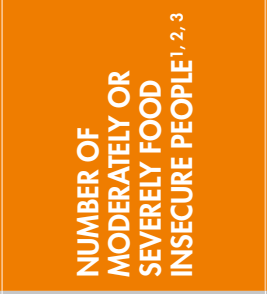 } & \multirow[t]{2}{*}{ 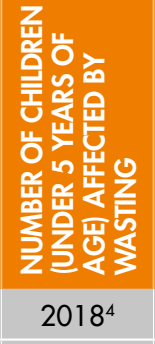 } & \multicolumn{2}{|c|}{ 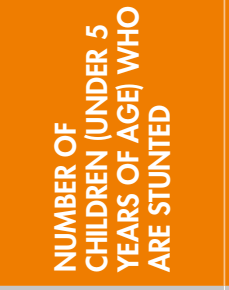 } & \multicolumn{2}{|c|}{ 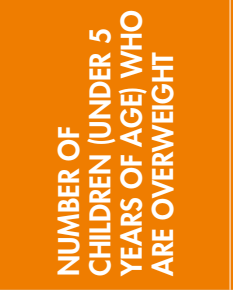 } & \multicolumn{2}{|c|}{ 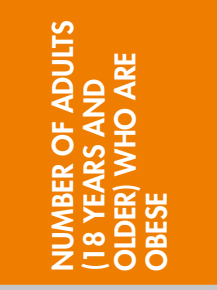 } & \multicolumn{2}{|c|}{ 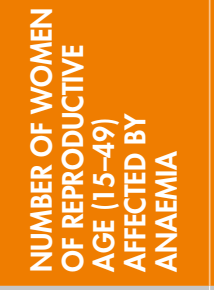 } & \multicolumn{2}{|c|}{ 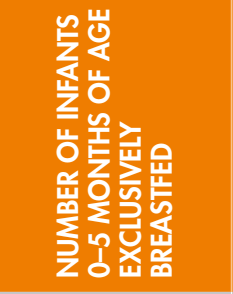 } & \multicolumn{2}{|c|}{ 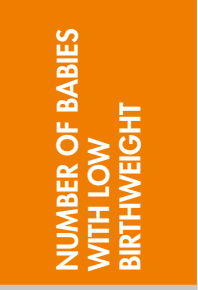 } \\
\hline & 2004-06 & $2016-18$ & $2014-16$ & $2016-18$ & $2014-16$ & 2016-18 & & $2012^{5}$ & $2018^{4}$ & $2012^{5}$ & $2018^{4}$ & 2012 & 2016 & 2012 & 2016 & $2012^{6}$ & $2018^{7}$ & 2012 & 2015 \\
\hline & (millions) & (millions) & (millions) & (millions) & (millions) & (millions) & (millions) & (millions) & (millions) & (millions) & (millions) & (millions) & (millions) & (millions) & (millions) & (millions) & (millions) & (millions) & ) (millions) \\
\hline $\begin{array}{l}\text { Northern Africa } \\
\text { (excluding Sudan) }\end{array}$ & 9.6 & 8.3 & 15.6 & 17.6 & 48.4 & 59.6 & n.a. & n.a. & n.a. & n.a. & n.a. & 28.1 & 33.9 & 14.5 & 15.5 & 1.8 & 1.7 & 0.5 & 0.5 \\
\hline Sub-Saharan Africa & 177.3 & 229.9 & 216.3 & 256.3 & 533.4 & 595.3 & 11.6 & 52.2 & 53.9 & 6.0 & 6.5 & 30.5 & 39.5 & 81.8 & 91.2 & 11.0 & 15.3 & 4.9 & 5.0 \\
\hline Eastern Africa & 113.7 & 129.9 & 102.5 & 116.0 & 243.5 & 271.3 & 4.1 & 23.7 & 24.0 & 2.7 & 2.9 & 7.7 & 10.7 & 25.9 & 30.1 & 6.3 & 8.5 & 1.9 & 1.9 \\
\hline Burundi & n.a. & n.a. & & & & & 0.1 & 0.9 & 1.1 & $<0.1$ & $<0.1$ & 0.2 & 0.2 & 0.6 & 0.7 & 0.3 & 0.4 & $<0.1$ & $<0.1$ \\
\hline Comoros & n.a. & n.a. & n.a. & n.a. & n.a. & n.a. & n.a. & $<0.1$ & n.a. & $<0.1$ & n.a. & $<0.1$ & $<0.1$ & $<0.1$ & 0.1 & $<0.1$ & n.a. & $<0.1$ & $<0.1$ \\
\hline Dibouti & 0.3 & 0.2 & n.a. & n.a. & n.a. & n.a. & n.a. & $<0.1$ & n.a. & $<0.1$ & n.a. & 0.1 & 0.1 & 0.1 & 0.1 & $<0.1$ & n.a. & n.a. & n.a. \\
\hline Eritrea & n.a. & n.a. & n.a. & n.a. & n.a. & n.a. & n.a. & 0.4 & n.a. & $<0.1$ & n.a. & 0.1 & 0.1 & 0.4 & 0.5 & 0.1 & n.a. & n.a. & n.a. \\
\hline Ethiopia & 30.5 & 21.6 & & & & & 1.5 & 6.2 & 5.8 & 0.3 & 0.4 & 1.3 & 1.9 & 4.7 & 5.8 & 1.5 & 1.8 & n.a. & n.a. \\
\hline Kenya & 10.2 & 14.6 & $9.0^{c}$ & $9.5^{c}$ & $26.7^{c}$ & $28.1^{\mathrm{c}}$ & 0.3 & 2.3 & 1.8 & 0.3 & 0.3 & 1.1 & 1.5 & 2.8 & 3.1 & 0.4 & 0.9 & 0.2 & 0.2 \\
\hline Madagascar & 6.4 & 11.4 & n.a. & n.a. & n.a. & n.a. & 0.3 & 1.7 & 1.8 & n.a. & $<0.1$ & 0.4 & 0.6 & 1.9 & 2.2 & 0.3 & n.a. & 0.1 & 0.1 \\
\hline Malawi & 3.4 & 3.3 & $9.1^{\mathrm{c}}$ & $9.6^{c}$ & $14.4^{c}$ & $15.3^{\mathrm{c}}$ & 0.1 & 1.3 & 1.1 & 0.2 & 0.1 & 0.3 & 0.4 & 1.1 & 1.4 & 0.4 & 0.4 & $<0.1$ & $<0.1$ \\
\hline Mauritius & $<0.1$ & $<0.1$ & 0.1 & 0.1 & 0.2 & 0.2 & n.a. & n.a. & n.a. & n.a. & n.a. & 0.1 & 0.1 & 0.1 & 0.1 & n.a. & n.a. & $<0.1$ & $<0.1$ \\
\hline Mozambique & 7.8 & 8.3 & 11.1 & 12.6 & 17.8 & 20.4 & n.a. & 1.9 & n.a. & 0.3 & n.a. & 0.6 & 0.8 & 2.9 & 3.4 & 0.4 & 0.4 & 0.1 & 0.2 \\
\hline Rwanda & 4.0 & 4.5 & & & & & $<0.1$ & 0.7 & 0.6 & 0.1 & 0.1 & 0.2 & 0.3 & 0.5 & 0.7 & 0.3 & 0.3 & $<0.1$ & $<0.1$ \\
\hline Seychelles & n.a. & n.a. & $<0.1^{c}$ & $<0.1^{c}$ & $<0.1^{c}$ & $<0.1^{c}$ & n.a. & $<0.1$ & n.a. & $<0.1$ & n.a. & $<0.1$ & $<0.1$ & $<0.1$ & $<0.1$ & n.a. & n.a. & $<0.1$ & $<0.1$ \\
\hline Somalia & n.a. & n.a. & n.a. & n.a. & n.a. & n.a. & n.a. & 0.6 & n.a. & 0.1 & n.a. & 0.3 & 0.4 & 1.0 & 1.1 & $<0.1$ & n.a. & n.a. & n.a. \\
\hline South Sudan & -- & n.a. & n.a. & n.a. & n.a. & n.a. & n.a. & 0.5 & n.a. & 0.1 & n.a. & n.a. & n.a. & 0.8 & 1.0 & 0.2 & n.a. & n.a. & n.a. \\
\hline Uganda & 6.9 & 17.6 & n.a. & n.a. & n.a. & n.a. & 0.3 & 2.4 & 2.2 & 0.4 & 0.3 & 0.6 & 0.8 & 2.3 & 2.6 & 0.9 & 1.1 & n.a. & n.a. \\
\hline $\begin{array}{l}\text { United Republic } \\
\text { of Tanzania }\end{array}$ & 13.6 & 17.6 & & & & & 0.4 & 3.0 & 3.2 & 0.4 & 0.3 & 1.4 & 1.9 & 4.3 & 4.7 & 0.9 & 1.2 & 0.2 & 0.2 \\
\hline Zambia & 6.2 & 8.0 & & & & & 0.2 & n.a. & 1.1 & n.a. & 0.2 & 0.4 & 0.5 & 1.0 & 1.3 & 0.3 & 0.5 & $<0.1$ & $<0.1$ \\
\hline Zimbabwe & 5.5 & 8.5 & & & & & 0.1 & 0.7 & 0.7 & 0.1 & 0.1 & 0.8 & 1.1 & 1.1 & 1.2 & 0.2 & 0.2 & $<0.1$ & $<0.1$ \\
\hline
\end{tabular}




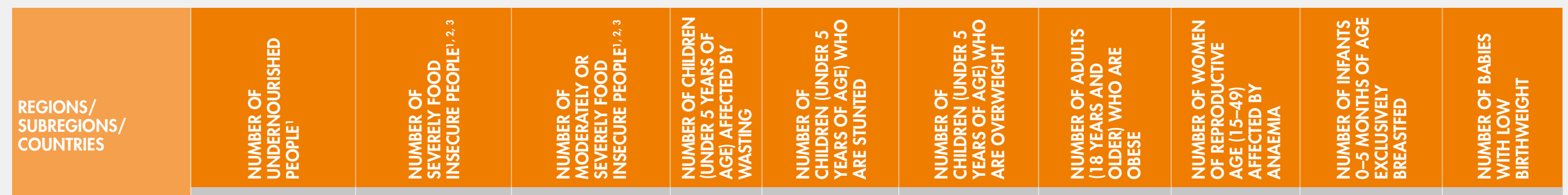

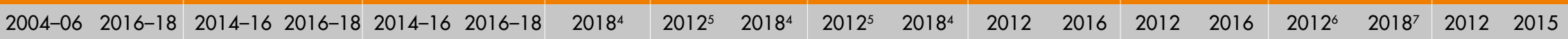

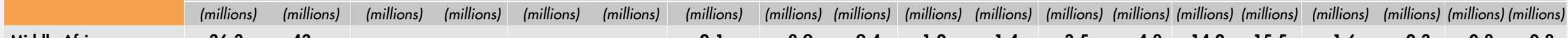

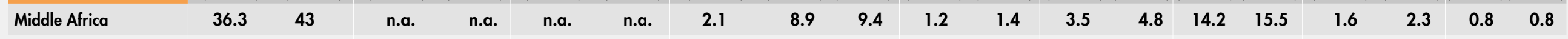

\begin{tabular}{|c|c|c|c|c|c|c|c|c|c|c|c|c|c|c|c|c|c|c|c|}
\hline Angola & 10.7 & 7.4 & 6.2 & n.a. & 18.0 & n.a. & 0.3 & n.a. & 2.0 & n.a. & 0.2 & 0.5 & 0.7 & 2.4 & 2.7 & n.a. & 0.4 & 0.2 & 0.2 \\
\hline Cameroon & 3.5 & 2.4 & 8.1 & 10.6 & 14.2 & 17.1 & 0.2 & 1.1 & 1.2 & 0.2 & 0.2 & 0.9 & 1.2 & 2.1 & 2.4 & 0.1 & 0.2 & $<0.1$ & 0.1 \\
\hline
\end{tabular}

Central African

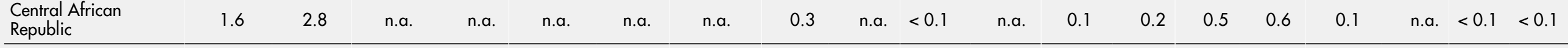

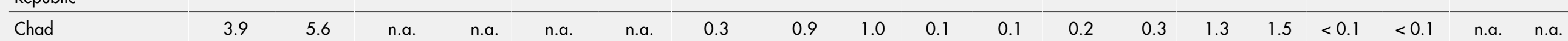

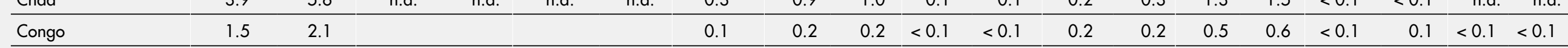

\begin{tabular}{|c|c|c|c|c|c|c|c|c|c|c|c|c|c|c|c|c|c|c|c|}
\hline $\begin{array}{l}\text { Democratic Republic } \\
\text { of the Congo }\end{array}$ & n.a. & n.a. & n.a. & n.a. & n.a. & n.a. & 1.1 & 5.3 & 5.7 & 0.6 & 0.6 & 1.5 & 2.0 & 7.0 & 7.4 & 1.0 & 1.5 & 0.3 & 0.4 \\
\hline Equatorial Guinea & n.a. & n.a. & n.a. & n.a. & n.a. & n.a. & n.a. & $<0.1$ & n.a. & $<0.1$ & n.a. & $<0.1$ & $<0.1$ & 0.1 & 0.1 & $<0.1$ & n.a. & n.a. & n.a. \\
\hline Gabon & 0.2 & 0.2 & & & & & n.a. & $<0.1$ & n.a. & $<0.1$ & n.a. & 0.1 & 0.1 & 0.2 & 0.3 & $<0.1$ & n.a. & $<0.1$ & $<0.1$ \\
\hline $\begin{array}{l}\text { Sao Tome and } \\
\text { Principe }\end{array}$ & $<0.1$ & $<0.1$ & n.a. & n.a. & n.a. & n.a. & $<0.1$ & $<0.1$ & $<0.1$ & $<0.1$ & $<0.1$ & $<0.1$ & $<0.1$ & $<0.1$ & $<0.1$ & $<0.1$ & $<0.1$ & $<0.1$ & $<0.1$ \\
\hline Southern Africa & 3.6 & 5.4 & 15.4 & 20.0 & 30.6 & 34.9 & 0.2 & 2.0 & 2.0 & 0.8 & 0.9 & 8.9 & 10.2 & 4.2 & 4.4 & n.a. & 0.5 & 0.2 & 0.2 \\
\hline Botswana & 0.6 & 0.6 & 0.8 & 0.9 & 1.4 & 1.6 & n.a. & n.a. & n.a. & n.a. & n.a. & 0.2 & 0.2 & 0.2 & 0.2 & $<0.1$ & n.a. & $<0.1$ & $<0.1$ \\
\hline Eswatini & 0.2 & 0.3 & n.a. & 0.4 & n.a. & 0.9 & $<0.1$ & 0.1 & $<0.1$ & $<0.1$ & $<0.1$ & 0.1 & 0.1 & 0.1 & 0.1 & $<0.1$ & $<0.1$ & $<0.1$ & $<0.1$ \\
\hline Lesotho & 0.2 & 0.3 & 1.1 & 1.1 & 1.7 & 1.7 & $<0.1$ & 0.1 & 0.1 & $<0.1$ & $<0.1$ & 0.1 & 0.2 & 0.1 & 0.2 & $<0.1$ & $<0.1$ & $<0.1$ & $<0.1$ \\
\hline Namibia & 0.5 & 0.7 & 1.0 & 1.0 & 1.6 & 1.7 & $<0.1$ & n.a. & 0.1 & n.a. & $<0.1$ & 0.2 & 0.2 & 0.2 & 0.2 & $<0.1$ & $<0.1$ & $<0.1$ & $<0.1$ \\
\hline South Africa & 2.1 & 3.5 & 12.2 & 16.6 & 25.1 & 29.0 & 0.1 & 1.5 & 1.6 & 0.9 & 0.8 & 8.3 & 9.5 & 3.7 & 3.8 & n.a. & 0.4 & 0.2 & 0.2 \\
\hline Western Africa & 33.2 & 51.6 & 51.6 & 64.3 & 160.2 & 177.2 & 5.1 & 17.7 & 18.5 & 1.3 & 1.3 & 10.3 & 13.8 & 37.4 & 41.2 & 2.7 & 4.2 & 2.0 & 2.1 \\
\hline Benin & 1.2 & 1.1 & & & & & 0.1 & n.a. & 0.6 & n.a. & $<0.1$ & 0.4 & 0.5 & 1.2 & 1.3 & 0.1 & 0.2 & $<0.1$ & $<0.1$ \\
\hline Burkina Faso & 3.3 & 3.8 & $1.6^{c}$ & n.a. & $7.4^{c}$ & n.a. & 0.3 & 1.0 & 0.7 & $<0.1$ & 0.1 & 0.3 & 0.4 & 1.9 & 2.1 & 0.2 & 0.4 & $<0.1$ & $<0.1$ \\
\hline Cabo Verde & $<0.1$ & $<0.1$ & n.a. & $0.1^{c}$ & n.a. & $0.2^{c}$ & n.a. & n.a. & n.a. & n.a. & n.a. & $<0.1$ & $<0.1$ & $<0.1$ & $<0.1$ & $<0.1$ & n.a. & n.a. & n.a. \\
\hline Côte d'Ivoire & 3.7 & 4.6 & & & & & 0.2 & 1.0 & 0.8 & 0.1 & 0.1 & 0.8 & 1.0 & 2.5 & 2.9 & 0.1 & 0.2 & 0.1 & 0.1 \\
\hline Gambia & 0.2 & 0.2 & n.a. & 0.7 & n.a. & 1.1 & $<0.1$ & 0.1 & 0.1 & $<0.1$ & $<0.1$ & 0.1 & 0.1 & 0.2 & 0.3 & $<0.1$ & $<0.1$ & $<0.1$ & $<0.1$ \\
\hline
\end{tabular}




\begin{tabular}{|c|c|c|c|c|c|c|c|c|c|c|c|c|c|c|c|c|c|c|c|}
\hline \multirow[t]{3}{*}{$\begin{array}{l}\text { REGIONS/ } \\
\text { SUBREGIONS/ } \\
\text { COUNTRIES }\end{array}$} & \multicolumn{2}{|c|}{ 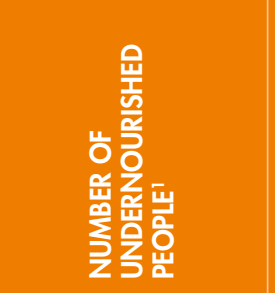 } & \multicolumn{2}{|c|}{ 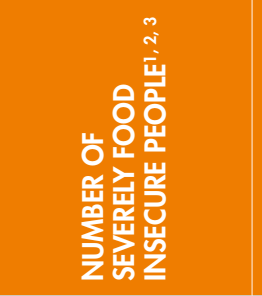 } & \multicolumn{2}{|c|}{ 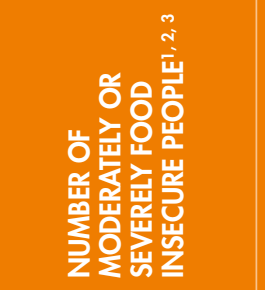 } & \multirow[t]{2}{*}{ 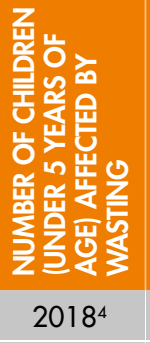 } & \multicolumn{2}{|c|}{ 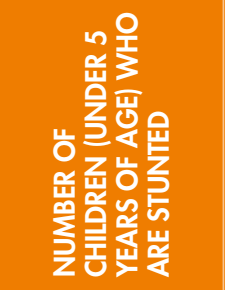 } & \multicolumn{2}{|c|}{ 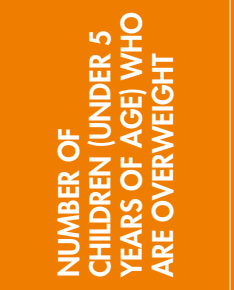 } & \multicolumn{2}{|c|}{ 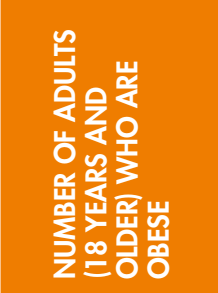 } & \multicolumn{2}{|c|}{ 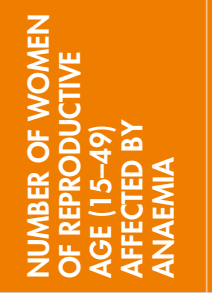 } & \multicolumn{2}{|c|}{ 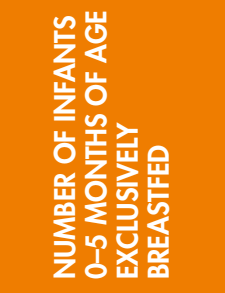 } & \multicolumn{2}{|c|}{ 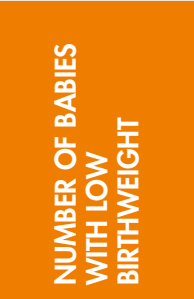 } \\
\hline & $2004-06$ & $2016-18$ & $2014-16$ & $2016-18$ & $2014-16$ & $2016-18$ & & $2012^{5}$ & $2018^{4}$ & $2012^{5}$ & $2018^{4}$ & 2012 & 2016 & 2012 & 2016 & $2012^{6}$ & $2018^{7}$ & 2012 & 2015 \\
\hline & (millions) & (millions) & (millions) & (millions) & (millions) & (millions) & (millions) & (millions) & (millions) & (millions) & (millions) & (millions) & (millions) & (millions) & (millions) & (millions) & (millions) & (millions) & (millions) \\
\hline Ghana & 2.0 & 1.6 & $2.2^{c}$ & $2.3^{c}$ & $13.7^{c}$ & $14.3^{c}$ & 0.2 & 0.8 & 0.7 & 0.1 & 0.1 & 1.2 & 1.5 & 3.2 & 3.3 & 0.4 & 0.4 & 0.1 & 0.1 \\
\hline Guinea & 2.1 & 2.1 & 5.0 & 5.9 & 8.8 & 9.4 & 0.2 & 0.6 & 0.6 & 0.1 & 0.1 & 0.3 & 0.4 & 1.4 & 1.5 & 0.1 & 0.1 & n.a. & n.a. \\
\hline Guinea-Bissau & 0.3 & 0.5 & n.a. & n.a. & n.a. & n.a. & $<0.1$ & 0.1 & 0.1 & $<0.1$ & $<0.1$ & 0.1 & 0.1 & 0.2 & 0.2 & $<0.1$ & $<0.1$ & $<0.1$ & $<0.1$ \\
\hline Liberia & 1.3 & 1.8 & 2.8 & 2.9 & 3.8 & 4.1 & $<0.1$ & 0.3 & 0.2 & n.a. & $<0.1$ & 0.2 & 0.2 & 0.4 & 0.4 & $<0.1$ & 0.1 & n.a. & n.a. \\
\hline Mali & 1.4 & 1.2 & n.a. & n.a. & n.a. & n.a. & 0.4 & 0.8 & 1.0 & $<0.1$ & 0.1 & 0.4 & 0.5 & 1.9 & 2.0 & 0.1 & 0.3 & n.a. & n.a. \\
\hline Mauritania & 0.4 & 0.5 & & & & & 0.1 & 0.1 & 0.2 & $<0.1$ & $<0.1$ & 0.2 & 0.3 & 0.3 & 0.4 & $<0.1$ & 0.1 & n.a. & n.a. \\
\hline Niger & 2.1 & 3.6 & 6.2 & 11.1 & 13.2 & 17.8 & 0.4 & 1.6 & 1.7 & 0.1 & $<0.1$ & 0.3 & 0.4 & 1.8 & 2.1 & 0.2 & n.a. & n.a. & n.a. \\
\hline Nigeria & 9.1 & 25.6 & $11.8^{c}$ & n.a. & $66.0^{c}$ & n.a. & 3.4 & 10.2 & 13.9 & 0.8 & 0.5 & 5.4 & 7.3 & 19.1 & 21.1 & 0.9 & 1.6 & n.a. & n.a. \\
\hline Senegal & 2.4 & 1.8 & & & & & 0.2 & 0.4 & 0.4 & $<0.1$ & $<0.1$ & 0.4 & 0.6 & 1.8 & 1.9 & 0.2 & 0.2 & $<0.1$ & 0.1 \\
\hline Sierra Leone & 2.1 & 1.9 & 4.5 & 5.5 & 6.0 & 6.9 & 0.1 & 0.5 & 0.4 & 0.1 & 0.1 & 0.2 & 0.3 & 0.7 & 0.8 & 0.1 & 0.1 & $<0.1$ & $<0.1$ \\
\hline Togo & 1.5 & 1.3 & 2.5 & 2.5 & 5.0 & 5.3 & 0.1 & 0.3 & 0.3 & $<0.1$ & $<0.1$ & 0.2 & 0.3 & 0.8 & 0.9 & 0.1 & 0.1 & $<0.1$ & $<0.1$ \\
\hline $\begin{array}{l}\text { Sub-Saharan Africa } \\
\text { (including Sudan) }\end{array}$ & 186.8 & 238.1 & 219.6 & 260.0 & 543.4 & 607.8 & n.a. & n.a. & n.a. & n.a. & n.a. & 31.5 & 41.2 & 84.4 & 94.3 & 11.5 & 16.0 & 5.1 & 5.2 \\
\hline ASIA* & 681.5 & 512.9 & 283.6 & 302.3 & 868.3 & 945.9 & 33.8 & 98.9 & 81.7 & 17.1 & 18.8 & 175.7 & 228.7 & 377.7 & 419.9 & 28.6 & 29.7 & 13.3 & 12.8 \\
\hline Central Asia & 6.5 & 4.0 & 1.5 & 2.3 & 8.0 & 11.2 & 0.3 & 1.1 & 0.8 & 0.7 & 0.7 & 5.9 & 7.4 & 5.9 & 6.2 & 0.5 & 0.6 & $<0.1$ & $<0.1$ \\
\hline Kazakhstan & 0.9 & n.r. & 0.2 & 0.4 & 1.2 & 1.7 & 0.1 & 0.2 & 0.2 & 0.2 & 0.2 & 2.1 & 2.5 & 1.4 & 1.4 & 0.1 & 0.1 & $<0.1$ & $<0.1$ \\
\hline Kyrgyzstan & 0.5 & 0.4 & 0.3 & 0.3 & 1.3 & 1.4 & $<0.1$ & 0.1 & 0.1 & 0.1 & 0.1 & 0.4 & 0.6 & 0.5 & 0.6 & 0.1 & 0.1 & $<0.1$ & $<0.1$ \\
\hline Tajikistan & n.a. & n.a. & 0.5 & 0.9 & 1.6 & 2.6 & 0.1 & 0.3 & 0.2 & 0.1 & $<0.1$ & 0.5 & 0.6 & 0.6 & 0.7 & 0.1 & 0.1 & $<0.1$ & $<0.1$ \\
\hline Turkmenistan & 0.2 & 0.3 & n.a. & n.a. & n.a. & n.a. & $<0.1$ & n.a. & 0.1 & n.a. & $<0.1$ & 0.5 & 0.6 & 0.5 & 0.5 & $<0.1$ & 0.1 & $<0.1$ & $<0.1$ \\
\hline Uzbekistan & 3.9 & 2.0 & & & & & n.a. & n.a. & n.a. & n.a. & n.a. & 2.4 & 3.1 & 3.0 & 3.0 & 0.2 & n.a. & $<0.1$ & $<0.1$ \\
\hline
\end{tabular}




\begin{tabular}{|c|c|c|c|c|c|c|c|c|c|c|c|c|c|c|c|c|c|c|c|}
\hline \multirow[t]{3}{*}{$\begin{array}{l}\text { REGIONS/ } \\
\text { SUBREGIONS/ } \\
\text { COUNTRIES }\end{array}$} & \multicolumn{2}{|c|}{ 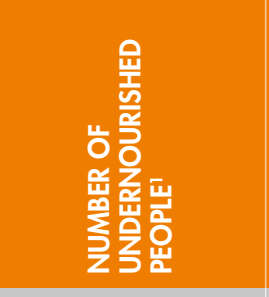 } & \multicolumn{2}{|c|}{ 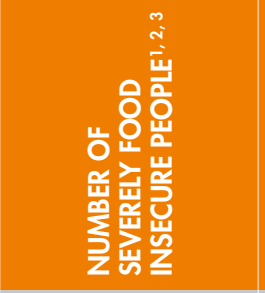 } & \multicolumn{2}{|c|}{ 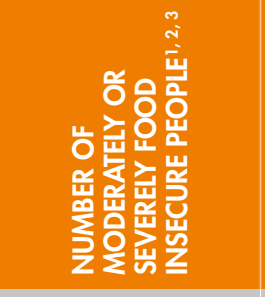 } & \multirow[t]{2}{*}{ 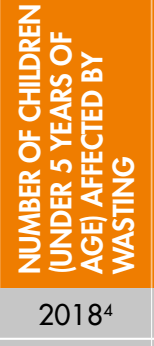 } & \multicolumn{2}{|c|}{ 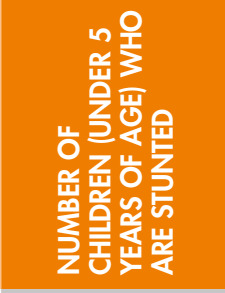 } & \multicolumn{2}{|c|}{ 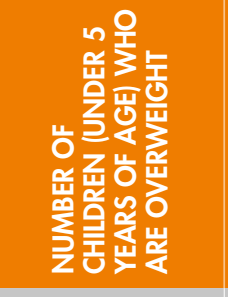 } & \multicolumn{2}{|c|}{ 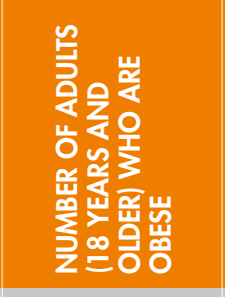 } & \multicolumn{2}{|c|}{ 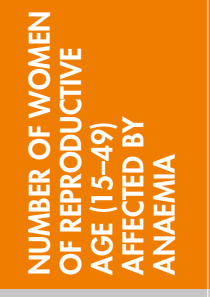 } & \multicolumn{2}{|c|}{ 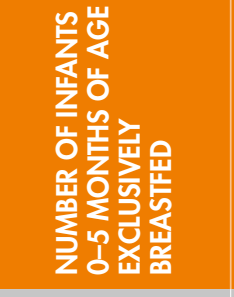 } & \multicolumn{2}{|c|}{ 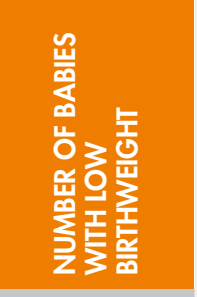 } \\
\hline & $2004-06$ & 2016-18 & $2014-16$ & $2016-18$ & $2014-16$ & $2016-18$ & & $2012^{5}$ & $2018^{4}$ & $2012^{5}$ & $2018^{4}$ & 2012 & 2016 & 2012 & 2016 & $2012^{6}$ & $2018^{7}$ & 2012 & 2015 \\
\hline & (millions) & (millions) & (millions) & (millions) & (millions) & (millions) & (millions) & (millions) & (millions) & (millions) & (millions) & (millions) & (millions) & (millions) & (millions) & (millions) & (millions) & (millions) & (millions) \\
\hline Eastern Asia* & 218.0 & 137.6 & 9.9 & 16.8 & 105.4 & 146.3 & 1.6 & 7.1 & 4.4 & 5.7 & 5.7 & 61.9 & 81.3 & 89.4 & 107.4 & 5.4 & 3.6 & 0.9 & 0.9 \\
\hline China & 206.0 & 122.4 & & & & & 1.6 & 7.8 & 6.9 & 5.5 & 7.7 & 54.7 & 72.9 & 78.1 & 95.0 & 4.7 & 3.0 & 0.9 & 0.8 \\
\hline China, mainland & 204.7 & 121.4 & & & & & n.a. & n.a. & n.a. & n.a. & n.a. & n.a. & n.a. & n.a. & n.a. & n.a. & n.a. & n.a. & n.a. \\
\hline $\begin{array}{l}\text { Taiwan Province of } \\
\text { China }\end{array}$ & 1.1 & 0.8 & & & & & n.a. & n.a. & n.a. & n.a. & n.a. & n.a. & n.a. & n.a. & n.a. & n.a. & n.a. & n.a. & n.a. \\
\hline $\begin{array}{l}\text { China, Hong Kong } \\
\text { SAR }\end{array}$ & n.r. & n.r. & & & & & n.a. & n.a. & n.a. & n.a. & n.a. & n.a. & n.a. & n.a. & n.a. & n.a. & n.a. & n.a. & n.a. \\
\hline China, Macao SAR & $<0.1$ & $<0.1$ & n.a. & n.a. & n.a. & n.a. & n.a. & n.a. & n.a. & n.a. & n.a. & n.a. & n.a. & n.a. & n.a. & n.a. & n.a. & n.a. & n.a. \\
\hline $\begin{array}{l}\text { Democratic People's } \\
\text { Republic of Korea }\end{array}$ & 8.4 & 12.2 & n.a. & n.a. & n.a. & n.a. & $<0.1$ & 0.5 & 0.3 & $<0.1$ & $<0.1$ & 1.1 & 1.3 & 2.0 & 2.2 & 0.2 & 0.3 & n.a. & n.a. \\
\hline Japan & n.r. & n.r. & 0.5 & 0.8 & 3.0 & 3.6 & n.a. & 0.4 & n.a. & 0.1 & n.a. & 4.1 & 4.7 & 5.2 & 5.6 & n.a. & n.a. & 0.1 & 0.1 \\
\hline Mongolia & 0.8 & 0.4 & 0.1 & 0.2 & 0.6 & 0.8 & $<0.1$ & $<0.1$ & $<0.1$ & $<0.1$ & $<0.1$ & 0.3 & 0.4 & 0.1 & 0.2 & $<0.1$ & $<0.1$ & $<0.1$ & $<0.1$ \\
\hline Republic of Korea & n.r. & n.r. & $0.1^{c}$ & 0.1 & $2.4^{c}$ & 2.8 & n.a. & 0.1 & n.a. & 0.2 & n.a. & 1.7 & 2.0 & 2.4 & 2.8 & n.a. & n.a. & $<0.1$ & $<0.1$ \\
\hline $\begin{array}{l}\text { Eastern Asia } \\
\text { (excluding China, } \\
\text { mainland) }\end{array}$ & 12.2 & 15.4 & 1.0 & 1.4 & 9.1 & 10.7 & n.a. & n.a. & n.a. & n.a. & n.a. & $<0.1$ & $<0.1$ & $<0.1$ & $<0.1$ & n.a. & n.a. & 0.2 & 0.2 \\
\hline South-eastern Asia & 103.6 & 61.2 & 26.3 & 33.0 & 118.4 & 131.9 & 5.0 & 16.5 & 14.4 & 3.3 & 4.4 & 21.7 & 29.4 & 43.1 & 48.5 & 3.9 & n.a. & 1.5 & 1.4 \\
\hline Brunei Darussalam & n.r. & $<0.1$ & n.a. & n.a. & n.a. & n.a. & n.a. & $<0.1$ & n.a. & $<0.1$ & n.a. & $<0.1$ & $<0.1$ & $<0.1$ & $<0.1$ & n.a. & n.a. & $<0.1$ & $<0.1$ \\
\hline Cambodia & 2.7 & 2.6 & 2.6 & 2.3 & 7.6 & 7.2 & 0.2 & 0.7 & 0.6 & $<0.1$ & $<0.1$ & 0.3 & 0.4 & 1.9 & 2.0 & 0.3 & 0.2 & $<0.1$ & $<0.1$ \\
\hline Indonesia & 44.1 & 22.0 & $2.8^{c}$ & $2.6^{c}$ & $22.4^{c}$ & $21.3^{c}$ & 3.3 & 9.3 & 8.8 & 2.9 & 2.8 & 8.7 & 12.0 & 17.7 & 20.2 & 2.0 & n.a. & 0.5 & 0.5 \\
\hline $\begin{array}{l}\text { Lao People's } \\
\text { Democratic Republic }\end{array}$ & 1.6 & 1.1 & n.a. & n.a. & n.a. & n.a. & n.a. & 0.3 & n.a. & $<0.1$ & n.a. & 0.1 & 0.2 & 0.6 & 0.7 & 0.1 & 0.1 & $<0.1$ & $<0.1$ \\
\hline Malaysia & 1.0 & 0.8 & & & & & 0.3 & n.a. & 0.5 & n.a. & 0.2 & 2.5 & 3.3 & 1.8 & 2.1 & n.a. & 0.2 & $<0.1$ & $<0.1$ \\
\hline Myanmar & 15.5 & 5.7 & n.a. & n.a. & n.a. & n.a. & 0.3 & 1.8 & 1.3 & 0.1 & 0.1 & 1.6 & 2.2 & 6.0 & 6.9 & 0.2 & 0.5 & 0.1 & 0.1 \\
\hline Philippines & 14.1 & 13.9 & 11.4 & 15.8 & 46.2 & 55.1 & 0.8 & 3.7 & 3.8 & 0.5 & 0.4 & 2.9 & 3.8 & 4.5 & 4.2 & 0.8 & n.a. & 0.5 & 0.5 \\
\hline Singapore & n.a. & n.a. & $<0.1$ & 0.1 & 0.2 & 0.2 & n.a. & n.a. & n.a. & n.a. & n.a. & 0.3 & 0.3 & 0.3 & 0.3 & n.a. & n.a. & $<0.1$ & $<0.1$ \\
\hline
\end{tabular}




\begin{tabular}{|c|c|c|c|c|c|c|c|c|c|c|c|c|c|c|c|c|c|c|c|}
\hline \multirow[t]{3}{*}{$\begin{array}{l}\text { REGIONS/ } \\
\text { SUBREGIONS/ } \\
\text { COUNTRIES }\end{array}$} & \multicolumn{2}{|c|}{ 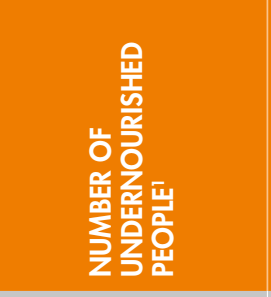 } & \multicolumn{2}{|c|}{ 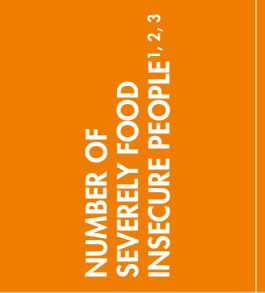 } & \multicolumn{2}{|c|}{ 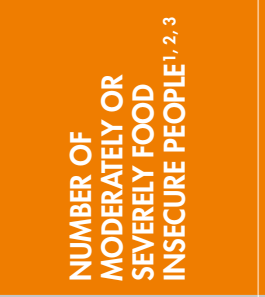 } & \multirow[t]{2}{*}{ 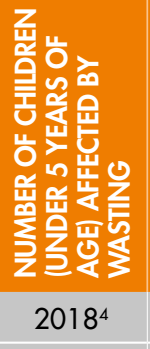 } & \multicolumn{2}{|c|}{ 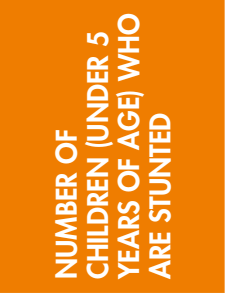 } & \multicolumn{2}{|c|}{ 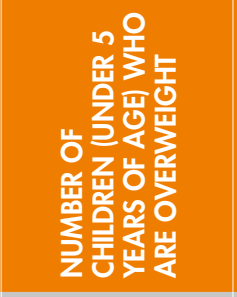 } & \multicolumn{2}{|c|}{ 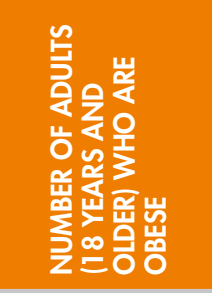 } & \multicolumn{2}{|c|}{ 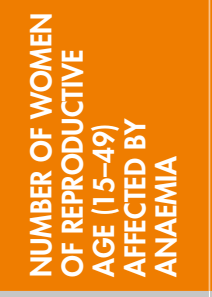 } & \multicolumn{2}{|c|}{ 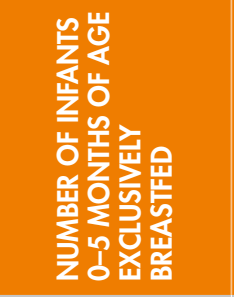 } & \multicolumn{2}{|c|}{ 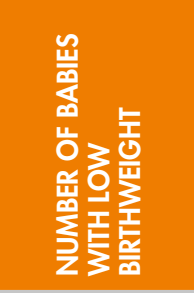 } \\
\hline & $2004-06$ & 2016-18 & $2014-16$ & $2016-18$ & $2014-16$ & $2016-18$ & & $2012^{5}$ & $2018^{4}$ & $2012^{5}$ & $2018^{4}$ & 2012 & 2016 & 2012 & 2016 & $2012^{6}$ & $2018^{7}$ & 2012 & 2015 \\
\hline & (millions) & (millions) & (millions) & (millions) & (millions) & (millions) & (millions) & (millions) & (millions) & (millions) & (millions) & (millions) & (millions) & (millions) & (millions) & (millions) & (millions) & (millions) & ) (millions) \\
\hline Thailand & 8.2 & 5.4 & & & & & 0.2 & 0.7 & 0.4 & 0.4 & 0.3 & 4.3 & 5.8 & 4.8 & 5.6 & 0.1 & 0.2 & $<0.1$ & $<0.1$ \\
\hline Timor-Leste & 0.3 & 0.3 & n.a. & n.a. & n.a. & n.a. & $<0.1$ & 0.1 & 0.1 & $<0.1$ & $<0.1$ & $<0.1$ & $<0.1$ & 0.1 & 0.1 & $<0.1$ & $<0.1$ & n.a. & n.a. \\
\hline Viet Nam & 15.3 & 8.8 & 1.6 & 2.2 & 15.4 & 13.8 & 0.5 & 1.7 & 1.9 & 0.3 & 0.4 & 1.0 & 1.5 & 5.4 & 6.3 & 0.3 & 0.4 & 0.1 & 0.1 \\
\hline Southern Asia & 334.0 & 277.7 & 222.8 & 223.9 & 562.2 & 578.1 & 25.8 & 69.5 & 57.9 & 5.3 & 5.5 & 46.9 & 62.5 & 218.5 & 234.2 & 16.9 & 19.3 & 10.3 & 9.8 \\
\hline Afghanistan & 8.3 & 10.6 & 5.2 & 6.5 & 15.2 & 19.3 & 0.5 & n.a. & 2.1 & n.a. & 0.3 & 0.5 & 0.7 & 2.4 & 3.2 & n.a. & 0.5 & n.a. & n.a. \\
\hline Bangladesh & 23.8 & 24.2 & 17.8 & 16.8 & 52.0 & 50.3 & 2.2 & 6.5 & 5.5 & 0.2 & 0.2 & 2.5 & 3.6 & 17.4 & 18.2 & 1.7 & 1.7 & 0.9 & 0.9 \\
\hline Bhutan & n.a. & n.a. & n.a. & n.a. & n.a. & n.a. & n.a. & $<0.1$ & n.a. & $<0.1$ & n.a. & $<0.1$ & $<0.1$ & 0.1 & 0.1 & $<0.1$ & $<0.1$ & $<0.1$ & $<0.1$ \\
\hline India & 253.9 & 194.4 & & & & & 25.2 & n.a. & 46.0 & n.a. & 2.9 & 24.1 & 32.8 & 165.6 & 175.6 & 11.4 & 13.4 & n.a. & n.a. \\
\hline $\begin{array}{l}\text { Iran } \\
\text { (Islamic Republic of) }\end{array}$ & 4.3 & 4.0 & & & & & n.a. & 0.5 & n.a. & n.a. & n.a. & 12.0 & 14.7 & 6.4 & 7.2 & 0.7 & n.a. & n.a. & n.a. \\
\hline Maldives & $<0.1$ & $<0.1$ & n.a. & n.a. & n.a. & n.a. & n.a. & $<0.1$ & n.a. & $<0.1$ & n.a. & $<0.1$ & $<0.1$ & $<0.1$ & $<0.1$ & $<0.1$ & n.a. & $<0.1$ & $<0.1$ \\
\hline Nepal & 4.1 & 2.5 & 2.5 & 2.3 & 8.4 & 9.3 & 0.3 & 1.3 & 1.0 & $<0.1$ & $<0.1$ & 0.5 & 0.7 & 2.6 & 2.8 & 0.4 & 0.4 & 0.1 & 0.1 \\
\hline Pakistan & 35.9 & 40.0 & & & & & 1.8 & 10.0 & 9.5 & 1.5 & 0.6 & 6.7 & 9.1 & 22.4 & 25.3 & 1.9 & 2.4 & n.a. & n.a. \\
\hline Sri Lanka & 3.6 & 1.9 & & & & & 0.2 & 0.3 & 0.3 & $<0.1$ & $<0.1$ & 0.6 & 0.8 & 1.6 & 1.7 & 0.3 & 0.3 & $<0.1$ & $<0.1$ \\
\hline $\begin{array}{l}\text { Southern Asia } \\
\text { (excluding India) }\end{array}$ & 80.2 & 83.4 & 51.0 & 48.5 & 198.3 & 188.5 & n.a. & n.a. & n.a. & n.a. & n.a. & n.a. & n.a. & n.a. & n.a. & 5.5 & 5.8 & n.a. & n.a. \\
\hline Western Asia & 19.5 & 32.3 & 23.1 & 26.4 & 74.3 & 78.4 & 1.1 & 4.6 & 4.2 & 2.2 & 2.5 & 39.3 & 48.0 & 20.8 & 23.7 & 1.8 & 1.3 & 0.6 & 0.6 \\
\hline Armenia & 0.2 & 0.1 & 0.1 & 0.1 & 0.8 & 1.0 & $<0.1$ & $<0.1$ & $<0.1$ & $<0.1$ & $<0.1$ & 0.4 & 0.5 & 0.2 & 0.2 & $<0.1$ & $<0.1$ & $<0.1$ & $<0.1$ \\
\hline Azerbaijan & 0.5 & n.r. & & & & & $<0.1$ & 0.1 & 0.1 & 0.1 & 0.1 & 1.2 & 1.4 & 1.0 & 1.0 & $<0.1$ & $<0.1$ & $<0.1$ & $<0.1$ \\
\hline Bahrain & n.a. & n.a. & & & & & n.a. & n.a. & n.a. & n.a. & n.a. & 0.3 & 0.3 & 0.1 & 0.1 & n.a. & n.a. & $<0.1$ & $<0.1$ \\
\hline Cyprus & $<0.1$ & $<0.1$ & & & & & n.a. & n.a. & n.a. & n.a. & n.a. & 0.2 & 0.2 & 0.1 & 0.1 & n.a. & n.a. & n.a. & n.a. \\
\hline Georgia & 0.3 & 0.3 & 0.3 & 0.3 & 1.2 & 1.3 & n.a. & $<0.1$ & n.a. & 0.1 & n.a. & 0.7 & 0.8 & 0.3 & 0.3 & $<0.1$ & n.a. & $<0.1$ & $<0.1$ \\
\hline Iraq & 7.6 & 11.1 & & & & & n.a. & 1.1 & n.a. & 0.6 & n.a. & 4.4 & 5.5 & 2.3 & 2.7 & 0.2 & 0.3 & n.a. & n.a. \\
\hline Israel & n.r. & n.r. & $<0.1^{c}$ & $<0.1^{c}$ & $0.7 c$ & $0.7^{c}$ & n.a. & n.a. & n.a. & n.a. & n.a. & 1.3 & 1.4 & 0.2 & 0.3 & n.a. & n.a. & $<0.1$ & $<0.1$ \\
\hline
\end{tabular}




\begin{tabular}{|c|c|c|c|c|c|c|c|c|c|c|c|c|c|c|c|c|c|c|c|}
\hline \multirow[t]{3}{*}{$\begin{array}{l}\text { REGIONS/ } \\
\text { SUBREGIONS/ } \\
\text { COUNTRIES }\end{array}$} & \multicolumn{2}{|c|}{ 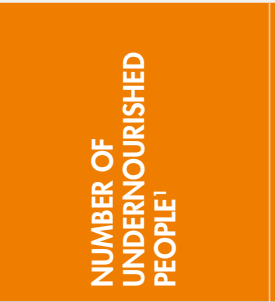 } & \multicolumn{2}{|c|}{ 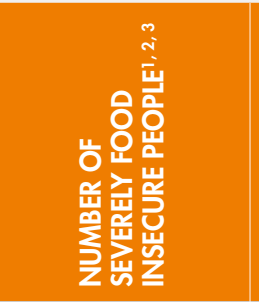 } & \multicolumn{2}{|c|}{ 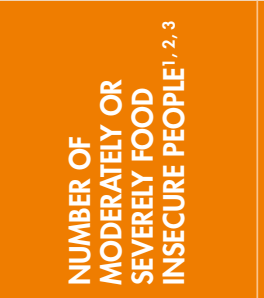 } & \multirow[t]{2}{*}{ 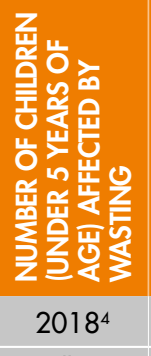 } & \multicolumn{2}{|c|}{ 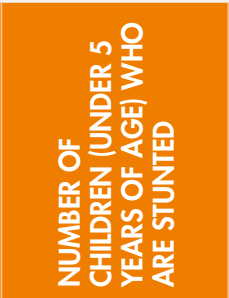 } & \multicolumn{2}{|c|}{ 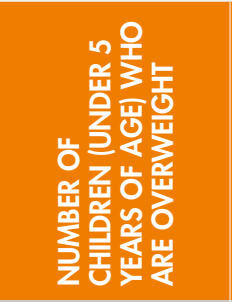 } & \multicolumn{2}{|c|}{ 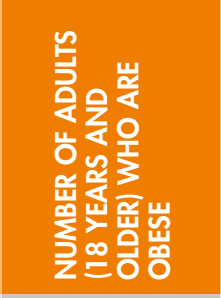 } & \multicolumn{2}{|c|}{ 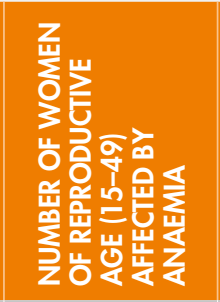 } & \multicolumn{2}{|c|}{ 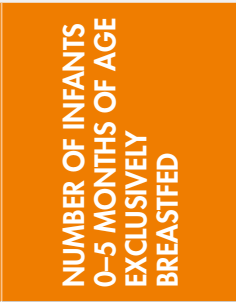 } & \multicolumn{2}{|c|}{ 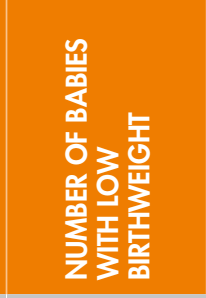 } \\
\hline & 2004-06 & 2016-18 & $2014-16$ & $2016-18$ & $2014-16$ & 2016-18 & & $2012^{5}$ & $2018^{4}$ & $2012^{5}$ & $2018^{4}$ & 2012 & 2016 & 2012 & 2016 & $2012^{6}$ & $2018^{7}$ & 2012 & 2015 \\
\hline & (millions) & (millions) & (millions) & (millions) & (millions) & (millions) & (millions) & (millions) & (millions) & (millions) & (millions) & (millions) & (millions) & (millions) & (millions) & (millions) & (millions) & (millions) & (millions) \\
\hline Jordan & 0.4 & 1.2 & & & & & n.a. & 0.1 & n.a. & 0.1 & n.a. & 1.3 & 1.6 & 0.6 & 0.7 & 0.1 & 0.1 & $<0.1$ & $<0.1$ \\
\hline Kuwait & n.r. & 0.1 & & & & & $<0.1$ & $<0.1$ & $<0.1$ & $<0.1$ & $<0.1$ & 0.8 & 1.0 & 0.2 & 0.3 & n.a. & n.a. & $<0.1$ & $<0.1$ \\
\hline Lebanon & 0.1 & 0.7 & n.a. & n.a. & n.a. & n.a. & n.a. & n.a. & n.a. & n.a. & n.a. & 1.0 & 1.2 & 0.4 & 0.5 & n.a. & n.a. & $<0.1$ & $<0.1$ \\
\hline Oman & 0.3 & 0.3 & n.a. & n.a. & n.a. & n.a. & $<0.1$ & $<0.1$ & 0.1 & $<0.1$ & $<0.1$ & 0.5 & 0.7 & 0.3 & 0.3 & n.a. & $<0.1$ & $<0.1$ & $<0.1$ \\
\hline Palestine & n.a. & n.a. & n.a. & $0.2^{c}$ & n.a. & $1.3^{c}$ & n.a. & n.a. & n.a. & n.a. & n.a. & n.a. & n.a. & n.a. & n.a. & n.a. & n.a. & $<0.1$ & $<0.1$ \\
\hline Qatar & n.a. & n.a. & n.a. & n.a. & n.a. & n.a. & n.a. & n.a. & n.a. & n.a. & n.a. & 0.5 & 0.7 & 0.1 & 0.1 & $<0.1$ & n.a. & $<0.1$ & $<0.1$ \\
\hline Saudi Arabia & 1.9 & 2.3 & & & & & n.a. & n.a. & n.a. & n.a. & n.a. & 5.9 & 7.2 & 3.0 & 3.4 & n.a. & n.a. & n.a. & n.a. \\
\hline Syrian Arab Republic & n.a. & n.a. & n.a. & n.a. & n.a. & n.a. & n.a. & 0.7 & n.a. & 0.5 & n.a. & 2.9 & 3.5 & 1.6 & 1.6 & 0.2 & n.a. & n.a. & n.a. \\
\hline Turkey & n.r. & n.r. & & & & & 0.1 & 0.8 & 0.7 & 0.6 & 0.7 & 14.8 & 17.6 & 5.9 & 6.5 & 0.6 & 0.4 & 0.2 & 0.1 \\
\hline United Arab Emirates & 0.2 & 0.2 & & & & & n.a. & n.a. & n.a. & n.a. & n.a. & 1.8 & 2.4 & 0.4 & 0.5 & n.a. & n.a. & $<0.1$ & $<0.1$ \\
\hline Yemen & 6.2 & 11.0 & n.a. & n.a. & n.a. & n.a. & 0.6 & 1.7 & 1.8 & 0.1 & 0.1 & 1.5 & 2.0 & 4.0 & 4.8 & n.a. & 0.1 & n.a. & n.a. \\
\hline $\begin{array}{l}\text { Central Asia and } \\
\text { Southern Asia }\end{array}$ & 340.5 & 281.7 & 224.3 & 226.2 & 570.2 & 589.3 & 26.1 & 70.6 & 58.8 & 6.0 & 6.2 & 52.8 & 69.9 & 224.4 & 240.4 & 17.4 & 19.9 & 10.4 & 9.9 \\
\hline $\begin{array}{l}\text { Eastern Asia and } \\
\text { South-eastern Asia* }\end{array}$ & 321.5 & 198.8 & 36.2 & 49.8 & 223.7 & 278.2 & 6.6 & 23.6 & 18.8 & 8.9 & 10.1 & 83.6 & 110.7 & 132.5 & 155.9 & 9.3 & 6.8 & 2.5 & 2.5 \\
\hline $\begin{array}{l}\text { Western Asia and } \\
\text { Northern Africa }\end{array}$ & 29.1 & 48.8 & 42.0 & 47.6 & 132.7 & 150.5 & 3.5 & 9.6 & 9.1 & 4.7 & 5.5 & 68.4 & 83.6 & 38.0 & 42.3 & 4.1 & 3.7 & 1.3 & 1.3 \\
\hline $\begin{array}{l}\text { LATIN AMERICA } \\
\text { AND THE } \\
\text { CARIBBEAN }\end{array}$ & 51.0 & 41.5 & n.a. & n.a. & n.a. & n.a. & 0.7 & 6.0 & 4.8 & 3.8 & 4.0 & 88.3 & 104.7 & 34.9 & 37.6 & 3.3 & n.a. & 0.9 & 0.9 \\
\hline Caribbean & 9.1 & 7.7 & n.a. & n.a. & n.a. & n.a. & 0.1 & 0.4 & 0.3 & 0.2 & 0.2 & 5.5 & 6.6 & 3.2 & 3.4 & 0.2 & 0.2 & $<0.1$ & $<0.1$ \\
\hline $\begin{array}{l}\text { Antigua and } \\
\text { Barbuda }\end{array}$ & n.a. & n.a. & n.a. & n.a. & n.a. & n.a. & n.a. & n.a. & n.a. & n.a. & n.a. & $<0.1$ & $<0.1$ & $<0.1$ & $<0.1$ & n.a. & n.a. & $<0.1$ & $<0.1$ \\
\hline Bahamas & n.a. & n.a. & n.a. & n.a. & n.a. & n.a. & n.a. & n.a. & n.a. & n.a. & n.a. & 0.1 & 0.1 & $<0.1$ & $<0.1$ & n.a. & n.a. & $<0.1$ & $<0.1$ \\
\hline Barbados & $<0.1$ & $<0.1$ & n.a. & n.a. & n.a. & n.a. & n.a. & $<0.1$ & n.a. & $<0.1$ & n.a. & $<0.1$ & 0.1 & $<0.1$ & $<0.1$ & $<0.1$ & n.a. & n.a. & n.a. \\
\hline Cuba & n.r. & n.r. & n.a. & n.a. & n.a. & n.a. & n.a. & n.a. & n.a. & n.a. & n.a. & 2.2 & 2.4 & 0.7 & 0.7 & 0.1 & $<0.1$ & $<0.1$ & $<0.1$ \\
\hline
\end{tabular}




\begin{tabular}{|c|c|c|c|c|c|c|c|c|c|c|c|c|c|c|c|c|c|c|c|}
\hline \multirow[t]{3}{*}{$\begin{array}{l}\text { REGIONS/ } \\
\text { SUBREGIONS/ } \\
\text { COUNTRIES }\end{array}$} & \multicolumn{2}{|c|}{ 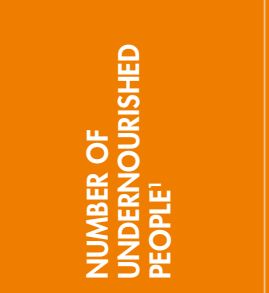 } & \multicolumn{2}{|c|}{ 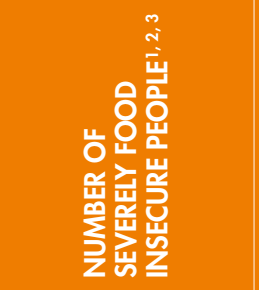 } & \multicolumn{2}{|c|}{ 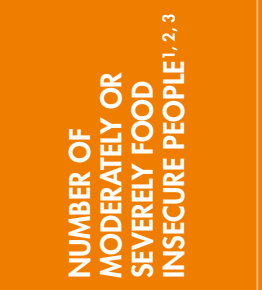 } & \multirow[t]{2}{*}{ 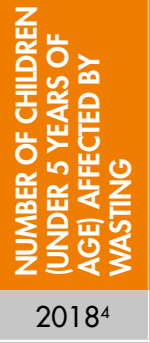 } & \multicolumn{2}{|c|}{ 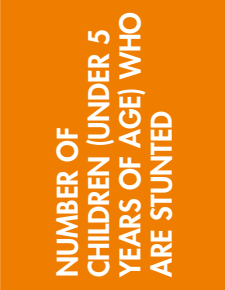 } & \multicolumn{2}{|c|}{ 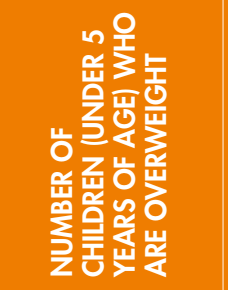 } & \multicolumn{2}{|c|}{ 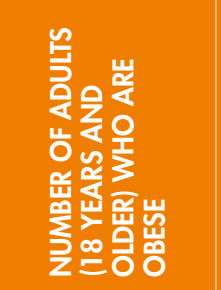 } & \multicolumn{2}{|c|}{ 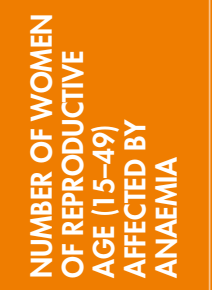 } & \multicolumn{2}{|c|}{ 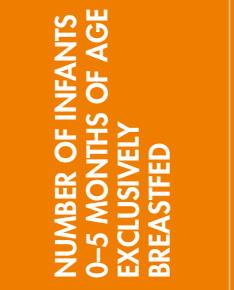 } & \multicolumn{2}{|c|}{ 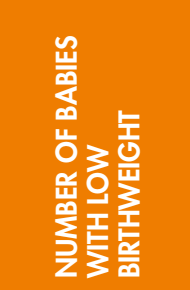 } \\
\hline & $2004-06$ & 2016-18 & $2014-16$ & $2016-18$ & $2014-16$ & $2016-18$ & & $2012^{5}$ & $2018^{4}$ & $2012^{5}$ & $2018^{4}$ & 2012 & 2016 & 2012 & 2016 & $2012^{6}$ & $2018^{7}$ & 2012 & 2015 \\
\hline & (millions) & (millions) & (millions) & (millions) & (millions) & (millions) & (millions) & (millions) & (millions) & (millions) & (millions) & (millions) & (millions) & (millions) & (millions) & (millions) & (millions) & (millions) & (millions) \\
\hline Dominica & $<0.1$ & $<0.1$ & n.a. & n.a. & n.a. & n.a. & n.a. & n.a. & n.a. & n.a. & n.a. & $<0.1$ & $<0.1$ & $<0.1$ & $<0.1$ & n.a. & n.a. & n.a. & n.a. \\
\hline Dominican Republic & 2.3 & 1.0 & & & & & $<0.1$ & n.a. & 0.1 & n.a. & 0.1 & 1.5 & 1.9 & 0.8 & 0.8 & $<0.1$ & $<0.1$ & $<0.1$ & $<0.1$ \\
\hline Grenada & n.a. & n.a. & n.a. & n.a. & n.a. & n.a. & n.a. & n.a. & n.a. & n.a. & n.a. & $<0.1$ & $<0.1$ & $<0.1$ & $<0.1$ & n.a. & n.a. & n.a. & n.a. \\
\hline Haiti & 5.3 & 5.4 & n.a. & n.a. & n.a. & n.a. & $<0.1$ & 0.3 & 0.3 & $<0.1$ & $<0.1$ & 1.0 & 1.3 & 1.3 & 1.3 & 0.1 & 0.1 & n.a. & n.a. \\
\hline Jamaica & 0.2 & 0.2 & & & & & $<0.1$ & $<0.1$ & $<0.1$ & $<0.1$ & $<0.1$ & 0.4 & 0.5 & 0.2 & 0.2 & $<0.1$ & n.a. & $<0.1$ & $<0.1$ \\
\hline Puerto Rico & n.a. & n.a. & n.a. & n.a. & n.a. & n.a. & n.a. & n.a. & n.a. & n.a. & n.a. & n.a. & n.a. & n.a. & n.a. & n.a. & n.a. & n.a. & n.a. \\
\hline Saint Kitts and Nevis & n.a. & n.a. & n.a. & n.a. & n.a. & n.a. & n.a. & n.a. & n.a. & n.a. & n.a. & $<0.1$ & $<0.1$ & n.a. & n.a. & n.a. & n.a. & n.a. & n.a. \\
\hline Saint Lucia & n.a. & n.a. & $<0.1^{c}$ & $<0.1^{c}$ & $<0.1^{c}$ & $<0.1^{c}$ & n.a. & $<0.1$ & n.a. & $<0.1$ & n.a. & $<0.1$ & $<0.1$ & $<0.1$ & $<0.1$ & $<0.1$ & n.a. & n.a. & n.a. \\
\hline $\begin{array}{l}\text { Saint Vincent and the } \\
\text { Grenadines }\end{array}$ & $<0.1$ & $<0.1$ & n.a. & n.a. & n.a. & n.a. & n.a. & n.a. & n.a. & n.a. & n.a. & $<0.1$ & $<0.1$ & $<0.1$ & $<0.1$ & n.a. & n.a. & n.a. & n.a. \\
\hline Trinidad and Tobago & 0.2 & $<0.1$ & n.a. & n.a. & n.a. & n.a. & n.a. & $<0.1$ & n.a. & $<0.1$ & n.a. & 0.2 & 0.2 & 0.1 & 0.1 & $<0.1$ & n.a. & $<0.1$ & $<0.1$ \\
\hline Central America & 12.3 & 10.8 & 18.2 & 18.8 & 55.5 & 56.2 & 0.2 & 2.6 & 2.1 & 1.1 & 1.1 & 25.4 & 30.4 & 6.9 & 7.4 & 0.7 & 1.1 & 0.3 & 0.3 \\
\hline Belize & $<0.1$ & $<0.1$ & n.a. & n.a. & n.a. & n.a. & $<0.1$ & $<0.1$ & $<0.1$ & $<0.1$ & $<0.1$ & $<0.1$ & $<0.1$ & $<0.1$ & $<0.1$ & $<0.1$ & $<0.1$ & $<0.1$ & $<0.1$ \\
\hline Costa Rica & 0.2 & 0.2 & 0.2 & 0.3 & 1.0 & 1.1 & n.a. & $<0.1$ & n.a. & $<0.1$ & n.a. & 0.8 & 0.9 & 0.2 & 0.2 & $<0.1$ & n.a. & $<0.1$ & $<0.1$ \\
\hline El Salvador & 0.6 & 0.6 & 0.9 & 0.8 & 2.7 & 2.5 & $<0.1$ & 0.1 & 0.1 & $<0.1$ & $<0.1$ & 0.8 & 1.0 & 0.3 & 0.4 & $<0.1$ & 0.1 & $<0.1$ & $<0.1$ \\
\hline Guatemala & 2.1 & 2.6 & 2.5 & 2.8 & 7.0 & 7.4 & $<0.1$ & 0.9 & 0.9 & 0.1 & 0.1 & 1.3 & 1.7 & 0.7 & 0.7 & 0.2 & 0.2 & $<0.1$ & $<0.1$ \\
\hline Honduras & 1.3 & 1.2 & 1.7 & 1.6 & 4.7 & 4.6 & n.a. & 0.2 & n.a. & 0.1 & n.a. & 0.8 & 1.0 & 0.3 & 0.4 & 0.1 & n.a. & $<0.1$ & $<0.1$ \\
\hline Mexico & 6.0 & 4.7 & 11.3 & 11.5 & 35.9 & 36.2 & 0.2 & 1.6 & 1.2 & 1.0 & 0.6 & 20.5 & 24.3 & 4.9 & 5.1 & 0.3 & 0.7 & 0.2 & 0.2 \\
\hline Nicaragua & 1.3 & 1.1 & & & & & n.a. & 0.1 & n.a. & 0.1 & n.a. & 0.7 & 0.9 & 0.2 & 0.3 & $<0.1$ & n.a. & $<0.1$ & $<0.1$ \\
\hline Panama & 0.8 & 0.4 & & & & & n.a. & 0.1 & n.a. & $<0.1$ & n.a. & 0.5 & 0.6 & 0.2 & 0.2 & n.a. & $<0.1$ & $<0.1$ & $<0.1$ \\
\hline South America & 29.6 & 23.1 & 25.0 & 34.9 & 99.1 & 130.8 & $0.4^{a}$ & 3.0 & $2.3^{\circ}$ & 2.5 & $2.6^{\circ}$ & 57.4 & 67.7 & 24.8 & 26.9 & 2.4 & n.a. & 0.6 & 0.6 \\
\hline Argentina & 1.9 & 2.1 & 2.5 & 5.0 & 8.3 & 14.2 & n.a. & n.a. & n.a. & n.a. & n.a. & 7.6 & 8.7 & 1.7 & 2.0 & 0.2 & n.a. & $<0.1$ & $<0.1$ \\
\hline
\end{tabular}




\begin{tabular}{|c|c|c|c|c|c|c|c|c|c|c|c|c|c|c|c|c|c|c|c|}
\hline \multirow[t]{3}{*}{$\begin{array}{l}\text { REGIONS/ } \\
\text { SUBREGIONS/ } \\
\text { COUNTRIES }\end{array}$} & \multicolumn{2}{|c|}{ 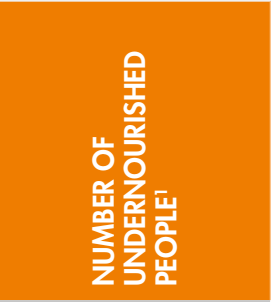 } & \multicolumn{2}{|c|}{ 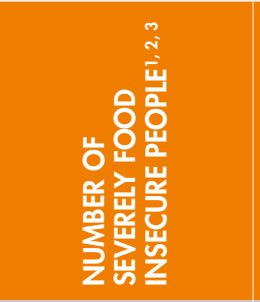 } & \multicolumn{2}{|c|}{ 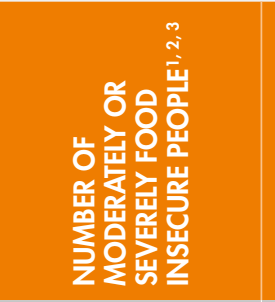 } & \multirow[t]{2}{*}{ 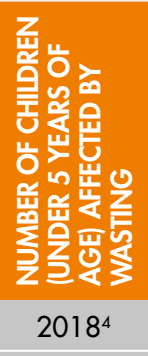 } & \multicolumn{2}{|c|}{ 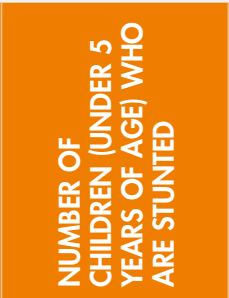 } & \multicolumn{2}{|c|}{ 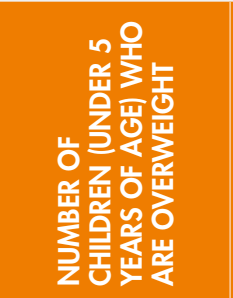 } & \multicolumn{2}{|c|}{ 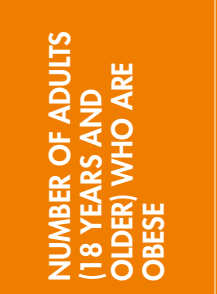 } & \multicolumn{2}{|c|}{ 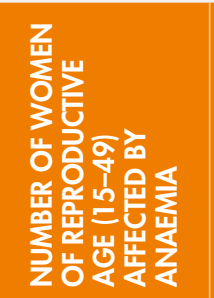 } & \multicolumn{2}{|c|}{ 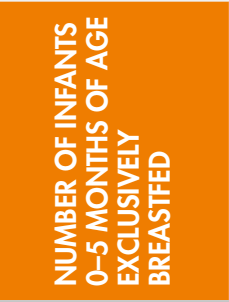 } & \multicolumn{2}{|c|}{ 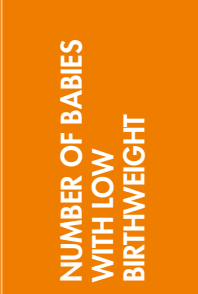 } \\
\hline & $2004-06$ & 2016-18 & $2014-16$ & $2016-18$ & $2014-16$ & 2016-18 & & $2012^{5}$ & $2018^{4}$ & $2012^{5}$ & $2018^{4}$ & 2012 & 2016 & 2012 & 2016 & $2012^{6}$ & $2018^{7}$ & 2012 & 2015 \\
\hline & (millions) & (millions) & (millions) & (millions) & (millions) & (millions) & (millions) & (millions) & (millions) & (millions) & (millions) & (millions) & (millions) & (millions) & (millions) & (millions) & (millions) & (millions) & (millions) \\
\hline $\begin{array}{l}\text { Bolivia } \\
\text { (Plurinational State of) }\end{array}$ & 2.8 & 1.9 & & & & & $<0.1$ & 0.2 & 0.2 & 0.1 & 0.1 & 1.0 & 1.3 & 0.8 & 0.8 & 0.2 & 0.1 & $<0.1$ & $<0.1$ \\
\hline Brazil & 8.6 & n.r. & & & & & n.a. & n.a. & n.a. & n.a. & n.a. & 27.8 & 33.1 & 14.1 & 15.5 & 1.2 & n.a. & 0.3 & 0.2 \\
\hline Chile & 0.6 & 0.5 & n.a. & $0.6^{c}$ & n.a. & $2.5^{c}$ & $<0.1$ & $<0.1$ & $<0.1$ & 0.1 & 0.1 & 3.4 & 3.9 & 0.5 & 0.7 & n.a. & n.a. & $<0.1$ & $<0.1$ \\
\hline Colombia & 4.2 & 2.4 & & & & & n.a. & 0.5 & n.a. & 0.2 & n.a. & 6.3 & 7.5 & 2.9 & 2.8 & n.a. & n.a. & $<0.1$ & $<0.1$ \\
\hline Ecuador & 2.3 & 1.3 & $1.1^{\mathrm{c}}$ & $1.2^{c}$ & $3.8^{c}$ & $3.9^{c}$ & $<0.1$ & 0.4 & 0.4 & 0.1 & 0.1 & 1.7 & 2.1 & 0.7 & 0.8 & n.a. & n.a. & $<0.1$ & $<0.1$ \\
\hline Guyana & $<0.1$ & $<0.1$ & n.a. & n.a. & n.a. & n.a. & $<0.1$ & $<0.1$ & $<0.1$ & $<0.1$ & $<0.1$ & 0.1 & 0.1 & 0.1 & 0.1 & $<0.1$ & $<0.1$ & $<0.1$ & $<0.1$ \\
\hline Paraguay & 0.7 & 0.7 & & & & & $<0.1$ & 0.1 & $<0.1$ & 0.1 & 0.1 & 0.7 & 0.9 & 0.3 & 0.4 & $<0.1$ & $<0.1$ & $<0.1$ & $<0.1$ \\
\hline Peru & 5.4 & 3.1 & & & & & $<0.1$ & 0.5 & 0.4 & 0.2 & 0.2 & 3.4 & 4.0 & 1.6 & 1.6 & 0.4 & 0.4 & $<0.1$ & $<0.1$ \\
\hline Suriname & $<0.1$ & $<0.1$ & n.a. & n.a. & n.a. & n.a. & n.a. & $<0.1$ & n.a. & $<0.1$ & n.a. & 0.1 & 0.1 & $<0.1$ & $<0.1$ & $<0.1$ & n.a. & $<0.1$ & $<0.1$ \\
\hline Uruguay & 0.1 & n.r. & 0.2 & 0.3 & 0.7 & 0.9 & n.a. & $<0.1$ & n.a. & $<0.1$ & n.a. & 0.7 & 0.7 & 0.2 & 0.2 & n.a. & n.a. & $<0.1$ & $<0.1$ \\
\hline $\begin{array}{l}\text { Venezuela } \\
\text { (Bolivarian Republic of) }\end{array}$ & 2.8 & 6.8 & & & & & n.a. & 0.4 & n.a. & 0.2 & n.a. & 4.6 & 5.4 & 1.8 & 2.0 & n.a. & n.a. & $<0.1$ & $<0.1$ \\
\hline OCEANIA & 1.8 & 2.5 & n.a. & n.a. & n.a. & n.a. & n.a. & n.a. & n.a. & n.a. & n.a. & 7.0 & 8.1 & 1.3 & 1.5 & n.a. & n.a. & $<0.1$ & $<0.1$ \\
\hline $\begin{array}{l}\text { Australia and New } \\
\text { Zealand }\end{array}$ & n.r. & n.r. & 0.8 & 1.1 & 3.2 & 3.9 & n.a. & n.a. & n.a. & n.a. & n.a. & 6.0 & 6.8 & 0.6 & 0.6 & n.a. & n.a. & $<0.1$ & $<0.1$ \\
\hline Australia & n.r. & n.r. & 0.6 & 0.9 & 2.7 & 3.3 & n.a. & n.a. & n.a. & n.a. & n.a. & 5.0 & 5.7 & 0.4 & 0.5 & n.a. & n.a. & $<0.1$ & $<0.1$ \\
\hline New Zealand & n.r. & n.r. & 0.1 & 0.2 & 0.5 & 0.7 & n.a. & n.a. & n.a. & n.a. & n.a. & 1.0 & 1.1 & 0.1 & 0.1 & n.a. & n.a. & $<0.1$ & $<0.1$ \\
\hline $\begin{array}{l}\text { Oceania excluding } \\
\text { Australia and New } \\
\text { Zealand }\end{array}$ & n.a. & n.a. & n.a. & n.a. & n.a. & n.a. & 0.1 & 0.5 & 0.5 & 0.1 & 0.1 & 1.1 & 1.3 & 0.8 & 0.9 & 0.1 & n.a. & $<0.1$ & $<0.1$ \\
\hline Melanesia & n.a. & n.a. & n.a. & n.a. & n.a. & n.a. & n.a. & n.a. & n.a. & n.a. & n.a. & 0.9 & 1.1 & 0.7 & 0.9 & 0.1 & n.a. & $<0.1$ & $<0.1$ \\
\hline Fiii & $<0.1$ & $<0.1$ & n.a. & n.a. & n.a. & n.a. & n.a. & n.a. & n.a. & n.a. & n.a. & 0.2 & 0.2 & 0.1 & 0.1 & n.a. & n.a. & n.a. & n.a. \\
\hline New Caledonia & $<0.1$ & $<0.1$ & n.a. & n.a. & n.a. & n.a. & n.a. & n.a. & n.a. & n.a. & n.a. & n.a. & n.a. & n.a. & n.a. & n.a. & n.a. & n.a. & n.a. \\
\hline
\end{tabular}




\begin{tabular}{|c|c|c|c|c|c|c|c|c|c|c|c|c|c|c|c|c|c|c|c|}
\hline \multirow[t]{3}{*}{$\begin{array}{l}\text { REGIONS/ } \\
\text { SUBREGIONS/ } \\
\text { COUNTRIES }\end{array}$} & \multicolumn{2}{|c|}{ 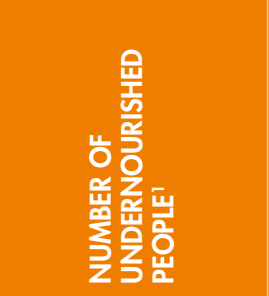 } & \multicolumn{2}{|c|}{ 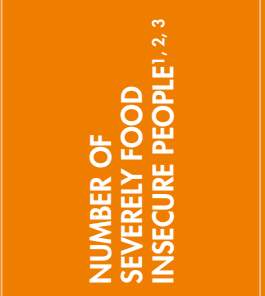 } & \multicolumn{2}{|c|}{ 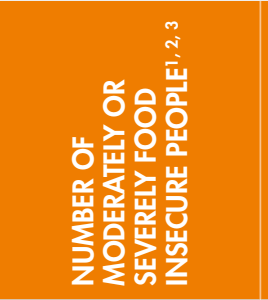 } & \multirow[t]{2}{*}{ 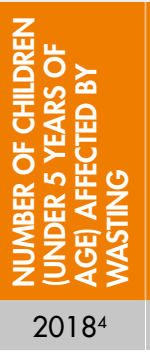 } & \multicolumn{2}{|c|}{ 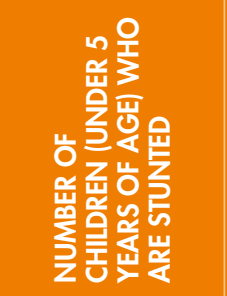 } & \multicolumn{2}{|c|}{ 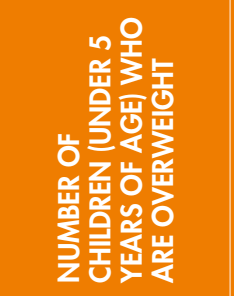 } & \multicolumn{2}{|c|}{ 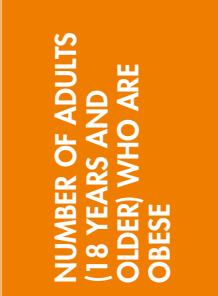 } & \multicolumn{2}{|c|}{ 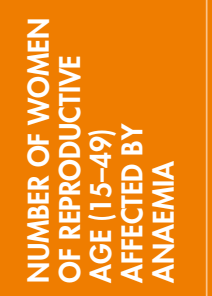 } & \multicolumn{2}{|c|}{ 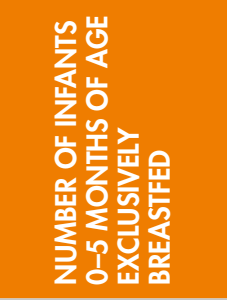 } & \multicolumn{2}{|c|}{ 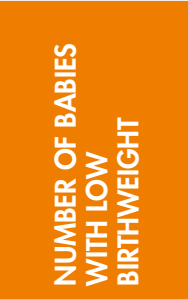 } \\
\hline & $2004-06$ & $2016-18$ & $2014-16$ & $2016-18$ & $2014-16$ & $2016-18$ & & $2012^{5}$ & $2018^{4}$ & $2012^{5}$ & $2018^{4}$ & 2012 & 2016 & 2012 & 2016 & $2012^{6}$ & $2018^{7}$ & 2012 & 2015 \\
\hline & (millions) & (millions) & (millions) & (millions) & (millions) & (millions) & (millions) & (millions) & (millions) & (millions) & (millions) & (millions) & (millions) & (millions) & (millions) & (millions) & (millions) & (millions) & (millions) \\
\hline Papua New Guinea & n.a. & n.a. & n.a. & n.a. & n.a. & n.a. & n.a. & 0.5 & n.a. & 0.1 & n.a. & 0.7 & 0.9 & 0.6 & 0.7 & 0.1 & n.a. & n.a. & n.a. \\
\hline Solomon Islands & $<0.1$ & $<0.1$ & n.a. & n.a. & n.a. & n.a. & $<0.1$ & n.a. & $<0.1$ & n.a. & $<0.1$ & 0.1 & 0.1 & 0.1 & 0.1 & $<0.1$ & $<0.1$ & n.a. & n.a. \\
\hline Vanuatu & $<0.1$ & $<0.1$ & n.a. & n.a. & n.a. & n.a. & $<0.1$ & n.a. & $<0.1$ & n.a. & $<0.1$ & $<0.1$ & $<0.1$ & $<0.1$ & $<0.1$ & $<0.1$ & $<0.1$ & $<0.1$ & $<0.1$ \\
\hline Micronesia & n.a. & n.a. & n.a. & n.a. & n.a. & n.a. & n.a. & n.a. & n.a. & n.a. & n.a. & 0.1 & 0.1 & $<0.1$ & $<0.1$ & $<0.1$ & n.a. & $<0.1$ & $<0.1$ \\
\hline Kiribati & $<0.1$ & $<0.1$ & n.a. & n.a. & n.a. & n.a. & n.a. & n.a. & n.a. & n.a. & n.a. & $<0.1$ & $<0.1$ & $<0.1$ & $<0.1$ & $<0.1$ & n.a. & n.a. & n.a. \\
\hline Marshall Islands & n.a. & n.a. & n.a. & n.a. & n.a. & n.a. & $<0.1$ & n.a. & $<0.1$ & n.a. & $<0.1$ & $<0.1$ & $<0.1$ & $<0.1$ & $<0.1$ & $<0.1$ & $<0.1$ & n.a. & n.a. \\
\hline $\begin{array}{l}\text { Micronesia } \\
\text { (Federated States of) }\end{array}$ & n.a. & n.a. & n.a. & n.a. & n.a. & n.a. & n.a. & n.a. & n.a. & n.a. & n.a. & $<0.1$ & $<0.1$ & $<0.1$ & $<0.1$ & n.a. & n.a. & n.a. & n.a. \\
\hline Nauru & n.a. & n.a. & n.a. & n.a. & n.a. & n.a. & n.a. & n.a. & n.a. & n.a. & n.a. & $<0.1$ & $<0.1$ & n.a. & n.a. & $<0.1$ & n.a. & n.a. & n.a. \\
\hline Palau & n.a. & n.a. & n.a. & n.a. & n.a. & n.a. & n.a. & n.a. & n.a. & n.a. & n.a. & $<0.1$ & $<0.1$ & n.a. & n.a. & n.a. & n.a. & n.a. & n.a. \\
\hline Polynesia & $<0.1$ & $<0.1$ & n.a. & n.a. & n.a. & n.a. & n.a. & n.a. & n.a. & n.a. & n.a. & 0.1 & 0.1 & $<0.1$ & $<0.1$ & $<0.1$ & $<0.1$ & $<0.1$ & $<0.1$ \\
\hline American Samoa & n.a. & n.a. & n.a. & n.a. & n.a. & n.a. & n.a. & n.a. & n.a. & n.a. & n.a. & n.a. & n.a. & n.a. & n.a. & n.a. & n.a. & n.a. & n.a. \\
\hline Cook Islands & n.a. & n.a. & n.a. & n.a. & n.a. & n.a. & n.a. & n.a. & n.a. & n.a. & n.a. & $<0.1$ & $<0.1$ & n.a. & n.a. & n.a. & n.a. & $<0.1$ & $<0.1$ \\
\hline French Polynesia & $<0.1$ & $<0.1$ & n.a. & n.a. & n.a. & n.a. & n.a. & n.a. & n.a. & n.a. & n.a. & n.a. & n.a. & n.a. & n.a. & n.a. & n.a. & n.a. & n.a. \\
\hline Nive & n.a. & n.a. & n.a. & n.a. & n.a. & n.a. & n.a. & n.a. & n.a. & n.a. & n.a. & $<0.1$ & $<0.1$ & n.a. & n.a. & n.a. & n.a. & n.a. & n.a. \\
\hline Samoa & $<0.1$ & $<0.1$ & n.a. & n.a. & n.a. & n.a. & $<0.1$ & n.a. & $<0.1$ & n.a. & $<0.1$ & $<0.1$ & 0.1 & $<0.1$ & $<0.1$ & $<0.1$ & $<0.1$ & n.a. & n.a. \\
\hline $\begin{array}{l}\text { Tokelau } \\
\text { (Associate Member) }\end{array}$ & n.a. & n.a. & n.a. & n.a. & n.a. & n.a. & n.a. & n.a. & n.a. & n.a. & n.a. & n.a. & n.a. & n.a. & n.a. & n.a. & n.a. & n.a. & n.a. \\
\hline Tonga & n.a. & n.a. & n.a. & n.a. & n.a. & n.a. & n.a. & $<0.1$ & n.a. & $<0.1$ & n.a. & $<0.1$ & $<0.1$ & $<0.1$ & $<0.1$ & $<0.1$ & n.a. & n.a. & n.a. \\
\hline Tuvalu & n.a. & n.a. & n.a. & n.a. & n.a. & n.a. & n.a. & n.a. & n.a. & n.a. & n.a. & $<0.1$ & $<0.1$ & n.a. & n.a. & $<0.1$ & n.a. & n.a. & n.a. \\
\hline $\begin{array}{l}\text { NORTHERN AMERICA } \\
\text { AND EUROPE }\end{array}$ & n.r. & n.r. & 15.3 & 12.5 & 101.9 & 92.7 & n.a. & n.a. & n.a. & n.a. & n.a. & 233.1 & 255.8 & 39.4 & 44.3 & n.a. & n.a. & 0.9 & 0.9 \\
\hline Northern America & n.r. & n.r. & 3.6 & 3.5 & 35.3 & 31.7 & 0.1 & 0.6 & 0.6 & 1.8 & 1.9 & 92.0 & 102.9 & 8.7 & 10.6 & 1.1 & 1.6 & 0.3 & 0.3 \\
\hline Bermuda & n.a. & n.a. & n.a. & n.a. & n.a. & n.a. & n.a. & n.a. & n.a. & n.a. & n.a. & n.a. & n.a. & n.a. & n.a. & n.a. & n.a. & n.a. & n.a. \\
\hline
\end{tabular}




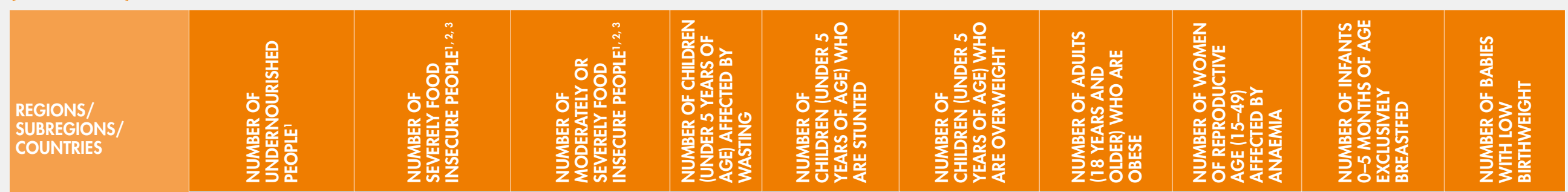

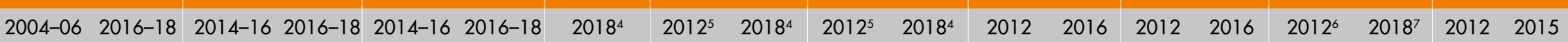

(millions) (millions) (millions) (millions) $\quad$ (millions) (millions) (millions) (millions) (millions) (millions) (millions) (millions) (millions) (millions) (millions) (millions) (millions) (millions) (millions)

\begin{tabular}{|c|c|c|c|c|c|c|c|c|c|c|c|c|c|c|c|c|c|c|c|}
\hline Canada & n.r. & n.r. & $0.2^{c}$ & n.a. & $1.8^{\mathrm{c}}$ & n.a. & n.a. & n.a. & n.a. & n.a. & n.a. & 8.0 & 9.1 & 0.7 & 0.8 & n.a. & n.a. & $<0.1$ & $<0.1$ \\
\hline Greenland & n.a. & n.a. & n.a. & n.a. & n.a. & n.a. & n.a. & n.a. & n.a. & n.a. & n.a. & n.a. & n.a. & n.a. & n.a. & n.a. & n.a. & n.a. & n.a. \\
\hline $\begin{array}{l}\text { United States } \\
\text { of America }\end{array}$ & n.r. & n.r. & $3.4^{c}$ & $3.3^{c}$ & $33.5^{c}$ & $29.9^{c}$ & 0.1 & 0.4 & 0.7 & 1.2 & 1.8 & 84.0 & 93.8 & 8.0 & 9.8 & 1.0 & 1.4 & 0.3 & 0.3 \\
\hline Europe & n.r. & n.r. & 11.7 & 9.1 & 66.6 & 61.0 & n.a. & n.a. & n.a. & n.a. & n.a. & 141.1 & 152.9 & 30.7 & 33.7 & n.a. & n.a. & 0.5 & 0.5 \\
\hline Eastern Europe & n.r. & n.r. & 3.5 & 2.8 & 32.3 & 30.8 & n.a. & n.a. & n.a. & n.a. & n.a. & 57.5 & 61.1 & 16.2 & 16.8 & n.a. & n.a. & 0.2 & 0.2 \\
\hline Belarus & 0.3 & n.r. & & & & & n.a. & n.a. & n.a. & n.a. & n.a. & 1.9 & 2.0 & 0.5 & 0.5 & $<0.1$ & n.a. & $<0.1$ & $<0.1$ \\
\hline Bulgaria & 0.5 & 0.3 & 0.1 & 0.1 & 1.0 & 0.8 & n.a. & n.a. & n.a. & n.a. & n.a. & 1.5 & 1.6 & 0.4 & 0.4 & n.a. & n.a. & $<0.1$ & $<0.1$ \\
\hline Czechia & n.r. & n.r. & 0.1 & $<0.1$ & 0.6 & 0.4 & n.a. & n.a. & n.a. & n.a. & n.a. & 2.3 & 2.5 & 0.6 & 0.6 & n.a. & n.a. & $<0.1$ & $<0.1$ \\
\hline Hungary & n.r. & n.r. & 0.1 & 0.1 & 1.0 & 0.8 & n.a. & n.a. & n.a. & n.a. & n.a. & 2.2 & 2.3 & 0.6 & 0.6 & n.a. & n.a. & $<0.1$ & $<0.1$ \\
\hline Poland & n.r. & n.r. & 0.6 & 0.3 & 3.3 & 2.0 & n.a. & 0.1 & 0.1 & n.a. & n.a. & 7.3 & 8.0 & 2.2 & 2.4 & n.a. & n.a. & $<0.1$ & $<0.1$ \\
\hline Republic of Moldova & n.a. & n.a. & 0.1 & 0.1 & 0.8 & 1.0 & n.a. & $<0.1$ & n.a. & $<0.1$ & n.a. & 0.5 & 0.5 & 0.3 & 0.3 & $<0.1$ & n.a. & $<0.1$ & $<0.1$ \\
\hline Romania & n.r. & n.r. & 1.1 & 0.8 & 3.8 & 2.9 & n.a. & n.a. & n.a. & n.a. & n.a. & 3.9 & 4.3 & 1.2 & 1.2 & n.a. & n.a. & $<0.1$ & $<0.1$ \\
\hline Russian Federation & n.r. & n.r. & 0.5 & $0.4^{c}$ & 11.8 & $8.9^{c}$ & n.a. & n.a. & n.a. & n.a. & n.a. & 27.8 & 29.3 & 7.7 & 8.0 & n.a. & n.a. & 0.1 & 0.1 \\
\hline Slovakia & 0.3 & 0.2 & $<0.1$ & $<0.1$ & 0.3 & 0.3 & n.a. & n.a. & n.a. & n.a. & n.a. & 0.9 & 1.0 & 0.3 & 0.4 & n.a. & n.a. & $<0.1$ & $<0.1$ \\
\hline Ukraine & n.r. & 1.5 & 0.8 & 0.8 & & & n.a. & n.a. & n.a. & n.a. & n.a. & 9.1 & 9.5 & 2.4 & 2.5 & 0.1 & n.a. & $<0.1$ & $<0.1$ \\
\hline Northern Europe & n.r. & n.r. & 3.2 & 1.7 & 8.8 & 6.3 & n.a. & n.a. & n.a. & n.a. & n.a. & 19.8 & 22.1 & 3.0 & 3.7 & n.a. & n.a. & $<0.1$ & $<0.1$ \\
\hline Denmark & n.r. & n.r. & $<0.1$ & 0.1 & 0.3 & 0.3 & n.a. & n.a. & n.a. & n.a. & n.a. & 0.9 & 1.0 & 0.2 & 0.2 & n.a. & n.a. & $<0.1$ & $<0.1$ \\
\hline Estonia & $<0.1$ & $<0.1$ & $<0.1$ & $<0.1$ & 0.1 & 0.1 & n.a. & n.a. & n.a. & n.a. & n.a. & 0.2 & 0.2 & 0.1 & 0.1 & n.a. & n.a. & $<0.1$ & $<0.1$ \\
\hline Finland & n.r. & n.r. & 0.1 & 0.1 & 0.5 & 0.5 & n.a. & n.a. & n.a. & n.a. & n.a. & 1.0 & 1.1 & 0.2 & 0.2 & n.a. & n.a. & $<0.1$ & $<0.1$ \\
\hline Iceland & n.r. & n.r. & $<0.1$ & $<0.1$ & $<0.1$ & $<0.1$ & n.a. & n.a. & n.a. & n.a. & n.a. & 0.1 & 0.1 & $<0.1$ & $<0.1$ & n.a. & n.a. & $<0.1$ & $<0.1$ \\
\hline Ireland & n.r. & n.r. & $0.2^{\mathrm{d}}$ & 0.1 & $0.4^{d}$ & 0.3 & n.a. & n.a. & n.a. & n.a. & n.a. & 0.8 & 1.0 & 0.1 & 0.2 & n.a. & n.a. & $<0.1$ & $<0.1$ \\
\hline Latvia & n.r. & n.r. & $<0.1$ & $<0.1$ & 0.2 & 0.2 & n.a. & n.a. & n.a. & n.a. & n.a. & 0.4 & 0.4 & 0.1 & 0.1 & n.a. & n.a. & $<0.1$ & $<0.1$ \\
\hline
\end{tabular}




\begin{tabular}{|c|c|c|c|c|c|c|c|c|c|c|c|c|c|c|c|c|c|c|c|}
\hline \multirow[t]{3}{*}{$\begin{array}{l}\text { REGIONS/ } \\
\text { SUBREGIONS/ } \\
\text { COUNTRIES }\end{array}$} & \multicolumn{2}{|c|}{ 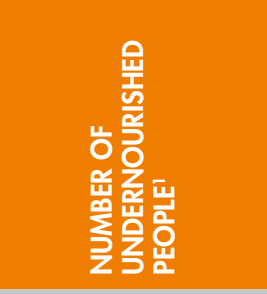 } & \multicolumn{2}{|c|}{ 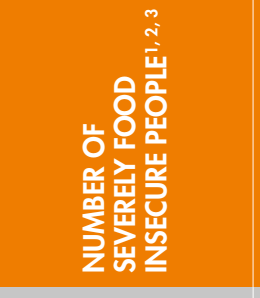 } & \multicolumn{2}{|c|}{ 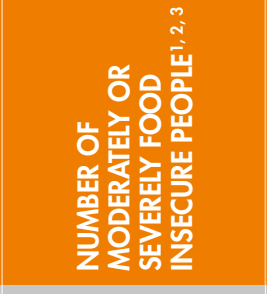 } & \multirow[t]{2}{*}{ 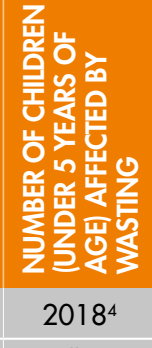 } & \multicolumn{2}{|c|}{ 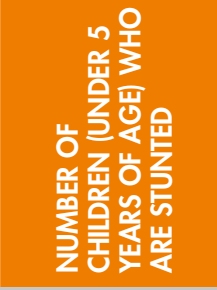 } & \multicolumn{2}{|c|}{ 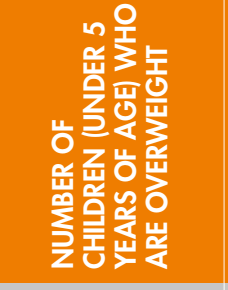 } & \multicolumn{2}{|c|}{ 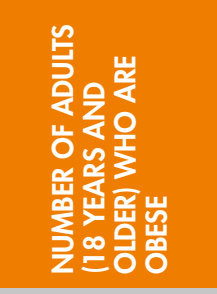 } & \multicolumn{2}{|c|}{ 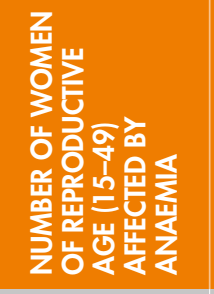 } & \multicolumn{2}{|c|}{ 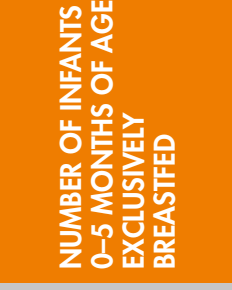 } & \multicolumn{2}{|c|}{ 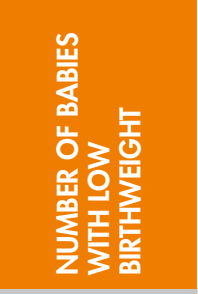 } \\
\hline & 2004-06 & 2016-18 & $2014-16$ & $2016-18$ & $2014-16$ & 2016-18 & & $2012^{5}$ & $2018^{4}$ & $2012^{5}$ & $2018^{4}$ & 2012 & 2016 & 2012 & 2016 & $2012^{6}$ & $2018^{7}$ & 2012 & 2015 \\
\hline & (millions) & (millions) & (millions) & (millions) & (millions) & (millions) & (millions) & (millions) & (millions) & (millions) & (millions) & (millions) & (millions) & (millions) & (millions) & (millions) & (millions) & (millions) & | (millions) \\
\hline Lithuania & n.r. & n.r. & $<0.1$ & $<0.1$ & 0.4 & 0.3 & n.a. & n.a. & n.a. & n.a. & n.a. & 0.7 & 0.7 & 0.2 & 0.2 & n.a. & n.a. & $<0.1$ & $<0.1$ \\
\hline Norway & n.r. & n.r. & 0.1 & 0.1 & 0.3 & 0.3 & n.a. & n.a. & n.a. & n.a. & n.a. & 0.9 & 1.0 & 0.1 & 0.2 & n.a. & n.a. & $<0.1$ & $<0.1$ \\
\hline Sweden & n.r. & n.r. & 0.1 & 0.1 & 0.4 & 0.5 & n.a. & n.a. & n.a. & n.a. & n.a. & 1.5 & 1.7 & 0.3 & 0.3 & n.a. & n.a. & $<0.1$ & $<0.1$ \\
\hline $\begin{array}{l}\text { United Kingdom of } \\
\text { Great Britain and } \\
\text { Northern Ireland }\end{array}$ & n.r. & n.r. & 2.6 & 1.2 & 6.1 & 3.7 & n.a. & n.a. & n.a. & n.a. & n.a. & 13.3 & 15.0 & 1.7 & 2.3 & n.a. & n.a. & $<0.1$ & $<0.1$ \\
\hline Southern Europe & n.r. & n.r. & 2.5 & 2.6 & 14.9 & 14.3 & n.a. & n.a. & n.a. & n.a. & n.a. & 29.0 & 31.6 & 5.6 & 6.2 & n.a. & n.a. & 0.1 & $<0.1$ \\
\hline Albania & 0.3 & 0.2 & 0.3 & 0.3 & 1.1 & 1.1 & $<0.1$ & $<0.1$ & $<0.1$ & $<0.1$ & $<0.1$ & 0.5 & 0.5 & 0.2 & 0.2 & $<0.1$ & $<0.1$ & $<0.1$ & $<0.1$ \\
\hline Andorra & n.a. & n.a. & n.a. & n.a. & n.a. & n.a. & n.a. & n.a. & n.a. & n.a. & n.a. & $<0.1$ & $<0.1$ & $<0.1$ & $<0.1$ & n.a. & n.a. & n.a. & n.a. \\
\hline $\begin{array}{l}\text { Bosnia and } \\
\text { Herzegovina }\end{array}$ & 0.1 & n.r. & $<0.1$ & $<0.1$ & 0.3 & 0.3 & n.a. & $<0.1$ & n.a. & $<0.1$ & n.a. & 0.5 & 0.6 & 0.3 & 0.3 & $<0.1$ & n.a. & $<0.1$ & $<0.1$ \\
\hline Croatia & 0.1 & n.r. & $<0.1$ & $<0.1$ & 0.3 & 0.3 & n.a. & n.a. & n.a. & n.a. & n.a. & 0.9 & 0.9 & 0.2 & 0.3 & n.a. & n.a. & $<0.1$ & $<0.1$ \\
\hline Greece & n.r. & n.r. & 0.3 & 0.3 & 1.8 & 1.9 & n.a. & n.a. & n.a. & n.a. & n.a. & 2.3 & 2.5 & 0.3 & 0.4 & n.a. & n.a. & $<0.1$ & $<0.1$ \\
\hline Italy & n.r. & n.r. & 0.7 & 0.6 & 4.8 & 4.2 & n.a. & n.a. & n.a. & n.a. & n.a. & 10.8 & 11.7 & 1.9 & 2.2 & n.a. & n.a. & $<0.1$ & $<0.1$ \\
\hline Malta & n.r. & n.r. & & & & & n.a. & n.a. & n.a. & n.a. & n.a. & 0.1 & 0.1 & $<0.1$ & $<0.1$ & n.a. & n.a. & $<0.1$ & $<0.1$ \\
\hline Montenegro & -- & n.r. & $<0.1$ & $<0.1$ & 0.1 & 0.1 & $<0.1$ & n.a. & $<0.1$ & n.a. & $<0.1$ & 0.1 & 0.1 & $<0.1$ & $<0.1$ & $<0.1$ & $<0.1$ & $<0.1$ & $<0.1$ \\
\hline North Macedonia & 0.1 & $<0.1$ & 0.1 & 0.1 & 0.3 & 0.3 & n.a. & $<0.1$ & n.a. & $<0.1$ & n.a. & 0.4 & 0.4 & 0.1 & 0.1 & $<0.1$ & n.a. & $<0.1$ & $<0.1$ \\
\hline Portugal & n.r. & n.r. & 0.4 & 0.3 & 1.6 & 1.2 & n.a. & n.a. & n.a. & n.a. & n.a. & 1.8 & 2.0 & 0.4 & 0.4 & n.a. & n.a. & $<0.1$ & $<0.1$ \\
\hline Serbia & -- & 0.5 & 0.1 & 0.1 & 0.9 & 1.0 & $<0.1$ & $<0.1$ & $<0.1$ & 0.1 & 0.1 & 1.6 & 1.8 & 0.5 & 0.6 & $<0.1$ & $<0.1$ & $<0.1$ & $<0.1$ \\
\hline Slovenia & n.r. & n.r. & & & & & n.a. & n.a. & n.a. & n.a. & n.a. & 0.4 & 0.4 & 0.1 & 0.1 & n.a. & n.a. & $<0.1$ & $<0.1$ \\
\hline Spain & n.r. & n.r. & 0.5 & 0.7 & 3.3 & 3.5 & n.a. & n.a. & n.a. & n.a. & n.a. & 9.6 & 10.5 & 1.5 & 1.7 & n.a. & n.a. & $<0.1$ & $<0.1$ \\
\hline Western Europe & n.r. & n.r. & 2.5 & 1.9 & 10.6 & 9.7 & n.a. & n.a. & n.a. & n.a. & n.a. & 34.8 & 38.1 & 6.0 & 7.0 & n.a. & n.a. & 0.1 & 0.1 \\
\hline Austria & n.r. & n.r. & 0.1 & 0.1 & 0.5 & 0.4 & n.a. & n.a. & n.a. & n.a. & n.a. & 1.4 & 1.5 & 0.3 & 0.3 & n.a. & n.a. & $<0.1$ & $<0.1$ \\
\hline Belgium & n.r. & n.r. & 0.4 & 0.4 & 1.0 & 1.2 & n.a. & n.a. & n.a. & n.a. & n.a. & 2.0 & 2.2 & 0.3 & 0.4 & n.a. & n.a. & $<0.1$ & $<0.1$ \\
\hline
\end{tabular}




\begin{tabular}{|c|c|c|c|c|c|c|c|c|c|c|c|c|c|c|c|c|c|c|c|}
\hline \multirow[t]{3}{*}{$\begin{array}{l}\text { REGIONS/ } \\
\text { SUBREGIONS/ } \\
\text { COUNTRIES }\end{array}$} & \multicolumn{2}{|c|}{ 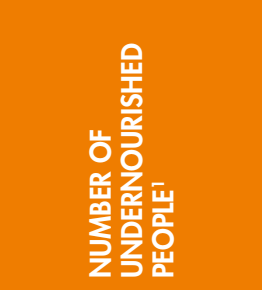 } & \multicolumn{2}{|c|}{ 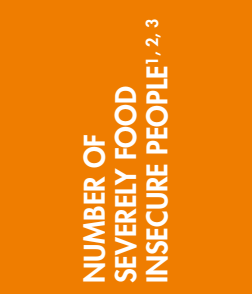 } & \multicolumn{2}{|c|}{ 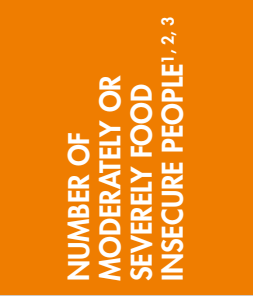 } & \multirow[t]{2}{*}{ 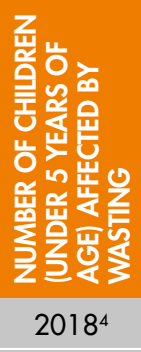 } & \multicolumn{2}{|c|}{ 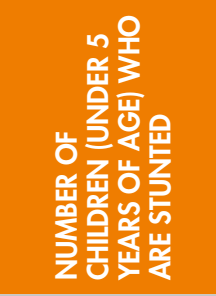 } & \multicolumn{2}{|c|}{ 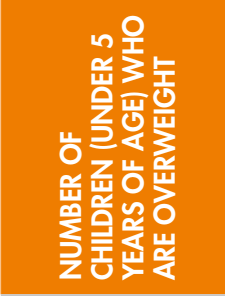 } & \multicolumn{2}{|c|}{ 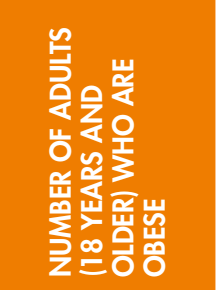 } & \multicolumn{2}{|c|}{ 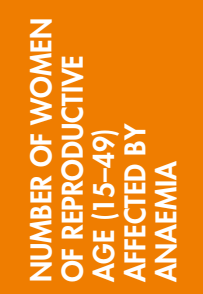 } & \multicolumn{2}{|c|}{ 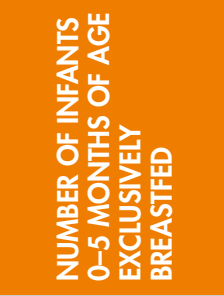 } & \multicolumn{2}{|c|}{ 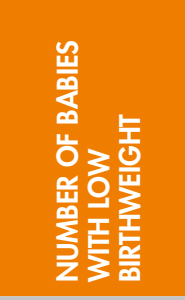 } \\
\hline & 2004-06 & 2016-18 & 2014-16 & $2016-18$ & $2014-16$ & $2016-18$ & & $2012^{5}$ & $2018^{4}$ & $2012^{5}$ & $2018^{4}$ & 2012 & 2016 & 2012 & 2016 & $2012^{6}$ & $2018^{7}$ & 2012 & 2015 \\
\hline & (millions) & (millions) & (millions) & (millions) & (millions) & (millions) & (millions) & (millions) & (millions) & (millions) & (millions) & (millions) & (millions) & (millions) & (millions) & (millions) & (millions) & (millions) & Imillion \\
\hline France & n.r. & n.r. & 1.0 & 0.5 & 4.4 & 4.1 & n.a. & n.a. & n.a. & n.a. & n.a. & 10.8 & 11.9 & 2.1 & 2.5 & n.a. & n.a. & $<0.1$ & $<0.1$ \\
\hline Germany & n.r. & n.r. & 0.8 & 0.6 & 3.4 & 3.0 & n.a. & n.a. & n.a. & n.a. & n.a. & 16.4 & 17.8 & 2.4 & 2.8 & n.a. & n.a. & $<0.1$ & $<0.1$ \\
\hline Luxembourg & n.r. & n.r. & $<0.1$ & $<0.1$ & $<0.1$ & $<0.1$ & n.a. & n.a. & n.a. & n.a. & n.a. & 0.1 & 0.1 & $<0.1$ & $<0.1$ & n.a. & n.a. & $<0.1$ & $<0.1$ \\
\hline Netherlands & n.r. & n.r. & 0.3 & 0.2 & 0.9 & 0.7 & n.a. & n.a. & n.a. & n.a. & n.a. & 2.8 & 3.1 & 0.5 & 0.6 & n.a. & n.a. & $<0.1$ & $<0.1$ \\
\hline Switzerland & n.r. & n.r. & 0.1 & 0.1 & 0.3 & 0.3 & n.a. & n.a. & n.a. & n.a. & n.a. & 1.3 & 1.4 & 0.3 & 0.4 & n.a. & n.a. & $<0.1$ & $<0.1$ \\
\hline
\end{tabular}

1 Regional estimates are included when more than 50 percent of population is covered. To reduce the margin of error estimates are presented as three-year averages.

${ }^{2} \mathrm{FAO}$ estimates of the number of people living in households where at least one adult has been found to be food insecure. To reduce the impact of year-to-year sampling variability, estimates are presented as three-year averages.

${ }_{3}^{3}$ Country-level results are presented only for those countries for which estimates are based on official national data

(see note c) or as provisional estimates, based on FAO data collected through the Gallup World Poll, for countries whose national relevant authorities provided permission to publish them. Note that consent to publish does not necessarily imply validation of the estimate by the national authorities involved and that the estimate is subject to revision as soon as suitable data from official national sources are available. Global, regional and subregional aggregates reflect data collected in approximately 150 countries.
${ }^{4}$ For regional estimates, values correspond to the model predicted estimate for the year 2018. For countries, the lates data available from 2013 to 2018 are used.

${ }^{5}$ For regional estimates, values correspond to the model predicted estimate for the year 2012. For countries, the lates data available from 2005 to 2012 are used.

${ }^{6}$ Regional estimates are included when more than 50 percent of population is covered. For countries, the latest data available from 2005 to 2012 are used.

${ }^{7}$ Regional estimates are included when more than 50 percent of population is covered. For countries, the latest date available from 2013 to 2018 are used.

Wasting, stunting, and overweight under 5 years of age and low birthweight regional aggregates exclude Japan. a. Consecutive low population coverage; interpret with caution. b. The Central Agency for Public Mobilization \& Statistics (CAPMAS) reports an estimate of severe food insecurity of 1.3 percent for 2015 , based on HIECS data, using the WFP consolidated approach for reporting indicators of food security Note that the two estimates are not directly comparable due to different definitions of "severe food insecurity".

c. Based on official national data.

d. The Government of Ireland reports estimates of the

"Proportion of the population at risk of food poverty" produced by the Central Statistics Office (CSO) and Economic and Social Research Institute (ESRI) as part of the Survey on Income and Social Conditions (SILC) 2015, as a proxy for SDG indicator 2.1.2. See https://irelandsdg.geohive.ie/datasets/sdg-2-1-2 prevalence-of-moderate-or-severe-food-insecurity-in-thepopulation-based-on-the-food-insecurity-experience-scalenuts-3-2015-ireland-cso-0si
$<0.1=$ less than 100000 people.

n.a. = data not available.

n.r. = data not reported. 


\section{ANNEX 1B. METHODOLOGICAL NOTES TO STATISTICAL TABLES UNDERNOURISHMENT}

Definition: Undernourishment is defined as the condition of an individual whose habitual food consumption is insufficient to provide, on average, the amount of dietary energy required to maintain a normal, active, healthy life.

How it is reported: The indicator is reported as a prevalence and is denominated as "prevalence of undernourishment" (PoU), which is an estimate of the percentage of individuals in the total population that are in a condition of undernourishment. National estimates are reported as three-year moving averages, to control for the low reliability of some of the underlying parameters, due for example to difficulties in capturing the year-to-year variation in food commodity stocks, one of the components of the annual food balance sheets, for which complete, reliable information is very scarce. Regional and global aggregates, on the other hand, are reported as annual estimates, on account of the fact that possible estimation errors are expected not to be correlated across countries.

Methodology: To compute an estimate of the prevalence of undernourishment in a population, the probability distribution of habitual dietary energy intake levels (expressed in kcal per person per day) for the average individual is modelled as a parametric probability density function (pdf), $f(x)$. The indicator is obtained as the cumulative probability that the habitual dietary energy intake $(x)$ is below the minimum dietary energy requirements (MDER) (i.e., the lowest limit of the range of energy requirements for the population's representative average individual) as in the formula below:

$$
P O U=\int_{x<M D E R} f(x \mid \theta) d x,
$$

where $\theta$ is a vector of parameters that characterizes the pdf. The distribution is assumed to be lognormal, and thus fully characterized by only two parameters: the mean dietary energy consumption (DEC), and its coefficient of variation (CV). In a few exceptional cases, a three-parameter skew-normal or skew-lognormal distribution is considered.'

Data sources: Different data sources are used to estimate the different parameters of the model.

Minimum dietary energy requirement (MDER): Human energy requirements for an individual in a given sex/age class are determined on the basis of normative requirements for basic metabolic rate (BMR) per kilogram of body mass, multiplied by the ideal weights that a healthy person of that class may have, given his or her height, and then multiplied by a coefficient of physical activity level (PAL) to take into account physical activity. ${ }^{2}$ Given that both healthy BMIs and PALs vary among active and healthy individuals of the same sex and age, a range of energy requirements applies to each sex and age group of the population. The MDER for the average individual in the population, that is the parameter used in the PoU formula, is obtained as the weighted average of the lower bounds of the energy requirement ranges for each sex and age group, using the shares of the population in each sex and age group as weights.

Information on the population structure by sex and age is available for most countries in the world and for each year from the UN Department of Economic and Social Affairs (DESA) Population Prospects, revised every two years. This edition of SOFI uses the 2017 revision of the World Population Prospects. ${ }^{3}$

Information on the median height in each sex and age group for a given country is derived from a recent demographic and health survey (DHS) or from other surveys that collect anthropometry data on children and adults. Even if such surveys do not refer to the same year for which the PoU is estimated, the impact of possible small intervening changes in median heights over the years on PoU estimates are expected to be negligible. 


\section{Dietary energy consumption (DEC), coefficient of variation} (CV) and skewness (Skew): When reliable data on food consumption are available from nationally representative household surveys that collect information on food consumption (such as, Living Standard Measurement Surveys or Household Incomes and Expenditure Surveys), the parameters that describe the distribution of average daily dietary energy requirement in the population can be estimated directly.

However, only very few countries conduct such surveys on an annual basis. This necessitates estimating them indirectly, or imputing them for the years when no suitable survey data are available. In such cases, DEC values are estimated from the dietary energy supply (DES) reported in the Food Balance Sheets (FBS), compiled by FAO for most countries in the world (see http://www.fao.org/economic/ess/fbs/en). This year, the FBS series were updated for the following 53 countries with the largest number of undernourished people, bringing them up to date through 2017: Afghanistan, Algeria, Angola, Bangladesh, Bolivia (Plurinational State of), Burkina Faso, Cambodia, Cameroon, Central African Republic, Chad, China (mainland), Colombia, Congo, Côte d'Ivoire, Democratic People's Republic of Korea, Democratic Republic of the Congo, Ecuador, Ethiopia, Guatemala, Guinea, Haiti, India, Indonesia, Iraq, Kenya, Madagascar, Malawi, Mexico, Mozambique, Myanmar, Nepal, Niger, Nigeria, Pakistan, Peru, Philippines, Rwanda, Senegal, Sierra Leone, South Africa, Sri Lanka, Sudan, Syrian Arab Republic, Tajikistan, Thailand, Uganda, United Republic of Tanzania, Uzbekistan, Venezuela (Bolivarian Republic of), Viet Nam, Yemen, Zambia and Zimbabwe.

In addition, FBS series for 28 European high-income countries were updated through 2016.

FBS are of no use to estimate the $\mathrm{CV}$, as they provide no information on the distribution of food consumption within a population. In the past FAO had made attempts at estimating the $\mathrm{CV}$ as a function of macroeconomic variables, such as per capita GDP, inequality in income (captured by the Gini index) and an index of the relative price of food. ${ }^{4}$ However, the ability to correctly project the CV of habitual food consumption in a population with such model is questionable, due to the sparsity of data on the Gini index and to reservations on the way in which the index of the relative price of food is compiled. It was therefore decided to revert to a simpler (and arguably more robust) method to linearly interpolate values of the CVs in the years between surveys. The main drawback of such modelling choice is that, when only one survey is available over the monitored period, the resulting value of the $\mathrm{CV}$ is kept constant over the entire period of assessment, and in any case from the year of last available survey up to the year 2015. Possible changes over time in the ability to access food by different strata of the population that are not fully reflected in changes in the average national food consumption are therefore not captured in PoU estimates.

PoU projections for 2018: Using the methods described above, PoU estimates are produced for all countries for which reliable FBS data are available up to 2017.

To generate national level three-year averages for 2016-18 and annual values at regional and global level in 2018, projections are needed.

As in the past editions of SOFI, PoU estimates for the current year are obtained by separately projecting each of the model's parameters, and by applying the PoU formula presented above to the projected parameters.

Projection of the DEC. The latest available data from national food balance sheets for most countries refer to a year between 2013 and 2017. To estimate a value of DEC for up to 2018, data on the per capita availability of cereals and meats, available from FAO's Trade and Markets Division, ${ }^{\mathbf{5}}$ are used to estimate the likely rates of change in per capita dietary energy availability from 2013, 2014, 2015, 2016 or 2017 (depending on the country) to 2018. Such rates of change are then applied to the latest available DEC values to project them up to 2018 . 
Projection of the CV. Until recently, the CV estimated for a country from last available food consumption survey data was always projected ahead with no change. Since 2014, however, FIES data provide evidence on recent changes in the extent of severe food insecurity that might closely reflect changes in the PoU. To the extent that such changes in PoU are not explained by changes in average food supplies, they can thus be used to infer the likely changes in the CV that might have occurred in the most recent year. Analysis of the combined set of historic PoU estimates reveals that, on average, and once differences in DEC and MDER have been controlled for, CVs explain about one-third of the differences in PoU across time and space. Possible changes in the CV from 2017 to 2018, to be considered in addition to projected changes in DEC described above, are thus imputed based on the results of an analysis of FIES data. For each country for which FIES data are available, the $\mathrm{CV}$ is revised by the amount that would generate one-third of a percentage point change in the PoU for each observed percentage point change in $\mathrm{FI}_{\text {sev }}$. For all other countries, the $\mathrm{CV}$ is kept constant to the estimated 2017 value.

Projection of the MDER. The MDER in 2018 is based on the projected population structure from the World Population Prospects (2017 revision, medium variant).

Challenges and limitations: While formally the state of being undernourished or not is a condition that applies to individuals, given the data usually available on a large scale it is impossible to reliably identify which individuals, in a certain group are actually undernourished. Through the statistical model described above, the indicator can only be computed with reference to a population or a group of individuals for which a representative sample is available.

The prevalence of undernourishment is thus an estimate of the percentage of individuals in that group that are in such condition and cannot be further disaggregated.

Due to the probabilistic nature of the inference and the margins of uncertainty associated with estimates of each of the parameters in the model, the precision of the PoU estimates is generally low. While it is not possible to formally compute margins of error around PoU estimates, these are expected to likely exceed 5 percent in most cases. For this reason, FAO does not consider PoU estimates that result to be lower than 2.5 percent as sufficiently reliable to be reported.

\section{References:}

FAO. 1996. The Sixth World Food Survey, pp. 114-143. Rome.

FAO. 2014. Advances in hunger measurement: traditional FAO methods and recent innovations. FAO Statistics Division Working Paper No. 14-04. Rome.

FAO. 2014. Refinements to the FAO methodology for estimating the prevalence of undernourishment indicator. FAO Statistics Division Working Paper No. 14-05. Rome.

L. Naiken. 2002. Keynote paper: FAO methodology for estimating the prevalence of undernourishment. In: FAO. Proceedings: Measurement and Assessment of Food Deprivation and Undernutrition International Scientific Symposium, Rome, 26-28 June 2002. Rome.

\section{FOOD INSECURITY AS MEASURED BY THE FOOD INSECURITY EXPERIENCE SCALE (FIES)}

Definition: Food insecurity as measured by this indicator refers to limited access to food, at the level of individuals or households, due to lack of money or other resources. The severity of food insecurity is measured using data collected with the Food Insecurity Experience Scale survey module (FIES-SM), a set of eight questions asking individual or households to self-report conditions and experiences typically associated with limited access to food.

Using sophisticated statistical techniques based on the Rasch measurement model, the information obtained in a survey is validated for internal consistency and converted into a quantitative measure along a scale of severity, ranging from low to high. Based on their responses to the FIES-SM items, the individuals or households interviewed in 
a nationally representative survey of the population are assigned a probability to be in one of three classes: food secure or only marginally insecure; moderately food insecure; and severely food insecure as defined by two globally set thresholds. Based on FIES data collected over three years from 2014 to 2016, FAO has established the FIES reference scale, which is used as the global standard for experience-based food-insecurity measures (Box 3), and to set the two reference thresholds of severity.

SDG Indicator 2.1.2 is obtained as the cumulated probability to be in either one of the two classes of moderate and severe food insecurity. A separate indicator $\left(\mathrm{FI}_{\text {sev }}\right)$ is computed by considering only the severe food-insecurity class.

How it is reported: In this report, FAO provides estimates of food insecurity at two different levels of severity: moderate or severe food insecurity (FImod+sev) and severe food insecurity (FIsev). For each of these two levels, two estimates are reported:

the prevalence $(\%)$ of individuals in the population living in households where at least one adult was found to be food insecure;

- the estimated number of individuals in the population living in households where at least one adult was found to be food insecure.

Data source: Since 2014, the eight-question FIES survey module has been applied in nationally representative samples of the adult population (defined as aged 15 or older) in more than 140 countries included in the Gallup ${ }^{\circledR}$ World Poll (GWP), covering 90 percent of the world population. In most countries, samples include about 1000 individuals, with larger samples of 3000 individuals in India and 5000 in mainland China.

For Burkina Faso, Cabo Verde, Canada, Chile, Ecuador, Ghana, Indonesia, Israel, Kenya, Malawi, Nigeria, Palestine, Republic of Korea (2014 and 2015), Russian Federation (2016, 2017 and 2018), Saint Lucia, Seychelles, and United States of America, national government survey data were used to calculate the prevalence estimates of food insecurity by applying FAO's statistical methods to adjust national results to the same global reference standard.

Methodology: The data were validated and used to construct a scale of food-insecurity severity using the Rasch model, which postulates that the probability of observing an affirmative answer by respondent $i$ to question $j$ is a logistic function of the distance, on an underlying scale of severity, between the position of the respondent, $a_{i}$, and that of the item, $b_{j}$.

$$
\operatorname{Prob}\left(X_{i, j}=\text { Yes }\right)=\frac{\exp \left(a_{i}-b_{j}\right)}{1+\exp \left(a_{i}-b_{j}\right)}
$$

By applying the Rasch model to the FIES data, it is possible to estimate the probability of being food insecure $\left(p_{i, L}\right)$ at each level of severity of food insecurity $L$ (moderate or severe, or severe), for each respondent $i$, with $0<p_{i, L}<1$.

The prevalence of food insecurity at each level of severity $\left(F I_{L}\right)$ in the population is computed as the weighted sum of the probability of being severely food insecure for all respondents $(i)$ in a sample:

$$
F I_{L}=\sum p_{i, L} w_{i}
$$

where $w_{i}$ are post-stratification weights that indicate the proportion of individuals or households in the national population represented by each record in the sample.

As only individuals aged 15 or more are sampled in the GWP, the prevalence estimates directly produced from these data refer to the population 15 years and older. To arrive at the prevalence and number of individuals (of all ages) in the population, an estimate is required of the number of people living in the households where at least one adult is estimated to be food insecure. This involves a multistep procedure detailed in Annex II of the Voices of the hungry technical report (see link in the "References" section, below). 
Regional and global aggregates of food insecurity at moderate or severe, and severe levels, $F I_{L}$, are computed as:

$$
F I_{L, r}=\frac{\sum_{c} F I_{L, c} \times N_{c}}{\sum_{c} N_{c}}
$$

where $r$ indicates the region, $F I_{L, \mathrm{c}}$ is the value of $F I$ at level $L$ estimated for country $c$ in the region and $N_{c}$ is the corresponding population size. When no estimate of $F I_{L}$ is available for a country, it is assumed to be equal to the population-weighted average of the estimated values of the remaining countries in the same region. A regional aggregate is produced only if the countries for which an estimate is available cover at least 50 percent of the region's population.

Universal thresholds are defined on the FIES global standard scale (a set of item parameter values based on results from all countries covered by the GWP in 2014-16) and converted into corresponding values on local scales. The process of calibrating each country's scale against the FIES global standard can be referred to as equating, and permits the production of internationally comparable measures of food-insecurity severity for individual respondents, as well as comparable national prevalence rates.

The problem stems from the fact that, when defined as a latent trait, the severity of food insecurity has no absolute reference against which it could be evaluated. The Rasch model allows to identify the relative position that the various items occupy on a scale that is denominated in logit units, but whose "zero" is arbitrarily set, usually to correspond to the mean estimated severity. This implies that the zero of the scale changes in each application. To produce comparable measures over time and across different populations requires establishing a common scale to use as a reference, and finding the formula needed to convert measures across different scales. As it is the case for converting measures of temperature across difference measuring scales (such as Celsius and Fahrenheit) this requires the identification of a number of "anchoring" points. In the FIES methodology, these anchoring points are the severity levels associated with the items whose relative position on the scale of severity can be considered equal to that of the corresponding items on the global reference scale. The "mapping" of the measures from one scale to the other is then obtained by finding the formula that equates the mean and the standard deviations of the common items' severity levels.

Challenges and limitations: When food-insecurity prevalence estimates are based on FIES data collected in the GWP, with national sample sizes of about 1000 in most countries, confidence intervals rarely exceed 20 percent of the measured prevalence (that is, prevalence rates of 50 percent would have margins of error of up to plus or minus 5 percent). Confidence intervals are likely to be much smaller, however, when national prevalence rates are estimated using larger samples and for estimates referring to aggregates of several countries. To reduce the impact of year-to-year sampling variability, country-level estimates are presented as three-year averages, computed as averages of all available years in the considered triennia.

Research by a joint team from FAO, IFAD, WFP and UNICEF is ongoing to further refine the current methodology. The team is exploring possible issues related to the reference period when questionnaires with different reference periods are used to collect data, and studying robust ways to limit the potential risk of inducing a bias, when adjusting country results to the global reference scale, by further accommodating possible differences in interpretation of the FIES items in different languages or cultural contexts.

\section{References:}

FAO. 2016. Methods for estimating comparable rates of food insecurity experienced by adults throughout the world. Rome.

FAO. 2018. Voices of the hungry. In: FAO [online].

Rome. www.fao.org/in-action/

voices-of-the-hungry 


\section{STUNTING, WASTING AND OVERWEIGHT IN CHILDREN UNDER FIVE YEARS OF AGE}

Definition of stunting: Height/length $(\mathrm{cm})$ for age (months) $<-2$ SD of the 2006 WHO Child Growth Standards median. Low height-for-age is an indicator that reflects the cumulative effects of undernutrition and infections since and even before birth. It may be the result of long-term nutritional deprivation, recurrent infections and lack of water and sanitation infrastructures.

How is stunting reported: The percentage of children aged 0-59 months who are below -2 standard deviation (SD) from the median height-for-age of the 2006 WHO Child Growth Standards.

Definition of wasting: Weight $(\mathrm{kg})$ for height/length $(\mathrm{cm})<-2$ SD of the 2006 WHO Child Growth Standards median. Low weight-for-height is an indicator of acute weight loss or a failure to gain weight and can be consequence of insufficient food intake and/or an incidence of infectious diseases, especially diarrhoea.

How is wasting reported: The percentage of children aged 0-59 months who are below -2 SD from the median weight-for-height of the 2006 WHO Child Growth Standards.

Definition of childhood overweight: Weight $(\mathrm{kg})$ for height/length $(\mathrm{cm})>+2$ SD of the $2006 \mathrm{WHO}$ Child Growth Standards median. This indicator reflects excessive weight gain for height generally due to energy intakes exceeding children's energy requirements.

How is the childhood overweight reported: The percentage of children aged 0-59 months who are over +2 SD from the median weight-for-height of the WHO Child Growth Standards.

Data source: UNICEF, WHO and International Bank for Reconstruction and Development/World Bank. 2019. UNICEF-WHO-The World Bank: Joint child malnutrition estimates - Levels and trends (March 2019 edition) [online]. https://data.unicef. org/topic/nutrition; www.who.int/nutgrowthdb/ estimates; https://data.worldbank.org
Methodology: National household surveys (MICS, DHS, national nutrition surveys, etc.) and national nutrition surveillance systems are the preferred primary data sources for child nutrition indicators. For entry in the database, they must be nationally representative, population-based surveys which present results based on the WHO Child Growth standards or provide access to the raw data enabling reanalysis.

A weighted analysis was carried out to account for the different country populations and ensure that the influence in the regional trend analysis of a country's survey estimate was proportional to the country's population. The population weights were derived from the UN Population Prospects, revision 2017. For each data point, the respective under-five population estimate for the specific survey year was obtained. If a survey was performed over an extended period, for example November 2013 to April 2014, the mean year in which most of the fieldwork was completed (in this case 2014) was used as the year from which to choose the respective population estimate. Weights of countries with single data points were derived by dividing the under-five population at the time of the survey by the sum of the countries' mean population in the whole region. For countries with multiple data points the weights were calculated by dividing the mean of the country's under-five population (over the observed years) by the sum of those mean populations of countries within the whole region.

A linear mixed-effect model was applied for each region or income group, using logistic transform of prevalence and results back-transformed to original scale. The final models were then used to project the trend of malnutrition in children from 1990 to 2018. Using the resulting prevalence estimates (after back-transformation), the total numbers affected were calculated by multiplying the prevalence and lower and upper limits of the confidence intervals by the subregional population derived from the UN population estimates.

Variables: region, subregion, country, survey year, sample size, minimum and maximum age surveyed, prevalence of stunting, prevalence of 
wasting, prevalence of severe wasting, prevalence of overweight, country population of under five years of age.

Challenges and limitations: The recommended periodicity for countries to report on stunting, overweight and wasting is every three to five years; however, for some countries data are available less frequently. While every effort has been made to maximize the comparability of statistics across countries and over time, country data may differ in terms of data collection methods, population coverage and estimation methods used. Survey estimates come with levels of uncertainty due to both sampling errors and non-sampling errors (technical measurement errors, recording errors, etc.). Neither of the two sources of error has been fully taken into account for deriving estimates at country or regional and global levels.

For the prevalence of wasting, as surveys are generally carried out during a specific period of the year, the estimates can be affected by seasonality. Seasonal factors related to wasting include food availability (e.g. preharvest periods) and disease (rainy season and diarrhoea, malaria, etc.), while natural disasters and conflicts can also show real shifts in trends that would need to be treated differently than a seasonal variation. Hence, country years estimates for wasting may not necessarily be comparable over time. Consequently, only the most recent (2018) estimates are provided.

\section{References:}

UNICEF, WHO and International Bank for Reconstruction and Development/World Bank. 2019. UNICEF-WHO-The World Bank: Joint child malnutrition estimates - Levels and trends (March 2019 edition) [online]. https://data.unicef.org/ topic/nutrition; www.who.int/nutgrowthdb/ estimates; https://data.worldbank.org WHO. 2010. Nutrition Landscape Information System (NLIS) country profile indicators: interpretation guide. Geneva, Switzerland. WHO. 2014. Comprehensive implementation plan on maternal, infant and young child nutrition. Geneva, Switzerland.

\section{EXCLUSIVE BREASTFEEDING}

Definition: Exclusive breastfeeding for infants < six months of age is defined as receiving only breast milk and no additional food or drink, not even water. Exclusive breastfeeding is a cornerstone of child survival and is the best food for newborns, as breast milk shapes the baby's microbiome, strengthens the immune system, and reduces the risk of developing chronic diseases.

Breastfeeding also benefits mothers by preventing postpartum haemorrhage and promoting uterine involution, decreasing risk of iron-deficiency anaemia, reducing the risk of various types of cancer and providing psychological benefits.

How exclusive breastfeeding is reported: Percentage of infants aged 0-5 months who are fed exclusively on breast milk with no additional food or drink, not even water, in the 24 hours preceding the survey.

Data source: UNICEF. 2019. Infant and Young Child Feeding. In: UNICEF Data: Monitoring the Situation of Children and Women [online]. New York, USA. https://data.unicef.org/topic/ nutrition/infant-and-young-child-feeding

\section{Methodology:}
Infants 0-5 months of age who received only breastmilk during the previous day

Infants $0-5$ months of age

This indicator includes breastfeeding by a wet nurse and feeding expressed breast milk.

The indicator is based on a recall of the previous day's feeding to a cross-section of infants $0-5$ months of age.

In 2012, the regional and global exclusive breastfeeding estimates were generated using the most recent estimate available for each country between 2005 and 2012. Similarly, 2018 estimates were developed using the most recent estimate available for each country between 2013 
and 2018. Global and regional estimates were calculated as weighted averages of the prevalence of exclusive breastfeeding in each country, using the total number of births from the World Population Prospects, 2017 revision (2012 for the baseline and 2018 for the current) as weights. Estimates are presented only where the available data are representative of at least 50 percent of corresponding regions' total number of births, unless otherwise noted.

Challenges and limitations: While a high proportion of countries collect data for exclusive breastfeeding, data are lacking in high-income countries in particular. The recommended periodicity of reporting on exclusive breastfeeding is every three to five years. However, for some countries, data are reported less frequently, meaning changes in feeding patterns are often not detected for several years after the change occurs.

Regional and global averages may be affected depending on which countries had data available for the periods considered in this report.

Using the previous day's feeding as a basis may cause the proportion of exclusively breastfed infants to be overestimated as some infants who may have been given other liquids or foods irregularly may not have received these in the day before the survey.

\section{References:}

UNICEF. 2019. Infant and young child feeding: exclusive breastfeeding, predominant breastfeeding. In: UNICEF Data: Monitoring the Situation of Children and Women [online]. New York, USA. https://data.unicef.org/topic/ nutrition/infant-and-young-child-feeding WHO. 2008. Indicators for assessing infant and young child feeding practices. Part 1: Definitions. Geneva, Switzerland.

WHO. 2010. Nutrition Landscape Information System (NLIS) country profile indicators: interpretation guide. Geneva, Switzerland. WHO. 2014. Comprehensive implementation plan on maternal, infant and young child nutrition. Geneva, Switzerland.

\section{LOW BIRTHWEIGHT}

Definition: Low birthweight is defined as a weight at birth of less than 2500 grams (less than $5.51 \mathrm{lbs}$ ), regardless of gestational age. A newborn's weight at birth is an important marker of maternal and foetal health and nutrition.

How is low birthweight reported: The percentage of newborns weighing less than 2500 grams (less than $5.51 \mathrm{lbs}$ ) at birth.

Data source: UNICEF and WHO. 2019. Low birthweight estimates, 2019. [Cited 10 May 2019]. https://data.unicef.org/topic/nutrition/ low-birthweight; https://www.who.int/ nutgrowthdb

Methodology: Nationally representative estimates of low birthweight prevalence can be derived from a range of sources, broadly defined as national administrative data or representative household surveys. National administrative data are those coming from national systems including Civil Registration and Vital Statistics (CRVS) systems, national Health Management Information Systems (HMIS) and birth registries. National household surveys which contain information about birthweight as well as key related indicators including maternal perception of size at birth (MICS, DHS) are also an important source of low birthweight data especially in contexts where many births are unweighed and/or data heaping is a problem. Prior to entry into the country data set, country data are reviewed for coverage and quality and adjusted where the source is a household survey. Administrative data are categorized as (i) high coverage, if representing $\geq 90$ percent of live births; (ii) medium coverage, if representing 80-90 percent of live births; or (iii) not included, if covering $<80$ percent of live births. To be included in the data set, survey data need to have:

i. a birthweight in the data set for at minimum 30 percent of the sample;

ii. a minimum of 200 birthweights in the data set;

iii. no indication of severe data heaping - this means that: a) $\leq 55$ percent of all birthweights 
can fall on the three most frequent birthweights (i.e. if $3000 \mathrm{~g}, 3500 \mathrm{~g}$ and $2500 \mathrm{~g}$ were the three most frequent birthweights, when added together, they have to make up $\leq 55$ percent of all birthweights in the data set); $b) \leq 10$ percent of all birthweights $\geq 4500 \mathrm{~g} ; \mathrm{c}) \leq 5$ percent of birthweights on tail ends of $500 \mathrm{~g}$ and $5000 \mathrm{~g}$; and

iv. undergo an adjustment for missing birthweights and heaping. ${ }^{6}$

Modelling methods were applied to the accepted (and for household survey data, accepted and adjusted) country data to generate annual country estimates from 2000 to 2015, with methods varying by availability and type of input data as follows:

- b-spline: data for countries with $\geq 8$ data points from higher coverage administrative sources with $\geq 1$ prior to 2005 and $\geq 1$ more point more recent than 2010 are smoothed with $b$-spline regression to generate annual low birthweight estimates. A b-spline regression model was used to predict the standard error and calculate 95 percent confidence intervals for the country-level low birthweight estimates. These low birthweight estimates follow very closely those included in the countries' own administrative reports.

- Hierarchical regression: data for countries not meeting requirements for $b$-spline but with $\geq 1$ low birthweight data point from any source meeting inclusion criteria are fitted into a model using covariates to generate annual low birthweight estimates, as well as uncertainty ranges, using a bootstrap approach. The model includes natural log of neonatal mortality rate; the proportion of children underweight (weight-for-age $\mathrm{z}$-score below minus two standard deviations from median weight for age of reference population); data type (higher quality administrative, lower quality administrative, household survey); UN region (e.g. Southern Asia, Caribbean); and a country-specific random effect. These low birthweight estimates may vary substantially from estimates reported by countries in administrative and survey reports, especially given that the household survey estimates are adjusted for missing birthweights and heaping, while survey reports often present a low birthweight estimate just for the children with a birthweight and with no adjustment for data heaping.

- No estimate: countries for which low birthweight input data were not available and/or did not meet inclusion criteria are indicated in the database as "no estimate". A total of 54 countries in the current country database were reported as having "no estimate". Despite not presenting an estimate for these individual 54 countries, annual low birthweight estimates were derived for them using the hierarchical regression methods detailed above but used only to input into regional and global estimates.

Modelled annual country estimates are used to generate regional and global estimates in 2000-2015. Global estimates are derived by summing the estimated number of live births weighing less than $2500 \mathrm{~g}$ for $195^{7}$ countries with an estimate in the United Nations regional grouping for each year and dividing by all live births in each year in those 195 countries. Regional estimates are similarly derived, based on countries in each regional grouping. To obtain the global and regional level estimates of uncertainty, 1000 low birthweight point estimates were made for each country for each year using either $b$-spline (by randomly sampling from a normal distribution plotted using the calculated standard error) or hierarchical regression approach (using a bootstrap approach). The country low birthweight estimates for each of the 1000 samples were summed at worldwide or regional level and the 2.5 th and 97.5 th centiles of the resulting distributions were used as the confidence intervals.

Challenges and limitations: A major limitation of monitoring low birthweight globally is the lack of birthweight data for many of the world's children. There is a notable bias among the unweighed, with those born to poorer, less educated, rural mothers being less likely to have a birthweight when compared with their richer, urban counterparts with more highly educated mothers. ${ }^{8}$ As the characteristics of the unweighed are risk factors 
for having a low birthweight, estimates that do not well represent these children may be lower than the true value. Furthermore, poor quality of available data with regard to excessive heaping on multiples of $500 \mathrm{~g}$ or $100 \mathrm{~g}$ exists in the majority of available data from $\mathrm{LMIC}^{\boldsymbol{9}}$ and can further bias low birthweight estimates. The methods applied to adjust for missing birthweights and heaping for survey estimates in the current database ${ }^{10}$ are meant to address the problem, however there were a total of 54 countries for which it was not possible to generate a reliable birthweight estimate. In addition, the confidence limits of the regional and global estimates may be artificially small given that about half of the modelled countries had a country-specific effect generated at random for each bootstrap prediction, some of which were positive and others negative, making the relative uncertainty at the regional and global level tend to be less than that at the individual country level.

\section{References:}

A.K. Blanc and T. Wardlaw. 2005. Monitoring low birth weight: An evaluation of international estimates and an updated estimation procedure. Bulletin World Health Organization, 83(3):

178-185.

H. Blencowe, J. Krasevec, M. de Onis, R.E. Black, X. An, G.A. Stevens, E. Borghi, C. Hayashi, D. Estevez, L. Cegolon, S. Shiekh, V.P. Hardy, J.E. Lawn and S. Cousens. 2019. National, regional, and worldwide estimates of low birthweight in 2015, with trends from 2000: a systematic analysis. The Lancet Global Health, 15 May 2019 [online]. http://dx.doi. org/10.1016/S2214-109X(18)30565-5

\section{ADULT OBESITY}

Definition: $B M I \geq 30.0 \mathrm{~kg} / \mathrm{m}^{2}$. The body mass index (BMI) is the ratio of weight-to-height commonly used to classify the nutritional status of adults. It is calculated as the body weight in kilograms divided by the square of the body height in meters $\left(\mathrm{kg} / \mathrm{m}^{2}\right)$. Obesity includes individuals with BMI equal or higher than $30 \mathrm{~kg} / \mathrm{m}^{2}$.

How is the indicator reported: Percentage of population of 18 years of age and over with BMI $\geq 30.0 \mathrm{~kg} / \mathrm{m}^{2}$ standardized by age and weighted by sex.
Data source: WHO. 2019. Global Health Observatory (GHO) data repository. In: World Health Organization [online]. Geneva, Switzerland. [Cited 10 May 2019] http://apps.who.int/gho/data/ node.main.A900A?lang=en

Methodology: A Bayesian hierarchical model was applied to selected population-based studies that had measured height and weight in adults aged 18 years and older to estimate trends from 1975 to 2014 in mean BMI and in the prevalence of BMI categories (underweight, overweight and obesity). The sample included 1698 population-based studies with more than 19.2 million participants aged 18 years or older, measured in 186 countries. The model incorporated nonlinear time trends and age patterns; national versus subnational and community representativeness; and whether data covered both rural and urban areas versus only one of them. The model also included covariates that help predict BMI, including national income, proportion of population living in urban areas, mean number of years of education, and summary measures of availability of different food types for human consumption.

Challenges and limitations: Some countries had few data sources and only 42 percent of included sources reported data for people older than 70 years.

\section{References:}

NCD Risk Factor Collaboration (NCD-RisC).

2016. Trends in adult body-mass index in 200 countries from 1975 to 2014: a pooled analysis of 1698 population-based measurement studies with 19.2 million participants. The Lancet, 387(10026): 1377-1396.

WHO. 2010. Nutrition Landscape Information System (NLIS) country profile indicators: interpretation guide. Geneva, Switzerland. 


\section{ANAEMIA IN WOMEN OF REPRODUCTIVE AGE}

Definition: [Haemoglobin] $<110 \mathrm{~g} /$ litre for pregnant women; [Haemoglobin] < 120g/litre for non-pregnant women. Anaemia is defined as a haemoglobin concentration below a specified cutoff point, which can change according to the age, sex, physiological status, smoking habits and altitude at which the population being assessed lives.

How is it reported: Percentage of women of reproductive age (15 to 49 years old) with haemoglobin concentration below $110 \mathrm{~g} /$ litre for pregnant women and below $120 \mathrm{~g} /$ litre for non-pregnant women.

\section{Data sources:}

WHO. 2018. Prevalence of anaemia in women of reproductive age (\%) (Global strategy for women's, children's and adolescents' health). In: Global Health Observatory indicator views [online]. Geneva, Switzerland. [Cited 10 may 2019]. http://apps.who.int/gho/data/node.imr. PREVANEMIA?lang=en

WHO. 2018. Micronutrients database. In: Vitamin and Mineral Nutrition Information System (VMNIS) [online]. Geneva, Switzerland. [Cited 10 may 2019]. www.who.int/vmnis/database

Methodology: National representative surveys, summary statistics from WHO's Vitamin and Mineral Nutrition Information Systems and, summary statistics reported by other national and international agencies.

Data for non-pregnant women and pregnant women were summed and weighted by the prevalence of pregnancy to generate one value for all women of reproductive age. Data were adjusted by altitude and, when available, smoking status.

Trends were modelled over time as a linear trend plus a smooth nonlinear trend, at national, regional, and global levels. The model used a weighted average of various bell-shaped densities to estimate full haemoglobin distributions, which might themselves be skewed.
The estimates are also informed by covariates that help predict haemoglobin concentrations, including maternal education, proportion of population in urban areas, mean latitude, prevalence of sickle cell disorders and thalassemia and mean BMI. All covariates were available for every country and year, except the prevalence of sickle cell disorders and thalassaemia, which was assumed as constant over time during the analysis period for each country.

Challenges and limitations: Despite a high proportion of countries having nationally representative survey data available for anaemia, there is still a lack of reporting on this indicator, especially in high-income countries. As a result, the estimates may not capture the full variation across countries and regions, trending to "shrink" towards global means when data are sparse.

\section{References:}

G.A. Stevens, M.M. Finucane, L.M. De-Regil, C.J. Paciorek, S.R. Flaxman, F. Branca,

J.P. Peña-Rosas, Z.A. Bhutta and M. Ezzati. 2013. Global, regional, and national trends in haemoglobin concentration and prevalence of total and severe anaemia in children and pregnant and non-pregnant women for 1995-2011: a systematic analysis of population-representative data. Lancet Global Health, 1(1): e16-25.

WHO. 2010. Nutrition Landscape Information System (NLIS) country profile indicators: interpretation guide. Geneva, Switzerland. WHO. 2014. Comprehensive implementation plan on maternal, infant and young child nutrition. Geneva, Switzerland.

WHO. 2015. The Global prevalence of anaemia in 2011. Geneva, Switzerland. 


\section{MMNGX 9}

\section{METHODOLOGIES PART 1}

\section{A. Food insecurity compared with other important indicators of human development}

This section provides additional details about the analysis presented in Box 4 "How do estimates of food insecurity compare with other important indicators of human development?" of Section 1.1. Spearman's rank correlations were computed between the national prevalence of food insecurity at moderate or severe levels (as three-year average in the period 2016-2018) and the most recent value available for other selected development indicators. Table A2.1 summarizes the source and description for each of these, in alphabetical order.

\section{B. Gender gap in accessing food}

This section provides additional details about the analysis performed in the section "Gender differences in food insecurity" of Section 1.1.

\footnotetext{
B 1. Prevalence of moderate or severe food insecurity among adults by gender

Figure 14 is derived using data collected by FAO. These data are collected at individual level. Each respondent (adult - 15 years or older) answers the FIES survey module by making reference to his/her own individual food-insecurity condition. For this reason, it is possible to disaggregate the results of food insecurity by male and female respondents. To do so, first, the possible presence of differential item functioning (DIF) between male and female respondents was checked, to make sure that differences between men and women in food-insecurity levels was not due to the fact that they may experience in a different way the same food-security conditions or that they may interpret the same question in a different way.
}

Results (not shown) point to no significant DIF between men and women. Based on this result, prevalence rates of food insecurity among men and women are calculated by applying different weighted raw score distributions (one for men and one for women) to the same probabilities of food insecurity, calculated at country level based on raw score parameters and errors obtained by the application of the Rasch model. This computation was performed for each year of data for each country. The results shown in the graph are based on the three-year-averaged country results in the period 2016-2018.

\section{B2. Regression analysis}

The text following Figure 14 in the report describes an analysis that aims at better understanding the determinants of gender gaps in accessing food, once controlling for other factors. The analysis is performed by pooling together individual-level FIES data collected by FAO in 145 countries, from 2014 to 2017, with the purpose of assessing the extent of any differences in the food-insecurity status of men and women, after controlling for socio-economic factors. A logistic regression is applied using the food-insecurity status as a dependent variable, established by considering the cross-country comparable probability of being food insecure at moderate or severe level for each country. If the probability is larger than 50 percent, the individual is classified as "food insecure" and the dependent variable takes the value of 1 , otherwise it assumes a value of 0 . Gender, area of residence (rural or small town versus large city or suburbs), poverty status, and education level of the respondents are included as independent variables. The year of data collection (between 2014 and 2017) is also included as a covariate. Results show that, after controlling for area of residence, poverty status and education level of the respondents, the odds of being food insecure are still approximately 10 percent higher for women than for men. 
TABLE A2.1

DEFINITION OF VARIABLES AND SOURCES

\begin{tabular}{ll} 
Variable & Source \\
Age dependency ratio & World Bank, WDI \\
\hline Basic drinking water & $\begin{array}{l}\text { WHO/UNICEF Joint } \\
\text { Monitoring Programme for } \\
\text { Water Supply, Sanitation and } \\
\text { sygiene (JMP) }\end{array}$ \\
\hline
\end{tabular}

Description

Age dependency ratio is the ratio of dependents (people younger than 15 or older than 64) to the working-age population (those aged 15-64).

The percentage of people using at least basic water services. Basic drinking water services are defined as drinking water from an improved source, provided collection time is not more than 30 minutes for a round trip. Improved water sources include piped water, boreholes or tube wells, protected dug wells, protected springs, and packaged or delivered water.

The percentage of people using at least basic sanitation services, that is, improved sanitation facilities that are not shared with other households.

Basic sanitation services WHO-UNICEF JMP Improved sanitation facilities include flush/pour flush to piped sewer systems, septic tanks or pit latrines; as well as ventilated improved pit latrines, compositing toilets or pit latrines with slabs.

GDP per capita based on purchasing power parity (PPP). PPP GDP is the gross domestic product converted to international dollars using purchasing power parity rates. Data are expressed in current international dollars, based on the 2011 International Comparison Program (ICP) round.

GDP per capita World Bank

Measures gender gaps in human development achievements by accounting

Gender Development

UNDP for disparities between women and men in three basic dimensions of human development - health, knowledge and living standards using the same component indicators as in the Human Development Index (HDI).

Measures the extent to which the distribution of income among individuals

\begin{tabular}{ll}
$\begin{array}{l}\text { Gini index income } \\
\text { inequality }\end{array}$ & World Bank \\
\hline $\begin{array}{l}\text { Health expenditure per } \\
\text { capita }\end{array}$ & WHO-World Bank \\
\hline
\end{tabular}

or households within an economy deviates from a perfectly equal distribution.

\begin{tabular}{|c|c|c|}
\hline $\begin{array}{l}\text { Health expenditure per } \\
\text { capita }\end{array}$ & WHO-World Bank & $\begin{array}{l}\text { Current expenditure on health per capita expressed in international dollars } \\
\text { at purchasing power parity (PPP). }\end{array}$ \\
\hline Human capital index & World Bank & $\begin{array}{l}\text { Calculates the contributions of health and education to worker productivity. } \\
\text { The final index score ranges from zero to one and measures the } \\
\text { productivity as a future worker of a child born today relative to the } \\
\text { benchmark of full health and complete education. }\end{array}$ \\
\hline $\begin{array}{l}\text { Labour force } \\
\text { participation rate }\end{array}$ & ILO-World Bank & $\begin{array}{l}\text { Labour force participation rate is the proportion of the population aged } \\
15-64 \text { that is economically active: all people who supply labour for the } \\
\text { production of goods and services during a specified period. }\end{array}$ \\
\hline Life expectancy at birth & WHO & $\begin{array}{l}\text { The number of years a newborn would live if prevailing patterns of } \\
\text { mortality at the time of its birth were to stay the same throughout its life. }\end{array}$ \\
\hline $\begin{array}{l}\text { Literacy rate - adult } \\
\text { total (\%) }\end{array}$ & UNESCO & $\begin{array}{l}\text { Percentage of population aged } 15 \text { years and over who can both read and } \\
\text { write with understanding a short simple statement about their everyday } \\
\text { life. }\end{array}$ \\
\hline $\begin{array}{l}\text { Mortality rate, } \\
\text { under } 5\end{array}$ & $\begin{array}{l}\text { UN Inter-agency Group for } \\
\text { Child Mortality Estimation }\end{array}$ & $\begin{array}{l}\text { An estimate of the number of babies that will die before reaching the age } \\
\text { of five years, out of each } 1000 \text { who were born alive. }\end{array}$ \\
\hline $\begin{array}{l}\text { Political Stability and } \\
\text { Absence of Violence }\end{array}$ & $\begin{array}{l}\text { The Worldwide Governance } \\
\text { Indicators }\end{array}$ & $\begin{array}{l}\text { Political Stability and Absence of Violence/Terrorism measures perceptions } \\
\text { of the likelihood of political instability and/or politically motivated } \\
\text { violence, including terrorism. }\end{array}$ \\
\hline Poverty headcount (\%) & World Bank & $\begin{array}{l}\text { Poverty headcount ratio at USD } 1.90 \text { a day is the percentage of the } \\
\text { population living on less than USD } 1.90 \text { a day at } 2011 \text { international } \\
\text { prices. }\end{array}$ \\
\hline Rural population (\%) & World Bank & $\begin{array}{l}\text { People living in rural areas as defined by national statistical offices. It is } \\
\text { calculated as the difference between total population and urban } \\
\text { population. }\end{array}$ \\
\hline
\end{tabular}

SOURCE: FAO 


\section{Macro-data analyses on the association between food insecurity and malnutrition}

This section refers to the analysis in Section 1.3 entitled "Links between food insecurity and various forms of malnutrition at the country level". Table A2.2 presents the variables used in this analysis.

\section{C1. Model specification}

A series of $n$ linear regression models were considered using $Y_{n}$ (the nutrition outcome of interest) as response variable, and the log-odds of the prevalence of moderate or severe food insecurity in the population (FI), prevalence of undernourishment (PoU) and extreme poverty rate (POV) as covariates. See the function below. Coefficients were standardized to allow comparability between the results of different regression models. Table A2.3 provides additional regression results in addition to Table 5 in Section 1.3.

$\log _{\mathrm{e}}\left(Y_{n}\right)=\beta_{0}+\beta_{1} \log _{\mathrm{e}}\left(\frac{F I}{1-F I}\right)+\beta_{2} \log _{\mathrm{e}}\left(\frac{P o U}{1-P o U}\right)$ $+\beta_{3} \log _{\mathrm{e}}\left(\frac{P O V}{1-P O V}\right)$

For a full description of the methodology and results, see: M. Del Grossi, A. Sattar,

C. Alvarez-Sanchez, A. Ishaq, S. Viviani, J. Feng, F. Yassin and C. Cafiero. forthcoming. The relevance of food security for nutrition: an empirical analysis at country level. Technical Paper. Rome, FAO.

\section{Microdata analyses on the association between food insecurity and malnutrition}

This section provides additional details about the analyses presented in the subsection of Section 1.3 entitled "Links between food insecurity and various forms of malnutrition at the household and individual levels".

\section{D1. Data sets}

The data sets used in the analyses were the following: Brazil 2006 Demographic and Health
Survey (DHS); Mexico 2012 National Health and Nutrition Survey (ENSANUT, by its Spanish acronym); United States 2013/14 National Health and Nutrition Survey; Kenya 2015/16 Integrated Household Budget Survey; Nepal 2016 DHS; Malawi 2016/17 Fourth Integrated Household Survey; Nigeria 2015/16 General Household Survey - Panel Wave 3 (Post Planting); Pakistan 2010 Panel Household Survey.

N.B. The Brazil data set includes adult anthropometry data for women only.

\section{D2. Definition of variables}

Food insecurity was constructed as a dichotomous variable $\left(\mathrm{FI}_{\text {mod+sev }}\right.$ or food secure/ mildly food insecure), based on experience-based food-insecurity scales data from each data set. Each country's food-insecurity scale was equated to the global reference scale following the FIES methodology (Box 3 ) to produce a cross-country comparable measure of food insecurity.

All the dependent variables were dichotomous (presence/absence of specific form of malnutrition). WHO Child Growth Standards and official cut-points were used for constructing the child and school-age children and adolescent anthropometric indicators. BMI cut-offs from WHO were used for constructing overweight and obesity indicators for adults.

Tables A2.4 and A2.5 present a brief description of each of the malnutrition indicators and the dependent variables.

\section{D3. Model specification}

Logistic regression equations were used to estimate the likelihood of an individual being malnourished given the food-insecurity status of their household. Regressions were estimated for each malnutrition outcome considered, while controlling for cluster (household) effects and relevant covariates (described below). For each country and outcome variable, alternative model specifications with various combinations of covariates and interaction terms were tried. Tables 6 and 7 report the results of the models with the lowest Akaike information criterion (AIC) and Bayesian information criterion (BIC). " 


\section{TABLE A2.2}

\section{DEFINITION OF VARIABLES AND SOURCES}

\begin{tabular}{|c|c|c|c|}
\hline Variable & Source & Period & Description \\
\hline $\begin{array}{l}\text { Undernourishment } \\
\text { (PoU) }\end{array}$ & FAO Statistics Division & 2014-2016 & $\begin{array}{l}\text { Percentage of individuals in the total population that } \\
\text { are in a condition of undernourishment (\%). }\end{array}$ \\
\hline Food insecurity (FI) & FAO Statistics Division & $2014-2016$ & $\begin{array}{l}\text { Percentage of individuals in the population living in } \\
\text { households where at least one adult was found to be } \\
\text { moderately or severely food insecure (\%). }\end{array}$ \\
\hline Extreme poverty (POV) & World Bank & $\begin{array}{l}\text { Last available value } \\
\text { from } 2013-2017\end{array}$ & $\begin{array}{l}\text { Poverty headcount ratio at USD } 1.90 \text { a day, } 2011 \\
\text { PPP (\% of the population). }\end{array}$ \\
\hline Stunting $\left(Y_{4}\right)$ & $\begin{array}{l}\text { UNICEF-WHO-World Bank } \\
\text { Group Joint Child } \\
\text { Malnutrition Estimates } 2019\end{array}$ & $\begin{array}{l}\text { Last available value } \\
\text { from } 2013-2017\end{array}$ & $\begin{array}{l}\text { Percentage of children aged 0-59 months who are } \\
\text { below }-2 \text { standard deviations (SD) from the median } \\
\text { height-for-age of the } 2006 \text { WHO Child Growth } \\
\text { Standards (\%). }\end{array}$ \\
\hline Wasting $\left(Y_{5}\right)$ & $\begin{array}{l}\text { UNICEF-WHO-World Bank } \\
\text { Group Joint Child } \\
\text { Malnutrition Estimates } 2019\end{array}$ & $\begin{array}{l}\text { Last available value } \\
\text { from } 2013-2017\end{array}$ & $\begin{array}{l}\text { Percentage of children aged 0-59 months who are } \\
\text { below }-2 \text { SD from the median weight-for-height of } \\
\text { the } 2006 \text { WHO Child Growth Standards (\%). }\end{array}$ \\
\hline $\begin{array}{l}\text { Overweight in } \\
\text { school-age children } \\
\text { and adolescents }\left(Y_{2}\right)\end{array}$ & $\begin{array}{l}\text { Global Health Observatory, } \\
\text { WHO }\end{array}$ & 2016 & $\begin{array}{l}\text { Percentage of children aged 5-19 years with } \\
\text { BMI > } 1 \text { SD of the median according to the WHO } \\
\text { growth reference for school-age children and } \\
\text { adolescents (\%). }\end{array}$ \\
\hline $\begin{array}{l}\text { Overweight in } \\
\text { children less than five } \\
\text { years of age }\left(Y_{3}\right)\end{array}$ & $\begin{array}{l}\text { Global Health Observatory, } \\
\text { WHO }\end{array}$ & $\begin{array}{l}\text { Last available value } \\
\text { from } 2012-2018\end{array}$ & $\begin{array}{l}\text { Percentage of children aged 0-59 months who are } \\
\text { above }+2 \text { SD from the median weight-for-height of } \\
\text { the } 2006 \text { WHO Child Growth Standards (\%). }\end{array}$ \\
\hline Adult obesity $\left(Y_{1}\right)$ & $\begin{array}{l}\text { Global Health Observatory, } \\
\text { WHO }\end{array}$ & 2016 & $\begin{array}{l}\text { Percentage of population of } 18 \text { years of age and } \\
\text { above with BMl } \geq 30.0 \mathrm{~kg} / \mathrm{m}^{2} \text { standardized by age } \\
\text { and weighted by sex }(\%) \text {. }\end{array}$ \\
\hline Anaemia $\left(Y_{6}\right)$ & $\begin{array}{l}\text { Global strategy for } \\
\text { women's, children's and } \\
\text { adolescents' health, WHO }\end{array}$ & 2016 & $\begin{array}{l}\text { Percentage of women of reproductive age ( } 15 \text { to } \\
49 \text { years old) with haemoglobin concentration } \\
\text { below } 110 \mathrm{~g} / \text { litre for pregnant women and below } \\
120 \mathrm{~g} / \text { litre for non-pregnant women (\%). }\end{array}$ \\
\hline
\end{tabular}

SOURCE: M. Del Grossi, A. Sattar, C. Alvarez-Sanchez, A. Ishaq, S. Viviani, J. Feng, F. Yassin and C. Cafiero. forthcoming. The relevance of food security for nutrition: an empirical analysis at country level. Technical Paper. Rome, FAO.

\section{TABLE A2.3}

\section{RESUITS}

\begin{tabular}{|c|c|c|c|c|c|c|}
\hline Dependent variable & $\begin{array}{l}\text { Sample size } \\
\text { (no. of countries) }\end{array}$ & $\beta_{1}$ & $\beta_{2}$ & $\beta_{3}$ & $\begin{array}{l}\text { Condition } \\
\text { Index (C.I) }\end{array}$ & Adj. $\mathbf{R}^{2}$ \\
\hline Adult obesity & 86 & $\begin{array}{l}0.308 \\
(0.031)\end{array}$ & $\begin{array}{l}-0.379 \\
(0.002)\end{array}$ & $\begin{array}{l}-0.635 \\
(0.000)\end{array}$ & 7.8 & 0.471 \\
\hline $\begin{array}{l}\text { Overweight in school-age } \\
\text { children and adolescents }\end{array}$ & 86 & $\begin{array}{l}-0.033 \\
(0.813)\end{array}$ & $\begin{array}{l}-0.279 \\
(0.016)\end{array}$ & $\begin{array}{l}-0.470 \\
(0.000)\end{array}$ & 7.8 & 0.495 \\
\hline $\begin{array}{l}\text { Overweight in children less } \\
\text { than five years of age }\end{array}$ & 47 & $\begin{array}{l}-0.132 \\
(0.503)\end{array}$ & $\begin{array}{l}-0.064 \\
(0.675)\end{array}$ & $\begin{array}{l}-0.438 \\
(0.041)\end{array}$ & 6.2 & 0.298 \\
\hline Stunting & 43 & $\begin{array}{c}0.001 \\
(0.995)\end{array}$ & $\begin{array}{c}0.222 \\
(0.077)\end{array}$ & $\begin{array}{c}0.638 \\
(0.001)\end{array}$ & 6.3 & 0.592 \\
\hline Wasting & 43 & $\begin{array}{l}-0.035 \\
(0.885)\end{array}$ & $\begin{array}{c}0.305 \\
(0.096)\end{array}$ & $\begin{array}{c}0.211 \\
(0.404)\end{array}$ & 6.3 & 0.127 \\
\hline Anaemia & 87 & $\begin{array}{c}0.404 \\
(0.011)\end{array}$ & $\begin{array}{c}0.161 \\
(0.214)\end{array}$ & $\begin{array}{c}0.090 \\
(0.542)\end{array}$ & 7.8 & 0.343 \\
\hline
\end{tabular}

NOTES: $\beta_{1}$ to $\beta_{3}$ : Standardized Coefficients; C.I.: highest Condition Index from collinearity diagnostics; Adj. R2: Adjusted R Square.

SOURCE: M. Del Grossi, A. Sattar, C. Alvarez-Sanchez, A. Ishaq, S. Viviani, J. Feng, F. Yassin and C. Cafiero. forthcoming. The relevance of food security for nutrition: an empirical analysis at country level. Technical Paper. Rome, FAO. 
TABLE A2.4

MALNUTRITION INDICATORS BY AGE/SEX CLASS (DEPENDENT VARIABLES)

\begin{tabular}{|c|c|c|}
\hline Age/sex class & Variable & Description \\
\hline \multirow[t]{3}{*}{ Children $<5$ years old } & Stunting & $\begin{array}{l}\text { Height/length-for-age }<-2 \text { SD of the median of the } 2006 \text { WHO Child Growth } \\
\text { Standards. }\end{array}$ \\
\hline & Wasting & $\begin{array}{l}\text { Weight-for-height/length }<-2 \text { SD of the median of the } 2006 \text { WHO Child } \\
\text { Growth Standards. }\end{array}$ \\
\hline & Overweight & $\begin{array}{l}\text { Weight-for-height/length > } 2 \text { SD of the median of the } 2006 \text { WHO Child } \\
\text { Growth Standards. }\end{array}$ \\
\hline $\begin{array}{l}\text { School-age children } \\
\text { and adolescents } \\
\text { (5-19 years old) }\end{array}$ & Overweight & $\begin{array}{l}\text { BMI-for-age } z \text {-score > } 1 \text { SD of the median of the WHO growth reference for } \\
\text { school-age children and adolescents. }\end{array}$ \\
\hline $\begin{array}{l}\text { Adults } \\
\text { ( } 18 \text { years old and older) }\end{array}$ & Obesity & $\mathrm{BMI} \geq 30 \mathrm{~kg} / \mathrm{m}^{2}$ standardized by age and weighted by sex. \\
\hline $\begin{array}{l}\text { Women } \\
15-49 \text { years old }\end{array}$ & Anaemia & $\begin{array}{l}\text { Non-pregnant women: haemoglobin }<120 \mathrm{~g} / \text { litre } \\
\text { Pregnant women: haemoglobin }<110 \mathrm{~g} / \text { litre. }\end{array}$ \\
\hline
\end{tabular}

SOURCE: A. Ishaq, C. Alvarez-Sanchez, M. Del Grossi, S. Viviani, J. Feng, F. Yassin, A. Kepple, A. Sattar and C. Cafiero. forthcoming. The relevance of household food security for nutrition: an empirical analysis based on survey data. Technical Paper. Rome, FAO.

"Whenever possible, analyses were conducted controlling for age, sex, income/consumption expenditure/wealth status (depending on what data was available in the survey), dependency ratio/household size, and area of residence. Ethnicity was also controlled for in all the analyses with the Brazil, Mexico, Nepal and United States of America data sets. The following covariates were used for controlling in selected analyses: maternal/ caregiver education (stunting, wasting, child overweight, and overweight and obesity in school-age children and adolescents), own education (overweight and obesity in school-age children and adolescents and adult obesity), access to clean drinking water and access to basic sanitation facilities (stunting, wasting, anaemia), overweight mother (child overweight), and number of pregnancies (anaemia).

For a full description of the methodology and results, see: A. Ishaq, C. Alvarez-Sanchez, M. Del Grossi, S. Viviani, J. Feng, F. Yassin, A. Kepple, A. Sattar and C. Cafiero. forthcoming. The relevance of household food security for nutrition: an empirical analysis based on survey data. Technical Paper. Rome, FAO. 


\section{TABLE A2.5}

\section{INDEPENDENT VARIABLES}

\begin{tabular}{|c|c|}
\hline Variable & Description \\
\hline $\begin{array}{l}\text { Food insecurity } \\
\left(\mathrm{FI}_{(\text {modtsev })}\right)\end{array}$ & $\begin{array}{l}\text { Food insecurity (mod+sev) } \\
\text { being defined for this analysis as a probability equal to } 0.5 \text { or higher of a household } \\
\text { insecure at moderate or severe level. }\end{array}$ \\
\hline Age & $\begin{array}{l}\text { For children }<5 \text { years old, age was categorized into four groups: }(0,2),(2,3),(3,4) \text { and }(4,5) . \\
\text { For individuals } 5 \text { years old and older, age in years (as a continuous variable) was used. }\end{array}$ \\
\hline $\begin{array}{l}\text { Access to basic drinking } \\
\text { water services }\end{array}$ & $\begin{array}{l}\text { Basic drinking water services are defined by WHO/UNICEF Joint Monitoring Programme for Water Supply, } \\
\text { Sanitation and Hygiene (JMP) as drinking water from an improved source, provided collection time is not } \\
\text { more than } 30 \text { minutes for a round trip. Improved water sources include piped water, boreholes or tube } \\
\text { wells, protected dug wells, protected springs, and packaged or delivered water. }\end{array}$ \\
\hline $\begin{array}{l}\text { Access to basic } \\
\text { sanitation services }\end{array}$ & $\begin{array}{l}\text { Basic sanitation services are defined by WHO/UNICEF JMP as improved sanitation facilities that are not } \\
\text { shared with other households. Improved sanitation facilities include flush/pour flush to piped sewer systems, } \\
\text { septic tanks or pit latrines; as well as ventilated improved pit latrines, compositing toilets or pit latrines with } \\
\text { slabs. }\end{array}$ \\
\hline Area of residence & Area of residence is defined as urban or rural, as indicated in the survey. \\
\hline Dependency ratio & $\begin{array}{l}\text { Ratio of dependents (people younger than } 15 \text { or older than 64) to the working-age population (those aged } \\
\text { 15-64). }\end{array}$ \\
\hline $\begin{array}{l}\text { Education level } \\
\text { of individual }\end{array}$ & $\begin{array}{l}\text { Education of the individual was categorized in four levels: no education or primary not completed; primary } \\
\text { completed; secondary completed; tertiary completed. }\end{array}$ \\
\hline $\begin{array}{l}\text { Education level of } \\
\text { mother/guardian of } \\
\text { child ( } 5 \text { years old) }\end{array}$ & $\begin{array}{l}\text { Education of the mother/guardian was categorized in four levels: no education or primary not completed; } \\
\text { primary completed; secondary completed; tertiary completed. }\end{array}$ \\
\hline Ethnicity & $\begin{array}{l}\text { For the United States of America, ethnicity is defined as being White, Black, Hispanic, Asian, or other. For } \\
\text { Brazil, it is defined as skin colour being white, black/brown, or yellow/indigenous. For Mexico, it is defined } \\
\text { as speaking an indigenous language or not. For Nepal, it is defined as being Brahman, Terai, Dalit, Newar, } \\
\text { Janajati, or Muslim. }\end{array}$ \\
\hline Household size & Number of household members. \\
\hline Number of pregnancies & Number of times a woman has been pregnant. \\
\hline Overweight mother & $\begin{array}{l}\text { Maternal overweight is equal to one if the child has an overweight mother } \\
\text { (BMI } \geq 25 \text { ). }\end{array}$ \\
\hline Region & Regions (at which survey samples are still representative). \\
\hline Sex & Sex is defined as male or female. \\
\hline $\begin{array}{l}\text { Welfare measures: } \\
\text { income/expenditure/ } \\
\text { wealth (based on } \\
\text { survey availability) }\end{array}$ & $\begin{array}{l}\text { Depending on the data availability, the welfare measures can be income per capita per day in } 2011 \text { PPP } \\
\text { (Brazil and United States of America); consumption expenditure per capita per day in } 2011 \text { PPP (Kenya, } \\
\text { Nigeria and Pakistan); or wealth indices (Mexico and Nepal). }\end{array}$ \\
\hline
\end{tabular}

SOURCE: A. Ishaq, C. Alvarez-Sanchez, M. Del Grossi, S. Viviani, J. Feng, F. Yassin, A. Kepple, A. Sattar and C. Cafiero. forthcoming. The relevance of household food security for nutrition: an empirical analysis based on survey data. Technical Paper. Rome, FAO. 


\section{$\operatorname{MN}=\mathrm{X}_{3}$}

\section{POU CHANGE POINT DEFINITIONS, METHODOLOGY AND COUNTRY LISTS}

\section{A. Definition of economic slowdown and downturn}

Economic slowdowns and downturns have been identified using the real annual rate of per capita GDP growth at constant 2010 prices, expressed in US dollars. "The change in country per capita growth across two successive years is computed to obtain a simple difference in growth. Thus, a slowdown is identified when per capita growth in the current year is positive but lower in magnitude compared with the previous year. Downturns are defined when the difference in per capita growth between two periods is negative. Furthermore, information on the frequency of economic slowdowns and downturns is provided by the number of consecutive years when a country experienced either of the two.

\section{B. PoU change point analysis and methodology}

A change point refers to the statistically significant change in the prevalence of undernourishment over time. In this report the focus is on increasing change points, i.e. a statistically significant and positive increase in the prevalence of undernourishment over two consecutive years. Change points in the PoU time series were identified by applying the multiple structural changes model proposed by Bai and Perron (1998). ${ }^{12}$ This involves finding the "best" combination of $n$ possible breaks subject to the constraint that distance between break intervals should be above a minimum length. Here "best" means minimum sum of squared residuals from an OLS regression of PoU on a set of dummies indicating the timing of the breaks. A minimum break interval of three years was imposed in the identification of the optimal segmentation. PoU in years 2005-2018 was used to identify change points between years 2006-2017. An additional constraint has been used to identify the relevant change points, i.e. only those characterized by a subsequent increasing tendency (estimated by an ordinary least squares method) for two consecutive years.

The change point analysis consists in identifying increasing PoU change points that correspond to the occurrence of an economic slowdown or downturn in low- and middle-income countries. Economic slowdowns and downturns are identified when they occur in one of the two years before the PoU change point, for instance, between 2013-2014 or 2014-2015 if the PoU change point occurs in 2015. Figure 24 shows the number of countries with PoU change points in correspondence with economic slowdowns or downturns by year (2006-2017). Table A3.1 lists 96 increases in PoU change point occurred in 65 countries in correspondence with economic slowdowns and downturns between years 2011-2017.

In order to identify low- and middle-income countries, the 2017 World Bank classification is used. Although Argentina and Panama are classified as high income countries in 2017 (Table A3.1) they are included in the analysis since they have been classified as upper-middleincome countries for the majority of the time (at least five out of seven years during the period 2011-2017). 
TABLE A3.1

COUNTRIES WITH AN INCREASE IN POU CHANGE POINT CORRESPONDING TO ECONOMIC SLOWDOWNS OR DOWNTURNS, YEARS 2011-2017

\begin{tabular}{|c|c|c|c|}
\hline Year & Country & Region & Income group \\
\hline 2011 & Belarus & Europe & Upper-middle-income \\
\hline 2011 & Central African Republic & Africa & Low-income \\
\hline 2011 & Jordan & Asia & Upper-middle-income \\
\hline 2011 & Lebanon & Asia & Upper-middle-income \\
\hline 2011 & Liberia & Africa & Low-income \\
\hline 2011 & Thailand & Asia & Upper-middle-income \\
\hline 2012 & Brazil & Latin America and the Caribbean & Upper-middle-income \\
\hline 2012 & Ecuador & Latin America and the Caribbean & Upper-middle-income \\
\hline 2012 & Guinea-Bissau & Africa & Low-income \\
\hline 2012 & Malawi & Africa & Low-income \\
\hline 2012 & Zimbabwe & Africa & Low-income \\
\hline 2013 & Botswana & Africa & Upper-middle-income \\
\hline 2013 & Burkina Faso & Africa & Low-income \\
\hline 2013 & Mongolia & Asia & Lower-middle-income \\
\hline 2013 & Uganda & Africa & Low-income \\
\hline 2013 & Uzbekistan & Asia & Lower-middle-income \\
\hline 2014 & Burundi & Africa & Low-income \\
\hline 2014 & Central African Republic & Africa & Low-income \\
\hline 2014 & Eritrea & Africa & Low-income \\
\hline 2014 & Indonesia & Asia & Lower-middle-income \\
\hline 2014 & Kazakhstan & Asia & Upper-middle-income \\
\hline 2014 & Mauritania & Africa & Lower-middle-income \\
\hline 2014 & Panama & Latin America and the Caribbean & High-income \\
\hline 2014 & Turkey & Asia & Upper-middle-income \\
\hline 2014 & Ukraine & Europe & Lower-middle-income \\
\hline 2014 & Venezuela (Bolivarian Republic of) & Latin America and the Caribbean & Upper-middle-income \\
\hline 2014 & Yemen & Asia & Low-income \\
\hline 2015 & Argentina & Latin America and the Caribbean & High-income \\
\hline 2015 & Benin & Africa & Low-income \\
\hline 2015 & Bolivia (Plurinational State of) & Latin America and the Caribbean & Lower-middle-income \\
\hline 2015 & Cameroon & Africa & Lower-middle-income \\
\hline 2015 & China & Asia & Upper-middle-income \\
\hline 2015 & Congo & Africa & Lower-middle-income \\
\hline 2015 & Côte d'Ivoire & Africa & Lower-middle-income \\
\hline 2015 & Gabon & Africa & Upper-middle-income \\
\hline 2015 & Kenya & Africa & Lower-middle-income \\
\hline 2015 & Malaysia & Asia & Upper-middle-income \\
\hline 2015 & Mali & Africa & Low-income \\
\hline 2015 & Morocco & Africa & Lower-middle-income \\
\hline 2015 & Mozambique & Africa & Low-income \\
\hline 2015 & Niger & Africa & Low-income \\
\hline 2015 & Nigeria & Africa & Lower-middle-income \\
\hline 2015 & South Africa & Africa & Upper-middle-income \\
\hline 2015 & Togo & Africa & Low-income \\
\hline 2015 & Turkmenistan & Asia & Upper-middle-income \\
\hline 2015 & United Republic of Tanzania & Africa & Low-income \\
\hline 2015 & Zambia & Africa & Lower-middle-income \\
\hline 2015 & Zimbabwe & Africa & Low-income \\
\hline
\end{tabular}




\begin{tabular}{|c|c|c|c|}
\hline Year & Country & Region & Income group \\
\hline 2016 & Argentina & Latin America and the Caribbean & High-income \\
\hline 2016 & Armenia & Asia & Upper-middle-income \\
\hline 2016 & Cameroon & Africa & Lower-middle-income \\
\hline 2016 & Gabon & Africa & Upper-middle-income \\
\hline 2016 & Gambia & Africa & Low-income \\
\hline 2016 & Georgia & Asia & Lower-middle-income \\
\hline 2016 & Jordan & Asia & Upper-middle-income \\
\hline 2016 & Kazakhstan & Asia & Upper-middle-income \\
\hline 2016 & Kyrgyzstan & Asia & Lower-middle-income \\
\hline 2016 & Mali & Africa & Low-income \\
\hline 2016 & Mauritania & Africa & Lower-middle-income \\
\hline 2016 & Mauritius & Africa & Upper-middle-income \\
\hline 2016 & Mongolia & Asia & Lower-middle-income \\
\hline 2016 & Nicaragua & Latin America and the Caribbean & Lower-middle-income \\
\hline 2016 & Niger & Africa & Low-income \\
\hline 2016 & Nigeria & Africa & Lower-middle-income \\
\hline 2016 & Panama & Latin America and the Caribbean & High-income \\
\hline 2016 & Sao Tome and Principe & Africa & Lower-middle-income \\
\hline 2016 & Suriname & Latin America and the Caribbean & Upper-middle-income \\
\hline 2016 & Tajikistan & Asia & Low-income \\
\hline 2016 & Tonga & Oceania & Upper-middle-income \\
\hline 2016 & Turkey & Asia & Upper-middle-income \\
\hline 2016 & Turkmenistan & Asia & Upper-middle-income \\
\hline 2016 & Ukraine & Europe & Lower-middle-income \\
\hline 2016 & Vanuatu & Oceania & Lower-middle-income \\
\hline 2016 & Venezuela (Bolivarian Republic of) & Latin America and the Caribbean & Upper-middle-income \\
\hline 2017 & Armenia & Asia & Upper-middle-income \\
\hline 2017 & Cabo Verde & Africa & Lower-middle-income \\
\hline 2017 & Cameroon & Africa & Lower-middle-income \\
\hline 2017 & Costa Rica & Latin America and the Caribbean & Upper-middle-income \\
\hline 2017 & Egypt & Africa & Lower-middle-income \\
\hline 2017 & Gambia & Africa & Low-income \\
\hline 2017 & Guatemala & Latin America and the Caribbean & Upper-middle-income \\
\hline 2017 & Guinea & Africa & Low-income \\
\hline 2017 & Guyana & Latin America and the Caribbean & Upper-middle-income \\
\hline 2017 & Malaysia & Asia & Upper-middle-income \\
\hline 2017 & Mongolia & Asia & Lower-middle-income \\
\hline 2017 & Myanmar & Asia & Lower-middle-income \\
\hline 2017 & Nicaragua & Latin America and the Caribbean & Lower-middle income \\
\hline 2017 & Niger & Africa & Low-income \\
\hline 2017 & Nigeria & Africa & Lower-middle-income \\
\hline 2017 & Panama & Latin America and the Caribbean & High-income \\
\hline 2017 & Samoa & Oceania & Upper-middle-income \\
\hline 2017 & Sao Tome and Principe & Africa & Lower-middle-income \\
\hline 2017 & Suriname & Latin America and the Caribbean & Upper-middle-income \\
\hline 2017 & Tonga & Oceania & Upper-middle-income \\
\hline 2017 & Turkey & Asia & Upper-middle-income \\
\hline 2017 & Turkmenistan & Asia & Upper-middle-income \\
\hline
\end{tabular}

SOURCES: FAO for PoU; for economic slowdowns and downturns, UN. 2019. National Accounts - Analysis of Main Aggregates. In: UNSTATS [online]. New York, USA.

[Cited 6 May 2019]. https://unstats.un.org/unsd/snaama 


\section{List of countries outside the confidence interval in the analysis of $\mathrm{PoU}$ change and economic growth}

In Figure 25 the difference in PoU between 2011 and 2017 is plotted against economic growth between the same years. Economic growth is the percentage change in real GDP per capita (constant 2010 USD prices) between 2011 and 2017, with the GDP deflator used to deflate growth in per capita GDP. Economic growth is computed using real per capita GDP comparing two points in time, 2011 and 2017, as:

$$
\frac{\text { per capita } G D P_{2017}-\text { per capita } G D P_{2011}}{\text { per capita } G D P_{2011}} * 100
$$

Country names are only reported in the figure for countries falling outside the 95 percent confidence interval, indicating countries whose values are more dispersed around the mean, i.e. higher or lower than predicted by economic growth. Low-income countries falling inside the 95 percent confidence interval are Benin, Burkina Faso, Burundi, Gambia, Guinea, Haiti, Liberia, Nepal, Sierra Leone and Yemen. Lower-middle-income countries falling in the 95 percent confidence interval are Bangladesh, Bhutan, Cambodia, Cameroon, Côte d'Ivoire, Djibouti, Egypt, India, Indonesia, Kiribati, Kyrgyzstan, Lao People's Democratic Republic, Lesotho, Morocco, Myanmar, Pakistan, Syrian Arab Republic, Tunisia, Ukraine, Uzbekistan, Vanuatu and Viet Nam. Upper-middle-income countries falling in the 95 percent confidence interval are Albania, Armenia, Belarus, Belize, Bosnia and Herzegovina, Botswana, Bulgaria, China, Costa Rica, Cuba, Ecuador, Fiji, Gabon, Guatemala, Guyana, Iran (Islamic Republic of), Jordan, Kazakhstan, Lebanon, Malaysia, Maldives, Marshall Islands, Mexico, Montenegro, North Macedonia, Paraguay, Peru, Romania, Russian Federation, Saint Vincent and the Grenadines, Samoa, Serbia, South Africa, Thailand, Tonga and Tuvalu.

\section{List of countries outside the confidence interval in the extreme poverty analysis}

Figure 31 shows the correlation between extreme poverty and PoU (graph A) and extreme poverty and stunting (graph B). Country names are only reported for countries falling outside the 95 percent confidence interval, indicating countries whose values are more dispersed around the mean, i.e. higher or lower than predicted by extreme poverty.

In Figure 31 (graph A), countries falling inside the 95 percent confidence interval are: Albania, Algeria, Armenia, Bangladesh, Burkina Faso, Burundi, Costa Rica, Côte d'Ivoire, Democratic Republic of the Congo, Ecuador, Egypt, Ethiopia, Gambia, Georgia, Guinea, Guinea-Bissau, Honduras, India, Indonesia, Iran (Islamic Republic of), Lao People's Democratic Republic, Malaysia, Mauritania, Mozambique, Myanmar, Niger, Sierra Leone, Tajikistan, Tunisia and Ukraine.

In Figure 31 (graph B), countries falling inside the 95 percent confidence interval are: Albania, Benin, Cameroon, Chad, Democratic Republic of the Congo, El Salvador, Gambia, Guinea, Kazakhstan, Kyrgyzstan, Liberia, Madagascar, Malawi, Montenegro, Rwanda, Sierra Leone, Solomon Islands, South Africa, Tajikistan, Thailand, Turkey, Uganda, United Republic of Tanzania, Zambia and Zimbabwe.

\section{E. List of countries with imputed values for Pol}

The analyses include some countries with imputed PoU. PoU is imputed whenever official data on DEC and/or CV are missing for that country. When unofficial estimates of DEC and CV are available, these are used to derive an estimate of the PoU to be included in the aggregates. When no estimates of DEC or CV are available, the PoU is imputed to the population-weighted average of the estimated values of the remaining countries in the same region. In both cases, although the country estimates are not disseminated by FAO, they are used to compute regional and global numbers and for other analytical purposes.

List of countries with imputed PoU:

Figure 24: Burundi, Eritrea, Tajikistan, and Tonga.

Figure 25: Bhutan, Burundi, Comoros, Democratic Republic of the Congo, Equatorial Guinea, Eritrea, Grenada, Marshall Islands, Micronesia (Federated States of), Papua New Guinea, Republic of Moldova, Syrian Arab Republic, Tajikistan, Tonga, and Tuvalu.

Figure 31: Bhutan, Burundi, Comoros, Democratic Republic of the Congo, Micronesia (Federated States of), Republic of Moldova, Saint Lucia, Tajikistan, Tonga, and Tuvalu. 


\section{MNTFX 4}

\section{ECONOMIC GROWTH AND CHANGE IN POU BETWEEN 2011 AND 2017}

\section{A. Evidence of statistical correlation between economic downturns and PoU between the years 2011 and 2017: model specification and results}

To explore whether the recent observed increases in the prevalence of undernourishment (PoU) are statistically associated with economic slowdowns and downturns, an analysis was undertaken on the relationship between changes in PoU and economic growth between 2011 and 2017. No attempt was made to model the complex mechanism and the diverse pathways by which economic growth and hunger are linked. This would require modelling the complex relationships between economic, social, anthropometric and policy variables, and assessing the intricate feedback routes between them. Instead, the analysis focuses on a reduced form of this complex system and attempts to assess the correlation between hunger and economic performance - i.e. fast rates of growth, slowdowns and downturns. The results complement those of the PoU change point analysis (see Figure 24 and Annex 3) and provide evidence that the relationship between economic downturns and PoU between the years of 2011 and 2017 is more than one of simple corresponding occurrence. Only economic downturns are considered (not slowdowns) for the reasons explained below.
The relationship between changes in PoU and economic growth between 2011 and 2017 is analysed based on the approach of Headey (2013), ${ }^{13}$ focusing on low- and middle-income countries. The approach involves a series of Ordinary Least Squares (OLS) regression analyses (Table A4.2) showing the correlation between the difference in the PoU and real per capita GDP growth between 2011 and 2017.

The years selected for this analysis (2011 and 2017) correspond to the recent period in which there are notable observed increases in PoU. As highlighted in Part 1 of this report and the two previous editions of the report, the prevalence of undernourishment and the number of undernourished people in the world began to increase at the aggregate world level in 2016. However, for many countries, especially lowand lower-middle-income countries, as well as countries affected by conflict and adverse climate events, undernourishment had already been on the rise as early as 2011. For this reason, the starting year of the analysis is the earliest year in which a notable number of countries first began to experience a rise in hunger, i.e. 2011, and the aim is to determine whether there is a statistical correlation between the rise in PoU and economic growth during this period (2011 and 2017). ${ }^{14}$

However, for comparability and to test the robustness of the results, the same analysis was also carried out using the period between 2000 and 2006, as well as the longer period between 2000 and 2017. The results show consistency in that the estimated coefficient of economic growth is negative and statistically significant across all three periods and specifications, although the coefficient is higher in magnitude between years 2011 and 2017, as expected. As suggested by Hendry (1995), ${ }^{15}$ when analysing long time periods it is necessary to exclude years of 
structural breaks in the economy in order not to affect the average results. For this reason, when doing the additional robustness checks in analysing the two seven-year periods of 2000-2006 and 2011-2017, the years marked by high volatility related to the global food price crisis and global financial crisis are omitted, i.e. 2007-2010 (see Figure 22 and Box 10 on the global food crisis and the global financial crisis of this period).

The dependent variable of the analysis is specified as the change in PoU between the years 2011 and 2017. It is a continuous variable having negative and positive values. ${ }^{16}$ The PoU is a measure of chronic undernourishment, so by definition changes in PoU occur slowly over time. For this reason, rather than focusing on a year-on-year setting, this analysis measures difference in PoU at two points that are far enough apart to allow for a sufficient change over time.

By definition the PoU is computed and smoothed over time and there is limited year-on-year variation in estimated values. In fact, PoU annual point estimates are calculated as a three-year moving average (for instance, PoU in 2015 refers to the average PoU for 2014-2016, PoU in 2016 refers to the average for 2015-2017). ${ }^{17}$ Thus, there is a two-year overlap in the PoU year-on-year time series, if all years are considered. Instead, by comparing the change in PoU between 2011 and 2017, there is a sufficient time lapse to identify variations. Given this choice, the analysis is focused on economic downturns only, since three points in time are needed to also capture economic slowdowns. An alternative specification for sensitivity analysis was also tested in which only years 2011, 2013, 2015 and 2017 are included, so that there is only a one-year overlap in the time series. This yielded similar results to those reported below. ${ }^{18}$

The independent variable - economic growth is the percentage change in real GDP per capita (constant 2010 USD prices) between 2011 and 2017, with the GDP deflator used to deflate growth in per capita GDP. Economic growth is computed using real per capita GDP comparing two points in time, 2011 and 2017, as:

$$
\frac{\text { per capita } G D P_{2017}-\text { per capita } G D P_{2011}}{\text { per capita } G D P_{2011}} * 100
$$

Real per capita GDP are from the UNSTAT website. An indicator of influence of outliers (dfbetas) was computed to identify outlier countries. The following countries with dfbetas greater than 0.17 were excluded from the analysis: Angola, Libya, Nauru, Somalia and Timor-Leste. ${ }^{19}$

An additional sensitivity analysis was carried out using a logistic model with a dependent dummy variable equal to 1 for PoU increases between 2011 and 2017 and equal to zero otherwise. The results confirm the statistical significance of the relationship between increases in PoU and changes in real per capita GDP during the period analysed.

Tables A4.1 and A4.2 provide the descriptive statistics and econometric results, respectively.

Considering the changes in PoU between 2011 and 2017, there are number of countries that do not show an increase in PoU between the two periods. As shown by the descriptive statistics (Table A4.1), 38 percent of the low- and middle-income countries (49 out of 130 countries) show an increase in PoU between 2011 and 2017, whereas 63 percent of the countries (81 out of 130) do not show an increase in PoU between these two years.

\section{B. Evidence of statistical association between changes in PoU between 2011 and 2017 and other drivers behind recent rise in prevalence of undernutrition: model specification and results}

Additional regression analyses were run to explore the statistical association between changes in PoU between the years 2011 and 2017 (dependent variable) and the three main drivers 
of PoU: economic downturns (analysed in this report), as well as conflict and climate extremes (analysed in previous report editions, 2017 and 2018, respectively).

The specification of the dependent variable is the same as explained above. Three dummy variables are used as regressors to capture the effects of these three drivers:

Economic downturns: a dummy variable equal to one if a country experiences negative economic growth between the years 2011 and 2017. Economic growth is computed in the same way as explained above.

- Climate variability and extremes: a dummy variable equal to one for countries with part of national cereal production or yield variance explained by climate factors for the period 2011-2016, as analysed and defined in the 2018 edition of this report. ${ }^{20}$ Climate vulnerability is identified for countries whose national cereal production and yield variance are highly and statistically significantly associated with temperature, rainfall and vegetation growth.
A country's climate vulnerability is defined over the period 2011-2016 and does not change over this time.

- Conflict: a dummy variable equal to one if a country is affected by conflict during 2011-2017, as analysed and defined in the 2017 edition of this report. ${ }^{21}$ In addition to this, as SOFI 2017 analysed conflict only up until 2015 and more recent data are now available, this information is updated for the years 2016 and 2017 using the Uppsala Conflict Data Program (UCDP). In this analysis, countries affected by conflict are defined as low- and middle-income countries and territories that have experienced conflict for at least five consecutive years between 2011-2017, and that have suffered 500 or more battle deaths during this period. ${ }^{22}$

Table A4.3 below reports the econometric results. Furthermore, in order to see how changes in PoU during 2011 and 2017 vary by the level of a country's income, Tables A4.4a and A4.4b present the interaction between the three drivers and the three dummies denoting the level of a country's income (low; lower-middle; upper-middle). 


\section{TABLE A4.1}

\section{DESCRIPTIVE STATISTICS OF POU AND ECONOMIC GROWTH BETWEEN 2011 AND 2017}

\begin{tabular}{|c|c|c|c|c|c|}
\hline Variables & Observations & Mean & Std. Dev. & Min & Max \\
\hline \multicolumn{6}{|l|}{ PoU } \\
\hline $\begin{array}{l}\text { Change in PoU between year } 2011 \\
\text { and } 2017\end{array}$ & 130 & 0.41 & 4.91 & -10.52 & 27.48 \\
\hline $\begin{array}{l}\text { Countries with increase in PoU between } \\
\text { years } 2011 \text { and } 2017\end{array}$ & 130 & 0.38 & 0.49 & 0 & 1 \\
\hline \multicolumn{6}{|l|}{ Economic growth } \\
\hline $\begin{array}{l}\text { Economic growth between } 2011 \text { and } 2017 \\
\text { (GDP deflator, } 2010 \text { constant prices) }\end{array}$ & 130 & 12.34 & 17.88 & -54.64 & 49.95 \\
\hline \multicolumn{6}{|l|}{ Conflict and climate vulnerability } \\
\hline Countries affected by conflict, $2011-2017$ & 130 & 0.17 & 0.38 & 0 & 1 \\
\hline $\begin{array}{l}\text { Countries with vulnerability to climate } \\
\text { extremes, } 2011-2016\end{array}$ & 120 & 0.35 & 0.48 & 0 & 1 \\
\hline \multicolumn{6}{|l|}{ Commodity dependence } \\
\hline $\begin{array}{l}\text { Low commodity-export- and } \\
\text { low commodity-import-dependent }\end{array}$ & 129 & 0.25 & 0.43 & 0 & 1 \\
\hline $\begin{array}{l}\text { Low commodity-export- and } \\
\text { high commodity-import-dependent }\end{array}$ & 129 & 0.19 & 0.40 & 0 & 1 \\
\hline $\begin{array}{l}\text { High commodity-export- and } \\
\text { low commodity-import-dependent }\end{array}$ & 129 & 0.25 & 0.43 & 0 & 1 \\
\hline $\begin{array}{l}\text { High commodity-export- and } \\
\text { high commodity-import-dependent }\end{array}$ & 129 & 0.31 & 0.46 & 0 & 1 \\
\hline \multicolumn{6}{|l|}{ Country income } \\
\hline Low-income countries & 130 & 0.25 & 0.44 & 0 & 1 \\
\hline Lower-middle-income countries & 130 & 0.34 & 0.48 & 0 & 1 \\
\hline Upper-middle-income countries & 130 & 0.41 & 0.49 & 0 & 1 \\
\hline
\end{tabular}

NOTES: Information on vulnerability to climate was not available for the following countries: Grenada, Maldives, Marshall Islands, Mauritius, Micronesia (Federated States of), Saint Lucia, Saint Vincent and the Grenadines, Sao Tome and Principe, Tonga, and Tuvalu. Information on commodity dependence is not available for South Sudan.

SOURCES: FAO elaboration based on FAO data for PoU and CPI inflation; on the National Accounts Main Aggregates Database, United Nations Statistics Division for economic growth; on FAO, IFAD, UNICEF, WFP and WH0. 2017. The State of Food Security and Nutrition in the World 2017. Building resilience for peace and food security. Rome, FAO and FAO, IFAD, UNICEF, WFP and WH0. 2018. The State of Food Security and Nutrition in the World 2018. Building climate resilience for food security and nutrition. Rome, FAO for countries affected by conflict and by climate vulnerability, respectively; on UNCTAD data for commodity dependence; on World Bank classification for the Gini index and the level of a country's income. 


\section{TABLE A4.2}

\section{REGRESSION OF THE CHANGE IN POU AND ECONOMIC GROWTH BETWEEN 2011 AND 2017}

\begin{tabular}{|c|c|c|c|c|c|c|c|c|}
\hline \multirow{2}{*}{$\begin{array}{l}\text { Variables } \\
\text { Economic growth between } \\
2011 \text { and } 2017 \\
\text { (GDP deflator) }\end{array}$} & \multicolumn{8}{|c|}{ PoU change } \\
\hline & $-0.152^{* * *}$ & $-0.159^{* * *}$ & $-0.141^{* * *}$ & $-0.155^{* * *}$ & $-0.151^{* * *}$ & $-0.150^{* * *}$ & $-0.149^{* * *}$ & $-0.149^{* * *}$ \\
\hline & $(-0.029)$ & $(-0.030)$ & $(-0.030)$ & $(-0.030)$ & $(-0.030)$ & $(-0.029)$ & $(-0.029)$ & $(-0.029)$ \\
\hline \multicolumn{9}{|l|}{ Country typology } \\
\hline \multicolumn{9}{|l|}{ I. Region } \\
\hline \multirow[t]{2}{*}{$\begin{array}{l}\text { Africa vs. Latin America } \\
\text { and the Caribbean } \\
\text { (reference category) }\end{array}$} & & 1.336 & & & & & & \\
\hline & & $(1.138)$ & & & & & & \\
\hline \multirow[t]{2}{*}{$\begin{array}{l}\text { Asia vs. Latin America } \\
\text { and the Caribbean } \\
\text { (reference category) }\end{array}$} & & $1.780^{*}$ & & & & & & \\
\hline & & $(0.954)$ & & & & & & \\
\hline \multirow[t]{2}{*}{$\begin{array}{l}\text { Oceania/Eastern Europe } \\
\text { vs. Latin America and } \\
\text { the Caribbean } \\
\text { (reference category) }\end{array}$} & & -0.04 & & & & & & \\
\hline & & $(0.898)$ & & & & & & \\
\hline \multicolumn{9}{|l|}{ II. Country income } \\
\hline \multirow[t]{2}{*}{$\begin{array}{l}\text { Lower-middle-income } \\
\text { vs. low-income countries } \\
\text { (reference category) }\end{array}$} & & & $-2.664^{* * *}$ & & & & & \\
\hline & & & $(1.016)$ & & & & & \\
\hline \multirow[t]{2}{*}{$\begin{array}{l}\text { Upper-middle-income } \\
\text { vs. low-income countries } \\
\text { (reference category) }\end{array}$} & & & $-2.114^{* *}$ & & & & & \\
\hline & & & $(1.065)$ & & & & & \\
\hline
\end{tabular}

\section{Commodity dependence}

Low commodity-export- and high commodity-import- vs.

low commodity-export- and low commodity-import-

dependent countries

(reference category)

High commodity-export- and low commodity-import- vs. low commodity-export- and low commodity-import-dependent countries (reference category)

High commodity-export- and high commodity-import- vs. low commodity-export- and low commodity-import-

dependent countries

(reference category) 
TABLE A4.2

(CONTINUED)

\begin{tabular}{|c|c|c|c|c|c|c|c|c|}
\hline Variables & \multicolumn{8}{|c|}{ PoU change } \\
\hline \multirow[t]{2}{*}{$\begin{array}{l}\text { Low-income food-deficit } \\
\text { countries }\end{array}$} & & \multicolumn{7}{|c|}{$1.867^{* * *}$} \\
\hline & & \multicolumn{7}{|c|}{$(0.784)$} \\
\hline \multirow[t]{2}{*}{$\begin{array}{l}\text { High commodity-export- } \\
\text { dependent countries }\end{array}$} & & & & \multicolumn{5}{|c|}{0.758} \\
\hline & & & & \multicolumn{5}{|c|}{$(0.648)$} \\
\hline \multirow[t]{2}{*}{$\begin{array}{l}\text { High commodity-import- } \\
\text { dependent countries }\end{array}$} & & & & & & \multicolumn{3}{|c|}{$1.170^{*}$} \\
\hline & & & & & & \multicolumn{3}{|c|}{$(0.700)$} \\
\hline \multirow[t]{2}{*}{ Net food importers } & & & & & & & & $1.650^{* *}$ \\
\hline & & & & & & & & $(0.669)$ \\
\hline \multirow[t]{2}{*}{ Constant } & $2.293^{* * *}$ & 1.387 & $3.913^{* * *}$ & $1.689^{* * *}$ & $1.540^{* * *}$ & $1.841^{* * *}$ & $1.662^{* *}$ & 1.086 \\
\hline & $(0.634)$ & $(0.924)$ & $(1.109)$ & $(0.662)$ & $(0.557)$ & $(0.586)$ & $(0.713)$ & $(0.695)$ \\
\hline Observations & 130 & 130 & 130 & 130 & 130 & 130 & 130 & 130 \\
\hline R-squared & 0.309 & 0.331 & 0.353 & 0.339 & 0.343 & 0.314 & 0.323 & 0.332 \\
\hline
\end{tabular}

NOTES: Statistical significance is reported for p-value $<0.01\left(^{* * *}\right)$, p-value $<0.05\left(^{* *}\right)$ and p-value $<0.1\left(^{*}\right)$. Standard errors are in parenthesis.

SOURCES: FAO elaboration based on FAO data for PoU; on the National Accounts Main Aggregates Database, United Nations Statistics Division for economic growth;

on UNCTAD data for commodity dependence; on World Bank classification for a country's income.

\section{TABLE A4.3}

\section{REGRESSION OF THE CHANGE IN PoU BETWEEN 2011 AND 2017 AND THE THREE DRIVERS OF PoU INCREASE}

\section{Variables}

Economic downturns (negative economic growth between 2011 and 2017)

\begin{tabular}{lcccc}
\hline & $(1.718)$ & & & $(1.580)$ \\
\hline Countries with vulnerability to climate extremes, 2011-2016 & & $2.436^{* *}$ & & $2.346^{* *}$ \\
\hline Countries affected by conflict, 2011-2017 & & $(1.085)$ & $(0.924)$ \\
\hline & & & $2.939^{*}$ & $2.248^{*}$ \\
\hline Constant & & & $(1.638)$ & $(1.347)$ \\
\hline & -0.379 & -0.451 & -0.0855 & $-1.640^{* * *}$ \\
\hline Observations & $(0.360)$ & $(0.393)$ & $(0.389)$ & $(0.484)$ \\
\hline R-squared & 130 & 120 & 130 & 120 \\
\hline
\end{tabular}

NOTES: Statistical significance is reported for p-value $<0.01\left(^{* * *}\right)$, p-value $<0.05\left(^{* *}\right)$ and p-value $<0.1\left(^{*}\right)$. Standard errors are in parenthesis.

SOURCES: FAO elaboration based on FAO data for PoU; on the National Accounts Main Aggregates Database, United Nations Statistics Division for economic slowdowns and downturns; on FAO, IFAD, UNICEF, WFP and WHO. 2017. The State of Food Security and Nutrition in the World 2017. Building resilience for peace and food security. Rome, FAO and FAO, IFAD, UNICEF, WFP and WHO. 2018. The State of Food Security and Nutrition in the World 2018. Building climate resilience for food security and nutrition. Rome, FAO for countries affected by conflict and by climate vulnerability, respectively. 
TABLE A4.4a

ESTIMATED COEFFICIENTS OF THE REGRESSIONS BETWEEN THE CHANGE IN POU (BETWEEN 2011 AND 2017) AND THE THREE DRIVERS OF POU - DRIVERS REGRESSED SEPARATELY FOR EACH INCOME GROUP

\begin{tabular}{|c|c|c|c|c|}
\hline & & (1) & (2) & (3) \\
\hline & & $\begin{array}{l}\text { Economic } \\
\text { downturns }\end{array}$ & $\begin{array}{c}\text { Climate } \\
\text { vulnerability }\end{array}$ & Conflict \\
\hline \multirow{2}{*}{ 1) } & \multirow{2}{*}{ Low-income } & $6.411^{*}$ & $5.427^{* *}$ & $8.126^{* *}$ \\
\hline & & $(3.783)$ & $(2.243)$ & (3.187) \\
\hline \multirow{2}{*}{ 2) } & \multirow{2}{*}{ Lower-middle-income } & 1.274 & 0.421 & 1.135 \\
\hline & & $(1.111)$ & $(0.792)$ & $(1.464)$ \\
\hline \multirow{2}{*}{ 3) } & \multirow{2}{*}{ Upper-middle-income } & $5.630^{* *}$ & 0.145 & -1.557 \\
\hline & & $(2.168)$ & $(1.506)$ & $(1.306)$ \\
\hline
\end{tabular}

\section{TABLE A4.4b}

\section{ESTIMATED COEFFICIENTS OF THE REGRESSIONS BETWEEN THE CHANGE IN POU (BETWEEN 2011 AND 2017)} AND THE THREE DRIVERS OF POU - DRIVERS REGRESSED TOGETHER FOR EACH INCOME GROUP

\begin{tabular}{|c|c|c|c|c|}
\hline & & (1) & (2) & (3) \\
\hline & & $\begin{array}{l}\text { Economic } \\
\text { downturns }\end{array}$ & $\begin{array}{c}\text { Climate } \\
\text { vulnerability }\end{array}$ & Conflict \\
\hline \multirow{2}{*}{ 1) } & \multirow{2}{*}{ Low-income } & $4.451^{*}$ & $4.887^{* *}$ & $5.531^{* * *}$ \\
\hline & & $(2.592)$ & (1.939) & (2.073) \\
\hline \multirow{2}{*}{ 2) } & \multirow{2}{*}{ Lower-middle-income } & 1.074 & 0.674 & 0.850 \\
\hline & & $(1.582)$ & $(0.827)$ & $(1.565)$ \\
\hline \multirow{2}{*}{ 3) } & \multirow{2}{*}{ Upper-middle-income } & $6.296^{* * *}$ & -0.694 & 0.0191 \\
\hline & & $(2.133)$ & $(1.145)$ & $(1.263)$ \\
\hline
\end{tabular}

NOTES: The tables report only key estimated coefficients of interest, i.e. the PoU change for countries that experience a given shock (downturn, climate or conflict) in a given income group (low, lower-middle or upper-middle), compared with the PoU change for countries in the same income group that do not experience that specific shock (reference category). Table A4.4a reports the estimated coefficient from nine different model specifications, where each driver is regressed separately for each income group. The estimated coefficients that are included but not reported in each model specification include: two dummies for the level of country income, a dummy for each driver of PoU change (either economic downturns, climate vulnerability or conflict), and two interaction terms between the driver of interest and each of the two dummies denoting the level of country income. Estimated coefficients in Table A4.4b derive from three model specifications that show the association between the PoU change and the three drivers regressed together for low-income countries (row 1), for lower-middle-income countries (row 2) and for upper-middle-income countries (row 3). Robust standard errors are in parentheses. Statistical significance is reported for p-value $<0.01\left(^{* * *}\right)$, p-value $<0.05\left(^{* *}\right)$ and p-value $<0.1\left(^{*}\right)$.

SOURCES: FAO elaboration based on FAO data for PoU; on the National Accounts Main Aggregates Database, United Nations Statistics Division for economic slowdowns and downturns; on FAO, IFAD, UNICEF, WFP and WH0. 2017. The State of Food Security and Nutrition in the World 2017. Building resilience for peace and food security. Rome, FA0 and FAO, IFAD, UNICEF, WFP and WHO. 2018. The State of Food Security and Nutrition in the World 2018. Building climate resilience for food security and nutrition. Rome, FAO for countries affected by conflict and by climate vulnerability, respectively; on World Bank classification for the level of a country's income. 


\section{ANTEX 5}

\section{THE MAIN DRIVERS OF CRISIS-LEVEL ACUTE FOOD INSECURITY IN 2018}

Table A5.1 is an extended version of Table 8, which reports information on 33 countries affected by food crises in 2018 in correspondence with significant economic shocks as analysed in the Global Report on Food Crises 2019.

\section{TABLE A5.1}

\section{COUNTRIES AND TERRITORIES WITH FOOD CRISES IN CORRESPONDENCE WITH ECONOMIC SHOCKS, 2018}

\begin{tabular}{|c|c|c|c|c|c|c|c|c|c|}
\hline \multirow[b]{2}{*}{$\begin{array}{l}z \\
\text { 이⿺ } \\
\text { w } \\
\text { d }\end{array}$} & \multirow[b]{2}{*}{ COUNTRY } & \multicolumn{3}{|c|}{$\begin{array}{c}\text { DRIVERS OF } \\
\text { FOOD CRISES } \\
\text { (main driver in orange) } \\
\end{array}$} & \multicolumn{3}{|l|}{ ECONOMIC SHOCKS } & \multicolumn{2}{|c|}{$\begin{array}{l}\text { NUMBER (millions) } \\
\text { PEOPLE IN IPC/CH } \\
\text { PHASE } 3 \text { AND } 4 \\
\end{array}$} \\
\hline & & 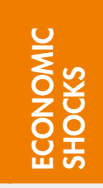 & 흘 & 宸 & DESCRIPIION & $\begin{array}{l}z \\
z \\
z \\
z \\
z \\
z\end{array}$ & $\begin{array}{l}z \\
0 \\
0 \\
0 \\
0 \\
0\end{array}$ & 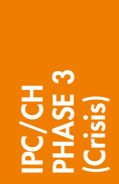 & 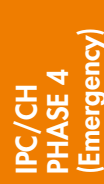 \\
\hline \multirow{11}{*}{$\frac{\overleftarrow{s}}{\frac{\mathbb{u}}{<}}$} & Burundi & - & $\bullet$ & • & $\begin{array}{l}\text { Economic downturn (consequent to } \\
\text { the } 2015 \text { political crisis); } \\
\text { food-import dependence. }\end{array}$ & - & & 1.7 & n.a. \\
\hline & Cameroon & $\bullet$ & - & $\bullet$ & $\begin{array}{l}\text { High food prices; low livestock } \\
\text { prices; low purchasing power } \\
\text { especially for pastoralists. }\end{array}$ & & $\bullet$ & 0.5 & 0 \\
\hline & $\begin{array}{l}\text { Central African } \\
\text { Republic }\end{array}$ & - & $\cdot$ & & High food prices. & & $\bullet$ & 1.4 & 0.5 \\
\hline & Chad & - & $\cdot$ & - & $\begin{array}{l}\text { Decreased wages; low purchasing } \\
\text { power; low livestock prices. }\end{array}$ & - & & 1 & 0 \\
\hline & $\begin{array}{l}\text { Democratic Republic } \\
\text { of the Congo }\end{array}$ & - & - & - & $\begin{array}{l}\text { Decreased wages; high food prices; } \\
\text { export restriction from Zambia. }\end{array}$ & $\cdot$ & & 9.7 & 3.4 \\
\hline & Diibouti & $\bullet$ & $\bullet$ & $\cdot$ & High food prices. & & $\cdot$ & 0.15 & n.a. \\
\hline & Eswatini & - & & • & $\begin{array}{l}\text { Unemployment; sluggish economic } \\
\text { growth. }\end{array}$ & & & 0.1 & 0.1 \\
\hline & Kenya & $\bullet$ & $\bullet$ & $\cdot$ & High food prices; income inequality. & & $\cdot$ & 2.6 & n.a. \\
\hline & Madagascar & $\bullet$ & & $\cdot$ & $\begin{array}{l}\text { High food and fuel prices; } \\
\text { low purchasing power. }\end{array}$ & - & & 1.1 & 0.4 \\
\hline & Malawi & - & & - & $\begin{array}{l}\text { High food prices; low wages and } \\
\text { labour opportunities. }\end{array}$ & $\bullet$ & & 2.9 & 0.4 \\
\hline & Mozambique & - & & - & High food prices. & & - & 1.4 & 0.4 \\
\hline
\end{tabular}




\begin{tabular}{|c|c|c|c|c|c|c|c|c|c|}
\hline \multirow[b]{2}{*}{$\frac{z}{\text { zo }}$} & \multirow[b]{2}{*}{ COUNTRY } & \multicolumn{3}{|c|}{$\begin{array}{l}\text { DRIVERS OF } \\
\text { FOOD CRISES } \\
\text { (main driver in orange) }\end{array}$} & \multicolumn{3}{|l|}{ ECONOMIC SHOCKS } & \multicolumn{2}{|c|}{$\begin{array}{l}\text { NUMBER (millions) } \\
\text { PEOPLE IN IPC/CH } \\
\text { PHASE } 3 \text { AND } 4\end{array}$} \\
\hline & & $\begin{array}{l}\text { U } \\
\text { on } \\
\text { 웡 } \\
\text { 8웄 }\end{array}$ & $\begin{array}{l}\text { 늘 } \\
\text { 는 } \\
\text { 8 }\end{array}$ & 宸 & DESCRIPTION & 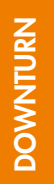 & $\begin{array}{l}z \\
8 \\
8 \\
8 \\
0 \\
5\end{array}$ & 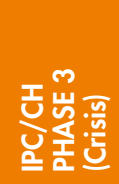 & 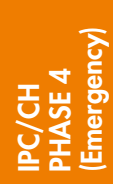 \\
\hline \multirow{7}{*}{$\frac{\mathbb{J}}{\frac{\mathbb{4}}{4}}$} & Niger & $\bullet$ & $\bullet$ & $\bullet$ & $\begin{array}{l}\text { Low livestock prices; low purchasing } \\
\text { power especially for pastoralists. }\end{array}$ & & $\bullet$ & 0.8 & 0 \\
\hline & Nigeria & $\bullet$ & - & $\bullet$ & $\begin{array}{l}\text { High food prices; low purchasing } \\
\text { power. }\end{array}$ & $\bullet$ & & 5.1 & 0.2 \\
\hline & South Sudan & $\bullet$ & - & $\bullet$ & $\begin{array}{l}\text { Hyperinflation; currency } \\
\text { depreciation. }\end{array}$ & $\bullet$ & & 4.4 & 1.7 \\
\hline & Sudan & $\bullet$ & $\bullet$ & $\bullet$ & $\begin{array}{l}\text { Downturn; currency depreciation; } \\
\text { high inflation; lack of income- } \\
\text { earning opportunities. }\end{array}$ & & $\bullet$ & 5.6 & 0.6 \\
\hline & Uganda & $\bullet$ & $\cdot$ & $\bullet$ & High food prices. & $\bullet$ & & 1.1 & n.a. \\
\hline & Zambia & $\bullet$ & & $\bullet$ & $\begin{array}{l}\text { High food prices; currency } \\
\text { depreciation. }\end{array}$ & & $\bullet$ & 0.9 & 0.3 \\
\hline & Zimbabwe & - & & $\bullet$ & $\begin{array}{l}\text { Currency depreciation; high food } \\
\text { prices; lack of labour opportunities. }\end{array}$ & $\bullet$ & & 1.9 & n.a. \\
\hline \multirow{10}{*}{ క̀ } & Afghanistan & $\bullet$ & $\cdot$ & $\bullet$ & Unemployment. & $\bullet$ & & 7.7 & 2.9 \\
\hline & Iraq & $\bullet$ & $\bullet$ & & $\begin{array}{l}\text { Low purchasing power; limited } \\
\text { economic opportunities. }\end{array}$ & - & & 2.5 & n.a. \\
\hline & Jordan & $\bullet$ & - & & High food prices. & & & 0.1 & n.a. \\
\hline & Lebanon & $\bullet$ & $\cdot$ & & High food prices. & & & 0.5 & n.a. \\
\hline & Myanmar & $\bullet$ & $\cdot$ & $\bullet$ & High food prices. & & $\bullet$ & 0.8 & n.a. \\
\hline & Pakistan & $\bullet$ & & $\cdot$ & Decreased wages; high food prices. & & & 2 & n.a. \\
\hline & Palestine & $\bullet$ & $\bullet$ & & $\begin{array}{l}\text { Low purchasing power; } \\
\text { unemployment. }\end{array}$ & & $\bullet$ & 1.7 & n.a. \\
\hline & $\begin{array}{l}\text { Syrian Arab } \\
\text { Republic }\end{array}$ & $\bullet$ & $\bullet$ & $\bullet$ & $\begin{array}{l}\text { Unemployment; low purchasing } \\
\text { power; high commodity prices. }\end{array}$ & & & 6.5 & n.a. \\
\hline & Turkey & $\bullet$ & $\cdot$ & & High food prices; weak currency. & $\bullet$ & & 0.2 & n.a. \\
\hline & Yemen & $\bullet$ & - & $\bullet$ & $\begin{array}{l}\text { Downturn; currency depreciation; } \\
\text { food import dependence; high food } \\
\text { prices; limited job opportunities. }\end{array}$ & $\bullet$ & & 10.9 & 5 \\
\hline
\end{tabular}

Ukraine $\quad$ L L L L $\quad$ Low purchasing power; high food prices; unemployment.

\begin{tabular}{|c|c|c|c|c|c|c|c|}
\hline \multirow{3}{*}{ 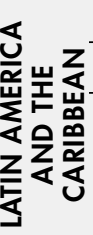 } & El Salvador & $\bullet$ & $\cdot$ & High food prices. & $\bullet$ & 0.2 & 0 \\
\hline & Guatemala & $\bullet$ & - & High food prices. & - & 0.6 & 0.2 \\
\hline & Haiti & $\bullet$ & $\bullet$ & $\begin{array}{l}\text { Low purchasing power; high prices } \\
\text { of food import commodities (maize } \\
\text { vegetable oil); low demand for } \\
\text { agricultural labour. }\end{array}$ & $\bullet$ & 1.9 & 0.4 \\
\hline & \multirow[t]{2}{*}{ Honduras } & - & $\cdot$ & High food prices. & - & 0.4 & 0.1 \\
\hline & & & & & & 79.5 & 16.6 \\
\hline
\end{tabular}

NOTES: Countries affected by food crises in 2018 where economic shocks are a driver of acute food insecurity as identified by the Global Report on Food (rises 2019 (GRFC). Information on economic shocks as drivers of food crises was not available in the GRFC 2019 for Jordan, Lebanon, Myanmar and Turkey. For these countries the information is obtained from the FAO Global Information and Early Warning System (GIEWS) Country briefs referring to the year 2018. Economic slowdowns and downturns are identified when they either occur in years 2015-2016 or 2016-2017 and are computed using the annual rate of per capita growth at constant prices.

SOURCE: FAO elaboration based on FSIN. 2019. Global Report on Food Crises 2019 [online]. [Cited 24 April 2019]. http://www.fsinplatform.org/sites/default/files/resources/files/ GRFC_2019-Full_Report.pdf and for economic slowdowns and downturns, UN. 2019. National Accounts - Analysis of Main Aggregates. In: UNSTATS [online]. New York, USA. [Cited 6 May 2019]. https://unstats.un.org/unsd/snaama and for additional information on economic shocks, FAO. 2019. GIEWS - Global Information and Early Warning System. In: FAO [online]. Rome. [Cited 19 June 2019]. http://www.fao.org/giews/en 


\section{ANNAX 6}

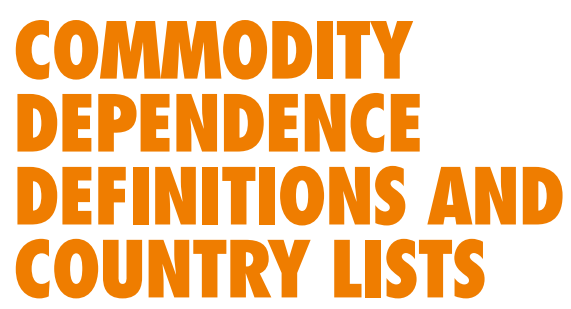

\section{A. Definition of commodity dependence}

Commodity dependence is identified by applying the criterion proposed by UNCTAD and FAO (2017) ${ }^{23}$ and Nkurunziza, Tsowou and Cazzaniga (2017). ${ }^{24}$ A country is considered a commodity-dependent country when it experiences a dependence on primary commodity export revenues, a dependence on primary commodity imports, or both. In particular, commodity-export dependence is defined as the ratio of exports of primary commodities (agricultural products; minerals; ores and metals; and oil) to total merchandise exports in monetary terms. These export primary commodities are classified according to the Standard International Trade Classification (SITC), that is, i.e. SITC 0 $+1+2+3+4+68+667+971$. When a country's export-dependence ratio is higher than the average, which is 0.60 for the sample of low- and middle-income countries during years 1995-2017, a country is considered as high commodity-export dependent.

Commodity-import dependence is defined as the ratio of imports of food (SITC $0+1+22+4$ ) and fuels (SITC 3) to total merchandise imports in monetary terms. When a country has a share of imports higher than the average, which is 0.30 for low- and middle-income countries, it is defined as a high commodity-import dependent country.

The data used to compute commodity dependence ratios are taken from UNCTADstat which provides yearly information on exports and imports by product in thousands of USD. ${ }^{25}$ The analysis in Part 2 of the report is undertaken on low- and middle-income countries as overall they report higher levels of food insecurity and malnutrition. The analysis focuses on 129 lowand middle-income countries for which data on commodity dependence and PoU are available across the years of analysis. The period of commodity price booms reported in Table 9 refers to years 2003-2011 (excluding years 2008-2009 of declining price trends).

\section{A1. A typology of primary commodity dependence: definition and list of countries \\ Following the classification proposed by UNCTAD and FAO (2017), ${ }^{26}$ Table A6.1 classifies countries in four groups according to their commodity-export and commodity-import dependence ratios as measured during years 1995-2017.}

Table A6.2 shows the list of countries in the four groups following the criteria reported in Table A6.l. In each of these groups countries are listed according to the level of country's income, as established by the World Bank classification. ${ }^{27}$

\section{A2. Net food importers}

According to the UNCTAD definition, countries are defined as net food-importing when they have a negative average food trade balance in the years from 2013 to 2015. Food refers to the category "food, basic excluding tea, coffee, cocoa and spices" corresponding to SITC $0+22+4$ less 07. 
Low commodity-dependent countries:

Commodity-export dependence $\leq 0.60$

Commodity-import dependence $\leq 0.30$
High commodity-import- and

low commodity-export-dependent countries:

Commodity-export dependence $\leq 0.60$

Commodity-import dependence $>0.30$
Low commodity-import- and

high commodity-export-dependent countries:

Commodity-export dependence $>0.60$

Commodity-import dependence $\leq 0.30$
High commodity-import- and

high commodity-export-dependent countries:

Commodity-export dependence $>0.60$

Commodity-import dependence $>0.30$

SOURCE: FAO elaboration based on UNCTAD data on commodity dependence.

COUNTRIES AND TERRITORIES BY TYPOLOGY OF PRIMARY COMMODITY DEPENDENCE (1995-2017)

\begin{tabular}{|c|c|c|c|}
\hline $\begin{array}{c}\text { A. Low commodity-dependent } \\
\text { (low import and low export) } \\
\text { countries } \\
\text { (LOW CD }=32 \text { ) }\end{array}$ & $\begin{array}{l}\text { B. High commodity-import- } \\
\text { and low commodity-export- } \\
\text { dependent countries } \\
\text { (HI-LE = 25) }\end{array}$ & $\begin{array}{l}\text { C. High commodity-export- } \\
\text { and low commodity-import- } \\
\text { dependent countries } \\
\text { (HE-LI = 34) }\end{array}$ & $\begin{array}{l}\text { D. High commodity-dependent } \\
\text { (high import and high export) } \\
\text { countries } \\
\text { (HE-HI = 43) }\end{array}$ \\
\hline $\begin{array}{l}\text { Low-income } \\
\text { Liberia } \\
\text { Lower-middle-income } \\
\text { Bangladesh } \\
\text { Bhutan } \\
\text { Cambodia } \\
\text { Diibouti } \\
\text { Egypt } \\
\text { El Salvador } \\
\text { Honduras } \\
\text { India } \\
\text { Indonesia } \\
\text { Lesotho } \\
\text { Philippines } \\
\text { Sri Lanka } \\
\text { Tunisia } \\
\text { Vanuatu } \\
\text { Viet Nam } \\
\text { Upper-middle-income } \\
\text { Brazil } \\
\text { Bulgaria } \\
\text { China } \\
\text { Costa Rica } \\
\text { Dominican Republic } \\
\text { Guatemala } \\
\text { North Macedonia } \\
\text { Malaysia } \\
\text { Marshall Islands } \\
\text { Mexico } \\
\text { Romania } \\
\text { Serbia } \\
\text { South Africa } \\
\text { Thailand } \\
\text { Turkey } \\
\text { Tuvalu }\end{array}$ & $\begin{array}{l}\text { Low-income } \\
\text { Comoros } \\
\text { Democratic People's Republic } \\
\text { of Korea } \\
\text { Haiti } \\
\text { Madagascar } \\
\text { Nepal } \\
\text { Lower-middle-income } \\
\text { Cabo Verde } \\
\text { Eswatini } \\
\text { Georgia } \\
\text { Lao People's Democratic } \\
\text { Republic } \\
\text { Morocco } \\
\text { Nicaragua } \\
\text { Pakistan } \\
\text { Republic of Moldova } \\
\text { Ukraine } \\
\text { West Bank and Gaza } \\
\text { Upper-middle-income } \\
\text { Albania } \\
\text { Belarus } \\
\text { Bosnia and Herzegovina } \\
\text { Dominica } \\
\text { Grenada } \\
\text { Jordan } \\
\text { Lebanon } \\
\text { Mauritius } \\
\text { Saint Vincent and } \\
\text { the Grenadines } \\
\text { Samoa }\end{array}$ & $\begin{array}{l}\text { Low-income } \\
\text { Burundi } \\
\text { Chad } \\
\text { Ethiopia } \\
\text { Malawi } \\
\text { Rwanda } \\
\text { Uganda } \\
\text { United Republic of Tanzania } \\
\text { Zimbabwe } \\
\text { Lower-middle-income } \\
\text { Angola } \\
\text { Bolivia (Plurinational State of) } \\
\text { Democratic Republic } \\
\text { of the Congo } \\
\text { Ghana } \\
\text { Kenya } \\
\text { Myanmar } \\
\text { Nigeria } \\
\text { Sudan } \\
\text { Uzbekistan } \\
\text { Zambia } \\
\text { Upper-middle-income } \\
\text { Algeria } \\
\text { Azerbaijan } \\
\text { Botswana } \\
\text { Colombia } \\
\text { Ecuador } \\
\text { Equatorial Guinea } \\
\text { Gabon } \\
\text { Iran (Islamic Republic of) } \\
\text { Kazakhstan } \\
\text { Libya } \\
\text { Namibia } \\
\text { Paraguay } \\
\text { Peru } \\
\text { Russian Federation } \\
\text { Turkmenistan } \\
\text { Venezuela (Bolivarian } \\
\text { Republic of) }\end{array}$ & $\begin{array}{l}\text { Low-income } \\
\text { Afghanistan } \\
\text { Benin } \\
\text { Burkina Faso } \\
\text { Central African Republic } \\
\text { Democratic Republic of the Congo } \\
\text { Eritrea } \\
\text { Gambia } \\
\text { Guinea } \\
\text { Guinea-Bissau } \\
\text { Mali } \\
\text { Mozambique } \\
\text { Niger } \\
\text { Senegal } \\
\text { Sierra Leone } \\
\text { Somalia } \\
\text { Syrian Arab Republic } \\
\text { Tajikistan } \\
\text { Togo } \\
\text { Yemen } \\
\text { Lower-middle-income } \\
\text { Cameroon } \\
\text { Côte d'Ivoire } \\
\text { Kiribati } \\
\text { Kyrgyzstan } \\
\text { Mauritania } \\
\text { Micronesia (Federated States of) } \\
\text { Mongolia } \\
\text { Papua New Guinea } \\
\text { Sao Tome and Principe } \\
\text { Solomon Islands } \\
\text { Timor-Leste } \\
\text { Upper-middle-income } \\
\text { Armenia } \\
\text { Belize } \\
\text { Cuba } \\
\text { Fiii } \\
\text { Guyana } \\
\text { Iraq } \\
\text { Jamaica } \\
\text { Maldives } \\
\text { Montenegro } \\
\text { Nauru } \\
\text { Saint Lucia } \\
\text { Suriname } \\
\text { Tonga }\end{array}$ \\
\hline
\end{tabular}

SOURCE: FAO elaboration based on UNCTAD data on commodity dependence and on the World Bank classification for the level of a country's income. 


\section{B. Countries with vulnerability to hunger and food crises}

Vulnerability refers to low- and middle-income countries that in recent years (2011-2017) reported a PoU change point increase, which denotes a significant increase in undernourishment, or experienced a food crisis in correspondence with economic shocks in 2018, as attested by the Global Report on Food Crises 2019. Out of the 134 countries analysed in Part 2 of this report, 86 countries listed in Table A6.3 experienced either a PoU change point increase between 2011 and 2017 (column G) or a food crisis in 2018 (column H), or both. It is also indicated whether countries are commodity dependent (columns E and F), the number of economic slowdowns or downturns experienced during 2011-2017 (I and J), and the severity of the latter (column K) given by the number of consecutive years with downturns. Finally, combining information from the last two year editions of this report, ${ }^{\mathbf{2 8}}$ Table A6.3 reports if countries have suffered from conflict and/or protracted crisis (columns L and M), and if they were vulnerable to climate in terms of production and yields (column N).

\section{TABLE A6.3}

\section{COUNTRIES WITH ECONOMIC SLOWDOWNS OR DOWNTURNS IN CORRESPONDENCE TO AN INCREASE IN POU CHANGE} POINT AND/OR AFFECTED BY FOOD CRISES

\begin{tabular}{|c|c|c|c|c|c|c|c|c|c|c|c|c|c|}
\hline \multirow[b]{2}{*}{$\begin{array}{l}\text { A. COUNTRIES WITH } \\
\text { ECONOMIC } \\
\text { SLOWDOWNS/ } \\
\text { DOWNTURNS IN } \\
\text { CORRESPONDENCE } \\
\text { TO AN INCREASE IN } \\
\text { POU (CHANGE POINT) } \\
\text { AND/OR AFFECTED } \\
\text { BY FOOD CRISIS }\end{array}$} & \multicolumn{2}{|c|}{ REGION } & INCOME & \multicolumn{2}{|c|}{$\begin{array}{l}\text { COMMODITY } \\
\text { DEPENDENCE }\end{array}$} & \multicolumn{2}{|c|}{$\begin{array}{l}\text { VULNERABILITY } \\
\text { TO HUNGER }\end{array}$} & \multicolumn{3}{|c|}{$\begin{array}{c}\text { ECONOMIC } \\
\text { SLOWDOWNS/ } \\
\text { DOWNTURNS }\end{array}$} & \multicolumn{3}{|c|}{ OTHER KEY DRIVERS } \\
\hline & 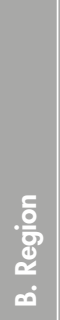 & 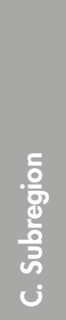 & 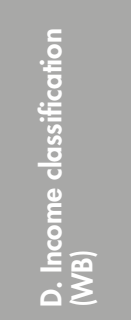 & 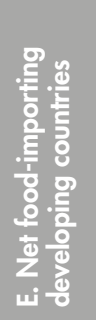 & 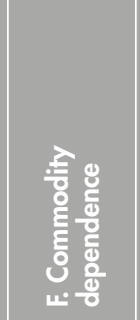 & 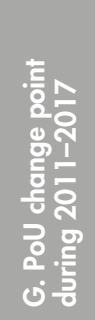 & 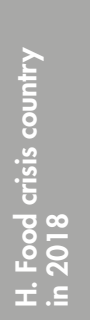 & 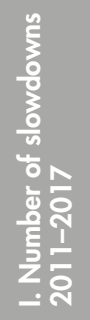 & 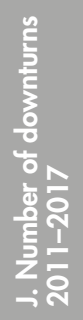 & 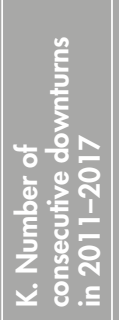 & 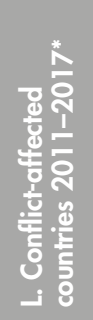 & 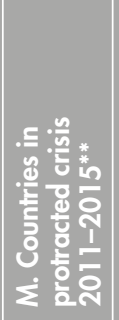 & 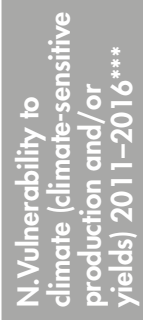 \\
\hline Burundi & \multirow{14}{*}{$\frac{\overleftarrow{s}}{\frac{\mathbb{\alpha}}{\alpha}}$} & \multirow{14}{*}{ 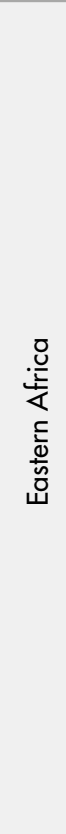 } & \multirow{10}{*}{$\begin{array}{l}\text { Low- } \\
\text { income }\end{array}$} & 1 & HE-LI & 1 & 1 & 2 & 2 & 1 & 0 & 1 & 0 \\
\hline Eritrea & & & & 1 & $\mathrm{HE}-\mathrm{HI}$ & 1 & 0 & 1 & 1 & 1 & 0 & 1 & 0 \\
\hline Madagascar & & & & 1 & LE-HI & 1 & 1 & 0 & 2 & 1 & 0 & 0 & 1 \\
\hline Malawi & & & & 0 & HE-LI & 1 & 1 & 1 & 2 & 1 & 0 & 0 & 1 \\
\hline Mozambique & & & & 1 & $\mathrm{HE}-\mathrm{HI}$ & 1 & 1 & 2 & 0 & 1 & 0 & 0 & 1 \\
\hline Rwanda & & & & 1 & HE-LI & 1 & 0 & 2 & 0 & 1 & 0 & 0 & 1 \\
\hline South Sudan & & & & - & - & 0 & 1 & 1 & 2 & 1 & 1 & 1 & 0 \\
\hline Uganda & & & & 0 & HE-LI & 1 & 1 & 2 & 2 & 1 & 1 & 0 & 1 \\
\hline $\begin{array}{l}\text { United Republic } \\
\text { of Tanzania }\end{array}$ & & & & 0 & HE-LI & 1 & 0 & 3 & 0 & 1 & 0 & 0 & 0 \\
\hline Zimbabwe & & & & 1 & HE-LI & 1 & 1 & 1 & 3 & 3 & 0 & 1 & 1 \\
\hline Diibuti & & & \multirow{3}{*}{$\begin{array}{l}\text { Lower- } \\
\text { middle- } \\
\text { income }\end{array}$} & 1 & LOW CD & 0 & 1 & 1 & 0 & 1 & 0 & 1 & 0 \\
\hline Kenya & & & & 1 & HE-LI & 1 & 1 & 3 & 0 & 1 & 0 & 1 & 0 \\
\hline Zambia & & & & 0 & HE-LI & 1 & 0 & 3 & 1 & 1 & 0 & 0 & 1 \\
\hline Mauritius & & & $\begin{array}{l}\text { Upper- } \\
\text { middle- } \\
\text { income }\end{array}$ & 1 & LE-HI & 1 & 0 & 2 & 0 & 1 & 0 & 0 & 0 \\
\hline
\end{tabular}


TABLE A6.3

(CONTINUED)

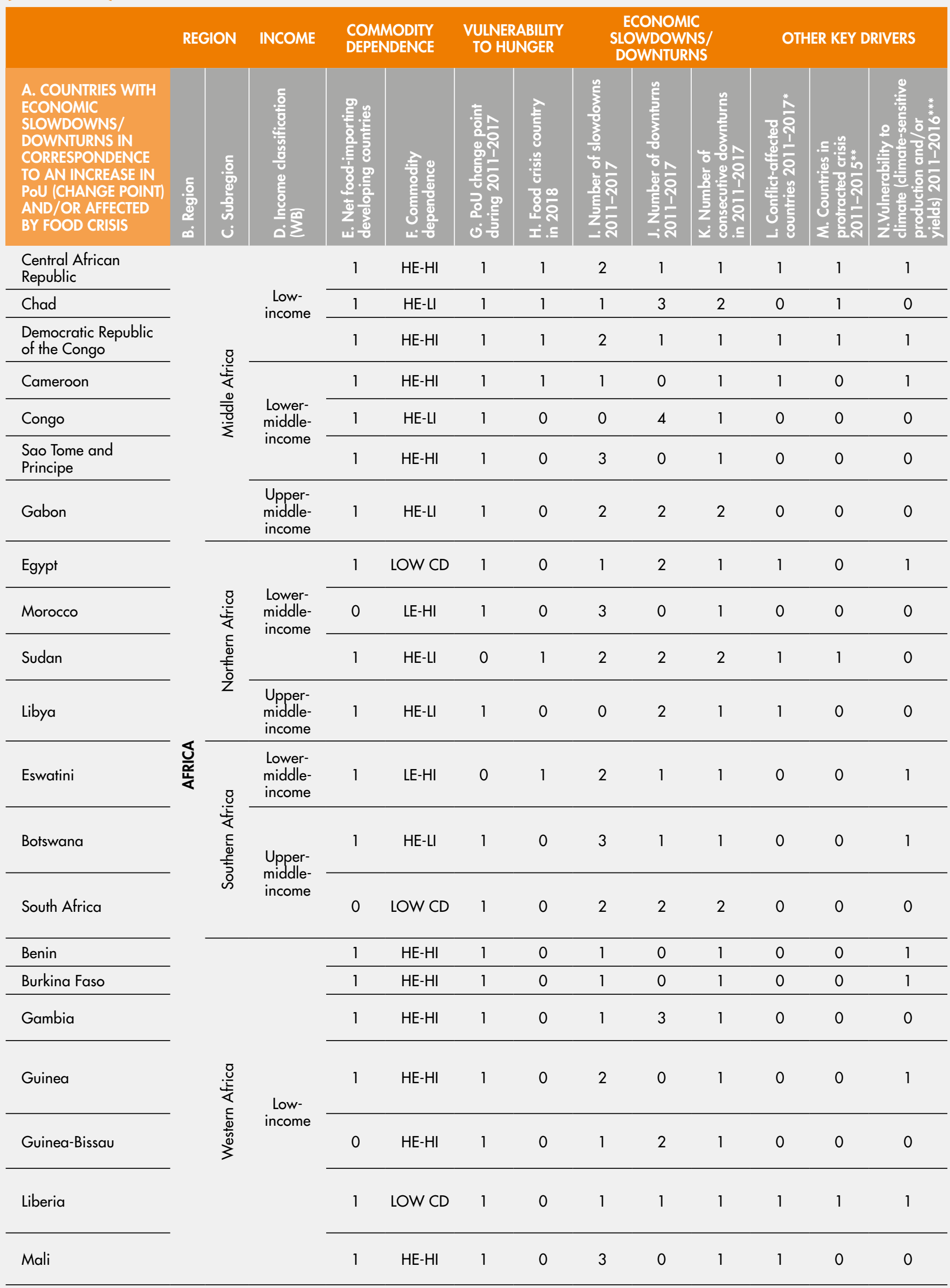




\begin{tabular}{|c|c|c|c|c|c|c|c|c|c|c|c|c|c|}
\hline & \multicolumn{2}{|c|}{ REGION } & \multirow{2}{*}{ 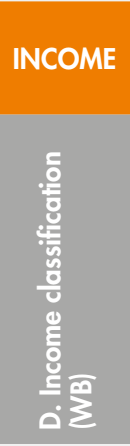 } & \multicolumn{2}{|c|}{$\begin{array}{l}\text { COMMODITY } \\
\text { DEPENDENCE }\end{array}$} & \multicolumn{2}{|c|}{$\begin{array}{l}\text { VULNERABILITY } \\
\text { TO HUNGER }\end{array}$} & \multicolumn{3}{|c|}{$\begin{array}{l}\text { ECONOMIC } \\
\text { SLOWDOWNS/ } \\
\text { DOWNTURNS }\end{array}$} & \multicolumn{3}{|c|}{ OTHER KEY DRIVERS } \\
\hline $\begin{array}{l}\text { A. COUNTRIES WITH } \\
\text { ECONOMIC } \\
\text { SLOWDOWNS/ } \\
\text { DOWNTURNS IN } \\
\text { CORRESPONDENCE } \\
\text { TO AN INCREASE IN } \\
\text { POU (CHANGE POINT) } \\
\text { AND/OR AFFECTED } \\
\text { BY FOOD CRISIS }\end{array}$ & ๑5 & 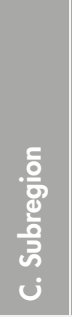 & & 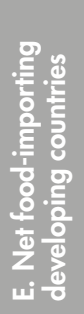 & 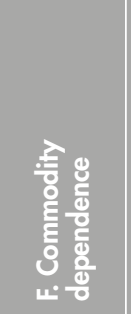 & 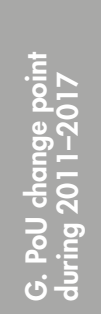 & 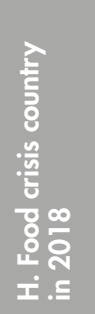 & 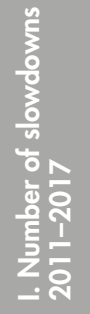 & 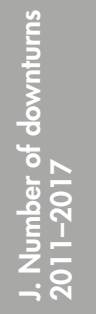 & 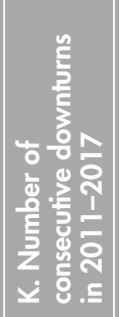 & 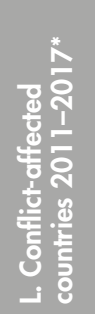 & 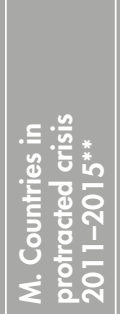 & 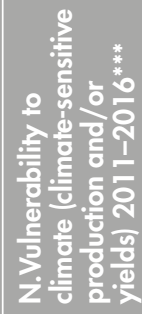 \\
\hline Niger & \multirow{6}{*}{$\frac{\overleftarrow{s}}{\frac{\underline{x}}{4}}$} & \multirow{6}{*}{ 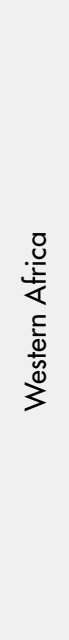 } & \multirow{2}{*}{$\begin{array}{l}\text { Low- } \\
\text { income }\end{array}$} & 1 & HE-HI & 1 & 1 & 3 & 1 & 1 & 0 & 1 & 0 \\
\hline Togo & & & & 1 & $\mathrm{HE}-\mathrm{HI}$ & 1 & 0 & 1 & 0 & 1 & 0 & 0 & 0 \\
\hline Cabo Verde & & & \multirow{4}{*}{$\begin{array}{l}\text { Lower- } \\
\text { middle- } \\
\text { income }\end{array}$} & 1 & LE-HI & 1 & 0 & 1 & 3 & 3 & 0 & 0 & 0 \\
\hline Côte d'Ivoire & & & & 1 & $\mathrm{HE}-\mathrm{HI}$ & 1 & 1 & 2 & 1 & 1 & 0 & 0 & 1 \\
\hline Mauritania & & & & 0 & HE-HI & 1 & 0 & 2 & 1 & 1 & 0 & 0 & 1 \\
\hline Nigeria & & & & 1 & HE-LI & 1 & 1 & 1 & 2 & 2 & 1 & 0 & 0 \\
\hline Haiti & \multirow{13}{*}{ 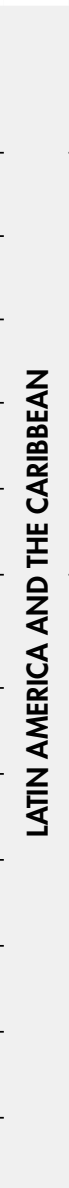 } & 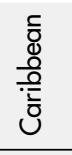 & $\begin{array}{l}\text { Low- } \\
\text { income }\end{array}$ & 1 & LE-HI & 0 & 1 & 2 & 2 & 1 & 0 & 1 & 1 \\
\hline El Salvador & & \multirow{5}{*}{ 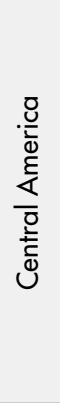 } & \multirow{3}{*}{$\begin{array}{l}\text { Lower- } \\
\text { middle- } \\
\text { income }\end{array}$} & 1 & LOW CD & 0 & 1 & 2 & 0 & 1 & 0 & 0 & 0 \\
\hline Honduras & & & & 0 & LOW CD & 0 & 1 & 2 & 0 & 1 & 0 & 0 & 1 \\
\hline Nicaragua & & & & 0 & LE-HI & 1 & 1 & 2 & 0 & 1 & 0 & 0 & 0 \\
\hline Costa Rica & & & Upper- & 0 & LOW CD & 1 & 0 & 3 & 0 & 1 & 0 & 0 & 1 \\
\hline Guatemala & & & income & 0 & LOW CD & 1 & 1 & 2 & 0 & 1 & 0 & 0 & 0 \\
\hline $\begin{array}{l}\text { Bolivia (Plurinational } \\
\text { State of) }\end{array}$ & & \multirow{7}{*}{ 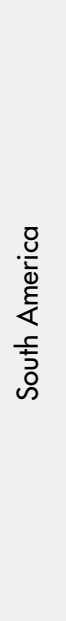 } & $\begin{array}{l}\text { Lower- } \\
\text { middle- } \\
\text { income }\end{array}$ & 0 & HE-LI & 1 & 0 & 2 & 0 & 1 & 0 & 0 & 0 \\
\hline Brazil & & & \multirow{6}{*}{$\begin{array}{l}\text { Upper- } \\
\text { middle- } \\
\text { income }\end{array}$} & 0 & LOW CD & 1 & 0 & 1 & 2 & 2 & 0 & 0 & 1 \\
\hline Ecuador & & & & 0 & HE-LI & 1 & 0 & 1 & 2 & 2 & 0 & 0 & 0 \\
\hline Guyana & & & & 0 & $\mathrm{HE}-\mathrm{HI}$ & 1 & 0 & 2 & 0 & 1 & 0 & 0 & 1 \\
\hline Paraguay & & & & 0 & HE-LI & 1 & 0 & 2 & 1 & 1 & 0 & 0 & 1 \\
\hline Suriname & & & & 1 & $\mathrm{HE}-\mathrm{HI}$ & 1 & 0 & 1 & 3 & 3 & 0 & 0 & 1 \\
\hline $\begin{array}{l}\text { Venezuela (Bolivarian } \\
\text { Republic of) }\end{array}$ & & & & 1 & HE-LI & 1 & 0 & 0 & 4 & 4 & 0 & 0 & 1 \\
\hline
\end{tabular}




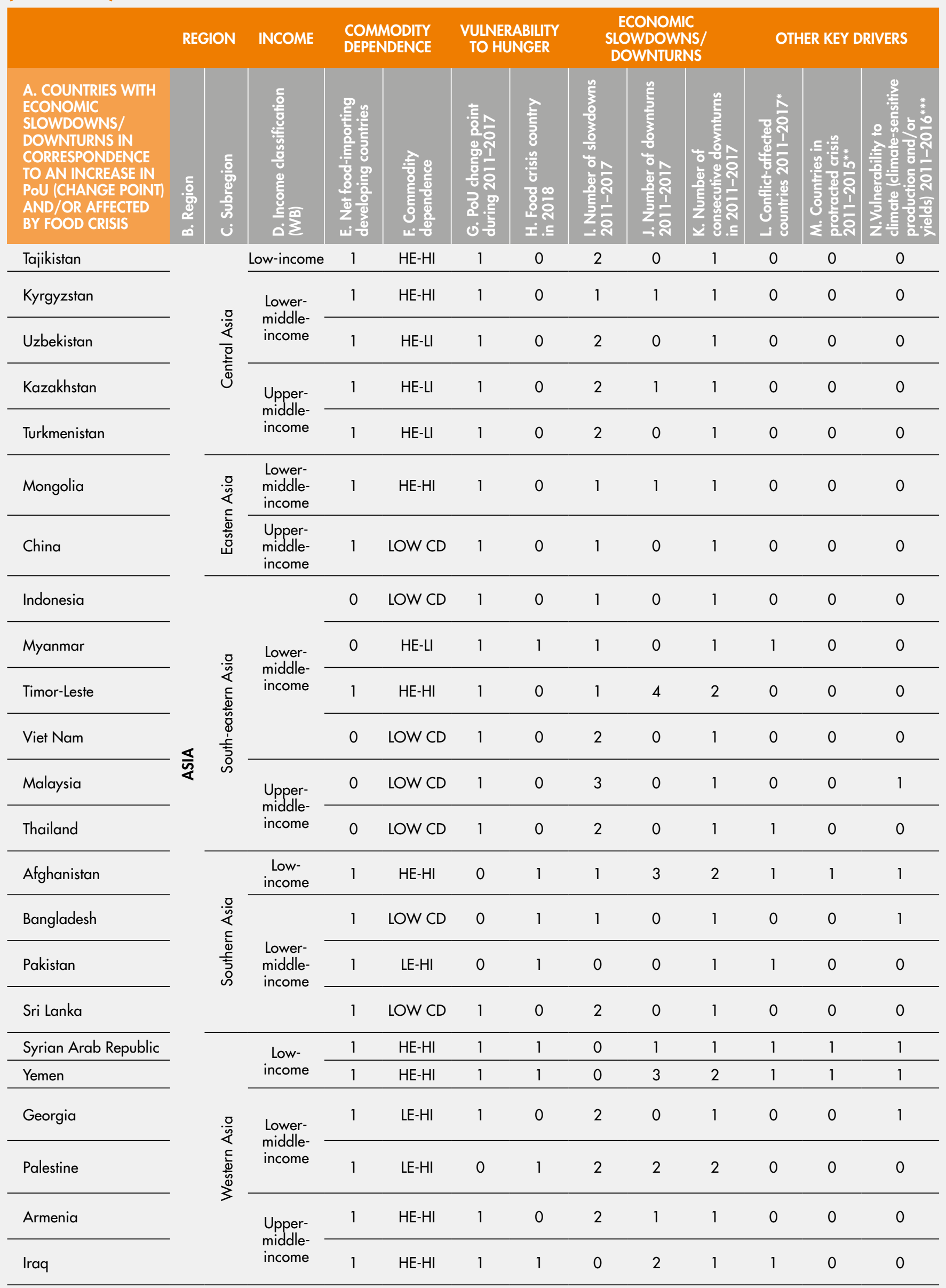




\begin{tabular}{|c|c|c|c|c|c|c|c|c|c|c|c|c|c|}
\hline & \multicolumn{2}{|c|}{ REGION } & \multirow{2}{*}{ 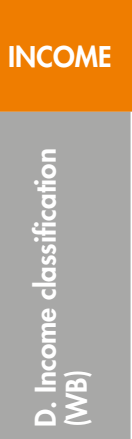 } & \multicolumn{2}{|c|}{$\begin{array}{l}\text { COMMODITY } \\
\text { DEPENDENCE }\end{array}$} & \multicolumn{2}{|c|}{$\begin{array}{l}\text { VULNERABILITY } \\
\text { TO HUNGER }\end{array}$} & \multicolumn{3}{|c|}{$\begin{array}{c}\text { ECONOMIC } \\
\text { SLOWDOWNS/ } \\
\text { DOWNTURNS }\end{array}$} & \multicolumn{3}{|c|}{ OTHER KEY DRIVERS } \\
\hline $\begin{array}{l}\text { A. COUNTRIES WITH } \\
\text { ECONOMIC } \\
\text { SLOWDOWNS/ } \\
\text { DOWNTURNS IN } \\
\text { CORRESPONDENCE } \\
\text { TO AN INCREASE IN } \\
\text { PoU (CHANGE POINT) } \\
\text { AND/OR AFFECTED } \\
\text { BY FOOD CRISIS }\end{array}$ & 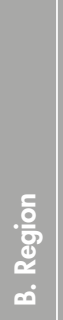 & 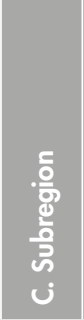 & & 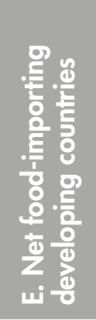 & 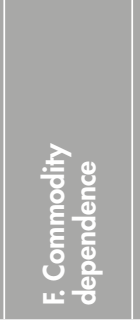 & 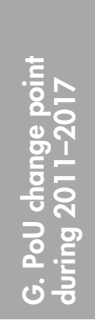 & 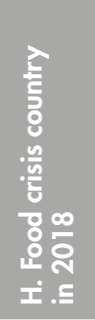 & 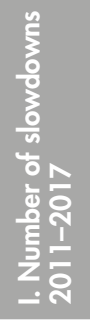 & 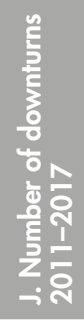 & 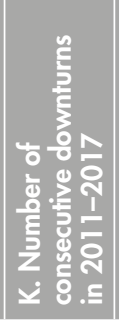 & 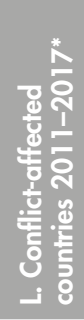 & 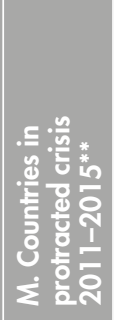 & 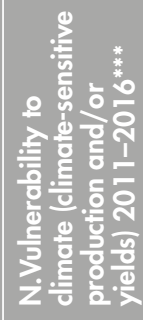 \\
\hline Jordan & \multirow{3}{*}{ ङ } & \multirow{3}{*}{$\begin{array}{l}\frac{0}{y} \\
\frac{5}{5} \\
\frac{5}{0} \\
\frac{d}{5} \\
3\end{array}$} & \multirow{3}{*}{$\begin{array}{l}\text { Upper- } \\
\text { middle- } \\
\text { income }\end{array}$} & 1 & LE-HI & 1 & 1 & 0 & 3 & 2 & 0 & 0 & 0 \\
\hline Lebanon & & & & 1 & LE-HI & 1 & 0 & 0 & 2 & 1 & 0 & 0 & 0 \\
\hline Turkey & & & & 0 & LOW CD & 1 & 0 & 3 & 0 & 1 & 1 & 0 & 0 \\
\hline Ukraine & \multirow{3}{*}{ 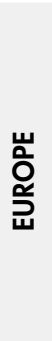 } & \multirow{2}{*}{ 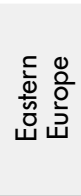 } & $\begin{array}{l}\text { Lower- } \\
\text { middle }\end{array}$ & 0 & LE-HI & 1 & 1 & 1 & 2 & 2 & 1 & 0 & 0 \\
\hline Belarus & & & $\begin{array}{l}\text { Upper- } \\
\text { middle- } \\
\text { income }\end{array}$ & 0 & LE-HI & 1 & 0 & 1 & 1 & 1 & 0 & 0 & 0 \\
\hline Albania & & 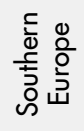 & $\begin{array}{l}\text { Upper- } \\
\text { middle- } \\
\text { income }\end{array}$ & 1 & LE-HI & 1 & 0 & 1 & 0 & 1 & 0 & 0 & 0 \\
\hline Vanuatu & $\stackrel{\nwarrow}{z}$ & $\begin{array}{l}\cdot \frac{0}{y} \\
\frac{0}{0} \\
\frac{0}{0} \\
\sum\end{array}$ & $\begin{array}{l}\text { Lower- } \\
\text { middle- } \\
\text { income }\end{array}$ & 1 & LOW CD & 1 & 0 & 0 & 2 & 1 & 0 & 0 & 0 \\
\hline Samoa & $c$ & $\cdot \frac{\overline{0}}{\tilde{y}}$ & Upper- & 1 & LE-HI & 1 & 0 & 1 & 2 & 1 & 0 & 0 & 0 \\
\hline Tonga & & $\widehat{0}$ & income & 1 & $\mathrm{HE}-\mathrm{HI}$ & 1 & 0 & 2 & 1 & 1 & 0 & 0 & 0 \\
\hline
\end{tabular}

NOTES: Column F shows the classification of country by typology of primary commodity dependence listed in Table A6.2; LOW CD refers to countries with low commodity dependence; LE-HI to countries with low commodity-export and high commodity-import dependence; HE-LI to countries with high commodity-export and low commodity-import dependence; and HE-HI to countries with high commodity-export and high commodity-import dependence. * Conflicts are defined and analysed as in the 2017 edition of this report that informs on years 1995-2015 (see FA0, IFAD, UNICEF, WFP and WH0. 2017. The State of Food Security and Nutrition in the World 2017. Building resilience for peace and food security, Annex 2, p. 102. Rome, FAO). In order to focus on years 2011-2017, information on conflict is updated for years 2016 and 2017 using the most recent data from the Uppsala Conflict Data Program (UCDP). ${ }^{* *}$ Countries in protracted crisis are defined and analysed as in the 2017 edition of this report (see FAO, IFAD, UNICEF, WFP and WHO. 2017. The State of Food Security and Nutrition in the World 2017. Building resilience for peace and food security, Annex 2, p. 102. Rome, FAO). ${ }^{* * *}$ (ountries with vulnerability to climate extremes are analysed and defined as in the 2018 edition of this report (see FAO, IFAD, UNICEF, WFP and WHO. 2018. The State of Food Security and Nutrition in the World 2018. Building climate resilience for food security and nutrition, Annexes 2 and 3. Rome, FAO).

SOURCES: FAO elaborations based on FAO data for PoU; on the National Accounts Main Aggregates Database, United Nations Statistics Division for economic slowdowns and downturns; on the 2017 edition of this report for information on conflict and protracted crises and the 2018 edition of this report for information on climate vulnerability; on UNCTAD data for commodity dependence; on World Bank classification for the level of a country's income; on the Global Report on Food Crises 2019 for information on food crises. 


\section{MNNBX 7}

\section{GLOSSARY}

\section{Acute food insecurity}

Food insecurity found in a specified area at a specific point in time and of a severity that threatens lives or livelihoods, or both, regardless of the causes, context or duration. Has relevance in providing strategic guidance to actions that focus on short-term objectives to prevent, mitigate or decrease severe food insecurity that threatens lives or livelihoods. ${ }^{29}$

\section{Anthropometry}

Use of human body measurements to obtain information about nutritional status.

\section{Balance of payments}

Refers to all economic transactions made by individuals, firms and government between the residents of a country and the rest of the world in a particular period of time.

\section{Chronic food insecurity}

Food insecurity that persists over time mainly due to structural causes. Can include seasonal food insecurity found in periods with non-exceptional conditions. Has relevance in providing strategic guidance to actions that focus on the medium- and long-term improvement of the quality and quantity of food consumption for an active and healthy life. ${ }^{30}$

\section{Commodity dependence}

In this report it refers to commodity-export and -import dependence experienced by low- and middle-income countries. Commodity-export dependence is defined as the ratio of exports of primary commodities (agricultural products, minerals, ores and metals, and oil) to total merchandise exports in monetary terms. Commodity-import dependence is defined as the ratio of imports of food to total merchandise imports in monetary terms. A country is considered as high commodity dependent when its export-dependence ratio is higher than 60 percent and/or its import-dependence ratio is higher than 30 percent.

\section{Commodity price boom}

It refers to the rise in many primary commodity prices, for instance food, oil, metals and the like, during the early 2000s. In this report, the years of the commodity price boom include the period 2003-2011, excluding years 2008 and 2009 where there was a sharp downturn in prices.

\section{Countercyclical policy}

In the context of an economic downturn or slowdown, countercyclical policies are all those policy measures aimed at counteracting the negative socio-economic effects of the economic downturn or slowdown.

\section{Dietary energy intake}

The energy content of food consumed.

\section{Dietary energy supply (DES)}

Food available for human consumption, expressed in kilocalories per person per day (kcal/person/day). At the country level, it is calculated as the food remaining for human use after deduction of all non-food utilizations (i.e. food $=$ production + imports + stock withdrawals - exports - industrial use - animal feed - seed wastage - additions to stock). Wastage includes loss of usable products occurring along distribution chains from farm gate (or port of import) up to retail level.

\section{Double-duty actions}

Double-duty actions include interventions, programmes and policies that have the potential to simultaneously reduce the risk or burden of both undernutrition (including wasting, stunting 
and micronutrient deficiency or insufficiency) and overweight, obesity or diet-related NCDs (including type 2 diabetes, cardiovascular disease and some cancers). Double-duty actions leverage the coexistence of multiple forms of malnutrition and their shared drivers to offer integrated solutions.

\section{Economic downturn}

Refers to a period of decline in economic activity or negative growth as measured by the growth rate in real GDP. It is a synonym for economic recession, a temporary or short-term downturn in economic growth, usually occurring over at least two consecutive quarters of decline. In the analyses and figures presented in this report, an economic downturn is identified using the year as a period of reference.

\section{Economic shock}

An unexpected or unpredictable event that is external to the specific economy and can either harm or boost it. A global financial crisis causing bank lending or credit to fall, or an economic downturn in a major trading partner of a country reflect demand-side shocks that can have multiple effects on spending and investment. A steep rise in oil and gas prices, natural disasters that result in sharp falls in production, or conflict that disrupts trade and production, are examples of supply-side shocks.

\section{Economic slowdown}

Refers to economic activity that is growing at a slower pace compared with the previous period. An economic slowdown occurs when real GDP growth declines from one period of time to another but it is still positive. In the analyses and figures presented in this report, an economic slowdown is identified using the year as the period of reference, although it is usually measured in quarters of a year.

\section{Elasticity}

Refers to the extent to which a variable is responsive to a change in another variable (e.g. income elasticity of poverty). In the econometric analyses presented in this report it is calculated as the percent change in the dependent variable after a unit change in the independent variable(s).

\section{Extreme poverty}

Refers to the percentage of people living on less than USD 1.90 a day (2011 PPP prices) in a country in a given year.

\section{Fiscal space}

The budgetary room that allows a government to provide resources for public purposes without undermining fiscal sustainability, i.e. the ability of a government to sustain its current spending, tax and other policies without threatening government solvency or defaulting on some of its liabilities.

\section{Food Insecurity Experience Scale}

An experience-based food security scale used to produce a measure of access to food at different levels of severity that can be compared across contexts. It relies on data obtained by asking people, directly in surveys, about the occurrence of conditions and behaviours that are known to reflect constrained access to food.

\section{Food security}

A situation that exists when all people, at all times, have physical, social and economic access to sufficient, safe and nutritious food that meets their dietary needs and food preferences for an active and healthy life. Based on this definition, four food security dimensions can be identified: food availability, economic and physical access to food, food utilization, and stability over time.

\section{Food security dimensions}

Refers to the four dimensions of food security:

a. Availability - This dimension addresses whether or not food is actually or potentially physically present, including aspects of production, food reserves, markets and transportation, and wild foods.

b. Access - If food is actually or potentially physically present, the next question is whether or not households and individuals have sufficient access to that food.

c. Utilization - If food is available and households have adequate access to it, the next question is whether or not households are maximizing the consumption of adequate nutrition and energy. Sufficient energy 
and nutrient intake by individuals is the result of good care and feeding practices, food preparation, dietary diversity and intra-household distribution of food. Combined with good biological utilization of food consumed, this determines the nutritional status of individuals.

d. Stability - If the dimensions of availability, access and utilization are sufficiently met, stability is the condition in which the whole system is stable, thus ensuring that households are food secure at all times. Stability issues can refer to short-term instability (which can lead to acute food insecurity) or mediumto long-term instability (which can lead to chronic food insecurity). Climatic, economic, social and political factors can all be a source of instability.

\section{Food systems}

The entire range of actors and their interlinked value-adding activities involved in the production, aggregation, processing, distribution, consumption and disposal of food products. Food systems comprise all food products that originate from crop and livestock production, forestry, fisheries and aquaculture, as well as the broader economic, societal and natural environments in which these diverse production systems are embedded.

\section{Foreign direct investment}

Refers to a category of investment where the objective is to establish a lasting interest by a resident enterprise in one economy (direct investor) in an enterprise (direct investment enterprise) that is resident in an economy different from the one of the direct investor. It implies the existence of a long-term relationship between the direct investor and the direct investment enterprise and a significant degree of influence on the management of the enterprise.

\section{Gini index}

Refers to the World Bank estimate and measures the extent to which the distribution of income (or, in some cases, consumption expenditure) among individuals or households within an economy deviates from a perfectly equal distribution. It is expressed as a percentage where 0 represents perfect equality and 100 perfect inequality.

\section{Global financial crisis}

An economic shock occurred in 2009, the result of a financial meltdown that originated in developed countries. This had serious implications for the real economy and affected several parts of the world simultaneously, including developing countries.

\section{Global food crisis}

An episode of a sharp increase in international agricultural commodity prices between 2007 and early 2008 - in the summer of 2008, these prices reached their highest level in thirty years, before declining in the second half of 2008.

\section{Healthy diet}

A balanced, diverse and appropriate selection of foods eaten over a period of time. A healthy diet ensures that the needs for macronutrients (proteins, fats and carbohydrates including dietary fibres) and essential micronutrients (vitamins, minerals and trace elements) are met specific to the person's gender, age, physical activity level and physiological state. For diets to be healthy: 1) daily needs of energy, vitamins and minerals should be met, but energy intake should not exceed needs; 2) consumption of fruit and vegetables is over $400 \mathrm{~g}$ per day; 3) intake of saturated fats is less than 10 percent of total energy intake; 4) intake of trans-fats is less than 1 percent of total energy intake; 5) intake of free sugars is less than 10 percent of total energy intake or, preferably, less than 5 percent; 6) intake of salt is less than 5 grams per day.

\footnotetext{
A healthy diet for infants and young children is similar to that for adults, but the following elements are also important: 1) Infants should be breastfed exclusively during the first 6 months of life; 2) Infants should be breastfed continuously until 2 years of age and beyond; 3) From 6 months of age, breast milk should be complemented with a variety of adequate, safe and nutrient-dense foods. Salt and sugars should not be added to complementary foods.
} 


\section{Hunger}

Hunger is an uncomfortable or painful physical sensation caused by insufficient consumption of dietary energy. In this report, the term hunger is synonymous with chronic undernourishment.

\section{Macronutrients}

These are the proteins, carbohydrates and fats available to be used for energy; measured in grams.

\section{Malnutrition}

An abnormal physiological condition caused by inadequate, unbalanced or excessive consumption of macronutrients and/or micronutrients. Malnutrition includes undernutrition (child stunting and wasting and vitamin and mineral deficiencies) as well as overweight and obesity.

\section{Marginalization}

It refers to the process of pushing particular groups of people - usually minorities such as indigenous people or rural women - to the edge of society by not allowing them to have an active participation, identity or place in society.

\section{Micronutrients}

Vitamins, minerals and other substances that are required by the body in small amounts; measured in milligrams or micrograms.

\section{Moderate food insecurity}

The level of severity of food insecurity, based on the Food Insecurity Experience Scale, at which people face uncertainties about their ability to obtain food and have been forced to reduce, at times during the year, the quality and/or quantity of food they consume due to lack of money or other resources. It thus refers to a lack of consistent access to food, which diminishes dietary quality, disrupts normal eating patterns, and can have negative consequences for nutrition, health and well-being.

\section{Multiple burden of malnutrition}

The coexistence of forms of undernutrition (child stunting and wasting and vitamin and mineral deficiencies) with overweight and obesity in the same country, community, household or individual.

\section{Net food importers}

Refers to countries or territories where the value of imports of basic foodstuffs outweighs the value of exports of basic foodstuffs. Net food importers experienced a negative average food trade balance from years 2013 to 2015 (for definition, see UNCTAD and FAO. 2017), ${ }^{31}$ where food refers to the basic food category excluding tea, coffee, cocoa and spices.

\section{Nutrition security}

A situation that exists when secure access to an appropriately nutritious diet is coupled with a sanitary environment and adequate health services and care, in order to ensure a healthy and active life for all household members. Nutrition security differs from food security in that it also considers the aspects of adequate caregiving practices, health and hygiene, in addition to dietary adequacy.

\section{Nutrition-sensitive intervention}

An action designed to address the underlying determinants of nutrition (which include household food security, care for mothers and children, and primary healthcare and sanitation) but not necessarily having nutrition as the predominant goal.

\section{Nutritional status}

The physiological state of an individual that results from the relationship between nutrient intake and requirements and the body's ability to digest, absorb and use these nutrients.

\section{Overweight and obesity}

Body weight that is above normal for height as a result of an excessive accumulation of fat. It is usually a manifestation of expending less energy than is consumed. In adults, overweight is defined as a BMI of $25 \mathrm{~kg} / \mathrm{m}^{2}$ or more, and obesity as a BMI of $30 \mathrm{~kg} / \mathrm{m}^{2}$ or more. In children under five years of age, overweight is defined as weight-for-height greater than 2 standard deviations above the WHO Child Growth Standards median, and obesity as weight-for-height greater than 3 standard deviations above the WHO Child Growth Standards median. 


\section{Prevalence of undernourishment}

An estimate of the proportion of the population that lacks enough dietary energy for a healthy, active life. It is FAO's traditional indicator used to monitor hunger at the global and regional level, as well as Sustainable Development Goal Indicator 2.1.1.

\section{Resilience}

Resilience is the ability of individuals, households, communities, cities, institutions, systems and societies to prevent, resist, absorb, adapt, respond and recover positively, efficiently and effectively when faced with a wide range of risks, while maintaining an acceptable level of functioning and without compromising long-term prospects for sustainable development, peace and security, human rights and well-being for all. ${ }^{32}$

\section{Risk}

The probability or likelihood of occurrence of hazardous events or trends multiplied by the impacts if these events or trends occur. Risk to food insecurity is the probability of food insecurity resulting from interactions between a natural or human-induced hazard/shock/stress and vulnerable conditions.

\section{Severe food insecurity}

The level of severity of food insecurity at which people have likely run out of food, experienced hunger and, at the most extreme, gone for days without eating, putting their health and well-being at grave risk, based on the Food Insecurity Experience Scale.

\section{Shared prosperity}

Refers to the average annual growth in income or consumption of the poorest 40 percent of the population (the bottom 40) within each country. ${ }^{33}$ It implies that if shared prosperity in a country is positive, the poor are getting richer. This concept is summarized by the shared prosperity

premium that is the difference between the annual income or consumption growth rate of the poorest (the bottom 40) and the annual growth rate of people at the mean of the income or consumption distribution. A positive premium indicates that the poorest 40 percent are getting a larger share of the overall income in the economy.

\section{Structural transformation}

Structural transformation is both a cause and an effect of economic growth. It involves a change in the composition of the economy away from a reliance on agriculture and towards industry and services, rising involvement in international trade, growing rural-urban migration and urbanization. It leads to profound political, cultural, social and environmental stresses, which must be managed for long-term sustainability.

\section{Stunting}

Low height-for-age, reflecting a past episode or episodes of sustained undernutrition. In children under five years of age, stunting is defined height-for-age less than -2 standard deviations below the WHO Child Growth Standards median.

\section{Terms of trade}

Refers to the ratio between a country's export prices over its import prices. It can be interpreted as the units of exports required to purchase a single unit of import.

\section{Undernourishment}

Undernourishment is defined as the condition in which an individual's habitual food consumption is insufficient to provide the amount of dietary energy required to maintain a normal, active, healthy life. For the purposes of this report, hunger is defined as being synonymous with chronic undernourishment.

\section{Undernutrition}

The outcome of poor nutritional intake in terms of quantity and/or quality, and/ or poor absorption and/or poor biological use of nutrients consumed as a result of repeated instances of disease. It includes being underweight for one's age, too short for one's age (stunted), dangerously thin for one's height (suffering from wasting) and deficient in vitamins and minerals (micronutrient deficiency).

\section{Vulnerability}

The conditions determined by physical, social, economic and environmental factors or 
processes that increase the susceptibility of an individual, a community, assets or systems to the impacts of hazards ${ }^{34}$ Vulnerability to food insecurity is the range of conditions that increases the susceptibility of a household to the impact on food security in case of a shock or hazard.

\author{
Wasting \\ Low weight-for-height, generally the result \\ of weight loss associated with a recent period \\ of inadequate dietary energy intake and/or \\ disease. In children under five years of age, \\ wasting is defined as weight-for-height less than \\ -2 standard deviations below the WHO Child \\ Growth Standards median.
}




\section{NOTES TO PART 1}

1 All statistical series published in The State of Food Security and Nutrition in the World are carefully revised prior to publication of each new edition to reflect all new information that FAO has received since the release of the previous edition. The process implies possible backward revisions of the entire series and readers are warned against comparing values of the indicators across different editions of the report and encouraged to always refer to the series as presented in the most current report.

2 Angola, Burundi, Cameroon, Central African Republic, Chad, Congo, Democratic Republic of the Congo, Eritrea, Ethiopia, Guinea-Bissau, Liberia, Mali, Nigeria, Rwanda, Senegal, South Sudan and Uganda (see Food and Agriculture Organization of the United Nations (FAO), International Fund for Agricultural Development (IFAD), United Nations Children's Fund (UNICEF), World Food Programme (WFP) and World Health Organization (WHO). 2017. The State of Food Security and Nutrition in the World 2017. Building resilience for peace and food security, Table A2.1, p.103. Rome, FAO).

3 Benin, Cameroon, Central African Republic, Chad, Congo, Côte d'Ivoire, Eritrea, Gabon, Guinea-Bissau, Madagascar, Mauritania, Mozambique, Namibia, Nigeria, South Africa, Togo, United Republic of Tanzania, Zambia and Zimbabwe Isee FAO, IFAD, UNICEF, WFP and WHO. 2018. The State of Food Security and Nutrition in the World 2018. Building climate resilience for food security and nutrition, Table A2.1, p. 151. Rome, FAO).

4 World Bank. 2018. Poverty and shared prosperity 2018. Piecing together the poverty puzzle. Washington, DC.

5 The list includes Iraq, Jordan, Lebanon, Palestine, Syrian Arab Republic and Yemen.

6 International Monetary Fund (IMF). 2019. IMF DataMapper - World Economic Outlook (April 2019). In: IMF [online]. Washington, DC. [Cited 6 May 2019]. https://www.imf. org/external/datamapper/datasets/WEO

7 IMF. 2019. IMF DataMapper - World Economic Outlook (April 2019). In: IMF [online]. Washington, DC. [Cited 6 May 2019]. https://www.imf.org/external/datamapper/datasets/WEO

8 FIES or compatible data collected by national institutions are used in this report to inform the estimates of SDG Indicator 2.1.2 and of the prevalence of severe food insecurity for the following countries: Burkina Faso, Cabo Verde, Canada, Chile, Dominican Republic, Ecuador, Ghana, Indonesia, Kenya, Malawi, Nigeria, Palestine, Republic of Korea, Saint Lucia, Seychelles and United States of America. FAO data collected through the Gallup World Poll are used to report on SDG 2.1.2 at national level for countries that have explicitly provided their authorization and to integrate official national data in producing regional and global estimates. Estimates for groups of countries are produced only when the population of the countries within the group for which data are available exceeds 50 percent of the total. For the specific methodology see Annex 1B; FIES measures the severity of food insecurity condition as experienced at any time during the reference period. For SDG monitoring purposes, the reference period is 12 months to ensure comparability of the estimates across countries. For other purposes (e.g. for short-term, continued monitoring of the situation in repeated surveys), the FIES survey module can be modified to use a one-month reference period.

9 One notable difference between PoU and $\mathrm{FI}_{\text {sev }}$ exists for Eastern Asia, where the PoU is estimated to be 8.3 percent in 2018 and 8.6 percent for the period 2016-18, driven by the value estimated for mainland China (see Annex 1A Table Al.1). $\mathrm{Fl}_{\text {sev }}$ in this region is only 1.1 percent, and mainland China is aligned with other countries. Excluding Eastern Asia, there is a close correspondence between the overall number of undernourished and of severely food-insecure people measured with the FIES and their distribution across regions. It is also important to highlight that the worrisome global trend for the PoU, which is no longer declining in the most recent years, does not change even if excluding Eastern Asia.

10 Centre for Monitoring Indian Economy Pvt. Ltd. (CMIE). 2019. 11 million jobs lost in 2018. Text by M. Vyas. In: CMIE [online]. Mumbai, India. [Cited 10 May 2019]. https://www.cmie.com/kommon/bin/sr. php?kall=warticle $\& d t=2019-01-08 \% 2009: 28: 37 \& \mathrm{msec}=666$

11 IMF. 2019. IMF DataMapper - World Economic Outlook (April 2019). In: IMF [online]. Washington, DC. [Cited 6 May 2019]. https://www.imf.org/external/datamapper/datasets/ WEO

12 Number of people living on less than USD 1.90 per day according to the World Bank Group.

13 N.H. Broussard. 2019. What explains gender differences in food insecurity? Food Policy, 83: 180-194. 
14 M.D Smith, M.P. Rabbitt and A. Coleman-Jensen. 2017. Who are the world's food insecure? New evidence from the Food and Agriculture Organization's Food Insecurity Experience Scale. World Development, 93: 402-412.

15 E.A. Wambogo, H. Ghattas, K.L. Leonard and N.R. Sahyoun. 2018. Validity of the Food Insecurity Experience Scale for use in sub-Saharan Africa and characteristics of food-insecure individuals. Current Developments in Nutrition, 2(9): nzy062.

16 F. Asfahani, S. Kadiyala and H. Ghattas. 2019. Food insecurity and subjective wellbeing among Arab youth living in varying contexts of political instability. Journal of Adolescent Health, 64(1): 70-78.

\section{E.A. Frongillo, H.T. Nguyen, M.D. Smith and}

A. Coleman-Jensen. 2017. Food insecurity is associated with subjective well-being among individuals from 138 countries in the 2014 Gallup World Poll. The Journal of Nutrition, 147(4): 680-687.

18 R. Perez-Escamilla and R.P. de Toledo Vianna. 2012. Food insecurity and the behavioral and intellectual development of children: a review of the evidence. Journal of Applied Research on Children: Informing Policy for Children at Risk, $3(1)$.

19 A.D. Jones. 2017. Food insecurity and mental health status: a global analysis of 149 countries. American Journal of Preventive Medicine, 53(2): 264-273.

20 R.E. Black, C.G. Victora, S.P. Walker, Z.A. Bhutta, P. Christian, M. de Onis, M. Ezzati, S. Grantham-McGregor, J. Katz, R. Martorell, R. Uauy and the Maternal and Child Nutrition Study Group. 2013. Maternal and child undernutrition and overweight in low-income and middleincome countries. The Lancet, 382(9890): 427-451.

21 The GBD 2015 Obesity Collaborators. 2017. Health effects of overweight and obesity in 195 countries over 25 years. New England Journal of Medicine, 377(1): 13-27.

22 R. Dobbs, C. Sawers, F. Thompson, J. Manyika, J.R. Woetzel, P. Child, S. McKenna and A. Spatharou. 2014. Overcoming obesity: an initial economic analysis. Discussion paper [online]. New York, USA, McKinsey Global Institute. [Cited 13 May 2019]. https://www.mckinsey.com/ /media/McKinsey/ Business\%2OFunctions/Economic\%20Studies\%20TEMP/Our\%20 Insights/How\%20the\%20world\%20could\%20better\%20 fight\%20obesity/MGI_Overcoming_obesity_Full_report.ashx
23 S. Horton and R.H. Steckel. 2013. Malnutrition: global economic losses attributable to malnutrition 1900-2000 and projections to 2050. In B. Lomborg, ed. How much have global problems cost the world? pp. 247-272. Cambridge, UK, Cambridge University Press.

24 UNICEF, WHO and World Bank. 2019. UNICEF-WHOThe World Bank: Joint child malnutrition estimates - Levels and trends (March 2019 edition) [online]. https://data.unicef. org/topic/nutrition; www.who.int/nutgrowthdb/estimates; https://data.worldbank.org

25 P. Christian, S.E. Lee, M. Donahue Angel, L.S. Adair, S.E. Arifeen, P. Ashorn, F.C. Barros et al. 2013. Risk of childhood undernutrition related to small-for-gestational age and preterm birth in low- and middle-income countries. International Journal of Epidemiology, 42(5): 1340-1355; F.R. Jornayvaz, P. Vollenweider, M. Bochud, V. Mooser, G. Waeber and P. Marques-Vidal. 2016. Low birth weight leads to obesity, diabetes and increased leptin levels in adults: the Colaus study. Cardiovascular Diabetology, 15(1): 73 .

26 UNICEF. 2019. Low birthweight. In: UNICEF data [online]. New York, USA [Cited 16 May 2019]. https://data. unicef.org/topic/nutrition/low-birthweight

27 J.A. Knight. 2011. Diseases and disorders associated with excess body weight. Annals of Clinical and Laboratory Science, 41(2): 107-121.

28 C.T. Miller and K.T. Downey. 1999. A meta-analysis of heavyweight and self-esteem. Personality and Social Psychology Review, 3(1): 68-84; F.S. Luppino, L.M. de Wit, P.F. Bouvy, T. Stijnen, P. Cuijpers, B.W. Penninx and F.G. Zitman. 2010. Overweight, obesity, and depression: a systematic review and meta-analysis of longitudinal studies. Archives of General Psychiatry, 67(3): 220-229.

29 T. Lehnert, D. Sonntag, A. Konnopka, S. Riedel-Heller and $\mathrm{H}-\mathrm{H}$. König. 2013. Economic costs of overweight and obesity. Best Practice \& Research Clinical Endocrinology \& Metabolism, 27(2): 105-115.

30 NCD Risk Factor Collaboration (NCD-RisC). 2019. Rising rural body-mass index is the main driver of the global obesity epidemic in adults. Nature, 569: 260-264.

31 WHO. 2018. Healthy Diet. Fact Sheet No. 394 [online]. Geneva, Switzerland. [Cited 16 May 2019]. https://www. 
who.int/nutrition/publications/nutrientrequirements/healthy_ diet_fact_sheet_394.pdf?ua=1

$32 \mathrm{WHO}$. 2013. Global action plan for the prevention and control of noncommunicable diseases: 2013-2020. Geneva, Switzerland.

$33 \mathrm{WHO}$. 2016. Report of the Commission on Ending Childhood Obesity. Geneva, Switzerland.

34 WHO. 2014. WHA Global Nutrition Targets 2025: Childhood overweight policy brief [online]. Geneva, Switzerland. [Cited 4 April 2019]. https://www.who.int/ nutrition/topics/globaltargets_overweight_policybrief.pdf

$35 \mathrm{FAO}$ and WHO. 2014. Conference Outcome Document: Framework for Action [online]. Second International Conference on Nutrition. Rome, 19-21 November 2014. ICN2 2014/3 Corr. 1. [Cited 4 April 2019]. http://www.fao.org/3/a-mm215e.pdf

36 United Nations (UN). 2016. Resolution adopted by the General Assembly on 1 April 2016-70/259. United Nations Decade of Action on Nutrition (2016-2025) [online]. UN General Assembly, Seventieth session, Agenda item 15 New York. A/RES/70/259 [Cited 4 April 2019].

http://www.un.org/en/ga/search/view_doc.asp?symbol=A/ RES/70/259

37 B.A. Swinburn, V.I. Kraak, S. Allender, V.J. Atkins, P.I. Baker, J.R. Bogard, H. Brinsden, A. Calvillo et al. 2019. The global syndemic of obesity, undernutrition, and climate change: The Lancet Commission report. The Lancet, 393(10173): 791-846.

38 N. Cohen and R.T. Ilieva. 2015. Transitioning the food system: A strategic practice management approach for cities. Environmental Innovation and Societal Transitions, 17: 199-217.

39 D. Mozaffarian, A. Afshin, N. Benowitz, V. Bittner, S. Daniels, H. Franch, D. Jacobs, W. Kraus, P. Kris-Etherton, D. Krummel, B. Popkin, L. Whitsel and N. Zakai. 2012. Population approaches to improve diet, physical activity, and smoking habits: a scientific statement from the American Heart Association. Circulation, 126(12): 1514-1563.

40 World Cancer Research Fund International. 2019. NOURISHING database. In: World Cancer Research Fund
International [online]. London. [Cited 25 April 2019]. https://www.wcrf.org/int/policy/nourishing-database

41 S. Wiggins, S. Keats, E. Han, S. Shimokawa, J. Alberto, V. Hernández and R. Moreira Clara. 2015. The rising cost of a healthy diet. Changing relative prices of foods in high-income and emerging economies. London, Overseas Development Institute (ODI).

42 P. Farrell, A.M. Thow, S. Abimbola, N. Faruqui and J. Negin. 2018. How food insecurity could lead to obesity in LMICs: when not enough is too much: a realist review of how food insecurity could lead to obesity in low- and middle-income countries. Health Promotion International, 33(5): 812-826.

43 A.M. Thow and S. Downs. 2014. Fiscal policy options with potential for improving diets for the prevention of non- communicable diseases (NCDs). Background paper for technical meeting on fiscal policies for improving diets. Geneva, Switzerland, WHO; A.M. Thow, S. Downs and S. Jan. 2014. A systematic review of the effectiveness of food taxes and subsidies to improve diets: Understanding the recent evidence. Nutrition Reviews, 72(9): 551-565.

$44 \mathrm{WHO}$. 2017. Tackling NCDs - 'Best buys' and other recommended interventions for the prevention and control of noncommunicable diseases [online]. Geneva, Switzerland. [Cited 8 May 2019]. https://apps.who.int/ iris/bitstream/handle/10665/259232/WHO-NMH-NVI17.9-eng.pdf? sequence=1\&isAllowed=y; M.T. Gorski and C.A. Roberto. 2015. Public health policies to encourage healthy eating habits: recent perspectives. Journal of Healthcare Leadership, 7: 81-90.

45 C. Álvarez-Sánchez, I. Contento, A. Jiménez-Aguilar, P. Koch, H.L. Gray, L.A. Guerra, J. Rivera-Dommarco, R. Uribe-Carvajal and T. Shamah-Levy. 2018. Does the Mexican sugar-sweetened beverage tax have a signaling effect? ENSANUT 2016. PloS One, 13(8): e0199337.

$46 \mathrm{WHO}$. 2016. Fiscal policies for diet and prevention of noncommunicable diseases. Geneva, Switzerland.

$47 \mathrm{WHO}$. 2016. Fiscal policies for diet and prevention of noncommunicable diseases. Geneva, Switzerland.

$48 \mathrm{FAO}$ and WHO. 2007. Food labelling. Fifth edition. Rome, FAO; WHO. 2019. Guiding principles and framework manual for front-of-pack labelling for promoting healthy diets 
[online]. Geneva, Switzerland. [Cited 27 May 2019]. https://www.who.int/nutrition/publications/policies/ guidingprinciples-labelling-promoting-healthydiet.pdf?ua=1

49 WHO. 2019. Countdown to 2023: WHO report on global trans fat elimination 2019 [online]. Geneva, Switzerland. [Cited 27 May 2019]. https://www.who.int/ docs/default-source/documents/replace-transfats/report-ontfa-elimination-2019.pdf? sfvrsn=c9378613_2

50 WHO. 2017. Double-duty actions for nutrition. Policy Brief [online]. Geneva, Switzerland. [Cited 24 April 2019]. https://apps.who.int/iris/bitstream/handle/10665/255414/ WHO-NMH-NHD-17.2-eng.pdf?ua=1

51 To derive the total number of obese people in the world, the number of obese adolescents aged 18 and 19 years old was subtracted from the number of obese adults to avoid double-counting, and the number of overweight children under five was used because obesity data is not available for this age group. FAO calculations are based on FAO data for the number of undernourished people; WHO. 2017. Global Health Observatory (GHO). In: World Health Organization [online]. Geneva, Switzerland. [Cited 2 May 2019]. http://apps.who.int/gho/data/node.imr.PREVANEMIA?lang=en for number of obese adults (18 years and above) and of school-age children and adolescents (5-19 years of age); UNICEF, WHO and World Bank. 2019. UNICEF-WHO-The World Bank: Joint child malnutrition estimates - Levels and trends (March 2019 edition) [online]. https://data.unicef.org/ topic/nutrition; www.who.int/nutgrowthdb/estimates;

https://data.worldbank.org for overweight in children under five; UN. 2017. World Population Prospects 2017. In: United Nations - DESA/Population Division [online]. New York, USA. [Cited 13 May 2019]. https://population.un.org/wpp for annual population by age.

52 FAO, IFAD, UNICEF, WFP and WHO. 2018. The State of Food Security and Nutrition in the World 2018. Building climate resilience for food security and nutrition. Rome, FAO.

53 Food insecurity is the prevalence of moderate or severe food insecurity $\left(\mathrm{FI}_{\text {mod+sev }}\right)$ in 2018, while nutritional outcomes are based on last available year. Correlations are computed using a different number of countries for each nutrition indicator, depending on data availability. For adult obesity and overweight in school-age children and adolescents, and for anaemia, the 86/87 countries for which data are available cover all income levels (low-income: 11 countries; lower-middle-income: $27 / 28$ countries; upper-middle-income:
24 countries; and high-income: 24 countries). For child stunting and wasting, high-income countries are not equally represented (low-income: 10 countries; lower-middleincome > 20 countries; upper-middle-income: 11 countries; high-income: 2 countries).

54 Prevalence of moderate or severe food insecurity (2014-2016), PoU (2014-2016), and poverty headcount ratio at USD 1.90 a day (2013-2017) are used here as independent variables. Use of the prevalence of undernourishment is intended to control for the more severe forms of food insecurity. Multicollinearity prevents from including $\mathrm{Fl}_{\text {sev }}$ directly as a control. As there are other structural indicators not controlled for, including those related to health and sanitation conditions or education levels, there may still be residual confounding. For details, see the technical note in Annex 2.

55 FAO, IFAD, UNICEF, WFP and WHO. 2017. The State of Food Security and Nutrition in the World 2017. Building resilience for peace and food security, pp. 25-26. Rome, FAO.

56 C. Hawkes, M. Chopra and S. Friel. 2009.

Globalization, trade and the nutrition transition. In R. Labonté, T. Schrecker, C. Packer and V. Runnels. Globalization and health: pathways, evidence and policy, pp. 235-262. New York, USA, Routledge.

57 A. Ishaq, C. Alvarez-Sanchez, M. Del Grossi, S. Viviani, J. Feng, F. Yassin, A. Kepple, A. Sattar and C. Cafiero. forthcoming. The relevance of household food security for nutrition: an empirical analysis based on survey data. Technical Paper. Rome, FAO.

58 For further details, see A. Ishaq, C. AlvarezSanchez, M. Del Grossi, S. Viviani, J. Feng, F. Yassin, A. Kepple, A. Sattar and C. Cafiero. forthcoming. The relevance of household food security for nutrition: an empirical analysis based on survey data. Technical Paper. Rome, FAO.

59 P. Farrell, A.M. Thow, S. Abimbola, N. Faruqui and J. Negin. 2018. How food insecurity could lead to obesity in LMICs: when not enough is too much: a realist review of how food insecurity could lead to obesity in low- and middle-income countries. Health Promotion International, 33(5): 812-826.

60 Not shown in Table 7, see the technical note in Annex 2 


\section{NOTES TO PART 2}

1 World Bank. 2019. Global Economic Prospects, January 2019: Darkening Skies. Washington, DC; International Monetary Fund (IMF). 2019. World Economic Outlook, April 2019: Growth Slowdown, Precarious Recovery. Washington, DC.

2 Food crises refer to the most severe forms/manifestations of acute food insecurity based on country-level analysis using the Integrated Food Security Phase Classification (IPC)/Cadre Harmonisé $(\mathrm{CH})$, as reported in the Global Report on Food Crises (see Food Security Information Network (FSIN). 2019. Global Report on Food Crises 2019 [online]. [Cited 24 April 2019]. http://www.fsinplatform.org/sites/default/files/ resources/files/GRFC_2019-Full_Report.pdf). Countries considered to be affected by food crises are those with any segment of the population in IPC/CH Phase 4 Emergency or Phase 5 Catastrophe; those with at least 1 million people in IPC/CH Phase 3 Crisis; and those for which an Inter-Agency Standing Committee (IASC) Humanitarian System-Wide Emergency Response was declared. The numbers of acute food insecure differ from the undernourishment estimates, and FIES-based severe food insecurity presented in Part 1, which are more globally comprehensive and measure chronic food deprivation.

3 United Nations (UN). 2018. World Economic Situation and Prospects 2018. New York, USA; United Nations Conference on Trade and Development (UNCTAD) and Food and Agriculture Organization of the United Nations (FAO). 2017. Commodities and Development Report 2017. Commodity markets, economic growth and development. New York, USA, UNCTAD.

4 IMF. 2019. World Economic Outlook, April 2019: Growth Slowdown, Precarious Recovery. Washington, DC.

5 World Bank. 2019. Global Economic Prospects, January 2019: Darkening Skies. Washington, DC; IMF. 2019. World Economic Outlook, April 2019: Growth Slowdown, Precarious Recovery. Washington, DC.

6 World Bank. 2019. Commodity Markets Outlook. Food price shocks: channels and implications. April 2019 [online]. Washington, DC. [Cited 24 May 2019]. https:// openknowledge.worldbank.org/bitstream/ handle/10986/31549/CMO-April-2019.pdf

7 IMF. 2019. World Economic Outlook, April 2019: Growth Slowdown, Precarious Recovery. Washington, DC.
8 World Bank. 2018. Special Focus 1. The Role of Major Emerging Markets in the Global Commodity Demand. In World Bank. Global Economic Prospects, June 2018, pp. 61-90. Washington, DC.

9 World Bank. 2018. Poverty and shared prosperity 2018. Piecing together the poverty puzzle. Washington, DC.

10 UN. 2018. World Economic Situation and Prospects 2018. New York, USA.

11 FAO, IFAD, UNICEF, WFP and WHO. 2017. The State of Food Security and Nutrition in the World 2017. Building resilience for peace and security. Rome, FAO; FAO, IFAD, UNICEF, WFP and WHO. 2018. The State of Food Security and Nutrition in the World 2018. Building climate resilience for food security and nutrition. Rome, FAO.

12 The PoU estimates the proportion of the population habitually not meeting the (average) minimum daily dietary-intake requirements. It uses the dietary energy consumption (DEC), which is computed as a three-year average. This means that the PoU is a highly smoothed data time series, which can be expected to reflect to some extent major variations in production in cases where a country is not able to compensate large production drops with stocks and imports. This way of computing and smoothing the PoU data means there will be insufficient variability between years, which makes direct year-on-year regression on economic slowdowns and downturns problematic.

13 Economic slowdowns and downturns have been identified using the growth rate of GDP per capita at constant 2010 prices, expressed in US dollars (USD). The change in the rate is computed for each country to obtain a simple difference in growth. See Annex 3 for full definitions.

14 See next section and Annex 6 for definition of commodity dependence.

15 The analysis is focused between 2011 and 2017 so that data points are sufficiently distant to detect changes and are not affected by sampling errors. On the other hand, it was not possible to undertake a statistical correlation analysis on year-on-year changes of PoU given the indicator is smoothed as noted.

16 E.W. Nafziger, F. Stewart and R. Väyrynen, eds. 2000. War, hunger, and displacement: Volumes 1 and 2. Oxford, UK, Oxford University Press; F. Stewart. 2002. Root causes 
of violent conflict in developing countries. British Medical Journal, 324(7333): 342-345; S.M. Murshed. 2002.

Conflict, civil war and underdevelopment: an introduction. Journal of Peace Research, 39(4): 387-393.

17 M. Amare, N.D. Jensen, B. Shiferaw and J.D. Cissé. 2018. Rainfall shocks and agricultural productivity: implication for rural household consumption. Agricultural Systems, 166: 79-89; M.R. Carter, P.D. Little, T. Mogues and W. Negatu. 2007. Poverty traps and natural disasters in Ethiopia and Honduras. World Development, 35(5): 835-856; R. Hill and H. Fuje. 2018. What is the impact of drought on prices? Evidence from Ethiopia [online]. [Cited 10 June 2019]. https://editorialexpress.com/cgi-bin/ conference/download.cgi?db_name=CSAE2018\&paper_ $i d=746$

18 FSIN. 2019. Global Report on Food Crises 2019 [online]. [Cited 24 April 2019]. http://www.fsinplatform.org/sites/ default/files/resources/files/GRFC_2019-Full_Report.pdf

19 Countries included faced a high severity and magnitude of acute food insecurity in the period from January to December 2018. The key information source is the countrylevel analysis based on the Integrated Food Security Phase Classification (IPC)/Cadre Harmonisé (CH).

20 The analysis is carried out by a multi-sector and multiagency technical team of experts (National IPC Technical Working Groups). For the global annual synthesis of country analyses, see FSIN. 2019. Global Report on Food Crises 2019 [online]. [Cited 24 April 2019]. http://www. fsinplatform.org/sites/default/files/resources/files/ GRFC_2019-Full_Report.pdf. For full individual country analyses, see www.ipcinfo.org

21 Identification of drivers, including economic shocks, is an analytical component of the Integrated Food Security Phase Classification (IPC)/Cadre Harmonisé (CH) analysis carried out by countries.

22 FAO, IFAD, UNICEF, WFP and WHO. 2017. The State of Food Security and Nutrition in the World 2017. Building resilience for peace and security. Rome, FAO. As highlighted in the 2017 report, conflict-induced economic contractions reduce employment and income opportunities, which in turn can increase poverty and reduce the ability of households to meet their food and healthcare needs.
23 Calculated as the average difference in GDP per capita growth between 2014 and 2017 for 18 countries where conflict and civil insecurity was the primary driver of the food crisis in 2018. Data source for GDP per capita growth is: UN. 2019. National Accounts - Analysis of Main Aggregates. In: UNSTATS [online]. New York, USA. [Cited 6 May 2019]. https://unstats.un.org/unsd/snaama; while conflict-driven food crisis countries are identified in FSIN. 2019. Global Report on Food Crises 2019 [online]. [Cited 24 April 2019]. http://www.fsinplatform.org/sites/ default/files/resources/files/GRFC_2019-Full_Report.pdf. Also see FAO, IFAD, UNICEF, WFP and WHO. 2017. The State of Food Security and Nutrition in the World 2017. Building resilience for peace and security. Rome, FAO, which presented evidence showing that armed conflict reduces the level of GDP per capita by 17.5 percent on average. Impacts vary widely though: the GDP of the Syrian Arab Republic fell by more than 50 percent between 2010 and 2015; Libya's GDP fell by 24 percent in 2014 after violence picked up; and in Yemen there was a GDP decline of an estimated 25-35 percent in 2015 alone.

24 FSIN. 2018. Global Report on Food Crises 2018 [online]. [Cited 24 April 2019]. https://docs.wfp.org/api/documents/ WFP-0000069227/download/? $\mathrm{ga}=2.160606203 .756747346 .1556271415$ -

1211808128.1528362052

25 UNICEF. 2009. Aggregate shocks, poor households and children: transmission channels and policy responses [online]. New York, USA. [Cited 3 May 2019]. https://www.unicef. org/policyanalysis/files/Postscript_Formatted_ aggregate_shocks_and_children_3.04.09.pdf; J. Báez, A. Fuchs and C. Rodríguez-Castelán. 2017. Shaking up economic progress: aggregate shocks in Latin America and the Caribbean. Washington, DC, World Bank.

26 UNCTAD. 2015. Commodities and Development Report 2015. Smallholder farmers and sustainable commodity development. New York, USA and Geneva, Switzerland.

27 The diversification of their productive and export activities is a pending task for many transition and developing economies. The UNCTAD Merchandise Trade Specialization Index confirms that, despite the rapid rate of growth of trade in many developing economies over the period 1995-2012, the degree of specialization in their export structures has not varied significantly. In a sample of relatively open developing economies, the index of export concentration has actually increased from the early 2000s (before the commodity 
boom) to 2012. Dependence on a smaller set of export products has increased in commodity exporters, including Chile, Colombia, Ecuador, the Bolivarian Republic of Venezuela and the group of transition economies as a whole. See Table 1.2 in UNCTAD. 2015. Commodities and Development Report 2015. Smallholder farmers and sustainable commodity development. New York, USA and Geneva, Switzerland; also see World Bank. 2017. Economic diversification: A priority for action, now more than ever. In: The World Bank [online]. Washington, DC. [Cited 25 April 2019]. https://blogs.worldbank.org/psd/economicdiversification-priority-action-now-more-ever

28 Building more competitive firms, moving resources into higher-value-added sectors and strengthening national technological capabilities cannot rely on market forces alone; effective industrial policies and dedicated efforts to support and coordinate private- and public-sector activities will also be crucial. UNCTAD and FAO. 2017. Commodities and Development Report 2017. Commodity markets, economic growth and development. New York, USA, UNCTAD.

29 UNCTAD and FAO. 2017. Commodities and Development Report 2017. Commodity markets, economic growth and development. New York, USA, UNCTAD.

30 UN. 2018. World economic situation and prospects 2018. New York, USA.

31 FSIN. 2017. Global Report on Food Crises, March 2017 [online]. [Cited 24 April 2019]. http://www.fao. org/3/a-br323e.pdf. IPC phase 3 and above or equivalent.

$32 \mathrm{C}$. Holleman and V. Conti. forthcoming. Role of income inequality in shaping outcomes on food insecurity. FAO Agricultural Development Economics Working Papers 19-06. Rome, FAO.

$33 \mathrm{C}$. Holleman and V. Conti. forthcoming. Role of income inequality in shaping outcomes on food insecurity. FAO Agricultural Development Economics Working Papers 19-06. Rome, FAO.

34 J.D. Nkurunziza, K. Tsowou and S. Cazzaniga. 2017. Commodity dependence and human development. African Development Review, 29(S1): 27-41.

35 F. Carmignani and D. Avom. 2010. The social development effects of primary commodity export dependence. Ecological Economics, 70(2): 317-330.
36 IMF. 2012. Chapter 4. Commodity Price Swings and Commodity Exporters. In IMF. World Economic Outlook, April 2012: Growth Resuming, Danger Remain, pp. 125-167. Washington, DC.

37 T. Becker and P. Mauro. 2006. Output drops and the shocks that matter. IMF Working Paper 06/172 [online]. [Cited 24 April 2019]. Washington, DC, IMF. https://www. imf.org/external/pubs/ft/wp/2006/wp06172.pdf

38 IMF and World Bank. 2011. Managing volatility in low-income countries: the role and potential for contingent financial instruments [online]. Washington, DC. [Cited 24 April 2019]. https://www.imf.org/external/np/pp/ eng/2011/103111a.pdf

39 UN. 2016. World Economic Situation and Prospects 2016. New York, USA.

40 See Figure II in UN. 2016. World Economic Situation and Prospects 2016. New York, USA.

41 F. van der Ploeg and S. Poelhekke. 2009. Volatility and the natural resource curse. Oxford Economic Papers, 61(4): 727-760.

$42 \mathrm{Or}$, in other words, the purchasing power of primary commodity exports, expressed in terms of the value of imports, decreases over time (Prebisch-Singer hypothesis). This generally holds despite relatively short boom periods associated with primary commodity price booms. The main reason is that with rising incomes, smaller shares of income are spent on primary goods (due to the higher income elasticity of demand for manufactured goods compared with primary goods). Thus, the argument goes that the reliance of low-income countries on commodity exports is not such a viable long-term development strategy given the downward trajectory of the value of their exports. D. Hallam. 2018. Revisiting Prebisch-Singer: what long-term trends in commodity prices tell us about the future of CDDCs. Background paper to the UNCTAD-FAO Commodities and Development Report 2017 [online]. Rome, FAO. [Cited 24 April 2019]. http://www.fao.org/3/i8331en/I8331EN. pdf; UNCTAD and FAO. 2017. Commodities and Development Report 2017. Commodity markets, economic growth and development. New York, USA, UNCTAD.

43 UNCTAD and FAO. 2017. Commodities and Development Report 2017. Commodity markets, economic growth and development. New York, USA, UNCTAD. 
44 UN. 2018. World Economic Situation and Prospects 2018, p. 65. New York, USA.

45 UNCTAD and FAO. 2017. Commodities and Development Report 2017. Commodity markets, economic growth and development. New York, USA, UNCTAD.

46 A.Z. Baharumshah, E. Lau and S. Fountas. 2003. On the sustainability of current account deficits: evidence from four ASEAN countries. Journal of Asian Economics, 14(3): 465-487.

47 UNCTAD. 2015. Commodities and Development Report 2015. Smallholder farmers and sustainable commodity development. New York, USA and Geneva, Switzerland.

48 WFP. 2016. Special working paper on devaluation of South Sudan pound: short-term food security implications [online]. [Cited 24 April 2019]. https://documents.wfp.org/ stellent/groups/public/documents/ena/wfp281309.pdf? $\mathrm{ga}=2.58362860 .756747346 .1556271415$ 1211808128.1528362052

49 S. Haggblade, P.B.R. Hazell and P.A. Dorosh. 2007. Sectoral growth linkages between agriculture and the rural nonfarm economy. In S. Haggblade, P. Hazell \& T. Reardon, eds. Transforming the rural nonfarm economy. Opportunities and threats in the developing world, pp. 141-182. Baltimore, USA, The John Hopkins University Press; S. Block. 1999. Agriculture and economic growth in Ethiopia: growth multipliers from a four-sector simulation model. Agricultural Economics, 20(3): 241-252.

50 G.G. Porto. 2015. Estimating household responses to trade reforms: Net consumers and net producers in rural Mexico. International Economics, 144: 116-142.

51 K.T. Sibhatu and M. Qaim. 2017. Rural food security, subsistence agriculture, and seasonality. PLoS One, 12(10): e0186406

52 Y.T. Lo, Y.H. Chang, M.S. Lee and M.L. Wahlqvist. 2009. Health and nutrition economics: diet costs are associated with diet quality. Asia Pacific Journal of Clinical Nutrition, 18(4): 598-604.

53 R. Green, L. Cornelsen, A.D Dangour, R. Turner, B. Shankar, M. Mazzocchi and R.D. Smith. 2013. The effect of rising food prices on food consumption: systematic review with meta-regression. British Medical Journal, 346: f3703.
54 L.L lannotti, M. Robles, H. Pachón and C. Chiarella. 2012. Food prices and poverty negatively affect micronutrient intakes in Guatemala. The Journal of Nutrition, 142(8): 1568-1576.

55 R. Gitau, M. Makasa, L. Kasonka, M. Sinkala, C. Chintu, A. Tomkins and S. Filteau. 2005. Maternal micronutrient status and decreased growth of Zambian infants born during and after the maize price increases resulting from the southern African drought of 2001-2002. Public Health Nutrition, 8(7): 837-843.

56 FAO. 2008. The State of Food Insecurity in the World 2008. High food prices and food security - threats and opportunities. Rome.

57 UNCTAD and FAO. 2017. Commodities and Development Report 2017. Commodity markets, economic growth and development. New York, USA, UNCTAD.

$58 \mathrm{~J}$. Birkenmaier, J. Huang and Y. Kim. 2016. Food insecurity and financial access during an economic recession: evidence from the 2008 SIPP. Journal of Poverty, 20(2): 194-213.

59 FAO and Pan American Health Organization (PAHO) 2017. Panorama of Food and Nutrition Security in Latin America and the Caribbean. Santiago de Chile, FAO.

60 World Bank. 2019. World Development Report 2019: the changing nature of work. Washington, DC. These shares fall as incomes grow: to 38 percent $1 \%$ of total employment in agriculture) and 16 percent (\% of GDP produced from agricultural output) in lower-middle-income countries; and to 3 percent and less than 2 percent, respectively, in high-income countries.

61 International Labour Organization (ILO). 2009. Global employment trends, January 2009. Geneva, Switzerland.

$62 \mathrm{~J}$. von Braun. 2008. Food and financial crises: Implications for agriculture and the poor. Washington, DC, International Food Policy Research Institute (IFPRI); IFAD. 2016. Rural Development Report 2016. Fostering inclusive rural transformation. Rome.

63 FAO, IFAD, UNICEF, WFP and WHO. 2018. The State of Food Security and Nutrition in the World 2018. Building climate resilience for food security and nutrition. Rome, FAO. 
64 H.J. Brinkman, S. de Pee, I. Sanogo, L. Subran and M.W. Bloem. 2010. High Food Prices and the Global Financial Crisis Have Reduced Access to Nutritious Food and Worsened Nutritional Status and Health. The Journal of Nutrition, 140(1): 153S-161S.

65 P.C. Tiwari and B. Joshi. 2012. Natural and socioeconomic factors affecting food security in the Himalayas. Food Security, 4(2): 195-207.

66 M. Maertens and A. Fabry. 2019. Creating more and better jobs in global food value chains. Paper prepared for the Future of Work in Agriculture Conference [online]. Washington, DC. [Cited 5 June 2019]. https://farmlabor. ucdavis.edu/sites/g/files/dgvnsk5936/files/inline-files/ Miet\%20Maertens\%3B\%20Global\%20Value\%20Chains.pdf

67 R. Edwards. 2019. Spillovers from Agricultural Processing. Paper prepared for the Future of Work in Agriculture Conference, Washington, DC.

68 C.P. Timmer. 2014. Managing structural transformation: a political economy approach. UNU WIDER Annual Lecture 18. Helsinki, United Nations University-World Institute for Development (UNU-WIDER).

69 WHO. 2011. Education: shared interests in well-being and development. Social Determinants of Health Sectoral Briefing Series No. 2. Geneva, Switzerland.

70 B.I. McPake. 2018. Crunching health expenditure numbers: important but treacherous terrain. The Lancet Global Health, 6(2): e124-e125.

$71 \mathrm{WHO}$. 2012. Social protection: shared interests in vulnerability reduction and development. Social Determinants of Health Sectoral Briefing Series No. 4. Geneva, Switzerland.

72 WHO. 2017. Together on the road to universal health coverage: a call to action. (WHO/HIS/HGF/17.1) [online]. Geneva, Switzerland. [Cited 24 April 2019]. https://apps. who.int/iris/bitstream/handle/10665/258962/WHO-HISHGF-17.1-eng.pdf? sequence $=1$

73 UN. 2019. World Economic Situation and Prospects 2019. New York, USA.
74 ILO. 2017. World Social Protection Report 2017-19. Universal social protection to achieve the Sustainable Development Goals. Geneva, Switzerland.

75 K. Xu, A. Soucat, J. Kutzkin, C. Brindley, N. Vande Maele, H. Touré, M. Aranguren Garcia et al. 2017. Public spending on health: a closer look at global trends. WHO/HIS/HGF/HF Working Paper/18.3 [online]. Geneva, Switzerland, WHO. [Cited 24 April 2019]. https://apps. who.int/iris/bitstream/handle/10665/276728/WHO-HISHGF-HF-WorkingPaper-18.3-eng.pdf?ua=1

76 P. Christian. 2010. Impact of the economic crisis and increase in food prices on child mortality: exploring nutritional pathways. The Journal of Nutrition, 140(1): 177S-181S

77 WHO. 2009. The financial crisis and global health: Report of a high-level consultation [online]. Geneva, Switzerland. [Cited 24 April 2019]. https://www.who.int/ topics/financial_crisis/financialcrisis_report_200902.pdf

78 A. Lusardi, D. Schneider and P. Tufano. 2015. The economic crisis and medical care use: comparative evidence from five high-income countries. Social Science Quarterly, 96(1): 202-213; A. Ruckert and R. Labonté. 2012. The global financial crisis and health equity: toward a conceptual framework. Critical Public Health, 22(3): 267-279.

79 K. Xu, D.B. Evans, G. Carrin, A.M. Aguilar-Rivera, P. Musgrove and T. Evans. 2007. Protecting households from catastrophic health spending. Health Affairs, 26(4): 972-983.

80 UNICEF and WHO. 2018. Drinking water, sanitation and hygiene in schools: global baseline report 2018. New York, USA, UNICEF and Geneva, Switzerland, WHO.

81 A. Prüss-Ustün, J. Wolf, C. Corvalán, R. Bos and M. Neira. 2016. Preventing disease through healthy environments: a global assessment of the burden of disease from environmental risks. Geneva, Switzerland, WHO.

82 ILO. 2017. World Social Protection Report 2017-19. Universal social protection to achieve the Sustainable Development Goals. Geneva, Switzerland; Overseas Development Institute (ODI). 2009. The global financial crisis: poverty and social protection. Evidence from 10 country case studies. Briefing paper, August 2009 [online]. London. [Cited 
24 April 2019]. https://www.odi.org/sites/odi.org.uk/files/ odi-assets/publications-opinion-files/4285.pdf

83 P.L. Engle and H.N. Ricciuti. 1995. Psychosocial aspects of care and nutrition. Food and Nutrition Bulletin, 16(4): 1-23; K. Michaelsen, L. Weaver, F. Branca and A. Robertson. 2003. Feeding and nutrition of infants and young children: guidelines for the WHO European Region, with emphasis on the former Soviet countries. Copenhagen, $\mathrm{WHO}$.

84 S. Dercon. 2002. Income risk, coping strategies, and safety nets. The World Bank Research Observer, 17(2): 141-166; D.J. McKenzie. 2003. How do households cope with aggregate shocks? Evidence from the Mexican peso crisis. World Development, 31(7): 1179-1199.

85 S. Dercon. 2002. Income risk, coping strategies, and safety nets. The World Bank Research Observer, 17(2): $141-166$.

86 I. Jo and B. Ik. 2018. Economic recession coping strategies in Nigeria: the case of rural dwellers in Moro local government area of Kwara State. Journal of Global Economics, 6(1): 6-9; T. Gödecke and H. Waibel. 2011. Rural-urban transformation and village economy in emerging market economies during economic crisis: empirical evidence from Thailand. Cambridge Journal of Regions, Economy and Society, 4(2): 205-219.

87 P. Paci, A. Revenga and B. Rijkers. 2009. Coping with crises. Why and how to protect employment and earnings. The World Bank Research Observer, 27(1): 106-141.

88 E. Skoufias. 2003. Economic crises and natural disasters: coping strategies and policy implications. World Development, 31(7): 1087-1102.

89 R. Mahadevan and S. Suardi. 2014. Regional differences pose challenges for food security policy: a case study of India. Regional Studies, 48(8): 1319-1336; C. Gundersen, B. Kreider and J. Pepper. 2011. The economics of food insecurity in the United States. Applied Economic Perspectives and Policy, 33(3): 281-303; D. Mallick and M. Rafi. 2010. Are female-headed households more food insecure? Evidence from Bangladesh. World Development, 38(4): 593-605; V. Mishra and R. Ray. 2009. Dietary diversity, food security and undernourishment: the Vietnamese evidence. Asian Economic Journal, 23(2): 225-247; R. Jha, R. Gaiha and A. Sharma. 2009. Calorie and micronutrient deprivation and poverty nutrition traps in rural India. World Development, 37(5): 982-991; M.H. Suryanarayana and D. Silva. 2007. Is targeting the poor a penalty on the food insecure? Poverty and food insecurity in India. Journal of Human Development, 8(1): 89-107; K. Beegle, G. Caretto, B. Davis and M. Migotto. 2006. Measuring food security using respondents' perception of food consumption adequacy. Research Paper No. 2006/88 [online]. Helsinki, UNU-WIDER. [Cited 13 May 2019]. http://www.wider.unu. edu/publications/rps/rps2006/rp200688.pdf; V. Molini. 2006. Food security in Vietnam during the 1990s: the empirical evidence. Research Paper No. 2006/67 [online]. Helsinki, UNU-WIDER. [Cited 13 May 2019]. https:// www.wider.unu.edu/sites/default/files/rp2006-67.pdf; L.N. Dien, N.M. Thang and M.E. Bentley. 2004. Food consumption patterns in the economic transition in Vietnam. Asia Pacific Journal of Clinical Nutrition, 13(1): 40-47; J. Coates, P. Webb and R. Houser. 2003. Measuring food insecurity: going beyond indicators of income and anthropometry [online]. Washington, DC, Food and Nutrition Technical Assistance (FANTA) Project. [Cited 13 May 2019]. https://www.fantaproject.org/sites/default/files/ resources/Measuring-Food-Insecurity-Bangladesh-2003_0. pdf; J. Gibson, J. Huang and S. Rozelle. 2003. Improving estimates of inequality and poverty from urban China's Household Income and Expenditure Survey. Review of Income and Wealth, 49(1): 53-68; W.L. Hamilton, J.T. Cook, W.W. Thompson, L.F. Buron, E.A. Frongillo Jr, C.M. Olson and C.A. Wehler. 1997. Household food security in the United States in 1995. Summary Report of the Food Security Measurement Project [online]. Washington, DC, United States Department of Agriculture (USDA). [Cited 13 May 2019]. https://fns-prod.azureedge.net/sites/ default/files/SUMRPT.PDF; S. Subramanian and A. Deaton. 1996. The demand for food and calories. Journal of Political Economy, 104(1): 133-162.

90 World Bank. 2018. Poverty and shared prosperity 2018. Piecing together the poverty puzzle. Washington, DC.

91 M.T. Ruel and H. Alderman. 2013. Nutrition-sensitive interventions and programmes: how can they help to accelerate progress in improving maternal and child nutrition? The Lancet, 382(9891): 536-551.

92 References to "poverty" in this report refer to monetary poverty, not multidimensional poverty measurements.

93 SDG 1 calls for reducing multidimensional poverty, not only income poverty. This often includes education, health 
and food security and nutrition. In this report, however, the analysis only considers income poverty and in most cases extreme poverty.

94 R. Martorell and A. Zongrone. 2012. Intergenerational influences on child growth and undernutrition. Paediatric and Perinatal Epidemiology, 26(Suppl. 1): 302-314; M. de Onis and F. Branca. 2016. Childhood stunting: a global perspective. Maternal \& Child Nutrition, 12(Suppl. 1): 12-26.

95 M. Peña and J. Bacallao. 2002. Malnutrition and poverty. Annual Review of Nutrition, 22: 241-253.

96 R. Nallari and B. Griffith. 2011. Understanding growth and poverty: theory, policy, and empirics. Washington, DC, World Bank.

97 A. Kraay. 2004. When is growth pro-poor? Cross-country evidence. Policy Research Working Paper 3225 [online]. Washington, DC, World Bank. [Cited 14 May 2019]. https://openknowledge.worldbank.org/bitstream/ handle/10986/14731/wps3225growth. pdf? sequence=1\&isAllowed=y; D. Dollar and A. Kraay. 2002. Growth is good for the poor. Journal of Economic Growth, 7(3): 195-225.

98 World Bank. 2005. Pro-Poor growth in the 1990s: Lessons and insights from 14 countries [online]. Washington, DC. [Cited 24 April 2019]. http://documents.worldbank.org/ curated/en/421141468027836341/Pro-Poor-growth-in-the1990s-Lessons-and-insights-from-14-countries

99 R. Nallari and B. Griffith. 2011. Understanding growth and poverty: theory, policy and empirics. Washington, DC, World Bank.

100 J.H. Lopez. 2004. Pro-growth, pro-poor: is there a trade-off? Policy Research Working Paper No.3378 [online]. Washington, DC, World Bank. [Cited 29 April 2019]. https://openknowledge.worldbank.org/bitstream/ handle/10986/14124/WPS3378.pdfẹsequence= 1\&isAllowed=y

101 M. Ravallion. 2001. Growth, inequality and poverty: looking beyond averages. World Development, 29(11): 1803-1815.

102 World Bank. 2019. World Development Indicators. In: World Bank DataBank [online]. Washington, DC. [Cited 10 February 2019]. https://databank.worldbank.org
103 World Bank. 2016. Poverty and Shared Prosperity 2016. Taking on inequality. Washington, DC.

104 M. Ravallion. 2001. Growth, inequality and poverty: looking beyond averages. World Development, 29(11): 1803-1815.

105 F. Bourguignon. 2003. The growth elasticity of poverty reduction: explaining heterogeneity across countries and time periods. Working Paper 28104 [online]. Washington, DC, World Bank. [Cited 29 April 2019]. http://documents. worldbank.org/curated/en/503161468780002293/ $\mathrm{pdf} / 28104 . \mathrm{pdf}$

106 S. Mary. 2018. How much does economic growth contribute to child stunting reductions? Economies, 6(4): 55.

107 M.T. Ruel and H. Alderman. 2013. Nutrition-sensitive interventions and programmes: how can they help to accelerate progress in improving maternal and child nutrition? The Lancet, 382(9891): 536-551.

108 L.C. Smith and L. Haddad. 2015. Reducing child undernutrition: past drivers and priorities for the post-MDG Era. World Development, 68: 180-204; S.A. O'Connell and C. Smith. 2016. Economic growth and child undernutrition. The Lancet Global Health, 4(12): e901-e902.

109 S. Mary. 2018. How much does economic growth contribute to child stunting reductions? Economies, 6(4): 55.

110 S. Vollmer, K. Harttgen, M.A. Subramanyam, J. Finlay, S. Klasen and S.V. Subramanian. 2014. Association between economic growth and early childhood undernutrition: evidence from 121 Demographic and Health Surveys from 36 low-income and middle-income countries. The lancet Global Health, 2(4): e225-e234; K. Harttgen, S. Klasen and S. Vollmer. 2013. Economic growth and child undernutrition in sub-Saharan Africa. Population and Development Review, 39(3): 397-412.

111 P. H-V. Eozenou and M. Shekar. 2017. Stunting reduction in sub-Saharan Africa [online]. Washington, DC, World Bank. [Cited 24 April 2019]. http://documents.worldbank. org/curated/en/126621505397202676/Stunting-reductionin-Sub-Saharan-Africa

112 K. Harttgen, S. Klasen and S. Vollmer. 2012. Economic growth and child undernutrition in Africa [online]. New York, USA, United Nations Development Programme (UNDP). 
[Cited 24 April 2019]. https://www.undp.org/content/dam/ rba/docs/Working\%20Papers/Economic\%20Growth\%20 and\%20Child\%20Undernutrition.pdf

113 M.E. McGovern, A. Krishna, V.M. Aguayo and S.V. Subramanian. 2017. A review of the evidence linking child stunting to economic outcomes. International Journal of Epidemiology, 46(4): 1171-1191.

114 S. Mary. 2018. How much does economic growth contribute to child stunting reductions? Economies, 6(4): 55. The back-of-the-envelope calculation estimate is within the range of existing similar estimates found in IFPRI. 2014. Global Nutrition Report 2014. Actions and accountability to accelerate the world's progress on nutrition. Washington, DC; E. Galasso and A. Wagstaff. 2017. The economic costs of stunting and how to reduce them. Policy Research Note PRN/17/05, March 2017 [online]. Washington, DC, World Bank. [Cited 13 May 2019]. http://pubdocs.worldbank.org/ en/536661487971403516/PRN05-March2017-EconomicCosts-of-Stunting.pdf

115 Z.A. Bhutta, J.K. Das, A. Rizvi, M.F. Gaffey, N. Walker, S. Horton, P. Webb, A. Lartey and R.E. Black. 2013.

Evidence-based interventions for improvement of maternal and child nutrition: what can be done and at what cost? The Lancet, 382(9890): 452-477; M.T. Ruel and H. Alderman. 2013. Nutrition-sensitive interventions and programmes: how can they help to accelerate progress in improving maternal and child nutrition? The Lancet, 382(9891): 536-551.

116 G. Egger, B. Swinburn and F.M. Amirul Islam. 2012. Economic growth and obesity: An interesting relationship with world-wide implications. Economics \& Human Biology, 10(2): 147-153; P.T. Pisa and N.M. Pisa. 2016. Economic growth and obesity in South African adults: an ecological analysis between 1994 and 2014. The European Journal of Public Health, 27(3): 404-409; A.M. Cotet Grecu and K.W. Rotthoff. 2013. Economic growth and obesity: findings of an obesity Kuznets curve. SSRN Electronic Journal.

117 C.P. Timmer. 2000. The macro dimensions of food security: economic growth, equitable distribution, and food price stability. Food Policy, 25(3): 283-295; C.P. Timmer. 2005. Food security and economic growth: an Asian perspective. Asian-Pacific Economic Literature, 19(1): 1-17.

118 M.D. Smith, W. Kassa and P. Winters. 2017. Assessing food insecurity in Latin America and the Caribbean using
FAO's Food Insecurity Experience Scale. Food Policy, 71: 48-61.

119 M.D. Smith, M.P. Rabbitt and A. Coleman- Jensen. 2017. Who are the world's food insecure? New evidence from the Food and Agriculture Organization's Food Insecurity Experience Scale. World Development, 93: 402-412.

120 C. Holleman and V. Conti. forthcoming. Role of income inequality in shaping outcomes on food insecurity. FAO Agricultural Development Economics Working Papers 19-06. Rome, FAO.

121 D. Narayan-Parker and P.L. Petesch, eds. 2002. From many lands. Voices of the poor. Washington, DC, Oxford University Press and the World Bank; World Bank. 2001. Kyrgyz Republic: poverty in the 1990s in the Kyrgyz Republic [online]. Washington, DC. [Cited 5 May 2019]. https:// openknowledge.worldbank.org/bitstream/ handle/10986/15496/multiOpage.pdf? sequence= 1\&isAllowed=y

122 A. De la $\bigcirc$ Campos, C. Villani, B. Davis and M. Takagi. 2018. Ending extreme poverty in rural areas: sustaining livelihoods to leave no one behind. Rome, FAO.

123 World Bank. 2018. Poverty and shared prosperity 2018. Piecing together the poverty puzzle. Washington, DC.

124 A. Gabriele and F. Schettino. 2008. Child malnutrition and mortality in developing countries: evidence from a cross-country analysis. Analyses of Social Issues and Public Policy, 8(1): 53-81.

$125 \mathrm{FAO}$ and WHO. 2014. Conference Outcome Document: Framework for Action [online]. Second International Conference on Nutrition. Rome, 19-21 November 2014 ICN2 2014/3 Corr.1. [Cited 16 May 2019]. http://www.fao.org/3/a-mm215e.pdf

126 Save the Children. 2016. Unequal portions: ending malnutrition for every last child [online]. London. [Cited 5 May 2019]. https://s3.savethechildren.it/public/files/ uploads/pubblicazioni/unequal-portions-ending-malnutritionevery-last-child.pdf

127 See WHO - Regional Office for the Eastern Mediterranean. 2014. Health inequities in the Eastern Mediterranean Region: selected country case studies. Cairo; L. Nasreddine, J.J. Ayoub and A. Al Jawaldeh. 2018. Review 
of the nutrition situation in the Eastern Mediterranean Region. Eastern Mediterranean Health Journal, 24(1): 77-91; R. Kim, I. Mejía-Guevara, D.J. Corsi, V.M. Aguayo and S.V. Subramanian. 2017. Relative importance of 13 correlates of child stunting in South Asia: insights from nationally representative data from Afghanistan, Bangladesh, India, Nepal, and Pakistan. Social Science \& Medicine, 187: 144-154.

128 N. Ikeda, Y. Irie and K. Shibuya. 2013. Determinants of reduced child stunting in Cambodia: analysis of pooled data from three demographic and health surveys. Bulletin of the World Health Organization, 91(5): 341-349.

129 S. Garcia, O.L. Sarmiento, I. Forde and T. Velasco. 2013. Socio-economic inequalities in malnutrition among children and adolescents in Colombia: the role of individual-, household- and community-level characteristics. Public Health Nutrition, 16(9): 1703-1718.

130 N. Fenske, J. Burns, T. Hothorn and E.A. Rehfuess. 2013. Understanding child stunting in India: a comprehensive analysis of socio-economic, nutritional and environmental determinants using additive quantile regression. PloS One, 8(11): e78692.

131 M.U. Mushtaq, S. Gull, U. Khurshid, U. Shahid, M.A. Shad and A.M. Siddiqui. 2011. Prevalence and sociodemographic correlates of stunting and thinness among Pakistani primary school children. BMC Public Health, 11: 790.

132 C. Brown, M. Ravallion and D. van de Walle. 2017. Are poor individuals mainly found in poor households? Evidence using nutrition data for Africa [online]. Washington, DC, World Bank. [Cited 24 April 2019]. http://documents. worldbank.org/curated/en/427491489094206188/pdf/ WPS8001.pdf

133 See C. Brown, M. Ravallion and D. van de Walle. 2017. Are poor individuals mainly found in poor households? Evidence using nutrition data for Africa [online]. Washington, DC, World Bank. [Cited 24 April 2019]. http://documents. worldbank.org/curated/en/427491489094206188/ pdf/WPS8001.pdf; S. Lambert, M. Ravallion and D. van de Walle. 2014. Intergenerational mobility and interpersonal inequality in an African economy. Journal of Development Economics, 110: 327-344; P.D. Vreyer and S. Lambert. 2016. Intrahousehold inequalities and poverty in Senegal. [online]. Washington, DC, World Bank. [Cited 24 April 2019]. http://pubdocs.worldbank. org/en/407221466181742385/intrahh-inequality-andpoverty-juin2016-2.pdf; D.E. Sahn and S.D. Younger. 2009. Measuring intra-household health inequality: explorations using the body mass index. Health Economics, 18(Suppl. 1): S13-S36; A. Wagstaff and N. Watanabe. 2000.

Socioeconomic Inequalities in Child Malnutrition in the Developing World. [online]. Washington, DC, World Bank. [Cited 24 April 2019]. https://openknowledge.worldbank. org/handle/10986/19791

134 Save the Children. 2016. Unequal portions: ending malnutrition for every last child [online]. London. [Cited 5 May 2019]. https://s3.savethechildren.it/public/files/ uploads/pubblicazioni/unequal-portions-ending-malnutritionevery-last-child.pdf; H. Alderman, S. Appleton, L. Haddad, L. Song and Y. Yohannes. 2005. Reducing child malnutrition: how far does income growth take us? CREDIT Research Paper 01/05 [online]. Nottingham, UK, Centre for Research in Economic Development and International Trade (CREDIT) of the University of Nottingham. [Cited 13 May 2019]. https:// www.nottingham.ac.uk/credit/documents/papers/01-05.pdf; V.D. Kien, H.Y Lee, Y.S. Nam, J. Oh, K.B. Giang and H.V. Minh. 2016. Trends in socioeconomic inequalities in child malnutrition in Vietnam: findings from the Multiple Indicator Cluster Surveys, 2000-2011. Global Health Action, 9(1): 29263.

135 G.R. Alexander, M. Kogan, D. Bader, W. Carlo, M. Allen and J. Mor. 2003. US birth weight/gestational age-specific neonatal mortality: 1995-1997 rates for whites, hispanics, and blacks. Pediatrics, 111(1): e61-e66; S.C. Gray, S.E. Edwards, B.D. Schultz and M.L. Miranda. 2014. Assessing the impact of race, social factors and air pollution on birth outcomes: a population-based study. Environmental Health, 13(1); S.L. Restrepo-Mesa, N. Zapata López, B.E. Parra Sosa, L.E. Escudero Vásquez and E. Atalah. 2014. Adolescent pregnancy: maternal characteristics and their association with birth weight of the newborn. Archivos Latinoamericanos De Nutricion, 64(2): 99-107.

136 Y. Balarajan, U. Ramakrishnan, E. Özaltin, A.H. Shankar and S. Subramanian. 2011. Anaemia in low-income and middle-income countries. The Lancet, 378(9809): 2123-2135; Z.A. Bhutta, T. Ahmed, R.E. Black, S. Cousens, K. Dewey, E. Giugliani, B.A. Haider et al. 2008. What works? Interventions for maternal and child undernutrition and survival. The Lancet, 371(9610): 417-440.

137 L.W. Niessen, D. Mohan, J.K. Akuoku, A.J. Mirelman, S. Ahmed, T.P. Koehlmoos, A. Trujillo, J. Khan and D.H. Peters. 
2018. Tackling socioeconomic inequalities and non-communicable diseases in low-income and middleincome countries under the Sustainable Development Agenda. The Lancet, 391(10134): 2036-2046; J. Williams, L. Allen, K. Wickramasinghe, B. Mikkelsen, N. Roberts and N. Townsend 2018. A systematic review of associations between non-communicable diseases and socioeconomic status within low- and lower-middle-income countries. Journal of Global Health, 8(2): 020409.

138 World Bank. 2018. All hands on deck - reducing stunting through multisector efforts in sub-Saharan Africa. Washington, DC.

139 World Bank. 2019. PovcalNet: an online analysis tool for global poverty monitoring. In: The World Bank [online]. Washington, DC. [Cited 9 February 2019]. http://iresearch. worldbank.org/PovcalNet/home.aspx, 2015 is the latest year available to analyse extreme poverty.

140 G.D. Dinsa, Y. Goryakin, E. Fumagalli and M. Suhrcke. 2012. Obesity and socioeconomic status in developing countries: a systematic review. Obesity Reviews: An Official Journal of the International Association for the Study of Obesity, 13(11): 1067-1079.

141 S. Newton, D. Braithwaite and T.F. Akinyemiju. 2017. Socio-economic status over the life course and obesity: Systematic review and meta-analysis. PloS One, 12(5): e0177151.

142 G.D. Dinsa, Y. Goryakin, E. Fumagalli and M. Suhrcke. 2012. Obesity and socioeconomic status in developing countries: a systematic review. Obesity Reviews: An Official Journal of the International Association for the Study of Obesity, 13(11): 1067-1079.

143 L.M. Jaacks, S. Vandevijvere, A. Pan, C.J. McGowan, C. Wallace, F. Imamura, D. Mozaffarian, B. Swinburn and M. Ezzati. 2019. The obesity transition: stages of the global epidemic. The Lancet Diabetes \& Endocrinology, 7(3): 231-240

144 Development Initiatives. 2017. Progress report 2017 [online]. Bristol, UK. [Cited 5 May 2019]. http://devinit.org/ wp-content/uploads/2018/06/Development-InitiativesProgress-Report-2017.pdf

145 S. Wu, Y. Ding, F. Wu, R. Li, Y. Hu, J. Hou and P. Mao. 2015. Socio-economic position as an intervention against overweight and obesity in children: a systematic review and meta-analysis. Scientific Reports, 5: 11354.

146 J.D. Ostry, A. Berg and C.G. Tsangarides.

2014. Redistribution, inequality, and growth. IMF Staff Discussion Notes, SDN/14/02 [online]. Washington, DC, IMF. [Cited 13 May 2019]. https://www.imf.org/ external/pubs/ft/sdn/2014/sdn1402.pdf; FAO and PAHO. 2017. Panorama of food and nutrition security in Latin America and the Caribbean 2017. Santiago de Chile, FAO.

147 Development Initiatives. 2017. Progress report 2017 [online]. Bristol, UK. [Cited 5 May 2019]. http://devinit.org/ wp-content/uploads/2018/06/Development-InitiativesProgress-Report-2017.pdf

148 World Bank. 2018. Poverty and shared prosperity 2018. Piecing together the poverty puzzle. Washington, DC.

149 Poverty reduction can occur through higher average growth, a narrowing in income inequality, or a combination of the two.

150 The most widely referenced measure of inequality is the Gini coefficient, which varies between 0 (complete equality) and 1 (complete inequality). Since this coefficient tends to be skewed toward inequality at the top, it is usually complemented by other indicators, for example the ratio between the income share of the richest and the poorest 20 percent of the population.

$151 \mathrm{FAO}$ and PAHO. 2017. Panorama of food and nutrition security in Latin America and the Caribbean 2017. Santiago de Chile, FAO.

152 World Bank. 2016. Poverty and shared prosperity 2016: Taking on inequality. Washington, DC.

153 M.V. Sánchez-Cantillo. 2009. Trade policy reform and poverty: successes and failures in Central America. CEPAL Review 98(August): 65-82.

154 In economics, a Kuznets curve graphs the hypothesis that as an economy develops, market forces first increase and then decrease economic inequality. The hypothesis was first advanced by economist Simon Kuznets in the 1950s and 1960 s.

155 S. Mary. 2018. How much does economic growth contribute to child stunting reductions? Economies, 6(4): 55; 
World Bank. 2016. Poverty and shared prosperity 2016: taking on inequality. Washington, DC; R. Kanbur. 2016. Economic growth and poverty reduction: the inequality connection. In International Social Science Council (ISSC), Institute of Development Studies (IDS) and UNESCO. World social science report 2016, Challenging inequalities: pathways to a just world, pp. 122-125. Paris, UNESCO; Asian Development Bank (ADB). 2012. Asian Development Outlook 2012. Confronting rising inequality in Asia. Manila; F. Carmignani and D. Avom. 2010. The social development effects of primary commodity export dependence. Ecological Economics, 70(2): 317-330.

156 C. Holleman and V. Conti. forthcoming. Role of income inequality in shaping outcomes on food insecurity. FAO Agricultural Development Economics Working Papers 19-06. Rome, FAO.

157 M. de Onis and F. Branca. 2016. Childhood stunting: a global perspective. Maternal \& Child Nutrition, 12(Suppl. 1): 12-26; R.E. Black, C.G. Victora, S.P. Walker, Z.A. Bhutta, P. Christian, M. de Onis, M. Ezzati, S. Grantham-McGregor, J. Katz, R. Martorell and R. Uauy. 2013. Maternal and child undernutrition and overweight in low-income and middleincome countries. The Lancet, 382(9890): 427-451.

158 A. Young. 2013. Inequality, the urban-rural gap, and migration. The Quarterly Journal of Economics, 128(4): 1727-1785.

159 FAO and Organisation for Economic Co-operation and Development (OECD). 2014. Opportunities for economic growth and job creation in relation to food security and nutrition [online]. Rome, FAO. [Cited 24 April 2019]. http://www.fao.org/3/a-bt682e.pdf

$160 \mathrm{FAO}$ and OECD. 2014. Opportunities for economic growth and job creation in relation to food security and nutrition [online]. Rome, FAO. [Cited 24 April 2019]. http://www.fao.org/3/a-bt682e.pdf

161 UNICEF, WHO and World Bank. 2019. UNICEF-WHOThe World Bank: Joint child malnutrition estimates - Levels and trends (March 2019 edition) [online]. https://data.unicef. org/topic/nutrition; www.who.int/nutgrowthdb/estimates; https://data.worldbank.org

162 Y. Balarajan, U. Ramakrishnan, E. Özaltin, A.H. Shankar and S. Subramanian. 2011. Anaemia in low-income and middle-income countries. The Lancet, 378(9809): 2123-2135.
163 Development Initiatives. 2018. Global Nutrition Report 2018. Bristol, UK.

164 UNICEF. 2016. From the first hour of life. New York, USA.

165 International Organization for Migration (IOM). 2015. World Migration Report 2015. Migrants and cities: new partnerships to manage mobility. Geneva, Switzerland.

$166 \mathrm{WHO}$. 2010. Hidden cities: unmasking and overcoming health inequities in urban settings. Geneva, Switzerland.

167 M. Ruel, J. Garrett and S. Yosef. 2017. Growing cities, new challenges. In IFPRI. Global Food Policy Report 2017, pp. 24-33. Washington, DC.

168 A. Ezeh, O. Oyebode, D. Satterthwaite, Y.-F. Chen, R. Ndugwa, J. Sartori, B. Mberuet et al. 2017. The history, geography, and sociology of slums and the health problems of people who live in slums. The Lancet, 389(10068): 547558; P. Menon, M.T. Ruel and S.S. Morris. 2000. Socioeconomic differentials in child stunting are consistently larger in urban than in rural areas. Food and Nutrition Bulletin, 21(3): 282-289; J.-C. Fotso. 2006. Child health inequities in developing countries: differences across urban and rural areas. International Journal for Equity in Health, 5: 9.

169 M. Ruel, J. Garrett and S. Yosef. 2017. Growing cities, new challenges. In IFPRI. Global Food Policy Report 2017, pp. 24-33. Washington, DC.

170 M. Ruel, J. Garrett and S. Yosef. 2017. Growing cities, new challenges. In IFPRI. Global Food Policy Report 2017, pp. 24-33. Washington, DC.

171 WHO. 2016. Global report on urban health: equitable, healthier cities for sustainable development. Geneva, Switzerland.

172 M. Ruel, J. Garrett and S. Yosef. 2017. Growing cities, new challenges. In IFPRI. Global Food Policy Report 2017, pp. 24-33. Washington, DC.

173 M.T. Ruel, J.L. Garrett, C. Hawkes and M.J. Cohen. 2010. The food, fuel, and financial crises affect the urban and rural poor disproportionately: a review of the evidence. The Journal of Nutrition, 140(1): 170S-176S. 
174 World Bank. 2009. Averting a human crisis during the global downturn: policy options from the World Bank's human development network [online]. Washington, DC. [Cited 5 May 2019]. http://siteresources.worldbank.org/NEWS/ Resources/AvertingTheHumanCrisis.pdf

$175 \mathrm{WHO}$. 2009. The financial crisis and global health: report of a high-level consultation [online]. Geneva, Switzerland. [Cited 24 April 2019]. https://www.who.int/ topics/financial_crisis/financialcrisis_report_200902.pdf

$176 \mathrm{WHO}$. 2009. The financial crisis and global health: report of a high-level consultation [online]. Geneva, Switzerland. [Cited 24 April 2019]. https://www.who.int/ topics/financial_crisis/financialcrisis_report_200902.pdf

177 M. Suhrcke, D. Stuckler, J.E. Suk, M. Desai, M. Senek, M. McKee, S. Tsolova et al. 2011. The impact of economic crises on communicable disease transmission and control: a systematic review of the evidence. PloS One, 6(6): e20724.

178 World Bank. 2009. Averting a human crisis during the global downturn: policy options from the World Bank's human development network [online]. Washington, DC. [Cited 5 May 2019]. http://siteresources.worldbank.org/NEWS/ Resources/AvertingTheHumanCrisis.pdf

179 WHO. 2018. Reducing stunting in children: equity considerations for achieving the Global Nutrition Targets 2025. Geneva, Switzerland.

180 World Economic Forum. 2017. The Inclusive Growth and Development Report 2017. Geneva, Switzerland.

181 M. Lipton. 2007. Farm water and rural poverty reduction in developing Asia. Irrigation and Drainage, 56(2-3): 127-146.

182 FAO. 2011. The State of Food and Agriculture 2010-11. Women in agriculture: closing the gender gap for development. Rome.

183 N. Cuffaro and G. D' Agostino. 2017. Land inequality and growth: meta-analysis and relevance for contemporary development in Africa. Working Paper No. 222 [online]. Rome, Università di Roma Tre. [Cited 5 May 2019]. http://dipeco.uniroma3.it/db/docs/WP\%20222.pdf

184 L. Erickson and D. Vollrath. 2004. Dimensions of land inequality and economic development. IMF Working Paper
WP/04/158. [online]. Washington, DC, IMF. [Cited 5 May 2019]. https://www.imf.org/external/pubs/ft/wp/2004/ wp04158.pdf

185 FAO. 2002. Gender and access to land. FAO Land Tenure Studies 4. Rome.

186 M. Christian, B. Evers and S. Barrientos. 2013. Women in value chains: making a difference. Revised Summit Briefing No. 6.3 - February 2013 [online]. Capturing the grains. [Cited 5 May 2019]. http://www.capturingthegains.org/ pdf/ctg_briefing_note_6.3.pdf

187 United Nations World Water Assessment Programme (WWAP). 2015. The United Nations World Water Development Report 2015. Water for a sustainable world. Paris, UNESCO.

188 FAO. 2011. The State of the World's Land and Water Resources for Food and Agriculture (SOLAW). Managing systems at risk. Rome, FAO, and London, Earthscan.

189 J. Popay, S. Escoral, M. Hernández, H. Johnston, J. Mathieson and L. Rispel. 2008. Understanding and Tackling social exclusion. Final Report to the WHO Commission on Social Determinants of Health. From the Social Exclusion Knowledge Network. February 2008 [online]. Geneva, Switzerland, WHO. [Cited 5 May 2019]. https://www.who.int/social_determinants/knowledge_ networks/final_reports/sekn_final\%20report_042008. pdf? $\operatorname{ua}=1$

190 Commission on Social Determinants of Health (CSDH). 2008. Closing the gap in a generation: health equity through action on the social determinants of health. Geneva, Switzerland, WHO; M. Marmot, E. Bloomer and P. Goldblatt. 2013. The role of social determinants in tackling health objectives in a context of economic crisis. Public Health Reviews, 35: 9.

191 Save the Children. 2016. Unequal portions: ending malnutrition for every last child [online]. London. [Cited 5 May 2019]. https://s3.savethechildren.it/public/files/ uploads/pubblicazioni/unequal-portions-ending-malnutritionevery-last-child.pdf

192 International Disability Alliance. 2018. Disability and food security: an unfinished policy agenda. Text by L. Stloukal. In: International Disability Alliance [online]. Geneva, Switzerland and New York, USA. [Cited 10 May 
2019]. http://www.internationaldisabilityalliance.org/faofood-insecurity; WHO and World Bank. 2011. World report on disability. Geneva, Switzerland, WHO.

193 G.R. Alexander, M. Kogan, D. Bader, W. Carlo, M. Allen and J. Mor. 2003. US birth weight/gestational age-specific neonatal mortality: 1995-1997 rates for whites, hispanics, and blacks. Pediatrics, 111(1): e61-e66; S. Wise. 2008. Improving the early life outcomes of indigenous children: implementing early childhood development at the local level. Issues paper No. 6 produced for the Closing the Gap Clearinghouse [online]. Canberra, Australian Institute of Health and Welfare. [Cited 5 May 2019]. https:// www.aihw.gov.au/getmedia/b46de39b-eeb5-4a98-87e844dad29f99b9/ctgc-ip06.pdf.aspx?inline=true; S.C. Gray, S.E. Edwards, B.D. Schultz and M.L. Miranda. 2014. Assessing the impact of race, social factors and air pollution on birth outcomes: a population-based study. Environmental Health, 13(1): 4; S.L. Restrepo-Mesa, N. Zapata López, B.E. Parra Sosa, L.E. Escudero Vásquez and E. Atalah. 2014. Adolescent pregnancy: maternal characteristics and their association with birth weight of the newborn. Archivos Latinoamericanos De Nutricion, 64(2): 99-107.

194 Y.S. Balarajan, W.W. Fawzi and S.V. Subramanian. 2013. Changing patterns of social inequalities in anaemia among women in India: cross-sectional study using nationally representative data. BMJ Open, 3(3): e002233; T. Shamah-Levy, S. Villalpando-Hernández, A. García-Guerra, V. Mundo-Rosas, F. Mejía-Rodríguez and C.P. Domínguez-Islas. 2009. Anemia in Mexican women: results of two national probabilistic surveys. Salud Pública de México, 51(Suppl. 4): 515-522; J.M. Brotanek, J. Gosz, M. Weitzmanand and G. Flores. 2007. Iron deficiency in early childhood in the United States: risk factors and racial/ethnic disparities. Pediatrics, 120(3): 568; Z. Mei, M.E. Cogswell, A.C. Looker, C.M. Pfeiffer, S.E. Cusick, D.A. Lacher and L.M. Grummer-Strawn. 2011. Assessment of iron status in US pregnant women from the National Health and Nutrition Examination Survey (NHANES), 1999-2006. The American Journal of Clinical Nutrition, 93(6): 1312-1320.

195 Save the Children. 2016. Unequal portions: ending malnutrition for every last child. London.

196 N. Larson, M. Story and M.C. Nelson. 2008. Bringing healthy foods home: examining inequalities in access to food stores. A research brief, February 2008 [online]. Princeton, USA, Robert Wood Johnson Foundation. [Cited 6 May 2019]. http://healthyeatingresearch.org/wp-content/
uploads/2013/12/HER-Bringing-Healthy-FoodsHome_7-2008.pdf

197 H. Malapit and A. Quisumbing. 2016. Gendered pathways to better nutrition. Rural 21: 15-17 [online]. [Cited 16 May 2019]. https://www.rural21.com/uploads/media/ rural2016_01-S15-17.pdf

198 A.R. Quisumbing and J.A. Maluccio. 2000. Intrahousehold allocation and gender relations: new empirical evidence from four developing countries. Food Consumption and Nutrition Division Discussion Paper No. 84 [online]. Washington, DC, IFPRI. [Cited 6 May 2019]. http://www.ifpri.org/publication/intrahousehold-allocationand-gender-relations

199 M. Eirnæes and C. Pörtner. 2004. Birth order and the intra-household allocation of time and education. Review of Economics and Statistics, 86: 1008-1019.

200 L.J. Haddad, J. Hoddinott and H. Alderman, eds. 1997 Intrahousehold resource allocation in developing countries: models, methods, and policy. Baltimore, USA, Johns Hopkins University; P.R. Berti. 2012. Intra-household distribution of food: a review of the literature and discussion of the implications for food fortification programs. Food and Nutrition Bulletin, 33(3 Suppl. 2): S1613-S1619.

201 H. Harris-Fry, N. Shrestha, A. Costello and N.M. Saville. 2017. Determination of intra-household food allocation between adults in South Asia: a systematic review. International Journal for Equity in Health, 16(1): 107; L.J. Haddad, J. Hoddinott and H. Alderman, eds. 1997. Intrahousehold resource allocation in developing countries: models, methods, and policy. Baltimore, USA, Johns Hopkins University; L.J. Haddad, C. Peña, C. Nishida, A. Quisumbing and A. Slack. 1996. Food security and nutrition implications of intra-household bias: a review of literature. FCND discussion paper No. 19 [online]. Washington, DC, IFPRI [Cited 6 May 2019]. http://ebrary. ifpri.org/utils/getfile/collection/p15738coll2/id/125582/ filename/125613.pdf

202 H. Harris-Fry, N. Shrestha, A. Costello and N.M. Saville. 2017. Determination of intra-household food allocation between adults in South Asia: a systematic review. International Journal for Equity in Health, 16(1): 107.

203 World Bank. 2018. Poverty and shared prosperity 2018. Piecing together the poverty puzzle. Washington, DC. 
204 A. Dang, and J. V. Meenakshi. 2017. The Nutrition transition and the intra-household double burden of malnutrition in India. ADBI Working Paper 725 [online]. Tokyo, Asian Development Bank Institute [Cited 6 May 2019]. https://www.adb.org/sites/default/files/ publication/297036/adbi-wp725.pdf; J. Garrett and M. Ruel. 2005. Stunted child-overweight mother pairs: prevalence and association with economic development and urbanization. Food and Nutrition Bulletin, 26(2): 209-221.

205 V. Oddo, J.H. Rah, R.D. Semba, K. Sun, N. Akhter, S. de Pee, R. Moench-Pfanner, M. Bloem and K. Kraemer. 2012. Predictors of maternal and child double burden of malnutrition in rural Indonesia and Bangladesh. The American Journal of Clinical Nutrition, 95(4): 951-958; J. Lee, R.F. Houser, A. Must, P.P. de Fulladolsa and O.I. Bermudez. 2010. Disentangling nutritional factors and household characteristics related to child stunting and maternal overweight in Guatemala. Economics \& Human Biology, 8(2): 188-196.

206 World Bank. 2008. Rising food prices: policy options and World Bank response [online]. Washington, DC. [Cited 7 May 2019]. http://siteresources.worldbank.org/ NEWS/Resources/risingfoodprices_backgroundnote_apr08. pdf; Q. Woodon and H. Zaman. 2009. Rising food prices in sub-Saharan Africa: poverty impact and policy responses. Policy Research Working Paper No. 4738. Washington, DC, World Bank.

207 M. Torero. 2016. Consistency between theory and practice in policy recommendations by international organizations for extreme price and extreme volatility situations. In M. Kalkuhl, J. von Braun and M. Torero, eds. Food price volatility and its implications for food security and policy, pp. 457-510. Cham, Switzerland, Springer International Publishing.

208 K. Roelen, R. Sabates-Wheeler and S. Deveraux. 2016. Social protection, inequality and social justice. In ISSC, IDS and UNESCO. World social science report 2016, Challenging inequalities: pathways to a just world, pp. 231-236. Paris, UNESCO.

209 N. Winder Rossi, F. Spano, R. Sabates-Wheeler and S. Kohnstamm. 2017. Social Protection and Resilience. Supporting livelihoods in protracted crises, fragile and humanitarian contexts. FAO Position Paper. Rome, FAO; C. O'Brien, Z. Scott, G. Smith, V. Barca, A. Kardan, R. Holmes, C. Watson and J. Congrave. 2018.
Shock-responsive social protection systems research: synthesis report. Oxford, UK, Oxford Policy Management.

210 M. Ultrichs and R. Slater. 2016. How can social protection build resilience? Insights from Ethiopia, Kenya and Uganda. Working paper [online]. London, ODI. [Cited 6 May 2019]. https://www.odi.org/sites/odi.org.uk/files/ resource-documents/11123.pdf

211 National Drought Management Authority (NDMA). 2016. Hunger Safety Net Programme scalability policy paper [online]. Nairobi. [Cited 6 May 2019]. https://www.hsnp. or.ke/index.php/our-work/downloads/category/1-userdownloads?download=51:scale-policy

212 Interagency Social Protection Assessments (ISPA). n.d. Social protection public works programs - introduction [online]. [Cited 6 May 2019]. https://ispatools.org/tools/ public-works-brochure.pdf

213 A. McCord. 2008. A typology for public works programming. Natural Resource Perspectives 121, December 2008 [online]. London, ODI. [Cited 6 May 2019]. https://www.odi.org/sites/odi.org.uk/files/odi-assets/ publications-opinion-files/3478.pdf

214 M. Gutierrez and J.E. Revilla. 2010. Building countercyclical fiscal policies in Latin America: the international experience. Policy Research Working Paper 5211 [online]. Washington, DC, World Bank [Cited 6 May 2019]. http://documents.worldbank.org/curated/ en/369021468266065700/pdf/WPS5211.pdf

215 B.J. Clements, R.A. de Mooii, S. Gupta and M. Keen, eds. 2015. Inequality and fiscal policy. Washington, DC, IMF.

216 M. Grosh, C. del Ninno, E. Tesliuc and A. Ouerghi. 2008. For protection and promotion: the design and implementation of effective safety nets. Washington, DC, World Bank.

217 J. D. Nkurunziza, K. Tsowou and S. Cazzaniga. 2017. Commodity dependence, growth and human development. Background document to the Commodities and Development Report 2017 [online]. Geneva, Switzerland, UNCTAD [Cited 6 May 2019]. https://unctad.org/en/PublicationsLibrary/ suc2017d5_en.pdf 
218 World Bank. 2018. The State of Social Safety Nets 2018. Washington, DC

219 M.V. Sánchez and M. Cicowiez. 2014. Trade-offs and payoffs of investing in human development. World Development, 62: 14-29.

220 C. Martinez-Fernandez and K. Choi. 2012. Skills development pathways in Asia. OECD Local Economic and Employment Development (LEED) Working Papers 2012/12 [online]. Paris, OECD. [Cited 6 May 2019]. https://www.oecd-ilibrary.org/docserver/5k94hdll|7vk-en. pdf?expires $=1557247103 \& i d=i d \& a c c n a m e=$ guest\&checksum $=$ 41709ABA403F40AF6DA39010A76E4AA7

221 I.S. Gill, A. Revenga and C. Zeballos. 2016. Grow, invest, insure: a game plan to end extreme poverty by 2030. Policy Research Working Paper 7892 [online]. Washington, DC, World Bank. [Cited 29 April 2019]. http://documents. worldbank.org/curated/en/924111479240600559/pdf/ WPS7892.pdf; A. De la $\bigcirc$ Campos, C. Villani, B. Davis and M. Takagi. 2018. Ending extreme poverty in rural areas: sustaining livelihoods to leave no one behind. Rome, FAO.

222 FAO. 2017. FAO social protection framework: promoting rural development for all. Rome, FAO.

223 I.S. Gill, A. Revenga and C. Zeballos. 2016. Grow, invest, insure: a game plan to end extreme poverty by 2030. Policy Research Working Paper 7892 [online]. Washington, DC, World Bank. [Cited 29 April 2019]. http://documents. worldbank.org/curated/en/924111479240600559/pdf/ WPS7892.pdf

224 I.S. Gill, A. Revenga and C. Zeballos. 2016. Grow, invest, insure: a game plan to end extreme poverty by 2030. Policy Research Working Paper 7892 [online]. Washington, DC, World Bank. [Cited 29 April 2019]. http://documents. worldbank.org/curated/en/924111479240600559/pdf/ WPS7892.pdf

225 UNCTAD and FAO. 2017. Commodities and Development Report 2017. Commodity markets, economic growth and development. New York, USA, UNCTAD.

226 OECD. 2017. Revisión de políticas nacionales de educación la educación en Costa Rica. Aspectos destacados. Paris.
227 IFAD. 2016. Rural Development Report 2016. Fostering inclusive rural transformation. Rome; S. Omamo. 2016. Why food and nutrition security matters for inclusive structural and rural transformation. IFAD Research Series 6. Rome, IFAD.

228 FAO. 2009. The State of Food Insecurity in the World 2009. Economic crises - impacts and lessons learned. Rome.

$229 \mathrm{FAO}$. 2017. The State of Food and Agriculture in the World 2017. Leveraging food systems for inclusive rural transformation. Rome.

230 FAO. 2009. The State of Food Insecurity in the World 2009. Economic crises - impacts and lessons learned. Rome.

$231 \mathrm{FAO}$. 2017. The State of Food and Agriculture in the World 2017. Leveraging food systems for inclusive rural transformation. Rome.

232 FAO. 2017. The State of Food and Agriculture in the World 2017. Leveraging food systems for inclusive rural transformation. Rome.

233 FAO. 2009. The State of Food Insecurity in the World. Economic crises - impacts and lessons learned. Rome.

234 FAO. 2009. The State of Food Insecurity in the World. Economic crises - impacts and lessons learned. Rome.

235 H. Walls, R. Smith, S. Cuevas and J. Hanefeld. forthcoming. International trade and investment: still the foundation for addressing nutrition-related non-communicable diseases in the era of Trump?

236 R. Remans, S.A. Wood, N. Saha, T.L. Anderman and R.S. Defries. 2014. Measuring nutritional diversity of national food supplies. Global Food Security, 3(3-4): 174-182.

237 O. Giuntella, M. Rieger and L. Rotunno. 2018. Weight gains from trade in foods: evidence from Mexico [online] Cambridge, USA, National Bureau of Economic Research. [Cited 6 May 2019]. https://www.nber.org/papers/ w24942.pdf

238 United Nations System Standing Committee on Nutrition (UNSCN). 2016. Enhancing coherence between trade policy and nutrition action: implementing the Framework for Action of the Second International Conference on Nutrition. Executive summary, May 2016 [online]. Rome. [Cited 6 May 
2019]. https://www.unscn.org/uploads/web/news/ document/ExSumm l-EN-WEBok.pdf

239 K. Stamoulis and A. Zezza. 2003. A conceptual framework for national agricultural, rural development, and food security strategies and policies. ESA Working Paper No. 03-17 [online]. Rome, FAO. [Cited 7 May 2019]. http://www.fao.org/3/ae050e/ae050e00.pdf

240 K. Stamoulis and A. Zezza. 2003. A conceptual framework for national agricultural, rural development, and food security strategies and policies. ESA Working Paper No. 03-17 [online]. Rome, FAO. [Cited 7 May 2019]. http://www.fao.org/3/ae050e/ae050e00.pdf

241 J.R. Behrman and A.B. Deolalikar. 1987. Will developing country nutrition improve with income? A case study for rural South India. Journal of Political Economy, 95(3): 492-507.

242 K. Stamoulis and A. Zezza. 2003. A conceptual framework for national agricultural, rural development, and food security strategies and policies. ESA Working Paper No. 03-17 [online]. Rome, FAO. [Cited 7 May 2019]. http://www.fao.org/3/ae050e/ae050e00.pdf; A. De la O Campos, C. Villani, B. Davis and M. Takagi. 2018. Ending extreme poverty in rural areas: sustaining livelihoods to leave no one behind. Rome, FAO.

243 FAO. 2015. Nutrition and social protection. Rome.

244 FAO and UNICEF. 2018. Impact evaluation of Lesotho's Child Grants Programme (CGP) and Sustainable Poverty Reduction through Income, Nutrition and access to Government Services (SPRINGS) project [online]. Rome, FAO. [Cited 7 May 2019]. https://www.unicef.org/evaldatabase/ files/CGP_SPRING_Evaluation_Final_Lesotho2018-001.pdf

245 WHO. 2018. Global Nutrition Policy Review 2016-2017: Country progress in creating enabling policy environments for promoting healthy diets and nutrition. Geneva, Switzerland.

$246 \mathrm{WHO}$. 2016. Accelerating nutrition improvements: best practices for scaling up. Examples from Ethiopia, Uganda and the United Republic of Tanzania [online]. Geneva, Switzerland. [Cited 7 May 2019]. https://apps.who.int/iris/ bitstream/handle/10665/252535/WHO-NMH-NHD-16.4eng.pdf?ua=1
247 OECD. 2018. Rural 3.0. A framework for rural development. Policy note. Paris.

248 IFAD. 2018. Household methodologies [online]. Tools and guidelines, lessons learned. [Cited 16 May 2019]. https://www.ifad.org/en/web/knowledge/publication/ asset/40253899

249 Department for International Development (DFID). 2005 Reducing poverty by tackling social exclusion. A DFID policy paper. London.

\section{NOTES TO ANNEXES}

1 For a detailed description of the method, see N. Wanner, C. Cafiero, N. Troubat and P. Conforti. 2014. Refinements to the $F A O$ methodology for estimating the prevalence of undernourishment indicator. FAO Statistics Division, Working Paper Series. ESS/14-05 [online]. Rome, FAO. [Cited 13 May 2019]. http://www.fao.org/3/a-i4046e.pdf

2 A person is considered healthy if his or her body mass index (BMI) indicates neither underweight nor overweight. Human Energy Requirements norms per kilogram of body mass are given in United Nations University (UNU), World Health Organzation (WHO) and FAO. 2004. Human energy requirements. Report of a joint UNU/WHO/FAO expert consultation. Rome, 17-24 October 2001. Rome, FAO.

3 See United Nations (UN). 2017. World Population Prospects 2017. In: United Nations - DESA/Population Division [online]. New York, USA. [Cited 13 May 2019]. https://population.un.org/wpp

4 See N. Wanner C. Cafiero, N. Troubat and P. Conforti. 2014. Refinements to the FAO methodology for estimating the prevalence of undernourishment indicator. FAO Statistics Division, Working Paper Series. ESS/14-05 [online]. Rome, FAO. [Cited 13 May 2019]. http://www.fao.org/3/ai4046e.pdf

5 FAO Trade and Markets Division has developed and maintains a Commodity Balance Sheet database (XCBS) that provides up-to-date and elementary information for analysis of the state of agricultural commodity markets at global and regional levels, as well as the food situation of all countries in the world. XCBS contains balance sheet-structured data for the major commodities in the following groups: cereals, dairy, meat, oil-bearing crops, sugar, tropical beverages, bananas and citrus since the 1980s. The data from 
XCBS are used in a number of systems and publications, such as FAO Global Information and Early Warning System (GIEWS), Agricultural Market Information System (AMIS), Food Outlook and Crop Prospects and Food Situation.

6 H. Blencowe, J. Krasevec, M. de Onis, R.E. Black, X. An, G.A. Stevens, E. Borghi, C. Hayashi, D. Estevez, L. Cegolon, S. Shiekh, V.P. Hardy, J.E. Lawn and S. Cousens. 2019. National, regional, and worldwide estimates of low birthweight in 2015, with trends from 2000: a systematic analysis. The Lancet Global Health, 15 May 2019 [online]. http://dx.doi.org/10.1016/S2214-109x(18)30565-5.

7 The estimates were derived for various regional groupings of which the UNICEF regional grouping has the largest number of countries $(n=202)$. Seven of the 202 countries did not have LBW input data or covariate data. It was therefore not possible to generate any estimates for these seven countries or include them in the regional and global estimates which are based on a total of 195 countries.

8 A.K. Blanc and T. Wardlaw. 2005. Monitoring low birth weight: an evaluation of international estimates and an updated estimation procedure. Bulletin of the World Health Organization, 83(3): 178-185.

9 A.K. Blanc and T. Wardlaw. 2005. Monitoring low birth weight: an evaluation of international estimates and an updated estimation procedure. Bulletin of the World Health Organization, 83(3): 178-185.

10 H. Blencowe, J. Krasevec, M. de Onis, R.E. Black, X. An, G.A. Stevens, E. Borghi, C. Hayashi, D. Estevez, L. Cegolon, S. Shiekh, V.P. Hardy, J.E. Lawn and S. Cousens. 2019. National, regional, and worldwide estimates of low birthweight in 2015, with trends from 2000: a systematic analysis. The Lancet Global Health, 15 May 2019 [online]. http://dx.doi.org/10.1016/S2214-109X(18)30565-5.

11 The full time series at country level is available at UN. 2019. National Accounts - Analysis of Main Aggregates. In: UNSTATS [online]. New York, USA. [Cited 6 May 2019]. https://unstats.un.org/unsd/snaama

$12 \mathrm{~J}$. Bai and P. Perron. 1998. Estimating and testing linear models with multiple structural changes. Econometrica, 66(1): 47-78.

13 D.D. Headey. 2013. The impact of the global food crisis on self-assessed food security. Policy Research Working
Paper 6329 [online]. Washington, DC, World Bank. [Cited 29 May 2019]. http://documents.worldbank.org/curated/ en/762131468267628816/pdf/wps6329.pdf

14 The period 2006-2010 was not considered for the following reasons: 1) there are only a handful of countries that experience increases in PoU during this period (see Box 10 and Figure 24); 2) this period is marked by high volatility related to the global food price crisis and global financial crisis (see Box 10), and there are no high frequency data of PoU during this high volatility, nor is PoU designed to capture such sharp and volatile swings in such a short period of time.

15 D.F. Hendry. 1995. Dynamic econometrics - advanced texts in econometrics. New York, USA, Oxford University Press.

16 A sensitivity analysis using a logistic model was undertaken, with a dependent variable defined as a zero-one dummy variable denoting countries with an increase in PoU between years 2011 and 2017 vs. countries with no increase. The results were consistent with the Ordinary Least Squares (OLS) analysis.

17 The PoU estimates the proportion of the population habitually meeting the (average) minimum daily dietary-intake requirements. It uses the DEC (dietary energy consumption), which is computed as a three-year average. This means that the PoU is a highly smoothed data time series, which can be expected to reflect to some extent major variations in production in cases where a country is not able to compensate for large production drops with stocks and imports. This way of computing and smoothing the PoU data means there will be insufficient variability between years, which makes direct year-on-year regression on economic slowdowns and downturns problematic.

18 This alternative model specification involved the computation of change in $\mathrm{PoU}$ and in economic growth between years 2011-2013, 2013-2015 and 2015-2017. The results show that an average 10 percent increase in economic growth is associated with a decrease in PoU of 0.4 percentage points occurring on average over a period of two years. Thus, if one considers the relevant seven-year period (2011-2017), a 10 percent increase in economic growth is approximately associated with a 1.3 percentage point decrease in PoU, where 1.3 is obtained multiplying the estimated coefficient of 0.4 by 3.5 (i.e. two-year average estimated coefficient, with 3.5 corresponding to a time span of seven years). Thus, this supports the robustness 
of the estimated coefficient associated with economic growth shown in Table A4.2. Further analysis can be done using GMM-IV procedures (see M. Arellano and S. Bond. 1991. Some tests of specification for panel data: Monte Carlo evidence and an application to employment equations. The Review of Economic Studies, 58(2): 277, but this is beyond the scope of the study, and in addition the PoU data available are not appropriate given the PoU is a three-year rolling average.

19 By means of robustness, regressions were also run including the five outlier countries. The estimated coefficient of economic growth remained statistically significant and negative, although lower in magnitude (i.e. estimated coefficient is -0.9 with outliers, compared to -1.5 without). Standard errors of the models were clustered at the regional level.

20 FAO, IFAD, UNICEF, WFP and WHO. 2018. The State of Food Security and Nutrition in the World 2018. Building climate resilience for food security and nutrition, Annexes 2 and 3. Rome, FAO.

21 FAO, IFAD, UNICEF, WFP and WHO. 2017. The State of Food Security and Nutrition in the World 2017. Building resilience for peace and food security, Annex 2. Rome, FAO.

22 In the 2017 edition of this report, the time frame spans from 1996 to 2015, focusing the analysis on four periods of five years: 1996-2000, 2001-2005, 2006-2010 and 2011-2015. For the purpose of the current report, only countries affected by conflict during the 2011-2015 period are considered, as well as additional countries with conflict in the most recent years (2016 and 2017).

23 UNCTAD and FAO. 2017. Commodities and Development Report 2017. commodity markets, economic growth and development. New York, USA, UNCTAD.

24 J.D. Nkurunziza, K. Tsowou and S. Cazzaniga. 2017. Commodity dependence and human development. African Development Review, 29(S1): 27-41.

25 Data are available at United Nations Conference on Trade and Development (UNCTAD). 2019. UNCTADStat. In: UNCTAD [online]. Geneva, Switzerland. [Cited 13 May 2019]. https://unctadstat.unctad.org/wds/ReportFolders/ reportFolders.aspx
26 UNCTAD and FAO. 2017. Commodities and Development Report 2017. Commodity markets, economic growth and development. New York, USA, UNCTAD.

27 The most recent World Bank classification (2017) defines countries with a gross national income (GNI) below or equal to USD 995 as low income; countries with a GNI in the range USD 996-USD 3895 as lower-middle income; countries with a GNI greater than USD 12055 as uppermiddle income. For further information see World Bank. 2019. World Bank country and lending groups. In: The World Bank [online]. Washington, DC. [Cited 13 May 2019]. https://datahelpdesk.worldbank.org/ knowledgebase/articles/906519-world-bank-country-andlending-groups

28 FAO, IFAD, UNICEF, WFP and WHO. 2017. The State of Food Security and Nutrition in the World 2017. Building resilience for peace and food security. Rome, FAO; FAO, IFAD, UNICEF, WFP and WHO. 2018. The State of Food Security and Nutrition in the World 2018. Building climate resilience for food security and nutrition. Rome, FAO.

29 IPC Global Partners. 2019. Integrated Food Security Phase Classification technical manual version 3.O. Evidence and standards for better food security and nutrition decisions. Rome.

30 IPC Global Partners. 2019. Integrated Food Security Phase Classification technical manual version 3.O. Evidence and standards for better food security and nutrition decisions. Rome.

31 UNCTAD and FAO. 2017. Commodities and Development Report 2017. Commodity markets, economic growth and development. New York, USA, UNCTAD.

32 UN Chief Executives Board for Coordination (CEB). 2017. Report of the High-Level Committee on Programmes at its thirty-fourth session. Annex III. CEB/2017/6 (6 November 2017).

33 World Bank. 2016. Poverty and Shared Prosperity 2016. Taking on inequality. Washington, DC.

34 United Nations General Assembly (UNGA). 2016. Report of the open-ended intergovernmental expert working group on indicators and terminology relating to disaster risk reduction. (1 December 2016). 


\section{NOTES ON GEOGRAPHIC REGIONS IN STATISTICAL TABLES IN PART I AND ANNEX i}

Countries revise their official statistics regularly for past periods as well as for the latest reporting period. The same holds for population data of the United Nations. Whenever this happens, estimates are revised accordingly. Therefore, users are advised to refer to changes in estimates over time only within the same edition of The State of Food Security and Nutrition in the World and refrain from comparing data published in editions for different years.

\section{Geographic regions}

This publication follows the composition of geographic regions as presented by the Statistics Division of the United Nations Secretariat primarily for use in its publications and databases (https://unstats.un.org/ unsd/methodology/m49). The assignment of countries or areas to specific groupings is for statistical convenience and does not imply any assumption regarding political or other affiliation of countries or territories by the United Nations. Please refer to the list on the right for the country composition of each region in Annex 1 tables as well as in Tables 1-4 in Section 1.1.

Countries, areas and territories for which there were insufficient or unreliable data for conducting the assessment are not reported and not included in the aggregates. Specifically:

- Northern Africa: In addition to the countries listed in the table, PoU and FIES include an estimate for Western Sahara. Child wasting, stunting and overweight, low birthweight, adult obesity, exclusive breastfeeding and anaemia estimates exclude Western Sahara

- Eastern Africa: With respect to the M49 classification, it excludes British Indian Ocean Territory, French Southern and Antarctic Territories, Mayotte, and Réunion.

- Western Africa: With respect to the M49 classification, it excludes Saint Helena.

- Asia and Eastern Asia: With respect to the M49 classification, low birthweight, child wasting, stunting and overweight aggregates exclude Japan.

- Caribbean: With respect to the M49 classification, it excludes Anguilla; Aruba; Bonaire, Sint Eustatius and
Saba; British Virgin Islands; Cayman Islands; Curaçao; Guadeloupe; Martinique;

Montserrat; Saint Barthélemy; Saint Martin (French Part); Sint Maarten (Dutch part); Turks and Caicos Islands; and United States Virgin Islands. In addition to these, anaemia estimates exclude Saint Kitts and Nevis. Adult obesity, child wasting, stunting and overweight, low birthweight and exclusive breastfeeding exclude Puerto Rico.

- South America: With respect to the M49 classification, it excludes Bouvet Island, Falkland Islands (Malvinas), French Guyana, and South Georgia and the South Sandwich Islands.

- Australia and New Zealand: With respect to the M49 classification, it excludes Christmas Island, Cocos (Keeling) Islands, Heard and McDonald Islands, and Norfolk Island.

- Melanesia: With respect to the M49 classification, anaemia, child wasting, stunting and overweight, low birthweight and exclusive breastfeeding estimates exclude New Caledonia.

- Micronesia: With respect to the M49 classification, it excludes Guam, Northern Mariana Islands, and US Minor Outlying Islands. In addition to these, anaemia estimates exclude Nauru and Palau.

- Polynesia: With respect to the M49 classification, it excludes Pitcairn Islands, and Wallis and Futuna Islands. Adult obesity, child wasting, stunting and overweight, low birthweight and exclusive breastfeeding estimates exclude American Samoa, French Polynesia and Tokelau. In addition, anaemia aggregates also exclude Cook Islands, Niue, and Tuvalu.

- Northern America: With respect to the M49 classification, it excludes Saint Pierre and Miquelon.

Adult obesity, anaemia, low birthweight and exclusive breastfeeding aggregates also exclude Bermuda and Greenland. Aggregates for wasting and stunting are based only on data for the United States of America.

- Northern Europe: With respect to the M49 classification, it excludes Åland Islands, Channel Islands, Faroe Islands, Isle of Man, and Svalbard and Jan Mayen Islands.

- Southern Europe: With respect to the M49 classification, it excludes
Gibraltar, Holy See, and San Marino. However, low birthweight estimates include San Marino.

- Western Europe: With respect to the M49 classification, it excludes Liechtenstein and Monaco. However, low birthweight estimates include Monaco.

\section{Other groupings}

Least Developed Countries, Land Locked Developing Countries, and Small Island Developing States groupings include the countries as presented by the Statistics Division of the United Nations (https://unstats. un.org/unsd/methodology/m49).

\section{- Small Island Developing States: Estimates} for child wasting, stunting and overweight, adult obesity, exclusive breastfeeding and low birthweight exclude American Samoa, Anguilla, Aruba, Bonaire, British Virgin Islands, Curaçao, French Polynesia, Guam, Montserrat, New Caledonia, Northern Mariana Islands, Puerto Rico, Sint Eustatius and Saba, Sint Maarten (Dutch part) and United States Virgin Islands. In addition, anaemia estimates exclude Cook Islands, Nauru, Niue, Palau, Saint Kitts and Nevis and Tuvalu.

High-income, upper-middle-income, lower-middle-income and low-income countries include the countries as presented by the World Bank classification for the 2018-2019 fiscal year (https:// datahelpdesk.worldbank.org/ knowledgebase/articles/906519world-bank-country-and-lendinggroups). For adult obesity, anaemia and low birthweight, the World Bank classification for the previous fiscal year was used.

\section{Low-income food-deficit countries (2016):}

Afghanistan, Bangladesh, Benin, Burkina Faso, Burundi, Cameroon, Central African Republic, Chad, Comoros, Côte d'Ivoire, Democratic People's Republic of Korea, Democratic Republic of the Congo, Djibouti, Eritrea, Ethiopia, Gambia, Ghana, Guinea, Guinea-Bissau, Haiti, India, Kenya, Kyrgyzstan, Lesotho, Liberia, Madagascar, Malawi, Mali, Mauritania, Mozambique, Nepal, Nicaragua, Niger, Nigeria, Pakistan, Papua New Guinea, Rwanda, Sao Tome and Principe, Senegal, Sierra Leone, Solomon Islands, Somalia, South Sudan, Sudan, Syrian Arab Republic, Tajikistan, Togo, Uganda, United Republic of Tanzania, Uzbekistan, Yemen, and Zimbabwe. 


\section{Composition of geographic regions}

AFRICA

Northern Africa: Algeria, Egypt, Libya, Morocco, Sudan, Tunisia and Western Sahara.

Sub-Saharan Africa

Eastern Africa: Burundi, Comoros, Djibouti, Eritrea, Ethiopia, Kenya, Madagascar, Malawi, Mauritius, Mozambique, Rwanda, Seychelles, Somalia, South Sudan, Uganda, United Republic of Tanzania, Zambia and Zimbabwe.

Middle Africa: Angola, Cameroon, Central African Republic, Chad, Congo, Democratic Republic of the Congo, Equatorial Guinea, Gabon, and Sao Tome and Principe.

Southern Africa: Botswana, Eswatini, Lesotho, Namibia and South Africa.

Western Africa: Benin, Burkina Faso, Cabo Verde, Côte d'Ivoire, Gambia, Ghana, Guinea, Guinea-Bissau, Liberia, Mali, Mauritania, Niger, Nigeria, Senegal, Sierra Leone and Togo.

\section{ASIA}

Central Asia: Kazakhstan, Kyrgyzstan, Tajikistan, Turkmenistan and Uzbekistan.

Eastern Asia: China, Democratic People's Republic of Korea, Japan, Mongolia and Republic of Korea.

South-eastern Asia: Brunei Darussalam, Cambodia, Indonesia, Lao People's Democratic Republic, Malaysia, Myanmar, Philippines, Singapore, Thailand, Timor-Leste and Viet Nam.

Southern Asia: Afghanistan, Bangladesh, Bhutan, India, Iran (Islamic Republic of), Maldives, Nepal, Pakistan and Sri Lanka.

Western Asia: Armenia, Azerbaijan, Bahrain, Cyprus, Georgia, Iraq, Israel, Jordan, Kuwait, Lebanon, Oman, Palestine, Qatar, Saudi Arabia, Syrian Arab Republic, Turkey, United Arab Emirates and Yemen.

\section{LATIN AMERICA AND THE CARIBBEAN}

Caribbean: Antigua and Barbuda, Bahamas, Barbados, Cuba, Dominica, Dominican Republic, Grenada, Haiti, Jamaica, Puerto Rico, Saint Kitts and Nevis, Saint Lucia, Saint Vincent and the Grenadines, and Trinidad and Tobago.

Latin America

Central America: Belize, Costa Rica, El Salvador, Guatemala, Honduras, Mexico, Nicaragua and Panama.

South America: Argentina, Bolivia (Plurinational State of), Brazil, Chile, Colombia, Ecuador, Guyana, Paraguay, Peru, Suriname, Uruguay and Venezuela (Bolivarian Republic of).

\section{OCEANIA}

Australia and New Zealand: Australia and New Zealand.

Oceania excluding Australia and New Zealand

Melanesia: Fiji, New Caledonia, Papua New Guinea, Solomon Islands and Vanuatu.

Micronesia: Kiribati, Marshall Islands, Micronesia (Federated States of), Nauru and Palau.

Polynesia: American Samoa, Cook Islands, French Polynesia, Niue, Samoa, Tokelau, Tonga and Tuvalu.

\section{NORTHERN AMERICA AND EUROPE}

Northern America: Bermuda, Canada, Greenland and United States of America.

Europe

Eastern Europe: Belarus, Bulgaria, Czechia, Hungary, Poland, Republic of Moldova, Romania, Russian Federation, Slovakia and Ukraine.

Northern Europe: Denmark, Estonia, Finland, Iceland, Ireland, Latvia, Lithuania, Norway, Sweden, and United Kingdom of Great Britain and Northern Ireland.

Southern Europe: Albania, Andorra, Bosnia and Herzegovina, Croatia, Greece, Italy, Malta, Montenegro, North Macedonia, Portugal, Serbia, Slovenia and Spain.

Western Europe: Austria, Belgium, France, Germany, Luxembourg, Netherlands and Switzerland. 


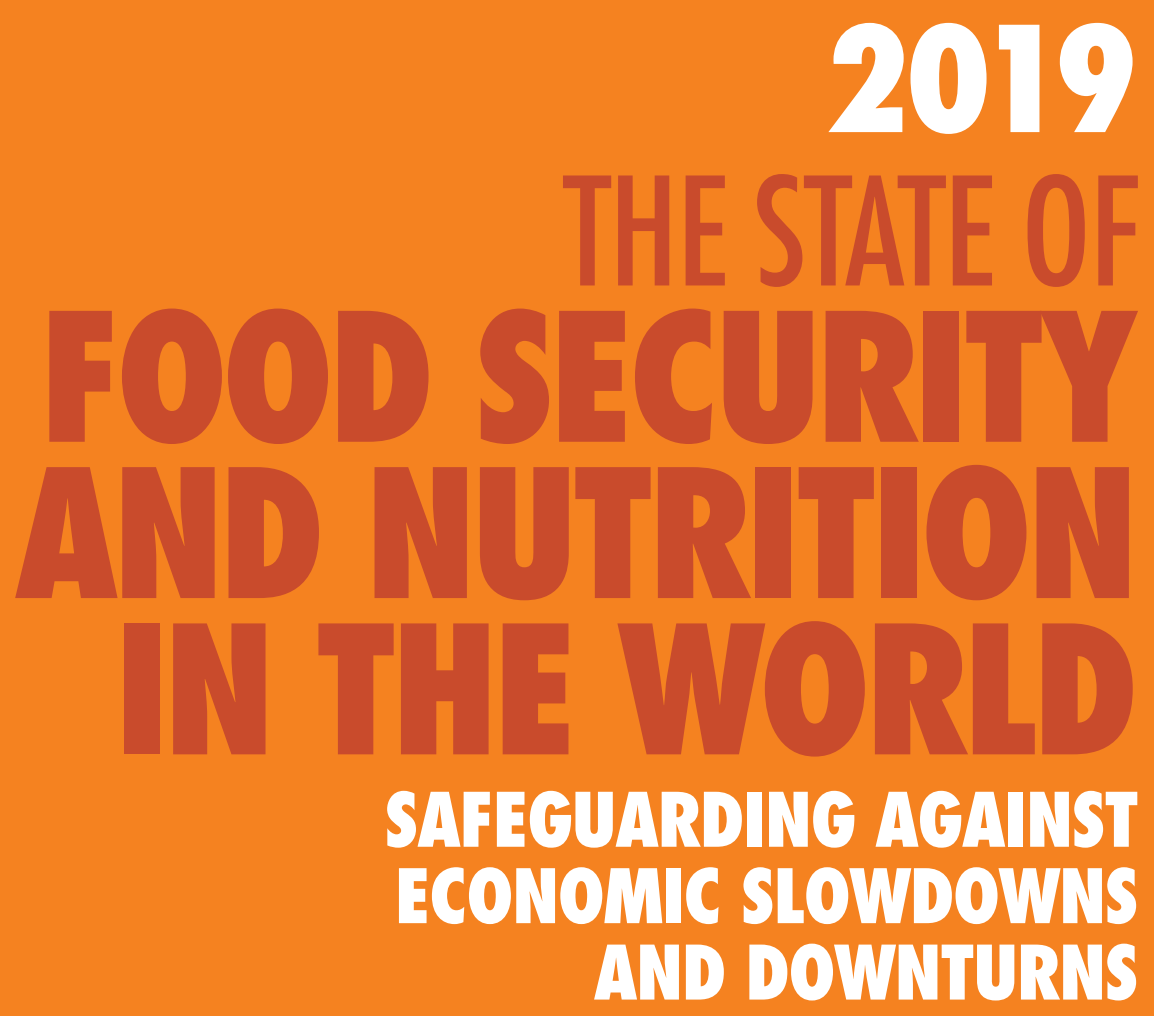

This year's report presents evidence that the absolute number of people who suffer from hunger continues to slowly increase. The report also highlights that food insecurity is more than just hunger. For the first time, the report provides evidence that many people in the world, even if not hungry, experience moderate food insecurity as they face uncertainties about their ability to obtain food and are forced to compromise on the quality and/or quantity of the food they consume. This phenomenon is observed globally, not only in low- and middle-income countries but also in high-income countries.

The report also shows that the world is not on track to meet global nutrition targets, including those on low birthweight and on reducing stunting among children under five years. Moreover, overweight and obesity continue to increase in all regions, particularly among school-age children and adults. The report stresses that no region is exempt from the epidemic of overweight and obesity, underscoring the necessity of multifaceted, multisectoral approaches to halt and reverse these worrying trends.

In light of the fragile state of the world economy, the report presents new evidence confirming that hunger has been on the rise for many countries where the economy has slowed down or contracted. Unpacking the links between economic slowdowns and downturns and food insecurity and malnutrition, the report contends that the effects of the former on the latter can only be offset by addressing the root causes of hunger and malnutrition: poverty, inequality and marginalization. The report concludes by recommending short- to long-term policies that address these underlying causes and safeguard food security and nutrition against economic slowdowns and downturns. 